
THE ASCENT OF PREHISTORIC MAN

MAN'S CULTURAL STAGES AND PHYSICAL DEVELOPMENT

TO THE END OF THE OLD STONE AGE

IDIAGONAL LINES INDICATE RACIAL PERIODS.

DOT SHOWS CONJECTURED DATE OF EXTINCTION]

ICE AC.ES

Cecososr-CLACIAS

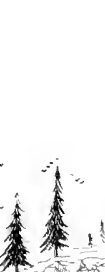

th GLACI

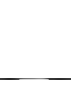

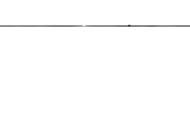

$$
\text { PILTDOWN MAN }
$$

300000

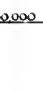

2nS INTERGLACINL

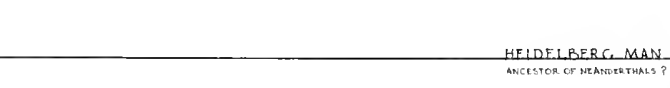
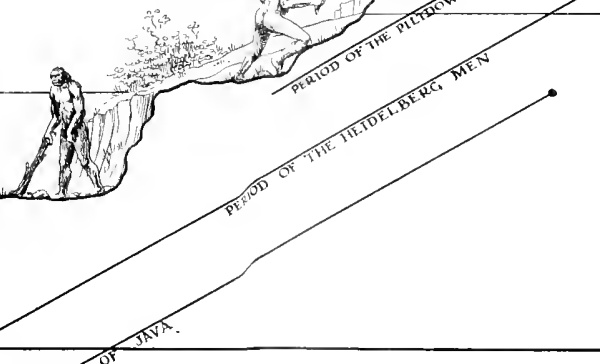

ind CLACIAL
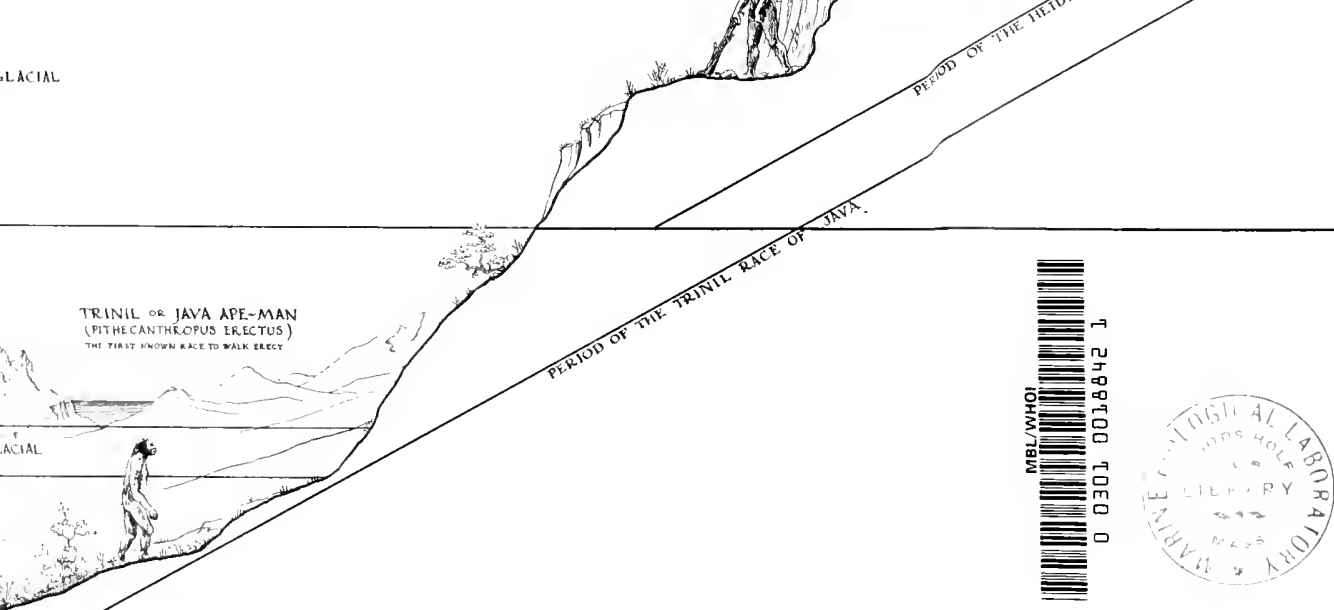

PRE-PALEOLITHIC

EOLITHIC? 





\section{THE BRAIN FROM APE TO MAN}





\section{THE BRAIN}

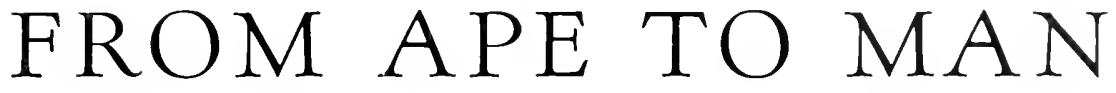

A CONTRIBUTION TO THE STUDY OF THE EVOLUTION AND DEVELOPMENT OF THE HUMAN BRAIN

BY FREDERICK TILNEY, PH.D.,M.D.

Professor of Neurology. Columbia Unuversity

With Chapters on the Reconstruction of the Gray

Matter in the Primate Brain Stem by

\section{HENRY ALSOP RILEY, A.M.,M.D.}

Assocrate Prutessot of Neurology. Columbra Unitersity

FOREWORD BY

HENRY FAIRFIELD OSBORN, sC.D.,LL.D.

Research Professor of Zoologs, Columba Linersity

557 ILLUSTRATIONS, MANY IN COLOR

VOLUME ONE

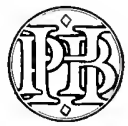

PAUL B $\cdot$ HOEBER $\cdot$ INC

NEW YORK, MCMXXVIII 
COPYright IUz 8 by paUl b. hoeber, inc. ALL RIGHTS RESERVED - PUBLISHED MAY 1928 PRINTED IN THE UNITED STATES OF AMERICA 
IN APPRECIATIVE ADMIRATION THIS BOOK

IS DEDICATED TO

\section{PROFESSOR HENRY FAIRFIELD OSBORN}

UNDER WHOSE INSPIRED LEADERSHIP THE

DIM PATHWAYS OF EVOLUTION AND

THE OBSCURE APPROACHES TO

THE FUTURE HAVE BECONE

MORE ACCESSIBLE TO

THOSE SEEKING

THE TRUTH

$*$

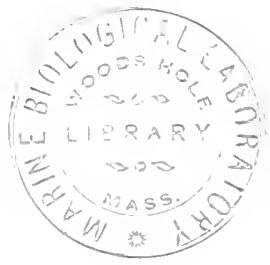





\section{PREIACE}

7 PHE study of the brain in all of its evolutionary aspects is at task requiring the labors of many investigators. Such studies are urgently

I needed because the cuestions surrounding this subject are assuming increasing prominenee in modern thought. No single work may eren aspire to a satisfactory completeness in dealing with the entire problem; therefore only certain aspects of it are approached in these volumes.

Since brain power admittedly is the secret of human suceess, the brain itself must be the pioneer hewing the path of man's progress; hence the genesis of this dominant organ is a vital issue which calls for most intensive research. The answers to the questions "whence came the human brain, and how" have become indispensable to modern understanding. Their value lies in the light thrown by them upon the course of man's long aseent and in their searching penctration through the dense veil which hides his future.

Upon directing our attention toward this future, there are many reasoms for asking whither we atre trending as a race. Does the path lead forward through repetitious ancient cycles of disaster, toward wars and revolutions, toward civic frustrations amid the preparations for future war in times of peace, toward further stupidities in the management of social organizations, toward grosser misconceptions of man and humanity, toward greater depths of superstitious delusion and human unworthiness with their full and final penalty of ultimate extinction? Catastrophe such as this has not infrecuently overtaken many races of men long since extinct. It is possible, however, that the supreme organ which created what there is of human succeding has still further benefits to confer.

And yet no satisfactory appraisal of these possibilities could be attempted without a thorough study of the processes by which the brain came into existence. To this study must be added some comprehension of the vii 
manner in which this master organ has progressively adapted itsolf for the effective distribution of its predominant powers.

These volumes dealing with the exolution of the brain of primates represent approximately lifteen years of preparation, collection and study. Ther emberly the neurolegical evidence based upen structural and behavioral studies of Lemur, Tarsius, Marmoset, Howling Monkey, Baboon, Macacus, Gibbon, Orang, Chimpanzer, Gorilla and Man. In this investigation, it has been my gond fortune to have aceess to the unusually complete collection of vertebrate brains arathered under the direction of Prof. George S. Huntington in Columbia University. Still more fortunate was my privilege of studying for many years under his personal supervision. Indeed, most of this work is the direct result of his inspiration, instruction and guidance. Each page bears some alfectionate memory of his influence, and the entire effort could have no liner reward than to be, if only in some small way, a pupil's tribute to his great master.

To Prof. Henry Fairfield Osborn I am also deeply indebted for his gracius counsel and his generosity in putting at my disposal many of the valuable collections of the American Museum of Natural History. The New York Zoological Garden and the New Vork Aquarium have both been constant and liberal contributors of valuable material. Many fine brain specimens, particularly of the great anthropoid apes, were presented to me by the Iate Mr. Carl Akeley after his last African expedition. One of the most valuable specimens in the collection is the brain of the young gorilla, John Daniel 1, an animal which lived for a relatively long time in captivity and offered an exceptional opportunity for the study of its behavioral reactions under the influences of domestic life.

It gives me espeeral pleasure to acknowledge my gratitude to President Nicholas Murray Butler and to Dean William Darrach for their interest in this research and particularly for having made possible the photographic reprouductions. 
The purpose of this work is to assemble and discust the evidence of evolution contained in the brains of primates.

The present volumes are the first part of a cerebral surver subdivided as follows:

I. The Brain from Ape to Man.

II. Brain Evolution from Mammals to Man.

III. The Brain from Fish to Man.

The treatise setting forth this evidence of cerebral evolution is unavoidably lengthy. It necessarily contains a large amount of technical detail. The full presentation of the facts, however, has been deened essential in order to substantiate the arguments and conclusions drawn from them. On the other hand, the convenience of those who would not be burdened by the tedium of detailed recitals has not been overlooked.

The text has been arranged in five parts. The first part recounts the observations made upon the Lower Primates; the seond, upon the Intermediate Primates; the third, upon the three Great Anthropoids; the fouth, upon Man; and the fifth summarizes all of the evidence adduced in the preceding parts.

At the end of the furst, second and third parts are sectional summaries inchuding interpretations and discussions of the facts as they bear upon the correlative evolution of structures in the brain stem and the behavioral development of the animals described.

In the fifth part a summary in conclusion discusses the evidence afforded by the entire group of primates. It gives the author's views concerning the significance of the evolutionary process which, it is believed, reveals itself clearly in this order of mammals.

In dealing with the technical problems involved in a discussion of the brain, it is recognized that many features might well have been treated more extensively. This recognition applies notably to the cerebral hemi- 
spheres, especially the cerebral cortex. It is doubtless unfortunate that such at condition exists, but an adecuate treatise on the neopallium alone would necessitate the addition of at least several volumes to the present work. The chief emphasis in this description and analysis has been latid upon the brain stem, an clement in the cerebrum which has hitherte been ton little dwelt upon. In the brain stem are included the medulla oblongata, the corebellum, the pens Varolii, the midbrain and the interbrain. Even of these parts the more intimate detals concerning the structure and erolution of the cerebellum and of the interbrain have not been discussed in evenso. These regions of the primate brain are at present being studied by my colleague, Prof. Henry Alsop Riley, and will shortly appear as separate publications.

In submitting the brain stem to study, several methods of analysis have been employed. Not only have the gross appearances in this part of the neuraxis been analyzed, but careful microscopic studies of serial sections of the brain have been made at the following critical levels:

Level of the pramidal decussation

Level of the caudal extremity of the dorsal sensory nuclei

Level of the caudal extremity of the inferior olivary body

Level thromen the midde ol the inferion olivary body

Level of the vestibular nuclei

Level of the cercbellar nuclei

Level of the inferior portion of the pons Varolii and the emergence of the sixth cranial nerve

Level through the middle of the pons Varolii

Level of the emergence of the fouth cranial nerve (nervus trochlearis)

Level of the inferior colliculus

Level of the superior colliculus

Level of the optic chiasm

Level of the anterior commissure. 
In addition to these microseopic studies, reconstructions alecording to the Bourne method have been employed. Such recenstructions, made at at magnification of 10 or 12 diameters, reveal the intimate chatacters and climensional relations of the gray matter. By no other means is it possible to acequire so comprehensive a conception of the eomplex nature of the internal structure in the brain stem. Dr. Riley has devoted himself to this work for a number of gears and as a result has produced a series ol most illuminating reconstruction models which present this aspect of the subject so as to disclose beyond all question the major nuclear movements in the ecolutionary process of the primate brain. I an indebted to Dr. Riley not merely for the production of this collection of unsurpased models, but equally for the careful deseriptions which he has given of them in the eleren chapters dealing with this phase ol the subject.

For the purpose of further checking the propertional relations of the various structures in the brain stem, several methods of mensuration have been employed. On the basis of these measurements, two series of coefficients were established: first, planimetric coctlicients in which the transverse proportions of a given structure were estimated in relation to the entire cross section by means of a planimeter. This method produced a series of ligures which aftord a basis of metric comparison ol homologeus structures. For the painstaking work in these protracted planimetric catculations I am indebted to Mrs. Seymour Basch, whose repeated measurements and remeatsurements of each structure required the most exacting application and produced results which are probably as close an approximation to actual facts as may be obtained. Second, estimates for Jongitudinal coefficients were made with the purpose of determining the relative length of each structure to the entire length of the brain stem.

While it is probably true that no method of mensuration may express adequately the relative proportions of the several structures considered 
in the brain stem, it seems fair to presume that by means of these two sets of calculations a fair degree of accuracy has been attained.

Even though every method which reasonably could be applied to the material has been used in controlling these observations, the fact still remains that this study lacks detailed investigation of the cellular elements of the various nuclear components. The addition of this detail must be left for later consideration, as the inclusion of such studies would of necessity too greatly expand the size of the present wert.

In dealing with the brain stem the treatment has not been that of an atlas, but rather that of a critical review with especial cmphasis upon the structures having the greatest evolutional significance. In the selection of such structures two groups were recognized:

First, those more plastic elements of recent acquisition which have been especially susceptible to adaptive intluences.

Second, the more inflexible, archaic components of the brain stem, which because of their great antiquity have acquired fundamental stability and respond but little to the inlluences of adaptation. Chief attention is directed to the first group from which a surprisingly rich harvest of evidence has been gathered.

The addition of the chapters dealing with the cultural phases of human development and the brain of prehistoric man was made upon the suggestion and with the assistance of Professor Osborn.

Prof. William K. Gregory of Columbia University has given me most gencrous assistance and I am especially grateful to him for his careful reading and criticism of the concluding chapters.

I also wish to cxpress my appreciation to Miss Christine D. Matthews of the American Museum of Natural History for her revisions in the tabulation showing the fossil remains of prehistoric man.

Throughout the entire preparation of the manuscript I have had the 
able and sympathetic assistance of Mrs. Alice G. Margulies, whose efforts in assembling the biblingraphy have provided valuable addenda for these desiring further references to the literature.

To make due acknowledgnent for all of the assistance I have received would necessitate setting forth a long list of my friends and associates. Among these, howerer, I cannot fail to mention Mr. Frank N. Doubledas, whose invaluable adviee has led to many important revisions in and additions to the text.

It also gives me great pleasure to mention the indispensable services of Miss Regina Unger in preparing the serial sections of the primate brains upon which this study is based. Miss Unger has for a number of rears been engaged in the technical production of brain series, particularly Pal-Ileigert preparations, which constitute one of the most highly valued accessions of the Neurologieal Department in Columbia University. Without these specimens, neither the mieroscopie nor reconstruction studies would have been possible.

In the preparation of the illustrations and text for publication, Miss Florence Fuller of the publishers' stafl has given most enthusiastic and helpful attention.

And, fmally, to my publisher, Mr. Paul B. Hoeber, I wish to acknowledge my deep indebtedness for his generosity and for the encouragement and unfailing inspiration which he has given me at all times.

New loRk, N. Y.

F. T.

March, I928. 



\section{FOREWORD}

7 HE discoreries in astronomy during the last checacte hatre not only widened the besundaries of our own universe but hate revealed the

L existence of universes far beyond our own. These discoreries prove that in our own and the outer universes exactly the same physical and chemical principles prevail, namely, gravitation, heat, light, the genesis of new compounds, development from nebulous and active phases inten dark and inert phases of death.

Marvelous als are these recent discoveries in astronomy, they are becoming comprehensible because of the uniformity of the laws and principles revealed to man through centuries of research. In brief, physics, astromomy and chemistry are alike coming within the field of exact science capable of measurement, calculation, prediction and prophece.

What a contrast is presented in the biological sciences, ancient and modern! With a wide circle of astronomic friends and with the most intense admiration for the achievements of astronomy and pure mathematics, I set believe that their problems are not nearly so diflicult or so balling as our problem. In anatomy, in physiology, in pathology, in heredity we have not yet reached even the threshold of exactitude. With increasing energy, refinement and ingenuity, we hnow all the organs revealed in comparative and human anatomy, in both their grosser and their finer structure. We know also the history of the rise of many of these organs in the course of past time and what their functions and relations are, but there is always the Great Beyond of the unknown, and perhaps unknowable, which is summed up in the word life.

Of all incomprehensible things in the universe Man stands in the front rank, and of all incomprehensible things in Man the supreme difficulty centers in human intelligence, human memory, human aspirations, human powers of 
discovery, research, and conguest of obstacles. The approach to this unknown lield of future human advance- the seat of the human mind and the constitution of the human mind - is along the great paths of human and comparative anatomy and of human and comparative psychology.

This volume contains the basis of what to our knowledge is the first profound study of the erenesis of the intimate or internal structure of the homan brain in comparison with the brains of animals more or less nearly related to man. It is a summary of frederick Tilney's lifework along largely new and original paths, pursued with the most unremitting intelligence and energy and yiclding a result of exceptional breadth, precision and exactitude which affords a new and strong ground on which neurologists, psychologists, pathologists, and students of animal and human behavior may advance further into the umkmown.

May we not add a further word of weleome to this splendid monograph at a time when we are mourning the loss of Georece Sumner Huntington, who laid the foundations of comparative anatomy for the Schos of Anatomy of Columbia University and who unfortunately passed away without witnessing the consummation of the rescarch and endeavors of one of his most distinguished students, namely, the linking of Man in all his parts and functions with the long lines of his ancestry.

NEw YORK, N. Y.

Hexri Falrfield OsborN March, Ioss. 


\section{CONTENTS}

VOLUME I

Píeface.

PME

viI

XV

FOREWORD.

List OF ILLUSTRATIONS.

xix

Introduction. The Primates: Leners, Monkeys, Apes and Man, Theik Peine in Nature

PART I. THE LONER Prinate

INTRODLCTION

$2 \mathrm{I}$

Chaptze

I. Lemur Mongoz, Its Brain and Behavior

23

11. Reconstruction of the Gray Matter in the Bram Stem of Lemur Mongoz.

111. Tarsius Spectrum, lts Brain and Behavior.

85

IV. Reconstruction of the Gray Matter in the Brain Stem of Tarsius Spectrum

V. Callithrix Jacehus, the Marmosct, Its Brain and Behavior.

135

Vl. Reconstruction of the Gray Matter in the Brain Stem of Cillithrix Jacehus

VIl. Mycetes Seniculus, Its Brain and Behavior.

$1 ; 3$

183

VIII. Reconstruction of the Gray Matter in the Brain Stem of Mycetes Seniculus I 9 I

1X. Comparative Summary of Structures Having Evolutional Signilicance in the

Brain Stems of the Lower Primates. .

\section{Part Il. The Intermediate Primates}

INTRODLCTION

Chapter

X. Papio Cynocephalus, the Common Dog-lleaded Baboon, Its Brain and Behavior . . . . . . . . . . . . . . . . 280

X1. Reconstruction of the Gray Matter in the Brain Stem of Papio Cynocephalus

NIl. Pithecus Rhesus, Macacus Rhesus, lts Brain and Behavior .

XIII. Reconstruction of the Gray Matter in the Brain Stem of Pithecus Rhesus $3+9$

XIV. Hylobates Hoolock, the Gibbon, Its Brain and Behavior. 39 I

XV. Reconstruction of the Gray Matter in the Brain Stem of Hylobates Hoolock 405

XVI. Comparative Summary of Structures Haring Evolutional Significance in the Brain Stems of the Intermediate Primates

$+47$

$$
\text { xĭi }
$$


( आP]1

1111. Simia Satrac, the Orane-Outang, Its Brain and Buthavior

1111. Recomstration of the Gras Natter in the Britin Stem of Simia Satyrus.

11. Troglodytes Niger, the Chimpanzex, Its Brain and Behas ior. it;

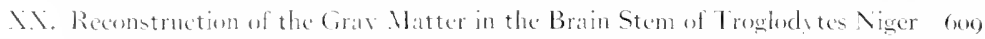

X\. Troglodytes Corilla, Its Brain and Behasior. $\quad 0123$

1.II. Reconstruction of the Ciras Matter in the Brain Stem of Trourlodites Gorill . . . . . . . . . . . . .

1.XII. Comparative Summary of Structures Having Loolutional Simnificance in the Brain Stems of the lligher Anthropuids

$$
\text { PART IV. MAX }
$$

INTRODL CTION

CHIPTER

D.IV. From Primitive to Madern Man

X.V. The Brain of Modern Man

XIVI. Reconstruction of the Gray Matter in the Iluman Bran Stem

XXV11. The Brain of Prehistoric Man

1.111. Man Past, Present and Future

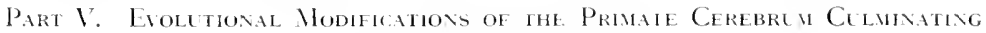
IN THE IIEMAN BRAIN

r.HAPHR

XX1. The Significance of the Structural Homoueneity and Specific Modifreations in the Primate Brain. Their Relations to the Progressive Adaption of

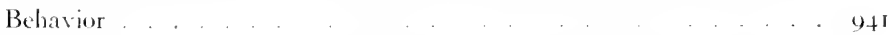

XX. The Internal Structure of the Brain Stem of the Primates. Its Evolutional Modifieation in Relation to the Derelopment of Behavior. Essential Similarities in Internal Elements.

Referinces for Further Readivg. 


\section{LIST OI ILLUSTRATIONS}

Fit: Rt

1. Brains of lower vertebrates compared with the human brain.

2. Brains of mammals companed with the human brain.

3. Brains of apes compared with the human brain

4. Comparison of skeletal structures, from lish to man

5. Lemur group in Madagatican habitat.

6. - Two views of Lemur mongoz

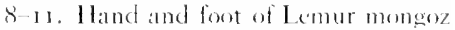

$12-1 ;$. Hand and foot of Lemur potto

16. Dorsal surface of brain, Lemur monguz

1-. Base of brain, Lemur momguz

IS. Left lateral surface of brain, Lemur mongoz .

19. Right lateral surface ol brain, Lemur mongoz

20. Ventral surface of britin stem, Lemur monger

21. Dorsal surface of brain stem, Lemur mongoz.

22. Lemur mongoz. Level of the pyramidal decussation.

23. Lemur mongoz. Level of caudal extremity of inferior olive

$P+1,1$

4

5

6

s., 9

23

$2^{-7}$

30,31

32,33

34

35

$3^{6}$

$3^{-}$

38

30

42

$4^{6}$

24, 25. Lemur mongoz. Level through midelle of inferior olive.

26. Lemur mongoz. Level of the restibutar complex.

2-. Lemur mongoz. Level of the cerebellar nuclei.

28. Lemur mongoz. Level al emerent fibers of sinth nerve.

20. Lenur mongoz. Lexel of caudal extremity of pons Varolii

30. Lemur mongoz. Level of the middle of the pons Varolii

31. Lemur mongoz. Level of emerenee of trochlear nerve.

32. Lemur mongoz. Level of the inferior colliculus.

33. Lemur mongoz. Level ol the superior collicutus.

34. Lemur mongoz. Level of the optic chiasm

35. Lemur mongoz. Lexel of the anterior commissure.

36. Ventral surface of gray matter of brain stem, Lemur mongoz (color)

$3^{-}$. Dorsal surface of gray matter of brain stem, Lemur mongoz (color)

$3^{8}$. Lateral surface of gray matter of brain stem, Lemur mongoz (color).

39, to. Two views of Tarsius spectrum.

$4^{1-4}+$. Hand and foot of Tarsius speetrum

$48,+9$

;0

$; 2$

is

$i^{-1}$

(30)

61

02

(x)

$(\infty)$

$-0$

$-3$

$-$

$-9$

86

45. Dorsal surface of brain of Tarsius spectrum .

88,89

46. Base of brain, Tarsius spectrum .

95

06

08

100

48. Ventral surface of brain stem of Tarsius spectrum.

IOI

49. Dorsal surface of brain stem of Tarsius spectrum.

102 
51. Tarsius spectrum. Level of the pramidal decussation.

52. Tarsius spectrum. Level of the dorsil sensory nuelei.

33. Tarsius spectrum. Fevel of caudal tip of inferior olive.

54. Tarsius spectrum. Level through middle of inferior olive.

55. Tarsius spectrum. Level of the vestibular comples

56. Tarsius spectrum. Level of andal extremity of trapezoid body

$5^{-}$. Tarsius spectrum. Level of the ecrebellar nuclei.

is. Tarsius spectrum. Level of the trochlear emergence.

50. Tarsius spectrum. Level of the inferior colliculus

(o). Tarsius spectrum. Level of the superior colliculus

61. Tarsius spectrmm. Lerel of the optic diasm.

62. Tarsius spectrum. Lexel of the anterior cemmissure.

63. Ventral surface of the gray matter of the Jorain stem, timsius spectrum (color)

64. Dursil surfice of the gray matter of the brain stem, tarsius spectrum (color).

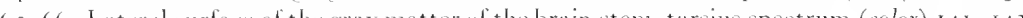

(1-, o8. Callithris iacelus (marmoset)

-3. Dorsal surface of brain, Cillithris facchus (marmoset).

- +. Base of brain, Callithrix jacelus (marmoset).

- 5. Left lateral surface of brain, Callithrix facchus (mamoset).

-6. Right lateral surface of brain. Callithrix iacehus (marmoset)

- - Ventral surliace of brain stem, Callithrix facchus (marmoset)

I6I

-8. Dursal surlace of brain stem, Callithrix jacehus (marmoset)

162

70 . Narmoset. Level of the prramidal decussation

So. Marmoset. Level of the dorsal sensory nuclei.

81. Mamoset. Ierel of the tip of the interior olive. 


\section{LIST OF ILLUSTRATIONS}

Jicine

ror-Io+. Hand and foot of Mrectes seniculus

[Pater

zoj- ros. Hand and foot of spider monkey .

108,100

I09, no. Distal extremities of prebensile tails, Mtreetes senicufus and Atches ater. $20(1), 201$

III. Dorsal surface of brain, Myectes seniculus

203

I z. Base of brain, Mreetes seniculus. . . .

20.4

113. Left lateral surface of brain, Mrcetes seniculus

$20 ;$

is . Right lateral surface of brain, Mycetes seniculus

206

115. Ventral surface of brain stem, Myeetes seniculus

$20^{-1}$

116. Dorsal surface of brain stem, Mycetes senieulus.

2018

II - Myectes seniculus. Level of the pyramidal decussation

$2(1)$

IIS. Nicetes seniculus. Level of the caludal extremity of the inferior wlive 215

II. Nreetes seniculus. Level through the middle of the inferior olive.

I20. Nycetes seniculus. Level of the nucleus ambiguts

218

121. Micetes seniculus. Level of the cerebellar nuclei.

220

122. Mycetes seniculus. Level of the vestibular nuclei.

221

123. Nyectes seniculus. Level of emergence of sisth nerve.

222

124. Nycetes seniculus. Level through middle of pons Varolii $22+$

12;. Mrcetes seniculus. Level of the inferior colliculus. 226

126. Nycetes seniculus. Level of the superior colliculus 228

12-. Nycetes seniculus. Level of the optic chiasm. . 226)

128. Nycetes seniculus. Level of the anterior commissure . . . . 230

120. Ventral surface of the gray matter of the brain stem, Nycetes seniculus (color) 235

I30. Dorsal surface of the gray matter of the brain stem, Mycetes seniculus (color). 237

131. Lateral surface of the gray matter of the brain stem, Mycetes seniculus (color) . 239

132. Habitat group. Baboon at the water hole. $2(x)$

133. Papio crnocephalus (babeon) ....... 201

$13 t^{-1} 3^{-}$. Hand and foot of Papio cynocephatus .

202,293

I 38. Dorsal surface of brain, Papio crnocephatus.

206

139. Base of brain, Papio cynocephatus. . . . . . 26

I †0. Right lateral surface of brain, Papio cynocephalus. 208

I+1. Left lateral surface of brain, Papio cynocephalus. . 209

142. Ventral surface of brain stem, Papio eynocephalus. 300

I 43. Dorsal surface of brain stem, Papio cynocephatus. 301

It+. Baboon. Level of the pyramidal decussation. . . . . 306

145. Baboon. Level of caudal extremity of nucleus of Burdach. . . 309

1.46. Baboon. Level of the caudal extremity of the inferior olivary nucleus . 3ir

It ${ }^{-}$. Baboon. Level through the middle of the inferior olive. 313

148. Baboon. Level of the vestibular nuclei ....... 3io

1 +9. Baboon. Level of the cerebellar nuclei . . . . . 310

I 50 . Baboon. Level of emergent fibers of sixth nerve and eaudat fibers of pons. 321

I 51 . Baboon. Level at middle of pons, showing entering trigeminal fibers. 324

152. Baboon. Level of inferior colliculus showing emergence of fourth nerve . 326

153. Baboon. Level of the inferior colliculus. . . . . . . . . $32^{-}$ 
15f. Balsemen. Level of the superior colliculus

isj. Babewn. Level of the eptic chiasm.

156). Babxen. Level of the anterien commissure

15 . Dorsal surface of the eras matter of the brain stem, Papionesoncephalus (color)

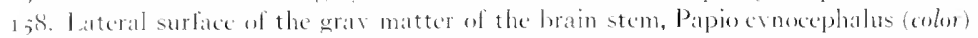

333

3i). Ventral surface of the gras matter of the bran stem, Papoevnocephalus (oolor)

y(x). Natcateds rhesus. Full-gremn monher and roung

$33^{-}$

$33(1)$

s6. 16. Iland and foot of Valeacus rhesus

$3+1$

16;. Dorsal surface ol brain of Vacacus rhesus

$3 ; 2,3 ; 3$

Iof. Base al brain of Macacus rhesus.

16-. Left lateral surtace of brain, Macacus rhesus

$30 x$

168. Right lateral surface of brain, Macacus rhesus

$3(11$

f(x). Ventral surfice of brain stem, Macacus rhesus

$3(12$

I-0. Dursal surfice of brain stem, Macalcus thesus

$3^{6,3}$

1-1. Malcacus. Lered of the pramidal decussation

$3^{(x)}$

1-2, Malcacus. Level of caudal limit of dorsal sensors nuelet.

$3^{(1-}$

y-3. Vacacus. Level al eatadal limit of interior olivary nucleus

$3^{(x)}$

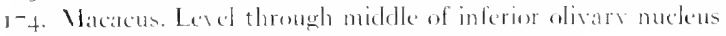

$3^{-2}$

1-5. Macacus. Level al the vestibular nuelei

$3^{-3}$

1-6. Nacaces. Level of the cerebeliar nucled

1-- Maracus. Ievel of the emerence of the sisth nerve

1-8. Macacus. Level through the middle of the pons Varolii

$3 \$ 1$

${ }^{-0}$. Iacacus. Level of the emerence of the trechlear nerve.

$3 \mathrm{~S}_{2}$

180. Nacacus. Ievel of the inferior collicutus

$38+$

181. Malcacus. Iencl of the superine colliculus

3 si

182. Macacus. Lexel of the optic chiasm

$38^{-}$

183. Macacus. Level of the anterior commissure

388

1st. Ventral surface of gray matter of brain stem. Pithecus rhesus (color).

393

38;. Dorsal surface of graty matter of brain stem, Pithecus rhesus (color).

186. lateral surlace ol gray matter of brain stem, Pithecus rhesus (color).

$30^{-}$

נ8-, $18 \%$. Hrobates sundactrilus (gibbon).

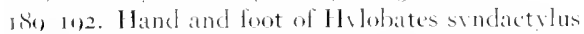

193. Dorsal surfice of brain, ll itobates hooluck

f(1), $f^{(1)}$

104. Base of brain, Hilobates hooloch

$+14$

$+15$

195. Left lateral sulatere of brain, Hylobates hoolock

$+16$

106. Right latcral surface ol brain, Holobites hoolech

$4^{-}$

no- Ventral surface of brain stem, Hylobates hooloch

418

wos. Dorsal surface of brain stem, Hylobates hoolock.

1uce. Gibbon. Level of the pramidal decussition.

200. Gibbon. Level of the caudal extremity of the inferior alive 


\section{LIST OF ILLUSTRATIONS}

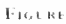

205. Gibbon. Level of the emergence of the sisth eranial nerve

P’a.t

206. Gibbon. Level through the midelle of the pons

$+36$

20-. Cibbon. Level of the emerence of the treshlear nerve

$+3^{-}$

$43 \mathrm{~s}$

208. Giblon. Level of the inferior colliculas

$+f^{\prime \prime}$

200, 2I0. Gibbon. Level of the superior cotliculas

$4+2,4+3$

211. Cibbon. Lerel of the aptic ahiasm

\section{$4+4$}

$4+5$

213. Ventral surlace of erat matter of brain stem, ll vobates heoloch (color)

$+1+1$

214. Dorsal surface of gras matter of brain stem, Hylobates hoolock (color)

$+51$

215. Lateral surface of gray matter of brain stem, J Jybaltes hoolock (color)

$+33$

216. Habitat group, orang-osutang, Sadong River, Borneo

tis

2. $\mathrm{I}^{-}$. Orang-outang, ereet pesture, showing dispropertion of arms and legs

zis. Orang-outang, showing anthropumorphous tendencies in head and liace.

4 tis

483

2I6 222. Hland and lose of the oramg-outang

$223+$ and B. Dorsal surlace of brain, orang-outang

$224 \mathrm{~A}$ and $\mathrm{B}$. Base of brain, orang-outang

$225 \mathrm{~A}$ and $\mathrm{B}$. Left lateral surlace ol brain, orang-outang

226 A and B. Right lateral surface of brain, orang-outang

22-. Ventral surface of brain stem of orang-outang

228. Dorsal surface ol brain stem, orang-outang

226. Orang-outang. Lerel of the pyramidal decussition

230. Orang-outang. Level of the caudal extremity of the dorsal sensory nuclei

231. Orang-outang. Level ol the caudal estremity of the inferior olive

232. Orang-outang. Level through middle of inferior olive

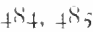

488,4 in

$+(3),+1) \mathrm{I}$

$+(1)+4,+1)$

$4(1),+1)$

500

5011

302

$31 ;$

अथ

;I 1

233. Orang-outang. Level of the restibular nuclei

iIt

316

234. Orang-outang. Level of the cerebelar nuclei

318

235. Orang-outang. Level near caudal limits of pons, emergent sisth nerve libers.

521

236. Orang-outang. Level of the middle of the pons Varolii

522

$23^{-}$. Orang-sutang. Levet of emerence of trochlear nerve.

524

238. Orang-outang. Level of the inferior colliculus

324

236. Orang-outang. Level of the superiur eslliculus

240. Orang-outang. Level of the optic chiasm . . . . . . . . . . . . $33^{\circ}$

24r. Ventral surface of gray natter of brain stem, Simia satyrus (color) . . . 535

242. Dorsal surface of gray matter of brain stem, Simia satyrus (color) . . . . . ; ;

243. Lateral surface of gray matter of brain stem, Simia satyrus (color). . . . . . 530

24. Habitat group, chimpanzee. . . . . . . . . . . . . . . . . it

$2+5,246$. Chimpanzee Susie. . . . . . . . . . . . . . 548, 540

$24^{-250}$. lland and foot of chimpanzee . . . . . . . . . . . . . . . . . 352,553

$251 \mathrm{~A}$ and $\mathrm{B}$. Dorsal surface of brain, chimpanzee . . . . . . . . . . . j60, j61

$252 \mathrm{~A}$ and B. Base of brain, chimpanzee . . . . . . . . . . . . . . . j(12, 3013

$253 \mathrm{~A}$ and $\mathrm{B}$. Left lateral surface of brain, chimpanzee . . . . . . . . . . $568,5(x)$

254. Ventral surface of the brain stem, chimpanzee. . . . . . . . . . . . . . 5 2

255. Dorsal surface of brain stem, chimpanzee. . . . . . . . . . . . . . ; 3 
Fink1

256. Chimpanzee. Level of the prramidal decussation

25-. Chimpanzee. Level of caudal extremity of inferior olie

258 . Chimpanzec. Leved through the middle of the inlerior shive

250. Chimpanzer. Level of the vestibular nuelei

$3 S_{1}$

260 262. Chimpinzee. Lerel of the cerebelliar nuclei

;n+t

263. Chimpinzee. Level of eaudal limit of pons, showing emerent sixth nerve fibers

26t. Level through pons, showing emerering sixth nere fibers

205. Chimpanzer. Level throunh the middle of the pons Varolit

sise

26x. Chimpanzer. Level of the emergence of the fourth nerve

;1) 3

26-- Chimpinzer. Level of the inferior colliculus

51) 4

ic)

2os. Chimpinzee Level al the superior colliculus

260. Chimpinzee. Level of the lateral genieulate body

ios 8

z-o. Chimpanzed Level of the optic chiasm.

$(x) 2$

2-1. Chimpanzee. Level of the anterior commissure.

(rot

2-2. Ventral surlace of grals matter of brain stem, Troglody tes niger (color)

606

2-3. Dorsal surface of gray matter of brain stem, Troglodytes niger (color).

$60^{-}$

$2^{-}$. Lateral surlace of urily matter of hrain stem, Troglodytes niger (color)

$01 \mathrm{I}$

275. Corillal group

() 13

2-6. Large male gorilka killed in the African Congo

$6,2+$

27-. Corilla gorilla.

6,25

2-8. Bronze statue ol grorilla and woman

$62-$

2-0. John Daniel in an amiable attitude

0,28

2ho. Six-rear-old gorilla, John Danied.

(120)

281. Cast ol gorilla taken in list hunt of Mr. Carl A keley

6,33

282. Young gorilla, John Daniel, showing breast-beating act

$63+$

283. Adult male gorilla.

$28+-28-$. Casts of hand and foot of the gorilla, John Daniel

30

288,289 . Casts of hand and foot of an adult mate gurilla

200, 201. Casts of the hand and foot of the gorilla, John Daniel

$6+1$

202 $\mathrm{A}$ and B. Dorsal surfice of brain, gorilla

$203 \mathrm{~A}$ and $\mathrm{B}$. Base of brain, gorilla

20) 4 and B. Left hemisphere of brain, gorilla

205. Ventral surface of brain stem, gorilla

$6+2$

$6+3$

$6+6,6,77$

$648,6+9$

$6,50,651$

206. Dorsal surface of brain stem, gorilla

6,54

6,55

297. Corilla. Level of the pyramidal decussation

6,58

208. Gorilla. Level of the dorsal sensory nuclei.

659

200. Gorilla. Level of caudal extremity of infertor olive

601

300. Gorilla. Level of the middle of the inferior olive

664

301, 302. Gorilla. Levet of the vestibular nuelei

668,660

303,304 . Gorilla. Level of the cerebellar nuclei

$6-0,6-1$

305. Gorilla. Level of the emergence of the sixth cranial nerve.

673

306. Gorillis. Level through the middle of the pons Varolii.

675

$3^{-1}$. Corilla. Level of the emergence of the trochlear nerve

677 
I'TUR

3es. Gorilla. Level of the inferior colliculus

PMe.

$(1-8$

$3^{20}$. Corilla. Level of the superior colliculus

(.80)

310. Gorilla. Level of the optic chiasm .

$68_{3}$

3IJ. Gorilla. Level of the anterior commissure

$\mathrm{OS}_{4}$

3iz. Ventral surface of gray matter ol brain stem, Troglodytes gorilla (color)

(1)

33. Dorsal surface of eray matter of brain stem, Troglodytes gorilla (color)

(is)

3r4. Lateral surface ol gray natter of brain stem, Trogled tes gorilla (color)

(x) 1

$315-318$. Four extinct races of prehistoric man

$-32$

310. Prof. Osborn's estimates of man's antiquity, industries, arts and ralees

320. Restoration of Pithecanthropus compared with human and anthropoid skulls.

$-31$

32r. Restorations of Jleidelberg and Piltdown man by Prolessor MeGregor.

$-36$

322. The Neanderthal race

-39)

323. The Cro-magnon race

$-+1$

$-+^{2}$

324. Stone implements representing the several stages ol Paleolithic culture

$+4$

25. "Eoliths" from Piltdown, Sussex

320. Contrasts between implements of the Palcolithic and Neolithic Ages

$-4^{6}$

32-. I: volution of lance point through several stages of the OId Stone Age

$-48$

328, 320. Nanufacturing llints.

330. Implements and ornaments typical of Upper Paleolithic Age

331. Australian native

$-50$

332. African pygmy group from the Belgian Congo.

$-53$

$-6,8$

333. African negro

$-6(x)$

334. American Indian.

$7-0$

33j. Eskimo.

336. Group of British seientists diseussing the Piltdoun skull

33-A and B. Dorsal surface of brain, I lomo sapiens.

$33{ }^{8} \mathrm{~A}$ and $\mathrm{B}$. Base of brain, 1 lomo sapiens.

$330 \mathrm{~A}$ and $\mathrm{B}$. Left lateral surface of brain, Ilomo sapiens.

$34^{\circ}$. Ventral surface of brain stem, Homo sapiens .

$3+\mathrm{I}$. Dorsal surface of brain stem, Homo sapiens.

342. Man. Level of the pyramidal decussation.

$-72$

$-73$

3+3. Nan. Level of caudal extremity of dorsal sensory nuclei

$\begin{array}{ll}-80, & -81 \\ -8+1 & -8 ;\end{array}$

344. Man. Level of caudal extremity of inferior olivary nucleus

$-02,-03$

$-06$

$-0-$

Si) I

345. Man. Level through middle of inferior olivary body .

$80 ;$

$80^{-}$

$34^{6}, 34^{-}$. Man. Level of the vestibular nuelei $\ldots \quad 812,813$

$34^{8}$. Man. Level of the cerebellar nuclei. .

800

349. Man. Level of inferior portion of pons and emergence of sixth nerve

816

350. Man. Level of the middle of the pons Varolii

818

$82 \mathrm{I}$

35I. Man. Level showing the emergence of the fourth or trochlear nerve.

$82 ;$

352, 353. Man. Level of the inferior colliculus.

828,820

354. Man. Level of the superior colliculus.

.831

355,356 . Man. Level of the optic chiasm.

833,834

$35^{-}$. Man. Level of the anterior commissure.

835 
$338,35 \%$. Lateral surlace of gray matter of brain stem, IJomo sapiens (color)

3(x). Dorsal surlace of gray matter of brain stem, l Jomo sapions (color)

361. Ventral surface of gray matter of lorain stem, I lomo sapiens (colon)

362365 . Fur views of an endecranial cast of a morlern louman skull.

$3^{6}\left(6-3^{-1}\right.$. Six views of the enderanial cast of Pitheanthropus erectus (Jivan Apemin)

$3^{-2} 3^{-}+$. Comparison of endecranial casts of gerilla, Pithecanthropus and llomo sapions

3-5. Functional featization of the brain outlined upon the left hemisplece ol the endereanial cast of Pithecanthropus crectus

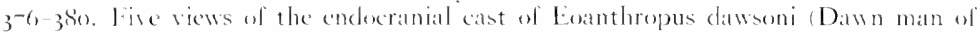
Piltdown).

3 fis. Functional localization of the brain wetined upon the left hemisphere of the endecranial cast of linanthropus. Piltelown.)

$3^{K 2} 3^{8-}$. Siv views of the enderanial cast ol flome neanderthalensis.

388. Veanelerthal llint workers

$3(x)-303$. Five vieus of the endereranial cast of the La Quina skull

30) 30x. Sin viens of the enderamial cast of the Cibraltar shull.

f(w). Functional lexalization of the brain outlined upon the led hemisphere of Ilomo neanderthalensis I il Chapelle aux Saints)

41. Finctional localization of the brain outlined upen the left hemisphere of the Predmost endecranial cast

41 3. Cro-malgnon artists making fresco in care of font-de-Gaume

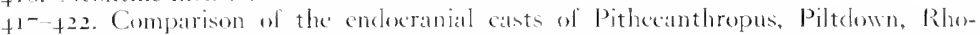
desian, Veanderthal and Predmost with mokern l lemo sapiens. y3t

+23 426. Size and contiguration of the dorsal and lateral surfaces of the human brain compared with those of lemur mongoz.

$42^{-}+30$. Size and conliguration of the dorsal and lateral surfaces of the human brain compared with those of Callithrix jacehus, the marmoset
4. Size and configuration of the dorsil and lateral surfaces of lomman bran compared with those of 1 frectes seniculus

43- 434. Size and configuration of the lorsal and lateral surfaces of louman bram com-

$433+38$. Size and contiguration of the dorsal and lateral surlates of the human brain compared with that ol Papou cynocephalus, the baboon.

compared with these of Pithecus rhesus, the macacus ofiz
$4+344^{6}$. Size and conliguration of the dorsal and lateral surlaces of the human bram

compared with these of Pithecus rhesus, the macalcus
$4+3+4^{6}$. Size and conliguration of the dorsal and lateral surlaces of the human bram compared with those of hylobates hoolock, the giblon

$44^{-}+50$. Size and conliguration of the dorsal and lateral surfices of the human brain

compased with those of Simia satyrus, the orang-outang. . . 9 3

$+51-4 ; 4$. Size and configuration ol the dorsal and lateral surfaces ol the human brain compared with those of Troglodstes niger, the chimpanzee . . . . . . (5)

$455-48$. Size and configuration of the dorsal and lateral surlaces of the human brain compared with those of Gorilla gorilla. . . . 98-

45). Principal primate horizons, showing coolutional aspansion of neopallium (color) 980 


\section{LIST OF ILLUSTRATIONS}

Irii

$1+1+1 \mathrm{kI}$

Pin

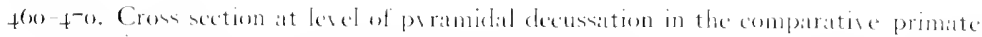
series.

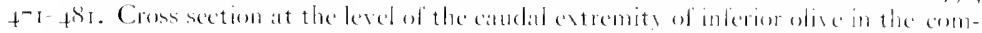
parative primate series.

$1(x), r(x))$

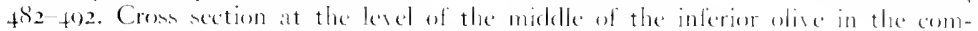
parative primate series.

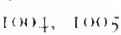

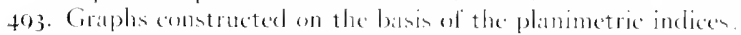

I (1) 10

$49+504$. Cross soction at the level of the vestibular nucled in the comparatioc primate sertes

I (1) 2, I 1113

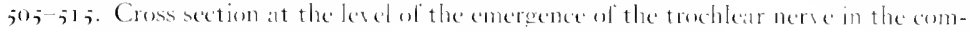
parative primalte series.

5o6. Graph based on planimetric indiees of the pontile nuclei

$1016,101^{-}$

$5^{--} ; 2^{-}$. Cross section at the level of the inferior colliculus in the comparative primate series

1022,1023

328-338. Cross section at the level of the superion colliculus in the comparative primate serices

1026, $102^{-}$

530. Graph based on planimetric indices of cerebral peduncle.

1028 



\section{INTRODUCTION}

THE PRIMATES: LEMURS, MONKEIS, APES AND IAN THEIR PLACE IN NATURE 



\section{THE BRAIN FROM APE TO MAN}

\section{INTRODUCTION}

Relative Importance of the Brain as Erolutional Evidence. Its Significance Compared with Other Parts of the Bods.

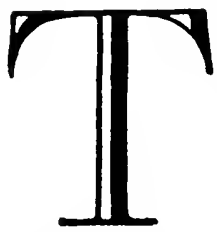

HE brain is conceded to be the master organ of the bods, the regulator of life, the source of human prouress. In this capacity how has it contributed to the evolution of mankind? Has it, as some authorities assume, passed through successive evolutional stages to reach its highest develepment?

Both of these questions imply the aceeptance of the Evolutionary Theory. If this hypothesis be correct, the human brain should prove an important witness in its favor. It may be expected to retain conclusive evidence of the evolutional process in at least three particulars:

1. It should manifest signs of its primitive origin from the lowest vertebrates (Fig. 1).

2. It should bear identifying marks of intimate asseciation with animals of its own class, the mammals (Fig. 2).

3. It should also have many specific details in common with members of the Primate Order to which man belongs, together with lemurs, tarsiers, monkeys and apes (Fig. 3).

A comparison of the human brain with that of its primate coordinates may thus become of utmost importance by disclosing the exact struetural basis of such evolution as has occurred in man from his carly prehuman beginnings. 


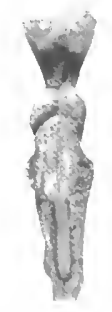

DOG FISH
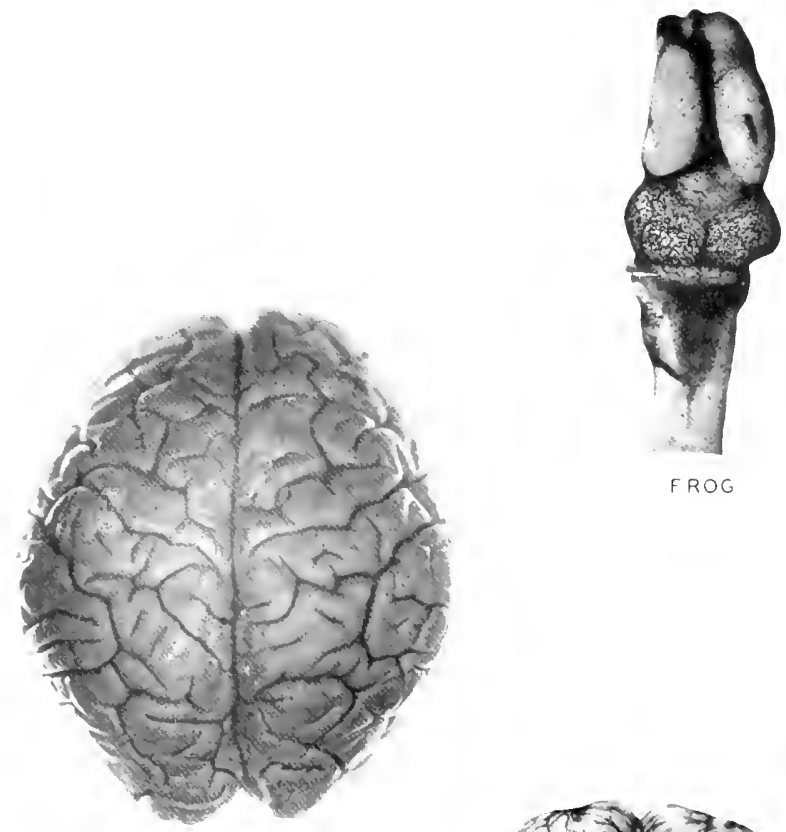

$$
\text { FROG }
$$

$$
\text { HUMAN }
$$

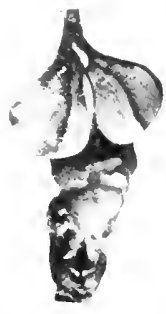

ALLIGATOR

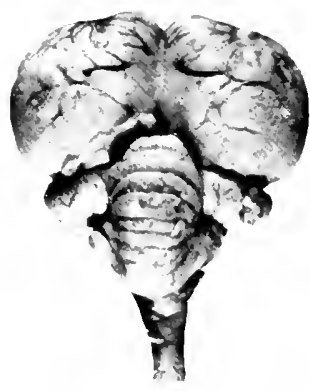

OSTRICH

FIG. I. BRAINS OF LOWER IERTEBRAIES COMPARED IITH TIIE HUILAN BRAIN. 


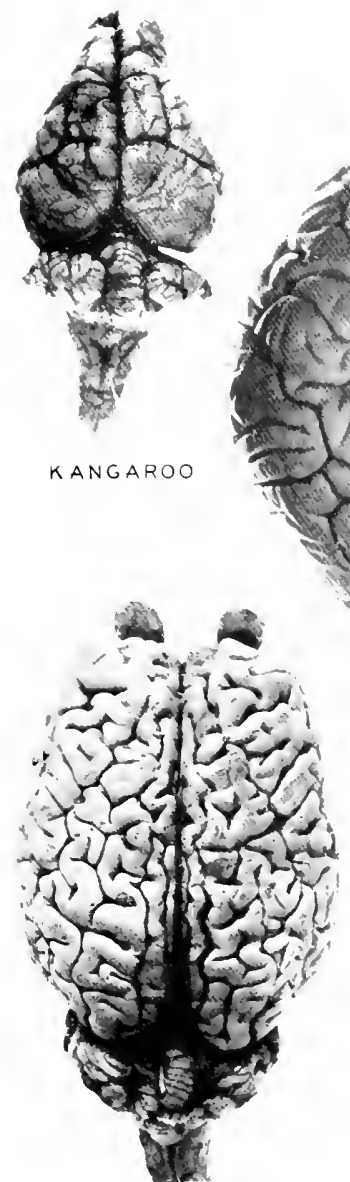

HORSE

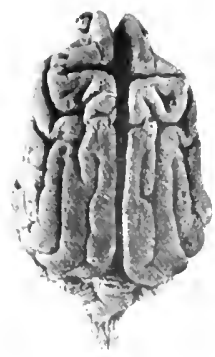

DOG

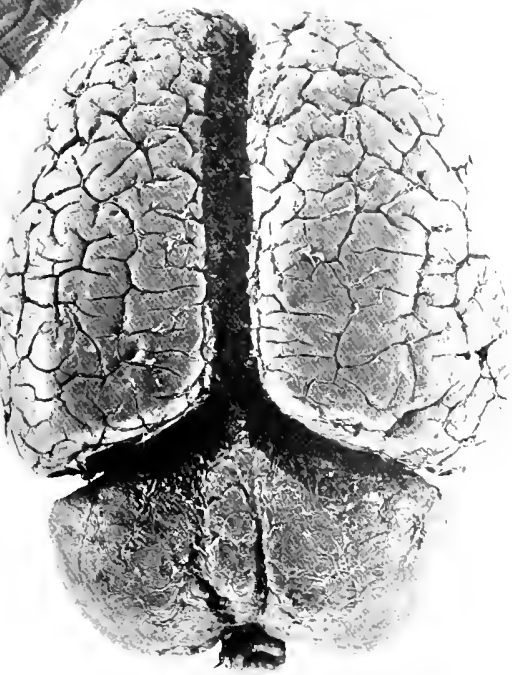

FLEPHANT

FIG. 2. BRAINS OF MAMMALS COMPARED WITH THE HLMAN BRAIV. 

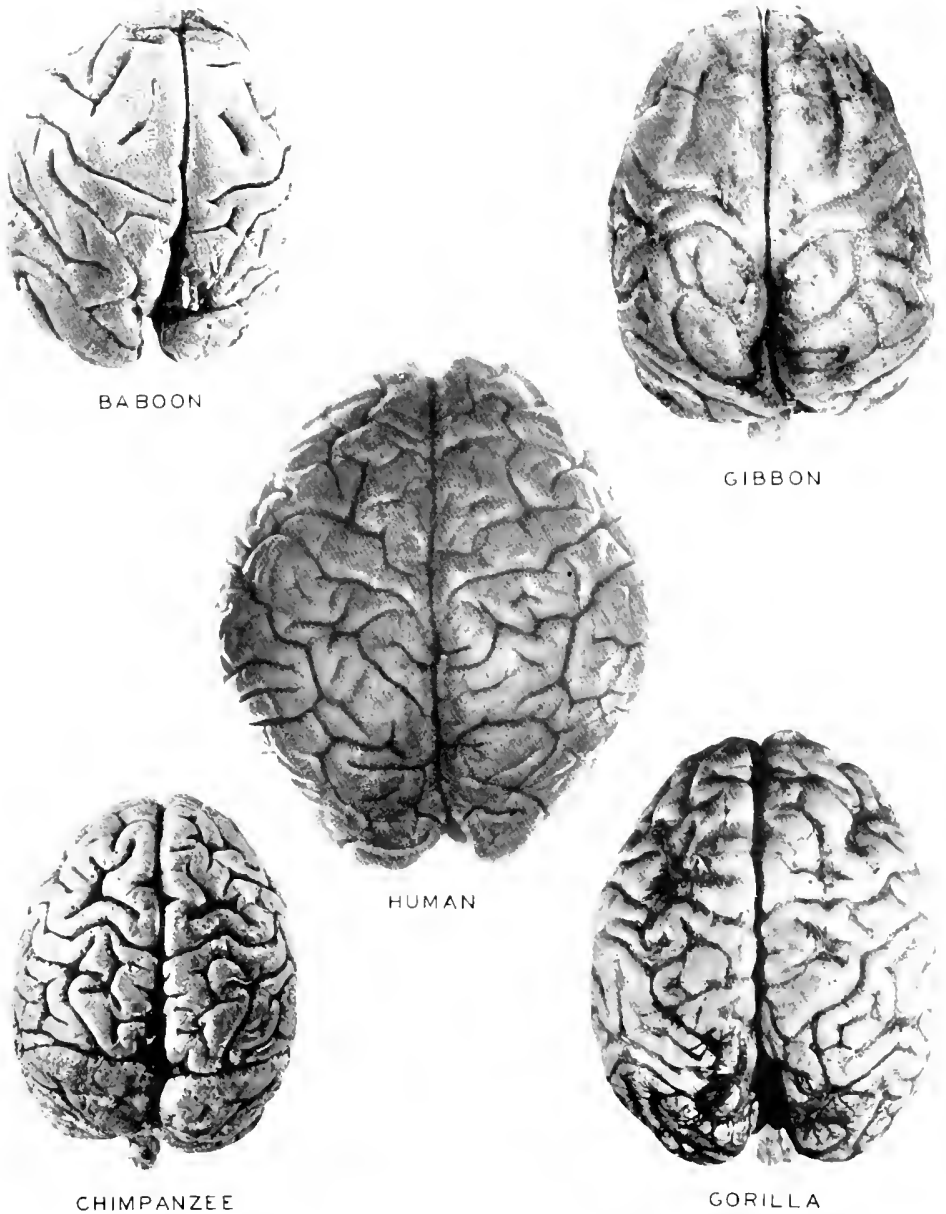

FIG. 3. BRAINS OF APES COMPARED WITH THE HLMAN BRAIN. 


\section{INTRODUCTION}

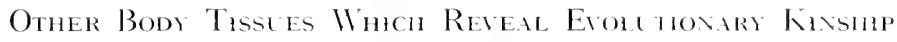
THE BLOOD

The actual existence of evolutionary hinship has already been revealed by many other organs and tissues of the body. The blosd, for example, has been most outspoken in this respect. Human blood serum injected inten the rabbit produces what is known as anti-human serum. This latter serum affords an exceedingly delicate test for human blood, either fresh or in the form of old and elried clots. If the blood tested be that of a domestic animal, such as the horse, sheep, pig or fowl, no reaction results from this scrum. Anti-horse serum, anti-sheep serum, anti-pig serum and anti-fowl serum may be prepared in a similar manner. These are sensitive agents for detecting the presence of horse, sheep, pig or fowl blood. An anti-serum may also be made for all animals and tests thus provided to detect the blood of similar species.

Investigations have shown that these blend tests may be employed to determine the degree of relationship existing between different kinds of animals. A prompt and often strong reaction is obtained only from the blond of the same species, while the blood of elosely allied species, such as that of the horse and donkey, gives a weaker, slower precipitation.

These precipitin tests support the supposition that there is some distant relation between the old-world monkers, apes and man. They atso make clear a less intimate relationship between the new-world monkeys and the human stoek. The lowest animals classified among the primates, the lemurs, give no, sign of blood relationship with man, although there is some indication of such a kinship with the lower new-world monkeys. Tarsius, however, is an exception to this rule. It bears a closer blood relation to man, simia and gibbon than it does to maeacus, the new-world monkeys or the cat.

Hemal tests demonstrate a relationship among all camivora closer than exists between carnivores and ungulates, while cetacean forms (whales and 

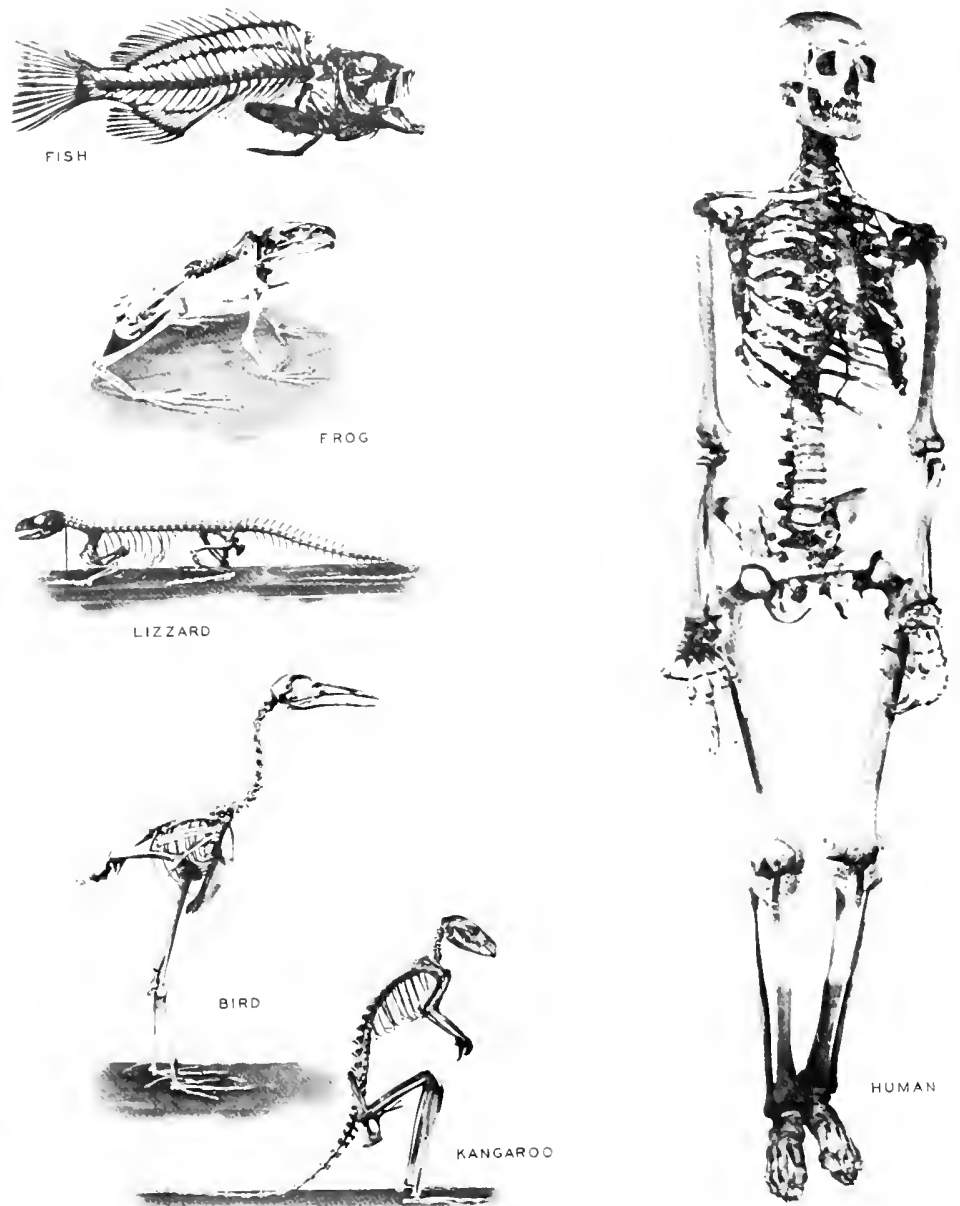

FIG. t. COMPARISON OF VERTEBRATES SHOWING THE ESSENTIAL 

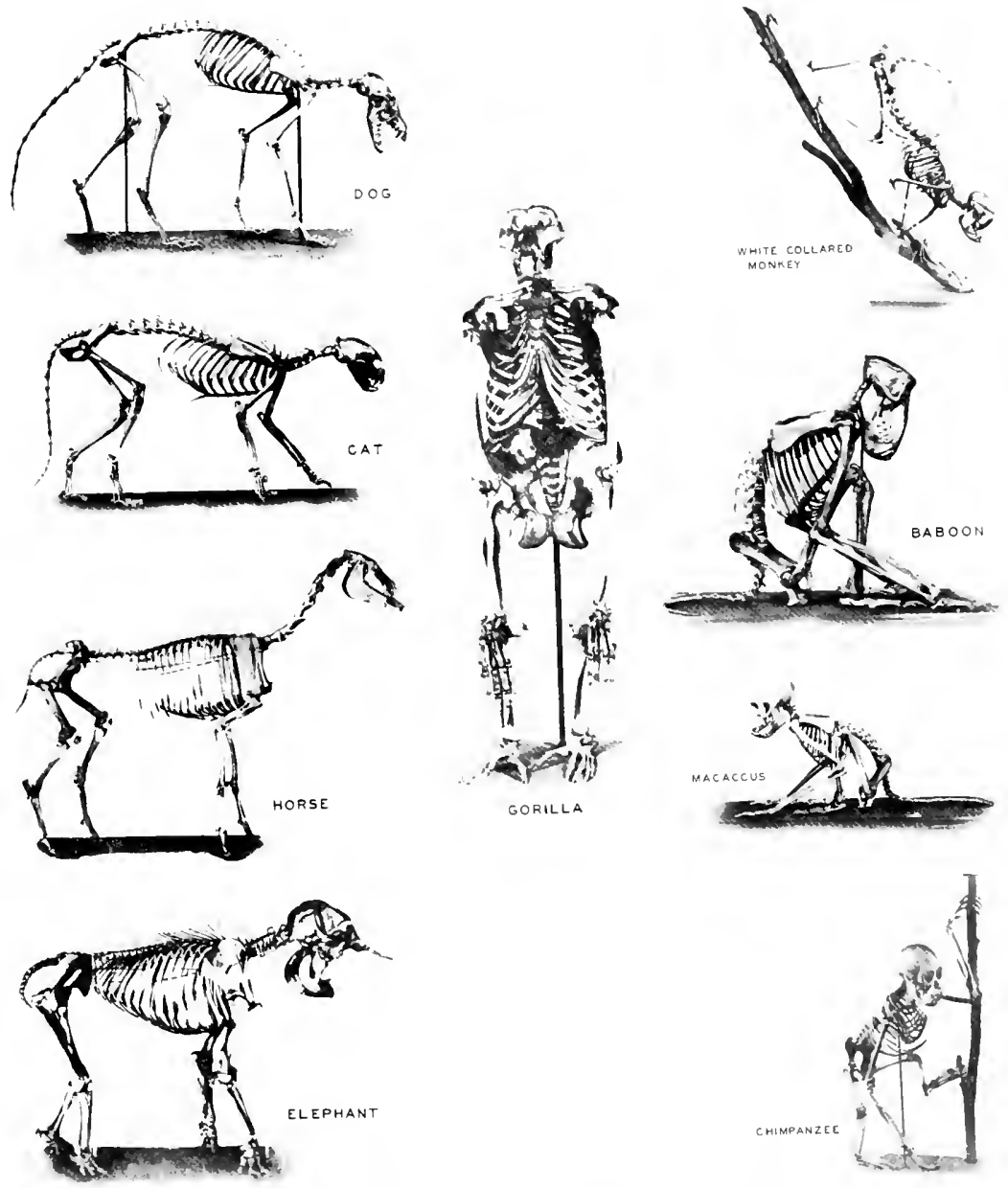

SIMILARITIES IN THE SKELETAL STRUCTLRES, FROM FISH TO MAN. 
porpoises) are more closcly allied to cud-chewing animals (ruminants) and pigs.

Blood reactions indicate that a strong interrelationship characterizes all reptilian forms, although there is some serial grading in these aflinities as among turtles, crocodiles, lizards and snakes respectively.

Avian blood tests show a striking similarity in the hemal constituency of all birds. This fact stands out in contrast to the mammalian blood which has a specilie variability in the intensity of its reactions dependent upon the order and family of the animals tested.

In general, the precipitin blood tests are among the most convineing proofs put forward in support of the evolutionary hypothesis.

\section{THE BONY SYSTEM}

The bony system of the body (Fig. $f$ ) is also an illuminating recorder of evolutional kinship. The skeleton of the fore- and hindlimbs sheds much light on the modifieations connected with the locomotor apparatus. In aceordance with the limb specialization as funs, paddles, wings, hoofs, paws, claws, hands or feet, the general propinquities in kinship may to a certain extent be estimated. The size and shape of the skull are equally significant in determining an exalet elassitication of species.

THE MUSCULAR SYSTEM

Another significant index of a zeneralized ground-plan in vertebrate organization is the muscular system. This system, while it demonstrates the great stability underlying the motor apparatus, discloses a llexibility capable of providing for the special needs of aquatic, amphibian, terrestrial and aterial life. It thus reveals propinquities in kinship amongst animals which have adjusted their locomotor apparatus to similar or closely allied conditions of environment. 
THE IIEART AND LETGS

The heart and the lungs afford important evidence of vertebrate relationship and evolution. The increase in specialization of the respiratory apparat tus, from the gill stages of the fish to the conditions of the mammalian pulmonary organs, is a most reliable means of distinction between classes and orders.

Eubryogenesis as Evidexce of Eyoluthonary Kinship

And finally, embryogenesis, coming as a cumination of reproductive activity, discloses the fact that all vertebrates-fishes, amphibians, reptiles, birds and mammals however different their form, habitat, mode of life and behavior - are cast in a structural mold of development faid down in accord with a common plan.

Each department of structural organization in the body contributes adequate testimony of a common ancestry. But no one of them portrays more than a single phase of rertebrate adaptation. Thus the blond represents the metabolic and biochemical adjustment of the animal. The usserns system and the muscles are indieative only of motor and locomotor capabilities. The teeth reveal the feeding habits and part of the protective meehanism. The genito-minary system bears witness to the variety of exeretory differentiation and the type of reproductive specialization. Embryogenesis summarizes the process of structural unfolding and thus discloses the general morphological plan of organization.

\section{The Brain as the Most Comprehensive Record of an Eiglutional Process}

The reasons why the brain contains the most comprehensive record of the evolutional process are readily perceived. As an organ its influences pervade and dominate all other systems of the body. It is the great trans- 
former of chergy which integrates all parts into a harmonionsly acting machine. It interprets all impressions from without. It projects all impulses from within. In its dual capacity of servant and master the brain has been peculiarty susceptible to the influence of that combination of factors described by Professor Osborn in his tetraplastic theory of evolution. The cerebrum has felt more, perhaps, than any other organ, the effects of action, reation and interaction. It has responded more extensively to its inorganic and vital emvironment because it comprises the most highly differentiated tissue of the organism. It has been equally sensitive to the influence of heredity-chromatim and life (cologrical) enviromment.

\section{The Comparison of the Human Brain whi the Brans of Other Prhates}

A structural comparison of the human brain with the brains of other members of the primate order illustrates in detail the progressive modifications in this evolutionary process. In this comparison the brain of man for many obvious reasoms is placed at the head of this order. It has been compared with the brains of Trogkodytes gorilla (gorilla), Troglodytes niger chimpanzee), Simia satyrus (orang-outang), Hylobates hoolock (gibbon), Papio cynocephalus (baboon), Macacus rhesus (common old-world monkey), Mycetes seniculus (South American howling monkey), Callathrix jacchus (marmoset), Tarsius spectrum (tarsier) and Lemur mongoz (lemur). These species comprise representatives of the highest and lowest primates.

The lemur represents the transition from some mammalian form which was predominantly arborcal. The weight, size and celerity of this animal adapt it especially to a Jofty arboreal habitat.

In most of the new-world monkeys the development of a prehensile tail greatly extends the range of motor activity. Due to increasing size and weight of body, the larger apes have shown a progressive tendency to desert their 
more inacessible arboreal retreats and approach nearer to the ground. The transition form semi-arboreal habitat to completely terrestrial life has culminated in the develepment of the ereet posture and plantigrade locesmotion with tree climbing but an incident in bipedal adjustment.

\section{CERTAN FLNDAMENTAL ADJLSTMENTS OF REHAIIOR}

In making the comparison of these primate brains, the chief object has been to note the struetural changes whereby the evolutional process has been advanced. Certain fundamental components of behavior have been simultaneously studied in relation to these structural modifications. These components include the following:

The development of the prehensile tail, its recession and final disappearance

The progressive adaptation of the hand for manual performanes other than those conecrned in focomotion

The adjustment of simultaneous movements in the eves, head and hands necessary to the execution of skilled acts

The gradual assumption of the erect posture

The increase of volitional control of the arms and the legs

The amplification of postural regulation in the body and extremities

The development and perfection of binocular vision

The progressive readjustments of visual, auditory and equilibratory reactions in passing from arboreal to ground-living habits

The modification of the automatic associated movements induced by such adjustments.

In comparing these species one with another, it is possible to observe the reflection of certain behavioral adjustments as they are mirrored by the organic constituents of the brain. In some cases, the range of variation in these behavioral reactions is so wide as to create most outspoken differences. 
Again, in closely allied species the contrast is not pronounced or convincing; but by comparing members in the primate group standing phyletically far apart from each other, the essential differences between them gather the full forec of their evolutional significance. They leave no room to doubt that a progressive functional development has gone hand in hand with impressive evolutional modifications in the structure of the brain.

\section{Bonds of Kinship hiong the Prinlates}

No attempt has been made to arrange the speeies in exact serial order. Such elassification would be open to numerous objections. A brief panoramic view of the primates may, however, disclose the broad bonds of kinship which link them together in the foremost place of the vertebrate phylum. One feature in this panorama is expecially noteworthy. There has been a strong tendency among the vertebrates to take refuge in the trees, cither to escape predacious contemporaries or otherwise to foster the opportunity to live. Its obvious purpose is to increase the measure of safety by extending the radius of retreat and making ascent from the ground a real biological advantage.

\section{MODIFICATIONS INDLCED BY TREE-DHELLING}

With the advent of the primates, this arboreal tendency was diverted into still another channel. Here it took the turn of affording an almost complete permanency of abode rather than a refuge in time of emergency. Such a change to more or Jess permanent tree-dwelling could but induce farreaching modifications. Not only did this life create a new type of habitat; it at once enforeed a new moke of transit orer the leafy highways of the tree tops. In order to obtain proper adjustment for such transportation, both hand and foot acquired the qualities of prehensile organs. Locomotion of this kind eventuated in the development of quadrumanal characters, with the foot 
departing from its more ancient patterns of hoof, paw or chaw and assuming the nearly complete grasping powers of the hand. The tail atso, in certain instances, participated in this specialization for arboreal feomotion.

These physical modifications actuated by tree life were quite as emphatically angmented by psychic inlluences arising from the new habitat. The background of the lives of almost all of the primates has played a deminant rôle in molding their behavior. The primeral forests and jungles, in their perpetual semi-darkness, created a domain whose subtle powers made themsetves felt in all primate reactions. It might be that the forest stend on the edge of a wide plain with a clear opening from which to look across toward the distant hills. The psychological effect of these factors, it must be clear, determined certain decisive attitudes on the part of the animals toward their environment. For example, there could not fail to be an alluring temptation in the green plain and its expansive freedom. To venture into this open space, bowever, the early primates required mechanisms which they did not as yet possess. Certain dangers lurked in and over the plain. Predatory creatures of every kind were there reptile, mammal and bird Jying in wait for just such an excursion. For the time, at least, the semi-darkness was safer with its limited riew and real security in the upper highways out of reach of these preying enemies.

THE LEMLRS AND TARSIERS, SHOWING THE EARLIEST

MODIFICATIONS OF PRIMATE STRLCTURE

With the lemurs, perhaps, there came the first modifications of structure leading to the more conspicuous groups of the primate kind. These animals, with their slender, furry bodies, their fox-like heads, their widely separated eyes and bushy tails, showed in both hands and feet the beginning differentiation of fingers and toes. This adaptation marks the transition from some lower form of mammal to the primates. It was in an epochal modification 
such as this that the primate order had its origin. Then began a tenancy of the trees which profoundly influenced these animals as they passed through their many and varied adaptations. Tarsius, in many respects even more than the lemurs, illustrates the effects of these new influences.

\section{THE CEBIDAE FORLSHADONERS OF A NEW RACE}

It is diflicult to discern the exact point at which the Hapalidae, most lamiliarly represented by the diminutive marmosets, took departure from the early beginnings of this primate line. Their appearance on the seene was probably a retrogressive step in the development of the new-world monkeys. Their smatl size, their lack of power both in body and brain, would scarcely permit of a dominating adjustment to their enviromment. In many respects their organization was inferior to that of the lemurs. This is particularly true in their manual differentiation, since the derelopment of their fore- and hindlimbs tended much more toward claws than hands. Nevertheless, for all their insignificance, there was that about them which suggested the (oming of a new race. The configuration of the head, the expression of the face, the relation of the eyes, the shape of the nose, the position of the mouth, all were prophetic of the more definitely ape-like tribes which were to follow. The arrival of the new-world monkers at length introduced all of the major simian characters. Throughout the large family of the Cebidae, quadrumanal development is well established. Most of the members of this group have also acquired prehensile tails.

INILL EXCES ACTIVATING MODIFICATION WHICII PRODLCED OLD-WORLD CONGENERS OF PRIMITINE SIMIANS

What influences activated the modification which produced the oldworld congeners of these South American simians is not clearly understood. It may have been a progressive tendency to increase in weight, added to the 
waning importance of the tail. In any event, the old-world monheres do not develep prehensile functions in their tails, and many of them, like the babenons, have ventured out of the trees to live more upon the enround. Mest of the latter show a distinct dogr-like development in mexde of life, in size and in form of body. In the gribbons for the first time is established the atsitity to walk upright, but with these animals forest life is still predominant in its influence. By means of their long arms they are capable of swinging from branch to branch with a marvelous agility. The absence of the tail in them, and the partial assumption of the ereet posture, are most significant as forerunners of developments in the larer anthropeids. In these latter a creat increase of weight enforced the habit of living nearer to the ground.

The first of these large anthropoids, the orang-outang, still shows its ancestral adherence to the forest, although it is able at times to stand and run. The chimpanzee, while it has great cleverness in climbing, secks the ground oftener and has learned to walk upon all fours, using the knuckles of the hand as a support in this act. Finally, the gorilla, often attaining the great weight of nearly four hundred pounds in adult life, has becn enmpelled by this reason to seck the support of the earth and only at times makes use of the heavier portions of the trees for refuge or retreat. Still, so indomitable is the arboreal tendeney, even in these great animals, that they have made but imperfect terrestrial adaptation and also at the same time they are only partially suited to tree life. Were it not for their prodigious strength, their limited arboreal activities woukl be even further curtailed.

All of the man-like apes are eapable of the upright posture, of standing and walking on the hind legs but in an awkward, inefficient manner. This is due to the fact that the foot in all three of these animals maintains predomimant characters of the hand and atfords at best an imperfect basis for bipedal locomotion. Y'et, notwithstanding such limitations as long, Cragging arms and inadequate feet, the great anthropoids are able to venture beyond the limit 
of their forest home. They are partially equipped to cope with some of the dangers lurking without. Their fordimbs are in part freed from the responsibilities of locomotion and so made avaibable for atets of self defense and even, to a considerable degree, for exploration.

Actual progress in the direction of human specialization had its beginnings in this recession of superarboreal tendencies and the establishment of a terrestrio-arboreal mode of life. Such a gradual recession may be seen in this panorama of the primates. It is apparent in the first indecisive yet promising steps that led the anthropoid out of his ancient forest dominion toward the inviting plain. And finally, with the complete recession of arboreal life, there began that long journey destined to lead over every sea and into every land, until no region of the carth remained for further concluest; until the complete acquisition of the upu ight posture and the full development of the hand had more and more bent the forces of nature to the designs of the races of man.

\section{Braix Developient Paralleling the Progressive DeVElopMent of Behatior}

Step by step the brain has kept pace with these progressive alterations. Its newer, recently aequired portions reveal a much more conspicuous response to this progress than its less plastic, more archaic elements. But old parts and new alike, aceording to their varying degrees of susceptibility, bear the certain imprint of adaptive change. Among the primates the biological formula determined by quadrumanal specialization and arboreal habitat has worked itsclf out through graded stages from lemur to man. The coolutional process of this gradual transition is disclosed by structural modifications of the nervous system. Beginning with the Lower Primates, such as the tarsiers, the advance may be traced through many intermediate phases of cerebral development to its ultimate goal in the humau brain. 


\section{PART I}

THE LOIIER PRINATES 


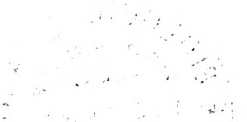




\section{INTRODUCTION TO PART I}

DHOSE mammalian forms oceupying the upper estremity of the
vertebrate phylum have, since the time of Linnateus, been known at
Primates, or chicf of mammats. It was Linnacus who, recognizing the anthropomorphous characteristies of this large group, created the term to designate their order. He further subdivided them into Humans, Simians and Prosimians.

\section{Tile Suborders ax the Order of Primales}

At present the orcter of primates is arranged in three suborders: (1) Lemuroidea, (2) Tarsioidea and (3) Anthropoidea. The first of these includes all of the prosimian forms of the lemur kind, while the third comprises all families of actual simians and man. Accorching to this arrangement the tarsiers oceupy an intermediate position between the other two suborders.

The following are the acepted families of these three suborders:

Suborder Lemuroidea:

Daubentonidac

Nycticebidae

Suborder Tarsioictea:

Tarsiidae
Suborder Anthropoidea:

Hapalidae

Cebidae

Lasiopygidac

Hylobatidac

Simiidae

Hominidae

In this discussion a slight rearrangement has been made to serve the purposes of presentation and at the same time to observe the dictates imposed by certain morphological similarities in the brain. Aceordingty, the primates are here considered in four distinct divisions: First, the lower primates which comprise the lemurs, tarsiers and alf of the new-world monkers (including 
marmosets and the Cebidae). The second group, or intermediate primates, includes all of the old-wortd Catarhine monkeys with the exeeption of the three ereat anthropoid apes. The third group, called the bigher anthropoids, inclueles the orang, the ehimpanzee and the grorilla; while the sole oceupant of the fourth group is Homo sapiens, although referenee is made to certain features in the development of the several races of prehistoric man. 


\section{Chapter 1 \\ LENUR MIONGOZ, ITS BRAIN AND BEHAVIOR}

Its Position among the Primates; Measurements and Brain Indices; Surface Appearance of the Brain; Internal Structure of the Brain Stem in Cross Section

7 PHE lemurs, so called because of their nocturnal and ghostly habits, represent the fowest level of primate organization. In all, there are I some fifty species of these animats referable to seventeen genera. Thirty-six of these species are indigenous to Madiagascar and its small adjacent islands. The remaining species have their habitat in Ethiopian and oriental regions. It is a fact of much interest that the rest of the world is quite devoid of these animals, although fossil remains indicate that the lemurs were much more widespread thronghout the globe in some earlier geotogical period.

External Appearance of the Lemur (Figs. ; 6 and 7)

The external appearance of the lemurs justifies the establishment of a suborder to contain these animals. They are readily distinguished from the apes and monkeys constituting the higher suborder of primates. One important distinguishing feature is the head, which in lemurs is more like that of the fox and is drawn out into a long muzzle. The face lacks the humanoid expression characteristic even of the lower apes. The tail, which may be long, is not prehensile; cheek pouches do not develop, nor do integumental callosities occur, although all these characters are frequently met with in the apes.

The lemurs have certain striking resemblanees to other primates, especially in the opposable fingers and toes, flattened digits and pectoral mammae. In all lemurs the sceond toe is provided with a sharp nail entirely 
unlike the other fingers and toes; while in tarsius the third toe also is furnished with a simitar nail (Firs. () and 11 ).

Certain important divergences exist between the suborders of primates, which involve the digits of the feet and hands. In lemurs the thumb and great toc are always well dereloped, while the second or third digit constantly manifests some abnormality; as, for example, a remarkable elongation of the third digit in Chiromys, an the complete absence of the index in Potto (Figs. 12 and 13 ). In the Anthropoidea, on the other hand, it is the hallux and the pellex which are subject to most marked variation.

In size the lemur is abeut equal to the domestic eat. The fur is thick and often worlly in texture. The eyes are larere and prominent, the ears long, with tufts of hair on their upper portions. The arms are not quite as long as the legs. The tail, usually about half as bong as the body, is sometimes inclined to be bushy. Feshy pads appear on the palms of the hands and feet as well as upon the palmar surface of the finerers, thus permitting the animal to grasp the branches of trees with great tenacity.

\section{The Lemlo's Habits in the llid State}

Little is known of the kemur's habits in the wild state. It is not strictly nocturnal, for some species are seen in search of food during the day as well as at night. They go in troupes often consisting of many individuals. They are rery noisy and live in the forests. One species alone frequents rocky places destitute of trees; namely, Lemur catta. The animals live upon fruits of various kinds, insects, birds' eggs and birds themselves when they can catch them. During the heat of the day they sleep with the head placed beneath the arm and the tail curled about the neck. When walking they go upon the hands and the feet both on the ground and in the trees, the tail being carried above the body in the manner of a balancing or steering organ. Their lour limbs are primarity used in locomotion and only to a limited 


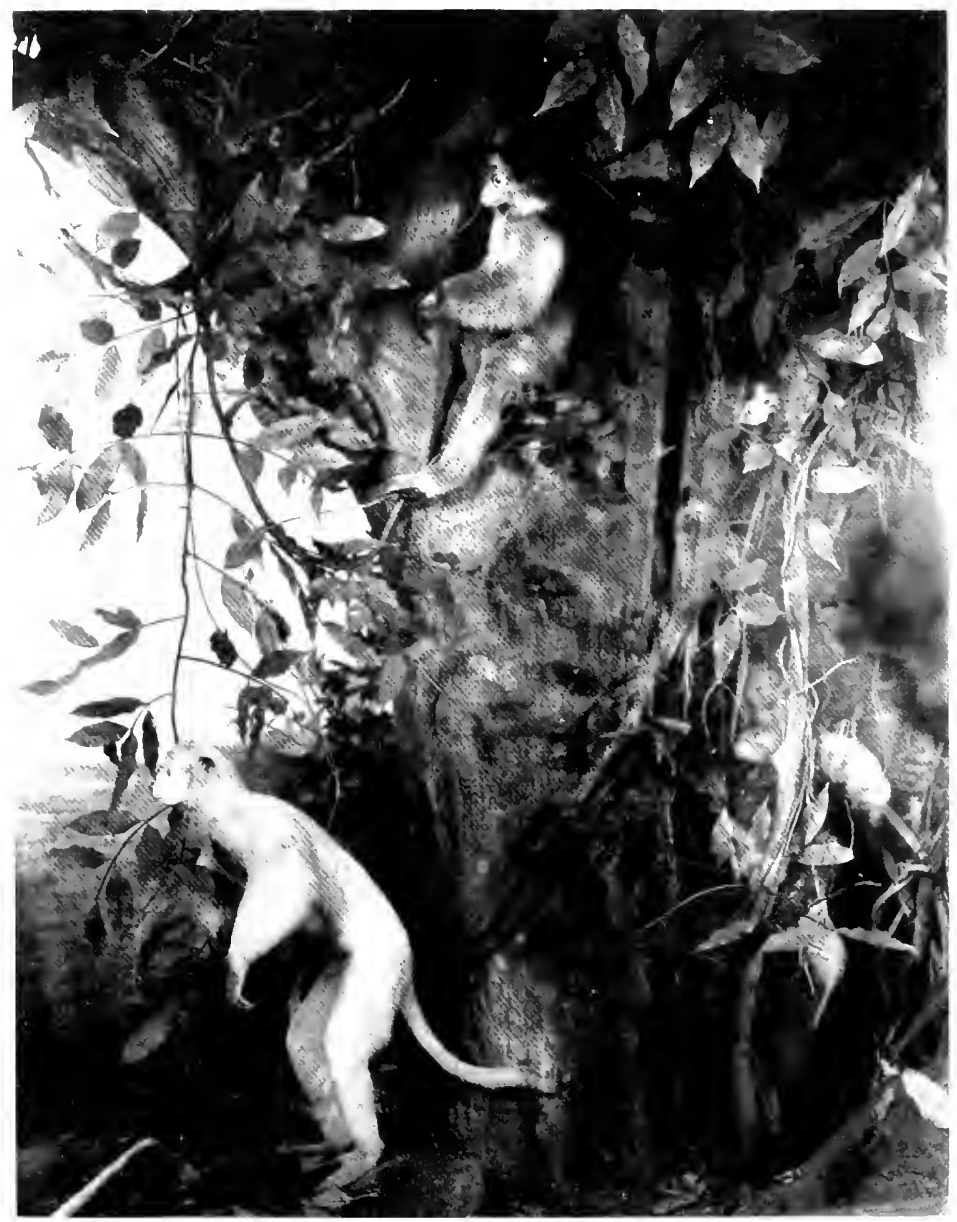

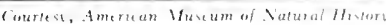

FIG. F. LEIILR GROLP IN II DAGASCAN HABITAT. 
degree serve the purposes of other volitional acts. The simulaneous movements in their eyes, head and hands neecesary to the exceution of skilled acts show a much more limited range of adaptation than in some of the higher apes. The tendency to assume the ereet position or to acquire a sitting pesture, eren in some partial degree, is not pronounced. Their derelopment of binocular vision is much less advaneed than in many of the Anthropoids.

\section{Actirites of Lentr Mongoz}

The first specimen of the Primates considered in this series is one of the sublamily Lemurinac, Lemur mongez.

This animal is clistributed along the northwest coast of Madagascar, from Baly to Marinda, and is also found in the islands of Anjouan, Comorro, Mohilla and Nossi-Be. It inhabits the forests and goes in large troupes, keeping to the uppermost branches of the highest trees. Its agility in leaping from tree to tree is most remarkable and so rapid that it can with difficulty be followed by the eye. Hunters say that it is easier to kill a bird on the wing than a lemur when leaping. If pursued, it has a habit of dropping suddenly frum the topmost branches into the bushes, giving the hunter the impression that the animal has been killed. This impression, however, is son dissipated upon seeing the lemur in another tree at a considerable clistance from the spot where it foll.

In the wild state the animals subsist largely upon bananas, but they are also fond of the brains of birds which they are most skillful in capturing. After fracturing the bird's skull with the teeth, as they might a nutshell, they suck the brain out of the brain-case. The lemur, however, does not eat the rest of the bird.

From this description of its activities, the great agility of the animal is evident, as is also the fact that it lives in an environment requiring the utmost 

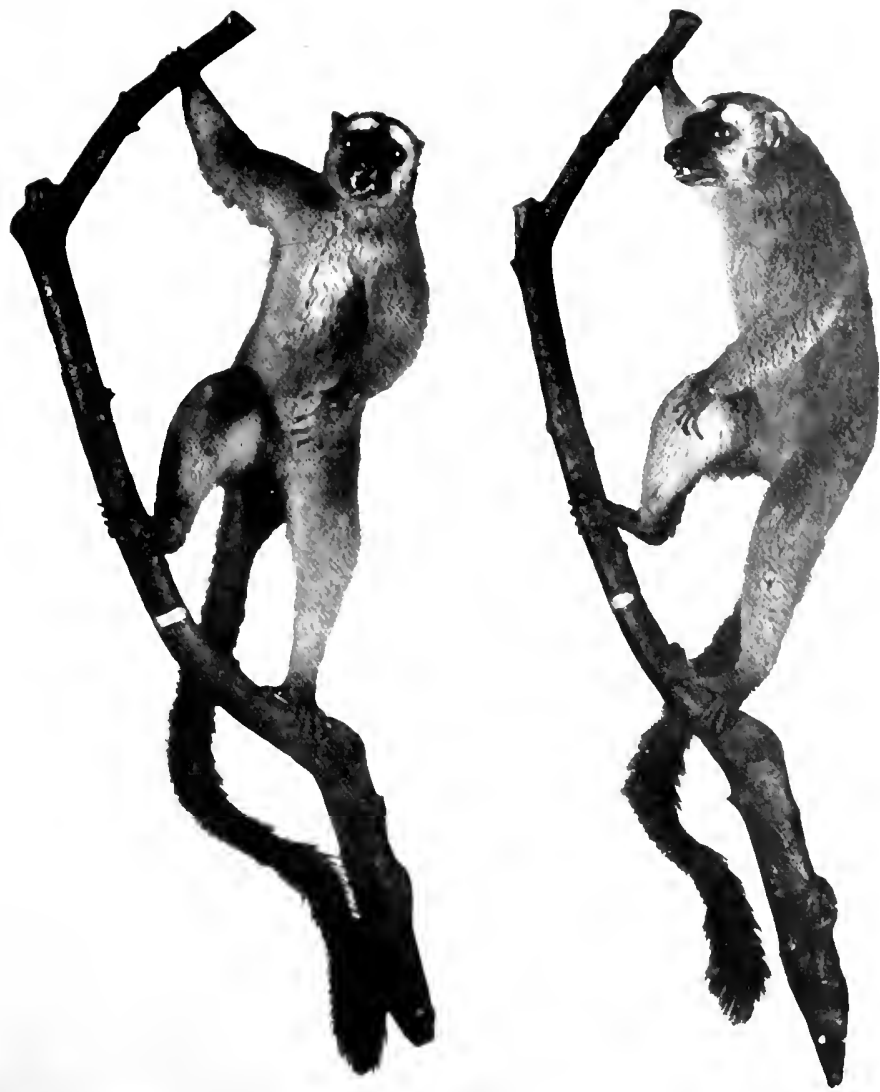

Courtesy, American Museum of Natural History

FIGS. 6 AND -. TWO VIEWS OF LEMLR MONGOZ. 
nicety in balancing and the greatest precision in all movements.

$$
\text { Measlrements and Indices of Lent R MoNgoz }
$$

The measurements of Lemur mongoz are:

Total length.

Skull in its occipito-nasal diameter.

Skull in its bitemporal diameter. .

Width of the brain case.
$8-6$ to $1,06 \mathrm{nmm}$.

76 to $82 \mathrm{~mm}$.

27 to 3 I $111 m$.

$3 ; \mathrm{nmm}$.

The dimensions of the brain, including the cerebellum and brain stem, are $t ; \mathrm{mm}$. longitudinally and $32.5 \mathrm{~mm}$. transversely.

Total weight of the brain I $8 \mathrm{gms}$.

Total water displacement 17 c.c.

Weight of the forebrain . . . . . . . . . . 14.5 grms. (inclading cndbrain and interbrain)

Weight of the midbrain. ............ $1 \mathrm{gm}$.

Weight of the hindbrain ............ $2.5 \mathrm{gms}$.

Upon the basis of these figures the following encephatic indices have been computed for the several divisions of the brain:

Fordbrain index

Midbrain index.

Hindbrain index.
8 I per cent

j per ecnt

$1+$ per cent

A forebrain index of 81 per cent definitely aligns this animal with those forms in which the inception of manual development is already under way. The highest forebrain index of what may be called the submanual group, such as the dog, cat and horse, is 80 per cent. The lemur marks the transition line between the manual and submanual groups. 


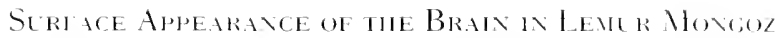

TIIE ITSLRAL PATIERX

Since it is the purpose of this comparative revien to deal with the structural evidenee of an adaptive unlolding in the brain, it will be impossible to present or discuss the morphologrical details with that completeness which might be expected in an atlas on the subject. Especial emphasis is laid upon structural features deemed to pussess the greatest evolutional signifuance. On the other hand, the elfort has been made to present the necessary topographical correlations appearing in the several different levels of the brain.

Thus, certain prominent features on the external surface of the brain appear to have such decisive erolutional signilicance as to reguire extended consideration. Other features are, so to speak, structurally incidental and are mentioned largely for purposes of identification and topography.

The type of the cercbial hemisphere of Lemur mongoz (Figs. 16 and $\mathrm{I}^{-}$) is graencephalic. It presents a relatively simple fissural pattern. There is a general temdency for the major fissure lines to arrange themselves about the Sylvian suleus, as is the rule in many of the errencephalie mammals of the lower orders. On the other hand, the circumsylvian disposition of the suke in lemur shows a distinct tendency to depart from that concentric arcuate arrangement so characteristic, for example, of the carnivores. The angulation of the fissure of Sylvius in lemur with the base line of the brain is between $j 5^{\circ}$ and $60^{\circ}$. The definite circumferential amangement of the other fissures which surround the fissure of Sylvius disappears to the extent that there may be found only a remmant of the postsylvian sulcus in the form of the suleus parallelus or superior temporal fissure. The sulcus lateratis also has lost much of its circumsylyan disposition and now exists as the main portion of the interparietal fissure. A well-defined sulcus in the area of transition between the frontal and orbital surfaces constitutes the fronto-orbital sulcus 
and indicates in a general way the pesition of the inferior frontal sulcus of the higher primates. A faint indentation on the boundary between the parietal and the frontal lobes marks the position of the sulcus centralis, but no
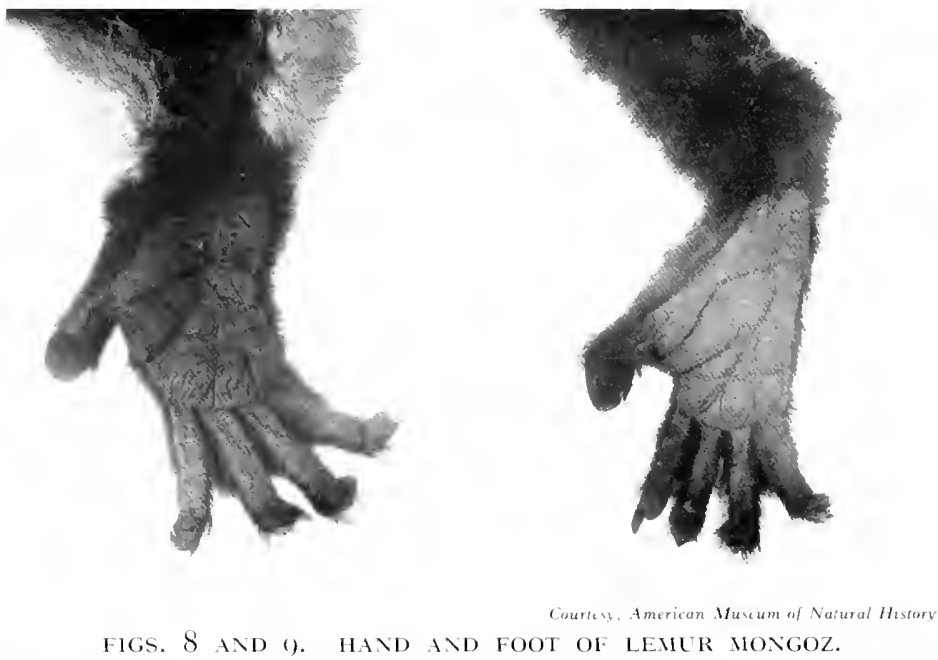

FIGS. 8 AND (). HAND AND FOOT OF LEMUR MONGOZ.

L.F. Palmar surface of hand showing digitation, palmar creases, phalangeal pads and opposable thumb. Rerim. Plantar surface of foot show ing plantar creases, digitation, long toes, plantar pads, distal phalanges and epprosible great toc.

fissural marking corresponding to the sulcus simiarum or any occipital marking on the lateral aspect of the brain is apparent. In fact, such expansion as has oceured in the differentiation of the occipital lobe confines itself almost exclusively to the mesial surface of the hemisphere. This primitive development of the oecipital lobe leaves a large portion of the cerebellum still uncovered by the overhanging cerebral hemisphere. It thus determines a condition intermediate between the cerebral development in all the monkeys and apes (in which the cerebellum is completely overhung by the cerebral hemisphere) and in lower mammals such as the carnivores (in which the cere- 
bellum is not so covered). The hemisphere of lemur is in many respects intemediate and transitional between the lower mammals and the higher primates (Fig. I 8 ).

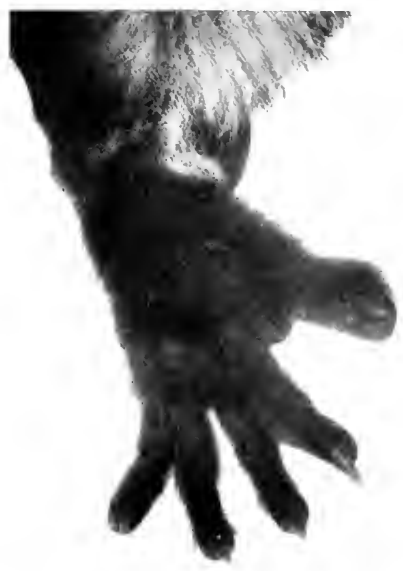

FIGS. 10 AXD I 1 .

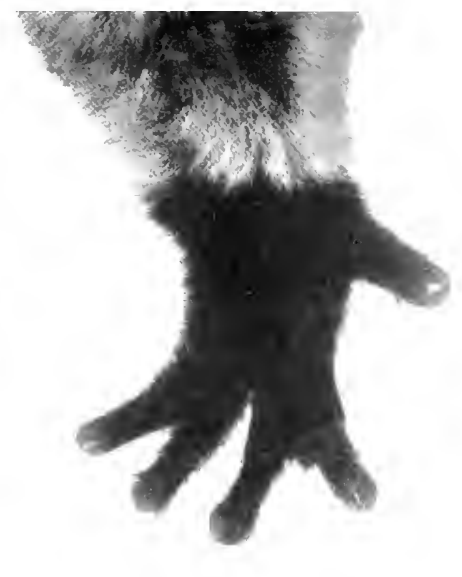

Courtest, Amercan Huseum of Natural History

OOT OF LEMLR MONGOZ.

LEFT. Dorsum of hand showing discrete digitation with tendency to syndactyle.

Right. Dorsum of fort showing toe-nails, digitation with marked syndactyle, and opposible great toe.

CONVOLUTIONS, LOBES AND OTHER SLRFACE CIARACTERISTICS

In the convolutions of the lemur brain only the first tendency may be scen to develop that gyral arrangemnet which is characteristic of the apes. The lobation of the hemispheres is correspondingly limited, the boundary between the frontal and parictal lobes existing as a faint indentation indicating the inception of the sulcus centralis. The division between the parietal and temporal lobes is more chearly defined in the boundary line established by the Sylvian fissure.

The temporal lobe has shown but slight advance over what is characteristic of the carnivores, with the possible exception of the disappearance of 
the rhinal lissure on the lateral aepeet, and a slight further protrusion down"lard of the tip of the temporal kbe. Noactual distinction of an oceipital lobe can be made upon the lateral surface although the mathings on the mesial
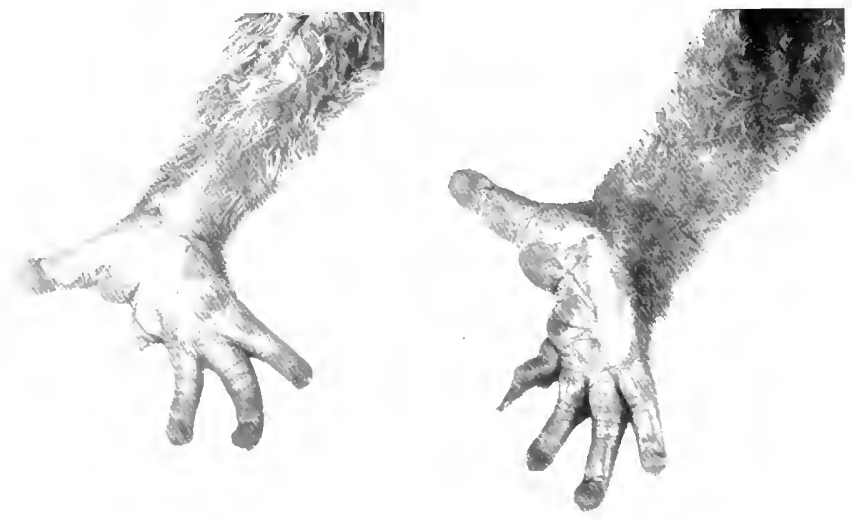

Courtest, Ameracan Museum of Vatural Hastors

FIGS. 12 AND 13. HAND AND FOOT OF LEMUR POTTO.

1.r.r. Palmar surfice of hand huming rudimentars develepment of index finger, palmar creases and oppositble thumb.

Ruenr. Plantir surfice of foot hrowing rudimentary acond toe and opposable hallux.

surface show that this specialization of the neopallium has afready begun to make definite expansions toward the execipital pole of the hemisphere.

On the orbital surface of the brain the two orbital concavities are fairly well marked. This surface has a general obliquity outward, which increases the prominence of this eoncarity and permits the orbital plane to pass over into the frontal surface without sharp angulation in the region of transition. The interorbital keels are well marked. The olfactory bulb is large and detachable for a certain distance, although the offactory tract is short and not detachable. The latter shows its greatest development in its lateral roots 
extending backward into the Sylyian fossa and exposing at trigomum olfate torium larger than in the higher primates. In the oecipital region there is a deep oceipital concavity, particularly about the midline, where the superior
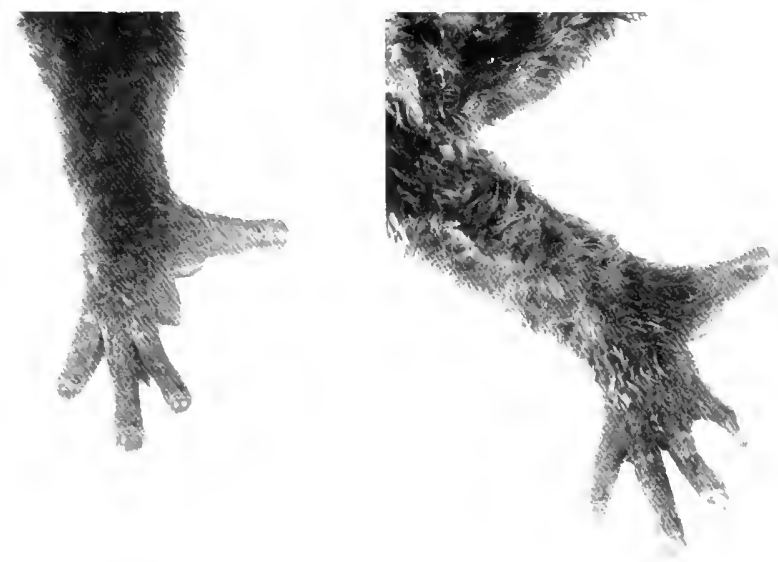

Courtes, Ametican Muscum of Nabral Hovor

FIGS. It AND 1 j. HAND AND FOOT OF LEMLR POTTO.

LEFT. Dorsum of hand showing finger-nails and moderate syndactyle.

Right. Dorsum of foot. Syndactyle net su conspicusns as in Lemur mongoz.

vermis of the cerebellum is lodged in what may be called the postsplenial fossa. The cerebellum in its tentorial surface presents a prominent superior vermis which appears as a ridge-pole in this sharply gabled surface. Its lateral extension is short because of the limited cerebellar hemisphere. The oceipital surface of the cerebellum shows the vermal portion as the most pronounced structure in this area, with two rather insignificant lateral extensions forming the hemispheres (Fig. 18).

The cerebellum of the lemur shows none of the tendency to form a vallecula into which the vermis gradually sinks on aceount of the increasing 
prominence of the lateral cerebellar lobes. In other words, the vermis cerebelli is equally as conspicueus as the lateral lobes.

In the tentorial surface, the folial sulei extend without interruption from
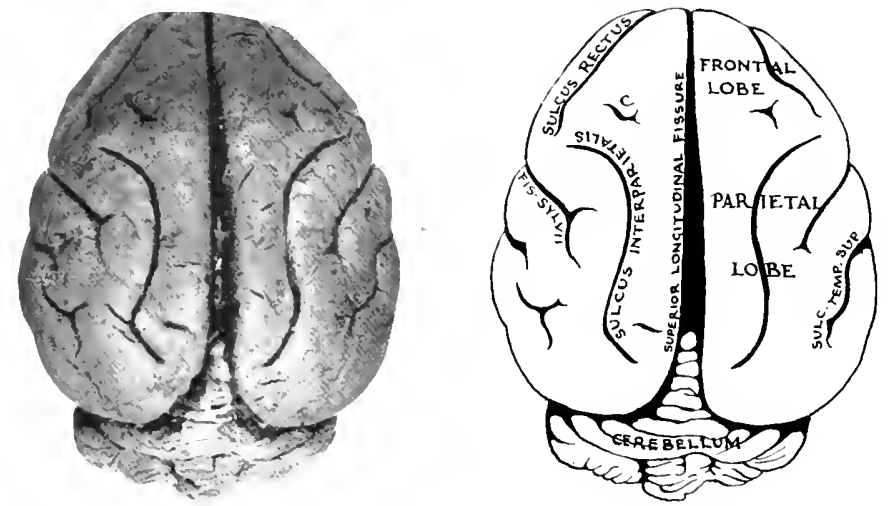

FIG. 16. DORSAL SLRFACE OF BRAIN, LEMLR MONGOZ.

[Actual Jength, $+3 \mathrm{~mm}$.]

Key to Dhagran. C., Sulcus Centralis; 11s. Silvi, Fissure of Sylvius; sterc. TEup. Sup., Sulcus

Temporalis Superior.

the vermis to the lateral lobes. On the occipital surface, however, two lateral paramedian sulci interrupt the course of the interfolial grooves, as they pass from the vermis to the lateral lobes.

\section{THE BRAIN STEM}

The markings on the several surfaces of the brain stem are not so decisive as in many other species of primates (Fig. 20).

The Oblongata. The oblongata upon its ventral surface presents a ventromedian sulcus and two ventrolateral sulei. In the more cephalic portion of the ventral surface the ventromedian sulcus is tlanked on either side by the pyramids which, in turn, are separated from the inferior olivary eminences by the ventrolateral sulei. The pyramids become progressively less well marked as they approach their caudal extremity, at which point 
there are faint indications of the pyramidal decussation. Somecrossing pyramidal strands remain chese to the surface and these partially interrupt the ventromedian suleus at this level.
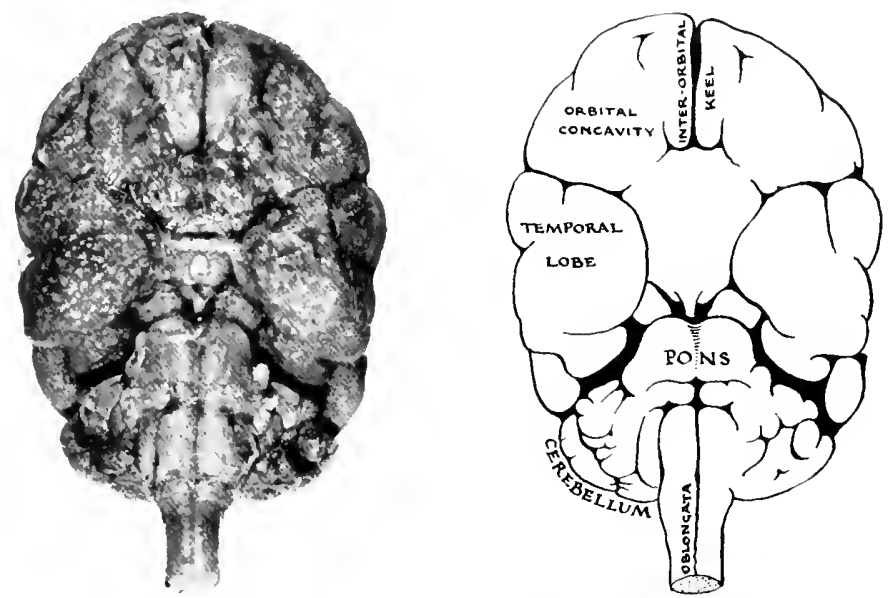

FIG. IT. BASE OF BRAIN, LEMUR MONGOZ.

(White dots are due to salt precipitation in fixative.)

The rather feeble relicf both of the pyramids and the inferior olives is taken to indicate a comparatively low organization in spheres of action which these two structures represent. In the case of the relatively insignificant pyramids the cortico-spinal connection between the motor cortex and spinal cord must be regarded as correspondingly small and volitional control of motion but poorly developed; likewise, in the case of the inferior olive, the lack of surface prominence suggests a relatively low degree of organization in the reflex control of simultaneous movements in eyes, head and hands, and in the facilitation of the coordination of all skilled learned performances.

The cephalic extremity of the oblongata on its ventral surface comes to an abrupt termination in the slight elevation produced by the pons Varolii, 
the line of demarcation between the pons and the oblongata griving rise to the bulbopontile sulcus.

At the point where the ventromedian suleus meets the bubspontile
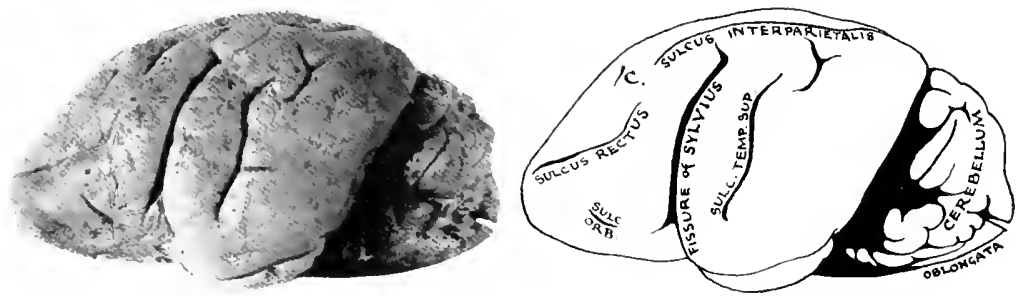

FIG. I8. LEFT LATERAL SURFACE OF BRAIN, LEML R NONGOZ. [Actual Length, f; $\mathrm{mm}$.]

Key ro Dhagkan. C, Sulcus Centralis; sulc. orb., Sulcus Orbitalis; sulc. tevp. sup., Sulcus Temporalis Superior.

suleus, there is a small blind pocket underlying the pons, the foramen cecum posticum. In the suleus between the inferior olive and the pyramid the twelfth nerve emerges from the oblongata (Fig. 20).

The Poxs Vגrolit. Continuing further cephalad, the brain stem is characterized by the presence of a relatively narrow and llat transverse band, the pons Varolii, lying in front of which is the optico-peduncular space. This space is bounded eephalically by the optic chiasm and optic tracts, and caudally by the convergent fibers of the cerebral peduncles. It contains the tuber cinereum, the region of attachment of the infundibular stalk, the postinfundibular eminence and the mammillary bodies.

A fairly well-pronounced median groove in the pons marks the position of the basilar artery.

In general, the degree of prominenee attained by the pons Varolii has been regarded as indicative of neopallial development. The pons provides ultimate connection between the cerebral cortex and cerebellum, and is 
necessary to the coordinative regulation of skilled movements. The small size of the pons in lemur thus suggests a poor capacity on the part of the animal to acquire or execute even a comparatively simple series of shilled acts.
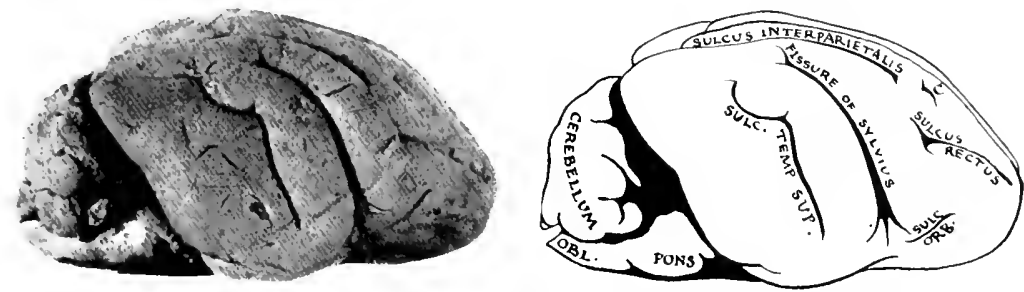

FIG. IQ. RIGHT LATERAL SLRFACE OF BRAIN, LEMLR MONGOZ. [Actu:al Length, $4 ; \mathrm{mm}$ ].

Lex to Dingram. C., Sulcus Centralis; obl., Oblongata; sule, orb, Sulcus Orbitalis; sele. temp. sup., Sulcus Temporalis Superior.

The Dorsal Surface of the Brain Sten. The dorsal surface of the brain stem in its axial portion is concealed by the overlapping cerebellum which presents a vermis with two small but well-marked lateral lobes. These lobes are clearly separated from the vermis by two distinct lateral paramedian sulci.

The small cerebellum of lemur emphasizes its limited range of skilled performances, especially as regards skilled acts of the upper extremities in purposes other than those essential to Iocomotion (Fig. I6).

When the cerebellum is removed by section through its peduncles, the dorsal aspect of the brain stem in its axial portion is revealed. The oblongata presents its typical ventricular and infraventricular portions. In the infraventricular area the dorsomedian seam indicates the line of fusion between the two alar plates of the bulb. The eminences of the clava and cuncus are not prominent. In the ventricular portion of the oblongata the gradual divarication of the alar plates exposing the floor of the fourth ventricle follows the same general outline as in other mammals. The inferior triangle of the 
fourth ventricle is bouncled laterally by a fairly prominent clava but a much less conspicuous cuneus. Both of these structures are most prominent in their caudal portions. At their cephalic extremities they become less conspre-
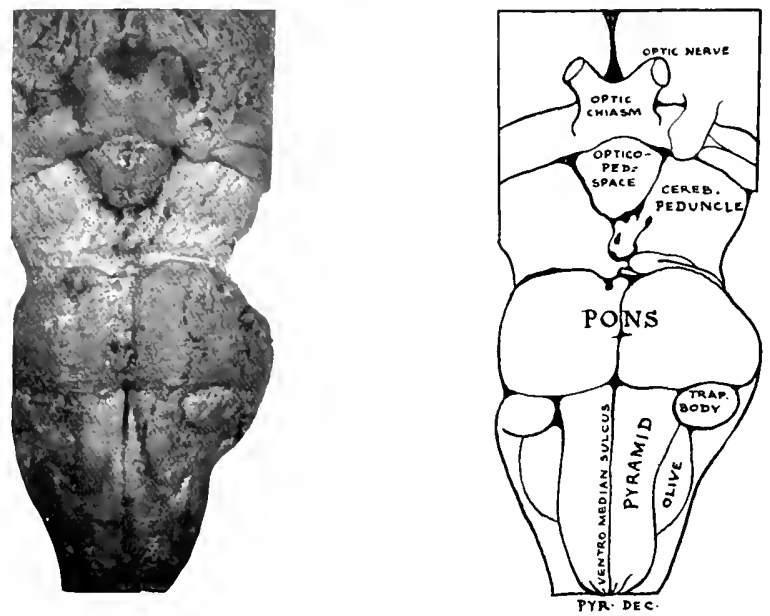

FIG. 20. VENTRAL SLRFACE OF BRAIN STEM, LEMUR MONGOZ. [Actual Length, $3 ; \mathrm{mm}$.]

Key to Diagrail. Cerlab. Peduncle, Cerebral Peduncle; optico-pedo-space, Opticopeduncular Space; PYR. DEC., Pyramidal Decussation; trap. BODr, Trapezoid Body.

wous as elevations. The decrease in surface relief is more marked in the cuneus than in the clara (Fig. 21 ).

The relatively slight development of the cuneus may be interpreted as due to a sensory representation of the forelimb which, as yet, has gained no marked prominence. The cuncus itself consists of nerve fibers and cells related to the transmission of sensory impulses arising in the upper trunk and forelimb. The types of sensory impulses passing over this conduction path pertain to the discriminative quality of sensibility, i.e., tactile, muscle, 
joint and posture discrimination. Marked prominence of the cuncus is significant particularly of highly developed eliscriminative sensibility in the hand. Conversely, a lack of such prominenee indicates an upper extremity
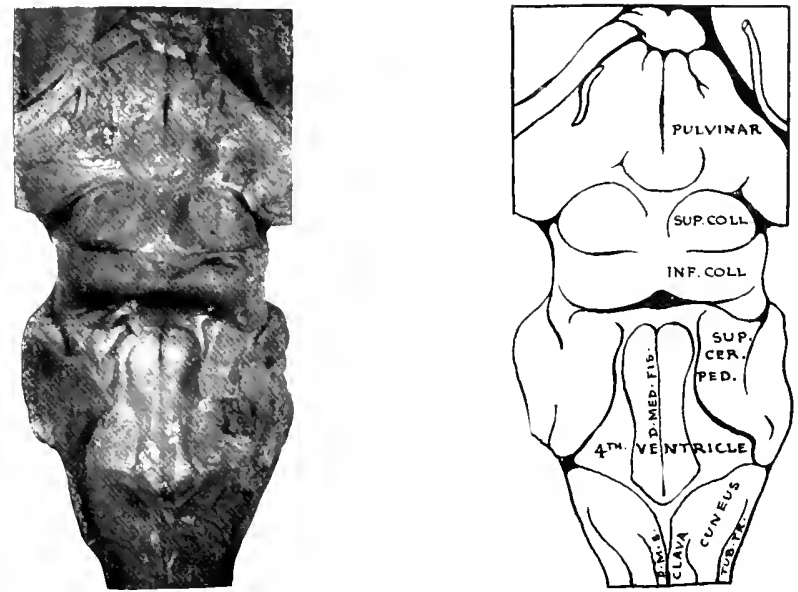

FIG. 2I. DORSAL SURFACE OF BRAIN STEM, LEMLR MONGOZ.

[Actual Length, $35 \mathrm{~mm}$.]

Key to Dlagray. D. Med. Fis., Dorsomedian Fissure; D.M.s., Dorsomedian Sulcus; IN. cull., Inferior Colliculus; stp. Cer. Ped., Superior Cerebelliar Peduncle; sep. coll., Superior Culliculus; tub. Tr., Tuberculum Trigemini.

and hand still mainly employed in locomotion. Of the two dorsal columns in lemur, the clava and cuneus, the former seems to be structurally emphasized because it represents the path of sensory conduction not only from the leg but also from the important steering and balancing organ, the tail. The cuneus in lemur is indicative of a forclimb as yet wholly inadecuate for advanced manual adaptation.

A fairly well-defined dorsolateral suleus extends upward upon either side of the dorsomedian seam, beeoming most prominent in the region between 
the concus and the clava. Other markings on the dorsal surface, as wetl ats upon the lateral surface of the oblongata, are faint and may only with ditlicultr be identified.

The Haxdorasi. The axial portion of the metencephalon presents upon its dorsal surface the cephatic continuation of the fourth ventrick, bounded upon either side by the middle and superior cerebellar peduncles. The markings on the floor of the fourth rentricke are not easy to discern. The median sulcus is prominent, running from the region just below the obex cephalad to the beginning of the iter. Well-defined striae acusticae cross the Hoor of the ventricke at the level of the lateral recesses. Their clirection from their pesint of entry toward the midline is almost at right angles to the median sulcus in the floor of the ventricle. Some fibers, hewever, have an oblicuity catudad from their point of entrance toward the midline. In the inferior triangle of the fourth rentricke a shallow depression upon either side of the median suleus indicates the position of the nucleus hypoghossus, lateral to which is a faintly marked fovea vagi. It is impossible to discover any distinctly demareated region corresponding to the area postrema or area plumiformis.

The cephalic triangle of the fourth ventricle is clevoid of distinct markings, although immediately above the striae acusticae may be seen a slight clevation, the eminentia abducentis. There is no cridence of a locus coeruleus.

The Midrrax. The dorsal aspect of the midbrain presents the characteristic quadrigeminal plate with the median sulcus intersected at right angles by the intercollicular sulcus. At the cephalic extremity of the median suleus there is a triangular expansion, the fovea pinealis, which lodges the epiphysis cerebri.

The superior colliculi are somewhat larger than the inferior colliculi, but both collicular elevations are well-defined and prominent tectal features. 
Near the cephalic extremity of the midbrain on the lateral aspect of the diencephalon are the mesial and lateral geniculate bodies.

The surface prominences on the ventral aspect of the midbrain, due to the presence of the two cerebral peduncles, present a relatively low relied. This fact is dependent upon the derelopment in this animal of a small pyramidal sistem. It also indicates that the fibers coming from the cerebral cortex to reach the cerebellum, in the interest of maintaining the proper coordination of the animal's limited skilled movements, are not numerous.

The markings upon the lateral aspect of the mictbrain, with the exception of the mesial geniculate body, are not pronounced. In fact, the entire reliel of the structures appearing upon the mesenecphalic surfaces, with the exception of those features already mentioned, conveys the impression that this is a particularly generatized portion of the neurasis devoid of many of the striking features characteristic of the higher forms.

Internal Structere of the Bran Stem ix Lemer Mojgoz

Some features which have a certain degree of prominence in surface outline assume more significant proportions when seen in cross sections of the brain stem. The sections of the axis in the lemur about to be discussed provide a survey of the internal structure at all of its critical levels. These descriptions begin with the sections at the fower end of the stem and proceed to higher levels of the more expanded portions of the brain.

LEVEL OF THE PIRAMIDAL DECISSATION (FIG. 22)

At the level of the pyramidal decussation the outstanding feature of the oblongata is the crossing of the pyramidal fibers $\left(P_{y} x\right)$ with the consequent separation of the ventral gray column (Ven) from the central gray matter ( $\mathrm{Cen}$ ) by the pyramidal fasciculi ( $\left.\mathrm{P}_{y}\right)$. 
The pramidal bundles forming this decussation are relatively narrow. in this respect bearing out the impression gained from the surface relief of the pyramid which indicates a limited capacity for volitional control over

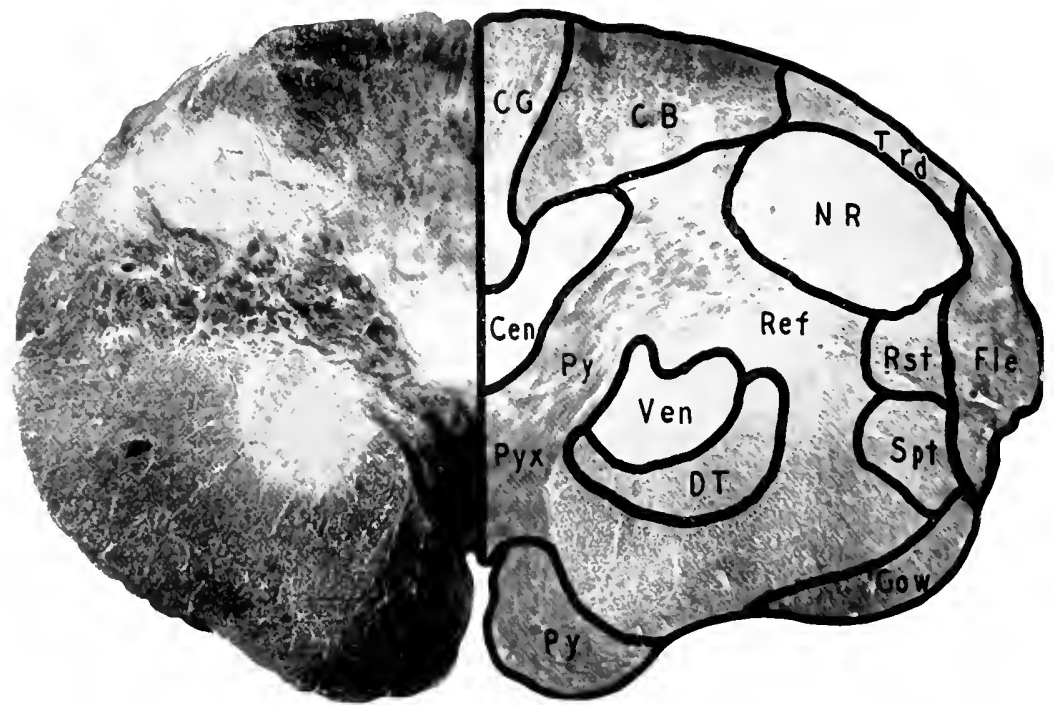

FIG. 22. LEMLR MONGOZ. LEVEL OF THE PYRAIIDAL DECUSSATION.

CB, Column of Burdach; CEN, Central Gray Matter; CG, Column of Goll; DT, Deiterso-spinal Tract; FLE, Dorsal Spinocerebellar Tract; Gow, Icntral Spinocerebellar Tract; NR, Nucleus of Rolando; PY, Pyramidal Tract, Pyramidal Fibers; Pxx, PyramidaI Decussation: Ref, Reticular Formation; Rst. Rubrospinal Tract: SPT, Spinothalamic Tract; TRD, Descending Trigeminal Tract; veN, Ventral Gray Mlatter. [Accession No. 147. ${ }^{*}$ Section 57 . Actual Size, $9 \times 5 \mathrm{~mm}$. In aIl actual neasurements fractions of the millimeter have been disregarded.]

the animal's voluntary muscles. As a corollary it may be inferred that the small pyramidal system bespeaks a small ability on the part of the animal to acquire learned reactions. From observation of lemurs in captivity, it is apparent that they learn little more, either by imitation or repetition, than in the free state.

*The numbers mentioned at the end of each caption in this and the following cross sections refer to the Study. Collection of the Columbia University Neurological Department. 
Another feature is the appearance of the caudal extremity of the nucleus of Goll together with an extensive bundle of fibers which surrounds it and forms the column of Goll (CG). This broad fiect of myelinized axons makes a long ascent from the spinal cord, arising in those levels which represent the dermatomes and proprioceptors of the tail and lower extremity. In lemur, the nucleus of Goll and the surreunding fasciculus have their special significance in the fact that the adjacent bundle of fibers in the column of Burdach is relatively more extensive. From this it mas be inferred that the parts of the body represented by the column of Burdach possess more funetional prominence than the parts represented by the more mesial collection of fibers in Goll's column. This ideat gains support from the fact that the column of Burdach represents the upper extremity. In lemur the manual differentiation of the forelimb is still far from complete. Although all of the principal elements entering into the formation of the hand are present, the upper extremity is in a distinctly low manual stage. The disparity in size of these two columns speaks in lavor of a less highly developed functional adaptation in the use of the hindlimb and the tail than in the forelimb and hand.

Another feature in the dorsal region of the section is the marked expansion of the substantia gelatinosa trigemini (nucleus of Rolando) (NR) which serves as a relay station for all fibers bearing impulses from the trigeminal areas of the face and head. This innervation includes regions anterior to the interparictal line drawn across the vertex of the skull from one external auditory meatus to the other. In an animal which has not yet developed a hand to serve in capturing prey for food, the head, and particularly the mouth, atfords an important organ of oflense and defense. Such an organ must be provided with an adequate sensory apparatus to guide it in these essential efforts of life. Its sensory rôle in clirecting the course of the animal as it makes its way through the leafy parts of the trees or through 
the underbrush supplements the sense of sight and thus facilitates passage amid obstacles in the environment. For this reason the head and face are amply provided with a sensory equipment.

The entire dorsal fied of the section is fundamentally sensory in its significance. Thus a line drawn transwersely through the central canal bounds a territory which represents the animal's capacity in discriminative censibility for the whole body. This territory may be spoken of as the dorsal field of sensom diserimination. It is the area of the central nervous system which allords the best index of an animal's capacity in discriminative sensibility. Beginning at the more lateral portion of this sensory field are the descending tract of the lifth nerve ( Trd) and the substantia gefatinosa (NR). These structures represent the head and face. The sensory representation of the neck and arm lies contiguous to the substantia gelatinosa (NR), while occupying a mesial position, adjacent to the dorsomesial septum, is the area concerned in sensory transmission from the tail and the leg (CG). Analysis of this sensory field in lemur indicates that innervation is more generously provided for the leg, tail, face and head than for the forelimb with its slightly dilferentiated hand. The type of sensibility which this area serves is preeminently discriminative. It is particularly involved in finer adjustments of body posture and contact relations with the outside world. Hence it not only plays an important part in affording discrimination in the analysis of elements encountered in the environment, but must also be regarded as the sensory substratum upon which the eomplexity of the skilled reactions depends.

Other structures in this level need mention for topographical identilication. Anong these are the ventral gray column ( Ven) which, because of the decussating bundles of the pyramid ( $P_{y x}$ ), has been detached from the central gray matter (Cen), the latter now lying in contact with the modian line and surrounding the small central canal. Dorsolateral 
to the ventral gray column are the seattered bundles of the pyramidal tract $\left(\mathrm{Py}_{\mathrm{y}}\right)$ as they begin to assemble in the position oceupied by them in their descent through the oblomgatat and into the spinal cord. On the periphery of the section is a narrew band of medullary substance, the circumferential zone, which contains the two large ascending spinocerebellar tracts Gow, Fle). Nesial to this zone and bordering upon the gray matter of the ventral gray column is the intermediate zone which in its ventral portion contains the two descending Deiterso-spinal tracts (DT) and, in its lateral portion, the spinothatamic and rubrospinal tracts ( $S_{p} t, R s t$ ).

LEYEL OF THE CALDAL EXTREMTTY OF THE INFERIOR OLIVE (FIG. 23)

At the level of the caudal extremity of the inferior olive the generat appearance of the section has changed considerably. The chief alteration is due to the presence in the ventral field of a new collection of gray matter. This is the inferior olivary nueleus ( $\mathrm{OO}$ ) which lies immediately dorsolateral to the fiber bundles eonstituting the prramid (Py). Dorsal to the ofive is a smatler mass, the dorsal accessory olive. Situated in fromt of the eentral gray matter (Cen) are fibers (Fai) arising in the dersal nuclear masses, which pass inward and forward to the midline where they undergo decussation. At this point they turn upward and constitute the mesial fillet. These decussating axons are internal arcuate fibers. Most of them take origin in the nucleus of Goll (NG) and contribute to the formation of the lowest portion of the mesial fillet which here represents the fower extremity and tail. The pyramid ( $\left.P_{y}\right)$ appears as a compact bundle oceupying the most ventromesial portion of the section. Its transverse and anteroposterior diameters give it the proportion of about 1 to 11 to the entire section. This ratio conveys some impression as to the relative importance of the pyramidal system in the 
regulation of rolitional morements. The dorsal columns of Goll and Burdach CG, CB ) are considerably increased in extent due to the presence in them of nuclear masses constituting the nucleus of Goll (NG) and the

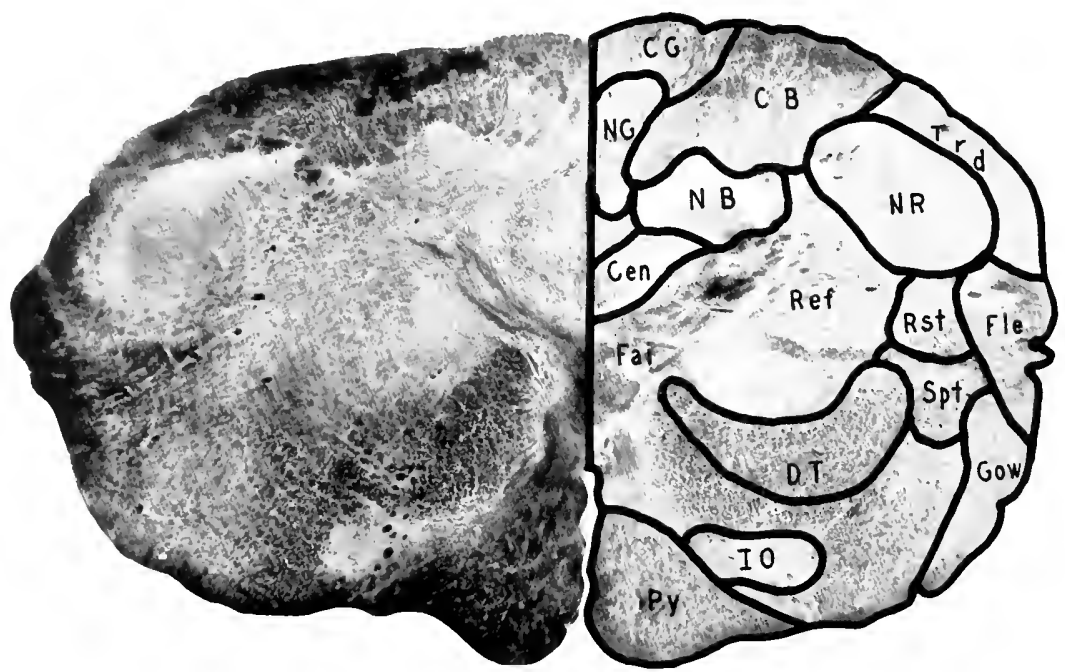

FIG. 23. LEML R MONGOZ. LEVEL OF CALDAL EXTREMITY OF INFERIOR OLIIE. CB, Column of Burdach; ceN, Central Gray Matter; $C_{\text {, }}$ Column of GoII; DT, Deiterso-spinal Tract; FAI, Internal Arcuate Fibers; fLe, Dorsal Spinocerebellar Tract; cow, Ventral Spinocerebellar Tract; 10, Inferiur Olive; NB, Nucleus of Burdach; NG, Nucleus of Goll; \R, Nucleus of Rolando; Py, Pyramidal Tract and Fibers; REF, Reticular Formation; RST, Rubrospinal Tract; SPT, Spinothalamic Tract; TRD, Descending Trigeminal Tract. [Accession No. 147. Section -5. Actual Size, Io $\times 6 \mathrm{~mm}$.]

nucleus of Burdach (NB). It is evident that the nucleus of Goll is smaller than that of Burdach. This appearance bears out the point already made as to the sensory predominance of the more lateral of the two bundles in the dorsal ficld. The fibers representing the hand and arm are more numerous and constitute a more conspicuous bundle than those representing the leg. In a similar manner, the substantia gelatinosa of Rolando (NR), as well 
as the descending tratet of the fifth nerve (Trd), stand out as prominent elements and add to the preeminent sensory character of the dorsal fiedd.

Dorsal to the pramidal tract and ventral to the fillet is an important bundle of fibers, namely the posterior longitudinal fasciculus, which is concened with the antomatie reflexes for the regulation of cortain primitive movements. Lateral to the fasciculus lomeritudinalis posterior is a considerable bundle representing the Deiterso-spinal tracts (DT), whese function is the conduction of those impulses neecsary to the adjustments of equilibrium.

\section{LEVEL THROLGH THE MIDDLE OF THE INFERIOR OLII}

$$
\text { (11GS. } 2+\text { AXD } 25 \text { ) }
$$

At the level through the middle of the inferior olive, the outstanding feature is the appearance of an irregular mass of gray matter lying in the rentral ficld near the pramid. This is the inferior olivary nucleus ( $\mathrm{O}$ ). Its signifieanee has already been touched upon in relation to the automatic regulation of simultaneous movements of the head, eres and hand and to the facilitation of the coordination of all skilled learned performances. This structure has a direct connection, through the central texmental tract, with the oculomotor nuclei and, through the olivary fasciculus of Helweg, with the cervical levels of the spinal cord. By means of many arcuate fibers it is also connected with the cerebellum. While there is no difficulty in identifying this structure in lemur, it is smaller and much more indefinite in outline than in most of the other species considered. The lemur thus appears to be provided with but a small amount of automatic regulation of simultaneous movements of hands, head and eyes. Mesial to the olive and adjacent to the midline of the section is the mesial fillet (Mf). This structure represents the continuation of the discriminative sensory pathway, being made up largely of fibers for sensation in the extremitics. The substantia gelatinosa (NR) and the accompanying descending trigeminal tract 
(Trd) are still prominent, while the dorsal columns of Goll and Burdach again give evidence that the more mesial of these fascienli, representing the leg and tail, is larger than the lateral one representing the upper extremity.

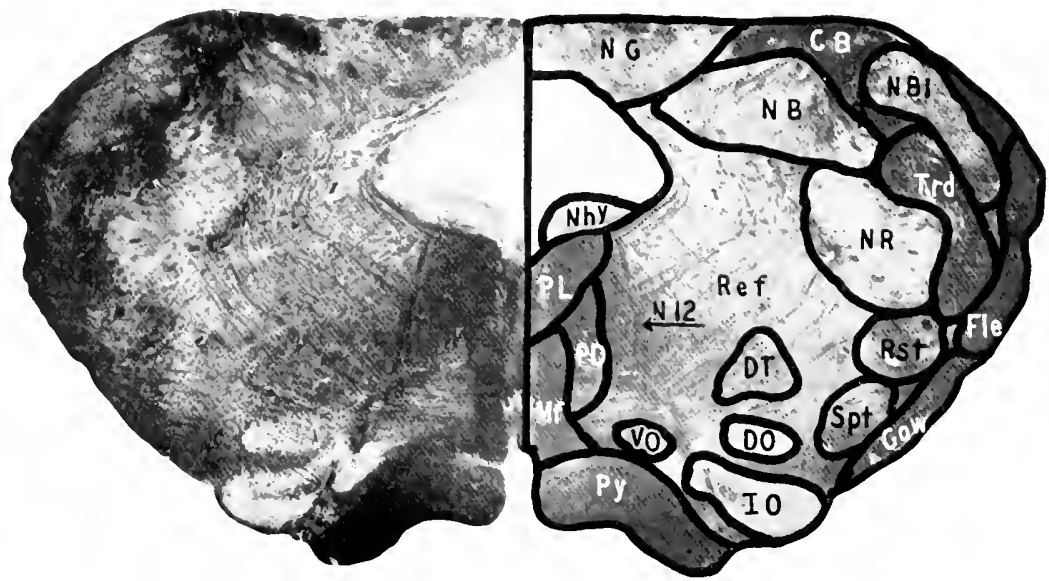

FIG. 24. LEMIR MONGOZ. LEVEL THROUGH MIDDLE OF INFERIOR OLIVE. CB, Columa of Burdach; Do, Dorsil Accessury Olive; DT, Deiterso-spinal Tract; FLE, Dursal Spinocerebellar Tract; Gow; Ventral Spinoeercbellar Tract; to, Inferior Olive; мF, Mesial Fillet; NB. Nucleus of Burdach; vBL, Nucleus of Blumenau; NG, Nucleus of Goll; NHr, Hypoglossal Nuclcus; NR, Nucleus of Rolando; Ni2, Hyponglossal Nerve; PD, Predorsal Bundle; PL, Posterinr Longitudinal Fasciculus; Pr, Pyramid; Ref, Reticular Formation; RST, Rubrospinal Tract; SPT, Spinothalamie Traet; TRD, Desecuding Trigeninal Tract; vo, Ventromesial Accessury Olive. [Accession No. 14-. Seetion 102. Actual Size, 1 I $\times 5$ mm.]

LEVEL OF THE VESTIBULAR NLCLEI (FIG. 26)

At the level of the restibular nuclei some noteworthy changes have occurred. They result primarily from the introduction of two additional sensory systems. One of these additional elements in the sphere of sensation, namely, the tuberculum acusticum $\left(\mathrm{T}_{\mathrm{u}} \mathrm{b}\right)$ is related to the sense of hearing; the other, connected with the function of balancing, is the restibular 
area. The tubereulum acusticum receives the fibers which arise in the cochlear portion of the internal car. In lemur it is particularly large, thus indicating a highly dereloped auditory sense.

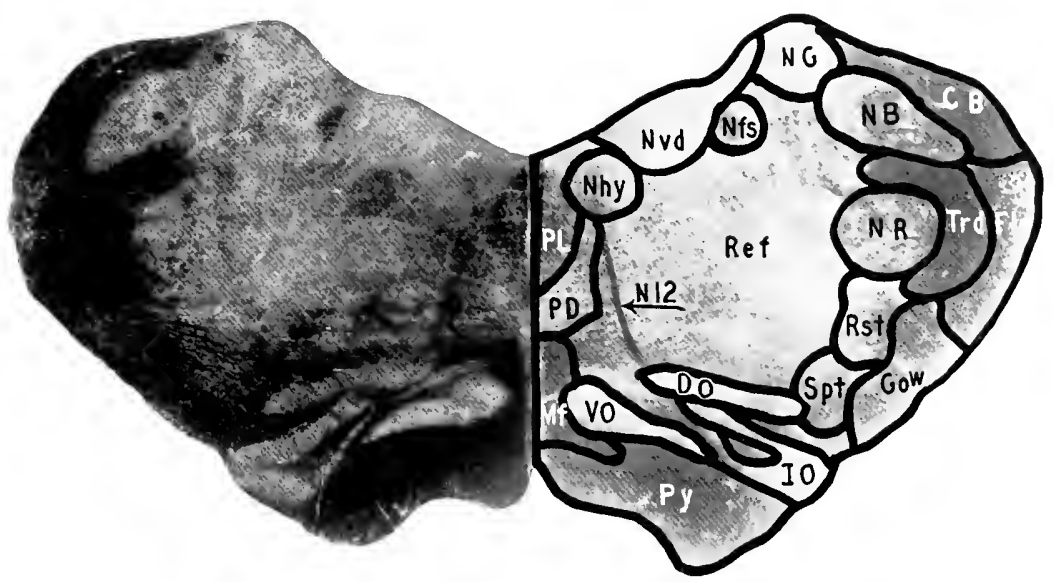

FIG. 2j. LEMUR MONGOZ. LEVEL THROLGH MIDDLE OF INFERIOR OLIVE.

CB, Column of Burdach; Do, Dorsal Accessory Olive; fle, Dorsal Spinocerebellar Tract; Gow, Ventral Spinocerebellar Tract; 10, Inferior Olive; MF, Mesial Fillet; NB, Nucleus of Burdach; NFs, Nucleus Fasciculus Solitarius: NG, Nucleus of Goll; Nmr, Hypoglossal Nucleus; NR, Nucleus of Rolando; NvD, Dorsal Vagal Nucleus; N12 Hypoglossal Nerve; PD, Predorsal Bundle, PL, Posterior Longitudinal Fasciculus; Pr, Pyramid: REF, Reticular Formation; RST, Rubrospinal Tract; SPT, Spinothalamic Tract; TRD, Descending Trigeminal Tract; vo, Ventromesial Accessory Olive. [Accession No. 147. Section 117. Actual Size it $x+m m$.]

In the region formerly occupied by the tracts and the nuelei for the conduction of impulses coming from the skin, the joints, the muscles and the bones of the extremities, there now appear two groups of cells and fibers for the reception of impulses arising in the proprioceptive organs of the restibule; i.e., the semicircular canals, utricle and saceule. These highly specialized parts of the internal ear play a fundamental rôle in equilibrium. Near the midline, in the dorsal freld, immediately beneath the floor of the fourth 
ventricle, is the triangular mucleus of Scbualbe (NSc), and lateral to this a large-celled nucleus known as Deiters' mucleus (ND). Together they constitute the vestibular area. Dispersed among the cells of Deiters'nucleus

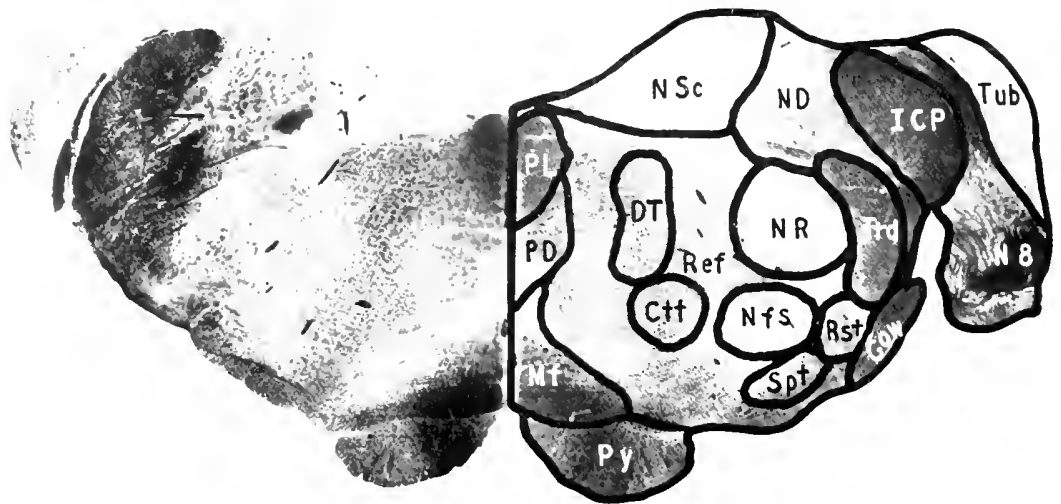

FIG. 26, LEMLR MONGOZ. LEVEL OF TIIE VESTIBULAR COMPLEX.

¿тT, Central Tegmental Tract; DT, Deiterso-spinal Tract; ,ow, Ventral Spinocerebellar Tract; ICP, Inferior Cerebellar Peduncle; mf, Mesial Fillet; nd. Nucleus of Deiters; Nfs, Facial Nucleus; nr, Nucleus of Rolando; ısc, Nucleus of Schwalbe (Triangularis); N8. Auditory Nerve; PD, Predorsal Bundle; p., Posterior Longitudinal Fasciculus; pr, Pramid; RIF, Reticular Formation; RST, Rubrospinal Tract; SPr, Spinothalamic Tract; $T_{R D}$, Descending Trigeminal Tract; tuB, Tuberculum Acusticum. [Accession No. 147. Section $13^{8 .}$ Actual Size, $1+Y+\mathrm{mm}$.]

are many scattered bundle's of nerve fibers representing essential connections of this nucleus. The relative dimensions of the two vestibular nuclei to the rest of the cross section are of especial internst. They provide a basis for estimating the degree of balancing function possessed by the lemur, whose life is spent primarily in the loftiest parts of trees and whose locomotion is adapted to the constantly varying movements of the tree tops. The animal is able to execute difficult locomotor feats with great precision and finds as much security in its balancing under these most diflicult circumstances as the quadruped doe's upon terra firma. It is quite in keeping, therefore, with the inherent behavioral requirements, to find the central representation of 
this important proprioceptive system so highly dereloped in these tree-living animals.

Situated between the tuberculum acusticum (Tub) and Deiters' nucleus is the restiform bod. (ICP) which represents an ageregation of ascending fibers from the spinal cord and oblongata on their way to thecerebellum. These ascending cerebellar fibers enme from sereral ditlerent soures and serve the purpose of convering to the cerebellum atferent impulses necessary, as it were, to orient the cerebeflum in its activity of transmitting to the muscles those impulses essential to coordination. An evact adjustment of action exists between the various groups of muscles in the body in order to maintain such coordination. Since the cerebellum is specialized to regulate the factors entering into this function, it naturally follows that the organ must at all times be in possession of information conceming the varying tensional status of all the muscles of the body. Were this not the case it would be impossible for the cerebellum to transmit to the muscles the tensional control essential to the execution of all muscular acts. Thus the significance of the afferent cerebellar connections as indicated by the restiform body may be clearly discerned. The degree of development of this structure discloses the extent to which the animal is dependent upon its conrdinating mechanism.

\section{LEYEL OF THE CEREBELLAR NLCLEI (FIG. 2-)}

At the level of the corebellar nuclei certain structures which furnish a criterion concerning the functional capacity of the cerebellum make their appearance for the first time. These are the cercbellar nuclei. Only a portion of the cerebellum is shown in this cross section. Structurally, the organ consists of a central division, the rermis (Ver), and two lateral lobes or hemispheres. The beginning of the lateral lobe is indicated in the cross section. Immediately mesial to the mass of medultary substance 
of the lateral lobe is a large, irregular and rather diffuse collection of cells, the nucleus dentatus ( $\mathrm{Ndt}$ ). From this nucleus arise the fibers which make their way out of the cerebellum, providing the eflerent pathway for

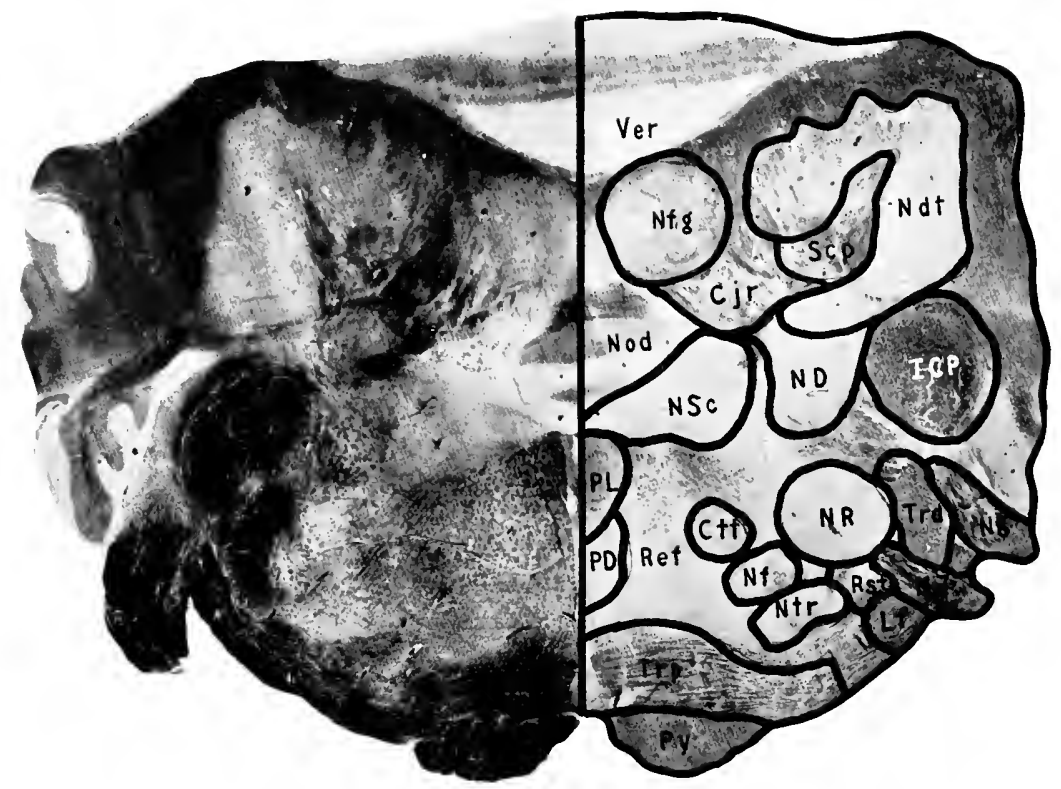

FIG. 2-. LEMUR MONGOZ. LEVEL OF THE CEREBELLAR NLCLEI.

GR, Juxtarestiform Body; CTT, Central Tegmental Tract; ir P, Inferior Cerebellar Peduncle; Lf, Lateral Fillet; ND, Nucleus of Deiters; NDT, Dentate Nucleus; VF, Facial Nucleus; NFo. Nucleus Fastigii; NoD, Vermis Cerebelli; NR, Nucleus of Rolando; : isc, Nucleus of Schwalbe (Triangularis); vTr, Trapezoid Nucleus; N-. Facial Nerve; 18, Auditory Nerve; PD, Predorsal Bundle; PL, Posterior Longitudinal Fasciculus; PY, Pyramid; REF, Reticular Formation: RST, Rubrospinal Tract; sCP, Superior Cerebellar Peduncle; TRD. Descending Trigeminal Tract; Trp, Trapezoid Body; ver, Vermis. [Accession No. 14-. Section 163. Actual Size, $1 ; \times 10 \mathrm{~mm}$.]

cerebellar impulses which regulate the coordinative control of the muscles. The relative size of the dentate nucleus is consequently of much significance, as it indicates to what degree the cerebellum contributes to the function of 
coordination. The nucleus may be, as in this instanes, an irregular, dilfuse mass of gray matter, or it may present itself as a complexly comooluted structure whose convolutions serve to increase its functional capacity. An animal having a small dentate nucleus should be capable of a relatively limited range of highly coordinated acts. It is of interest to mote that in lemur this nucleus is neither well defined nor extensive in size, from which it may be inferred that the clegree of coordinative control dependent upon the cerebellum is relatively less in this animal than in some of the higher primates.

Mesial to the dentate nucleus is another aggregation of nerve cells. This is the nucleus fastigii ( $\mathrm{Nfg}$ ). By means of libers constituting the juxtarestiform body $(\mathrm{C} \mathrm{jr})$, it is comnected with those nuclei in the lloor of the fourth ventricle which receive impulses from the semicircular canals, utricle and saccule. The nucleus fastigii is, therefore, a structure intimately concerned with the function of balancing and may be regarded as one of the higher elaborating stations for equilibratory control. Its comparatively large size in lemur has a significance similar to that of the large nuclei of Schwabe and Deiters, unquestionably indicating the great need on the part of the animal for a highly organized balancing control.

It is presumed that functionally the vermis ( Ver) is concerned with the maintenance of coordinative control of the axial and paraxial musculature of the body. This is a portion of the cerebellum which manifests the greatest phyletic constancy, whereas the lateral lobes, because they are functionally related to the museles of the extremities, vary according as the upper and lower extremities are capable of more or less complex performances. Another feature at this level is the trapezoid body (Trp), and adjacent to it the trapezoid nucleus $(\mathrm{Ntr})$. The trapezoid body is situated immediately dorsal to the pyramid ( Py ) and consists of a complex system of decussating frbers. These crossing fibers represent the decussation in the 
secondary auditory pathway. They provide the means for the conveyance of impressions received by the cochlea of the internal car to the higher auditory centers. Immediately lateral to the trapezoid body is a chense bundle of fibers, the lateral fillet (Lf), constituting the secondary pathway for auditory impulses. The nucleus of the seventh nerve which supplies motor innervation to the facial muscles ( $\mathrm{Nf}$ ) and a spray of libers, the lirst part of the seventh nerve, which extends dorsomesially toward the llow of the ventricke, are also features of this level.

LEVEL OF THE EMERGENT FIBERS OF THE SIXTH NERIE (FIG. 28)

At the level of the emergent fibers of the sixth nerve, some minor changes have occurred which are noteworthy as preparing the way for the marked transition observed in the next suceeding sections. One significant feature is the appearance of these emergent fibers of the abducens nerve, the sixth nerve of the cranial series, which arises in a nucleus situated near the midline beneath the Iloor of the fourth ventricle. These emergent fibers proceed forward and outward, penetrating the corpus trapezoidcum in their course and finally emerging at the junction of the ventrolateral and bulbopontile sulei. The abducens nucleus supplies the external rectus muscle of the eycball and has special significance in that it sets the paee for all movements of lateral gaze involving both eyeballs. The appearance of the superior cercbellar peduncle, taking origin in the dentate mucleus, adds another feature to this level. This bundle represents the discrete aggregation of nerve fibers by means of which impulses arising in the cerebellum leave this organ on their way to the several levels of the neuraxis. They have their ultimate distribution to the muscles in the interest of proper courdination. The superior cerebellar peduncle is the one great pathway out of the cerebellum; henee its relative size furnishes a valuable index of corcbellar function. Another peduncular structure connected with 
the cerebellum also appears at this level, the middle cerebellar peduncle. The significance of this pedunck becomes more evident at the higher levels of the stem. Funetionally it is the final connecting link between the corebral

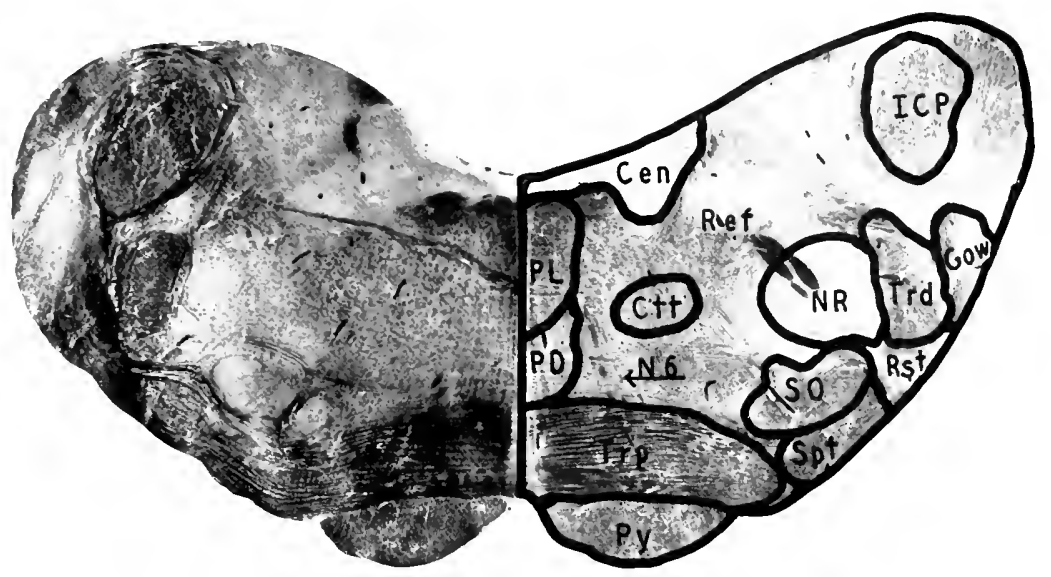

FIG. 28. LENIR MONGOZ. LEVEL OF EMERGENT FIBERS OF SINTH \ERVE. ¿EN, Central Gray Vatter; CrT, Central Tegmental Tract; Gow, Ventral Spinocerebellar Tract; ICP, Inferior Cerebellar Peduncle; $\backslash R$, Nucleus of Rolando; 6 , Abducens Nerve; PD, Predorsal Bundle; PL, Posterior Longitudinal Fasciculus; Pr. Pyramid; kEF. Reticular Formation; RST, Rubrospinal Tract; so, Superior Olive: SPT, Spinothalimic Tract; TRD, Descending Trigeminal Tract; TRP, Trapezoid Body. [Accession No. 14-. Section 173. Actual Size, $15 \times 5 \mathrm{~mm}$.]

hemispheres and the lateral lobes of the cercbellum. The inforior cerebellar peduncle has begun to spread out its lasciculi like a fan as it enters the medullary substance of the cerebellum immediately lateral to the dentate nucleus. Much significance attaches to the physiological importance of these three cerebellar pectuncles. Collectively they constitute a reliable index for estimating the degree of coordination possessed by the animal, and thus reveal the extent to which the more complex muscular performances have been developed. The size of the inferior cerebellar peduncle provides a 
scale for measuring the relative anount of afferent inflow to the cerebellum. The superior ecrebellar peduncle gives a similar opportunity regarding the relative outlow from the cerebellum, while the middle cerebellar peduncte furnishes the means of estimating the degree of communicational capacity between the cerebral cortex (where all courses of sustained volitional action take origin) and the cerebellum which coordinates the morements of such action.

LEYEL OF THE CAEDAL EXTREMITY OF THE PONS YAROLH (FIG. 29)

At the level of the caudal extremity of the pons Varolii, several marked changes have occured. Most conspicuous among these is the appearance of a fairly wide band of transverse fibers extending across the ventral surface of the brain stem and constituting the stratum superficiale of the pons Varolii. This layer has nuw become the most ventral element in the neuraxis. It lies in front of the prramidal fibers ( $\mathrm{Py}_{\mathrm{y}}$ ) which, in consequence, have lost their surface position and are no longer seen in relief along the ventral aspect of the stem. The appearance of the pyramidal tract itself is also altered in such a manner that it no longer maintains its compact solidarity. It now appears as a collection of seattered bundles. This dissemination of the pyramidal fasciculi is due to a number of transverse pontile fibers which weave themselves among the descending pyramidal bundles and thus constitute a complex layer of the pons Varolii known as the stratum complexum. The appearance in this stratum of numerous nerve cells still further complicates the structure. These cellular elements form an irregular mass of gray matter of considerable size scattered amidst the pyramidal and transverse pontile fibers. They constitute the pomtile nuclei ( PN). From the degree of development, both in the pontile nuclei and the transverse pontile fibers, inference may be drawn regarding the range of skilled volitional morements with which the animal is endowed. The anatomi- 
cal and phrsiological reasons for this inference are not far to seck. Such fibers as constitute the transwerse fasciculi of the pons have their origin in the cercbral cortex of the frontal, parietal, oceipital and temporal lobes. Deseend-

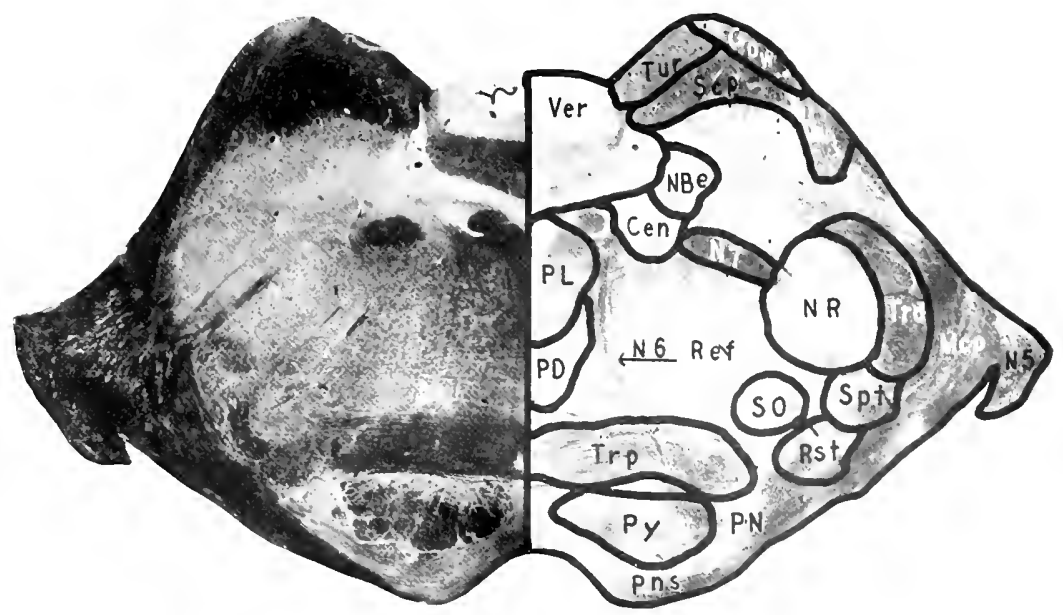

FIG. 29. LEMLR MONGOZ. LEVEL OF CALDAL EXTREMITY OF PONS VAROLII.

CEx, Central Griy Matter; gow, Ventral Spinocerebellar Tract; MCP, Middle Cerebellar Peduncle; NBE,

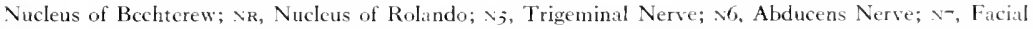
Nerve; PD, Predorsal Bundle; PL, Posterior Longitudinal Fasciculus; PN, Pontile Nuclei; PNs, Puns; Pr, Pyramid; Ref, Reticular Formation; rst, Rubrospinal Tract; scP, Superior Cerebellar Peduncle; so, Superior Olive; SPT, Spinothal:mic Tract; TRD, Descending Trigeminal Tract; TRP, Trapezoid Body: rUR, Tractus Uncinatus of Russel (Hook Bundle); VEr, Vermis. [Accession No. 14. Section 188. Actual Size, $1 ; \times 7 \mathrm{~mm} .1$

ing from these origins they make their entrance into the cerebral peduncle and ultimately reach the pons. At this point they alter their direction from the vertical to the horizontal plane, thereafter pursuing a transverse course. Many of these fibers end in the pontile nuclei of the same side for a relay here. The relaying axons then undergo decussation across the midline and eventually enter the middle cerebellar peduncte (Mcp). Some pallio- 
pontile libers, however, cross the midline and receive their relay in the contrabiteral pontile nuelei whose axons in turn pass into the middle cerebellar peduncle. This peduncle extends into the cerebellum and its fibers finally ramify among the various lobules constituting the lateral cerebellar lobes. By means of the pallio-pontile libers the major functional divisions of the cerebral hemispheres establish direct communication with the lateral lobes of the exebellum. Experimental and clinico-pathological observations warrant the opinion that these connections are essential to propereoordination in the more complex motor performances of the animal. The pathway between the cercbrat cortex and the cerebellum, in a functional sense, parallels the conduction tract which conveys impulses necessary to the voluntary control of action. The latter pathway provides for the transmission of nervous energy involved in the purpose and pattern of the act to be performed. This includes the incentive, initiation, design, direction and ultimate inhibition of the act. The pallio-pontile connections provide for concurrent impulses which regulate the coordinative and postural attributes necessary to the exceution of such voluntary performances.

The slight degree of development in the transverse fibers of the pons, as well as in the pontile nuclei and the middle cerebellar peduncle in lemur, points conclusively to a motor organization capable of but a limited range and variety of the more highly synthetized voluntary performances. This fact is corroborated by the rather feeble development of the pyramidal system. In this sense the pons Varolii and its several constituents may be accepted as an index of the extent to which the cerebral cortex has developed. They provicle a structural basis for estimating the range of adaptation and degree of volitional adjustment of which the animal is capable.

The position of the cerebellum is similar to that of the lower Ievels, and the cross section shows especially well the medullar vestibule consisting of all the fibers assembled from the middle and inferior cerebellar pedun- 
cles, which near its center contains the much reduced cephalie entremits of the nucleus dentatus. At a considerable distance rentrally from the dentate nucleus is the superior cerebellar peduncle (Sep). At the lateral extremity of the section and penetrating the superficial pontile fibers, the fifth eranial nerve ( $\left.N_{j}\right)$ makes its way into the brain stem. These fibers constitute the motor and sensery roots of the trigeminal nerve, the motor root of which may be traced to its nucleus of origin close in the angle of the fourth ventricle, the nucleus masticatorius of the lifth nerve supplying the muscles of mastication.

\section{LEIEL AT THE MIDDLE OF THE PONS VAROLII (FIG. 30)}

At the level at the middle of the pons Varolii this structure attains its full dimensions and displays its three major layers, the stratum superficiale, the stratum profundum and the intermediate stratum complexum. Scattered among the transverse fibers of the stratum complexum are the much separated bundles of the pyramidal system (Py) and also the accumulated mass of gray matter constituting the pontile nuclei $(\mathrm{PN})$. The fibers emerging from the pontile nuclei become collected both in the superficial and deep layers of the pons and pass laterally to enter the bundle constituting the middle cerebellar peduncle ( Mep). As atready indicated, the pontile nuclei, together with the fibers entering into and forming the middle cerebellar peduncke, may be accepted as evidence concerning the degree of cooperative innervation existing between the portions of the brain having to do with skilled movements and the coordination of such movements. The relatively small size of these structures in lemur points to a correspondingly limited range of skilled performances.

That portion of the axial stem, which comprises the several layers of the pons and contains the pontile nuclei together with the scattered fibers of the pyramidal fasciculi, constitutes what is known as the basis, whose 
dorsal boundary is created by a narrow band of transversely disposed fasciculi forming the mesial fillet (Mf). This line of boundary indicates the division between the basis pontis situated ventrally and the tegmentum

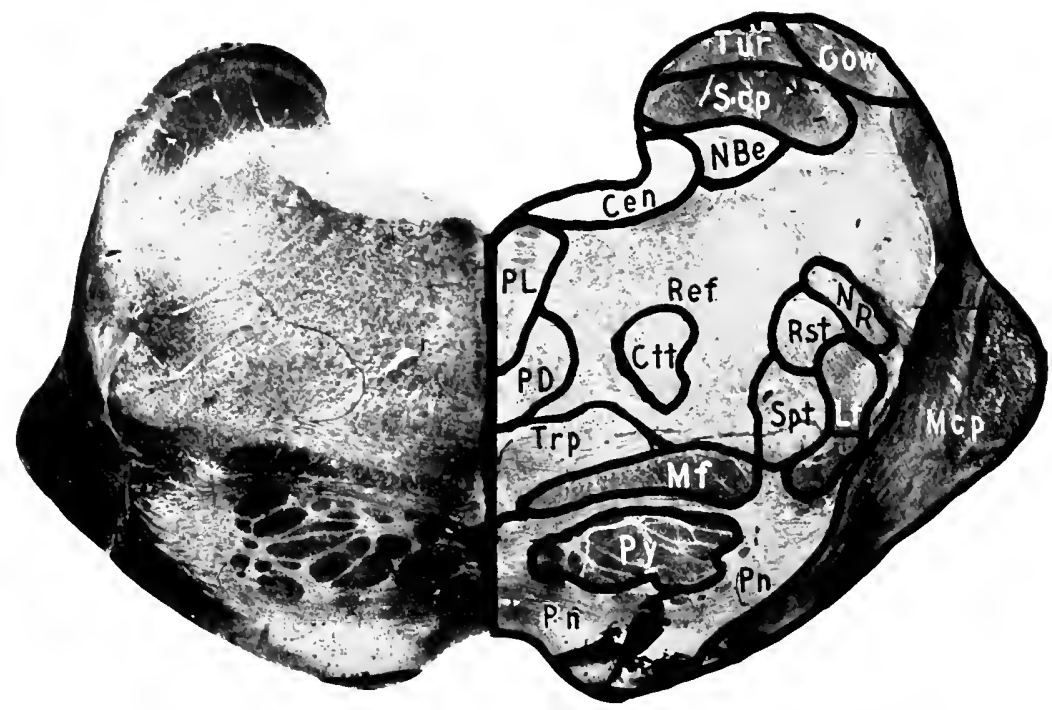

FIG. 3O. LEMIUR MONGOZ, LEVEL OF THE MIDDLE OF THE PONS VAROLII. CEN, Central Gray Natter; CT, Central Tegmental Tract; Gow, Ventral Spinocerebellar Tract; Lf, Lateral Fillet; MF, Mesial Fillet; MCP, Middle CcrebcIlar Peduncle; NBE, Nucleas of Von Bechterew; Nr, Nucleus of Rolando; PD, Predorsal Bundle; PL, Postcrior Longitudinal Fasciculus; PN, Pontile Nuclci; Pr, Pyramid; REF, Reticular Formation; RST, Rubrospinal Tract; SCP, Superior Cerebellar Peduncle; SPT, Spinothalamic Tract; TRP, Trapezoid Body; tUr, Tractus Uncinatus of Russel (1 look Bundle). (Accession No. I.77. Section 208. Actual Size, $14 \times 5 \mathrm{~mm}$.]

pontis, situated dorsally. In the dorsolateral aspect of the section are three conspicuous tracts, the ventral spinocerebellar tract (Gow) making its way toward the vermis, ventral to which is the tractus uncinatus of Russel ( Tur), while immediately in front of this is the superior cerebellar peduncle $(S c p)$. In the angle between the superior corebellar peduncle 
and the central gray matter (Cen), immediately bencath the floor of the fourth ventricke, is a small collection of medium-sized nerve cells constituting the mucleus of ron Bechterew ( N Be) which is one of the group of

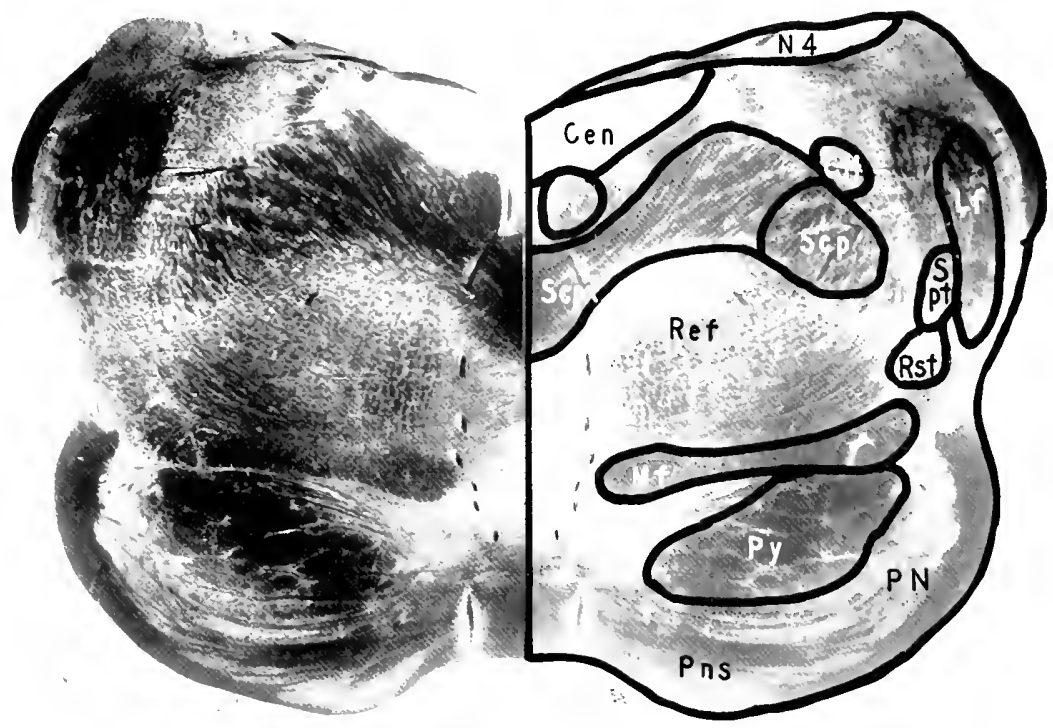

FIG. 3I. LEMUR MONGOZ. LEVEL OF EMERGENCE OF TROCHLEAR NERTE. cev, Central Gray Matter; crr, Central Tegmental Tract; LF, Lateral Fillet; MF, Mesial Fillet; N4, Trochlear Nerve; pl, Posterior Longitudinal Fasciculus; PN, Pontile Nuclei; P\s, Pons; Pr, Pyramid; Ref, Reticular Formation; RST, Rubrospinal Tract; SCP, Superior Cerebellar Peduncle; SCPX, Crossing of the Superior Cerebellar Peduncle; spr, Spinocerebellar Tract. [Accession No. $1_{4}^{7}$. Section 245 . Actual Size, I $\times 6 \mathrm{~mm}$.]

vestibular nuclei. Ventral to this nucleus are the ascending root fibers of the trigeminal nerve known as the tractus mesencephalici trigemini. A large collection of small nerve cells lies at the border of the tegmentum opposite the middle cerebellar peduncle. This is the dorsal nucleus of the lateral fillet. 
LEIEL OF THE INFERIOR COLLICLLL'S (1IG. 32)

At the level of the inferior colliculus, the appearance of eertain striking features alters the external conliguration of the stem. Among these

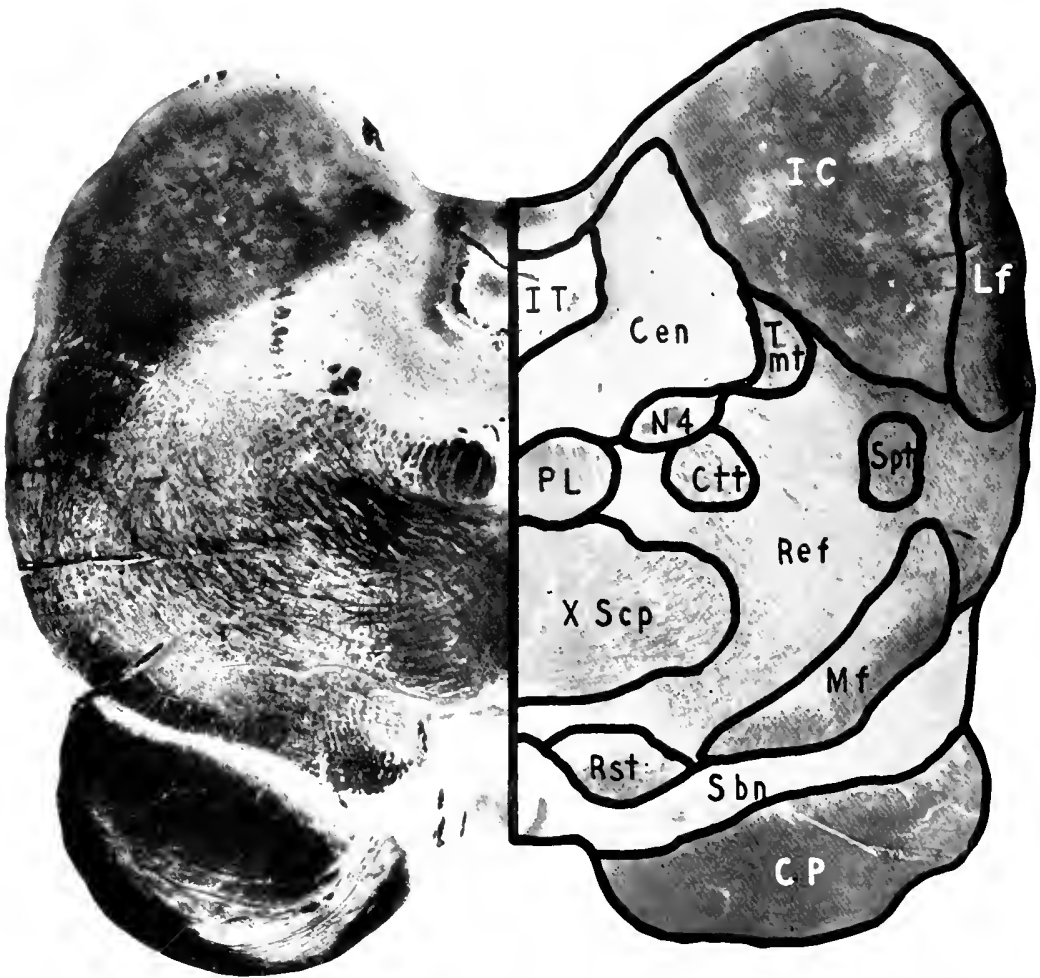

FIG. 32. LEMUR NONGOZ, LENEL OF THE MFERIOR COLLICULUS.

CeN, Central Gray Matter; ctr, Central Tegmental Tract; CP, Cerebral Peduncle; rc, Inferior Colliculus; IT, Aqueduct of Sylvius; LF, Lateral Fillet; MF, Mesial Fillet; N4. Trochlear Nerve; PL, Posterior Longitudinal Fasciculus; REF, Reticular Formation; RSt, Rubrospinal Tract; sBN, Substantia Nigra; spt, Spinothalamic Tract; Tat, Tractus Mesencephalici Trigemini; xscP, Crossing of Superior Cercbellar Peduncle. [Accession No. 14-. Section 25. Actual Size, $11 \times-\mathrm{mm}$.] 
features may be noted the narrowing of the ventricular space to form the beginning of the Sylvian aqueduct and the appearance of two large nuclear masses situated in the clorsolateral portion of the licld. These structures constitute the inferior colliculi ( IC), distinguishing characteristice of the quadrigeminal plate in the midbrain. Ventrally the transverse continuity of the pons Varolii is interrupted by the disappearance of the decussating pontile fibers, causing a sulcus to appear on the ventral aspect of the stem which marks the beginning of the eerebral peduncles (CP) and interpeduncular space. The inferior colliculi are significant because they represent primurdial receiving stations for the sense of hearing. In many of the lower forms of vertebrates they are the chief centers for auditory sense. In most of the higher forms, especially in mammals, they have delegated much of their original dominance in auditory function to cortical areas of the cerebral hemispheres. Their conspicuous size in lemur indicates that they have here retained much of their primordial significance. They appear to provide a correlating center for auditory impulses essential in determining rapid automatic motor responses incited by auditory stimuli. While these lower centers of hearing have lost much of their autonomy during the process of telencephalization (that is, the progressive advancement of higher synthetic control to the endbrain), they have not entirely surrendered their auditory functions. Through the inferior colliculi the animal is able to respond to auditory stimuli by adequate motor reactions without submitting these stimuli of hearing to the supervision of the higher and more deliberative centers of the cerebral cortex. The fundamental need in the life of these animals for an apparatus which reacts immediately to threatening sounds by automatic movements of escape or attitudes of defense may readily be understood. At the same time, this very tendency for auditory stimulation to be shortcircuited in the interest of producing immediate and defmitely crystallized automatic reactions cannot fail to create a certain degree of limitation in the 
adaptability of motor responses excited by auditory stimuli. It does, as it were, deprive the reaction of a deliberative quality, a period of lateney and reflection in which the acts in response to sound may be made more complete, more precise and more effectively adjusted to the several alternatives of action developing in a given situation.

Lateral to the inferior colliculus is the brachium conjunctirum posticum which constitutes a connecting link in the auditory pathway to the mesial geniculate body. Ventral to the colliculus is the lateral fillet (LI), making its entrance into the primordial receiving station for the sense of hearing. A large mass of transversely disposed fibers sweeping toward the midline comprises the two major divisions of the superior cerebellar peduncle (XSep) now about to undergo decussation preparatory to entering the red nucleus.

The pramidal tracts, together with the descending fibers which constitute the pallio-pontile tracts, are situated along the ventral aspect of the axis in a discretcly collected bundle of fibers (CP). A few of the more cephalic transverse fibers of the pons, together with some of the pontile nuclei, are shown ventral to the pyramidal fibers and the fibers of the pallio-pontile system. Dorsal to the pyramidal fibers and stretehing transversely across the section from the midline to the periphery is a mass of gray matter containing cells of several sizes and constituting the caudal extremity of an important nucleus known as the substantia nigra (Sbn). It is presumed that this nuclear mass is essential to the regulation of automatic associated movements. Since it assumes such striking proportions in lemur, the inference seems warranted that this type of motor reaction is especially characteristic of these anmals. The central gray matter ( $\mathrm{Cen}$ ) has become greatly enlarged and surrounds the caudal extremity of the aqueduct of Sylvius, the roofplate of which is formed by the superior medullary velum which supports the eephalic extremity of the vermis 
cerebelli. At the lateral extremity of the central grats matter are screral scattered bundles of nerve fibers, the mesencephalic root of the trigeminal nerve $(\mathrm{T} m \mathrm{t})$, while along the rentral border of the central gray matter are two or three small bundles of fibers, the descending fasciculi of the trochlear nerve $\left(\mathrm{N}_{+}\right)$.

LEVEL OF THE SUPERIOR COLLICLLLS (FIG. 33 )

At the level of the superior colliculus, prominent tectal structures of the mesencephatom make their appearance. They are the much redueed remmants of the optic lobes which form the most conspicuous elements in the midbrain of the lower classes of vertebrates. Here they retain a certain degree of stratification reminiscent of the optic lobes. Three distinct layers or strata of alternating cell and fiber distribution may be discerned microscopically in the area indicated as stratum griseum superficiale.

Still other layers may be differentiated in this teetal region of the midbrain. The optic lobes have been progressively superseded in the importance of their visual function as the cortex of the cerebral hemispheres expanded and became more intimately concerned in those higher associational syntheses necessary for a fuller sensory adjustment to the external world. This supersedence on the part of the cerebral cortex involves not only the sense of vision and the sense of hearing, but quite as much the general body sense in all those various modalities which are essential to the production of highly organized volitional movements. That all of these specialized forms of sensation, including those which put the animal in touch with elements in its environment more or less remote from its own body, as well as those requiring actual contact with the body surfaces, have in their more primitive states been represented by parts of the brain less highly organized than the cerebral eortex, there can be no doubt. By a slow and gradual process, proceeding step by step from species to species, and only incompletely 
consummating its progress as it sought new sensory lields for further cxpansion, the functions related to sensibility have attained their fullest representation in the pallium of the cerebral hemispheres. This stepping-up process

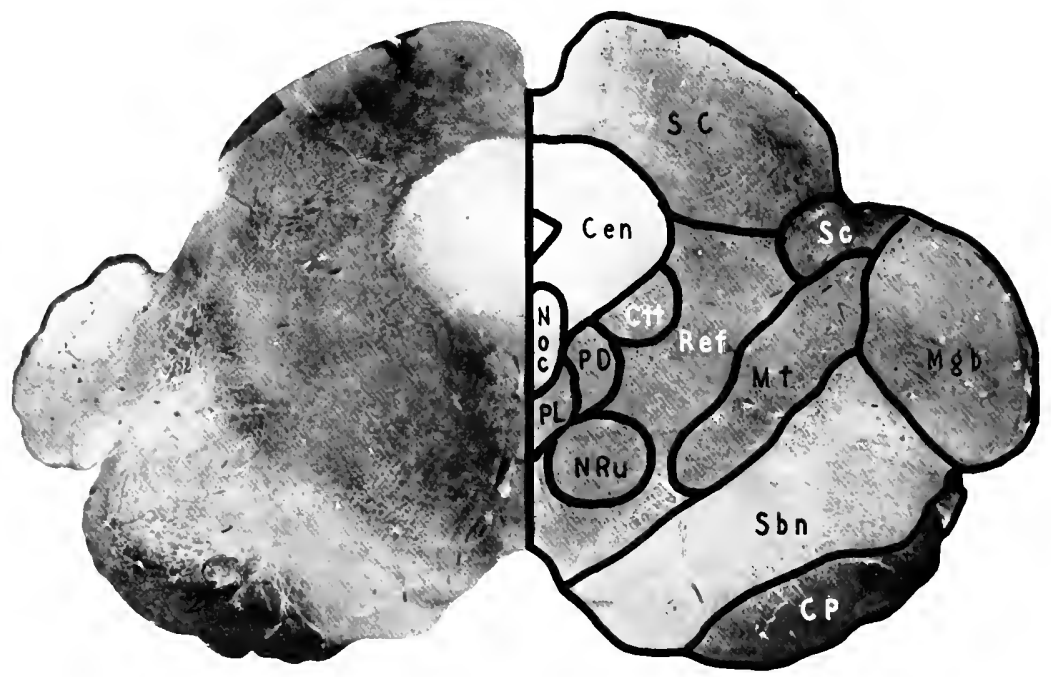

FIG. 33. LEMLR MONGOZ. LEIEL OF THE SLPERIOR COLLICULUS.

CEN, Central Gray Matter; CP, Cerebral Peduncle; CTt, Central Tegmental Tract; MGb, Mesial Geniculate Budy; if, Mesial Fillet; Nor. Nucleus Oculomotorius; NKu, Nucleus Ruber; PD, Predorsal Bundle; PL, Posterior Longitudinal Fasciculus; ker, Reticular Formation; sB., Substantia Nigra: sc, Superior Colliculus. [Accession No. 147. Scction 300. Actual Size, $19 \times 19 \mathrm{~mm}$.]

from a lower, Jess highly organized region to a higher and more expansible territory in the end-brain, is spoken of as telencepbalization. Yet in no ease has this transference upward been made at one such stricle that the entire allegianee of a certain form of sensibility is advaneed from its more lowly sphere of structural organization to its new domain in a higher region. The gradual projection from lower to higher centers is elearly demonstrated in the phyletie series of the vertebrates. Nowhere is there a more marked instance 
of this partial and graded telencephalization than in the case of the optic lobes which uttimately give over their dominanee in visual function to the aceipital area of the cerebral hemispheres. Even within the limited range of the primate order there is still evidence of this slow transference from a highly organized visual region in the midbran to the more highly developed visual centers of the aecipital lobe. The stratification already noted in the superior collicular region which retains, even in this high form of mammal, at least ten of the original fourteen cortical layers of the optic lobe, indicates that teleneephalization has by no means attained its full expression in lemur. It must be inferred, therefore, that some at least of the primordial visual function is vested in these still highly differentiated tectal structures of the midbrain. This supposition is further borne out by the large number of optic fibers which end in the superior colliculi. Some of these fibers are shown immediately lateral to the stratum griseum superficiale.

Another feature at this level of the brain stem is the oculomotor nucleus (Noc). This nucleus gives rise to the third cranial nerve whose fibers supply all but two of the muscles which move the eycball within the orbit. It also innervates the intrinsic muscles of the eve, the constrictor iridis and the muscle of the ciliary body which regulates the convexity of the lens. In addition, the oculomotor nueleus sends fibers to the levator palpebrae muscle which produces elevation of the upper eyelicl. This portion of the midbrain therefore is preeminently related to the visual sense. Not only is this true as to the structures concerned with the actual receipt of visual impressions, but quite as much in the transmission of motor impulses requisite to the muscular adjustments of the eyes in visual fixtaion and in visual pursuit of objects. The fact that this oculomotor nucleus (Noc) shows a striking simplicity in its development indicates a relatively low degree of oculomotor organization. It implies that the lemur's vision is as yet only partially binocular; that in the main the animal is still using its eyes 
as far-distance receptors. The adjustment of ocular morement is at yet so ineomplete that the animal has not learned the many advantages arising from a more exact stereoscopic vision for objects near at hand. Ocular converence brings the visual axes into such a position as to make pussible the more diseriminating serutiny of objects near the animal. It secures the more exact effects of perspective and proportion characteristic of complete binocular vision. The relatively small size of the oculomotor nucleus in lemur indicates an imperfectly developed binocular vision, while the lack of internuchar commissures implies that the muscles of the two eyes have not as yet acquired the intimate intermuseular cooperation characteristic of animals which have developed a high degree of binocular fusion and stereoseopic vision.

Another feature is the appearance of the red nuckeus (NRu), a collection of nerve cells in which at least two great systems of fibers receive relay. One of these systems is especially concerned in the efferent conduction of impulses arising in the cerebellum and destined for distribution in the lower kevels of the axis. The nucleus ruber (NRu) in lemur is a relatively small structure. Its size is in proportion to the correspondingly small number of fibers forming the superior cerebellar peduncte. Th is small red nucleus signilies a limited functional capacity for the distribution of impulses essential to the coordinative control, more particularly the eoordinative control of complex notor reactions in the upper and lower extremities.

The two cerebral peduncles (CP) extend along the ventral surface and are becoming more divergent as each approaches its corresponding eerebral hemisphere. At the basis of the peduncle are the collected fibers of the pyramickal system and also of the pallio-pontile system. Immediately dorsal to these bundles of libers is an extensive mass of gray matter, the substantia nigra (Sbn), the significance of which has already been diseussed in connection with the control of certain automatic associated move- 
ments of a primordial character fargety vested in the midbrain. Immediately dorsal to the substantia nigra is the mesial fillet (M/f), while oceupying positions in front of the ecufomotor nuckei are two decussations. One of

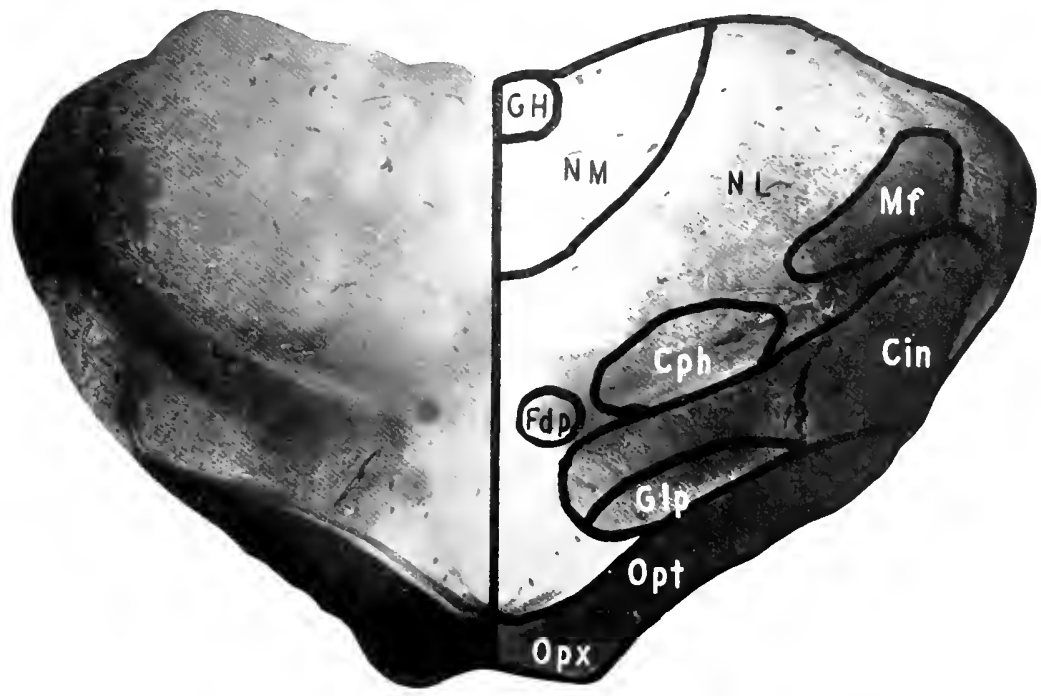

F1G. 3t. LEMUR MONGOZ. LEVEL OF THE OPTIC CIIASM.

CIN, Internal Capsule; CPH, Corpus Hypothalamicum; fDP, Descending Pillar of Fornix; Gir, Ganglion Habenulae; GLP, Globus Pallidus; . MF, Mesial Fillet; NL, Nucleus Lateralis Thalami; Nu, Nucleus Medialis Thalami; OPT, Optic tract; opx, Optic Chiasm. [Accession No. 147. Section 363. Actual Size, $25 \times 15 \mathrm{~mm}$.]

these is the dorsal decussation of Neynert through which the emergent fibers of the third nerve make their way toward the surface. Ventral to the dorsal decussation of Meynert is the smaller decussation of Forel. These decussations represent respectively the crossing of the fibers arising in the reticular formation of the midbrain to enter into the predorsal bundle (PD) and the decussating descending fibers arising in the red nucleus to form the rubrospinal tract. 
I.LIEL OI THE OPIIC CHIASII (FIG. 34)

At the level of the optic chiasm the elecussation in the optic pathway is "the identitying feature (Opx). Another salient element is the optic

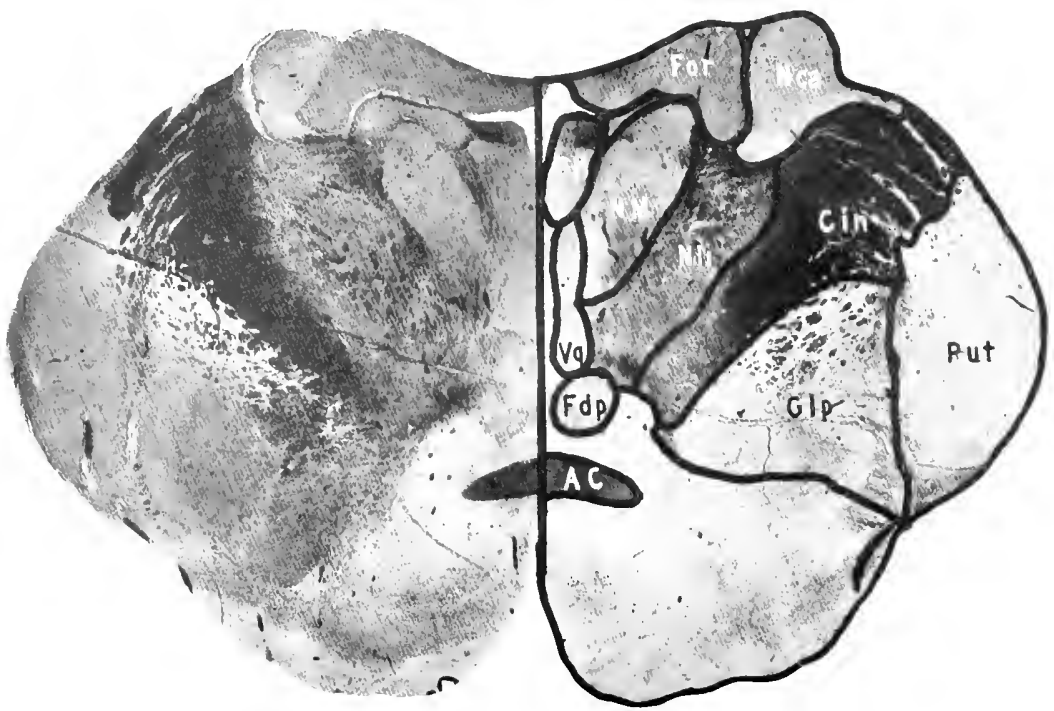

FIG. 3j. LEMUR MONGOZ. LEVEL OF THE ANTERIOR COMMISSURE.

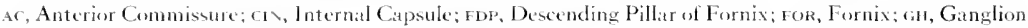
llabenulac; G1.P, Glabus Pallidus; n, Nucleus Nedialis Thalami; . LL, Nucleus Lateralis Internus Thalami; NCA, Caudate Nucleus; Pet, Putamen; vo. Fasciculus of Vicq d'Azyr. [Accession No. 1.47. Section 417. Actual Size, $20 \times 10 \mathrm{~mm}$.]

thalamus which represents the last grat reday station in the pathway of all types of sensibility with the execption of olfactory sense. It completes the conduction pathway of body sensibility. Dorsal to the optic chiasm are crossing fibers which constitute the supra-optic commissure of Meynert. Immediately dorsal to this is a large mass of gray matter containing cells for the most part of the motor type and forming the globus 
pallidus $(\mathrm{G} \mathrm{P})$. This is one of the mest important portions of the endbrain. Being especialfy encerned with the regulation of automatic associated movements, it constitutes an outstanding division of the basal teleneephalic ganglia. Resting upon and dorsal to the globus pallidus is a fairly large mass of myelinated nerve fibers representing axons which arise in the moter cortex and descend as the pyramidal system. Asseciated with these are the many fibers which form the main part of the pallio-pontile system. The mass of fibers situated between the thatamus and the grlobus pallidus constitutes a portion of the internal eapsule ( $\mathrm{Cin}$ ). In contact with the dorsal aspect of the internal capsule is a mass of gray matter sumounded by at considerable capsule of myelinized fibers. This is the corpus hypothalamicum ( $\mathrm{CPh}_{\mathrm{P}}$ ) which contains the hypothalamic nucleus of Luys and the adjacent medullary substance comprising the two fields of Forel known as Hr and H2. Mesial to the corpus hypothalamicum is the fasciculus of Vicy d'Anr and rentral to this a bundle of small, weakly staining fibers, the descending pillar of the fornix $\left(\mathrm{Fd}_{\mathrm{p}}\right)$.

LEVEL OF THE ANTERIOR COMMISSLRE (FIG. 3j)

At the level of the anterior commissure (AC) the section illustrates the cephalic fimit of the brain stem, the last remaining structure of which is the anterior portion of the optic thalamus. Other structures of topographical interest at this level are indicated in the caption. 



\section{ChAPTER II}

\section{RECONSTRUCTION OF THE GRAY MATTER IN THE BRAIN STEM OF LEMUR MONGOZ}

P PHE impression eonveyed by a survey of cross sections of the brain stem does not give any such realistic idea of the muclear masses ats that obtained from a study of reconstructions by the Bourne mothod. Such reconstructions of the gray matter are here employed to make more comprehensible the proportions of these nuclear structures which bear the most signifieant evidence ol crolutional unfolding in the brain stem. It is to be noted, however, that these reconstructions do not disclose the dimensions or relations of the nuclear masses which oceupy positions within the reticular formation. It is equally moteworthy that these deeper lying collular collections comstitute the more arehaically fined and least variableckements in the composition of the axial gray matter, while the superficial nuclear acrgregations represent the recently acquired, nore plastic structures of the stem. The tri-dimensional demonstration of the gray matter afforded by reconstructions facilitates the visualization of these colements and establishes for each structure a discrete morphological entity of its own.

In the following deseriptions, only the structures seeming to have salient evolutional significance have been selected for discussion. Any complete anatomical analysis of the constituents of the brain stem belorgs more properly to the realm of an anatomical atlas. The structures to be considered here include: the dorsal sensory nuclei, the inferior olivary nucleus, the reticular formation, the pontile nuclei, the vestibular nuclei, the enchlear nucleus, the inferior and superior colliculi, the substantia nigra and the red muckus.

\section{The Dorsal Sensory Nuclei}

In lemur the sensory nucleus of Goll begins as a slender extension from the central gray column close to the midline and separated from 
its fellow of the opposite side by the dorsal septum. The base remains narrow while the distal portion presents a tendeney to swing and spread lateralls.

At a slightly higher level the first indication of the sensory nucleus of Burdach appears as a llat, bilateral thickening in the dorselateral portion of the central gray coltumn. The two nuclei then extend dorsally with the same lateral swing which is characteristic of the dersal gray masses and of the substantia gelatinosa Rolandi preparatory to the opening of the fourth rentricle. As these nuclei of Goll and Burdach increase in size, ther develop at their dorsal extremities orerhanging masses of nuckear material, almost arboreal in form, but limited to the laterat aspects of the main trunks of the muckeus. The more lateral of these nuclear appendages forms the external nucleus of Burdach. Its leaf-like appearance is produced by the breaking-up of the nuclear material by the bundles of fibers of the column of Burdach which are here secking their cells of relay. The substantia gelatinosa of Rolando which forms the cap sumounting the dorsal horns passes insensibly into the substantia gelatinosa trigemini with a marked lateral inchination in accordance with the common lateral swing of these nuclear columns, until it almost reaches the lateral meridian. As this swing takes place, the substantia gelatinosa Rolandi, slender in the spinal cord, rapidly increases in size to become the substantia gelatinosa trigemini of the oblongata. These three dorsal columns of gray matter expand and diverge in almost parallel parabolic rows. The substantia gelatinosa trigemini approaches the lateral surlace of the cord and, losing its int imate contact with the reticular formation, cxtends upward in a position so constant that it may be used as an orienting structure in the study of the stem. The nuclear gray column reaches upward to the midpontine level where dorsomesial to it there appears the motor nucleus of the trigeminus nerve. At the midolivary level the substantia gelatinosa trigemini presents a definite constriction which has been 


\section{RECONSTRUCTION OF LEMIUR MONGOZ}

termed the "waist of the trigeminal nucleus." At its cephalie extremity the nucleus increases in all its diameters as it prepares to meet the entering mass of fibers constituting the dorsal root of the Gasserian gan-
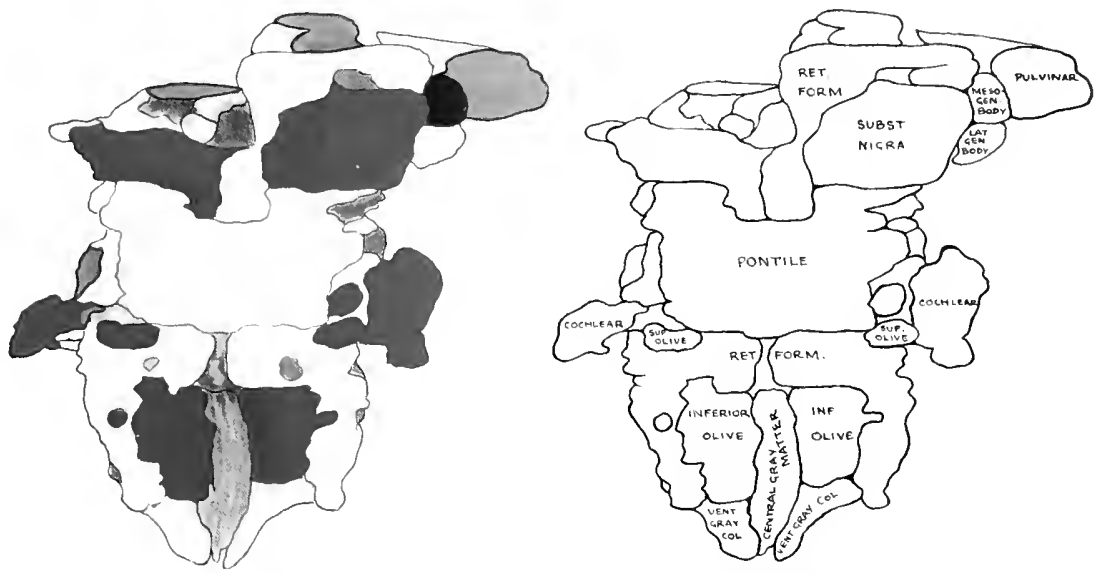

FIG. 36. VENTRAL SURFACE OF GRAY MATTER OF BRAIN STEM, LEML MONGOZ. Key to Dagran. cochlear, Cochlcar Nucleus; 1NF, olive, Inferior Olive; lat. gen. bodi, Lateral Geniculate Body; mfso-gen. bodr, Mesial Geniculate Body; pontrle, Pontile Nuclei; Ret. Forw., Reticular Formation; SUbst. Nigra, Substantia Nigra; sup. Olive. Superior Olive; Vext, gray Col., Ventral Gray Column.

glion. The nucleus extends somewhat above the entering fibers in order to afford relay cells for the short ascending arms of the incoming axons.

\section{The Inferior Olmary Body}

The reconstruction of the inferior olivary body in lemur consists in large part of the dorsal and ventral accessory olivary nuclei. The main mass of the inferior olive seems to be a later addition, developing in a position between the two accessory nuclei as a new structure presenting in the higher forms a saccular fundus and two branches. 
The rentral accessory (paleo-olive) nucleus appears somewhat bekm the mid-decussational lerel of the oblongata as an wal mass directed mesialfy and slightly dorsally. It presents no secondary plications and after appearing as a small oval collection of nerve eells it extends transversely to form a Hattened band of nuclear material. Mesially it fuses with the extremity of the dorsal accessory nucleus. The dorsal accessory nucleus appears as a round nuclear accumulation imbededed in this ventral surface of the reticular formation. It spreads rapidy into a thin Lamina which fuses with the mesial extremity of the ventral accessory olive. The chief olivary nucleus appears as a loop between the lateral extremities of the acessory olivary nucle with which it fuses. There are no reduplications in this loop.

\section{Tile Reticl lar Formation}

In the reconstruction, the reticular formation presents an extensive mass of nuclear material traversed by great numbers of seattered nerve fibers. It is roughy quadrilateral in shape and forms the main pertion of the tegmentum of the oblongata, pons and midbrain. In it develop the various muclei of termination and origin of the medullary and pontile cranial nerves. Upon its surface it presents the indentations made by the rarious asecending and descending tracts of the brain stem; while at varions levels it is piereed by the wide swinging bundles of decussating fibers constituting the mesial and lateral fillets and the inferior cerebellar peduncles. It forms a matrix along the mesial septum for the posterior longitudinal fasciculus, the predorsal bundle and other longitudinal fasciculi.

The reticular formation, in affording passage to the various white fiber tracts, seems to serve as a semi-tluid medium which surrounds these tracts on all sides, supporting them in a soft, gelatinous matrix. It begins at about the level of origin of the decussation of the pyramidal tracts and, extending ventrally, dorsally and laterally, receives the cephalic termination of the 
ventral gray column. It affords attachment to the muclei of Goll and Burdach dorsally and to the substantia gelatinosa trigemini lateratly, which, howerer, becomes separated from the reticular formation at a higher level by the
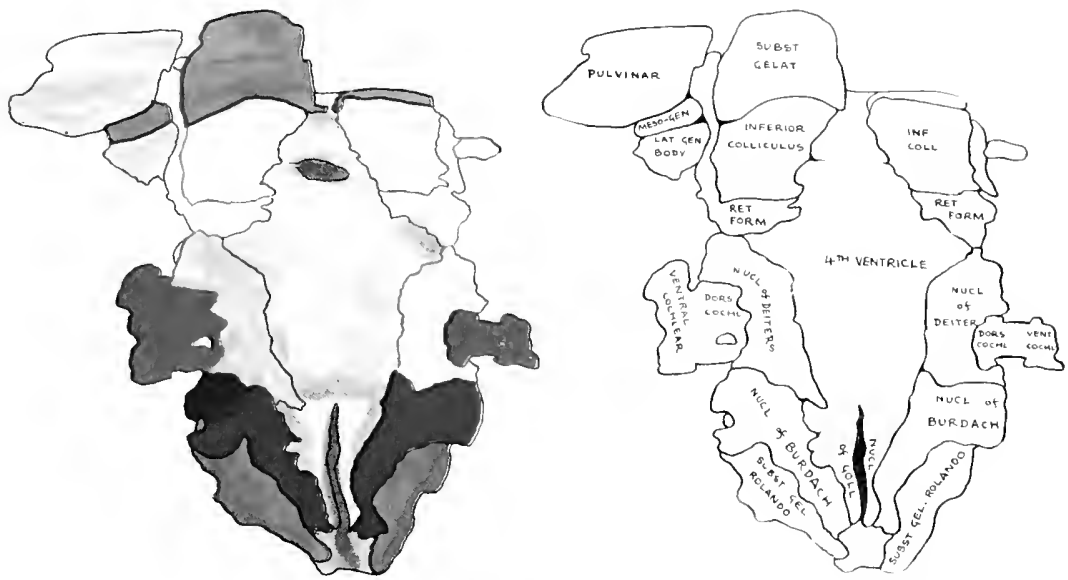

FIG. 37. DORSAL SURFACE OF GRAY MATTER OF BRAIN STEM, LEMUR MONGOZ.

Key to Diagran. dors. Cochl., Dorsal Cochlear Nucleus; iNF. Coll., Inferior Colliculus; Lat. gen, body, Lateral Geniculate Body; meso-gex., Mesial Geniculate Budy; Nect. of Berdarn, Nucleus of Burdach; secl. OF Deiter, Nucleus of Deiters; Necl. OF Gold, Nucleus of Goll; RET. Form., Reticular Furmation; subst. Gelat., Substantia Gelatinosa; stbst, gel. kolaydo, Substantia Gelatinosa of Rolando; vrNt. wonk., Ventral Cuchlear Nucleus.

entering vestibular and cochlear nerves and the lateral fillet.

Arising from the dorsal and ventral cochlear nuclei of both the homolateral and contralateral nuclear complexes, the fibers of the trapezoid body develop as a boundary between the reticular formation and the deep layer of the pontile nuclear masses. This body lies in a recess in the ventral surface of the reticular formation. Passing laterally from the superior olive, the trapezoid body forms the lateral fillet which then skirts the edge of the reticular formation, piercing it in some areas as its fibers pass upward to end 
in the inferior colliculus. From the inferior collieulus arises the inferior brachium which occupies a growe on the lateral surface of the mesencephalic reticular formation until it reaches and ends in the mesial geniculate body. The reticular formation is most extensive at the level of the inferior olivary nuclei which develop in its rentral portion. It forms the main mass of the gray matter of the brain stem.

Between the levels of the vestibular complex and the inferior colliculus, the reticular formation sends out a long, slender process on the lateral surface of the pons and midbrain to form an enveloping layer over the superior cerebellar peduncle.

The reticular formation contains the rentral portions of the twellth, sivth, fourth and third nerve nuclei, while the dorsal portions of these nuclei project into the eentral gray matter. In the upper medullary and fower pontile regions the reticular formation presents the specialized condensations forming the vestibular nuclei.

In the mesencephalon the reticular formation approaches but does not come into actual fusion with the substantia nigra. Laterally it forms a support for the mesial geniculate body, while dorsolaterally it becomes continuous with the inferios and superior colliculi. At its cephalic extremity it is continuous with the zona incerta of the diencephalon and fuses with the thalamic gray matter.

\section{The Pontile Nuclei}

Reconstruction of this mass of gray matter provides one of the most striking differential features in the brain stem of primates. This nuclear aggregation, forming with the pallio-spinal and pallio-pontile tracts the basilar portion of the metencephalon, presents a relatively simple arrangement. The pontile nuclei begin rather suddenly at the trapezoid level and show but little tendency to expansion caudally into the ob ongata. The 
nuclear mass is divisible into a superficial, ventral layer and a deep, dorsal fayer, both of which are comlluent laterally and mesially in an area surrounding the descending pallio-pontile and pallio-spinal tracts. The pyramidal
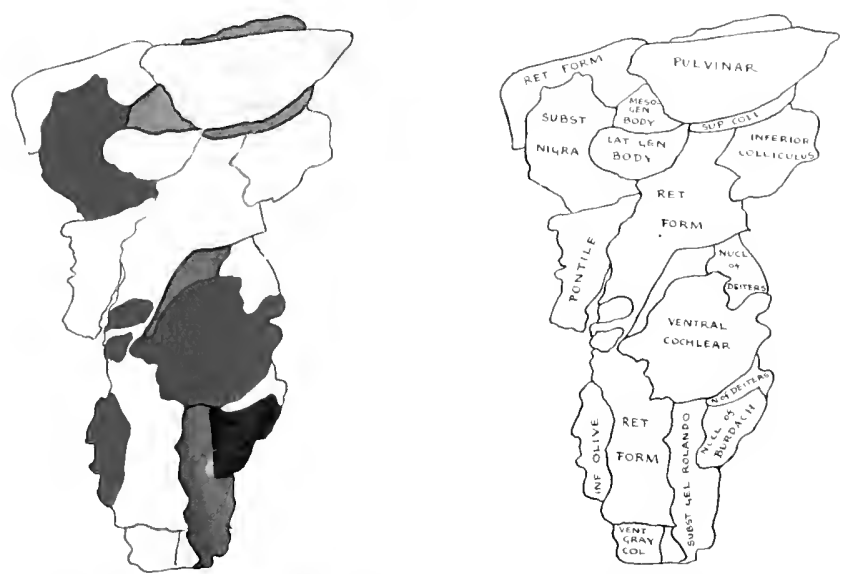

FIG. 38. LATERAL SURFACE OF GRAY MATTER OF BRAIX STEM, LEMLR MONGOZ. Key to Diagram. inf. Olve, Inferior Olive; Lat. GeN. Body, Lateral Geniculate Budy; meso-gen. Body, Mesial Geniculate Body; Nugl. of Berdath, Nucleus of Burdach; Necl. OF deiters and N. OF DetTers, Nucleus of Deiters; ret. roru., Retieular Formation; SUBSt, Get. rolando, Substantia Gelatinosa of Rolando; scest. NGgra, Substantia Nigra; SUP. Coll., Superior Colliculus; Vent. Gray Col., Ventral Gray Column.

tract is separated into fasciculi by the transverse pontile fibers only to a limited extent and in the main appears as a single heavy mass of fibers. The pontile nuclear masses are large and their continuity is not materially interrupted by the decussating ponto-ccrebellar fibers. The decp layer of the nuclear mass is continuous at its cephalic extremity with the substantia nigra. Marked condensations of nuclear material appear laterally and mesially. They conncet the superficial and deep layers of the pontile nucleus and form lateral and mesial buttresses for the substantia nigra. 


\section{The Vestible ar Nuclei}

In reconstruction this mass of gray matter first makes its appearance as the Iarge nucleus of Deiters at a point a little abore the mid-clecussational prramidal level. It appears as a small, wedge-shaped mass of gray matter located between the upper extremity of the nucleus of Burdach, the mucleus of Goll and the central gray matter. It also participates in the general lateral swing occasioned by the opening of the fourth ventricle and rapidy increases in size. It occupies a position bencath the eentral gray matter and in relation with the cephalic extremity of the nucleus of Burdach. In the mid-rentrieular region the triangular nucleus of Schwalbe makes its appearance mesial to the nucleus of Deiters and in relation with the central gray matter. The nucleus of Deiters gradually dwindles as it extends cephalad, while the triangular nucleus is continued upward as a large, irregular mass in the lateral reticular formation corsal to the substantia gelatinosa trigemini. Dorsally and cephalically the nucleus of ron Bechterew appears as a small, indefunite mass of gray matter in the lateral wall of the fourth ventricle close to the thin subependymal layer of central gray matter.

\section{The Cochlear Nuclei}

The reconstruction of this muclear mass shows a large ventral cochlear nucleus which extends for a considerable distance into the fower pontile regions of the brain stem. It is separated from the ventrolateral angle of the tegmentum of the stem by the collected mass of the middle and inferior cerebellar peduncles and the descending trigeminal tract. It is connected with the stem only by the fibers of the cochlear nerve.

The large dorsal cochlear nucleus is situated at the extreme dorsolateral angle of the tegmentum in the extremity of the lateral angle of the fourth ventricke. It begins below the recess and extends about an equal distance above the reess. It is limited in extent by the pontile peduncular fibers but 
extends for some distance mesially under the subependymat laser of the central gray matter of the fourth ventricle. It lies immediately dorsal to the vestibular nuclei, separating this mass from contact w ith the gray matter of the floor of the fourth rentricle. Between the ventral and corsal coehlear nuclei are connectine strands of nuckear material as well as the root fibers of the cochlear nerve and secondary fibers of the cochlear tratet.

\section{The Colliclei}

In recomstruction, these masses of gray matter are about ecfual in size and extent. They appear as rounded clevations on the tectum of the midbrain, occupying the cutire width of the dorsal aspect of the axis. They are continuous laterally with the corsal extension of the reticular formation of the mesencephaton. Mesially and clorsally they are continuous across the midline with each other by means of the dorsal gray matter which serves as a matrix for the superior and inferior collicular commissures. The colliculi are separated from the central gray matter by these collicular commissures and by the peripheral fiber condensation which is disposed as a fringe along the line of contact between the central gray matter and the reticular formation. The inferior colliculus is sharply separated from the large superior colliculus by a narrow, linger-like process sent out by the mesencephalic reticular formation, while the superior colliculus merges insensibly into the subpineal region of the cpithalamus. The surface of the mesencephalic reticular formation is traversed in this region by the passage of the two brachia connecting the colliculi with the geniculate bodies.

\section{The Substantia Nigra}

As reconstructed, this mass of gray matter appears as a gradual transformation in the deep layer of the pontile nuclear mass, assuming its characteristic coloration and form at the junction of the isthmus and midbrain. It 
is supported not only by the deep pontile layer, but also rests upon the two buttresses which form laterally and mesially in the pontile gray matter. It is clense and heavy in lemur and is connected mesially to its fellow of the opposite side by means of the interpeduncular gray matter which appears to be quite undifferentiated. This interpeduncular gray matter is continuous with the structures forming the hypencephalon. In the lateral portion of the substantia nigra there develops a discrete nucleus containing many tangled nerve fibers which pass dorsally into the texmentum. The substantia nigra gradually attenuates and disappears. It is not continuous with any definite gray mass in the thatamic region of the brain.

\section{Tile Niclel's Rlber}

The reconstruction of this nuclear mass, so predominant in sections of the mesencephalon in man and the higher primates, is relatively insignifieant in size. The melens is located in the most cephalie portion of the mesencephalon extending into the reticular formation of the diencephalon. It is relatively indistinet and poorly demarcated from the surrounding tissue by the encapsulating fibers of the superior cerebellar peduncle.

\section{Tiie Central Gray Matter}

In the upper regions of the spinal cord this nuclear mass is roughly quadrikateral, receiving the bases of the two dorsal gray columns and ventrolaterally the two ventral gray columns. Passing upward, the central gray matter receives the bases of the developing nuclei of Goll and Burdach and then gives off dorsally a narrow, tongue-like extension which passes along the dorsal median septum. As the caudal extremity of the fourth ventricle is approached, the entire central gray matter migrates dorsally, carrying the eentral canal with it, and as the dorsal gray columns begin to diverge, the quadrilateral body of gray matter gradually flattens dorsoventrally and 
the central canal emerges dorsally into the fourth rentricle, thus disposing the contral gray matter as two hateral halves connected across the midline. This lateral displacement continues until at last the gray matter becomes llat tened out in an almost transwerse plane as the How of the fourth ventriele. From the edges of the lateral walls of the fourth ventriele the ependymal lining continues across the ron of the fourth ventricke which caudally is formed by the inferior medulary velum. In this locality the rool is inviginated by the chorioidal plexuses of the fourth ventricle and here the laser of central gras matter, which at best is extremely attenuated on the row of the fourth ventricle, practically coases to exist.

In the midpontile portion of the fourth ventrick the cercbellum enters into the roof of the ventricle and ecphalad to the cerebellum the superior medulary velum contains the superior cerebellar peduncles. Approaching the upper portion of the metencephalon the lateral walls gradually become convergent until they meet just caudad to the inferior colliculus. At this point the fourth cranial nerves decussate in this reconstituted roof of the ventricular cavity. The lateral walls of the fourth ventricle are formed from below upward by the nuclei of the columns of Goll and Burdach, the nuclei of Deiters and Schwalbe and the inferior cerebellar peduncle. The lateral walls fail at the lateral recesses but appear again as the middle cercbellar peduncle. Cephalically the superior cerebellar peduncles lie in the rapidly converging lateral walls of the cephalic portion of the fourth ventricle.

The floor of the fourth ventricle is comparatively smooth and presents but little modelling. The underlying nuclear masses and fiber tracts produce scarcely any impression on the floor which is stretched evenly from side to side and from below upward. It is in general diamond-shaped, beginning from the opening of the central canal caudally, spreading to its greatest width at the level of the Iateral recesses and then rapidly narrowing as the aqueduct of Sylvius is approached. 
In the oblongata the rounded dorsal surface of the hypoglessal nueleus passes backward and invades to a limited extent the central gray matter. In the metencephaton the dorsal surface of the abducens nerve passes somewhat further dorsally, whike in the mesencephalon the trochlear and oculomotor nuclei extend decply into the central gray matter. The central gray matter in the regions of the mesenecphaton forms a complete investment for the central canal and as the diencephaton is approached, it becomes continuns with the central gray matter underlying the ependymal lining of the ventricle of the diencephalon. Dersally at the junction of the tectal region with the habenular region, the central gray matter is penetrated by the habenular and the pesterior commissures. 


\section{Chapter III \\ TARSIUS SPECTRUN, ITS BRAIN AND BEHAYIOR}

Its Position among the Primates; Mcasurements and Brain Indices; Surface Appearance of the Brain; Internal Structure of the Brain Stem

ARSIUS oceupies a unigue position among the primates. It has been
singled out by eminent authorities to carry upward the line of
human derivation from some lower mammalian form. In this rôle it deserves efosest serutiny regarding its structure and behavior.

\section{Appearance and Bematior of Tarsius}

In size, the animal is about as Iarge as a small squirrel. It is peculiar in appearance because of its closely set, protruding eyes, its long tufted tail, its protruding ears, and the disc-like pads upon the ends of its fingers and toes.

The tarsiers inhabit some of the Malay Islands. They are noted for two curious habits: they can rotate their heads until they look directly backwards; and they leap with astonishing speed among the trees from bough to bough in pursuit of insects. Mr. Le Gros Clark has reeently given the most detailed description of the tarsier's behavior in captivity. He diseusses the alfinities of tarsius to lemurs and the insectivores on the one hand, and the anthropoids on the other. In this discussion he recalls the opinion of the Royal Zoological Society of London, previously expressed, to the effect that whatever its definitive allocations, tarsius shoukd be placed in a suborder of primates (Tarsioidea) which is intermediate between I.emuroidea and Anthropoidea. 
86 THE LOWER PRINATES

Clark's observation on tarsius eovers a period of three years in Sarawak. During this time he was never fortunate enough to sce one of the animals in the wild state. Such specimens as he observed were captured by the Dyaks
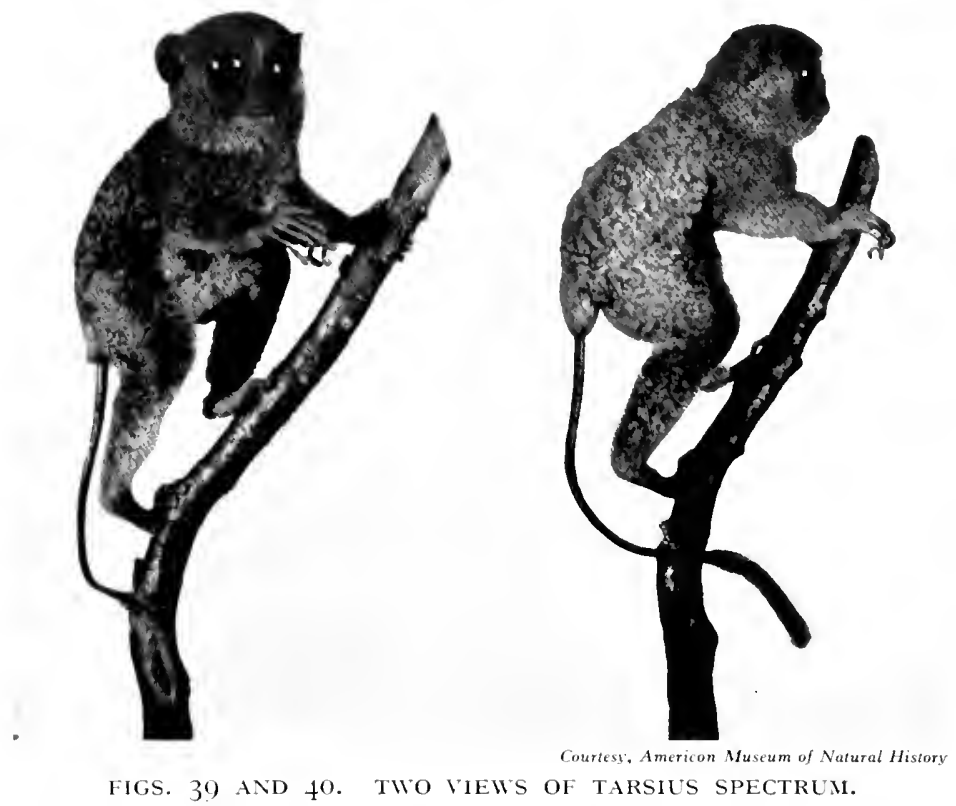

FIGS. 39 AND 40 . TWO VIEWS OF TARSIUS SPECTRUM.

while felling trees. The animal was easily caught during the daytime. It acted almost stupidly, as though its diurnal vision was imperfect. In the main, it made most ineffectual efforts to escape, at the most pivoting on a branch in such a way as to put the latter between itself and its pursuer.

It lives in the jungle of secondary type, particularly in a low country, and for the most part passes its time clinging in a vertical position to branches 
of trees and underbrush. The manner in which it supports itself in this vertical posture is interesting and peculiar. With the fingers and toes it holds the branch in prehensile grasp, meantime pressing its long slender tail against the branch very much in the manner of a spring. If the tail is pulled away from its support, tarsier tends to sag downward. The tail, however, is in no sense prehensile, nor is it used, with the exception above mentioned, in other functions than as a balancing and steering organ during lecomotion.

Tarsius is humanoid in reproducing a single offspring at a time. It is not gregarious, as many of the other primates are, but goes in pairs. After the breeding season the female and her young usually live alone together. There is no evidence that these animals build nests, or even live in the holes of trees. When sleeping, the head sinks downward, much as that of an old man asleep in his chair. Often the young tarsius will perch upon the mother's head while she is thus sleeping, and in this position fall asleep itself. This is an interesting motor combination, plainly showing that the mechanism for maintaining the vertical clinging posture operates perfectly even though the animal sleeps.

The general behavior of tarsius seems extremely stereotypecl. It is capable of but little acquisition under training, and in captivity is apparently unable to make new adaptations. In spite of its enormous eyes, it has difficulty in securing its food during the daytime, grasping awkwardly at grasshoppers or other insects offered to it. This no doubt is due to the fact that its visual apparatus is specialized for nocturnal hunting, and also because the retina possesses no macula.

Characteristic in the motor activity of the tarsier are its marvelous leaps from branch to branch, which are so swift as almost to defy the human eve. It is said that the animal is able to capture small insects on the wing in its leaps. On the ground it leaps also like a frog, but awkwardly. When it lands it sprawls, and then hops away again. Only occasionally does 
it walk and then its gait is ineffective and ungainly. Insects, especially grasshoppers, are the main staple of its ford supply, but it is also partial to milk and drinks water.
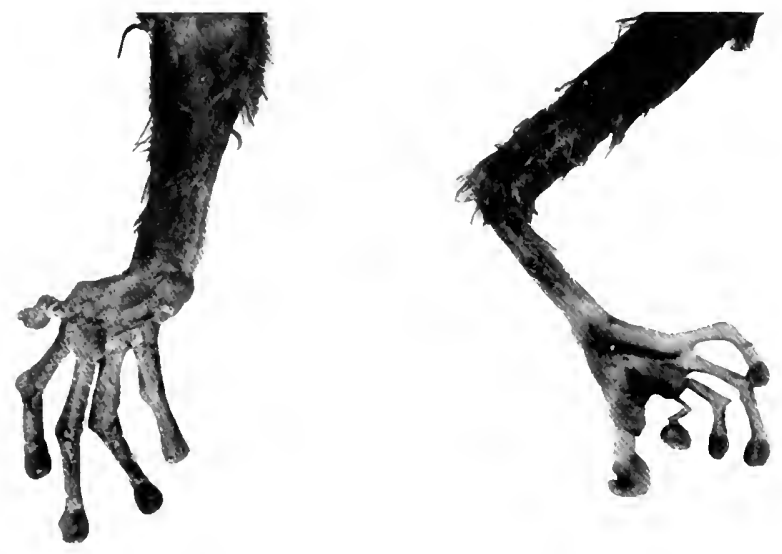

Courless, Amercan Museum of Natural History

FIGS. + I AND +2. HAND AND FOOT OF TARSIUS SPECTRUM.

Lefr. Palmar surface of hand showing rudimentary development of the palm, palmar pads, pronounced digitation, disc-like specialization on the distat phalanx of each finger.

Right. Plantar surface of foot showing rudimentary sole and heel, long hallux partially opposable, and disc-like specialization on the end of each tore.

Tarsius performs its toilet much as a cat does. When it comes to the hind legs it grasps one and then the other with its hands, and thus keeps itself scrupulously clean. It is not known to make vocal sounds indicative of fear or anger, and only on rare occasions has it been heard to squeak, most particularly when young. It is probably not the case that the mother carries her offspring with her teeth in the manner of a cat. This act Clark has never observed. As with many other primates, the infant tarsius grasps and clings 
to the hair on the abdominal wall of the mother. The eyes are open at birth, and many ractions appear at onec which are often long dedayed in such animals as the rat, cat, dor and higher primates.
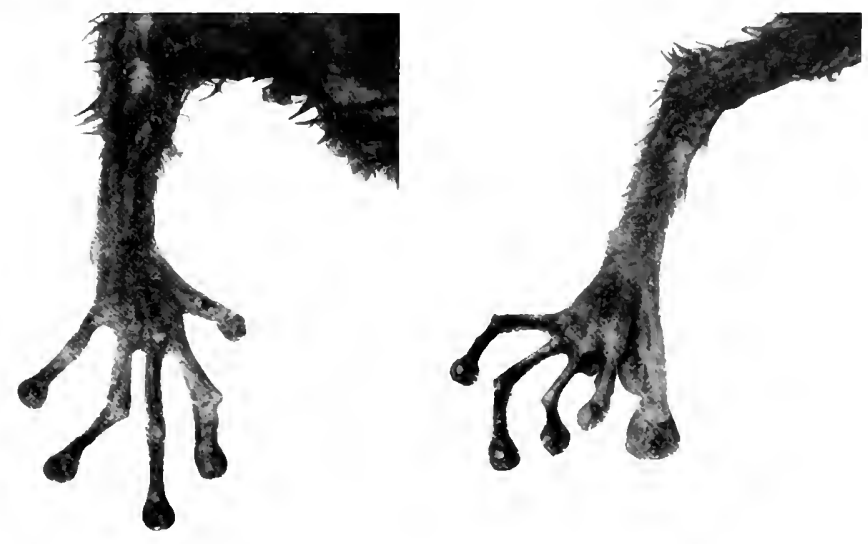

Courtest. Amertan Museum of Vatural hastor.

FIGS. 43 AND 4 . HAND AND FOOT OF TARSILS SPECTRLM.

Left. Dorsum of hand showing disc-like specialization on finger tips, with daws instead of nails. Thumb partly opposable.

Rigнт. Dorsum of fort. Each toe shows the marked disc-like specialization on the distal phalanu; the great toe is short with little or no opposability.

The contention that tarsius may be in the direct line of human ancestry is borne out by its blood tests. Clark has shown that tarsius has a defmite blood relationship with man, chimpanzee and gibbon. On the other hand, the blood reactions are negative with macacus, nycticebus, the cat and the squirrel. The hands are peculiar for their long and slender fingers and short thumbs; the nails resemble claws. The feet are long, the toes slender; the index and middle digits have true claws. The palms of the hands and soles of the feet are provided with arch-like pads. 
In a personal communication, Mr. Harry Raven tells of hunting tarsius both in Dutch Borneo and Celebes. The animals were usually in second growth of the forest, or the scrubby forest abong river banks. They are entirely nocturnal and frecuently found in clumps of bambor or in vines that surround the trunks of large forest trees. He hunted at night with at jacklight. The first time he saw tarsius, two or three of them were together and he caught the reflection of the eres of one, shot and wounded it. When it was pieked up it squeaked, a sharp, piereing squeak. The other two answered the call and when the wounded one was shaken it would repeat the squeaking until the others came up clese. The animals are extremely active, probably the quickest jumpers of all mammals. When they are grasping a small branch, they can twist their heads in the direction they are going to jump, so quickly that it is almost impossible to see it-more quickly than the cye can follow. It is as though they were looking in one direction and jumping in another, they turn their heads with such great speed. In captivity they are pugnacious and cannot be tamed, although it is difficult to keep them for long. In habits tarsius is close to the galago of South Africa, which lives in thickets and dense forests; in fact, their habits are nearly identical.

\section{Affinities of Tarsils to Other Primates}

G. Elliot Smith, who has given much attention to the affinities of the primates, says: "It is well to recall the fact that the brain of tarsius exhibits decisive evidence of the femuroid status in the calearine region, in the Sylvian fissure and in numerous traits which have been enumerated. In the degree of caudal extension of its hemispheres, it is even further removed from the insectivora and more pithecoid than the lemurs. But the evidence of cerebral anatomy lends no more support than $I$ believe the structure of the rest of the body does to the view that the approximation of tarsius to the apes implies its separation from the lemurs. So far as its brain is concerned, Tarsius is a 
lemur of the lemurs, to use an expression of Professor Howe's. It is certainly more nearly related to the apes than most other lemurs. But on the other hand, all the apes and lemurs are linked by a much choser bond of affinity, the one to the other, than are any of them to the other mammals. Tarsius is unquestionably the most primitive living primate."

A. A. W. Hubrecht, on the other hand, maintains that "tarsius is not a lemur at all. It should never have been placed among the lemurs. Its position is somewhere between an unknown type of insectivores and our modern monkeys and man."

Memoirs published within recent vears by Forsyth-Major, Earke and Standing have made it perfectly clear that the demonstration of the allinities of tarsius to the apes does not in any way affect the recognition of the fact that it is at least as nearly related to the lemurs. So that Hubrecht's proposal to restriet the term primates to tarsius and the apes lacks any adecuate justification.

G. Elliot Smith speaks again even more emphatically concerning the position of tarsius. He has, in fact, come to the conclusion that tarsius is much more primitive and at the same time distinctly more pithecoid than the lemurs. He believes that the primate stem flowed from its source among a group of tarsius-like mammals. The apes and the lemurs were merely dirergent branches of this stem and the latter, the lemurs, as a suborder atthough definitely specialized in structure, remained nearer to the Tarsiidae than to the apes.

The primates, he asserts, consist of three divergent phyla which have all departed in varying degrees and in different ways from their original common ancestor which must have been a creature in many respects like tarsius, but more macrosmatic and possessed of a small and less highly specialized visual cortex.

Woollard, on the basis of an exhaustive anatomical study, con- 
chudes that tarsius is a lemur annectant to the early Eocene primitive placentak. Standing at the base of the primate stem, it reaches forth to the simian forms and is annectant to the Anthropoidca.

In stating his views concerning the alluities of tarsius, E. D. Cope chamed that "the genus Anaptomorphus is the most simian lemur ret discosered and probably represents the family from which the anthropoid monkers and men were derived. The animal was nocturnal in its habits and had a number of resemblances to Tarsius which is perhaps its nearest ally among the lemurs."

Mathew and Granger both are in general acoord with this view when they say that "There are several characters in addition to the larger braincase in which the skull of Tarsius is more modernized than that of the Lower Eocene Anaptomomplous, but in some other genera of this group the dentition is much nearer to Tarsius and the skull construction may likewise have been nearer."

In regard to tarsius, Earle likewise believes that this is evidently at type nearly between the lemurs and the apes, but with many essential characters belonging to the former group. Some of its anthropoid characters are nascent, so to speak. They are just developing, and as in the case of the orbit of tarsius, it is not ret fully differentiated into the higher type of true anthropoids. The anthropoids diverged from a lemurine stock probably not carlier than the Upper Eocene. This deduction is supported by the fact that the first lemurs to appear are insectivorous in their affinities.

Sonntag also believes that the Eocene Anaptomorphidac gave rise to tarsius and the monkers arose from a tarsioid ancestor.

Wood-Jones, however, has assumed what is perhaps the most radical attitude in holding that tarsius "like man shows primitive cranial architecture. His kidncy is formed on human lines, his aortic arch is arranged as in man, and in a word he shows with man the basal mammalian simplicity of the primate group. He is a most highly specialized little creature on his own cur- 
ions lines and ret he retains with man a host of these astonishingh primitive features that place this odd couple at the baseof the primatestem. He lingers today a specialized primitive primate nearer akin to man than any other animal known to the zoologist. Tarsius dates right back in the form of Anaptomorphus to the base of the Eocene period and at that astonishingty early epoch he had already ganed his own peeuliar specializations. His companion in primitiveness-homo-has his own specialization."

The paleontologicat evidence reviewed by Professor Greagory seems to be against Wood-Jones" view that the existing tarsius is the nearest living relative of man. "Tarsius may well paralled the human condition in construction of the placenta and in a few other points noted by Wencl-Jones, but its relationships to man are plainly very indirect and must be traced backward along gradually converging lines to the primitive Tarsiod stocks which gave rise at different times and at diflerent places to the higher groups of Tarsius."

"Neither tarsius itself nor its own Eocene relatives mentioned above appear to be directly ancestral either to the platyrrbine or to the catarrbine divisions of the Anthropoidea. Nevertheless, tarsius parallels the higher primates in so many characters of the brain, skull, reproductive organs and other parts that a very remote common ancestry of the three suborders seems highly probable."

\section{Measurenents of Tarsius}

The average measurements of tarsius are:

Body length.

1 fo $\mathrm{mm}$.

Tail

$208 \mathrm{~mm}$.

Head length. 4) $\mathrm{mm}$.

Head breadth $32 \mathrm{~mm}$.

Upper extremity. $109 \mathrm{~mm}$.

Lower extremity $177 \mathrm{~mm}$.

Total weight 023 gms. 
Strface Appearayce of the Brain in Tarsiles

The cerebral hemisphere of tarsiers is lissencephalie, the fissure of Sylvius being the sole indication of sulcal marking. In general contour the brain of tarsius is elongate, its greatest length being $21 \mathrm{~mm}$., its greatest width $20 \mathrm{~mm}$. The length is further augmented by the addition of a pronounced bulbus olfactorius which projects forward for a considerable distance beyond the frontal region. In this regard the tarsial brain is as primitive as many of the lower mammals and even approaches reptilian conditions. None of the primates possesses a bulbar development comparable in prominenec to that of tarsius. In fact, it is in exactly this olfactory detail that all of the Anthropoidea manifest that marked insolution signilicant of a progressive microsmatic development.

THE LISSENCEPHALIC CHARACTER OF TIE CEREBRAL CORTEX

The Sylvian lissure, although clearly distinguishable, has none of those features which characterize it in the apes and man. It unquestionably corresponds to that suprarhinal fold which forms the mammalian pseudo-Sylvian fissure. Lobation of the tarsier's hemisphere is almost negligible. The Sylvian indentation separates a poorly developed frontal lobe from a feebly delineated temporal area. The occipital pole has extended caudact so that the cerebral hemisphere covers a large portion of the tentorial surface of the cerebellum. This is a defmitely pithecoid character. On the other hand, that total absence of boundary between the occipital and parictal as well as between the parietal and Irontal areas bespeaks a neopallium of such pronounced generalization that it might well serve for the lowest of mammalian forms. With the exception of the marmoset, no such lissencephatic condition of the cerebral cortex is encomntered among the primates. In the Hapalidae, how- 
ever, the lack of fissures in the neopallium may be attributed to a retrograde process in the cortex which, according to one interpretation at least, represents a secondary degenerate stage predueed during the evolution of the
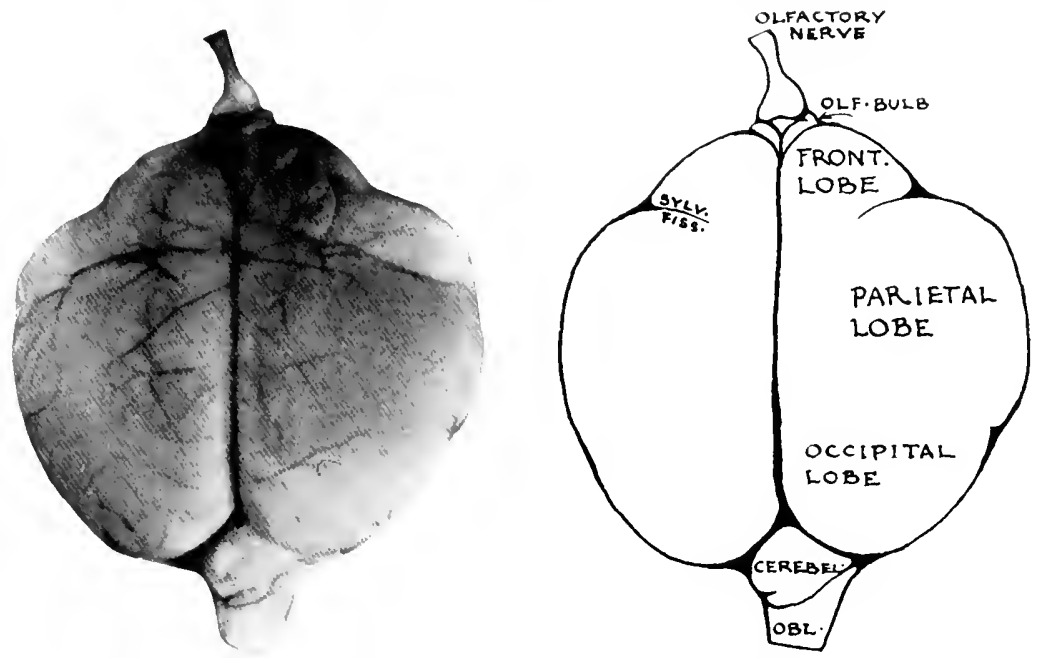

FIG. 45. DORSAL SLRFACE OF BRAIN OF TARSICS SPECTRLM. [Actual Length, $21 \mathrm{~mm}$.]

Key to Diakat. Cerebel., Cerebellum; rrovt. robe, Frontal Lobe; obl., Oblongati; olf. betb, Olfactory Bulb; sylv. Fiss., Sylvian Fissure.

Cebidae. The simple condition of the hemispheres of tarsius would seem, on the other hand, to represent the retention of definitely primitive characters in a brain in many other respects affeeted by marked progressive tendeneies.

ORBITAL CONCAVITIES AND OLFACTORY BULB

The basal surface of the hemisphere presents two ill-defined orbital concavities although the orbits in tarsius are extremely large. The lack of prominence of these concavities is due to the fact that the frontal lobe is poorly developed. The olfactory bulb is large, protruding rostrad in front of the 
(1) 0

frontal pole and passing backward into a short stubby offactory tract which terminates in a prominent tuberculum olfactorium. This protraction of the bulb is not found in lemurs. The tubereulum is embraced by the olfactory
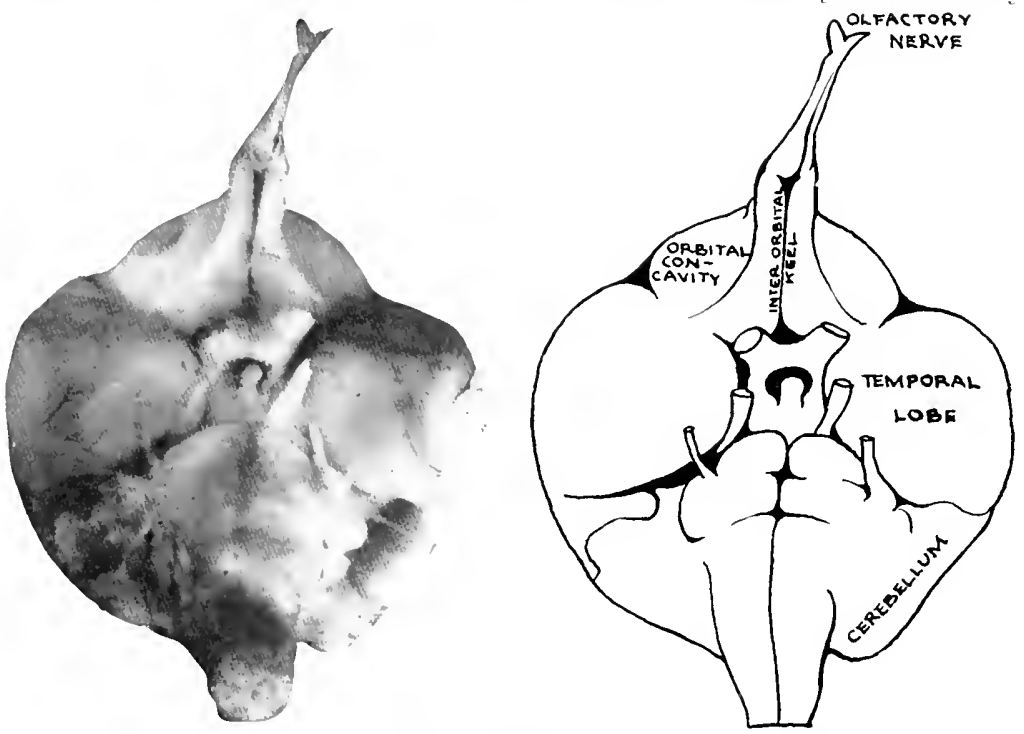

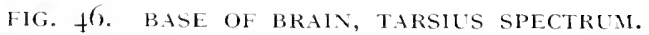

[Actual I ength, $21 \mathrm{~mm}$.]

striate and bounded posteriorly by a well-defined perforated space and diagonal band of Broca. The two offactory bulbs and tracts together constitute a most pronounced interorbital kecl.

The olfactory bulb is further identified in tarsius by its connection with the olfactory portion of the nasal mucosa through a single olfactory nerve. The fila olfactoria, undoubtedly because of the large size of the orbits, have coaleseed to form a single strand, although near the entrance into the olfactory bulb there is some evidence of the spreading-out characteristic of other primates. 
THE OPTIC CHIASM

The optic chiasm is llat and broad and gives the impression of generally greater thickness than in other forms, due to the fact that almost all of the optic fibers undergo decussation. Very few optic fibers in tarsius are uncrossed. The interpeduncular space is small, bounded by feebly developed cerebral peduncles, while the temporal lobes are broad and flat, each filling a more or less irregular quadrate area in the lateral portion of the middle fossia.

THE VENTRICLES AND THE VISLAL CORTEX

The ventricular system of the hemispheres is particularly significant, inasmuch as the lateral ventricle develops a pesterior horn extending into the occipital region, which is not the case in any of the lemurs. The ventricular extension of the olfactory peduncle characteristic of many mammals is, however, being obliterated. The visual cortex of the cerebral hemisphere shows a marked increase as compared with lower mammals and even the lemurs. It is casily detected by the naked eye and occupies nearly one-third of the entire neopallium.

\section{TIIE CEREBELLL M}

The cerebelum is notable as indicating those lateral expansions which in higher primates become the most important part of the organ, namely, the lateral cerebellar lobes. Tarsius in many respects is an excellent prototype in most simple terms for the subsequent extensive development of the primate cerebellum. Its tentorial surface lies at an angle of about $-0^{\circ}$ with the axis of the stem, thus showing the early tendencies which eventually carry this surface more nearly into the horizontal. The occipital lobe covers most of the tentorial surface which consists largely of the superior vermal 
portion of the cerebellum. A well-defined Hocculus and parafloceulus are attached along the region of confluence with the axis.

The oecipital surface also oceupies a vertical position and as yet has not
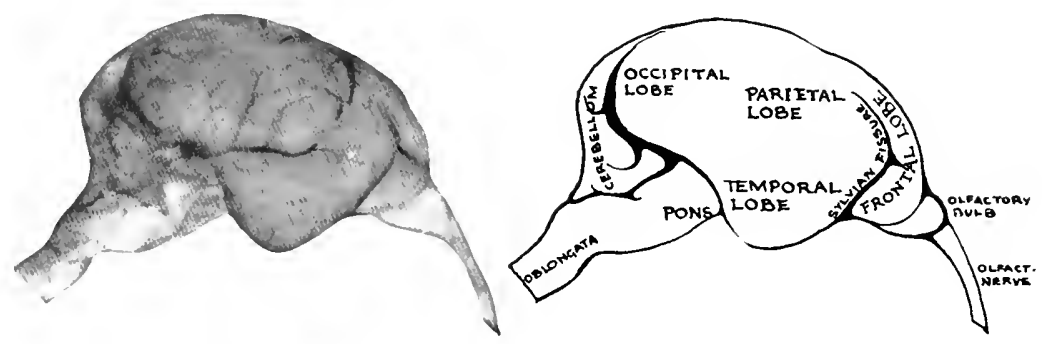

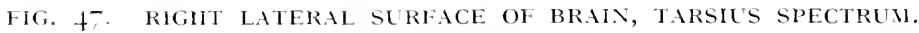

[Actual Length, $21 \mathrm{~mm}$.]

been tipped backward, as is the case in higher primates. This fact accounts for the exposed position of the urula and nodule which have not yet undergone that introversion which produces their ultimate intraventricular relation characteristic of most of the anthropoids.

The fissures of the cerebellum have an almost diagrammatic clearness in producing the three major subdivisions of the cerebellum. The fissura prima appears upon the tentorial surface and extends outward from the vermis upon the fateral lobe without sulcal interruption. This is likewise true of several other fissures of this surface. The fissura secunda appears in relation with the occipital surface but, as in other mammals, it does not extend out upon the lateral expansion of the cerebellum, being interrupted by the presence of a definite paramedian sulcus. All things considered, the cerebellum of tarsius is the most primitive of all primates, and yet it foreshadows in so many notable details the future development of this organ in apes and man that it must be regarded as inherently anthropoid. 


\section{The Bran Stem in Tarshes}

THE VENTRAL SURFACE

The ventral appearance of the brain stem in tarsius is peculiar because of the relatively small size of the pons Varolii, the pyramids, the inferior olivary eminences and the cerebral peduncles. All of these are cridences of a low degree of development in the neokinetic organization of the animal. Its voluntary control of motor activity, its dispensation of courdinative control of the muscles, its measure of simultaneous regulation in the movements of the head, cyes and hands, could not be other than extremely simple and generalized on the basis of these structures. The pyramids appear as two narrow bands extending caudad from the fower border of the pons toward the upper cervical region of the spinal cord. The pons itself is a narrow, flat band of very little surface prominence. Caudal to it the corpus trapezoideum occupies a transverse position upon the surface of the axis. Tat sius is the only primate in which the corpus trapezoideum is entirely exposed in this position. This fact does not imply any greater organization in the auditory apparatus of the animal, but does denote how poorly the pons Varolii has developed.

The olive makes a very small protuberance lateral to the py ramid and is separated from it by a wide area hardly justifying the term preolivary sulcus. The emergent fibers of the hypoglossal nerve, however, make their appearance on the surface in close relation to the olivary eminence. Two small peduncles form the caudal boundary of a limited optico-peduncular space whose eephalic boundary is provided by the massive optic chiasm and tracts.

THE DORSAL SURFACE

The dorsal surface, upon removal of the cerebellum, shows a poorly defined clava, cuncus and tuberculum trigemini. The floor of the fourth 
ventricle has its usual boundaries but shows in a most indefinite way these surface markings which characterize it in Anthropoidea. This dorsal surface of the brain stem, however, assumes great prominence because of the develop-
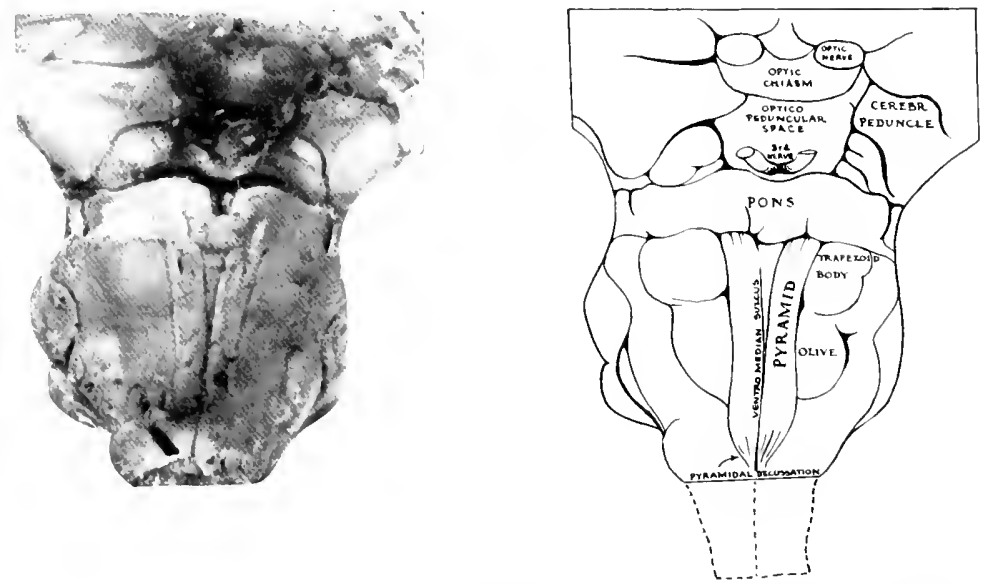

FIG. 48. VENTRAL SURFACE OF BRAIN STEM OF TARSILS SPECTRLM. [Actual Length, $16 \mathrm{~mm}$.]

Key to Dlagkan. Cerebr.-pedencle, Cerebral Peduncle.

ments in the mesencephalic roofplate. Here the inferior colliculus and mesial geniculate body are larger and better defined than in all other primates. The superior colliculus attains dimensioms almost warranting the designation of optic Iobe, but in any event much more conspicuous than in lemurs, monkeys, apes or man.

Thus, in the feeble development of certain features whose progressive expansion characterizes the line of evolutional development in the primates, tarsius appears to be an expression of this process in its simplest terms. It indicates this primitiveness quite as much in the superior and inferior colliculi of the midbrain. In spite of the lact that the animal has made such notable 
gains in the telencephalization of vision, the primordial receiving anters for this sense still maintain a high degree of prominence in the midbrain. This primitive feature becomes progressively more prominent in descending
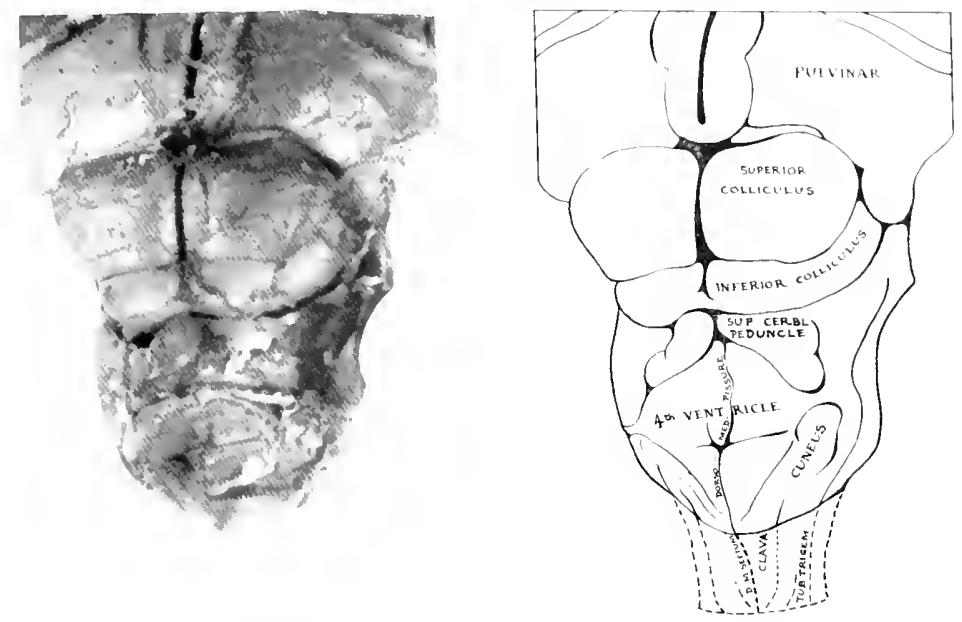

TIG. 49. DORSAL SLRFACE OF BRAIN STEM OF TARSILS SPECTRLY. [Actual Length, if $\mathrm{mm}$.]

Key to Diagram. dorso-sifd. Fissure, Dorsomedian fissure; D. M. Septiv, Dotsomedian Septum; slp. Cerebl. Peduncle, Superior Cirebellar Pedunde; trb. Trigem. Tuberculum Trigemini.

the vertebrate scale to its convergene upon the reptilian basis of mammalian differentiation, at which level it reaches its full expansion in the uptic lobes.

\section{Internal Structure of the Brain Sten}

The impression obtained from a microscopic review of the brain stem is that of a primitive mammalian organization. The structural details are, so to speak, still in the crude. They have none of that refmed definition which distinguishes the higher primates and man. All of the topographical features 
throughout the stem show an indecisive differentiation. This feature is particukarly noted in the cranial nerves whose emergent fibers by comparison with other primates seem coarse and heary. The nuelear territories and tract

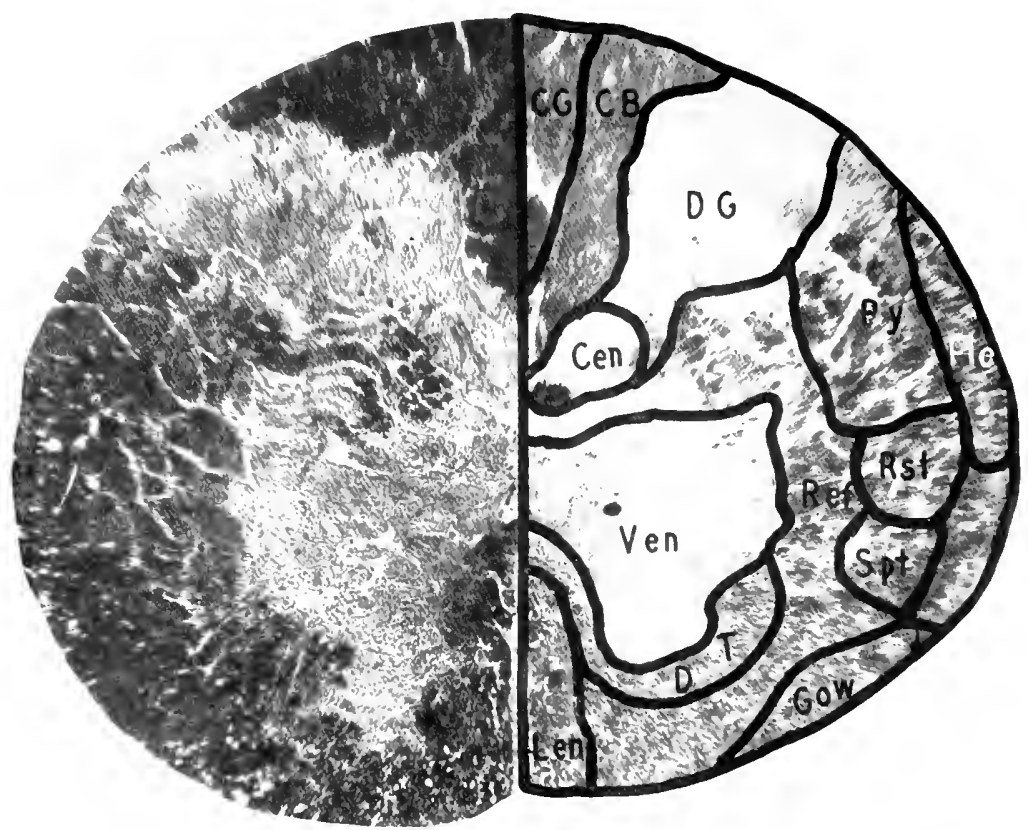

FIG. jO. TARSIUS SPECTRUN. LEVEL OF TIE FIRST CERVICAL SEGMENT. Cen, Central Gray Matter; CB, Column of Burdach; Co, Column of Goll; DG, Dorsal Gray Column; DT, Deiterso-spinal Tract; f1.t, Dursal Spinocerebellar Tract; gow, Ventral Spinocerebellar Tract; Py, Crossed and Uncrossed Pyramidal Tract; REF, Reticular Formation; RST, Rubrospinal Tract; spt, Spinothalamic Traet; ven, Ventral Gray Column. [Accession No. 210. Section 26. Actual Size, $3 \times 2$ mm.]

regions alike are indefinite in their boundaries. Some noteworthy specializations appear in particular mechanisms, such, for example, as the pronounced expansion of the ventral gray column connected with the origin of the spinal 
accessory nerve, and the large dimensions of the vestibular area. These features will be especially dealt with in the interpretation of their physiological significance.

\section{LEVEL OF TIIE PYRAMIIDAL DECLSSATION (FIG, ;1)}

At this level the characteristic feature is the crossing from one sicle to the other of pyramidal fibers ( Pyx). This is much less regular than in other primates. The crossing strands are somewhat indiscriminate in their disposition. The bundles tend to interlace and have little of that suceessive crossing first from one side and then from the other, notable in hiencer primates. There is a suggestion, particularly at the caudal end of the decussation, that some fibers may make their way into the dorsal columns after the manner of eertain lower mammals. This observation needs experimental confirmation. PatWeigert preparations scarcely more than suggest this possibility. In all details the pyramidal crossing seems more primitive than in any other primates. If some fibers actually do enter the dorsal columns, the conception of tarsius as a much generalized intermediate form gains further support. The central gray matter $(\mathrm{Cen})$ is large and rectangular in outline, containing near its center the central canal. Its greatest diameters are in the antero-posterior direction. It is connected with a large dorsal gray column by a cervix of somewhat irregular outline, but separated from the ventral gray column by the crossing pyramidal fibers which assume a juxtagriseal position in dense bundles after they have decussated. The large size of the ventral gray column (Ven) is notable, particularly as there appear to arise in it many fibers which take a course backward and outward, characteristic of the spinal accessory nerve. These fibers constitute a nerve of much larger size and generally more conspicuous than in any of the apes. This fact, in conjunction with the great prominence of the ventral gray column, suggests the probable specialization in connection with one of the peculiar habits of 
tarsius, namely, the turning of its head completely around so that it can look backward as well as to the front. The anmal moves its head rather than its eres in its risual pursuit of objects. This requires a highly specialized arrical

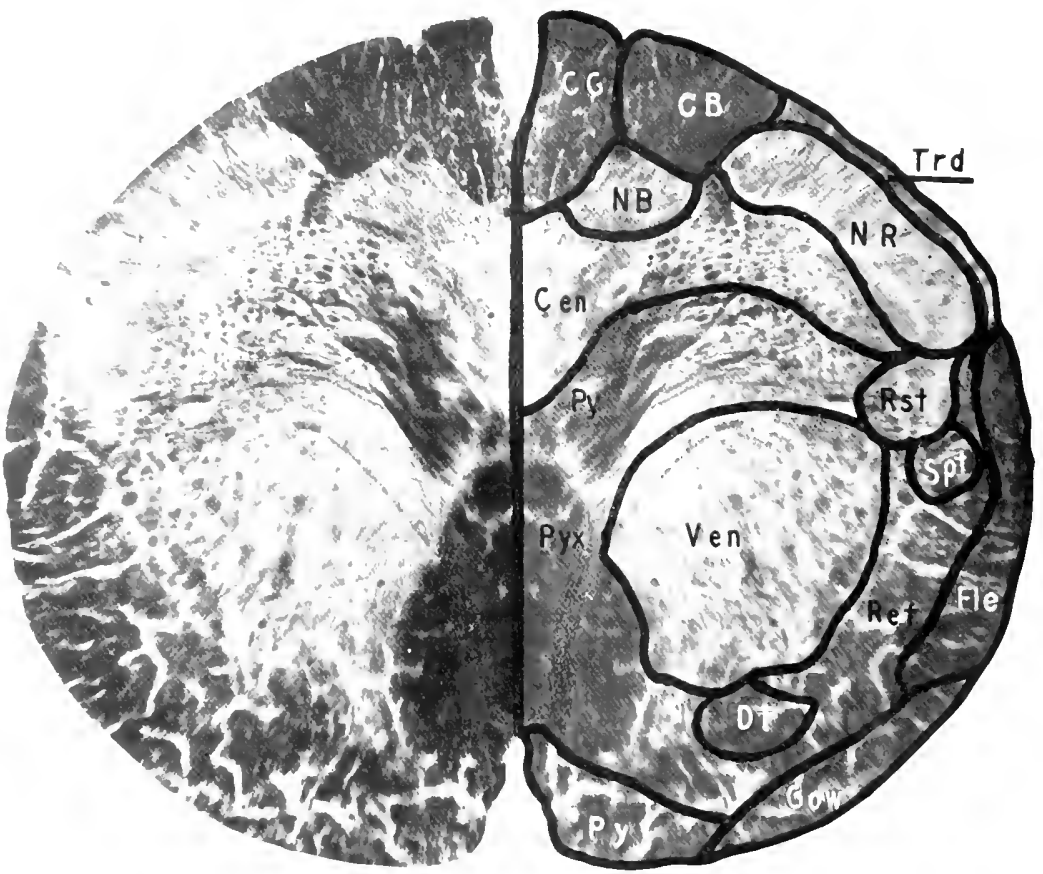

FIG. jI. TARSILS SPECTRLM. LEVEL OF THE PYRAMIDAL DECLSSATION. a b, Column of Burdach; rex, Central Gray Matter; cr, Column of Goll; DT, Deiterss-spinal Tract; $1 \mathrm{LE}$, Dorsal Spinocerebellar Tract; cow, Ventral Spinocerebellar Tract; NB, Nuckus of Burdach; NR, Nucleus of Rolando; pr, Pyramid; PYx, Pramidal Decussation; ReF, Reticular Formation; Rst, Rubruspinal Tract; spr, Spinothalamic Tract; TkD, Descending Trigeminal Tract; N.N, Ventral Gray Matter. [Accession No. 210. Section 6j. Actual Size $+<3 \mathrm{~mm}$.]

musculature, which no doubt determines the prominent spinal accessory feature in this region of the brain stem. 
The dorsal fied consists of a small column of Goll (CG), a large column of Burdach (CB) and an extensive substantia grelatinosa (NR). Adjacent to the latter is a well-edefined descending trigeminal tract (Trd). The separation of the dorsal gray column is less pronounced than in many of the higher forms. The general proportions of the elements entering in to this fiekl suggest at once a tail and Iower extremity which give rise to a sensory inthux much less than that from the hand and arm. It is probably the case that in tarsius diflerentiation of the upper extremity is more effective than of the hower extremity. The great speed and accuracy with which the hands are employed in the capture of insects, and at the same time for prehensile purposes in alighting after its remarkable leaps, would secm to imply a specialization in the upper extremity much superior to that in the hind limbs.

The tail has no prehensile characteristics, and while it acts in a supplementary manner for supporting the clinging posture of the animal, its activities inclicate no great increment of sensory influx. The size of the nucleus of Rolando is indicative of facial innervation, which is essential to the animal in guiding its locomotion.

The lateral white column contains in its cireumferential zone the spinocerebellar tracts (Fle, Gow) white in the intermediate zone are the rubrespinal (Rst), Deiterso-spinal (DT) and spinothalamic tracts ( $S_{p} t$ ). The pyramidal status denotes a behavioral complex consisting of relatively few components and extremely poor in its pattern for skilled acts.

\section{CALDAL EXTTREMHT OF THE DORSAL SENSORY NLCLEI (FIG. ;2)}

Here the chief feature is the appearance of the three nuclear structures representing discriminative sensory transmission from the body. The nucleus of Goll (NG) is well defined but shows no evidence of the modian unpaired nucleus of Bischolf. This deficiency in tarsius harmonizes with the fact that the animal's tail is not highly specialized, although it acts in spring- 
like capacity, aiding the animal to cling in vertical position. The tail has no prehensile qualities but serves in the general capacity of a steering and balancing organ much as in the tailed monkers of the old world.

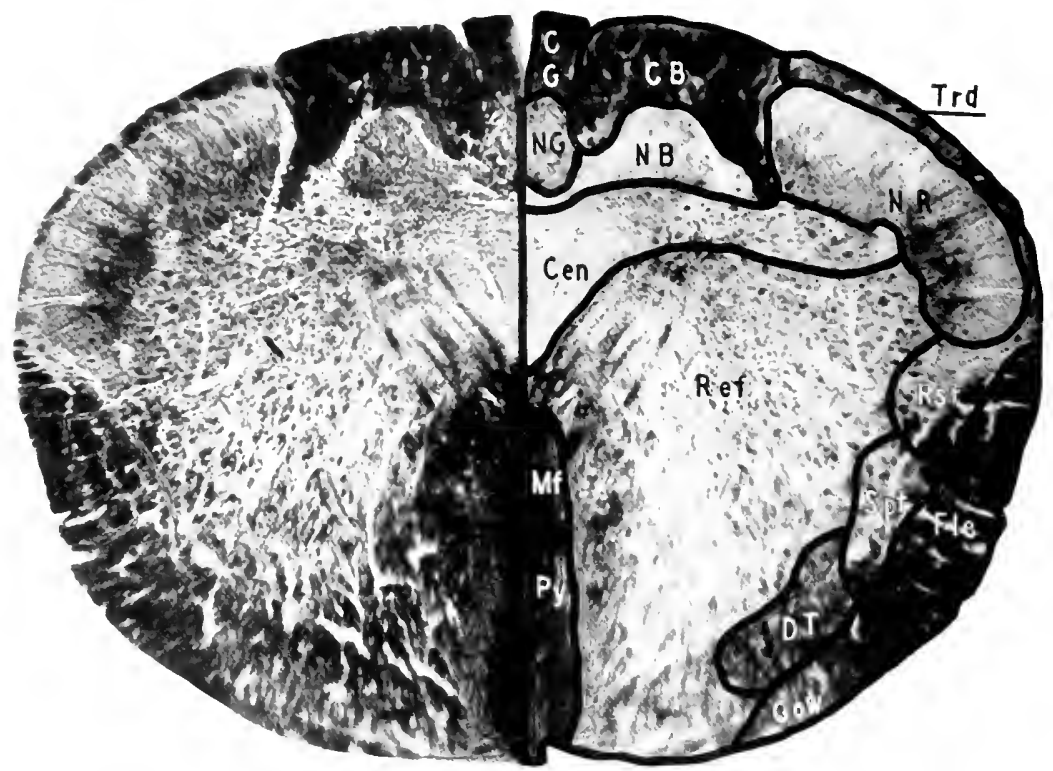

FIG. 52. TARSILS SPECTRLN. LEVEL OF THE DORSAL SENSORY NLCLEI. AEv, Central Gray Matter; cB, Column of Burdach; CG, Column of Goll; DT, Deiterso-spinal Tract; FLe, Dorsal Spineserebellar Tract; cow, Ventral Spinecerebellar Tract; Mf, Mesial Fillet; NB, Nucleus of Burdach; NG, Nucleus of Goll; NR, Nucleas of Rolando; Pr. Pyramid; Ref, Reticular Formation; Rst, Rubrospinal Tract; spt, Spinothalamic Tract; Tro, Desecending Trigeminal Tract. [Accession No. $2 \mathrm{Io}$. Section 72. Actual Size, $6 x+m m$.

The nucleus of Burdach (NB) is considerably larger than the nucleus of Goll. This fact gains considerable weight when the columns of Burdach and Goll are contrasted. Tarsius seems to possess a mechanism for sensory eonduction more extensive in the representation of its hands and arms 
than of its feet, lege and tail. In contrast with the lemur and marmoset, this relation approaches nearer to the more highly dereloped anthroperds. The explanation, however, depends probably not somuch upon the hierh specialization in the upper extremities, as upon the low specialization in the lower extremities. Tarsius uses the hind leges much as does a frog. It leaps from branch to branch and hops upon the surface of the geround. The specializattion of the legs is thus not particularly advanced for purposes of locomotion. It is inferior to that in the forelimbs for such acts as the animal clereleps in connection with procuring louel.

The nucleus of Rolando (NR) is particularly prominent as a sensory element. This is also true of the descending trigeminal tract ( $\operatorname{Trd}$ ), from which it is obvious that the semsory innervation of the head and face plays a conspicuous part in directing the animal's lecomotion. The head and face are especially provided with vibrissac about the chin, mouth, and beneath the nose. Supraorbital vibrissate also exist. The central gray matter ( $\mathrm{Cen}$ ) occupies a pesition in the center of the section but has shown considerable migration dorsad, thus manifesting the general tendency to assume its characteristic position in the lloor of the fourth ventricle. The ventral gray column has entirely disappeared, and its position is occupied by a continuous irregular mass representing the formatio reticularis grisea (Ref). Contiguous with the latter on its lateral aspect is the intermediate medullary substance which contains the rubrospinal (Rst), spinothalamic ( $S_{p} t$ ) and Deiterso-spinal (DT) tracts.

On the periphery is the circumferential zone which contains the ventral (Gow) and dorsal (FIe) spinocerebellar tracts. Immediately adjacent to the ventromedial suleus is a dense mass of decussating axons composed of internal arcuate fibers arising in the nucleus of Goll ( $\mathrm{NG}$ ). These decussating fibers form the lower portion of the mesial lillet (Mf). 
LEVEL OF THE CACDAL EXTREMITY OF THE INFERIOK OLIE (1-IG, j3)

At this level the lower tip of the inferior olive makes its appearance (IO). An important fact conecrning this structure in tarsius is its indecisive

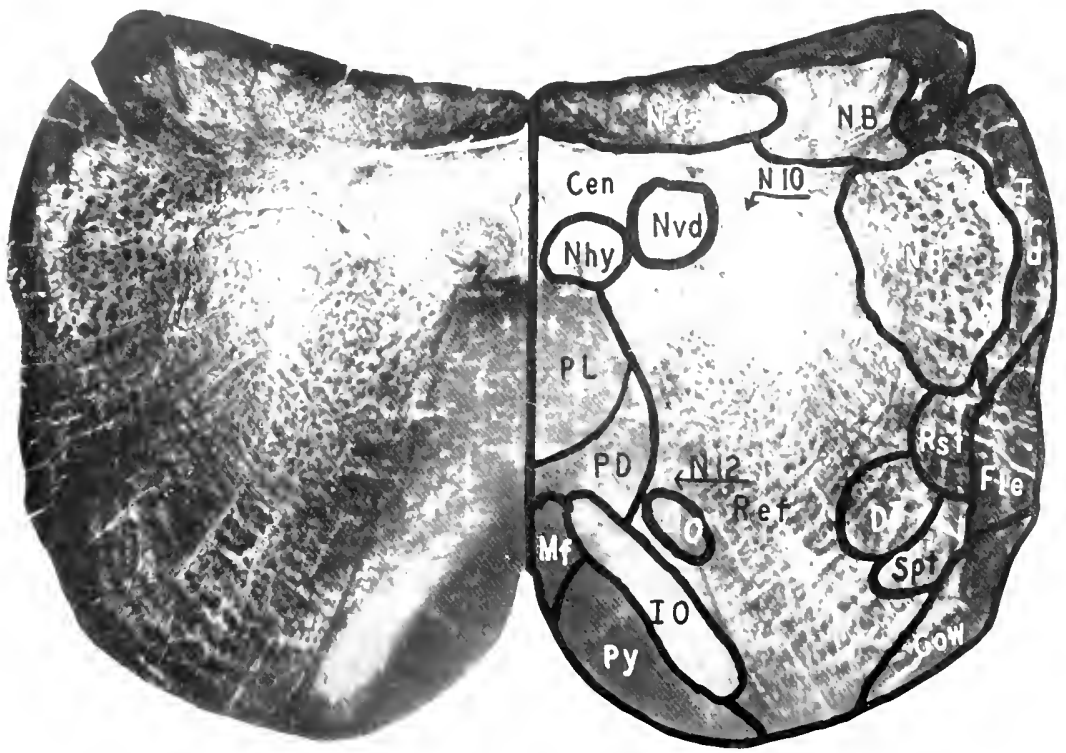

FIC. 53. TARSILS SPECTRLM. LEVEL OF CALDAL TIP OF INIERIOR OLIVE.

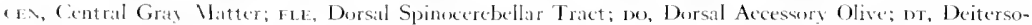
spinal Tract; cow; Ventral Spinocerebellar Traet; us, Inferior Olive; MF, Mesial Fillet; vB, Nucleus of Burdach; vo, Nucleus of Goll; vir, Ilypoglossal Nucleus; Nr, Nucleus of Rolindo; Non, Dorsal Viaral Nucleus;

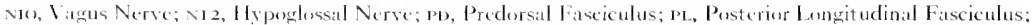
r, Pramid; Rı r. Reticular Formation; Rs I, Rubrospinal Trate spt, Spinuthalanic Tratet: TRD, Descending Trigeminal Tract. [Aceession No. 210 . Section 1)i. Actual Size $6<3 \mathrm{~mm}$.]

outline. Its diminutive size as compared with that of other primates is also notable. Nesial to the olive is the pyramid (Py) which likewise is small. Dorsomesial to the pyramid is the mesial fillet (Mf), still receiv- 
ing some contributions from the internal areuate fibers arising in the nucleus of Burdach (NB). By contrast, the extensive size of the persterior Iongitudinal fasciculus (PL) and of the predorsal bundle (PD) denotes the importance of these colliculo-spinal and other midbrain connections.

The central gray matter $\left(\mathrm{Ce}^{\mathrm{n}}\right)$ is oval in outline and still morc dorsal in position. It contains in its center a much enlarged central canal, while in its rentromesial area is the nucleus hypoglossus (Nhy). This nucleus has none of the discrete distinetion in its boundaries notable in the higher primates. The emergent tibers passing from it appear in larger and coarser bundles than is the case in any other species examined.

In a position dorsal to the central gray matter are the chicf nucleiof the dorsal sensory field. Their relation discloses the preponderance of the mucleus of Burdach (NB) as compared with the nucleus of Goll (NG). The large size of the nucleus of Rolando (NR) and of the descending trigeminal tract ( $\mathrm{Trd}$ ) calls attention to the important role of the head and face as a sensery director of the animal's locomotion.

The outline of the corsal aspect of the section shows an increasing concavity due to the presence of the uvula ecrebelli in this position. The fibers of the spinal accessory nerve pass ventrolaterally through the nucleus of Rolands (NR) toward their point of emergence. The reticular formation (Ref) occupies the greatest portion of the section at this lerel. In its lateral periphery is the nucleus ambiguus from which the emergent fibers of the vagus nerve pass backward and inward toward the central gray matter in the first part of their intramedullary course. The reticular formation is further specialized to form the nucleus funiculus latcralis and is penetrated by many long internal arcuate fibers. It is noteworthy that these latter elements have none of the conspicuous appearance characteristic of higher primates. They, like the mesial fillet and the pramid of 
tarsius, indicate a less highly organized condition in discriminative sensibility and roluntary motor controt.

It seems obvious from the known behavior of the animal that its range of skilled morements is comparatively limited. From these structures in the brain stem it is permissible to conclude that tarsiers in exeneral acquire but little increase in their motor attainments under the influence of traning. This level might well pass for the corresponding region in the cat or rabbit; in fact, its components have a close resemblance to marsupial organization. The medullary substance in the intermediate zone contains the rubrospinal and spinothalamic tracts (Rst, $S_{p} t$ ), while on the circumference are the two ascending cercbellar fascicles (Fle, Gow).

A small collection of gray matter dorsal to the main body of the olive is the dorsal accessory olivary nucleus (DO).

LEVEL TIROLGH THE MIDDLE OF THE INFERIOR OLIYARY NLCLELS (FIG. j4)

At this level the inferior olive is conspicuous because of its structurat inferiority as compared with other species. This nucleus in tarsius consists of an aggregation of gray matter, so poorly differentiated from the formatio reticularis that it might appear as an intrinsic part of this formation. The portion of the nucleus which may be discerned appears to correspond to the mesial accessory olive in other forms. A ren small mass of cells lateral to this structure represents the inferior olive itself. Thus the most conspicuous portion of the nucleus seems to represent what is usually described as the paleo-olive. Compared with either the cat or the rabbit, the olive in tarsius is distinctly more primitive, and this certainly is the case in comparison with all other primates. Judged alone by the criteria of this structure, it woukl seem that the tarsier oceupies a low position in the organization of its central nervous system; one which might, however, serve most advantageously as a fairty unbiased founctation for extensive further modifications. In the inter- 
pretation of olivary function, tarsius is an important witness concerning the activity of this nucleus. If, as is assumed to be the fact, the olivary nucleus is essential to simultancous coordination of the hands, eres and head in complex

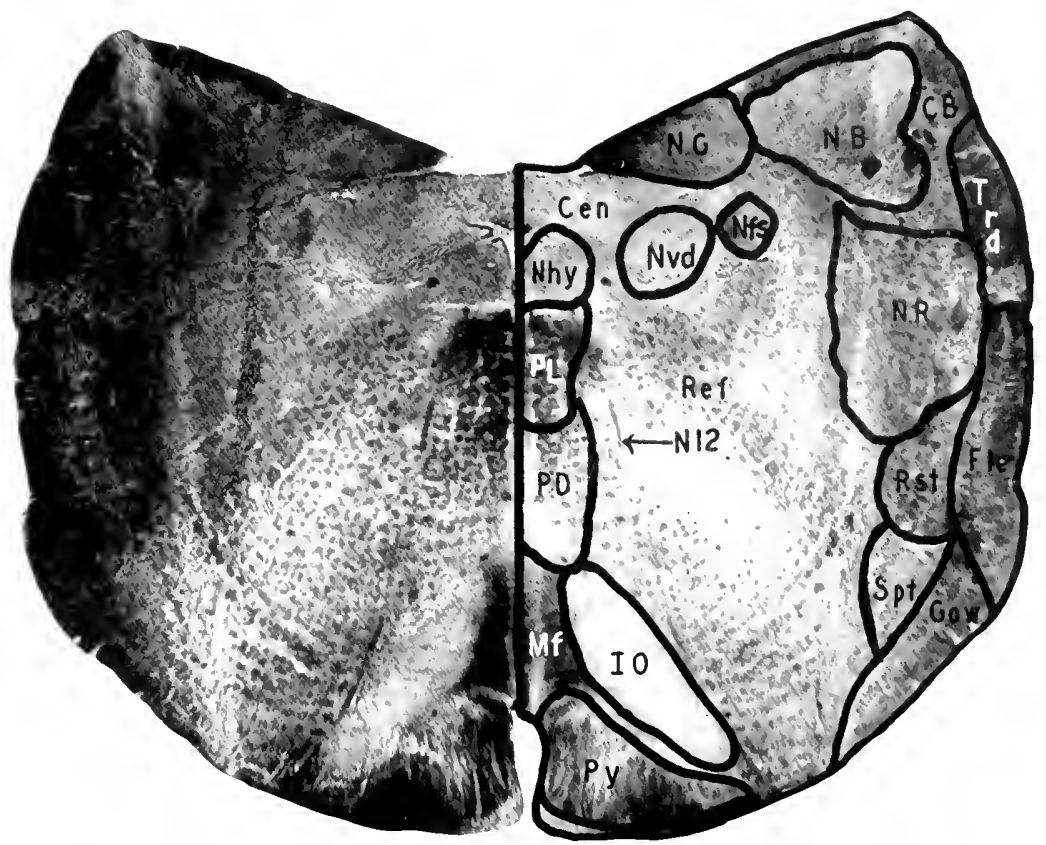

FIG. j4. TARSIUS SPECTRUII. LEIEL THROLGH IIDDLE OF INIERIOR OLIVE. CB, Column of Burdach; CE\, Central Gray Matter; He, Dersal Spinocerebellar Tract; gew, Ventral Spinocerebellar Tract; to, Inferim Olive; Mr, Mesial Fillet; NB, Nucleus of Burdich; No, Nucleus Fasciculus Solitarius; ve, Nucleus of Gull; vin, Hypoglossal Nucleus; NR, Nucleus of Rolunde; Wv, Dorsal Vagal Nucleus; Nr2, 11 ypoglossal Nerve; 1'D, Predorsal Bundle; pr, Posterior Longitudinal Fasciculus; PY, Pyramid; REF, Reticular Formation; RST, Rubrospinal Tract; sPr, Spinothalamic Tract; TRD, Descending Trigeminal Tract. [Accession No. 2 I0. Section 10\%. Actual Size, $-x+m m$.]

skilled acts and helps to facilitate the coordination of all skilled learned performances, its inferior development in the tarsier implies a low development of such activity. 
It has already been noted that the animal is able to turn its head completely around so that it may in effect look both forward and backward. Such rotation is due to the fact that the animal mores its eyes relatively little in the visual pursuit of objects. If it wishes to cover its visual field it does so in great measure by movements of the head. This predominance of eephatogrvic action overocular movement may account for the extensive development of the ventral gray column in those cervical regioms of the spinal cord in which the spinal aceessory nerve takes origin. Thus may be explained the preminence of the neck muscles in acts of visual pursuit, as well as the inconsiderable development of the inferior olive. From the behavior of tarsius it is clear that the animal does not cmploy the muscles of the eres, hands and head in many acts requiring intimate cooperation. It is essentially a nocturnal hunter, and this fact in itself limits its manual activitics to a somewhat restricted range of performanee. The remarkable dexterity of the tarsier in capturing insects on the wing, as it is said to do, probably represents the acme of its skilled achievement. This no doubt is a highly specialized act, but it is no more complex than that manifested by many birds which capture their prey whike on the wing. Such development of skill would not necessarily make great demand upon the olivary mechanism. Two other facts support the view that tarsiers do mot require particular exactitude in the simultaneous control of the head, eye and hand muscles, i.e., the absence of retinal maculat and the more or less complete decussation of fibers in the optic chiasm. Both of these important conditions imply the absence of stereoscopic rision, as they also indicate the lack of those visual specializations essential to the development of highly skilled acts. The indispensable relation of simultaneous coordination of head, cre and hand in such acts as handwriting is obvious. In acts of this kind the eyes follow the hand, and the head comperates with the eyes in this exact visual guidance. Tarsius is capable of no reactions comparable in any sense to such a highly dereloped skilled performance. It manifests no 
motor pattern which necessitates simultaneous association of the ocular, cervical and brachial musculature. It is not surprising in this light that the inferior olive is poorly cleveloped in tarsius and in marked comtrast to the proportions and configuration of higher primates.

The other features at this fevel serve to bear out the observations already made concerning the motor and sensory organization, as these functions are illustrated by the small size of the promid and mesial fillet.

The great importance of the animal's automatic associated movements is indicated by the size of its midbrain bundles, the pesterior fonnitudinal and predorsal fasciculi (PL, PD). The central erray matter has assumed its position in the floor of the fourth ventricle, and above the central canal a massive obex marks the proint of rentricular transition. The nucleus of the hypoglossal nerve has all the indecisiveness in boundary characteristic of lower levels. Its emergent fibers are coarse and heavy. Lateral to this nucleus is the clorsal vagal nucleus ( Nvd). In the corsolateral angle of the central gray matter is the nucleus of the fasciculus solitarius ( Nfs).

The muclei of Goll and Burdach (NG, NB) are both prominent and partially invested by fibers forming their corresponding columns. The nucleus of Burdach is remarkable in tarsius for the very high derelopment of the ancillary nucleus of Blumenau. The nucleus of Rolando (NR) and the descending trigeminal tract ( Trd) are further removed from the periphery due to the moving of the dorsal spinocerebellar tract into a more dorsal position. The reticular formation still oceupies the largest portion of the section and is characterized by its diffuse arrangement ( $R$ e. $f$ ). In its ventrolateral portion may be disecrned the mucleus funiculus lateralis.

LEVEL OF THE VESTIBLLAR NLCLEI (FIG. jj)

At the level of the vestibular nuclei the dorsal sensory field has changed in character, as is the rule in all primates. It still represents proprioceptors, 
but of a highly specialized order. This ficld, formerly occupied by the nuclei of Goll and Burdach, has given place to the nucleus of Deiters (ND) and the nucleus of Schwalbe (NSc), both of which have acquired remark-

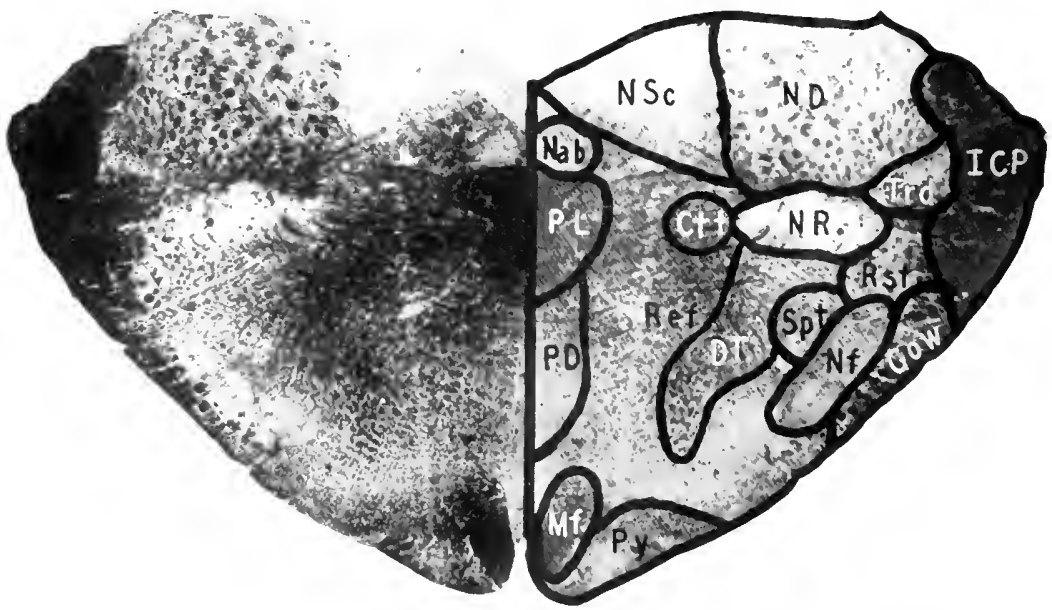

FIG. jj. TARSIUS SPECTRLM. LEVEL OF THE VESIBULAR COMPLEX.

Crt, Central Tegmental Tract; Dr, Dejterse-spinal Tract; cow, Ventral Spinocerdedlar Tract; icp, Inferior Cerebellar Peduncle; MF, Mesial Fillet; NAB, Nucleus Abducentis; ND, Deiters' Nuclens; NF, Facial Nucleus; NR, Nucleus of Rulando; Nese. Nucleus of Schwalbe; PD, Predorsal Bundle; l’L, Posterior Longitudinal Fasciculus; PY, Pyramid; REF, Reticular Formation: RST, Rubrospinal Tract; sı'T, Spinothalamic Tract; TRo, Descending Trigeminal Tract. [Aceession No. 310. Section 1 fo. Actual Size $\rightarrow \times 3$ mm.]

able dimensions as compared with other primates. The Deitersal area in tarsius is larger than in the eat, rabbit, kangaroo, horse, dog, or any of the primates. The triangular nucleus of Schwalbe, while large, is perhaps not so striking in comparison with other forms.

To find such extensive development in the balancing mechanism of tarsius implies that the animal requires a most highly efficient apparatus for equilibrium. The behavior of tarsius bears out this supposition. There is nothing perhaps in its postural requirements while at rest which may sug- 
gest extensive equifibratory needs; but the long, swift leaps which it makes, not unlike volplaning, would almost certainly recuire a capable mechanism for maintaining balance. Compared with other primates, tarsius may be considered quite alone in the specialization of this peeuliar flight-like type of locomotion. In the case of lemur and mamoset, the leaping propensities have a different character, appearing to be intermediate steps in a continuous process of passing from onc point of support to auother. In this act, afl four extremities and the tail participate. The gribbon is another example of Hight-like passage through the trees, but in the case of this latter primate, the arms are the principal means of focomotion in the fong swings from branch to branch. Tarsius, on the other hand, executes its keaps more in the nature of long dives or upward hops in which it glictes through the air for considerable distanees in order to reach its next objective. If it is true that in these dives it capt ures inseets on the wing, then the delicate balancing needed for its locomotion is all the more apparent.

The great prominenee of the vestibular area must depend upon some such specialization as this in tarsius, although it is to be regretted that no authentic statements are forthcoming concerning the actual equilibratory derelopment of this animal. It is remarkable and noteworthy, however, that tarsius leads all the primates, and for that matter most of the mammals, in the high specialization of its vestibular nuclei.

At this level the fourth ventricle is widely open and the laterat recesses communicate with it over its dorsolateral angle. The uvula fills the entire ventricular cavity. On the lateral margin of Deiters' nucleus (ND) are the collected bundles of the inferior cerebellar peduncle (ICP), while ventral to the nucleus is the substantia gelatinosa of Rolando (NR). Along the outer border of the latter structure lies the descending trigeminal tract ( $\operatorname{Tr}$ ). The rubrospinal ( R s t) and spinothalamic tracts $\left(S_{p} t\right)$ occupy a position upon the outer edge of the formatio reticularis ( $\mathrm{Re}$ ) . The posterior 
longrudinal fasciculus (PL) has been augmented by the addition of fibers from Deiters' nucleus, whose course may be traced inward and backward from this nucleus. Some of the caudal fibers of the restibular division

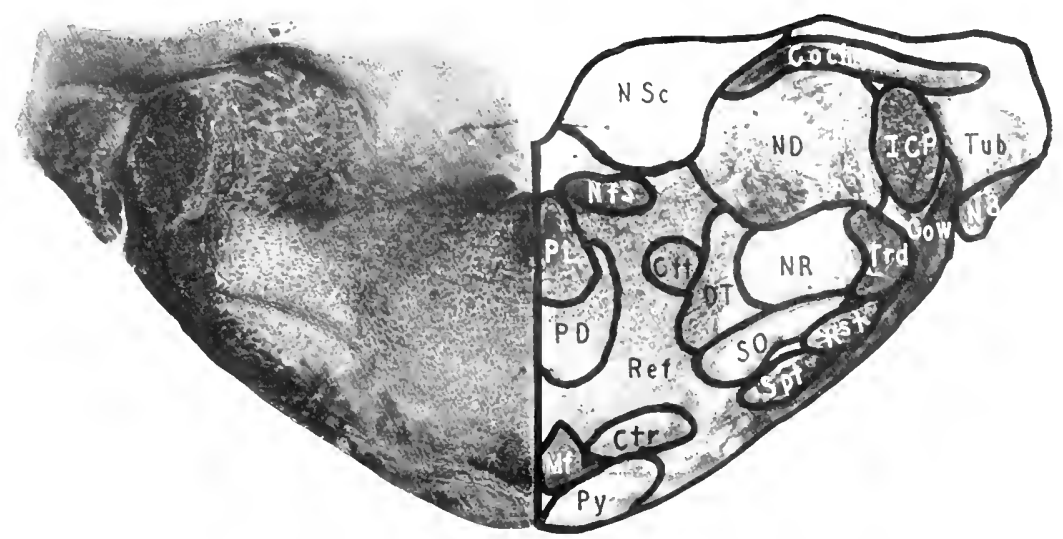

FIG. ;6. TARSHLS SPECTRUII. LEVEL OF CAUDAL EXTREMITY OF TR.APEZOID BODY.

corı, Cochlear Fibers; cok, Trapezuid Budly; ctт, Central Teqmental Tract; Dr, Deiterso-spinal Tract; Gow, Ventral Spincerebellar Tract; ıc, Inferior Cerebellat Peduncle; wf, Mesial Fillet; ND, Deitersal Area; N8, Auditury Nerve; NFs, Genu uf Facial Nerve; nr, Nuclus of Rolande; Nse. Nuckus of Schwalbe; PD, Predorsal Bundle; pL, Posterior lsongitudinal Fasciculus; PY, Pyramid; REF, Reticular Formation; RST, Rubrespinal Tract; so, Superior Olive; spt, Spinothalamic Tract; tRD, Descending Trigeminal Traet; tub, Tuberculum Acusticum. [Accession No. 210 . Section 153. Actual Size - $\because 3 \mathrm{~mm}$.]

of the cighth nerve pass through the descending trigeminal tract and the substantia gelatinosa to enter Deiters' mucleus. A large nuclear structure on the periphery of the reticular formation gives rise to the furst portion of the facial nerve. This is the nucleus facialis ( $\mathrm{Nf}$ ). The fibers arising in it pass backward and inward toward the floor of the fourth ventricle in the form of a heavy spray. This nucleus in tarsius is nearer the periphery of the section than in any of the other primates and the fibers constituting the first portion of the facial nerve are coarser than observed in other species. 
Both of these enditions are in cleser aceord with the subprimate mammals than with the Anthropoidear.

Mesial to the facial muckeus is a disseminated collection of asons reaching backward toward Deiters' nucleus. These form the beginning of the Deiterso-spinal tracts (DT). Immediately dorsal to the posterior longitudinal fasciculus is the caudal extremity of the nucleus abducent is (Nab). The predorsal bundle (PD) is large and indicates to what degree the animal depends on its automatic movenents. This observation becomes more significant in view of the small size of the pyramid which calls attention to the relatively mearer control of voluntary movement pessessed by tarsius. The mesial fillet (Mf) occupying a position dersal to the pyramid, denotes a low degree of discriminative sensibility in the animal.

All of these facts collectively signify an animal of a simple motor organization and extremely limited in such behavior as is conditioned by learning and imitation.

LEVEL OF THE CEREBELLAR NUCLEI (FIG. ;-)

Characteristic features at this level are the appearance of the heary bundles comstituting the intramedullary portions of the sixth and serenth cranial nerves ( $N 6, N_{7}$ ). The fibers of the vestibular division of the eighth nerve make their way to Deiters' nucleus between the restiform body (ICP) and the descending trigeminal tract (Trd). Some libers of the acoustic division ( N8) of the cighth nerve appear in relation to the tubercuIum acusticum (Tub). The fourth ventricle is still further reduced in size. Its roof is formed by the median portion of the cerebellum in which is situated the roof nucleus ( $\mathrm{Nfg}$ ). Heavy bundles of fibers entering the juxtarestiform body pass backward and inward from Deiters'nuckens to the nucleus of the roof. Lateral to these fibers in the median vestibule of the cerebellum is a collection of gray matter forming the nucleus dentatus and 
the nucleus emboliform is (NDt). It is impossible to discern distinctive boundaries between these two nuclear masses. Even by means of reconstruction these nuelei do not disclose any distinet individualization. It is henee deemed

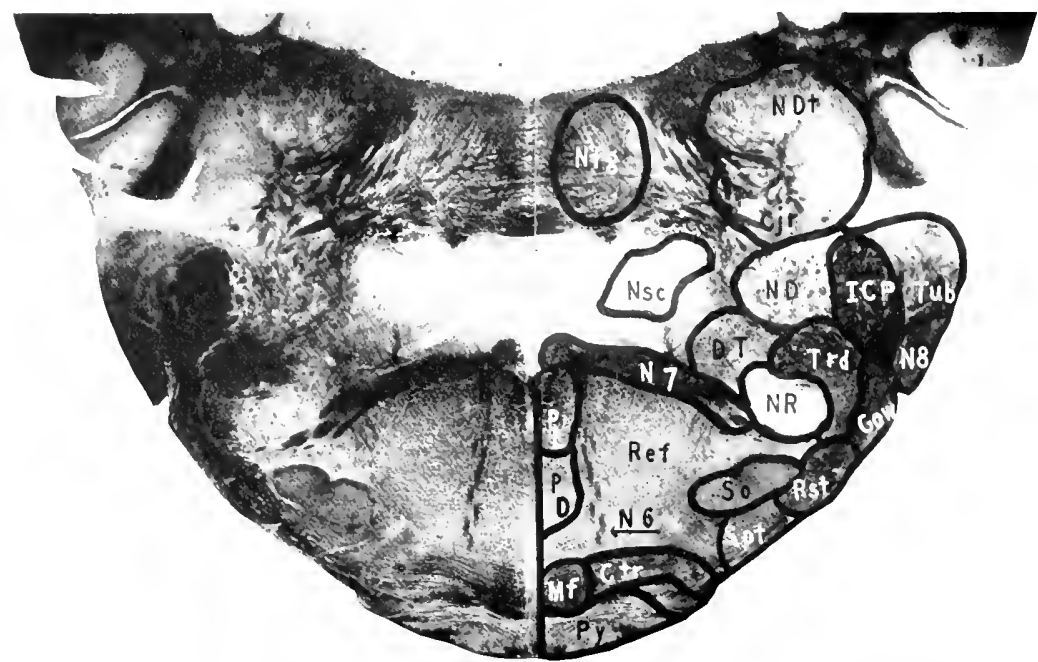

FIG. 5- TARSILS SPECTRLAI. LEVEL OF THE CEREBELLAR NUCLEI.

Gr, Justarestiform Body; CTR, Trapezoid Body; Dr, Deitersal Tract; Gow, Ventral Spinocerebellar Tract; ICP, Inferior Cerebullar Peduncle; mf. Mesial Fillet; ND, Deitersal Area; Not, Cerebellar Nuclei, Lateral Group; NFG, Cerebellir Nuclei, Mesial Group; Nr, Nucleus of Rolando; Nsc, Nucleus of Schwalbe; N6, Abdueens Nerve; N7, Facial Nerve; N8, Eighth Nerve; pL, Posterior Longitudinal Fasciculus; pD, Predorsal Bundle; 1', Pyramid; Ref, Reticular Formation; Rsı, Rubrospinal Tract; so, Superior Olive; Sp', Spinothalamic Tract; TRD, Descending Trigeminal Tract; TC'B, Tuberculum Acusticum. \{Accession No. $2 ı 0$. Section 163. Actuil Size $8 \times 5 \mathrm{~mm}$.]

advisable to designate this collection as the dentate mass. The outstanding feature regarding it is its lack of definition and the entire absence of any tendency toward convolution which characterizes this nucleus in the higher primates. In tarsius the dentate nueleus is small and, as might be inferred from it, the lateral lobes of the ecrebellum are poorly developed. This condition indicates an animal provided with a low degree of coordinative control, 
a fact which permits of the conclusion that the extremities, and particularly the upper extremities, are capable of the simplest motor patterns only This index of motor organization is an added argument supporting the view that tarsius is but meagerly endowed in behavioral reactions.

Adjacent to the ventromedian suleus of the fourth ventricle, and beneath the ventricular floor, is the dense circular bundle representing the second portion of the seventh nerve $(\mathrm{N}-$ ). Lateral to this facial bundle are the heavy fibers of the abdueems nerve $(\mathrm{N} 6)$, which make their way directly forward toward the trapezoid body ( Ctr). They arise in the abducens nucleus which is situated ventral to the triangular nucleus. It is of interest in this connection to note the difluse character of the triangular nucleus. Its boundaries have none of the definition characteristic of the higher species. Many fibers traverse it, giving the impression of a nuclear territory which has not yet thoroughly established its own autonomy.

The origin of the Deiterso-spinal fibers (DT) is clearly seen. The restilorm body (ICP), the substantia gelatinosa of Rolando (NR) and the descending trigeminal tract ( Trd) all occupy their usual positions. The trapezoid body $\left(\mathrm{Ctr}\right.$ ), with its large superior olive ( $\left.\mathrm{S}_{0}\right)$ and its extensive decussation, indicates the degree of development in auditory conduction. The retieular formation ( $R$ ef) is extensive and contains no discretely diflerentiated territories.

Adjacent to the raphe, the posterior longitudinal and predorsal bunctles (PL, PD) appear in the unusually large dimensions characteristic of tarsius. The mesial fillet (Mf) is still partially obscured by the crossing fibers of the trapezoid decussation ( $\mathrm{Ctr}$ ), while the relatively small size of the pyramid ( $\mathrm{Py}$ ) is decisively shown in comparison to the rest of the seetion. It is noteworthy that the entire trapezoid body remains without being submerged by pontile fibers. Tarsius is the only one of the primates in which this is the case. Although the corpus trapezoideum is only partially 
exposed in lemur and marmoset, the pons Varoliz is so poorly dereloped in tarsius as to latve this anditory decussation wholly uncosered. This fact again speaks in favor of the low development attaned by tarsius in the organization of its skilled performances.

The summatry of features in this region of the axis clearly calls attention to the large size of both the auditory and balancing mechanisms of the animal. It is cqually emphatic in denoting the relatively low development of voluntary control possessed by tarsius. It clearly indicates the ample provision made for that more fundamental regulation of motion afforded by the posterion longitudinal fasciculus and predorsal bundle. Attention is also called to the rather coarse appearance of both emergent and intersegmental fibers which are in such contrast to the finer architectonies of the higher species.

LEIEL OF THE EMERGENCE OF THE TROCHLEAR NERYE (FIG. ;8)

At this level the main features of the posterior isthmus are apparent. The roof plate of the fourth ventriele is here formed by the superior medullary velum upon which rests the lingula of the cerebellum. Passing thromgh the relum are the decussating fibers of the tonchlear nerve $\left(\mathrm{N}_{+}\right)$which cmeres from this region of the brain stem. The fourth ventricke is much redued in size as it approaches the caudal oriliee of the aqueduct. The gray matter in its floor ( Cen) shows no specialization, and ventral to it are the dense bundles of the posterior loneritudinal fascieulus (P L) and the predorsal bundle (PD). Lateral to the central gray matter ( Cen) are the axons constituting the mesenecphalic root of the trigeminal nerve, outside of which are the fasciculus uncinatus of Russe) (hook bundle) (Tur) and some libers of the rentrospinal cerelsellar tract (Gow). In the dorsolateral pesition of the section are the fibers forming the lateral fillet (Lf) now ascending on its way to the inferior colliculus. The fibers of the superior cerebellar peduncle (Scp) occupy a position mesial to the hook bundle of Russel. Some hori- 
zontal fibers are already in process of crossing toward the midline in a position dorsal to the posterior longitudinal fasciculus (PL). This forms part of the dorsal decussation of the superior cerebellar peduncle.

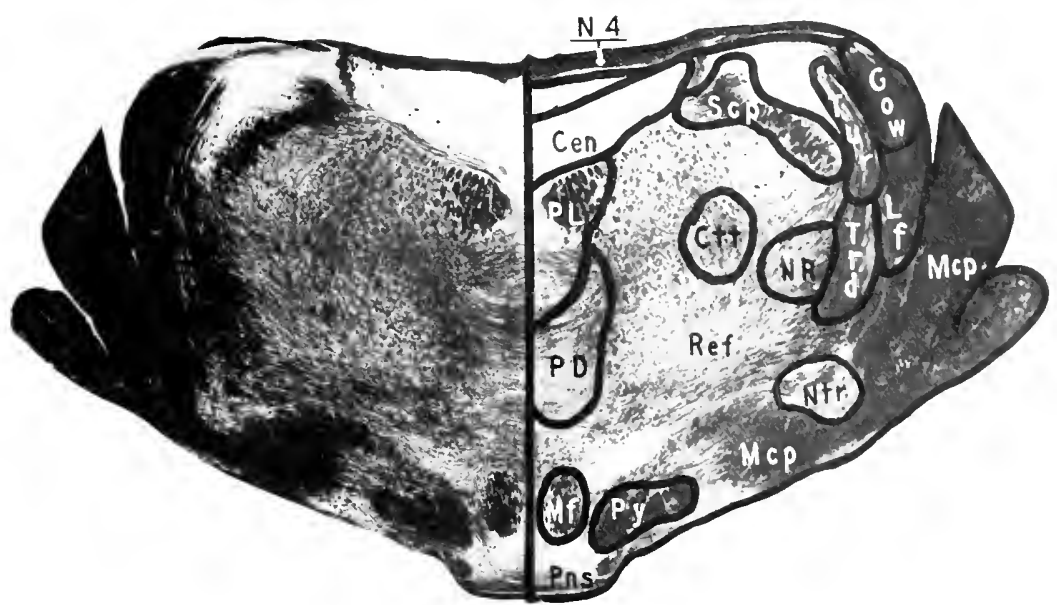

FIG. ;8. TARSIUS SPECTRUM. LEIEL OF THE TROCHLEAR EMERGENCE.

Cen, Central Gray Matter; CtT, Central Tegmental Tract; gow, Ventral Spincerebellar Tract: LF, Lateral

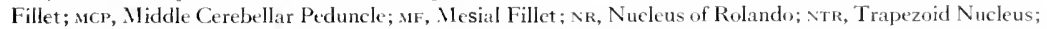
N4, Trochlear Nerve; PD, Predorsal Bundle; PL, Posterior Longitudinal Fasciculus; PNs, Pons; Pr, Pyramid; REF, Reticular Formation; SCP. Superior Cerebellar Peduncle; TRD, Descending Trigeminal Tract; tCR, Tractus Uncinatus of Russel (Hook Bundle). [Accession No. 210 . Section 19;. Actual Size $9 \times ; \mathrm{mm}$.]

The fibers constituting the ventral peduncular decussation have already moved into a position nearer the midline. This latter disposition in the decussation of the superior cerebellar peduncle is characteristic of all of the primates. The arrangement of the more dorsal fibers in tarsius, however, corresponds more to the conditions in the cat and the rabbit in which the dorsal decussating axons from the superior cerebellar peduncle tend to take up positions dorsal to the bundles of the posterior longitudinal fasciculus. 
In another respect the superior cerebellar peduncles show primitive characteristies in tarsius. This appears in the lact that the crossing of this crebellar connection begins much lower down than is the case in any of the other primates. As in other instances, the peduncle crosses in two divisions, but the more dorsal division decussates cartier in tarsius than in other forms, leaving a dense ventral bundle in the lateral portion of the reticular formation. These more ventral fibers eventually move inward to complete the superior peduncular decussation. Especial importanee attaches to this division of the decussation, as it represents a less highly organized cerebellar comnection than in any of the other primates.

The rentral portion of the section contains a small collection of pontile tibers and nuclei. The number of the crossing fibers in the pons is so fimited that it is diflicult to distinguish the three typical strata of this portion of the stem. On the other hand, there is a slight separation of the pramidal fibers by transverse axons passing through them in the pons region. Pyramidal dissemination, however, has none of those characteristic features prominent in all of the other primates. The mesial fillet ( MIf) oecupies a position immediately dorsal to the pramid. In the lateral portion of the section is the upper extremity of the trapezoid nuckeus ( $\mathrm{Ner}$ ). In general appearance this level is notable for the unusually meager representation of the pontile nucki and the primitive manner in which the superior cerebellar peduncle undergoes its decussation.

\section{LEVEL OF THE INFERIOR COLLICULUS (FIG. 39)}

Here, the special features are the marked development of the tectum (IC) and the pons (Pns). This latter character of the brain stem in tarsius deserves particular consideration. In several ways it differs from the corresponding structure in all other primates. The lowermost transverse fibers of the pons Varolii do not make their appearance until the level of the 


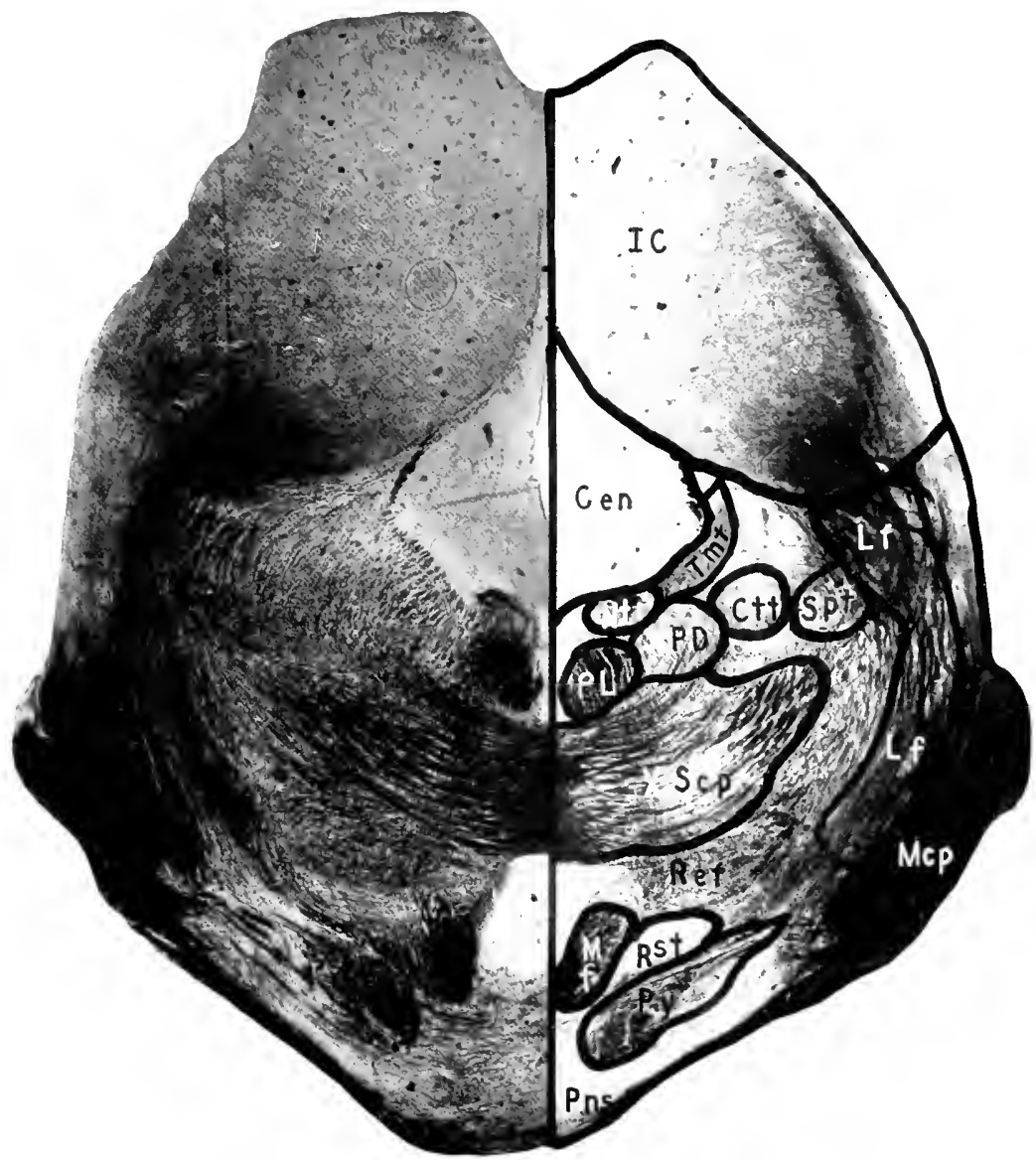

FIG. j9. TARSIUS SPECTRUM. LEVEL OF THE INFERIOR COLLICULUS.

CE\, Central Gray Matter; CIT, Central Tegmental Tract; IC, Inferior Colliculus; LF, Lateral Fillet; MF, Mesial Fillet; исP, Niddle Cercbellar Peduncle; Nтr, Nucleus Trochlearis; PD, Pridorsal Bundle; PL, Posterior Longitudinal Fasciculus; PNS, Pons; Pr, Pyramid; REF, Reticular Formation; Rs r, Rubrospinal Tract; sPt, Spinothalamic Tract; TMr, Mesencephalic Root of Fifth Nerve; xscP, Decussation of Superior Cerebellar Peduncle. [Accession No. 210. Section 205. Actual Size $9 \times 9 \mathrm{~mm}$.] 
trochlear decussation is reached. In other words, the bubopontile sulcus holds a much more cephalic position than in other species. It is even higher than in the cat and most roclents. This position of the suleus clearly indicates the inferior development of the pons Varolii. The internal pontile structure, however, does not depart from the type of organization characteristic of it elsewhere. In it may be discened the three typical strata. A peculiarity in their arangement is the fact that the stratum superficiale dees not, as in other species of primates, appear as the most cauclal element in the pons. Fibers from the stratum complexum make their way across the stem in the direction of the middle cerebellar peduncle before there is eviclence of the more superficial transwerse axons. This gives rise to an unusual appearance, in that the pyramid maintains its ventral pesition in the stem although pontile fibers are already present. It is usually the case that in the candal portion of the pons, superficial transverse fibers cross in front of the pyramid and thus exclude the latter from a position on the surface. This arrangement of fibers makes the pyramid in tarsius appear much longer than in other species, while the pons is actually much shorter. Nor is the peculiarity of the pontile fibers limited alone to this late appearance of the superficial stratum. Such decussation as the pontile fibers do make, exerts a feeble influence upon the long suprasegmental systems. The pyramid, for example, which in all other primates becomes separated into more or less scattered bundles, shows little of such tendency in tarsius. The manner in which the pyramidal system maintains its integrated constitneney and seems in this way to force the pontile fibers to sweep around rather than through it, is another fact emphasizing the low organization of the pons Varoliz in tarsius.

The marked tendency of the mesial fillet to stretch out transversely in the pons su as to form the boundary between the tegmentum and the basis, is almost entirely absent in tarsius. The fillet maintains its position relatively near the median line, where it appears as a dense bundle. All of these phenom 
ena, as they affect respectively the appearance of the pyramid and the mesial fillet, denote the slight influence exerted by the pontile fibers upen the course of such suprasegmental systems. Such a pons ats that of tarsius could not belong to an animal with more than a meager neokinctic condowment. As a behavioral index it grives a rating lower than the Felidac and about equal to some of the rodents. A capacity so low as this implies a low cerebral organization which might well serve as the stepping stone in the progressive aseent from lower mammalia toward the primates. The suface appeanance of the mesencephalic tectum strongly suggests that the inferior colliculus is a functionally important structure. Its general and microserpic characters support this view. It is pronounced in size even when eompared with many subprimate forms. Mensuration also indicates that the inferior colliculus plays an important role in the sense of hearing. That part of the animal's behavior dictated by auditory stimuli is characterized by prompt reflex responses. Tarsius consumes little time in reflecting upon the nature of sounds which it hears. It employs such stimuli with ahmost automatic directness to produce such reactions as guarantec its immediate safety or provoke fundamental activities. Furthermore, these auditory stimuli call forth at best only a most limited scries of motor reactions. This conception is substantiated by the meager derelopment of auditory areas in the temporal lobe of the brain, as well as by the auditory suprasegmental connections between the midbrain and the endbrain.

Tarsius also retains in the microscopic appearance of its inferior colliculus much of that organization characteristic of lower forms. In the cortex mesencephalica posterior it is possible to identify nine distinct strata. This arrangement harks back to the lower vertebrates, so that the large size of the inferior colliculus, in conjunction with its architectonic specialization signifies a retention of the primordial midbrain control over the function of hearing. 
The central gray matter is quadrilateral in outline surrounded by the collicular eminences and contains a contral canal consicterably elongated in the dorsorentral direction. It is of interest in this connection to note a number of small diverticula connected with the central canal. Such appearances are common in the adults of many subprimate mammals, but become less conspieuns in the higher members of the primate group. Ontogenetically, these craginations are boubtless related to those extensions of the Sylvian arpueduct observed in many lower mammals and connected with the development of both the inferior and superior colliculi. Traced further back they are doubtless remnants of the phyletically ancient ventrickes of the optic and auditory lobes of the midbrain.

In the rentral aspect of the gray matter is the trochlear nucleus ( $\mathrm{Ntr}$ ), which is notable because of its indefinite boundaries and the profusion of fibers interspersed throughout its entire mass. It is a nuclear collection of unusual size, sugeresting that the fourth merve in tarsius must play an important rôle. In conjunction with the closely set, protruding eyes, it may be that convergence of the visual axes has assumed great phrsiological prominence in these animals. Their acquisition of binocular vision has cloubtless already set on foot these specializations which culminate in the development of sterenscopic function. On the other hand, the absence of a retinal macula might call the validity of this view in question. However this may be, it is clear that the tarsiers need and employ the superior oblique muscle of the orbit in such a manner as to require a large nucleus for its innervation.

The course of the trochlear nerve is of interest because in its emergence it departs somewhat from the course pursued in other primates. In emerging from its nuclear origin, it passes immediately dorsad following a path restricted to the central gray matter. It has no descending portion characteristic of members of this group. It leaves the dorsal rather than the dorsomesial aspect of its nucleus. Its entire course gives the impression of 
shortening due to compression in the stem, particularly about the region of the posterior isthmus.

Subjacent to the trochlear nucleus are the dense bundle of the posterior longitudinal fasciculus (PL) and the predorsal bundle (PD). On the periphery of the central gray matter is the mesencephalie root of the fifth nerve ( $T \mathrm{mt})$. The reticular formation at this level is extensive, but its details are considerably obscured by the decussation of the superior cerebellar peduncle (XSep).

LEVEL OF THE SUPERIOR COLLICILUS (FIG. (O)

At this level certain features peculiar to Tarsius become apparent. Most conspicuous among these is the unusually large size of the entire tectal region. Iet, in spite of execptional dimensions, the superior collieulus (SC) presents less stratigraphical specialization than might be expected from its size. The colliculus as a whole appears to be a region extremely rich in cellular elements.

In contrast to the large proportions of the colliculus, the extremely small size of the cerebral peduncle (CP) is another striking feature of the midbrain. Considered together, they impart to this segment of the tarsial stem a characteristic appearance different from all other primates. The small size of the cercbral peduncle is dependent primarily upon the meagre contributions made by the neopallium to the pallio-pontile system. It is also dependent upon the relatively small volume of the pyramidal system.

Thus, the peduncle is indicative of an animal whose behavioral patterns are extremely rudimentary and limited. It is another fact confirming the opinion that tarsius has little capacity in the acquisition of learned skilled acts and that its biological formula in adaptive reaction is determined largely by its automatic associative combinations. 
If comparison were made between tarsius and some of the lower mammalian forms-camivores, rodents and cren marsupials-on the basis of the cerebral peduncle, the tarsier would be forced into at position

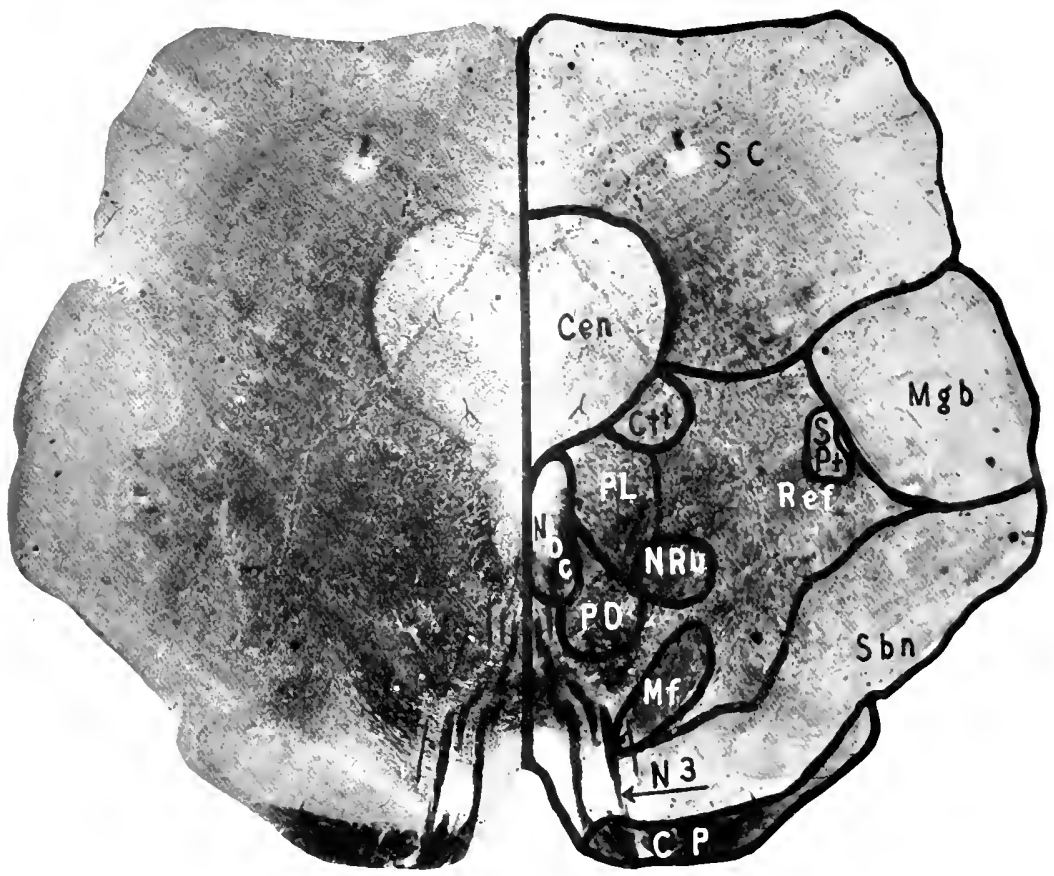

FIG. 60. TARSIUS SPECTRUN. LEVEL OF THE SLPERIOR COLLICLLUS. CEN, Central Gray Matter; CtT, Central Tegmental Tract; CP, Cerebral Peduncle; Mr, Mesial Fillet; MGB, Nesial Geniculate Body; N3, Oculomotor Nerve; NRC, Nucleus Ruber; Noc, Oculomotor Nucleus; PD, Predorsal Bundle; r'L, Postcrior Longitudinal Fasciculus; RLF, Reticular Formation; sBN, Substantia Nigra; sc, Superior Colliculus; spt, Spinothalamic Tract. [Accession No. 210 . Section 250. Actual Size $9 \times 7 \mathrm{~mm}$.]

of relative inferiority. It may perhaps, to some extent at least, excel certain of the marsupial species. Its primitiveness is again emphasized by the extreme dimensions of the superior colliculus. This strueture, because of its size, by 
permitting a certain dewree of latitude, might be considered an "optic lobe." The disposition of the central canal in this midbrain recion would carry further suggestiveness in this line of interpetation. The large lateral diverticulum extending in the direction of the colliculus is strongly reminiscent of the lateral mescencephalic extension characterizing the brain of many lower vertebrates.

One notable advance in the brain of tarsius toward primate dillerentiation is the defmite progress which it has made in extending the visual cortex. On the other hand, it is improbable that such advance las gone so far as to relieve the superior colliculus of much of its primitive visual function. Such a view attributes to the optic portion of the mesencephalic roof a large retention of activities related to vision, a condition which again declares the primitive organization of the brain in this animal.

Accompanying these strikingly primitive characters in the cerebral peduncle and the superior colliculus are other features at this level which bear testimony of similar moment. The substantia nigra (Sbn), for example, is an even more extensive structure than it is in lemurs. It thus stands out in contrast to this structure in all others of the primate order. The reticular formation (Ref) likewise is more conspicuous and much more diffuse. In it may be distinguished a poorly defined nueleus ruber (NRu) of relatively small size. Along the ventrolateral border of the substantia nigra are the two divisions of the mesial fillet (Mf), the ventral portion lying in close proximity to the emergent fibers of the nerve, the dorsal portion bordering the brachium geniculatum and lying ventral to the spinothalamic tract (Spt). The central gray matter $(\mathrm{Cen})$ is more extensive and also more pyriform than in other primates. It eontains in its ventral apex the dorsal and rentral divisions of the oculomotor nucleus (Noc) which is characterized by the fact that but few fibers enter the aculomotor decussation. This latter observation is in harmony with the statement made by the late 
Dr. John Hunter to the effect that the nucleus of Perlia, although present in tarsius, is extremcly small. The inference to be drawn from these correlated facts again indicates an animal poorly equipped in the neural mechanisms necessary for binocular stereoseopic vision. Hence in the organization of visual function the tarsier occupies a position betow the Jemurs and new-world monkeys.

The importance of that ocular advanee which distinguishes the primates from all other mammalian orders cannot be overestimated. It has been a momentous factor in the corolutionary process. What effects must have been produced in consecutence of forward-looking eyes eyes so related to cach other that both visual axes could be directed upon an object cither nearby or at a distance, eyes which no longer looked more or less independently to one side or to the other - it is defficult to estimate in measurable terms. In the final outerme of constructive development this new ocular relation must have borne in the weightiest manner upon that enormous superstructure of skilled mexements which has had its supreme expression in the achievements of man. Whether tarsius represents the earliest hesitating steps in this direction, whether it has made real progress over some even simpler prototype in visual organization, is a question beside the print. This animal is illustrative of one of those early steps, if not the earliest, toward that inestimable consummation of visual activity in the acquisition of skilled movements which at length came to be the distinguishing feature in the neokinetic progress of the primates.

Lateral to the nucleus of the third nerve is an extensive fasciculus longitudinalis posterior (PL) whose ventral extremity borders upon the large collection of fibers constituting the predorsal bundle (PD). In the concavity of this extensive collection of axoms is the central tegmental tract (Ctt) now drawn closely in toward its ultimate position of contact with the eentral gray matter. Bordering this substance in its more dorsal 
region is the ascending trigeminal tract. Arcuate fibers passing inward from the region of this latter tract sweep forward to decussate in the dorsal decussation of Neynert. Deeussating fibers occupying a still more ventral

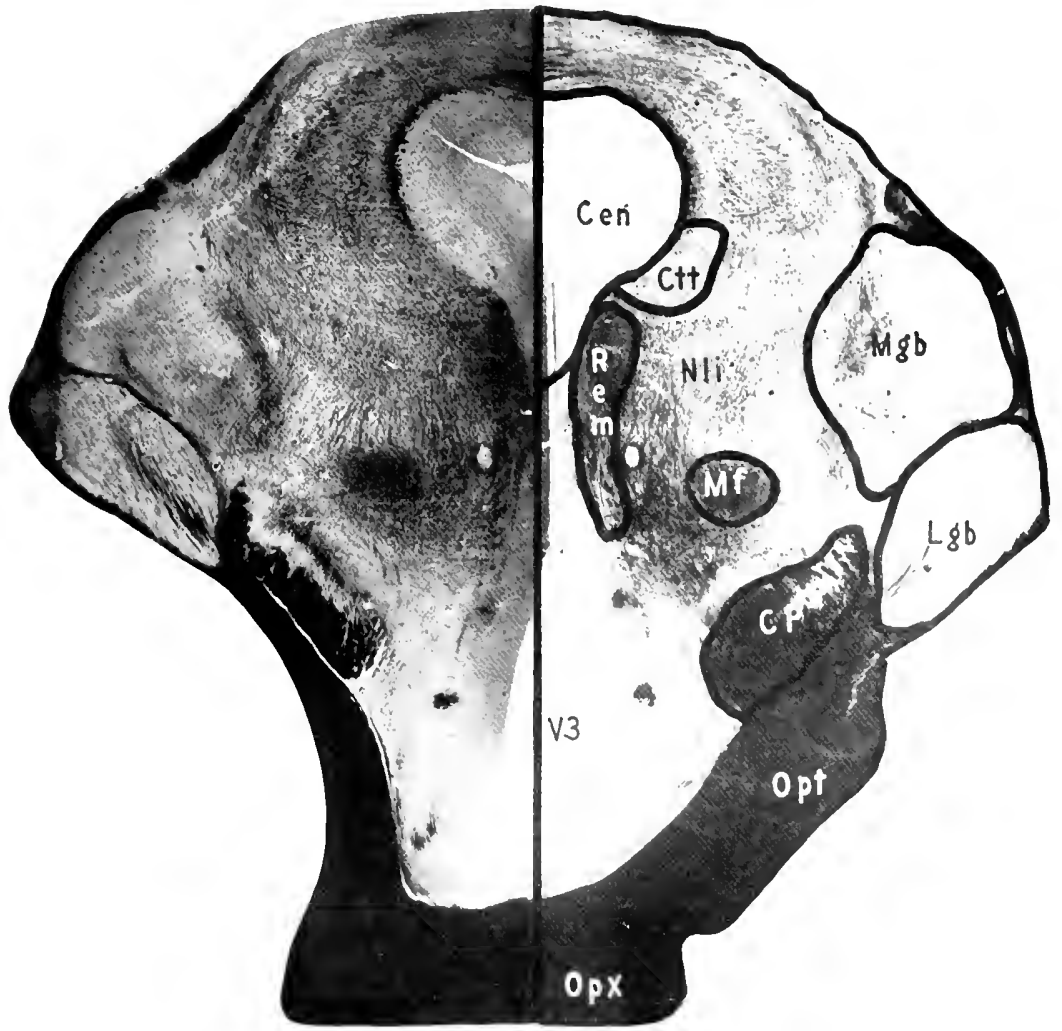

FIG. 6I, TARSIUS SPECTRUM, LEVEL OF THE OPTIC CHIASM.

(Ev, Central Gray Matter; ctr, Central Tegmental Tract; cP, Cerebral Peduncke; LgB, Lateral Geniculate Body; MF, Mesial Fillet; MGB, Mesial Geniculate Body; NLI, Nucleus Lateralis Internus Thalami; OPT, Optic Tract; opx, Optic Chiasm; REM, Tratetus Retroflexus of Mevnert; v3, Third Ventricle. [Accession No. 210. Section 26r. Actual Size $10 \times 10 \mathrm{~mm}$.] 
position constitute the decussation of Forel, many of whose axons appear to take origin in the red nucleus (NRu), cross the midline and enter into that deseendiner bundle which constitutes the rubrospinal tract. On the

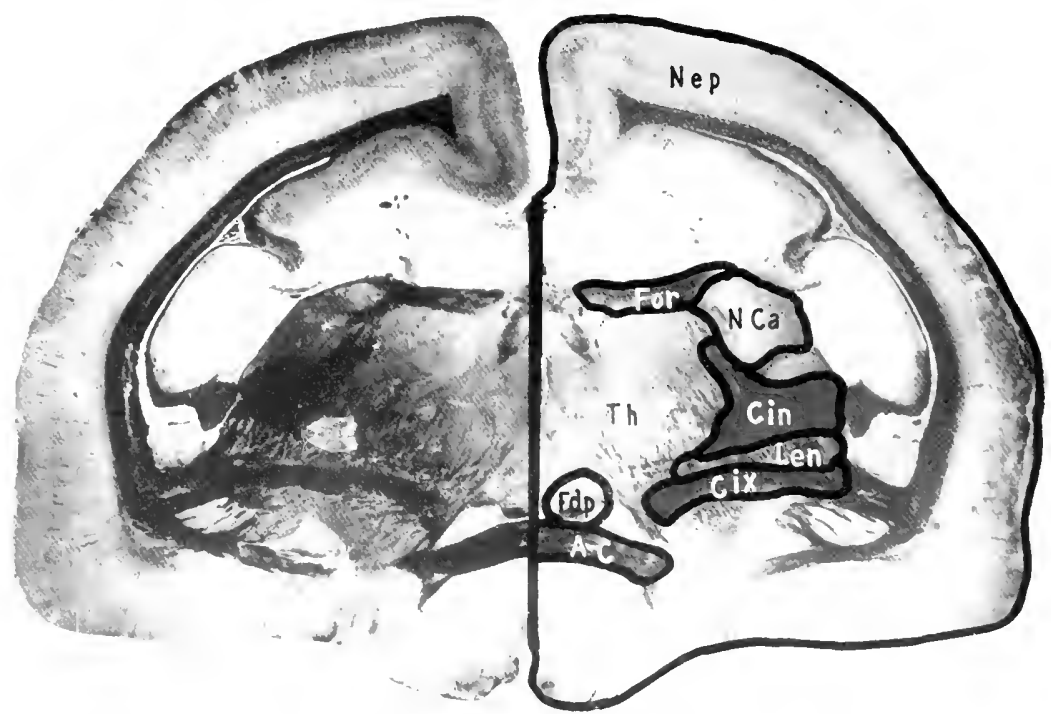

FIG. 62. TARSILS SPECTRCM. LEIEL OF THE ANTERIOR COMMISSLRE. Ar, Anterior Commissure; al Internal Capsule: ax, External Capsule; rne, Descending Pillar of Fornix;

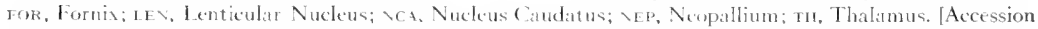
No. 210 . Section 305. Actual Size is $x-\mathrm{mm}$.]

lateral periphery of the section and ventral to the superior colliculus is the mesial genieulate bedy ( $\mathrm{Igb})$.

LEVEL OF THE OPTIC CIIASM (FIG. 6I)

At the level of the optic chiasm the brain stem is seen approaching its caudal extremity. The third rentricte is here flanked upon either side by the massive thalamic wroups of nuelei, and the roof formed by some fibers 
of the posterior commissure. Other clements of interest at this level are indicated by letters in the eaption.

LEVEL OF THE ANIERIOR COMMISSTRE (119, 62)

At the level of the anterior commissure the brain stem has come to its caudal termination. The struetures at this lerel are indicated by letters specified in the caption. 



\section{Chapter IV}

\section{RECONSTRUCTION OF THE GRAY MATTER IN TIIE BRAIN STEMI OF TARSIUS SPECTRUM}

PHE reconstruction of the gray matter of tarsius presents a constitu-
tion more elemental in character than that encountered in any other
species ol the primate series. In general eontour the reconstruction is distinctly profiform, beginning with the small dimensions at the most cephalic of the cervical levels and expanding rapidly in the medulla, maintaining a uniform width in the pons and midbrain, but presenting at the upper portion of the midbrain near its iunction with the diencephalon a mathed increase in its lateral development. Viewed from the side the reconstruction has a singularly llat appearanee on the dorsal surface which continues upward to the junction of the metencephalon with the mesencephalen. The ventral contour shows a gradual but continued increase in the dorsoventral dimension from the medulla to the isthmus. At the junction of the metencephalon with the mesencephalon, the dorsoventral diameter of the recomstruction approximately doubles itself by the sudden appearance of the colliculi which rise dorsally in a precipitous, "almost palisade-like outgrowth from the dorsal surface of the neuraxis. The eollieuli almost immediately assume their extreme vertical diameter, producing a right angle transition between the caudal limit of the collieular plate and the plane presented by the lloor of the fourth ventricle. This space, empty in the reconstruction, is oceupied by the mass of the cerobellum which lies in contact with the collicular plates throughout the major portion of its cephalic surface.

The geniculate bodies make their appearance at a level unusually low in the brain stem, taking on recognizable form on the lateral aspect of the mesencephalon. The mesial geniculate body, developing first at a point 
opposite the midelle of the inferior colliculus, continuing upward and increasing sradually in width is joined by the lateral geniculate which rapidly develops into a large mass applied to the lateral surface of the midbrain. The superior colliculus is unusually large and appears as a direct continuation upward of the collicular plate, presenting a llat plateau-like structure which extends to the upper limit of the reconstruction. The ventral surface presents a marked development of what corresponds to the interpenduncular gray matter, in this case, however, protruding between and ventral to the peduncles. The interpeduncular gray matter continues forwatd as a protrusion which extends ventrally from the surfarce of the brain stem for a considerable distance. The major portion of the brain stem is formed by the reticular formation which has a particularly undiflerentiated appearance and serves as a support for the more specialized structures of the stem which develop upen its several surfices.

The presence of a small quantity of reticular formation in the angle between the ventral and chosal gray homs, indicates that at the lowest levels of the reconstruction the decussation of the pyomidal tract has already. begun. The first sections of the reconstruction correspond to the lowermost limit of the medulla oblongata and have an appearance almost typically that of the spinal cord, with the exception of the small mass of the reticular formation already mentioned. The contral gray matter is distinctly $V$-shaped in appearance, presenting delinite ventral gray horns and dorsolateral extensions with a distinct cap of gray matter, the substantia grelatinosa of Rolando. For a short distance the substantia gelationsa of Rolando continues upward on both sides of the midline separated by a rather deep groove in which lie the clorsal white columns of the spinal cord and medulla oblongata. The dorsal horns, however, soon show a tendency to deviate outward, the tips of the horns first turning laterally and then somewhat ventrally, as the dorsal gray horms separate themselves one from the other. The ventral gray column 


\section{RECONSTRUCTION OF TARSIUS SPECTRUN}

presents a typical appearance, is rather irregular in contour and rapidly diminishes in sizc.

The reticular formation appearine in the angle between the dorsal and
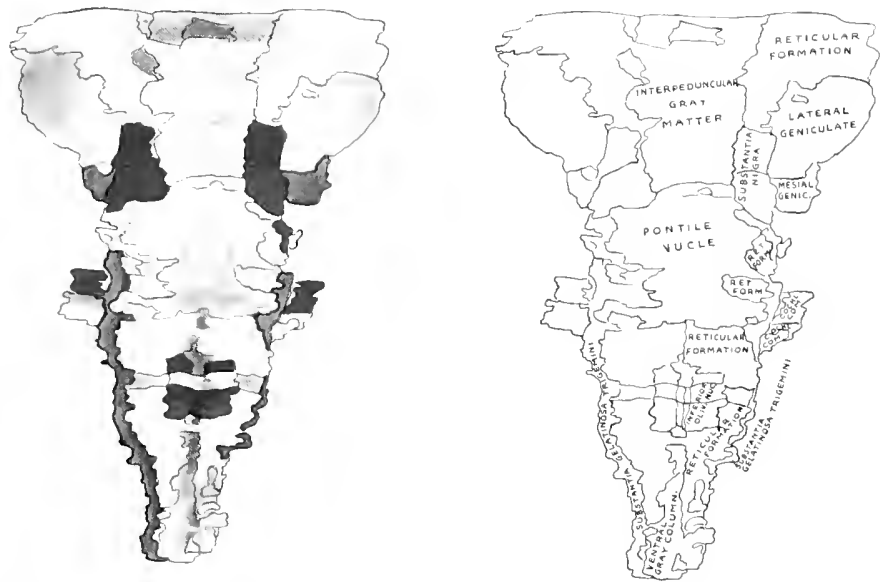

FIG. 63. VENTRAL SURFACE OF THE GRAY MATTER OF THE BRAN STEM, TARSIUS SPECTRUN.

Key to Diagram. Cochl, com., Cochlear Complex; inferior oliv. Net., Inferior Olivary Nucleus; mesiai GENic, Mesial Geniculate Body; Ri:T. ForM., Reticular Formation.

ventral gray columns gradually increases in size and assumes the position which is being vacated by the ventral gray column. The central gray matter continues upward relatively unchanged until the point at which the miclei of Rolando begin to diverge one from the other. At this point the ventral gray matter rather rapidly approaches the surface and becomes somewhat flattened out from side to side.

\section{Tile Dorsal Medullary Nuclei}

The nucleus of Goll is the first of the medullary nuclei to appear with, of course, the exception of the nucleus of Rolando. This nucleus appears a short 
distance abroce the point at which the nuclei of Rolando begin to diverege one from the other. The nucleus appears on either side of the midline as a small protrusion of gray matter from the dorsal surface of the central gray matter. These relatively insignifieant dorsal protrusions lie close to the midline and increase very slightly in size as they continue upward. As the opening of the fourth ventricle is approatched, these nuclei assume somewhat larger proportions and form a part of the lateral wall of the ventricle, extending laterally but never raising themselves to any extent from the surface. The nuclei of Goll continuc upward to a point only slightly above the opening of the fourth ventricle in the lateral ventricular wall, and come to a rather abrupt termination.

The nucleas of Burdach appears at a higher level than the nucleus of Goll, as a llat sessile elevation on the dorsal surface of the central gray matter lateral to the nueleus of Goll. It slowly but gradually increases in size, diverging rather markedly from its fellow of the opposite side as the fourth ventrick opens. It extends upward to about the midrentricular level. In the upper portion of its course it arrives at a ecrtain deceree of independence from the wall of the ventricle and rises dorsally to a moderate degree in a wellmarked prominence in the dorsolateral angle of the brain stem. It rather suddenty terminates and its place is taken by the nuclei of the vestibular complex.

The substantia gelatinosa Rolandi continues upward as a direct profongation of the substantia gelatinosa of the spinal cord into the medulla oblongata. These two nuclei show the first indication of the opening of the fourth ventricle by their divergence one from the other, thus allowing the central gray matter to approach the dorsal surface of the oblongata. Contimuing to diverge, the nuclei assume considerable lateral proportions, are supported directly on their mesial aspeet by the reticular formation, and finally reach the lateral meridian of the brain stem. From this point they 
continue along the lateral surface of the medulla oblongat al, present al delinite constriction in the lower portion of the metencephalon, the waist of the trigeminal nucleus. They then extend somewhat dorsally and still further
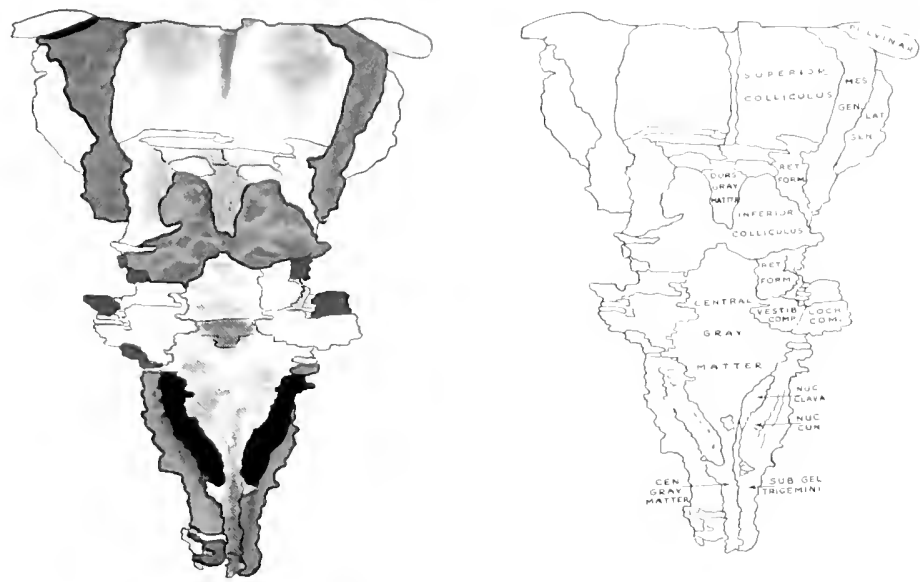

FIG. 64. DORSAL SURFACE OF THE GRAY MATTER OF THEBRAIN STEM, TARSILS SPECTRLYI.

Key to Diagrair. cen. gray nattek, Central Gray Matter; coch. Con., Circhlear Complex; dors, gray

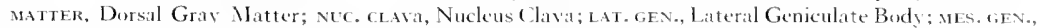
Mesial Geniculate Budy; Nec. (IN., Nucleus Cuneatus; RET. Form., Reticular Formatinn; SUb. GEL. TRIgemini, Substantia Gelatimosa Trigemini; vestib. com., Vestibular Complex.

laterally to come to an end in an expanded upper extremity. In their course upward these nuclei, originally situated in an oblique direction from before, backward and outward, gradually turn upon a vertical axis until their long diameter is directed almost precisely dorsoventrally. They terminate at the mid-metencephalic level above the upper limit of the vestibular complex.

\section{The Inferior Olivary Nuclel's}

The inferior olivary nucleus appears at a level corresponding almost exactly with the opening of the fourth ventricle as a narrow, somewhat crescentic lamina of gray matter, situated almost on the ventral surface of the oblongata, and applied to the reticular formation. The two nuclei are 
separated, one from the other, by the prramidal tracts which lie on the immediate ventral aspeet of the brain stem. These muclei continue upward in this same position, increasing to a moderate extent chichly by an increment in their most ventral portion which assumes a somewhat chub-shaped appearance. There is but litte indieation of the derelopment of the accessory and main olivary nuclei, the entire nucleus apparently consisting of a single lamina of gray matter. There is not the slightest indication of the formation of a fundus; neither is there any intimation of plication in the arrangement of the lamina. At its upper extremity the inferior olivary nucleus is the most ventrat of all of the structures of the brain stem. The nucleus continues upward to a point somewhat below the level of the greatest width of the ventricle. It then rapidly diminishes and eomes to an abrupt termination.

\section{The Reticliar formation}

This mass of nuclear material makes its first appearance in the lowermost level of the reconstruction as a small accumulation of gray matter situated in the angle between the dorsal and ventral gray columns. It contimues upward in this location, very gradually increasing in size, and replaces the ventral gray column thremgh the merging of the latter into the undifferentiated reticular formation. From this point upward the reticular formation assumes the position of the major constituent of the brain stem, being retatively massive and supporting the various specializations which appear on its several surfaces. From the point of the disappearance of the ventral gray column, the reticular formation rapidly increases in size both laterally and ventrally being separated in the midline by the longitudinally coursing fiber bundles which form the raphe and by the inferior olivary nucleus which appears as a special condensation in the ventromesial angle of the formation. Above the level of the inferior olivary nucleus, the reticular formation of either side closely approaches the midline, the space occupied by the raphe 
being redueed to a mere slit between the mesial surfaces of the reticular formation extending backward to the central gray matter. The reticular formation on its lateral aspect forms a support for the substantia gelatinosa of
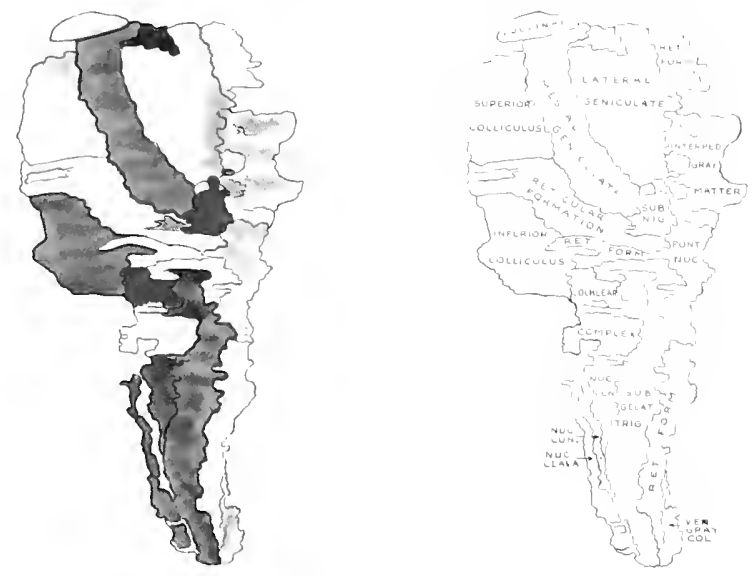

FIG. 6;. LATERAL SURFACE OF THE GRAY MATTER OF THE BRAIX STEM, TARSILS SPECTRLM.

Key to Diagram. interped. gray matter, Interpeduncular Gray Matter; Néc. Clava, Nucleus Clava; nuc. cun., Nucleus Cuneatus; pont. nuc., Pontile Nucleus: ret. Form., Reticular Formation; sub. Gelat. TRig., Substantia Gelatinosa Trigemini; st B. Nig., Substantia Nigra; ven. gray col., Ventral Gray Column.

Rolando which lies in a bed excavated from its lateral surface. Dorsally the reticular formation is in close relationship with the central gray matter forming the floor of the fourth ventricle, the dorsal surface of the reticular formation supporting the central gray matter throughout its entire lateral extent.

The reticular formation in the oblongata presents no definite special nuclear collections on its surface with the exception of the inferior olivary nucleus and the substantia gelatinosa of Rolando. At the junction of the oblongata with the metencephalon, the ventral surface of the reticular formation becomes irregular and recedes from the surface, giving place to the 
nuclear collections which form the very porty organized system of the pontile nuelei. Its ventral surface, partially covered by the irregular pontile nuclei, shows two grooves, one which proceds laterally and dorsally in a somewhat spiral fashion about the lateral surface of the reticular formation toward the inferior collieulus, representing the course of the lateral fillet as this bundle of fibers secks its nuclens of termination in the inferior colliculus. In its more rentral portion, largely covered over and concealed from view by the pontile nuclei, the reticular formation presents another groove which indicates the course of the mesial fillet, which in this form maintains an almost undeviating upward course in the ventromesial angle of the formation throughout the entire length of the brain stem to end in the nuckei of the thalamus. In the upper half of the metencephalon the reticular formation is almost entirely eovered by the pontile nuclei rentrally, and in its lateral aspect in this region it presents a particularly irregular outline. As the reticular formation is followed into the mesencephalon, it can be seen to send a prolongation laterally and dorsally which passes backward in a rather massive lamina of gray matter into the space separating the superior and inferior colliculi, extending dorsally and mesially in the space separating the two colliculi to join in the midline dorsally. In the mesencephalon the reticular formation is almost entirely obscured from view ventrally by the fusion of the uppermost part of the pontile nuclei with the indifferent gray matter filling the interpeduncular space. Lateral to this there appears the substantia nigra which is separated from the ventral surface of the reticular formation by aseending and deseending bundles of fibers. The lateral aspect of the retieular formation in the mesencephaton is entirely obseured by the exceptionally low appearanee of the geniculate bodies which develop considerably below the mid-mesencephalic level. In the meseneephaton the only portions of the reticular formation which can be seen are those which form the dorsolateral expansions, extending into the space between the superior and inferior eol- 
liculi, and a small rentromesial insinuation which appears between the mesial extremity of the substantia nigra and the interpeduncular gray matter.
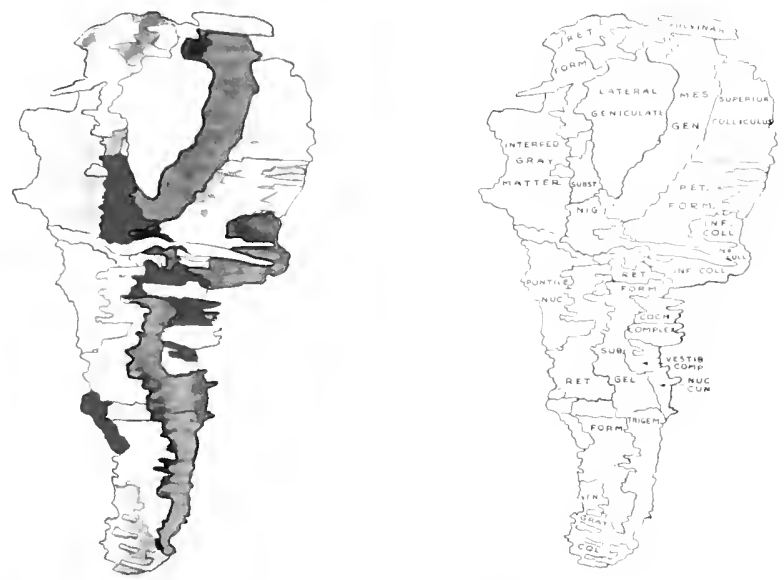

FIG. 66. LATERAL SURFACE OF TIIE GRAY MATTER OE THE BRAIX STEM, TARSIUS SPECTRUM.

Key to Diagram. coch. complex, Cochlear Complex; inf. coll., Inferino Colliculus; interpin. gray

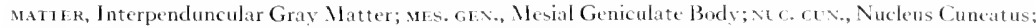
pontile nec., Pontile Nuclei; Ret. Form., Reticular Formation; sub. ger. trigem.. Subatintia Gelatinesai

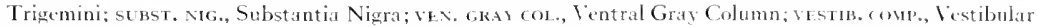
Complex.

On the dorsal aspect of the reconstruction, the reticular formation only appears in the region immediately caudal to the isthmus, at which point its dorsolateral angle is seen between the central gray matter mesially, and the substantia gelatinosa of Rolando laterally. In this region, the reticular formation sends dorsally and mesially a thin prolongation which extends around and finally completely surrounds a tunnel which is occupied by the superior cerebellar peduncle. This pectuncle in the tarsius is very small, insignificant and occupies a flattened, oval tunnel, directed upward, inward and forward. The superior cerebellar peduncle continues this course inrough the reticular formation of the mesencephalon, decussating across the midline to end in the 
special tegmental nuclear condensation of the mesencephalon, the red nuckeus. The reticular formation in the mid-mesencephalie recrion extends around the central gray matter in the form of a thin lamina which separates the central gray matter from the inferior and superior colliculi, and forms a support for the rentrolateral angle of both colliculi.

Above the level of the substantia nigra the reticular formation again appears between the interpeduncular gray matter and the lateral geniculate as a massive develepment, extremely irregular in its arrangement andextending upward to become continuous with the nuclei and reticular formation of the diencephaton.

\section{The Pontile Nucler}

The pontile nuclei appear at about the midrentricular level as small, isolated collections of gray matter on the ventral surface of the brain stem. These collections of gray matter develop chielly near the midline, but scattered nuclear masses can be seen extending outward to form small discrete accumulations. Abrve the midventricular level, the pontile nuclei become somewhat larger and form a definite lamina of gray matter which assumes a fair derree of thickness and a relatively extensive lateral disposition, covering a small segment of the ventral aspect of the gray matter of the brain stem. This mass of pontile nuclei gradually develops out of the isolated groups of gray mattex which form the pontile nuclei in the lower portions of the metencephalon. They rapidly extend laterally, continue upward and then rapidly diminish by drawing toward the midline, where they end in contact, if not by fusion with the undifferentiated interpeduncular gray matter. The pontile nucki, where they assume any proportions at all, appear only as a simple lamina of gray matter forming the ventral contour of the gray matter of the brain stem. They show no tendency whatsoever to establish any degree of complexity and do not interlace with the bundles of the pyramidal tract which lie in a compact group dorsal to the middle of the pontile lamina. 


\section{Tue Vestibular Nichei}

A relatively short distance above the opening of the fourth ventricle there appears a specialization in the reticular formation which lics between the nuckens of Burdach and the floor of the fourth ventrick. This specialization consists of groups of fibers, rather foosely arranged in a matrix of gray matter, thus presenting the typical appearance of the mucteus of the descending root of the vestibular complex. This mass of gray matter enlarges in size, and very soon assumes the characteristic arangement of the nucleus of Deiters. As it increases in size, the nucleus of Burdach correspondingly decreases, and as the nucleus of Burdach comes to an end, the nucleus of Deiters assumes its full proportions. In tarsius the mucleus of Deiters is a relatively large collection of gray matter, and occupies the outer third of the dorsal portion of the tegmentum directly ventral to the floor of the fourth ventricle. As the nucleus of Burdach terminates, the nucleus of Deiters comes to the surface and appears on the corsolateral aspect of the neuraxial tegmentum. The increase in size of the gray matter in this region shows a very definite effect upon the ascending nucleus of Rolando which is displaced to a distinctly rentral position by the increasing mass of the Deitersal complex. The nucleus reaches its maximum proportions at a point somewhat above the mid-ventricular level where, in its mesial portion, there develops a small area somewhat more homogeneous in appearance, which is the triangular nucleus of Schwalbe. This nucleus forms part of the lateral wall of the ventricle underlying the ependymal floor and is in contact laterally with the Deitersal complex. At this point there appear the cochlear nuclei in connection with the entrance of the cochlear roots, and the clorsal cochlear nucleus overlies the nucleus of Deiters, hiding it from view. Having assumed its maximum proportions, the nucleus of Deiters rapidy diminishes and disappears, giving place to a rather large collection of reticular substance situated lateral to the central gray matter. As the nucleus of Deiters approaches the 
surface it presents the typical tongue-shaped prolongation laterally and ventrally in the curve of which is disposed the ascending inferior cerebellar peduncle which at this point passes between the vestibular and the cochlear complex to enter the cerebellum. No definite evidence of a nucleus of rom Bechterew could be obtained in the sections.

\section{Tile Cochlear Nuclei}

These nuclei appear at the mid-rentricular level of the brain stem opposite the lateral recess of the fourth ventricle. This nuclear mass in tarsius presents a lateral and a mesial group rather than the generally accepted division of the cochlear mucleus into a ventral and dorsal division. The lateral division of the cochlear nucleus is a well-defined mass of gray matter which lies lateral to the recess of the fourth ventricle connected by strands of gray matter with the mesial cochlear mucleus. The lateral cochlear nucleus appears to be considerably more extensive than the mesial portion of the nucleas and differentiates as a rather definite mass of gray matter almost independent of the gray matter of the stem itself. There could be identified no definite troughlike form of the nucleus which is the usual arrangement seen in the higher primates. The mesial cochlear nucleus is a rather poorly defined nuclear mass which is situated in the recess of the fourth ventricle and is immediately superimposed upon the Deitersal complex which underlies it. It does not extend upward or downward as lar as the lateral division of the mucleus and is a relatively insignificant mass of gray matter.

\section{The Colliculi}

These masses of gray matter, together with the geniculate bodies, form the predominating and outstanding development of the gray matter in the brain stem of tarsius. They are relatively massive in appearance and oceupy the tectal portion of the meseneephalon. The superior colliculi are very much 
larger than the inferior colliculi. The inferior colliculi appear at the dorsolateral angle of the brain stem at lirst as small rounded collections of gray matter. These expand conmously in succeeding sections, rapidy assuming their maximum proportions. They are situated lateral to a dorsal prolongation of the central gray matter. They are roughly oral in outline, the axis being directed somewhat from before, backward and inward. Having rapidly assumed their graatest dimensions, the colliculi continue upward for a short distanee and then begin to contract. They are in relation laterally with a prolongation of the reticular formation which arises in the dorsolateral angle of the tegmentum, and sweeps around the colliculi sending a prolongation upward to interpose itself between the upper limits of the inferior colliculus and the lower limits of the superior colliculus. The colliculi are supported ventrally by the reticular formation and mesially by the gray matter of the central formation. As seen in the cross sections the inferior colliculus corresponds fairly accurately with the general conformation of the inferior colliculus in the whole primate series, being represented chictly by a core of white matter, upen which are superimposed sucessive layers of white and gray matter. The superior colliculus, however, presents a very different appearance, having a typical cortex with a core of medullary substance. The superior colliculus makes its appearanee slightly above the point of termination of the inferior colliculus, as a small, clorsomesially situated mass of gray matter. This rapidly enlarges in size, spreading laterally and presenting a ventral prolongation which continues forward laterally along the outer aspect of the dorsal portion of the brain stem. Central to the superior colliculus, there appears a prolongation of the reticular formation dorsally around the central gray matter which is situated in the center of the reconstruction. As the superior colliculus is followed upward it assumes greater and greater proportions, becoming considerably thicker, and presents a rery definite plateau-like appearanee on its clorsal aspect, which turns at a sharp angle 
ventrally and taterally into the lateral prolongation which continues forward toward the mesial genienlate body. The superior colliculus continues upward to the point of junction of the mesencephaton with the diencephaton, where it rapidly contracts and comes to a termination.

\section{The Sibstaxtia Nigra}

This mass of gray matter appears at about the junction of the metencephaton with the mesencephaton in the ventromesial aspect of the brain stem, as a direct continuation upward of a thin lamina of reticular formation which is found to undertie the metencephalie pontile nuclei. The substantia nigra is situated obliquely from before, backward and outward, as a rather definite lamina of gray matter of mediocre dimensions. It continues upward in this position relatively unchanged, being in relationship mesially with the development of the interpeduncular gray matter, and dorsally with the reticular formation of the mesencephalic tegmentum. Laterally the substantia nigra is in relationship with the origin of the mesial geniculate body and somewhat more cephalically, with the beginning of the lateral geniculate body. In the lateral portion of this lamina of gray matter there develops the lateral mucleus of the substantia nigra which has been found to be present in the brain stems of all of the primates. This forms a rather complicated tangle of nerve libers arising from a definite nuclear formation, which seems to turn backward into the mesencephatic tegmentum. The substantia nigra continues upward to a point somewhat above the beginning of the superior colliculus, and then comes to an end being replaced by various developments of the reticular formation, which in this region assumes very considerable proportions and extreme complexity.

\section{The Central Gray Matter}

The central gray matter appears in the lowest levels of the model as a more or less $v$-shaped mass of nuclear material, presenting at its ventrolateral 


\section{RECONSTRUCTION OF TARSIUS SPECTRUM}

angles the ventral gray columns and at its dorsolateral angles the connect ions of the eentral gray matter with the substantia gelatinosa of Rolando. Continuing upward, the central gray matter retains very much the same position, the eonnection between it and the ventral gray column being cut across by the decussating fibers of the pramidal tract. As the dorsal gray columns begin to diverge, the central gray matter migrates dorsally, becoming llattened out, and then gives rise to the dorsal medullary nuclei, while to its ventral aspect is attached the retieular formation. Continuing upward the central gray matter gives rise to the nucleus of the column of Goll, and at a somewhat higher level, to the nueleus of the column of Burdach. As the floor of the fourth ventricle begins to open, the central gray matter comes to the surface and forms the floor of the fourth rentricle which presents a shallow depression, concave from side to side and from above downward. The gray matter of the floor of the fourth ventricle is spread out in a relatively thin sheet, and presents no particular modeling produced by the underlying structures of the floor of the fourth ventricke. It is continued outward into the lateral recesses and covers the nucleus of Deiters and the triangular nucleus of Schwalbe. It is encroached upon at the angle of the mesial cochlear nucleus which extends considerably toward the midline. Having passed the level of the lateral recess of the fourth ventricle, the gray matter contracts toward the formation of the aqueduct of Sylvius, and the central canal is soon reconstituted by the development of the roof of the fourth ventricle and the lower portion of the aqueduct of Sylvius. It here is in direct relationship with the dorsal prolongation of the reticular formation which surrounds it on either side, and receives the superior cerebellar peduncle. Continuing upward, the central gray matter again forms a complete canal which is rather massive and presents walls of considerable thickness. The aqueduct itself is an elongated dorsoventral slit rather than an oral opening, and the central gray matter is continued backward in a long drawn-out projection 
between the mesial aspects of the inferior colliculi. Continuing upward in the mesencephakon, the central gray matter becomes more rounded about the aqueduet of Sylvius, being surrounded by a dorsal prolongation of the reticular formation which separates it from actual contact with the superimposed superior colliculi. In the middle portion of the mesencephalon the central gray matter rapidly begins to extend ventrally forming a long slit-like structure which is surrounded by thick walls of gray matter which then become continuous with the interpeduncular gray matter. Continuing upward, the central gray matter of the mesencephalon becomes continuous with the central gray matter of the dienecphalon surrounding the slit-like third ventricle. The interpeduncular gray matter presents a rather massive development immediately above the pontile nuclei. This presents considerable proportions and contains a central ventrick. Continuing upward, with a definite ventral evagination, the interpeduncular gray matter fuses with the rentral probngation of the central gray matter as the junction of the mesencephaton with the diencephalon is approached. The interpeduncular gray matter presents at a relatively low level the condensations representing the mammillary bodies which appear at a level between the superior and inferior colliculi.

\section{The Geniculate Bodies}

These bodies since they form a definite part of the brain stem of tarsius, are described in connection with the gray matter of the brain stem.

The mesial geniculate body is the first one to appear and the first evidences of its existence are found caudal to the termination of the inferior colliculus. It appears as an oval mass of gray matter, situated lateral to the substantia nigra and directed outward and backward. It increases in size, shifts somewhat laterally and then dorsally and continues up as a rapidly increasing mass of gray matter in contact laterally with the ventral aspect 
of the lateral prolongation of the superior colliculus. It then becomes stretched out latcrally in a relatively thin lamina of gras matter which continues apward into the diencephaton.

The lateral geniculate body appears at a slightly higher level than the mesial geniculate body and is situated somewhat rentral to it. It forms the most prominent structure on the ventrolateral aspect of the brain stem. It consists of a relatively massive collection of gray matter, situated lateral and ventral to the mass of the mesial geniculate. It is disposed in an oblique direction from before backward and outward, and presents at its rentrat extremity a series of prolongations which receive or give origin to masses of fibers. Continuing upward, the lateral genienlate, rapidly diminishing, ends somewhat caudal to the upper limit of the mesial geniculate which extends further upward. 



\section{Chapter $V$}

\section{CALLITHRIX JACCIUS, THE MARMIOSET, ITS BRAIN AND BEIHAVIOR}

Its Position among the Primates; Measurements and Brain Indices; Surface Appearance of the Brain; Internal Structure of the Brain Stem in Cross Section

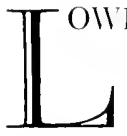

EST among the Anthropoidea are the Hapalictac or marmosets. These animals belong to the group of new-world monkeys. They inhabit South and Central Ameriea. Their digits are for the most part clawed, with the exception of the great toe which alone bears a flat nail. The tail is long, bushy and ringed, a condition characteristic of many of the lower groups of mammals but not observed among the higher apes. Unlike most of the South American monkeys, the tail of marmoset is not prehensile. In size they are about as large as a small squirrel and are covered with a thick silky fur. Although naturally timid, they readily become accustomed to those with whom they are familiar in captivity. The female produces two or three young at a birth and in this respect is unlike other Anthropoidea. In facial appearance, in size and shape of head, the Hapalidae convey a much more ape-like impression than do the lemurs. On the other hand, their specialization in limb, particularly with reference to the hand, scems hardly so far advanced as in the Lemuridae. The eyes are much closer together and separated by a flat, narrow nose, suggesting the possibility of some degree, at least, of binocular vision, although it seems probable that even in this respect, the animal's visual function has not attained a high degree of differentiation.

On the whole, the marmosets, because of their very small size, seem but retrograde steps in the differentiation which culminates in the strikingly 
outspoken features of the simian tribes. This relatively large family of newworld primates, however, because of its convergences and divergences within this order of mammals, should aflord interesting evidence in the structure of

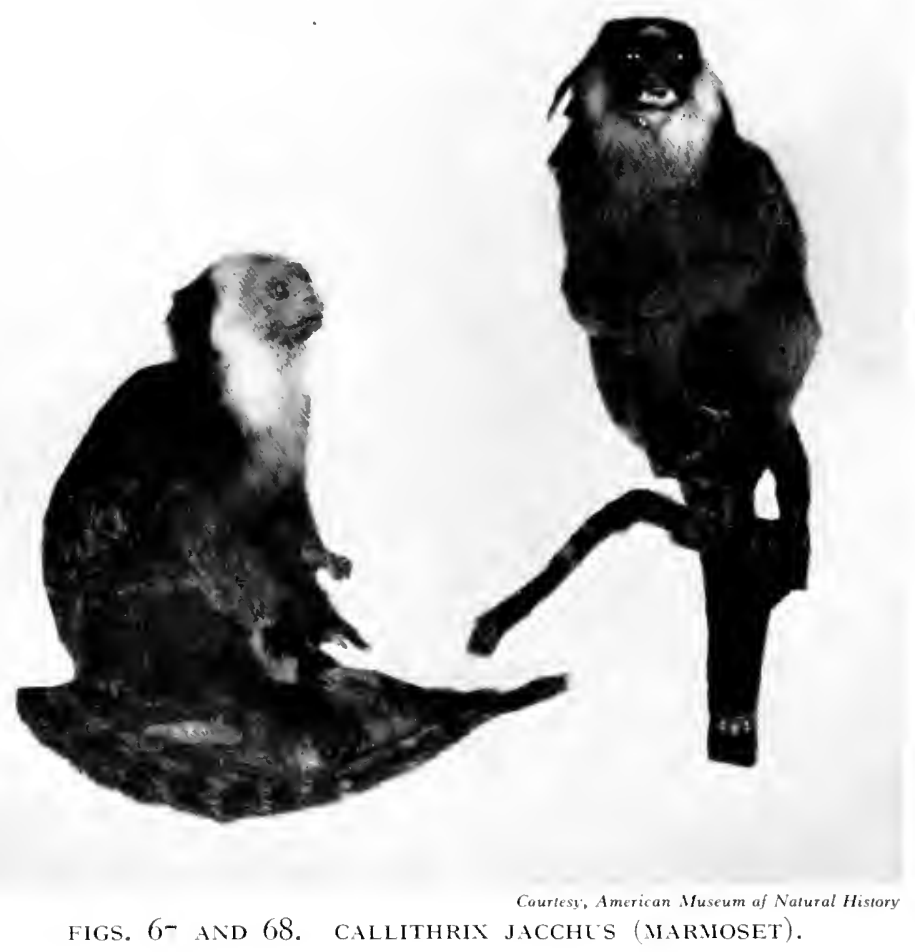

its central nervous system and more particularly in the brain. The species here described is Callithrix jacchus. The greater number of the species included in the genus Callithrix are natives of Brazil, one species formerly 
extending its range as far as Bolivia, another being indigenons to Colombia. There are records of Callithrix jacelus having also been found in the island of Marajo, lying between the mouths of the Amazon and Parí Rivers.

The marmeset has a black face with white spots. There are cross-bands on the back and tail. The animal lives in the tree tops or smaller underbrush. The claws upon its feet and hands cnable it to climb along the limbs and up the trunks of trees much in the manner of a squirrel. It has a cat-like agility but does not make long and daring leaps like the lemur. It often loses its hold upon the branches and falls from considerable heights to the ground without sustaining apparent injury. For this reason, and perhaps because of its small size, it is not in need of the extreme degree of prehensile power in either fore- or hindlimbs. It may also be because of this fact that its tail has failed to develop prehensile qualities. While in captivity it shows little tendeney to acquire reactions which it does not already possess in the free state. It does not lend itself to training or the acquisition of tricks, as do many of the other anthropoid forms. The animal lives upen worms, insects and fruits. It is known also to invade the nests of birds and suck the egors. Only exceptionally, however, does it prey upon bird-life, and in such exceptions it may occasionally be able to overpower one of the smaller birds or unprotected young. It has little of the acquisitive celerity manifested by the lemur.

\section{Measurements and Indices of Callithrix Jacchus}

Total length of the animal............. $510 \mathrm{~mm}$.

Length of the tail. ................. $29 ; \mathrm{mm}$.

Length of the foot.................. 6. 6. $\mathrm{mm}$.

Diameters of the skull

Occipito-nasal. ................. $+2 \mathrm{~mm}$.

Bitemporal. .................. 22.; $\mathrm{mm}$.

Length of the brain case............. $35 \mathrm{~mm}$. . 
Brain, including cerebellum and brain stem without meninges

Longitudinal. . . . . . . . . . . . . . . $31 \mathrm{~mm}$.

Transverse .............. . . . . . . . $23 \mathrm{~mm}$.
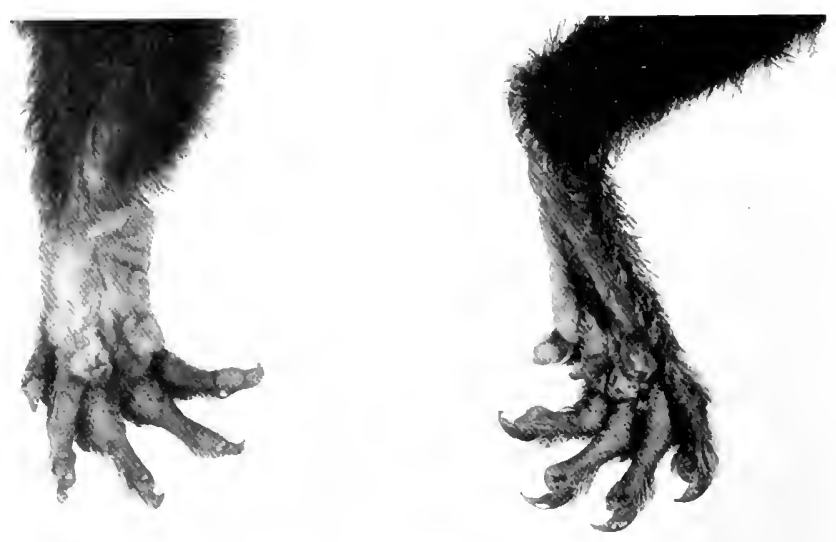

Courtest, American Museum of Natural History

FIGS. 6() AND -O. HAND AND FOOT OF MARMOSET.

Ler r. Palmar surface of hand showing poorly developed palm, rudimentary thumb, wedl-defined digitation, with claws instead of finger-nails.

Rignt. Plantar surface of the font showing imperfectly developed heel and sole, rudimentary great toe, claws instead of toe-nails.

Total weight of the brain............. 6.2 gms.

Total water displacement of the brain........6 c.c.

Weight of forebrain................ $4.75 \mathrm{gms}$.

Weight of midbrain................ 0.25 gms.

Weight of hindbrain............... 1.2 gms.

On the basis of these figures the following encephalic indices were computed for the several divisions of the brain: 
Forebrain index... $80 . j$ per eent

Midbrain index.

$0 . j$ percent

Hindbrain index

I1). () per cent
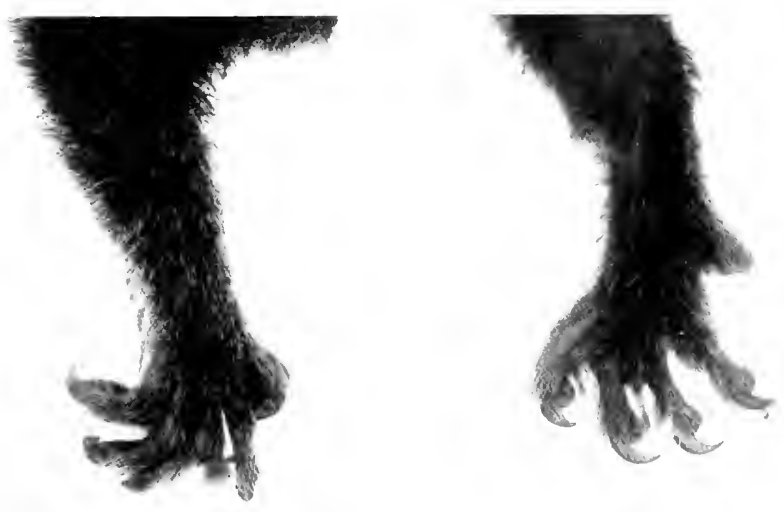

Courtesy, American Museum of Natural History

FIGS. - I AND 72. IHAND AND FOOT OF MARMOSET.

LEFT. Dorsum of hand showing poorly developed thumb, and claws instead of finger-nails. Right. Dorsum of foot showing rudimentary toe, claws instead of toe-nails.

These indices align the animal in a definitely submanual group with a forebrain index slightly below that of the lemur and only slightly above the forebrain index characteristic of mammals possessed of paws and claws.

Surface Appearance of the Brain in Callithrix Jaccius

THE FISSURAL PATTERN

The surface appearance of the hemisphere in the marmoset gives the impression at first glance of a lissencephalic brain. Further inspection, however, shows that at least three fissures constitute an indefinite fissural pattern 
in this animal. The Sylvian fissure is a prominent sulcus whose angulation with the base line of the brain is slightly less than $50^{\circ}$, showing in this regard a general tendeney to approach the condition of the higher primates. The
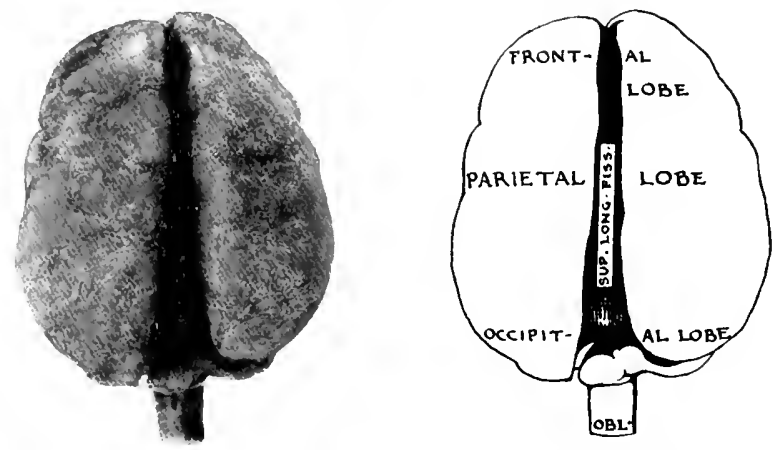

FIG. 73. DORSAL SLRFACE OF BRAIN, CALLITHRIX JACCILS (MARMOSET). [Actual I ength, 2i) $\mathrm{mm}$.]

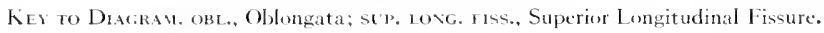

Sylvian fissure, however, is relatively short and extends backward and upward for something less than half the distance of the entire lateral surface. Below and behind the Sylvian lissure is a slight indenture indicating the position of the superior temporal fissure, corresponding in its general position to the sulcus parallelus in the lemur's brain. A slight indenture above and in front of the Sylvian fissure indicates the position of the sulcus centralis which forms the faint boundary by means of which the limits between the frontal and parietal lobes may be established. There is no evidence of any parietal sulci or of any incisure which may be considered as the homologue of the suleus simiarum.

\section{LOBATION}

The lobation in the marmoset brain, therefore, is only most rudimentarily outlined. Distinction may be made between the parietal, parieto- 
frontal and temporal regions by the boundary established through the Sylvian fissure. No boundary exists which indicates the actual limits between the parietal and the frontal tobes except the faint indenture already indicated
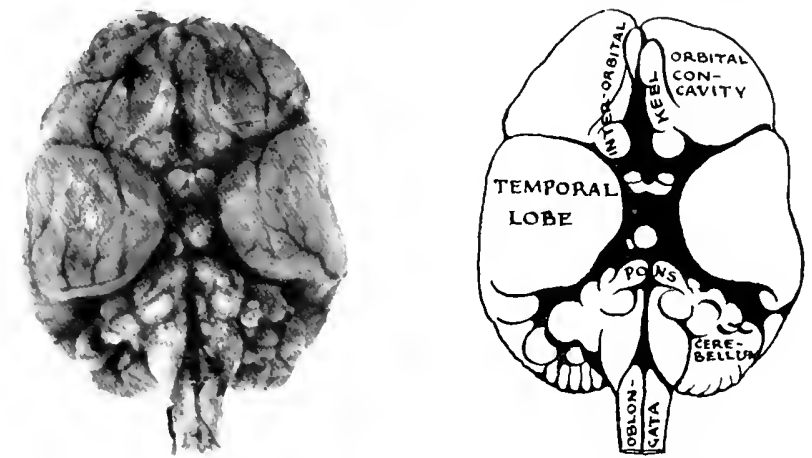

FIG. - + . BASE OF BRAIN, CALLITHRIX JACCHLS (MARMOSET),

[Actual Length, $29 \mathrm{~mm}$.]

as the probable inception of the sulcus centralis which, however, is not a constant marking in the marmoset brain. In many species it does not appear at all. As no boundary line exists in the oceipital region, it is impossible to describe the limits between the parietal and the occipital lobes. The latter lobe, however, has apparently expanded considerably in its general dimensions because the pole of the brain now completely overhangs the cerebellum and assumes more closely the general outline of this region in the higher primates. While it is possible to identify the general topography of the frontal, parietal, temporal and occipital lobes in the brain of marmoset, no reliable landmarks may be established as marking the boundaries of these four great hemispheral divisions. The impression conveyed by the survey of the brain in the Hapalidae is that even if this family has definitely entered the lists of the primate kind, its advance has been a most diffident one. While the hemisphere shows the general outline characteristic of the primate endbrain, it has 
mone of the beld mathings in the way of lissures and eonvolutions which ultimately become the identifying (Fig. -j) features of this part of the nervous system in primates. The marmoset brain may be considered as
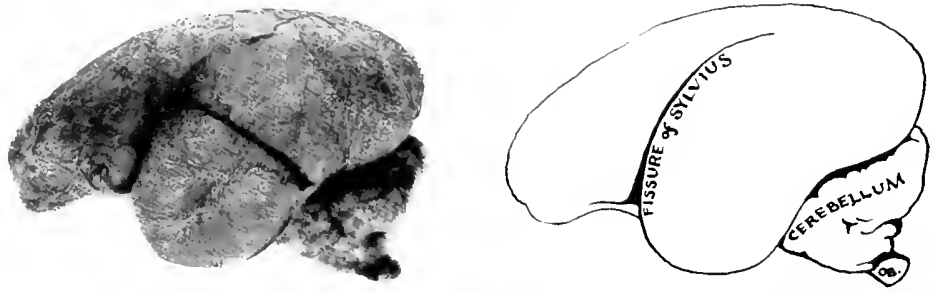

FIG. - ;. IEFT LATERAL SLRFACE OF BRAIN, CALLITHRIX JACCHUS (MARMOSET). [Actual Length, $31 \mathrm{~mm}$.]

Key to Diagray. Ob., Oblongata.

something more than a mere transitional form. It must be taken to represent a transition already achieved from the lower mammals into the primate order but also manifesting certain retrograde changes.

\section{TIIE ORBITAL SLRFACE}

On the orbital surface the brain has all of the typical markings of the lower primates. The two orbital concavities are well defined. The inception of these concavities seen in the lemur's brain is here carried to its ultimate development. The orbital surface now rests upon an expanded orbital plate of the frontal bone. The interorbital keels are also well defmed and more marked than in the lemur brain. The olfactory bubs, though fairly large, are less pronounced than in the lemur, and the olfactory tract is detachable as far back as the trigonum which is fairly prominent (Fig. 74 ).

THE OCCIPITAL REGION OF THE BASAL SURFACE

In the occipital region of the basal surface a well-marked occipital concavity cxists which is most emphasized in and about the midline, particu- 
larly in the region of the postsplenial fossa. This concavity aceommodates the upward protrusion of the cerebellum. The cerebellum upon its tentorial surface is almost completely overhung by the occipital pole of the hemisphere.
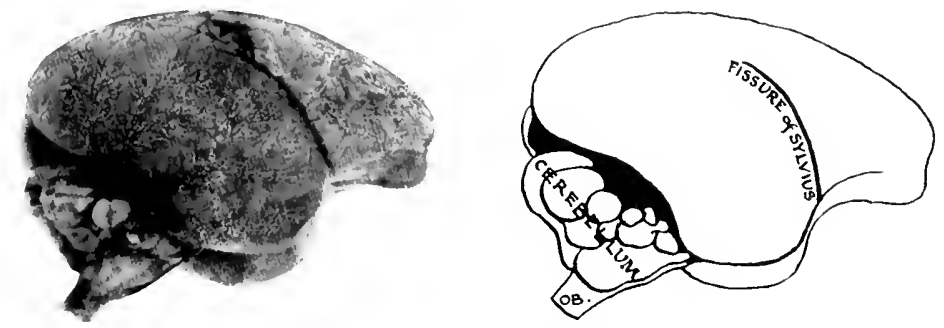

FIG. -6. RIGHT LATERALSLRFACE OFBRAIX, CALLITHRIX JACCHLS (IIARMOSET). [Actual Length, $31 \mathrm{~mm}$.]

Key ro Diagray. ob., Oblongata.

The superior vermal portion of the cerebellum is more conspicuous than the lateral lobes which show but slight expansion. On the occipital surface the vermis is also the outstanding feature. It represents scarcely less than a third of this surface and stands out conspicuously against the poorly dereloped lateral expansions of the cerebellum. The two paramedian sulei interrupt the passage of the interfolial fissures from the inferior vermis to the lateral lobe. No such sulcus, however, exists on the tentorial surface. While the cerebral hemispheres of marmoset assign the animal to a definite place among the primates, the simplicity of the brain indicates the relatively low position of the Hapalidac (Fig. -6).

\section{THE SURFACE MARKINGS OF THE BRAIN STEM}

The surface markings of the brain stem are in general much less distinct than in the higher primates. In many respects, they are less impressive than in Lemur mongoz. The oblongata on its ventral surface presents a ventromesial sulcus and two faintly marked ventrolateral sulci. Neither the 
pyramids nor the inferior olivary bodies have any distinct surface relief, nor is it possible to detect any superficial indieation of the pyramidal decussation. The refative insignifieance of the pyramidal system indicates an
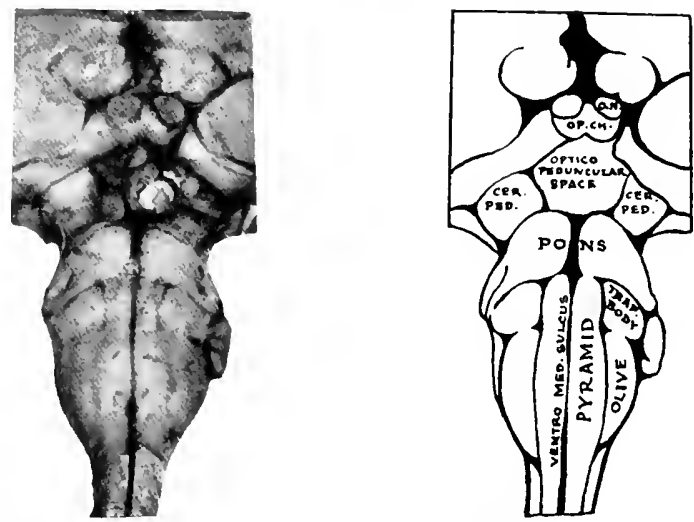

FIG. -- . VENTRAL SURFACE OF BRAIN STEM, CALLITHRIX JACCHUS

(MARMOSET).

[Actual Length, $22 \mathrm{~mm}$.]

Key to Dagkan. uk. ped., Cerebral Peduncle; O.N., Optic Nerve; op. Ch., Optic Chiasm. trap; RODr, Trapezuid Body; VENTRO MED, stucus, Ventromedian Sulcus.

extremely limited range of volitional performances and in this respect places the animal even Iower in the scale than the lemur. The bulbopontile sulcus is diflicult to make out except in fresh specimens, and the pons itself is a llat, narrow band conveying the impression that the animal has not developed a pallio-cerebellar connection capable of producing any large degree of corrdinative control over skilled movements. On the dorsal aspect of the oblongata there is a slight mesial eminence indicating the presence of the column and muckeus of Goll. No simitar lateral prominence adjacent to it gives surface indication of the column of Burdach. This fact seems to indicate that the tail and lower extremity are more prominent functional elements than the forelimb (Fig. -8 ). 
THE CEREBELLLM, THE FOLRTII VENTRICLE AND IIIE MIDBRAIN

The cerebellum is small, presenting a large median portion, the vermis, and two limited lateral expansions, the lateral hemispheres. The size of the
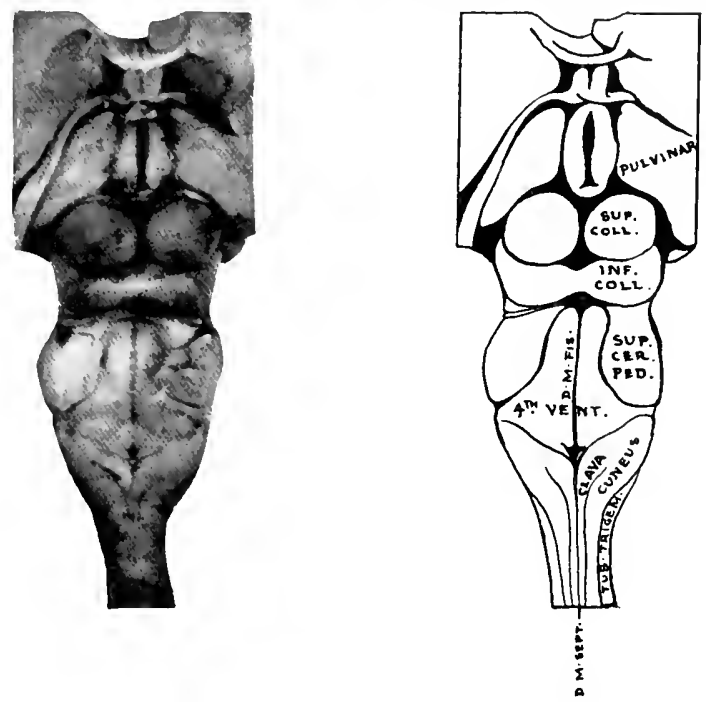

FIG. 78 . DORSAL SURFACE OF BRAIN STEM, CALLITHRIX JACCHUS (MARMOSET).

[Aetual Length, $22 \mathrm{~mm}$.]

Key to Diagram. D. M. Fis., Dorsomedian Fissure; D. M. SEPT., Dorsomedian Septum; INF. Coll., Inferior Collieulus; ste. Cer. Ped., Superior Cerebellar Peduncle; ste. Cokl., Superior Colliculus; tub. Trigen.,

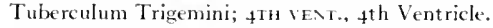

cerebellum, particularly of its lateral tobe, indicates a coordinating organ with a low degree of functional capacity. From this it may be inferred that the animal's attainment in complex voluntary movements is extremcly limited. On removal of the cerebellum the fourth ventricle is revealed, bounded upon either side in its inferior triangle by an inconspicuous clava and in its superior triangle by the superior and middle cerebellar peduncles. 
The flow of the ventricte, even with high magnilication, shows few of the characteristic markings usually observed in this region of the brain. It is not possible to detect striae acusticae crossing the lloor. The lateral recesses are narrow and the configuration of the rhombencephaton is much more compressed in its cephato-candal relations than is the case with the fourth ventricle of other primates. In the ventral region of the midbrain the cerebral peduncles may be observed, diverging as they approach the cerebral hemispheres and thus bringing to light the interpeduncular space. The cercbral pedunctes, however, make but a faint relief on the ventrat mesencephatic surface. On the dorsal aspect of the midbrain the inferior and superior colliculi are well marked and give the impression that the primordial stations for both vision and hearing have a high degree of representation in these primates. The insignificant development of the cercbral peduncles speaks again in favor of a low organization for volitional skilled acts controlled through the agency of the pyramidal system.

\section{I.vternal Structure of the Brain Stem in Callithrix Jacchles}

LEVEL OF THE PYRAMIDAL DECUSSATION (FIG. - 9 )

At this level two notable features are present, i.e., the decussation of the pyramidal tracts ( $\mathrm{Prx}$ ) which has the effect of separating the ventral gray column (Ven) from the central gray matter ( Cen), and the presence of the caudal extremity of the nucleus of Goll (NG). This mucteus is surrounded by a massive tract of fibers, the cotumn of Goll, which ascends from the lumbosacral and lower thoracic segments of the cord. From the sensory standpoint, it represents chiefly the tail and lower limb. Immediatery adjacent and lateral to the tract of Goll is the tract of Burdach (CB) which, however, presents a size relatively equal in comparison with the more mesial sensory pathway. Lateral to Goll's tract is the large substantia gelatinosa (NR) bordering upon which is the descending tract of the fifth 
nerve ( Trd). This dorsal ficld of sensory discrimination, cmbracing the three major sensory territories of the besdr, the head and later, neek and upper extremity, leg and tail, is almost as conspicuous as in lemur. Its pro-

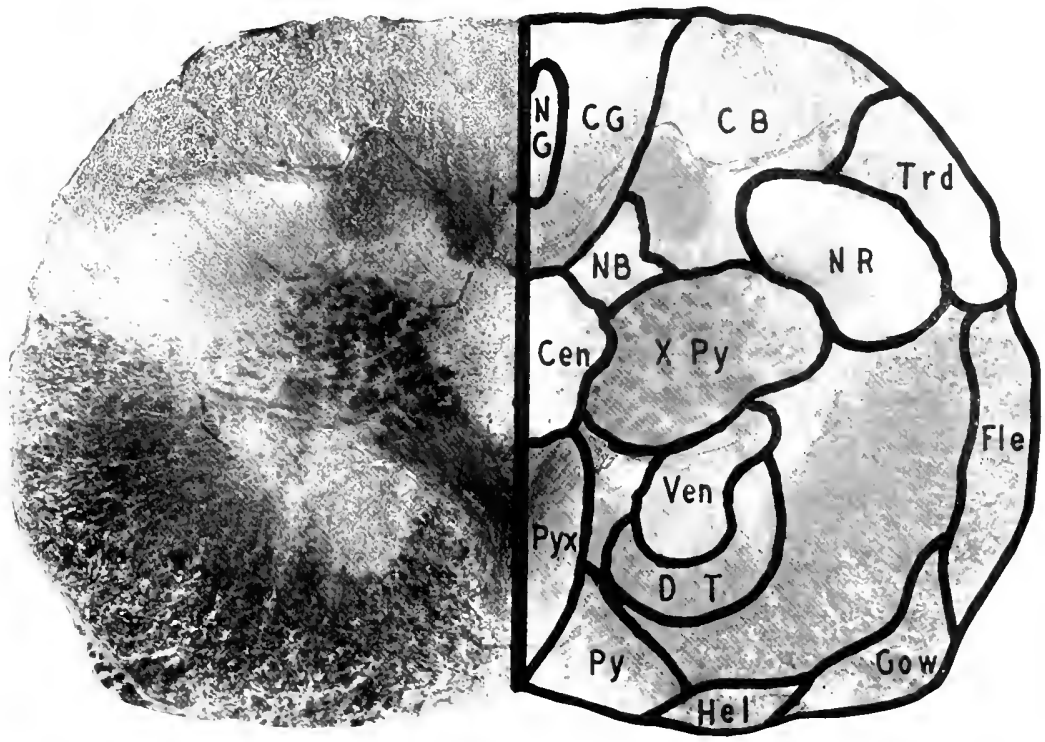

FIG. -9. MARMOSET, LEVEL OF THE PYRAMIDAL DEClSSATION.

CEN, Central Gray Matter; CB, Column of Burdach; CG, Column of Goll; DT, Deiterso-spinal Tract; FLE, Dorsal Spinocerebellar Tract; Gow. Ventral Spinocerebellar Tract; Hel, Spino-olivary Tract of Helweg; NB, Nucleus of Burdach; NG, Nucleus of Goll, NR, Nucleus of Rolando; pr, Pyramid; prx, Prramidal Decussation; TRD, Descending Trigeminal Tract; VEN, Ventrat Grity Matter; XPs, Crossed Py ramidal Tract. [Accession No. 146. Section 4. Actual Size $5 \times 3 \mathrm{~mm}$.]

portional development of gray matter, as well as the size of the tracts, has practically the same connotation as in the lower form already described. Thus, sensory conduction from the $\mathrm{keg}$ and tail, head and face is less amply represented than that from the arm and neck. The significance of this relative disproportion is obvious at a grlance. The head, forearm and the hand are 
functionally more prominent than the hind extremity with its poorly difforentiated font. This disproportion is less striking than in lemur, for although marmoset makes but limited use of its hand, its tail and hind leg

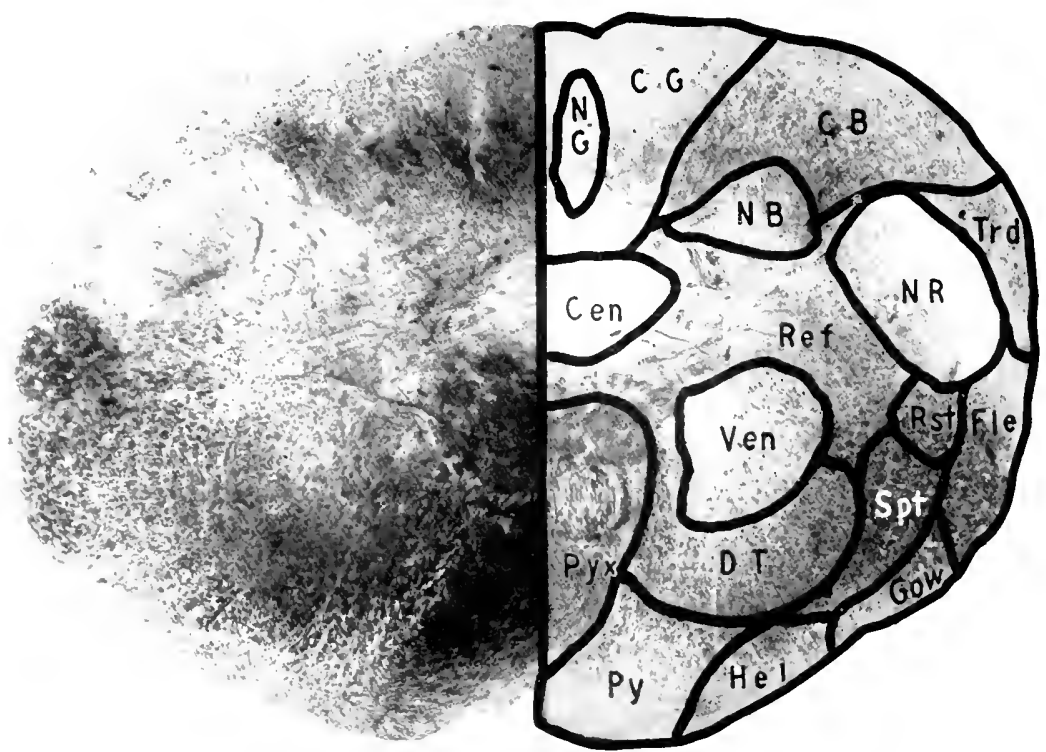

FIG. 80. MARMOSET. LEVEL OF THE DORSAL SENSORY NLCLEI.

CB, Column of Burdach; CEN, Central Gray Matter; cG, Column of Goll; DT. Deitersi-spinal Tract; FLE, Dorsal Spinocerebellar Tract; cow, lentral Spinocerebellar Tract; hec, Spino-olivary Tract of Helweg; \B, Nucleus of Burdach; >G. Nucleus of Goll; \R, Nucleus of Rolindo; PY, Prramid, Pıx, Pyramidal Decussation; REF, Reticular Formation; Rst, Rubrespinal Tract; sirt, Spinothalimic Tract; trd, Descending Trigeminal Tratet; Vex, Ventral Gray Matter. [Accession No. 146. Section 8. Actual Size $6 \times+\mathrm{mm}$.]

manifest as much adaptive significance as in the case of lemur. That the discriminative type of sensibility has a low representation in marmoset, thus providing a meager substratum for the development of its skilled acts, is further substantiated by the fact that the pyramidal tract (Py) is a 


\section{CALLITHRIX JACCHUS, THE MARMOSET}

small bundle of fibers in this animal. This creates the impression that the pyramidal system in its relation to the control of voluntary movement plays but a small part in the animal's somatic behavior.

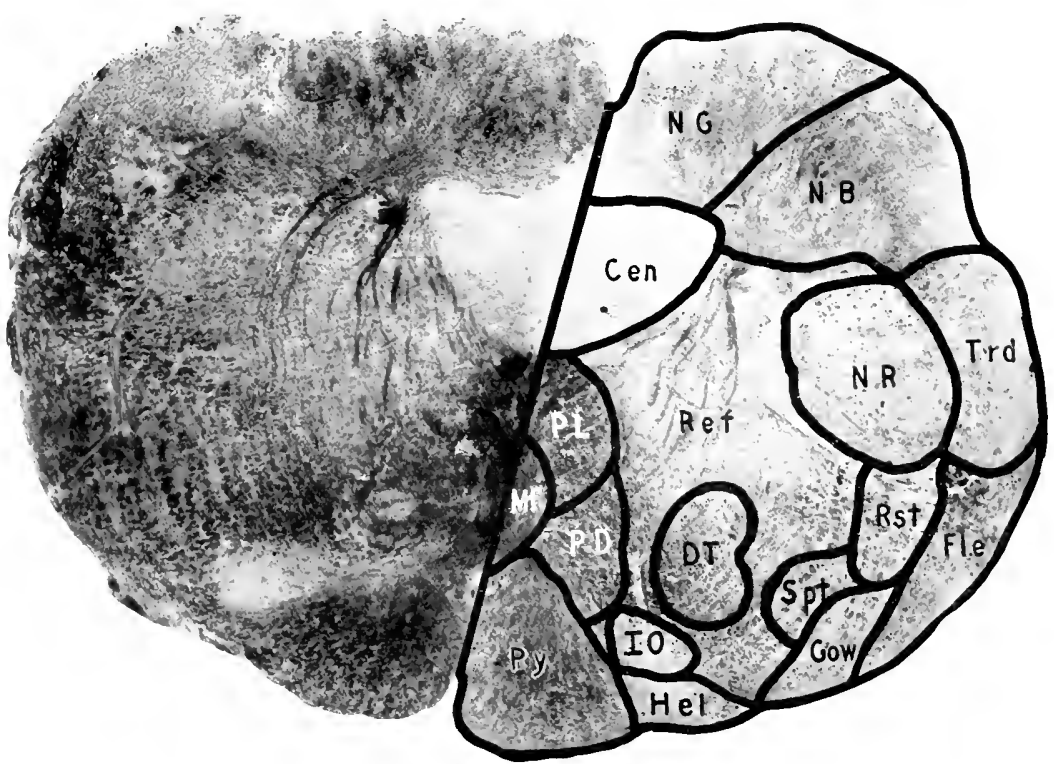

FIG. 8I. MARMOSET. LEVEL OF THE TIP OF THE INFERIOR OLINE.

Cex, Central Gray Matter; dr, Deitersu-spinal Tract; rle, Dorsal Spinecercbellar Traet; gow, Ventral Spinocerebellar Trict; hel, Spino-olivary Tract of Helweg; Io, Inferior Olive; vf, Me sial Fillet; >B, Nucleus of Burdach; \G, Nucleus of Goll; NR, Nucleus of Rolando; PD, Predorsal Bundle; PL, Posterior Longitudinal Fasciculus; PI, Pyramid; REF, Reticular Formation; RST, Rubrospinal Tract; spr, Spinsthatamic Tract; TRD, Descending Trigeminal Tract. [Accession No. ${ }_{4} 6$. Section 22. Actual Size $8 \times 5 \mathrm{~mm}$.]

LEYEL OF THE CAUDAL EXTREMITY OF THE INFERIOR OLIVE (FIG. 8 J)

The appearance of the caudal limit of the inferior olivary body (IO) adds another striking feature to the next level. This structure 
acupies its usuat position dorsal to the pramidal bundles. It is of relativel smath size and irregular outline. While it has nearty the same prominence as in lemur, in many respects it seems more poorly defined as a distinctive structure in the oblengata. Its edges are not so clearty demareated. This holds true of the olivary body at all hevels in the marmoset, in which it appears to be a poorly developed constituent indicating a kow degree of organization in the ofivary sphere of action. Its function, as atready described, is related to the automatic controt of simultaneous morements of the hand, head and eye in the performance of skilled acts. Certainly there are no acts executed by this animal which indicate the necessity of any vers chese condinative comperation between eye, bead and hand.

The pramid ( Py) here reveats its dimensions in the cross section and again signifies a conduction bundle with rather low capacity for distributing volitional motor impulses. Dorsal to the prramidal fibers and adjacent to the midline are the lirst agrgregations of fibers which enter into the mesial filket ( $\mathrm{If}$ ). This bundle is formed by decussating arcuate fibers arising in the nuclei of Goll and Burdach which sweep forward across the midline where they take a cephatic course toward the higher levels of the brain. It furnishes some idea as to the extensiveness of the secondary sensory pathway.

LEVEL THROLGH THE MDDLE OF THE INFERIOR OLIE (FIG. 82)

At the level through the middle of the inferior olivary body, although this body appears in its greatest dimensions, it gives the impression of a poorly developed structure. Its relatively small size supports the supposition that the coordinative control of simultaneous movements of head, eye and hand and the coordination of all skilled learned performances are comparatively slight in this animal. The relative functional signifieance of the nucleus of Goll as compared with that of Burdach is obrious by the con- 
trast in size of these nuclei as they lie sibe by side in the dorsal portion of the section ( NG, NB). The mesial fillet ( $/ \mathrm{f}$ ) has attained more prominence because of the addition to it of a fareger number of arenate fibers.

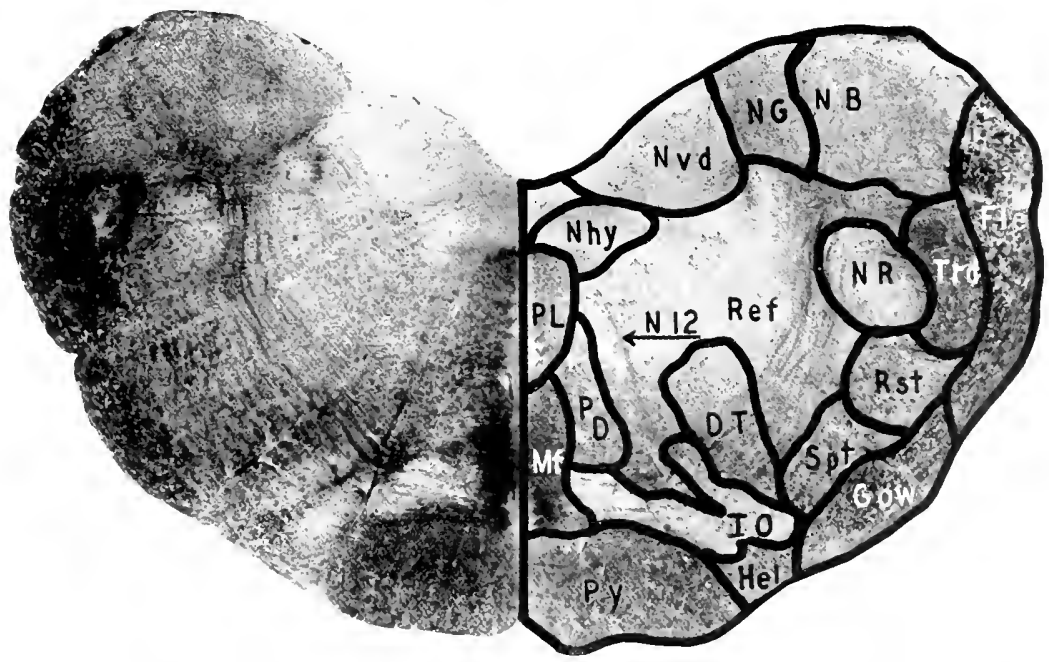

FJG. 82. MARMOSET. LEVEL THROLGH THE MIDDLE OF THE INFERIOR OLIVE. Dr, Deiterso-spinal Tract; fle, Dorsal Spinocerebellar Tract; gow, Ventral Spinocerebellar Tract; hel, Spino-olivary Tract of Helweg; Io, Inferior Olive; Mr, Mesial Fillet;, $\mathrm{B}$, Nucleus of Burdach; ng, Nucleus of

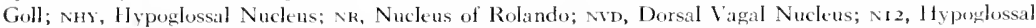
Nerve; PD, Predorsal Bundle; PL, Posterier Longitudinal Fasciculus; PY, Pyramid; ReF, Reticular Formation; RST, Rubrospinal Tract; spt, Spinothalimic Tract; TRD, Descending Trigeminal Tract. [Accession No. 146 . Section 37. Actual Size $8 \times+m m$.]

LEVEL OF THE VESTIBULAR NUCLEI AND TLBERCLLUM ACLSTICUM (FIG. 83)

At the level of the restibular nuclei and tuberculum acusticum, the cross sections are characterized by the wide separation of the lateral walls of the fourth ventricle and the appearance of the vermis cerebelli in relation with the rentricle. In the position formerly oceupied by the nuclei of Goll and Burdach are two prominent nuclear masses intimately concerned 
with afferent conduction. These nuclei are especially related to a type of conduction which has to do with the maintenance of equilibrium. They receive impulses from the receptive organs of the semicircular canals, utricle and

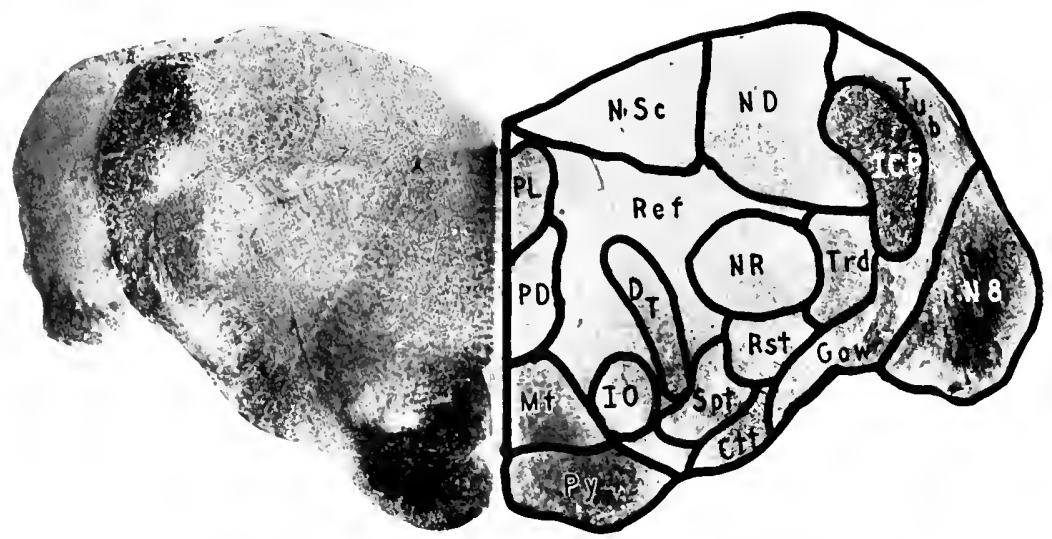

F1G. 83. MARMOSET. LEVEL OF THE NESTIBLLAR NLCLEI AND TLBERCULUM ACUSTICUM.

Cтт, Central Tegmental Tract; nt, Deiterso-spinal Tract; gow, Ventral Spinocercbellar Tract; icp, Inferior Cerebellar Peduncle; 10, Inferior Olive; MF, Mesial Fillet; ND. Deiters' Nucleus; NR, Nucleus of Rolando; NSC, Nucleus of Schwalbe; N8, Auditory Nerve; pn, Predorsal Bundle; Pr., Posterior Longitudinal Fasciculus; PY, Pyramid; ReF, Reticular Formation; Rst, Rubrospinal Tract; Spt, Spinothalamic Tract; tro, Descending Trigeminal Tract; rub, Tuberculum Acusticum. [Accession No. 146. Section 67. Actual Size $10 \times 4 \mathrm{~mm}$.]

saccule. The two nuclei which have thus replaced the columns of Goll and Burdach are the nucleus triangularis of Schwabe (NSe) and the nucleus magnocellularis of Deiters (ND). The size of these nuclei and their fiber connections with the vestibular mechanism indicates a high degree of organization in the reflex acts connected with balancing. These vestibular nuclei are outstanding features in the section. In their general dimensions they correspond with the similar structures of lemur, a fact which would seem to justify the inference that the marmosets are as well equipped in balaneing 
function as the lemurs. The restiform body (ICP), which represents the aggregation of asecuding fibers passing to the vermis of the exebethum, aflords a suggestive index of coordinative controt. The development of such

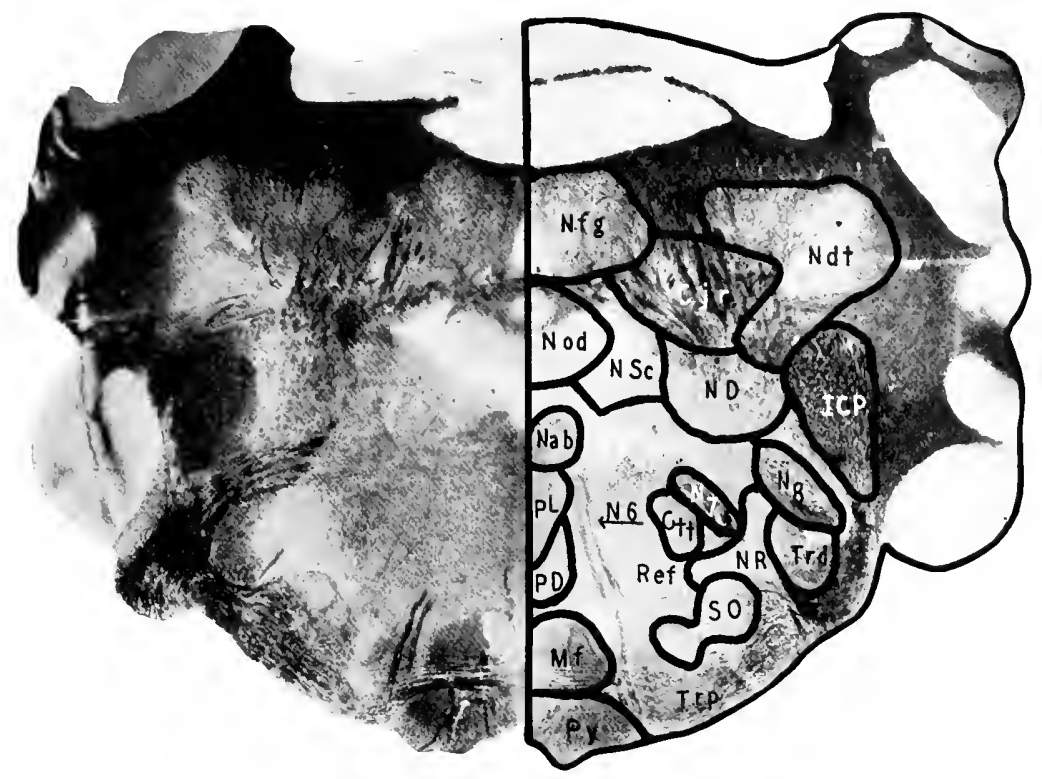

FIG. 84. MARMOSET. LEVEL OF THE CEREBELLAR NCCLEI.

CJR, Juxtarestiform Body; CTT, Central Tegmental Tract; ICP, Inferior Cerebellitr Peduncle; MF, Mesial Fillet; NAB, Abducens Nucleus; ND, Deiters' Nucleus; NDT, Dentate Nucleus; NFG, Cerebellir Nuclei, Mesial

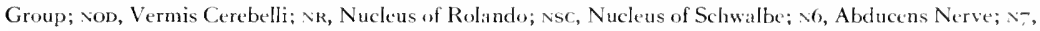
Facial Nerve; N8, Auditory Nerve; PD, Predorsal Bundle; PL, Pusterior Longitudinal Fasciculus; pr, Pyramid; REF, Reticular Formation; so, Superior Olive; TRD, Descending Trigeminal Tract; TRP, Trapezoid Body. [Accession No. 146. Suction 92. Actuil Size $10 \times 7 \mathrm{~mm}$.]

control in marmoset appears to be relatively Jess than in other primates, a supposition which finds support in the relatively Jow degree of organization in the cerebellum. 
LEVEL OF THE CEREBELLAR NLCLEI (FIC. 84)

At the level of the cerebellat nuclei the intimate relation between the medulfa oblomgata and the cercbellum is clear, while an inclex to the degree of cerebellar control of motion is furnished in the presenee of the main efferent cerebellar nucleus, the nucleus dentatus ( $\mathrm{Ndt}$ ). Occupying the most ventral position in the cross section is the pyramid ( $\mathrm{P}_{y}$ ) immediately dorsal to which is the trapezoid body (Trp) made up of crossing fibers entering the secondary pathway for the conduction of anditory stimuli. The reticular formation (Ref) occupies an extensive area along whose ventral border is the superior ofiary body ( $\mathrm{SO}$ ), a way station in the pathway of hearing.

LEVEL AT THE MIDDLE OF THE PONS VAROLH (IIG. $8 j$ )

At the level at the middle of the pons Varolii this structure attains its maximum dimensions and comsists of its three typical layers, the stratum superficiale, the stratum complexum and the stratum profundum. The stratum superficiale continues directly into the midelle cerebellar pectuncle ( 1 cp). The stratum complexum contains many transverse pontocerebcllar libers together with the scattered fasciculi of the pyramidal system (Py) and the pontile nuclei $\left(\mathrm{P}_{\mathrm{n}}\right)$. The general dimensions of all of the structures occupying the basis pont is afford a significant index of the animal's degree of adaptation. The relatively small size of the pyramidal system is clearly demonstrated. The equally small size of the pons, including the pontile contribution of libers, which goes to make up the midde cerebellar peduncle, is significant of connections which provide but limited means for the anmal's organization of a complicated motor adjustment. It may be inferred from this evidence that the marmoset is perty endowed with motor activities having a high degree of adaptive llexibility and that the entire range of its motor effectiveness is limited to narrowly prescribed motion formulas. The 
animal does not possess the celerity, the dexterity or the muscular power to adapt itself to an extensive natural enviromment. Neither has it the capacity to create out of its environmental conditions new combinations which

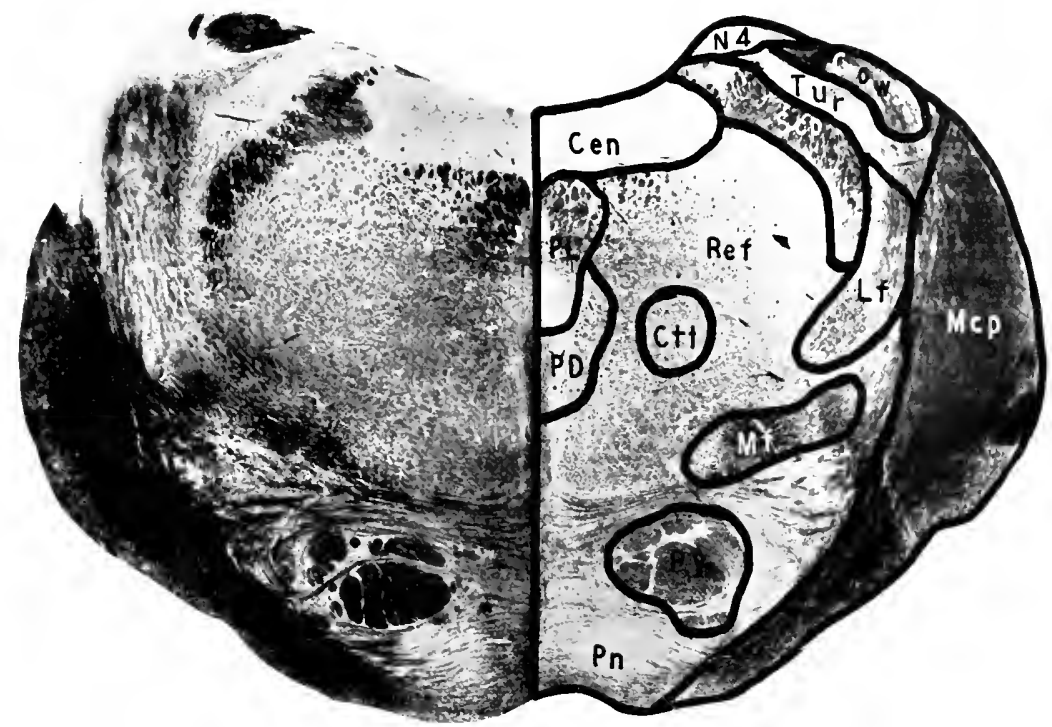

FIG. 8;. MARMOSET. LENEL AT THE MIDDLE OF THE PONS VAROLH.

CEv, Central Gray Matter; CTT, Central Tegmental Tract; Gow, Ventral Spinecerebeilar Tract; Lf, Lateral Fillet; мcP, Niddle. Cerebellar Peduncle; MF, Mesial Fillet; Nł. Trochlear Nerve; pd. Predorsal Bundle; PL, Posterior Longitudinal Fascieulus; PN, Pontile Nuclei; Py, Pyramid; Ref, Reticular Formation; scP, Superior Cerebel]ar Peduncle; te r, Tractus Uncinatus of Russel (1 lowk Bundle). (Accession No. I f6. Section 1 23. Actual Size $9 \times 5 \mathrm{~mm}$.

would necessitate the development of a more complex motor organization. Hence it lives within a limited sphere of action whose requirements demand a relatively simple motor organization.

LEVEL OF THE INFERIOR COLLICULUS (FIG. 86)

At the level of the inferior colliculus the most significant moditication is the appearance of this elevation ( $\mathrm{lC}$ ), the primordial relay station 
for the sense of hearing. This structure in the marmoset shows a high degree of development which mas be taken to indicate an auditory sense still having a large representation at this lower level in the brain. Here, as in

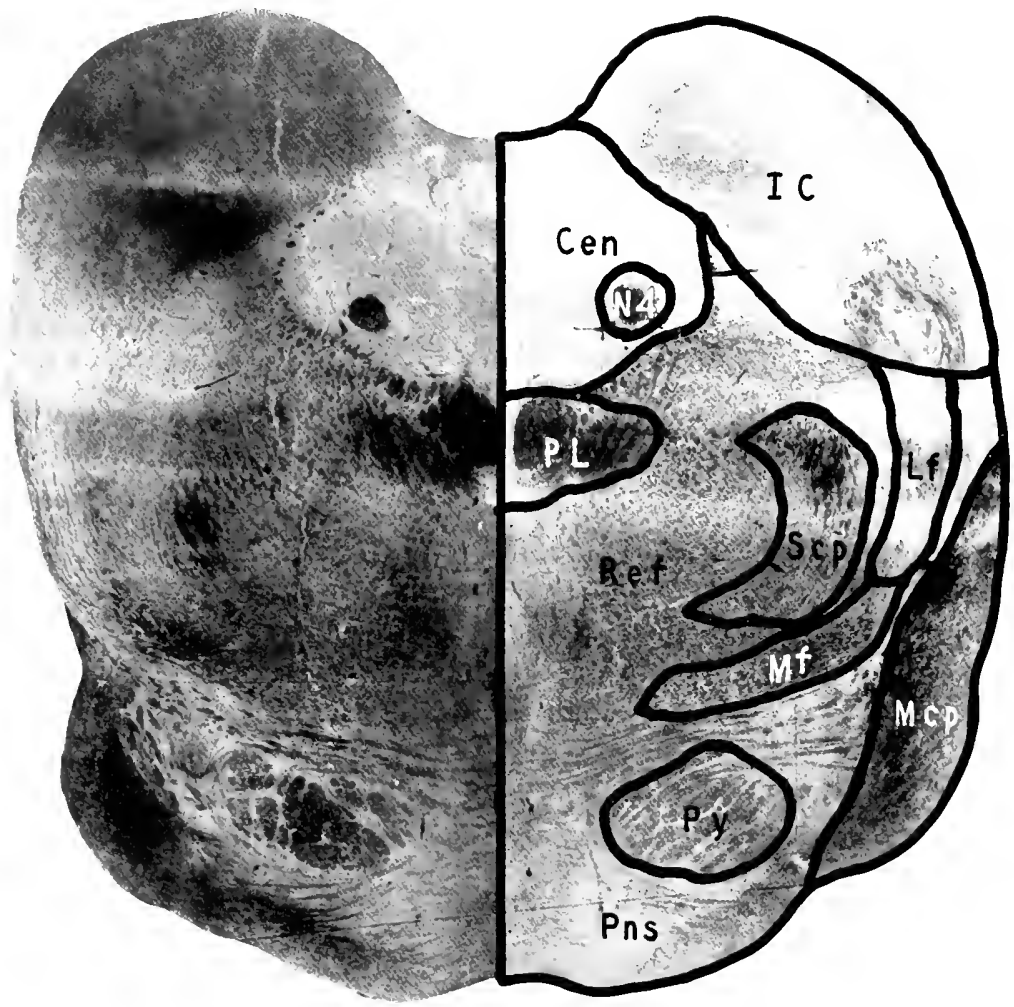

FIG. 86, MARMOSET. LEIEL OF THE INFERIOR COLLICLLLS.

CEN, Central Gray Matter; It, Inferior Colliculus, 1.F, Lateral Fillet; MCP, Middle Cerebellar Peduncle; MF, Mlesial Fillet; N4, Trochlear Nerve; PL., Posterior Lungitudinal Fasciculus; PXs, Pons, PY, Pyramid; REF, Reticular Formation; scr, Superior Cerebellar Peduncle. [Accession Nu. 146. Section 139. Actual Size $9 \times-\mathrm{mm}$.] 
the case of lemur, this primordial auditory organization appears to be in the interest of rapid automatic reactions in response to auditor stimuli. It provides for immediate readjustments of body posture against impending attack or other peril, the approach of which is indicated by sounds. Also, as in the case of lemur, this provision for immediate reaction in response to sound imposes a definite degree of limitation in the range and scope of motor activity. It deprives the animal of certain deliberative and rellective elements which furnish a period of latency in the selection of alternative courses of action designed to meet emergencies which may develop. The superior cerebeliar peduncle $(\mathrm{Sep})$ appears as a creseent extending inward and forward preparatory to its decussation. The prramid ( $P_{y}$ ) still presents a disseminated appearance and interspersed among its fascieuli are chusters of the pontile nuclei. Lateral to the mesial fillet ( Mf $)$ is a long, sweeping mass of fibers on their way to the inferior colliculus, the axons of which constitute the lateral fillet (Lf). Dorsolateral to the mestal fillet is a bundle of fibers constituting the rubrospinal tract and spinothalamic tract. The central gray matter ( $\mathrm{C} \cdot \mathrm{n}$ ) has greatly increased in size and now almost surrounds the small cavity constituting the caudal orifice of the Srlvian aqueduct whose roof is formed by the superior medullary velum and by the decussating fibers of the trochlear nerve. Between the two inferior colliculi, resting upon the decussation of the trochlear nerve, are the lingular folia of the cerebellum.

LeVel of the superior CEREbeliar peduncular declssation (Fig. 8-)

The next cross section is introduced to show the decussation of the superior cerebellar peduncle (XSep) preparatory to its entrance into the red nucleus. The section selected discloses this decussation at its maximum and affords another illustration of the relatively poor development of the cerebello-rubro-spinal connections, which implies a low degree of organiza- 
tion in corselinative control. This section also shows the caudal extremity of a large mass of grat matter situated rentral to the mosial fillet (Mf). namely, the substantia nigra $(S / n)$. This mass, as in lemur, assumes

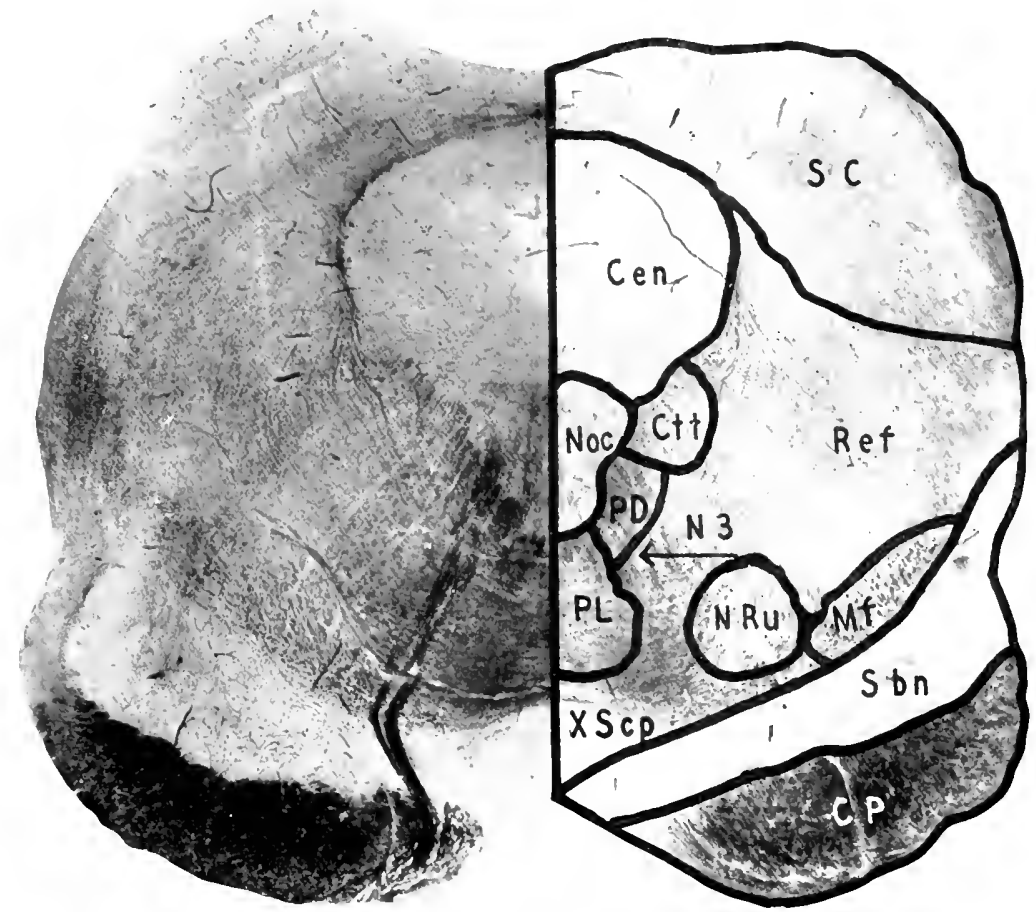

FIG. 8-. MARMOSET. LEVEL OF THE SUPERIOR CEREBELLAR PEDUNCLLAR DECLSSATION.

Cev, Central Gray Matter; (P, Cerebral Peduncle; rtt, Central Tegmental Tract; Mf, Nesial Fillet; noc, Oculomotor Nucleus; NRt, Nucleus Ruber; 13, Oculomotor Nerre; pD. Predorsal Bundle; Pl, Posterior

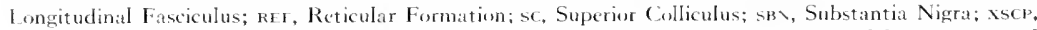
Decussation of the Superior Cerebellar Peduncle. [Accession No. 1 fo. Section 162. Actual Size $1 x^{-}-\mathrm{mm}$.]

large proportions. If the substantia nigra is concerned with the control of certain automatic associated movements, as has been presumed by many 
authorities, then it is fair to believe that the marmoset is pessessed of a high deurec of automatic associative control. Such a presumption would aceord well with its recognized inferiority in the development of wolitional control of movement. The animal, being poorly provided with such entrol, would of necessity require a considerable degree of automat ic and associatire regulation to carry on the performances essential to its natural motor adjustments. The probability of this supposition is further attested by the large size of the basal ganglia in the forebrain. These structures, comprising the grobus pallidus and candate muclei, are usmally regarded as part of the mechanism essential to the control of automatic associated moxements. The pramidal nerve fibers are uow collected in a compact bundle alcompanied by other axons representing the pallio-ponto-cerebellar system. A large mass of decussating fibers dorsal to the central gray matter constitutes the commissure of the superior colliculi. The central gray matter ( Cen), much enlarged in size, surrounds the small aqueduct of Sylvius. Ventromesially it contains the nucleus oculomotorius (Noc). A superficial layer of gray matter forms the stratum griseum superficiale of the superior colliculus, while lateral to this the brachium conjunctivum posticum is extending forward to the mesial geniculate body.

\section{LEVEL OF TIIE SUPERIOR COLLICLLL'S (FIG. 88)}

At the level of the superior colliculus the most distinguishing feature is the appearance of the tectal plate of the midbrain whose surface relief has previously been referred to as particularly prominent. The superior colliculus itself presents a defunite degree of stratification reminiscent of the optic Iobes in the birds, reptiles, amphibia and fish. The most superlicial layer consists of the stratum griseum superficiale. This part of the brain still retains some of its original dominanee in visual function. While it is true that much or most of the higher visual syntheses have their representation 
in the cerebral cortex of the occipital lobe, it is probably true also that the superior colliculus maintains its primordial arrangement in the interest of certain primitive and immediate rellex reactions in response to visual stimuli.

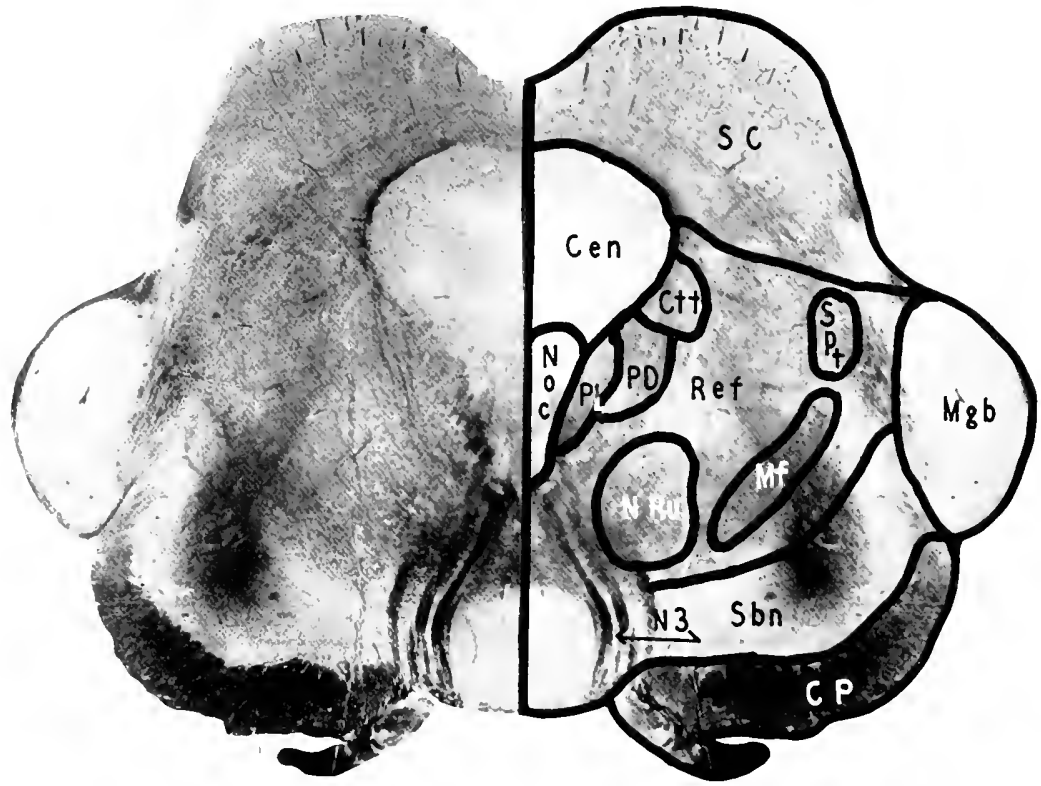

FIG. 88. MARMOSET. LEVEL OF THE SLPERIOR COLLICLLLS.

CEv, Central Graty Matter; (P, Cerebral Peduncle; CтT, Central Tegmental Tract; MF, Mesial Fillet; MGP, Ilesial Geniculate Body; Voc, Oculomoter Nucleus; NRu, Nucleus Ruber; N3. Oculomotor Nerve; PD, Predorsal Bundle; PL, Posterior Longitudinal Fasciculus; REF, Reticular Formation; SBN, Substantia Nigra; sc, Superior Colliculus; SPT, Spinothalamic. Tract. [Accession No. $14^{6}$. Section 167 . Actual Size $10 \times 6 \mathrm{~mm}$.]

In this particular, the case is similar to that of the inferior colliculus which has apparently retained much of its primordial auditory function. The necessity for quick, decisive motor responses as a reaction to visual stimuli on the part of the narmoset must be obvious. Most of the an imal's reactions to visual stimulation result in very rapid movements of the head, eyes, neck and limbs. 
These movements have much of the quality of immediate rellex responses. They resemble but little the motor reactions characterized by any marked degree of deliberate refleetion in selecting alternative courses of action which may arise in connection with any giren situation. For this reason apparently the superior colliculus retains much of its primitive conspicuity as well as much of its original structural organization. The evidenee atlorded by marmoset indicates that vision has attained only partial telencephalization in this form.

Also of importance is the appearance of the large substantia nigra (Sbn) which again points to the possibility of the animal's large endowment in automatic associative control of movement. In the most ventral portion of the basis are the fibers constituting the cerebral peduncle (CP). A lateral protrusion in juxtaposition to the substantia nigra is the mesial eneniculate body ( $M g b$ ) alcong whose periphery is situated the brachium conjunctirum posticum containing auditory frbers on their way from the inferior colliculus. Dorsal to the mesial fillet $(\mathrm{Mf})$ is a collection of large motor cells, the nucleus ruber (NRu), which gives origin to the rubrospinal tract, the connecting link between the cerebelhum and the final common pathway of the cerebrospinal axis. The central gray matter $(C e n)$ is now greatly increased in size and surrounds a small aquechet of Sylvius. At its ventromesial angle it contains the nucleus oculomotorius ( $\mathrm{Noc}$ ) which gives rise to the third cranial nerve supplying all the muscles of the eyeball with the exception of the external rectus and the superior oblique. An important feature of this nucleus is the fact that it is very poorly supplied with internuclear or commissural fibers. The two nuclei maintain a certain degree of indepenclence. This perhaps is no more marked than in lemur, but it is distinctly more pronounced than in the higher apes and man. It is probable that marmoset possesses but a smalldegree of power to converge the visual axes and in consequence has a limited amount of stereoscopic vision. Passing forward from the nucleus of the third nerve are its emergent fibers. 
180

\section{LEYEL OF THE OPTIC CIIASM (FIG, 80)}

At the level of the optic chiasm the identifying feature is the decussation in the optic pathway $(\mathrm{Opt})$. The optic thalamus is also represented. This is

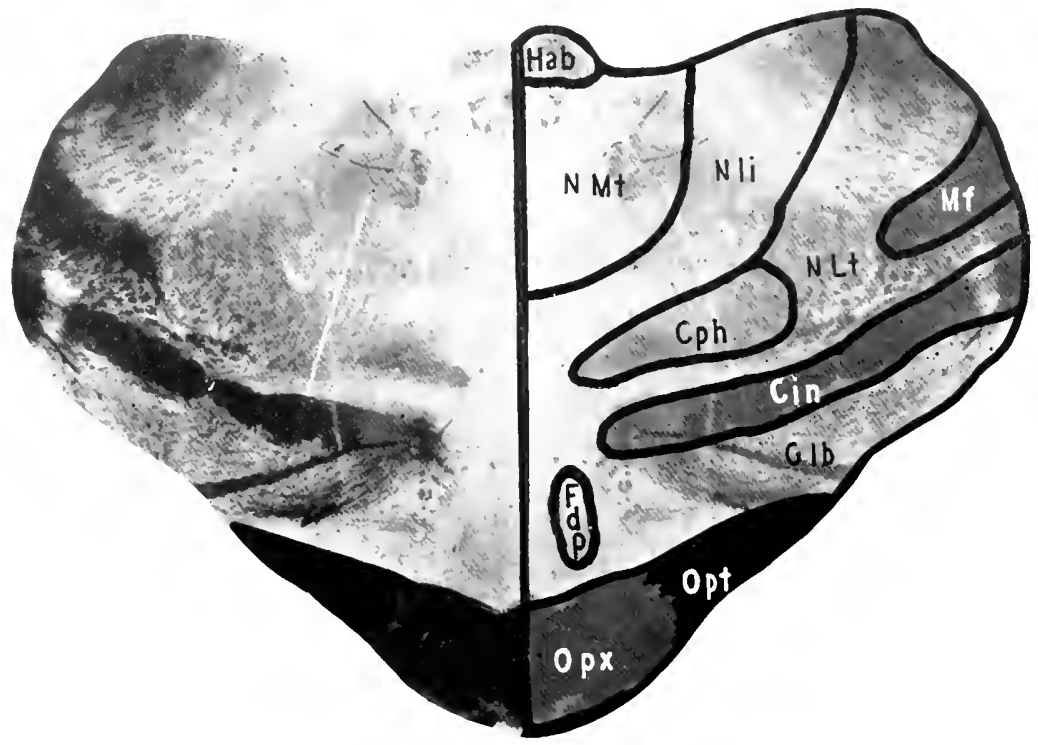

FIG. 89, MARMOSET. LENEL OF THE OPTIC CHIASM.

CaN, Internal Capsule; CPH, Corpus Iypothalamicum; FDP, Descending Pillars of the Fornix; GLb, Globus Pallidus; нab, Nucleus Ilabenulae; ur, Mesial Fillet; Nur, Mledial Nucleus of the Thal:amus; NL, Internal Lateral Nucleus of the Thalamus; Nit, External lateral Nucleus of the Thalamus; opr, Optic Tract; opx, Optic Chia am. [Accession No. 1 fo. Section 210. Actual Size in $\times$ I 2 mm.]

an important structure inasmuch as it represents the last great relay station for the conduction of all types of sensibility with the exception of the olfactory sense. Situated ventral to the main nuclei of the optic thalamus is a diffuse collection of fibers and gray matter, the corpus hypothalamicum 
$(\mathrm{Cph})$. The nucleus which forms the central core of this body is surrounded by two fields of white matter constituting field $\mathrm{H}_{\mathrm{I}}$ and ficld $\mathrm{H}_{2}$ of Forel. Lateral to the optic thalamus and the nucleus hypothalamicus is a dense

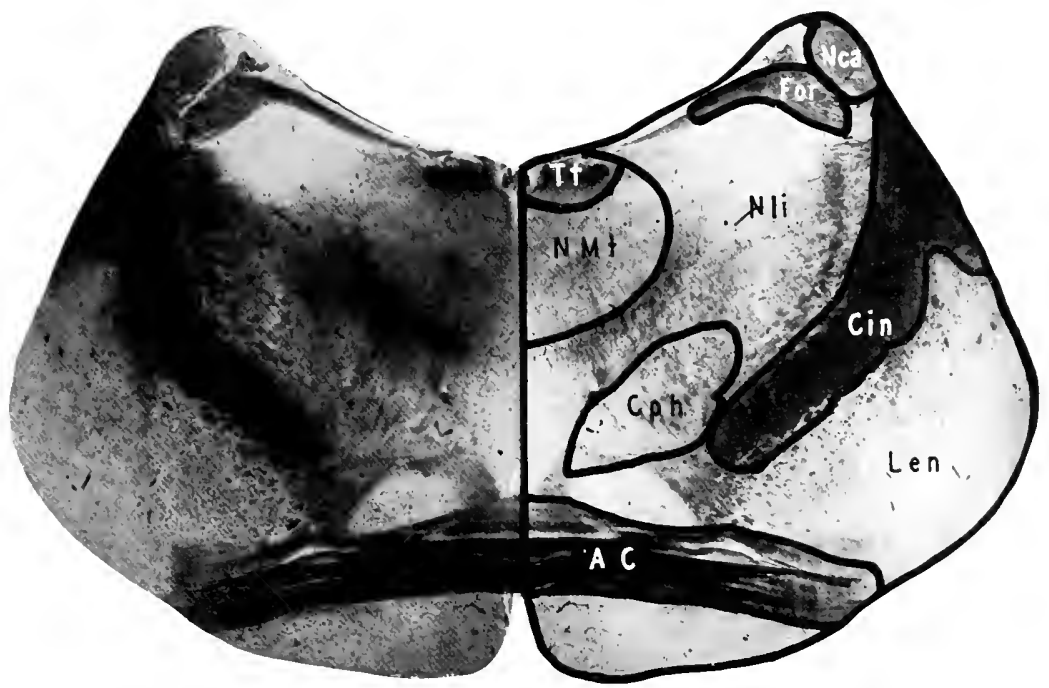

FIG. 9O. MARMOSET. LEVEL OF THE ANTERIOR COMMISSURE.

AC, Anterior Commissure; ciN, Internal Capsule; $\mathrm{CPH}$, Corpus Hypothalamicum; For, Fornix: LEN, Lenticular Nucleus; NCA, Caudate Nucleus; nмт, Medial Nucleus of the Thalamus; NLI, Internal Lateral Nucleus of the Thalamus; tт, Tacnia Thalami. [Accession No. 146. Section 241. Actual Size $15 \times 6 \mathrm{~mm}$.]

band of medullary substance comprising a portion of the internal capsule (Cin); while ventral to this massive bundle of myelinized axons is a large nuclear mass, the globus pallidus (Glb). This structure takes its importance from the fact that it is one of the main basal ganglia regulating automatic associated movements. Immediately mesial to the globus pallidus is a bundle of faintly staining fibers, the descending pillars of the fornix ( $\mathrm{Fd} p$ ). 


\section{LEIEL (H: THE ANIERIOR COMMISSLRE (IAG. (H)}

At the level of the anterior commissure ( $\mathrm{AC}$ ) is illustrated the anterior evtremity of the optic thatamus and a portion of the tuberculum anticum thatami (N.11t). Lateral to the thatamus is a dense mass of libers representing the internal capsule ( Cin), lateral to which is a portion of the corpus striatum, the kenticular mucleus (Len). 
CinPTER VI

\section{RECONSTRUCTION OF THE GRAY MATTER IN THE BRAIN STEM OF CALLITHRIX JACCHUS}

\section{Dorsal Sexsory Niclet}

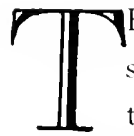
HE nucleus of Goll lirst becomes apparent in the reconstruction as a small sessike projection connected with the dorsal surface of the central gray columm. It rapidly extends dorsally as a narrow prolongation of the central gray column and presents at its extremity a laterally flaring termination. It is situated close to the midline and separated from the dersal median septum by a thin lamina of fibers. At a somewhat higher level a small collection of gray matter appears in the dorsal portion of the reticular formation. This consists of the nucleus of Burdach which, like the sensory nucleus of Goll, rapidly expands as it extends cephalad. Attached laterally to the main nuclcar mass and presenting the characteristic arboreal form seen in the lemur is the external nucleus of Burdach (Blumenau). The effect of the opening of the fourth ventricle is already apparent in the diverent arrangement of the overhanging dorsal masses of the nuclei of Goll and Burdach. As these nuclei take their origin from the central gray column and the reticular formation mesial to the point of confluence between the dorsal gray column of the spinal cord and the central gray column, the former is showly and gradually shifted laterally, and its expanded cap, the substantia gelatinosa Rolandi, under the influence of the opening ventricle, shows a similar lateral inclination. The transition from the Rolandic to the trigeminal gelatinosa occurs without sharp line of demarcation except that the trigeminal gelatinosa is constantly increasing in size as it ascends. In outline this structure presents a serrated surface, the indentations being occupied by the 
deseending trigeminal tract libers. The nuclear mass itself is triangular in form, its apex being mesially direeted, while the base is disposed laterally in contact with the descending trigeminal fibers. The nucleus continues upward in its fixed location so constant as to afford an orienting point for other internal structures of the bulb, to the midpontine level where, after expanding, it rapidly undergoes contraction and disappears.

\section{The InFERior Olitary Niclel's}

Reconstruction of this mass of gray matter resembles very closely the nucleus as described in lemur. The inferior olive forms a flat, double ribbon with its single plication situated ventrolaterally and close to the surface of the brain stem. Its free extremities are directed dorsomesially and turn slightly dorsally at their terminations. There is little indication of the devel(spment of the secondary plications characteristic of this nuclear mass in the higher primates.

The approach of the nucleus to the surface oceasions a slight elevation which corresponds to the relief of the olive so conspicuous in the human brain stem. The chief olivary nucleus, as in the kemur, is poorly developed. The plicated turn of the nucleus appears somewhat thicker and heavier than the two limbs of the nuclear mass formed by the accessory olivary nuclei which stretch dorsomesially toward the median raphe of the oblongata.

The inferior olivary nucleus in the marmoset, as in the lemur, consists mainly of the two accessory melei. The main inferior olivary nucleus is only suggested. The ventral accessory nucleus appears at the upper decussational level of the pyramidal tract as a flattened band directed mesially and slightly dorsally. It ascends, diminishing in width and approaching the midline. The dorsal accessory uucleus is a mass of nuclear material which rapidly flattens out and is embedded in the ventral surface of the reticular formation. It also tends to approach the midline and attenuates as it ascends. 
The main olivary nucleus appears as a small mass of nuclear material between the actual extremities of the accessory olives with which it fuses. It presents no plications.
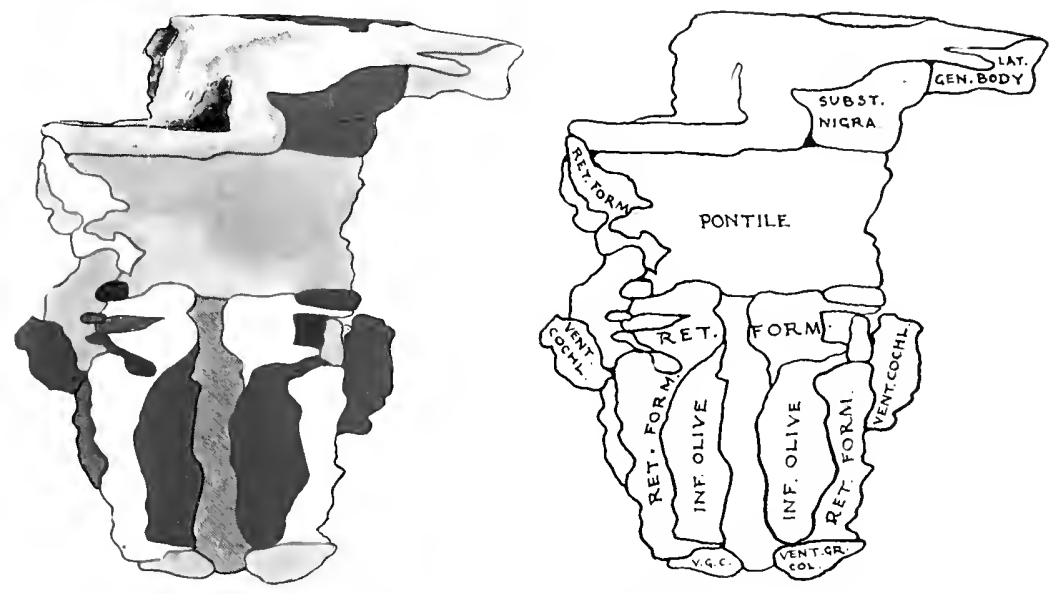

FIG. 91. IENTRAL SURFACE OF THE GRAY MATIER OF THE BRAIN STEM, CALLITHRIX JACCHUS.

Key to Diagram. INF. Olive, Inferior Olive; lat. geN. Body, Lateral Geniculate Body; Poগtile, Puntile Nuclei; Ret. For.s., Reticular Formation; SUbSt. Nigra, Substantia Nigra; vevt, cochl., Ventral Cochlear Nucleus; v. G. C. and VENT. Gr. COL., Ventral Gray Column.

\section{The Reticular Formation}

Reconstruction of the reticular formation reveals in general the same characteristics found in the lemur. It provides a matrix through which numerous fasciculi make their way. It is surrounded, except dorsally, by fiber masses passing upward or downward through the stem. Dorsally it comes into contact and merges with the subependymal gray matter which appears as the continuation of the central gray column. The reticular formation originates as small masses of nuclear material appearing between the decussating bundles of the pyramidal tract, which, as these fibers are 
gradually drawn together into a compact bundle, coalesee to form a recognizable structure.

In the pontile levels, the reticular formation is separated from the deep laver of the pontile nuclei by the trapezoid body. This structure at higher levets forms a part of the lateral boundary of the reticular formation.

The dispesition of the reticular formation in marmoset is similar to that in lemur. It supplies the main gray mass of the brain stem, affording a matrix in which condensations of nuclear material appear as discrete nuclei. The lateral nuclei of the reticular formation and the superior ofivary nuclei are but little better developed than in the lemur. In the region of the midbrain the nucleus ruber appears as a special condensation of the reticular formation, surrounded by its fiber capsule derived from the superior cerebellar peduncle and the striato-rubral tract. In its dorsomesial aspect there are embedded successively the nuclei of the mesial somatic motor cell column, the hypoglossal, the abducens, the trechlear and the oculomotor nuclei. The vestibular nuclei appear, as in the lemur, in the dorsolateral angle of the tegmentum. The nucleus of Deiters first appears as a wedge between the reticular formation and the central gray matter. The ecphalic extremity of the reticular formation comes into rather intimate relation with the substantia nigra but does not fuse with it. Actual fusion takes place between the reticular formation and the zona incerta of the diencephalon and with the caudoventral portion of the central thatamic gray matter.

\section{The Pontile Nuclei}

In reconstruction these nuclear masses appear rather abruptly at the level of the trapezoid body. There is no substantial indication of the areiform nuclei in the oblongata which appear in higher primates as caudal prolongations of the pontile nuclei along the ventral surface of the pramidal tracts. The pontile nuclei appear as bilateral nuclear masses mainly disposed 
mesially and laterally to the descending pallio-pontile and pallio-spinal systems of fibers. These mesial and lateral nuclear masses are connected by relatively light bridges of nuelear material. There is but little evidence
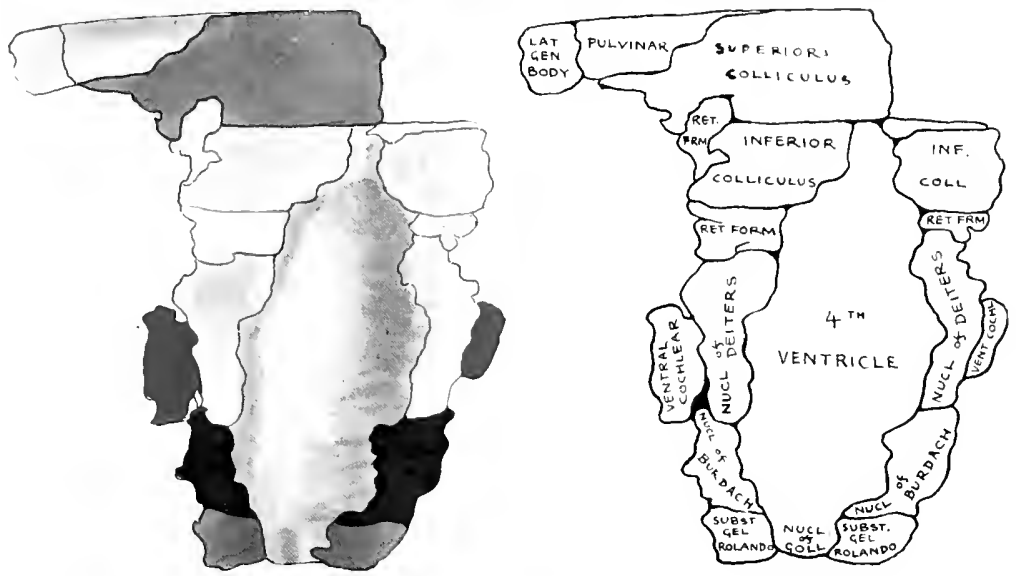

FIG. 92. DORSAL SURFACE OF THE GRAY MATTER OF THE BRAIN STEM, CALLITHRIX JACCHUS.

Key to Diagram. NF. Coll,, Inferior Colliculus; Lat. geN. Body, Lateral Geniculate Body; NCcL. Of Burdach, Nucleus of Burdach; NeCl. OF DEITERs, Nucleus of Deiters; Nect. OF coll. Nucleus of Goll; Ret.

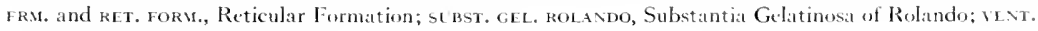
соснц., Ventral Cochlear Nucleus.

pointing toward the development of the invading strips of nuclear material so richly present in the higher forms. Cephalically the pontile nuclei become continuous with the relatively massive substantia nigra chiclly by means of the mesial and lateral condensations of nuelear material already mentioned in the study of the brain stem of Jemur as the lateral and mesial buttresses.

\section{The Vestibular Núclei}

Reconstruction of this mass of nuclear substance discloses a small, wedge-shaped area lying between the nuclei of the columns of Goll and Bur- 
dach, the central gray matter and the reticular formation at the dorsolateral angle of the latter. The large mucleus of Deiters first appears at the lower decussational level of the pyramidal tract and, rapidly expanding, reaches its greatest diameter at the midrentricular level of the brain stem. From this regrom it diminishes as higher levels are approached. As it diminishes in butk the restibular nuclei increase to their maximum and then recede to give place to the cochlear nuclei. At the midventricular level the nucleus of Deiters and the nucleus of Schwalbe both begin to diminish. The vestibular melei are carried upward about the lateral walls of the ventricle by the small meleus of von Bechterew which is so poorly differentiated as to make adequate representation in this model impossible.

\section{The Cochlear Neclei}

As shown in the reconstruction, the cochlear complex consists of both the ventrat cochlear nucleus and the dorsal cochlear nuclens which are situated directly ventral to the subependymal gray matter of the lloor of the lateral recess of the fourth ventricke. The dorsal cochlear nucleus is situated in the lateral ventrieular recess and is more or less oval in outline. It extends for a short distance above and betow the limits of the lateral ventricular recess. It also extends mesially for a short chistance under the ventricular gray matter.

\section{The Substantia Nigra}

The reconstruction of this mass of gray matter resembles the nucleus found in lemur. It appears to be continuous with the deep layer of the pontile nuclei, supported throughout its entire transverse extent by this lamina, while at its extremities it rests upon the lateral and mesial buttresses of the pontile nuclei. Mesially it is connected with its fellow of the opposite side by the undifferentiated ventral interpeduneular gray matter. In its lateral por- 
tion is found the discrete nucleus described in comnection with Iemur, from which nerve fibers pass dorsomesially into the meseneephalic tegmentum. Its cephalic termination is uncertain as it seems to attenuate and disappear
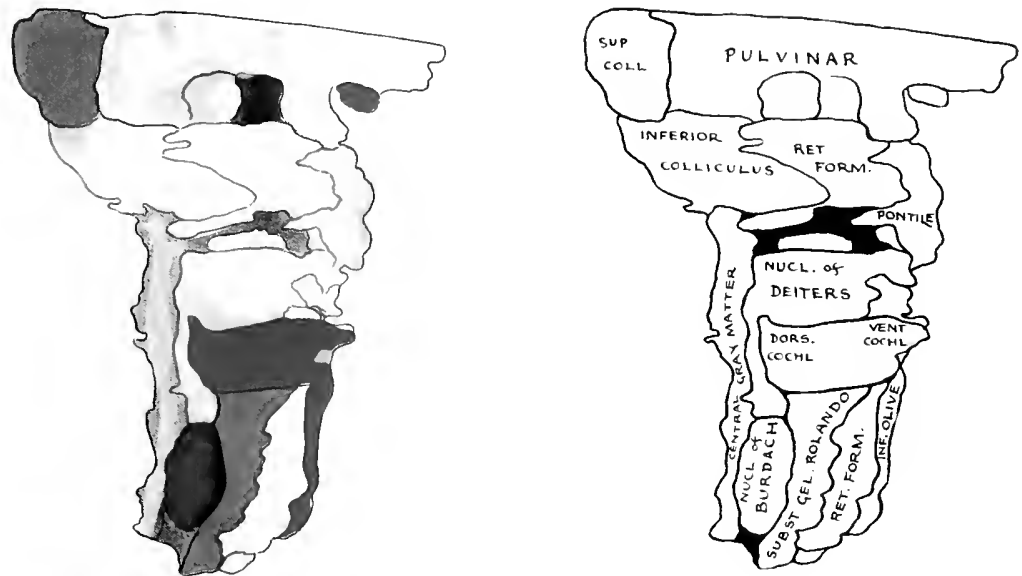

FIG. 93. LATERAL SLRFACE OF THE GRAY MATTER OF THE BRAIN STEM, CALLITHRIX JACCHLS.

Key to Dhagrau. dors. cochl., Dorsal Cexhlear Nucleas; ivf. Olve, Inferior Olive; Nuce. OF burdach, Nucleus of Burdich; Necl. Of Deiters, Nucleus ut Deiters; Povtile, Pontile Nuclei; Ret. Forv., Reticular Formation; Subst. Gel. Rolaxdo, Substantia Gelatinosa of Rolando; sup. Col I., Supertor Colliculus; Vext. Cochi., Ventral Cichlear Nucleus.

with no continuity with the thalamic structures, although it appears to be replaced by the zona incerta of the diencephaton.

\section{The Colliculi}

In the reconstruction, the inferior colliculus arises at the lower mesencephalic level from the reticular formation laterally and the tectal gray matter surrounding the upper extremity of the fourth ventricle mesially. It is separated from the superior cerelellar peduncle by a narrow lateral prolongation from the reticular formation of the mesencephalic tegmentum. Mesially 
it is in contact with the dorsal undiflerentiated gray matter surrounding the ventrick and the Sylvian aqueduct, while its lateral extremity appears to rest upon the lateral and dorsal extensions of the reticular formation. The inferior colliculus is quite massive and presents a marked expansion on the dorsal surface of the meseneephalon. It is separated from the superior colliculus by a narow groove in which the reticular formation underlying the inferior colliculus comes to the surface. The superior colliculus is a massive strueture and presents a well-marked surface clevation on the dorsal aspect of the mesencephalon. It also is continuous mesially with the undifferentiated dorsal gray matter. Laterally it comes inte clese relation with the inferior brachium and rentrally with the dorsal extensions of the reticular formation. Cephalically the superior colliculus does not make contact with the thalamic nuclei, being separated from them by a dorsal extension of the reticular formation.

\section{The Cextral Gray Matter}

In the reconstruction, the sheet of gray matter in the floor of the fourth ventricle seems featureless and is disposed as a that, smooth stratum. The underlying structures produce no marked prominences or depressions in its surface. As the midbrain is approached, the lleor of the ventricle decreases in size, the side walls and roof approach each other and thicken materially so that when the aqueduet of Sylvius is formed, the lateral walls and roof present subependymal gray matter fully as bulky as the gray matter of the floor of the aqueduct. Cephalically the central gray matter is continuous with the gray matter underlying the ependymal lining of the third ventricle, forming the mesial group of the thalamic nuclei. The dorsal gray matter is continuous with the epithalamic structures, the ventral gray matter with the hypencephalic region. 


\section{Chapter Vil}

\section{MYCETES SENICULUS, ITS BRAIN AND BEIHAVIOR}

Its Position among the Primates; Measurements and Brain Indices; Surface Appearance of the Brain; Internal Structure of the Brain Stem in Cross Section

PHE Cebidac are in general much laree than the Hapalidae and
more ape-like in appearanee than the lemurs. The tail, atthough
short in a few instanees, is usually long and definitely prehensile. It is not covered with hair at its extremity and in this part especially manifests its prehensile characters. These animals vary eonsiderably in size; some species are but little larger than the marmoset, while the larger members of the family are only a little smaller than some of the old-wortd monkeys. In general they are about as large as a fox-terrier. The development of the tail attains its highest degree of specialization in the spider monkey (Ateles) and the woolly monkey (Lagothrix). In these Cebidae the tail is so much diflerentiated in its prehensile function as to justify speaking of it as a fifth band. By means of this fifth hand the monkey swings its way along among the branches, procuring many advantacreous positions of the body which enable it to use both fore- and hindlimbs in the manner of hands. It can reach, grasp and even hurl small objects by means of its tail. When not in use, the tail is carried erect over the head. This highly specialized sensory organ adds an important element to the behavioral organization of the animal, some evidence of which must be reflected in the central nervous system.

The howling monkeys constitute an interesting group of the Cebidae. While they are not possessed of a tail so highly diflerentiated as the spider monkeys, this organ none the less has great efficiency in its prehensile 


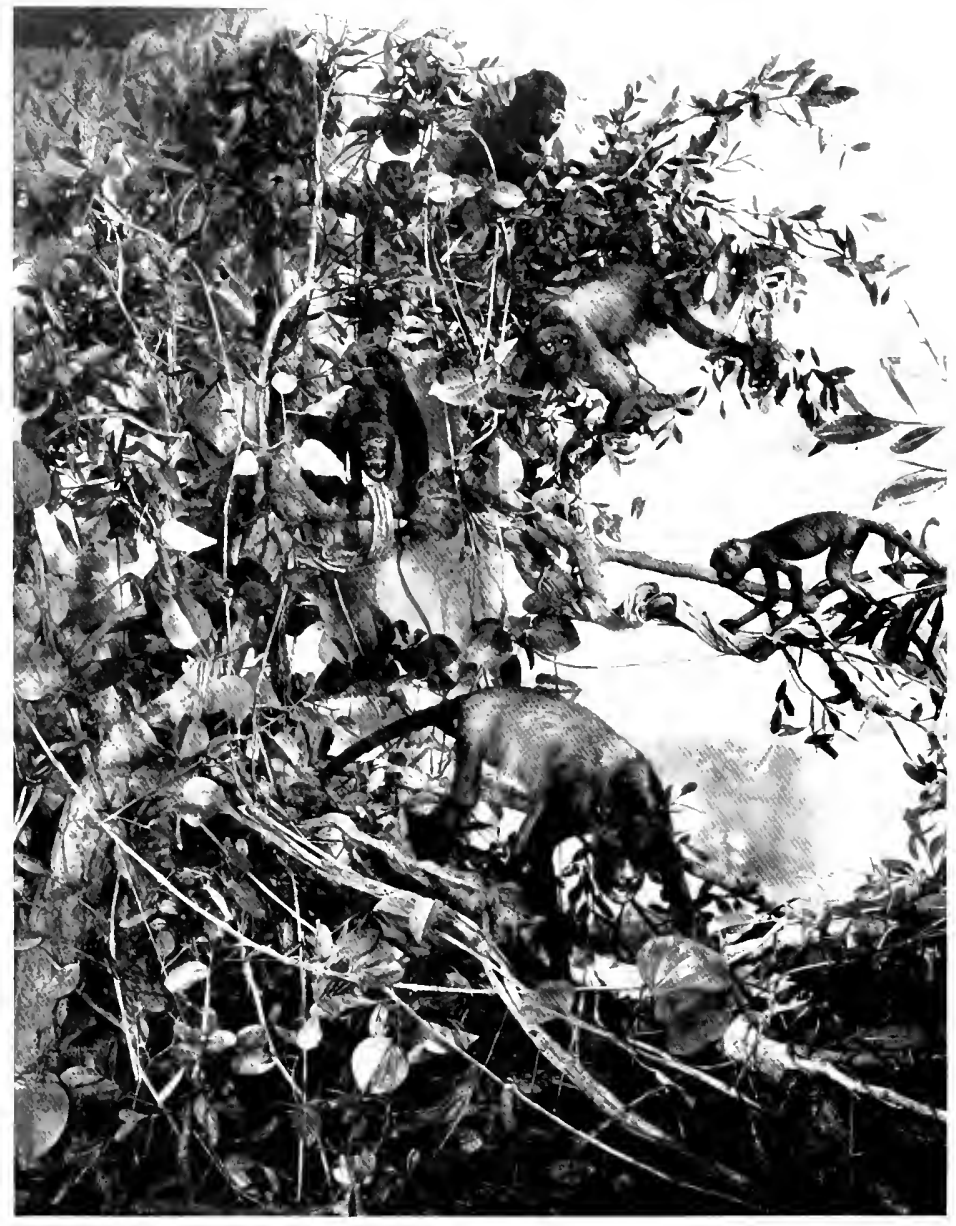

Courtell. Ameriean Museum of Vatural Hotor

FIG. 94. H.ABITAT GROLP OF MYCETES SENICLLLS, THE RED HOWLANG MONKEY OF SOLTH AMERICA. 
capacities. In addition to this specialization, the howling monkers have a sinus-like diverticulum in the larynx larger than that of any of the other American monkeys. The hyoid bone is much enlarged and contains a carern-
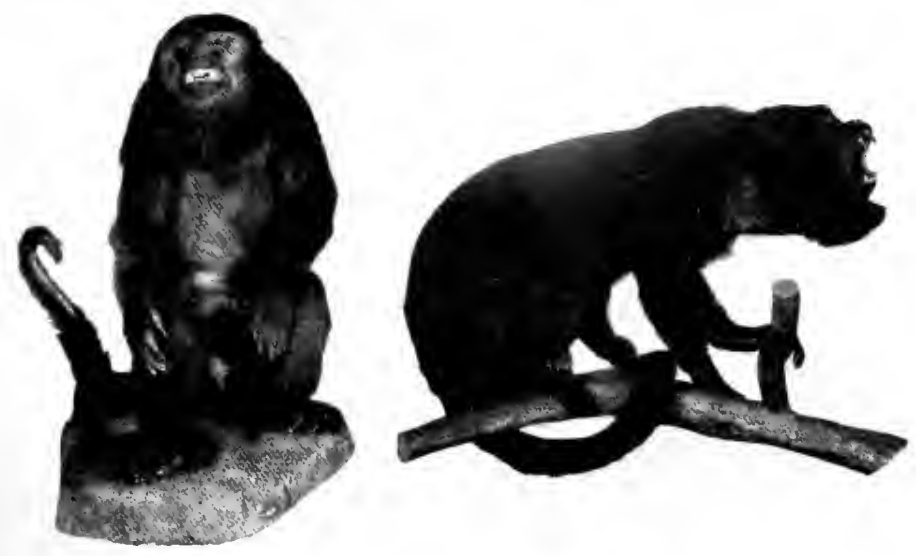

Courtesy; Amencan Museum of Natural Hostory.

FIGS. $9 j$ AND 96 . TWO VIEWS OF MYCETES SENICULUS, THE RED HOWLING MONKEY OF SOUTH AMERICA, SHOWING ITS PREHENSILE TAIL.

ous dilatation, while the mandible, in order to protect the underlying structures, is likewise unusually large and heavy (Fig. 9j).

The howling monkeys also possess an opposable thumb and welldeveloped toes. They are described as being the most ferocious of South American monkeys, at the same time having the lowest degree of intelligence. Their mournful howlings are often audible for miles around. Their cries are supposed to be employed as a means of defense in order to intimidate their enemies. Their vocal powers are so awe-inspiring that the 
natives have associated certain almost supernatural attributes with these animals. For cxample, it is claimed that these monkess are capable of forming a bridere to span a river by means of their tails. But while the prehensile

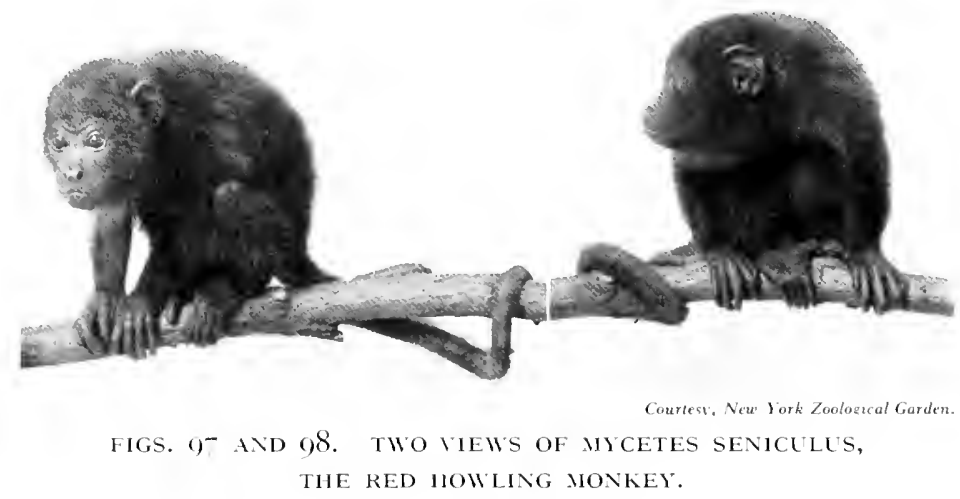

tail makes pussible many feats of locomotion little short of miraculous, it seems clear that these bridge-building propensities are quite legendary. Not only is the thumb of mycetes well dereloped and opposable, but the hand as a whole is highly specialized. The face is naked with the exeeption of a heavy beard which hangs beneath the chin. The movenents of the howting monkey are relatively slow when compared to those of the lemur or even of the spider monkey. The animals appear to be sullen in temper, and are practically untamable, soon dying in captivity. Whether or not their intelligence is of a low order and their adaptability to conditions outside of their natural environment small, it is certain that they are among the least attractive of all the primates in disposition. Their fur is usually black, but in some cases it is brown or reddish-brown. In most species the sexes are alike in color. 


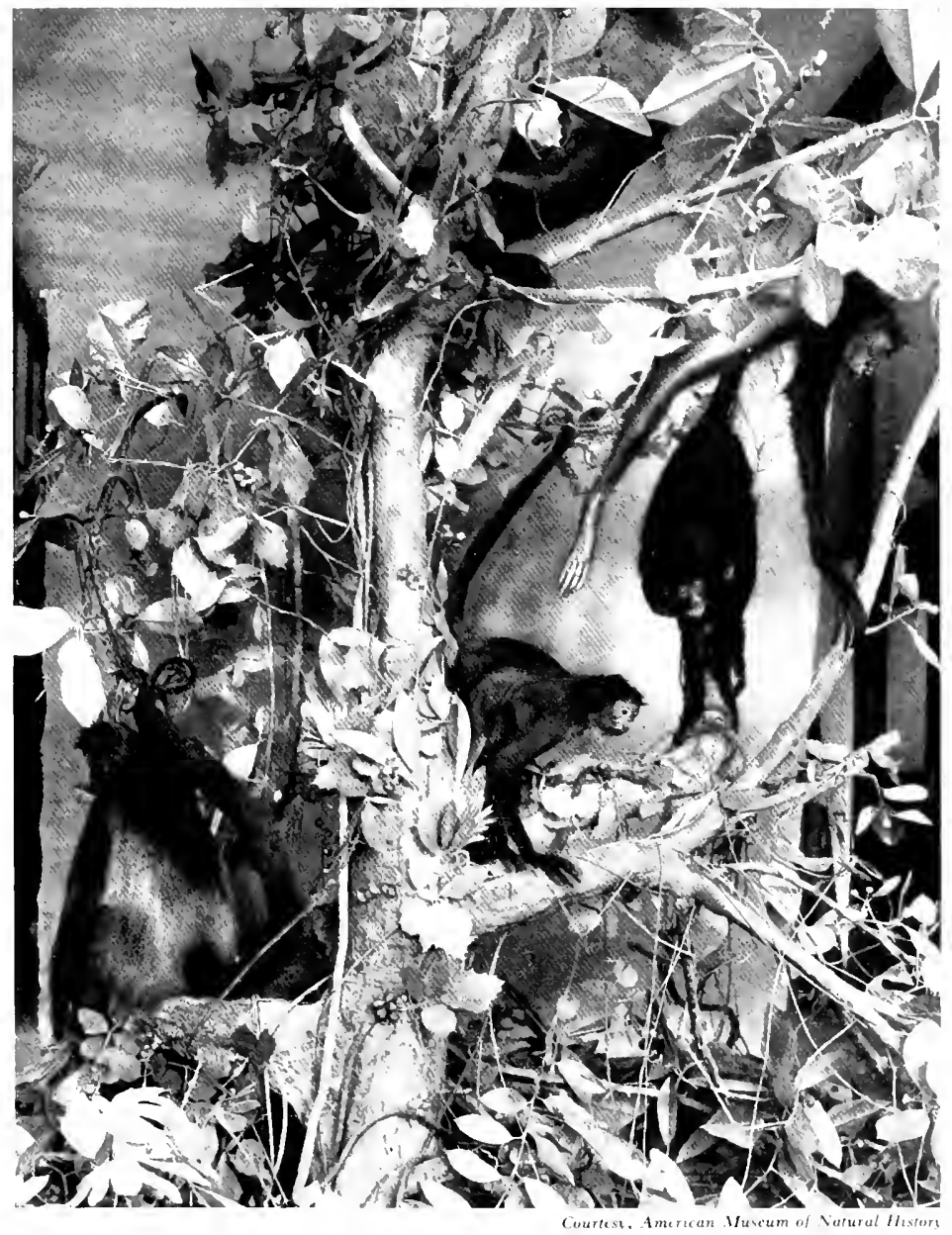

FIG. ()9. HABITAT GROLP OF ATELES ATER, THE SPIDER MONKEY. 
I (1) 6 THE LOWER PRIMATES

The species here described is Mycetes seniculus, also known as Alouatta seniculus, the red howling monkey. The red howler has its habitat in Cartagena and Colombia. It lives in the forests near the Rio Negro but has also

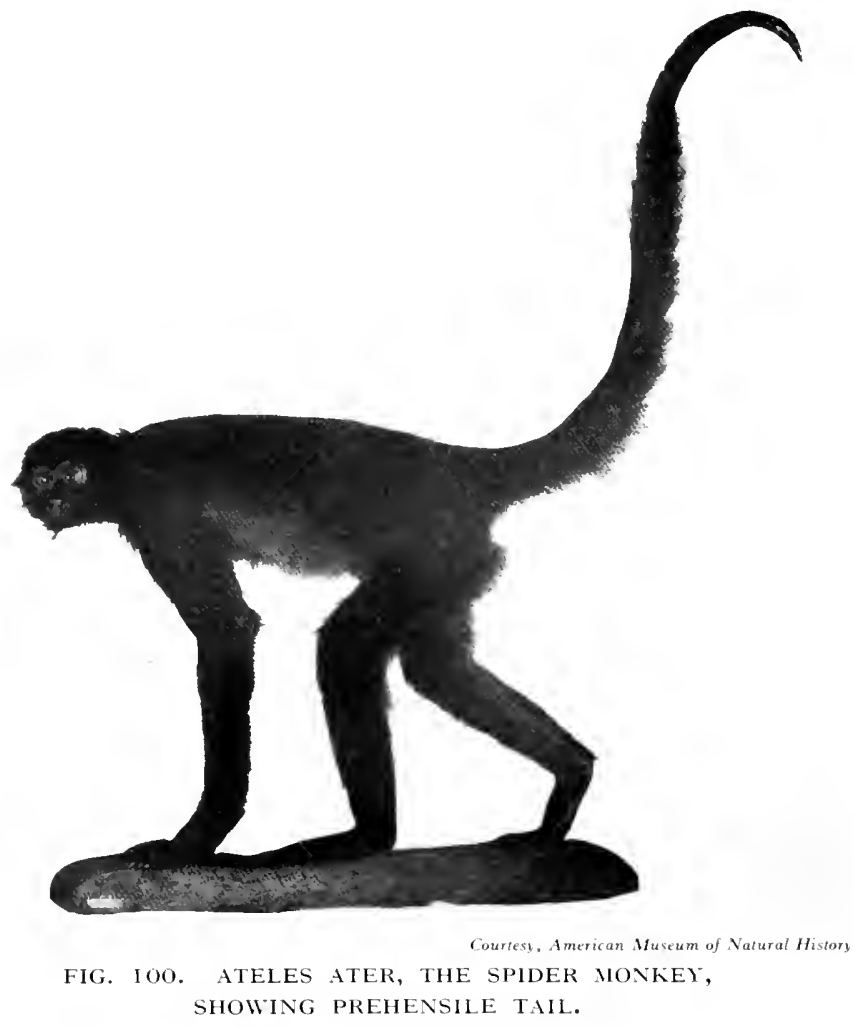

been described in Brazil. The animal's fore- and hindlimbs are about of equal length, that is, between ten and twelve inches long. The length of the body, 
exchusive of the tail, is from eighteen to twenty inches, while the tail is about thirty inches in length. When these howlers are seen in the forests, three or four of them are usually together on the topmost branches of the trees. They live Iargely on fruit, although, like other South American monkess, they are said to feed also on caterpillars and insects.

Geveral Behavioral Texdencies - Thomdités Observatiovs

In comnection with the general behavioral tendencies of Mreetes seniculus, observations made by Professor Edwin L. Thorndy ke, of Columbia University, upon several South American monkeys of the Cebus type speecies not stated) are of particular importanee. They represent the pioneer elfort in the attempt to investigate by accurate psychological method certain aspects of simian behavior. Professor Thorndyke was chielly interested in the manner in which monkeys may vary from other mammals in the general mental functions revealed by their methods of learning, as well as how they may vary from adult civilized human beings. He reognized three different modes by means of which knowledge may be acquired, namely, learning by trial and accidental success, learning by imitation, and learning by ideation. In the latter case the situation calls up some idea which then arouses the act or may in some way modify it. This, in fact, is the method of learning obviously employed in all advances of civilization.

Professor Thorndyke devised certain more or less complicated experiments by means of which he tested the monkeys. These tests consisted chictly of boxes with pegs, bolts, single bars, double bars, hooks, strings and wooden plugs. He arranged the plugs or Ioops in various combinations, the mastery of which was essential to release the animal from confinement or to admit it to a goal containing food. The tests made with such apparatus yiclded negative results and made it clear that monkeys do not Icarn by reasoning. They do, however, form more associations and associations of 
greater variety than other mammals. Their combination of such associations is remarkably stow and ineffective in providing any new behavioral acquisition by this means. Nor were experiments involving the discrimination of

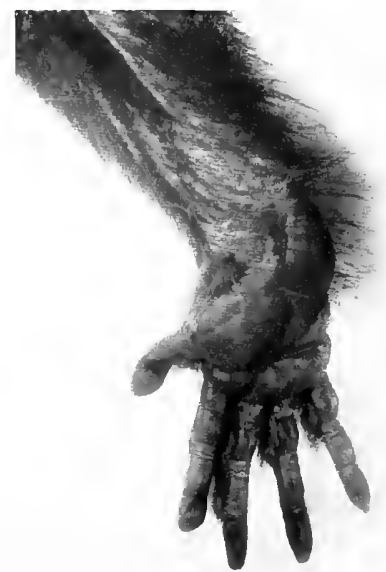

FIGS. IOI AND IO2. HAND AND FOOT OF MYCETES SENICULUS.

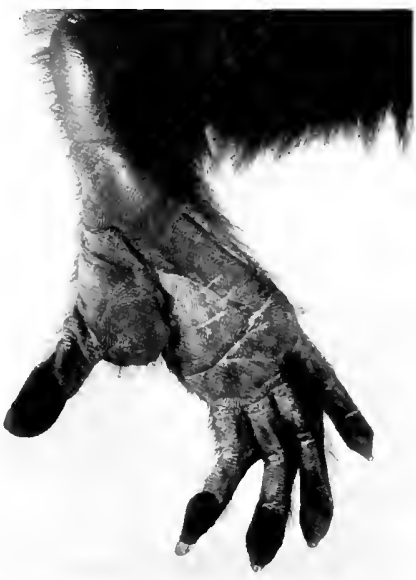

Courlest. Ameruan Museum of Natural History

LEFT. Palmar surface of hand, showing digitation, well-developed balls of fingers and long, opposable thumb. Rıghr. Plantar surface of foot showing fairly well-developed heel and narrow sole, long finger-like toes, with long, prehensile hatlux.

eertain signals designed to set in motion definite lines of action any more productive of evidence. In experiments under the influence of human tuition the problem was - ean the monkey learn and does he commonly learn and do things, not by mere selection of the act from amongst the acts done by him, but by getting some idea and then himself providing the act because it is associated in his mind with that idea? As the result of these tests, the conclusion was a negative one. The records which were carefully made show no signs of any influenee of tuition to which the animal was subjected. The systematic experiments designed to detect the presence of the ability to learn from 
human beings were almost unanimous against this possibility. Theoretically, it is likely that monkeys learn more from watching each other than from watching human beings. Professor Thorndyke's observations in this
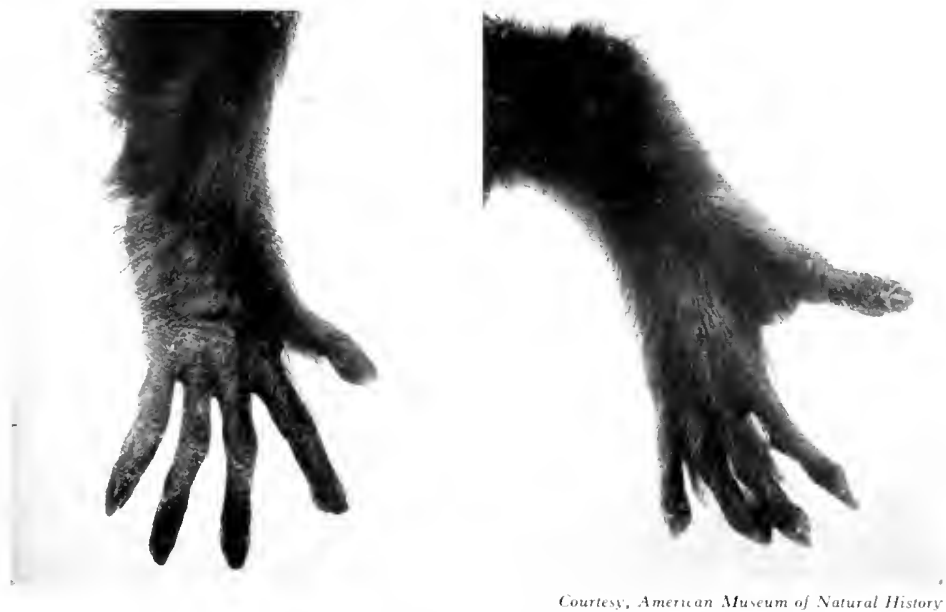

FIGS. 103 AND 1O4. HAND AND FOOT OF MYCETES SENICULUS. LEFT. Dorsum of hand showing well-marked fingers and finger-nails.

Right. Dorsum of foot showing well-developed hallux, long finger-like toes and prominent toe-nails.

connection were somewhat limited. They do not seem to favor the hypothesis that these monkeys have any general ability to learn to do things by seeing them done by others, even of their own kind. This question is still to some extent an open one, requiring much more extensive study than it has yet received.

Concerning the general mental development of monkeys, Thorndyke believes that they represent a certain advance from the generalized mammalian type toward man. This is particularly true of their sensory equipment and their localized vision. Their motor equipment provides for the coor- 
dinated movements of the ere and the hand. In their method of learning, associative processes are quicker in formation of associations and there is a greater number of such associations as well as greater delicacy, complexity

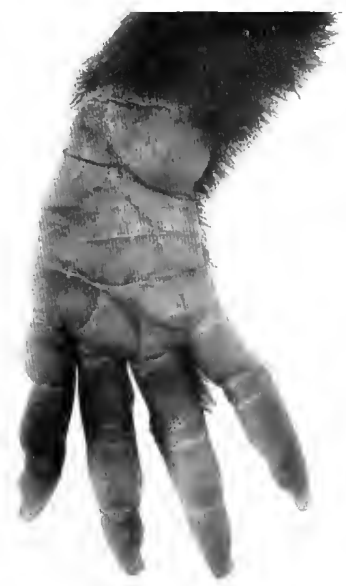

FIGS. $10 ;$ AND IO6. HAND AND FOOT OF SPIDER MONKEY.

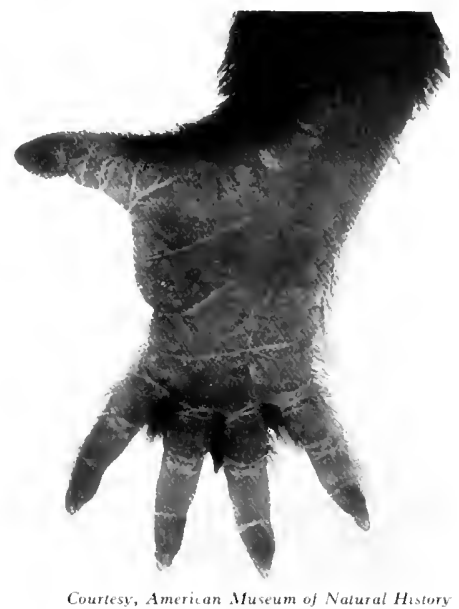

Courtest, American Museum of Nalural History

LeFt. Palmar surface of hand showing well-developed palm, marked digitation with complete absence of the thumb.

Right. Plantar surface of the foot showing long sole, small heel, short opposable hallux and long toes.

and permanency in their representation. Yet, in spite of this increase as compared with lower mammals, these associations fail in their full significance as utilizable behavioral components, probably because they lack close interassociation. Thorndyke feels that there is nothing surprising in the comparative absence of free ideas in these monkeys. The only demonstrable intellectual advance of the monkeys over the mammals in general is the change from a few, narrowly confined, practical associations to a far greater assortment of them. This fact may turn out to be at the bottom of the 
only demonstrable adrance in man. It is in reality an advance due to the brain acting with increased delieacy, bringing in its train the lunctions which distinguish human mental faculty from that of all other animals.

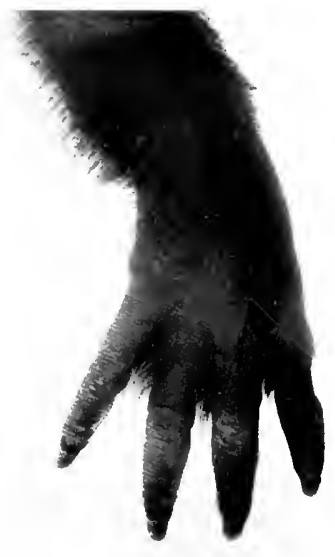

FIGS. IOT AND IOS. 11AND AND FOOT OF SPIDER MONKEY.

LEFT. Dorsum ol hand, showing wetl-developed fingers and finger-nails, absence of the thumb.

Right. Dorsum of the foot showing long metatarsus, Jong toes, opposible hallux, well marked toe-nails.

Brain Measurements and Indices in Micetes Seniculus

Diameters of the skull

Occipito-nasal $-8 \mathrm{~mm}$.

Bitemporal. $+2 \mathrm{~mm}$.

Length of the brain case. ;6 $\mathrm{mm}$.

Brain, including cerebellum and brain stem

Longitudinal $j 2 \mathrm{~mm}$. Transverse. 40 $\mathrm{mm}$. 
Total weight of the brain... . . . . . . . 24.jgms.

Water displacement of the brain............ 24.; c.e.

Height of the forebrain. . . . . . . . . . . 20 20 gms.

Weight of the midbrain. ..... .......... I

Weight of the hindbrain... . . . . . . . . $3.5 \mathrm{gms}$.

On the basis of these figures, the following indices were computed for the several divisions of the brain:

Forebrain inclex 81.6 per cent

Midbrain index. 4. 8 per cent

Hindbrain index 13.6 per cent

These indiees definitely place the animal in the manual group.

Surface Appearance of the Brain in Mrcetes Seniculus THE FISSURAL PATTERN

The surface of the hemispheres of the brain is gyrencephalic with the most marked fissuring in the parictal, temporal and occipital regions. The frontal lobe has but few sulei. The fissure of Sylvius is a prominent landmark upon the lateral surface. Below and parallel to it is the superior temporal fissure, separating an inferior from a superior temporal convolution. Several interupted sulei in the parietal region oceupy the position of the interparictal fissure, while a small sulcus in the usual position of the fissura semilunaris separates the aecipital from the parietal lobe. A short precentral suleus extends horizontally from the sagittal line toward the fissure of Sylvius. The rentral extremity of this lissure falls eonsiderably short of the latter sulcus. While this fissure may be easily discerned as the fissure of Rolando, its perpendicular relation to the great longitudinal fissure is reminiscent of the fissura cruciata of lower mammals. One deep lissure is present in the rostral 

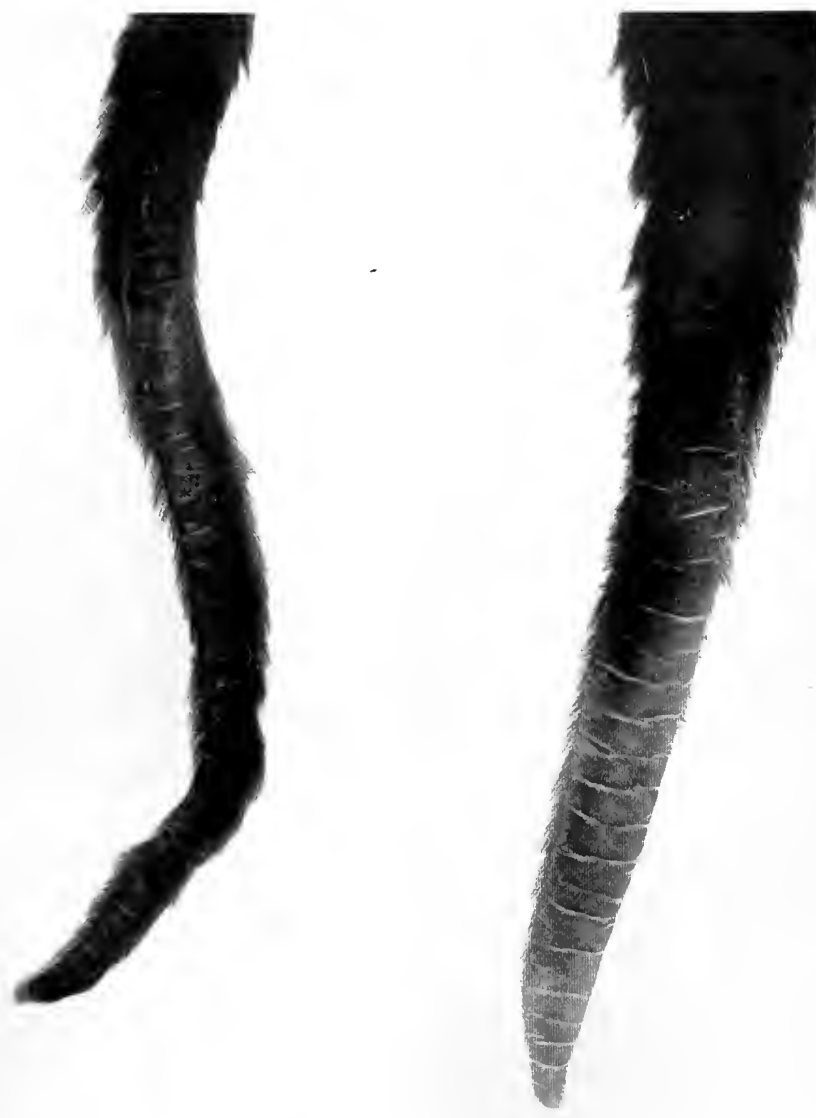

Courtess, American Mfuseum of Vatural Hisiory

MYCETES SENICULUS, HOWLING MONKEY

ATELES ATER, SPIDER MONKEY

FIGS. IO9 AND IIO. DISTAL EXTREMITIES OF PREHENSILE TAILS.

The rugae in the tails indicate the high degree of sensory specialization in consequence of which these monkeys are able to employ the tail as a "ifth hand."

[203] 
extremity of the frontal lobe separating a small inferior frontal convolution from a large superior frontal convolution. Several indefnite, interrupted sulci are seen on the orbital surface of the frontal lobe. Upon the mesial surface
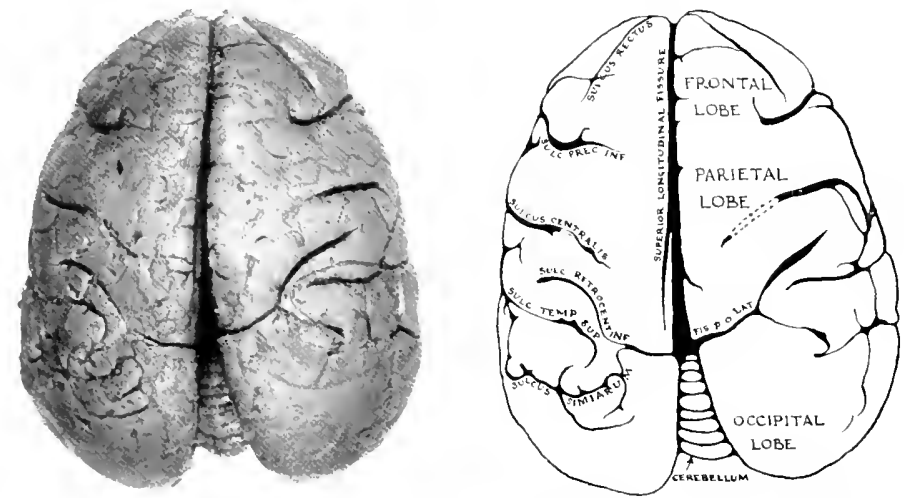

FIG. 11I. DORSAL SLRFACE OF BRAIN, MYCETES SENICLLLS.

[Actuil Length, $+6, \mathrm{~mm}$. .]

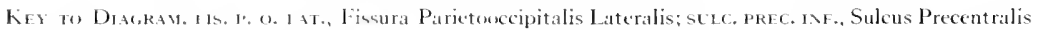

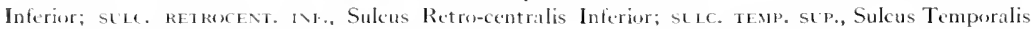
Superior.

the indication of the general line and direction of the marginal sulens is indicated by a series of interrupted fissures. The calcarine and collateral fissures are well defined, as is also the supracallosal fissure. The corpus callosim is larger than in marmoset and lemur. The splenium in particular is somewhat thicker than in the lower forms already considered.

The lateral appearance of the hemisphere in mycetes gives the impression of a marked advance as compared with lemur and marmoset. The brain is clefinitely grencephalic and its fissural patterns are rendered conspicuous by the appearance of the well-marked Sylvian sulcus which is no longer dominated by any suggestion of a ciremsylyan arrangement of convolutions. Although there is no such marked development in the sulcus simiarum 
as appears in the more advanced primates, the inception of th is fissure is seen in the occipital lobe. The central fissure extends from the vertex of the hemisphere downward and forward toward the main Sylvian fissure in the
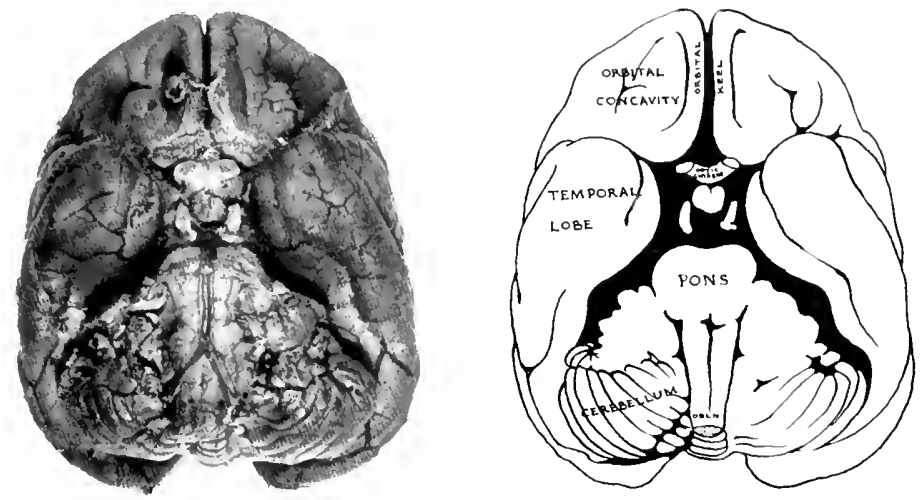

FIG. I12. BASE OF BRAIN, MYCETES SENICLLUS.

[Actual Length, $46 \mathrm{~mm}$.]

Key to Dhagkai. OBLN., Oblongatil.

region between the parietal and frontal areas. Its angulation with the superior longitudinal sinus is something less than $90^{\circ}$. Likewise, the angle of the Sylvian suleus with the base line of the brain is a little less than $45^{\circ}$, showing a general disposition on the part of this fissure to depart from its primitive vertical position and incline itself more toward the horizontal.

\section{LOBATION OF MYCETES' BRAIN}

The lobation in the mycetes' brain is much more distinct than in the primates below it. This is due to the fact that the major sulci are all well defined. A short fissure indicates the position of the precentral sulcus in the frontal area, and deep fissures situated well forward toward the orbital surface indicate the positions of the suleus precentralis inferior and the sulcus 
frontomarginalis. The parietal hobe is well demareated, its caudal boundary being established by the inception of the sulcus simiarum. The occipital lobe as a whole shows considerably more expansion than in the case of lemur or
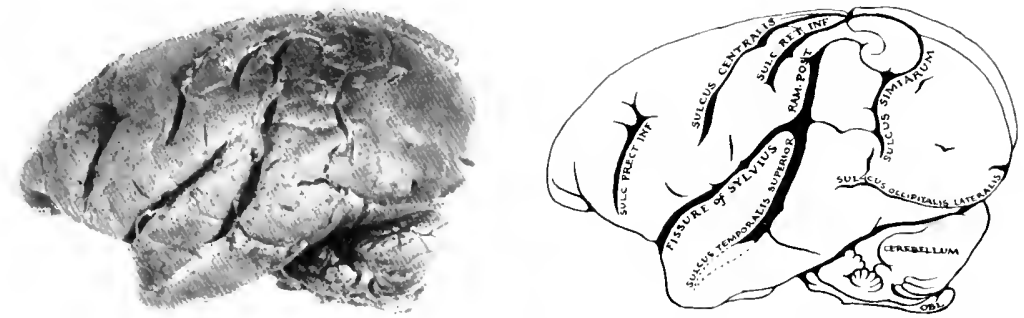

FIG. II3. LEFT LATERAL SURFACE OF BRAIN, MCETES SENICULUS.

[Actual I e.ngth, $52 \mathrm{~mm}$.]

Key to Dlagka.h. obe, Oblongatiz; Ra\}. pest., Ramus Posterior of Superior Temporal Sulcus; sulc. I'RECT. INF., Sulcus Precentralis Inferior; stze. RET. INF., Sulcus Retrocentralis Inferior.

marmoset. The temporal lobe, perhaps more than any other portion of the lateral surface, shows a tendency toward that progressive adrance which eventuates in the fully developed characters of this region in the primate brain.

THE BASAL SLRFACE OF THE HEMISPHERE AND THE OCCIPITAL CONCAVITY

On the basal surface of the hemisphere, the two orbital concavities are well defined, as are also the interorbital keels. The olfactory bulb and tract show a considerable decline in prominence and are detachable as far back as the trigonum olfactorium. The lateral root of the olfactory tract is much less prominent than in cither the marmoset or the lemur, indicating in a general way the tendency toward deflorescence in the development of the olfactory central mechanism.

The occipital concavity is pronounced in mycetes due both to the expansion of the lateral lobes of the cerebellum and the further expansion of the 
occipital lobe of the hemisphere itself. This concavity is deepest in the midline where it appears as the postsplenial fossa for the accommodation of the protuberant superior vermis of the cerebellum.
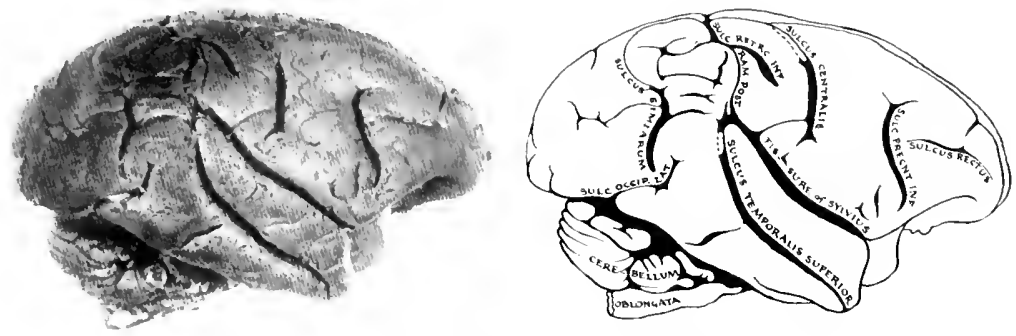

FIG. 11 4. RIGHT LATERAL SURFACE OF BRAIN, MYCETES SENICULUS.

[Actual Length, $52 \mathrm{~mm}$.]

Kiex to Diagram. rair. post., Ramus Posterior of Superior Temporal Sulcus; sulc, occip. Lat., Sulcus Occipitalis Lateralis; sulc. Precnt. INF., Sulcus Precentralis Inferior; sulc. retrc. INF., Sulcus Retrocentralis Inferior.

\section{THE CEREBELLUM}

In the cerebeflum, certain advances are prominent, consecuent primarily upon the pronounced expansion of the lateral lobes. The tentorial surface is entirely overhung by the oceipital lobes. It is gabled from its lateral extremity toward the median ridge-pole formed by the vermis cerebelli. The interfolial sulci pass without interuption from the vermis to the lateral lobes. On the occipital surface the expansion of the hemispheres of the cerebellum is an even more conspicuous feature. The inferior vermis still occupies a prominent position on this surface but its proportions are reduced to about a sixth of the entire expanse of this region. In the lower forms the vermis constitutes a third of this area. Two deep paramedian sulci interrupt the passage of the interfolial fissures from the vermis to the lateral lobes. A feature of much importanee in connection with the petroso-ventricular surface of the cerebellum in mycetes is the extreme development of the floceulus. 
The floceutus in these monkeys, as well as in Ateles and Lagothrix, all species in which the prehensile tail has become highly specialized, reaches a higher point of clevelopment than in any other primates. Whether this prominence
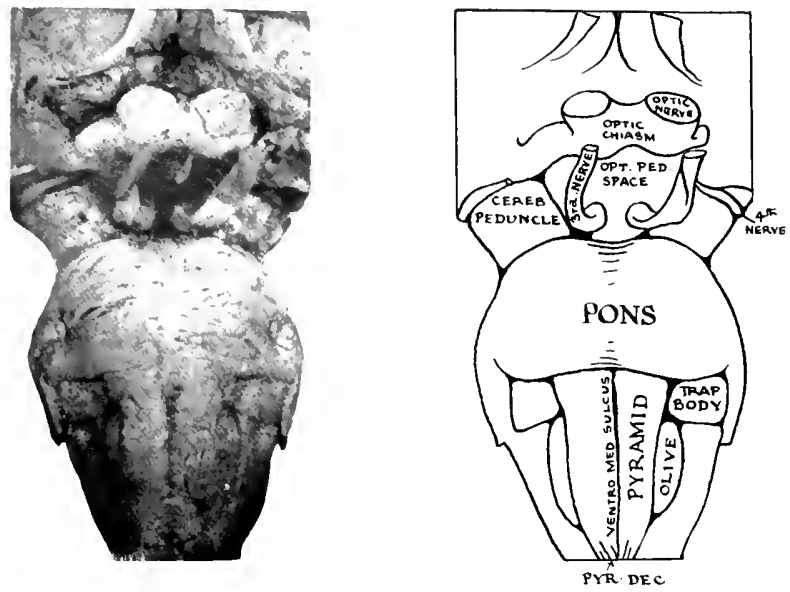

FIG. 11 \% VENTRAL SURFACE OF BRAIN STEM, MHCETES SENICULUS.

[Actual Length, $34 \mathrm{~mm}$.]

Key to Diagran. Cereb. Pedenche, Cerebral Peduncle; opt. Ped. SPacr, Opticopeduncular Space; pre.

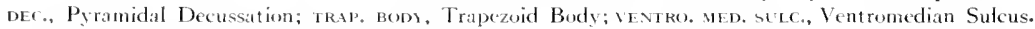

of the floceulus is due, as has been thought to be the ease by several authorities, to the additional responsibilities imposed upon the coordinative mechanism in response to the prehensile tail is a question needing further investigation.

THE BRAIN STEM

The surface markings of the brain stem in mycetes are more pronounced than in lemur or marmoset, atthough in only a few instances do they attain the prominence observed in the higher apes. The oblongata upon its ventral 
surface presents a ventromesial suleus which is interrupted at its caudal extremity by the decussating pramidal hibers. Upon either side of this suleus are two well-defined pyramids indicating an animal having a wider
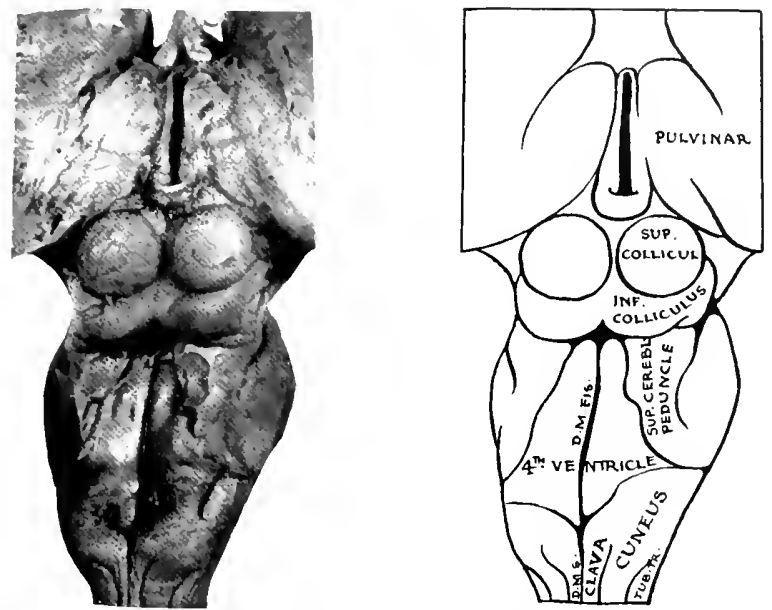

FIG. II6. DORSAL SURFACE OF BRAIN STEM, MYCETES SENICULUS. [Actual Length, $34 \mathrm{~mm}$.]

Key to Diagrais. D. M. Fis., Dorsomedian Fissure; D.M.s., Dorsomedian Sulcus; INF. Colmculus, Inferior Colliculus; sup. Cerebl, peduncle, Superior Cerebellar Peduncle; sep. Collicui., Superior Colliculus; TUB. TR., Tuberculum Trigemini.

range of volitional control than is true of cither lemur or marmoset. Lateral to each pyramid is a small olivary eminence.

The dorsal surface is characterized by the presence of the two enlargements representing the cohumns of Goll and Burdach. While both of these structures are prominent, the column of Goll is slightly larger than the column of Burdach. The increment in the column of Goll rellects the appearance of a highly developed prehensile tail which adds what some authorities 
speak of as a fifth hand to the animal's motor and sensory equipment. Although the prehensile adaptability of the tail in mycetes is hardy to be compared with that of the woolly monkey (Lacothrix) or the spidermonkey (Ateles), the caudal appendage of the howling monkey is an important organ which the animal uses with great deftness and skill. The increment in the column of Burdach is also significant. It reflects a further differentiation of the hand with the eonsequent development of new motor capacities as well as acquisitions in manual dexterity and precision. In proportion as the forelimb has emancipated itself from its limitations as a locomotor organ, it has expanded its potentialities in mastery of the enviromment and has added immeasurably to the upbuilding of new behavioral reactions.

One feature of the brain stem which differentiates mycetes from lemur and marmoset is the size of the cerebellum.

The pons Varolii is also considerably larger than in the lower forms. The inference from the size of the cerebellum in conjunction with that of the pons seems to be that mycetes possesses a fairly wide range of accuired skilled movements and employs the forelimbs for other purposes than those of locomotion.

DORSAL ASPECT OF THE MHDBRAIN

The dorsal aspect of the midbrain presents two well-defined sets of collicular eminences whose prominence suggests the persistence of certain visual and auditory functions primordially vested in the mesencephalon.

\section{Internal Structure of the Brain Stem in Mycetes Seniculus}

The internal structure of the brain stem in mycetes gives the impression that all of the structures thus far recognized as criteria in estimating bchavioral reactions stand out with a clearness of definition not observed in either the marmoset or the lemur. 
IEIEL OF THE PIRAMIDAL DECLSSA110N (1.16, I 1-)

At the level of the pramidal deeussation the drief feature is the eressing of the prramidal bundles and the effect which these crossing libers have upon

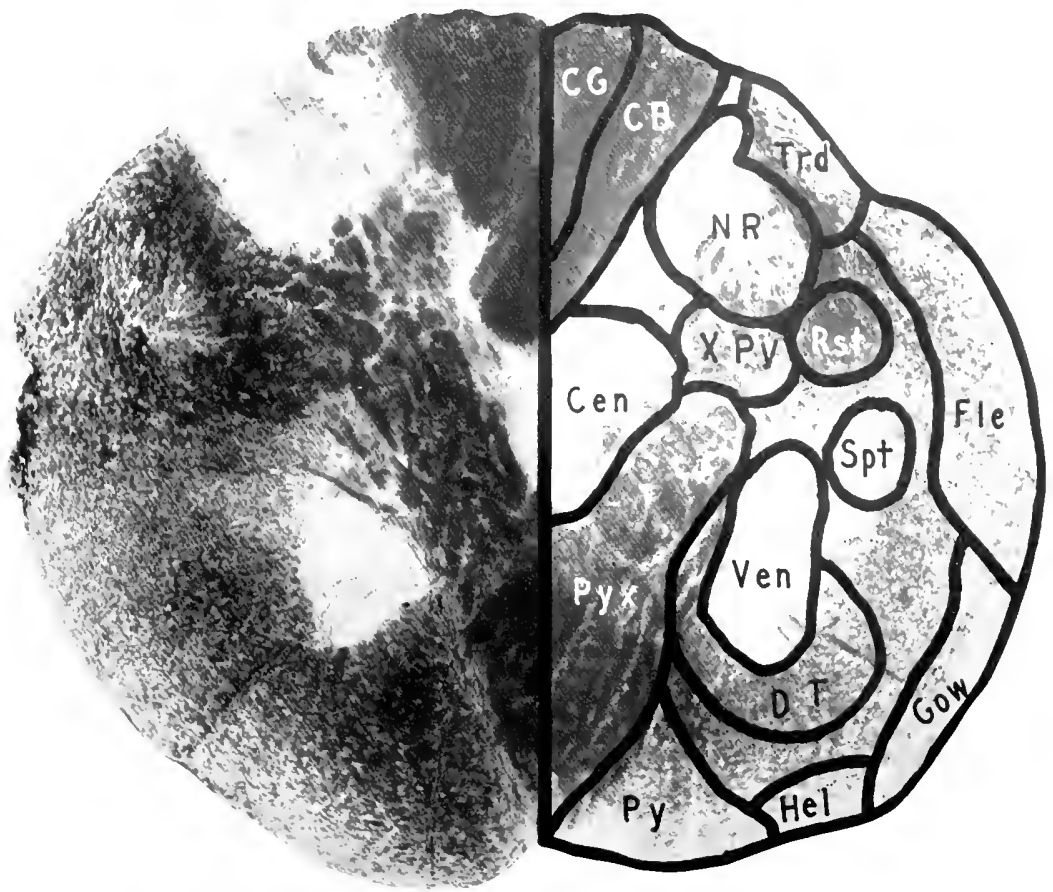

FIG. IJ . MYCETES SENICULUS. LEVEL OF THE PYRAMIDAL DECLSSATION. CB, Column of Burdach; CEN, Central Gray Matter; CG, Column of Goll; DT, Dcitcrso-spinal Tract; Fle, Dorsal Spinocerebellar Tract; Gow, Ventral Spinocercbellar Tract; fel, Spino-olivary Tract of Helweg; NR, Nucleus of Rolando; Pr, Pyramid; Prx, Pyramidal Decussation; Rst, Rubrospinal Tract; spt, Spinothalamic Tract; tRD, Descending Trigeminal Tract; ven, Ventral Gray Column; xpy, Crossed Pyramidal Tract. [Accession No. 1.8. Section 15. Actual size $8 \times 7 \mathrm{~mm}$.]

the arrangement of the gray matter. The decussation is shown at Pyx. Its final accomplishment and the formation of a crossed pyramidal tract about 
to pass into the spinal eord is indicated at XPy, while the as ret uncrossed pertion of the pramid is shown at Pr. Compared with the lower forms, both the pramid and the bundles constituting its decussation are larger in relation to the rest of the cross section. This increase in size of the pyramidal system is significant of aceessions to volitional control over the muscles, more particularly the muscles of the upper extremities.

The importance of this accession is noteworthy sinee this animal, when compared with these already discussed, has developed a highly specialized hand. Eren in this particular, howerer, it has some of the defects chatacteristic of the higher anthropoid apes, especially in the relative shortness of the thumb when compared with the other digits. Nerertheless, because the thumb is opposable, it gives a definitely new capacity to the upper extremity as a grasping organ and thus induces a train of comsequences with far-reaching influences. The hand now becomes an instrument for analyzing elements in the enviromment. It assumes new activities in grasping and manipulating objects, and finally in submitting them to closer visual serutiny. The manual development, because it adds to the equipment of these animals by providing a more eflicient means for exploring their surroundings, inaugurates the processes neessary to the eventual psychological differentiation between what is intrinsically part of the animal and what is definitely external to it. Thus an important step in constructing the psychic elements which distinguish between self and extra-self is established. The large size of the pyramidal decussation indicates an increment in volitional control especially demanded to meet the new motor possibilities of a well-dereloped hand.

Quite as much does the expansion of a dorsal sensory field denote functional increments in the sphere of sensibility in conseguence of manual and caudal development. The additions in the eohumn of Goll (CG) represent sensory expansions mainly due to the prehensile tail which, if it has not attained in myeetes the degree of functional differentiation waranting the 
designation of a fifth hand, as in Ateles, none the less has become an organ possessed of delicate sensory discrimination. It is probable that the acquisition of such a prehensile tail is chiefly accountable for expansion in the column of Goll since no further provecative specialization has oceurred in the hind $\operatorname{leg}$ or foot.

One particular development in comnection with the nucleus of Goll is the median unpaired nucleus of Bischoff which is situated at the caudal extremity of the dorsal sensory muclei in justaposition to the dorsal median septum. This nuckeus was first described by Bischotl in 1800 . It develops according to Zechandelaar in animals possessed of tails used prehensilety, as in the spider monkeys, or as supporting organs in the kangaroos, or as in the Cetacea acting as propelling organs. Its presence in mycetes indicates the high degree of development of the prehensile tail in this animal.

Even more striking, however, is the expansion of the column of Burdach (CB) at this level, for which but one interpretation seems reasonable, namely, the appearance of a highly differentiated hand. The degree of discriminative sensibility now rested in the cutancous and subcutaneous struetures of this hand provides the ability to estimate the consistency of objects, to detect differences in their size and shape, texture and temperature, moisture and dryness, as well as other physical qualities which may be appreciated by manual contact. To these sensory discriminatiens are added ot hers equally important because they take their significance from the sensery impressions created by new ranges of motion. These new possibilities suggest that there has evolved from the simple and but little differentiated forelimb originally specialized for locomotion, an organ so highly modified that it may almost be considered new. New also are the arenues of contact with life which the hand has created, adding immeasurably to the stream of behavioral reactions of which the animal is capable. 
It is diflicult to estimate all of the far-reaching consequences of this progressive differentiation of the upper extremity. The advent of the hand not only brings into existence an acquisitive exphorer in the environment, but, by releasing the forelimbs from the responsibility of locomotion, it influences profoundly both the posture and the method of locomotion itself. In such a capacity it dictates new tendencies in the selection of habitat. It provides new means of defense and offense and thus may affect the matter of food supply and metabolism. It becomes an instrument of investigation and contrivance, the creator of a wide range of gestures and hence of symbols, and fually through its acency as a means of communication, leads on to the vocal acompaniments which ultimately eventuate in verbal speech. Having such importance in the synthesis of reactions which characterize the complex output of behavioral performances in the highest form, the significance of this dorsal sensory field in the oblongata cannot be overestimated. There may be certain difliculties, perhaps, in maintaining that the progressive differentiation of the hand has been one of the chief factors in the later expansions of consciousness. Fet it must be clear that the animal possessed of such at discriminating orean requires more extensive sensory areas in the brain than the animal not similarly equipped. The increase of these sensory areas which represent the acquisitions of manual diserimination cannot fail to have a widespread influence by amplifying the sensory syntheses which cnter into consciomsness. The growing importance of the hand as a sensery organ is witnessed by another interesting fact. The portion of the dorsal sensory field in mycetes allotted to the transmission of sensory impulses from the head and face is not proportionally large when compared with the areas for receiving impressions from the extremities. Both the substantia gelatinosa and the descending trigeminal tract ( $\mathrm{Trd}$ ) are relatively smaller than in Icmur or mamoset. The apparent reason for this relative decrease in prominence may be sought in the fact that the face and head have lost some of their 
primitive responsibility in the diection of Ineonotion. This function, in part at least, is now delegated to the more effectively organized receptive organ, the hand.

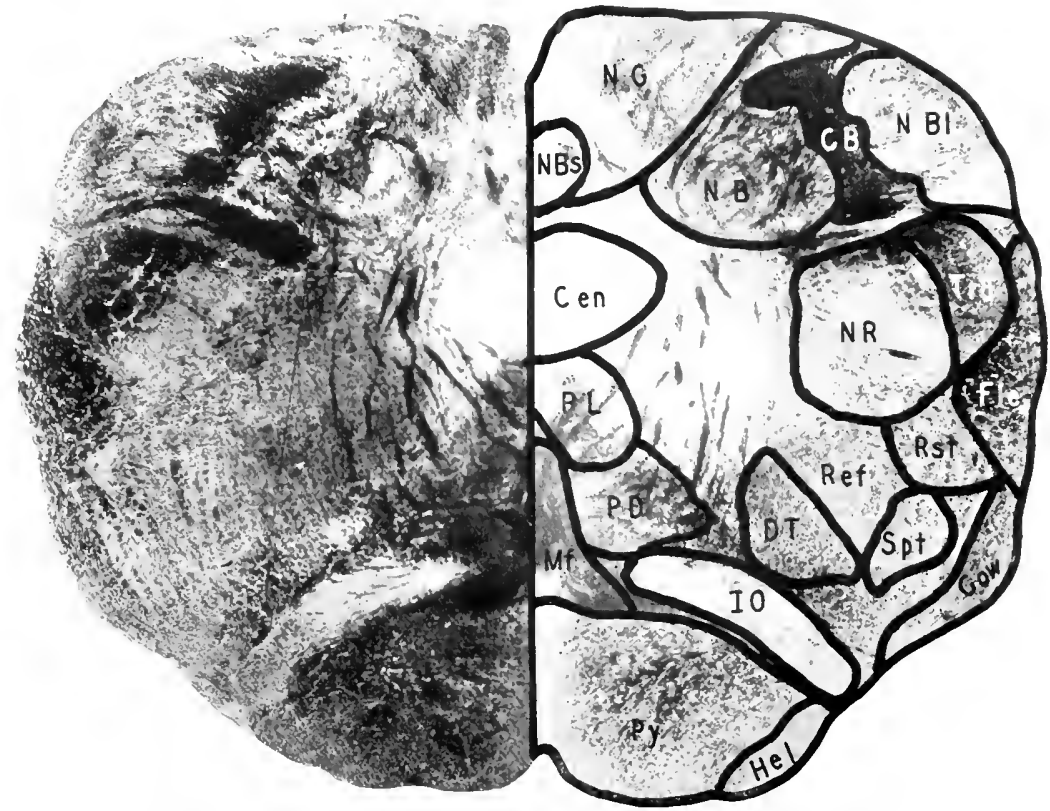

FIG. II 8 . MYCETES SENICULLS. LEVEL OF THE CALDAL EXTREMITY OF THE INFERIOR OLIVE.

$\mathrm{CB}$, Column of Burdach; ( I. ., Central Gray Matter; DT, Deiterso-spinal Tract; FLe, Dursal Spincerebellar Tract; Gow, Ventral Spinocerebellar Tract; nel, Spino-olivary Trat of Ilelweg; Io. Inferior Olive; MF, Mesial Fillet; NB, Nucleus of Burdach; NBs, Nucleus of Bischoff; NBe, Nucleus of Blumenau; NG, Nucleus of Goll; NR, Nucleus of Rolando; PL, Posterior Longitudinal Fascieulus; pD, Predorsal Bundle; pr, Pyramid; REF, Reticular Formation; Rst, Rubrospinal Tract; SPT, Spinothalamic Tract; TRD, Descending Trigeminal Tract. [Accession No. 148 . Section 8 5. Actual Size 1 i $\times 7 \mathrm{~mm}$.]

LEVEl OF THE CAUDAL EXTREMITY OF THE INFERIOR OLIVE (FIG. I I8)

At the level of the caudal extremity of the inferior olive, a clearer impression is obtained of the relative size of the pyramidal system ( Py). There 
is evidently a definite aceession in motor control, particularly in the regulation of the moxements in the upper extremity. The structures in the dorsal sensory fietd have oceasioned a ceneral broadening in the diameters in this region and also show an increase both in fiber richness and extensiveness of the nuclear collections. The nucleus of Goll (NG) appears to be of about the same size as the nucleus of Burdach (NB). The increase in the latter clement indicates the addition of a highly developed hand. A corresponding increase in the mesial fillet ( $M f$ ) indieates increments in the function of discriminative sensibility already made apparent by expansions in the dorsal columms of Goll and Burdach. A feature of much importance is the inferior ohvary body ( 10 ) whose caudal extremity is seen in this section. Here, as elsewhere in the brain stem of mycetes, the olivary bedy fails to show that clearcut delimitation characteristic of these forms in which the structure attains its highest differentiation. Since the inferior olive is functionally active in the coordination of simultaneous movements in head, eyes and forearm, and sinee it facilitates the coordination of all skilled learned performances, it should be more highly specialized in this species than in the lemur or mamoset. Diflerentiation of the olive depends upon the extent to which cooperative morements of the eyes, head and hand are coordinated. Such movements manifest an increase of eflectiveness in proportion as the animal is able, by means of the hand, to bring objects inte closer scrutiny by the eyes. This ocular, cephalic and brachial adjustment is also proportional to the degree of aceuracy with which head and eye movements are capable of following manipulations of the hand.

The substantia gelatinosa of Rolando (NR) and its accompanying desecnding tract of the fifth nerve ( Trd) are prominent features at this level although comparatively smaller than in lemur or marmoset. The signifieance of this apparent decrease in the sensory representation of the head 
and face has already been identified as a concomitant development dependent upon the increase in functional capacity of the hand for directing locomotion.

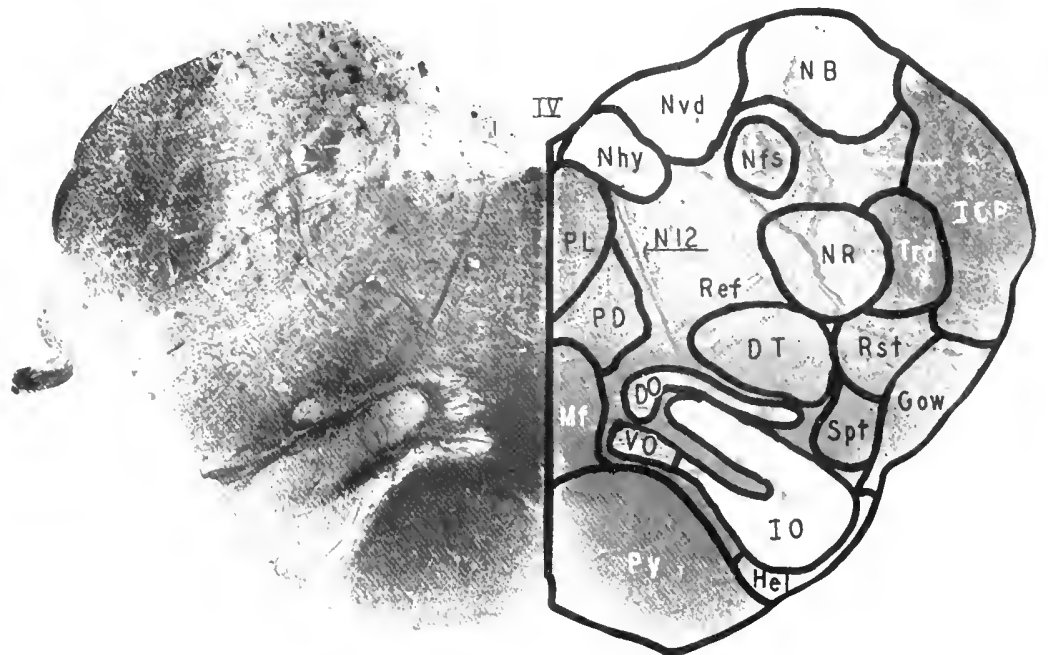

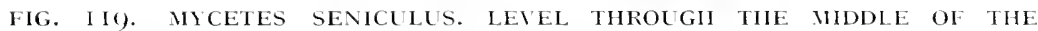
INFERIOR OLIVE.

Do, Dorsal Olive; DT, Deiterso-spinal Tract; Gow, Ventral Spinocerebellar Tract; ne1, Spino-ulivary Traet of Helweg; ICP, Inferior Cerebellar Peduncle; Io, Inferior Olive; s., Mesial Fillet; $\mathbf{n}$, Nucleus of Burditeh; NFS, Facial Nucleus; NHY, Nucleus Ilypoglossus; NR, Nucleus of Rolando; Nvd, Dursal Vagal Nucleus; N 2. Hypoglossal Nerve; Pd, Predorsal Bundle; P’, Posterior Longitudinal Fasciculus; Py, Py ramid; k1.r, Reticular Formation; RST, Rubrospinal Tract; sPT, Spinothalamic Tract; TRD, Descending Trigeminal Tract; vo, Ventral Accessory Olive; rv, Fourth Ventricle. [Accession No. 148. Section 145 . Actual Size $13 \times 6 \mathrm{~mm}$.]

LEIEL THROUGII THE MIDDLE OF THE INFERIOR OLIVE (FIG. I IO)

At the level through the middle of the inferior olive (1O) it is evident that the unfolding which has occurred in the olivary body is considerable. Not only is there an increase in size, but there is also a tendency for this structure to assume the characteristic outline which identifies it in the higher species. It has, however, little of the convoluted appearance so prominent in the larger simians. It is now possible to recognize the main olive and several 
aceessory portions, i.e., the rentral accessory olive ( $\mathrm{VO}$ ) and the dorsal accessor olive (DO). The significance of this increase both in definition and size of the olivary body may be understood in relation to the animal's

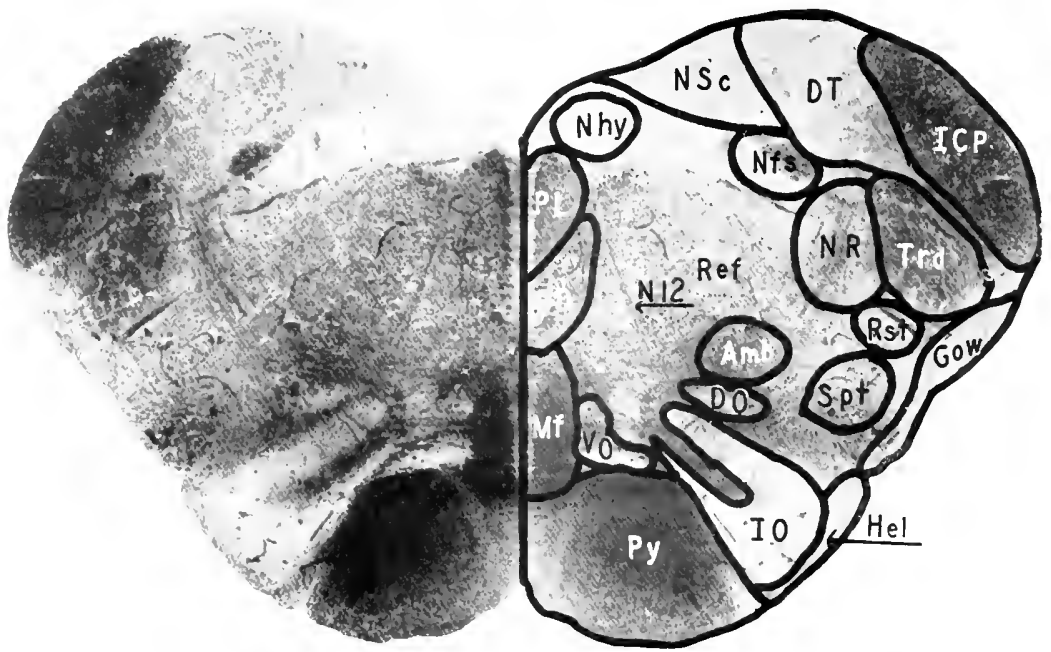

FIG. I20. MYCETES SENICULUS. LEVEL OF THE NUCLEUS AMBIGULS.

Anb, Nucleus Ambiguus; nt, Deiters Nucleus; m, Dorsal Accessory Olive; cow, Dorsal Spinocerebellar

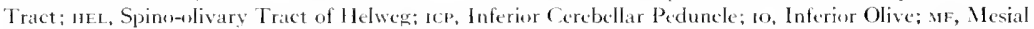
Fillet: VHy, Hypoglossal Nucleus: NFs, Fasciculus Solitarius and Nucleus; Nsc, Nucleus of Schwalbe; Nr, Nucleus of Rolindo; Nr2, llypoglossal Nerve; PL, Posterior Longitudinal Fasciculus; pD, Predorsal Fasciculus; Py, Pyramid; REF, Reticular Formation; RST, Rubrospinal Tract; SFro, Spinotlallamic Tract; Tro, Descending Trigeminal Tract; vo, Ventral Accessury Olive. [Aceession No. 148. Section 155. Actual Size $13<6 \mathrm{~mm}$.]

need of more accurate coordination in the simultaneous movements of eyes, head and hands for the new motor attainments acquired in consecuence of manual development.

LEVEL OF THE NUCLEUS SLPPLYING MOTOR FIBERS TO THE LARYNX (FIG. I 2O)

At this level, a noteworthy specialization appears in the more fixed portion of the brain stem which throughout the primate series, generally speak- 
ing, shows little or no adaptive modifieation. In the case of the howling monkey, however, there is a striking degree of prominence in the development of those nuclei which have control of the laryos and hence resulate vice production. It is perhaps not surprising to find the nucleus ambiguus $(A m b)$ as well as the dorsal vagal nucleus, which are related to motor and sensory control of the larynx, highly developed in these animals. One of the chatacteristic physiological features of mycetes is the terrifying sonnd which they produce by their vocal organs and from which they have earned their distinguishing cognomen, howling monkers.

LEVEL OF TIIE IESTIBCLAR AND CEREBELLAR NLCLEI (IIGS. I 2 I AND I 22)

Here at the level of the restibular and cerebellar nuclei there are indications of the extent to which the balancing and coordinating mechanisms have developed. The vestibular nuclei, comprising the triangular nucleus of Schwalbe (NSc) and the nucleus of Deiters (ND), occupy a position in relation with the tloor of the fourth ventricle; while the cercbellar nuclei, which consist of the nucleus dentatus ( $\mathrm{Ndt}$ ) and the nucleus fastigii ( $\mathrm{Nfg}$ ), are situated in the medullary substance of the vermal portion of the cerebellum. The vestibular nuclei are important receiving centers of the balancing mechanism and this, to a certain extent, is also true of the nucleus fastigii, which is connected with the vestibular mechanism by means of the juxtarestiform body. The dentate nucleus, on the other hand, has quite a different significance, being an index of the degree of efferent conduction provided for the cerebellar impulses. The major outllow from the cerebellum is conveyed by axons which take their origin in the dentate nucleus and constitute the superior cerebellar peduncle. Thus, the nucleus dentatus offers a means of estimating the relative amount of coordinative influence which the cerebellum is capable of contributing to the muscles. 
In regard to this nucleus in mycetes, it is important to note that the structure is not only more extensive in its general dimensions, but also begins to manifest, even if in a somewhat ill-defined manner, that tendency toward

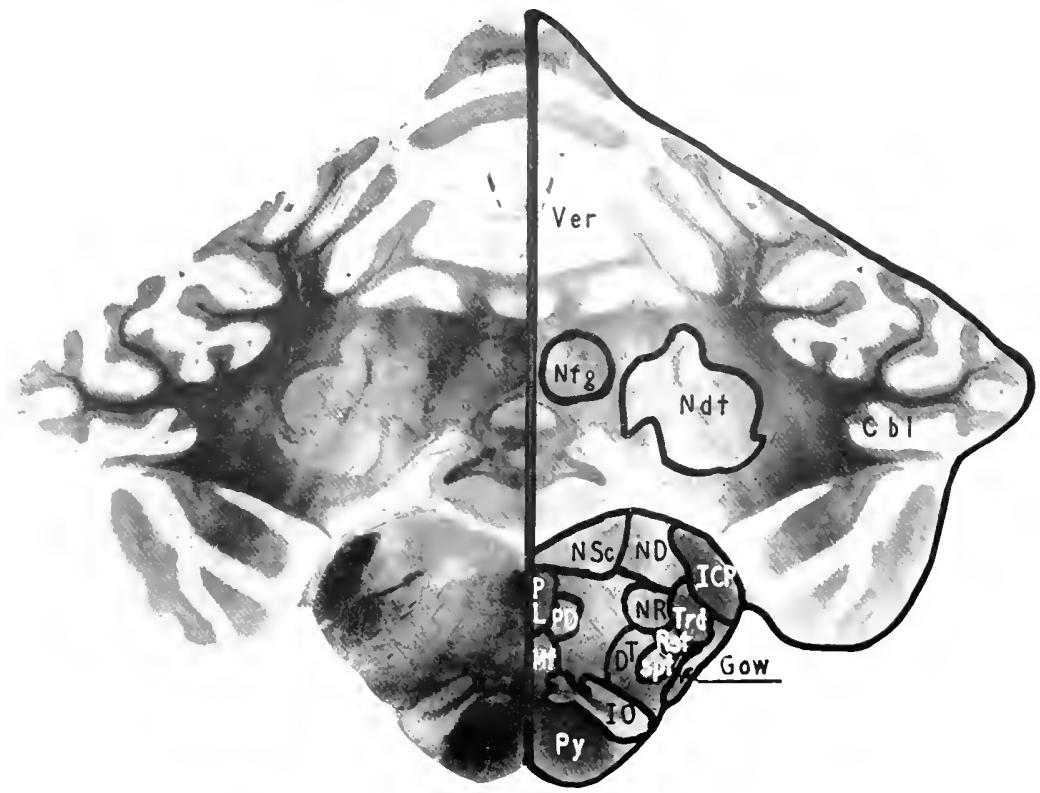

FIG. I 21. MYCETES SENiCULUS. LEVEL OF THE CEREBELLAR NUCLEI.

CBL, Lateral Lobe of Cercbellum; рт, Deitersal Tract; Gow, Ventral Spinocerebellar Tract; ICP, Inferior Cerebellar Peduncle; 10 , Inferior Olive; 11 , Mesial Fillet; ND, Deiters' Nucleus; Not, Dentate Nucleus; Nic, Nucleus Fastigii; Nr, Nucleus of Rolande; sse, Nucleus of Schwalbe; pD, Predorsal Bundle; PL, Posterior Longitudinal Fasciculus; ps, Pyramid; RST, Rubrospinal Tract; SPT, Spinothalamic Tract; TRD, Descending Trigeminal Tract; $1 \mathrm{k}$, Vermis of Cerebel]um. [Accession No. 148. Section i6o. Actual Size $13 \times 9 \mathrm{~mm}$.]

convolution of its surfaces typical of the higher primates. It may be inferred, therefore, that the degree of coordination which the cerebellum furnishes to the somatic muscles is greater in mycetes than in lemur or marmoset. The necessity of such coordination becomes clear in the light of the increased 
complexity in motion resulting from a greater volitional control of the upper extremities. Not alone is this inerement in coordination essential to the newer moxements of the hand, but now there is the further need of coordina-

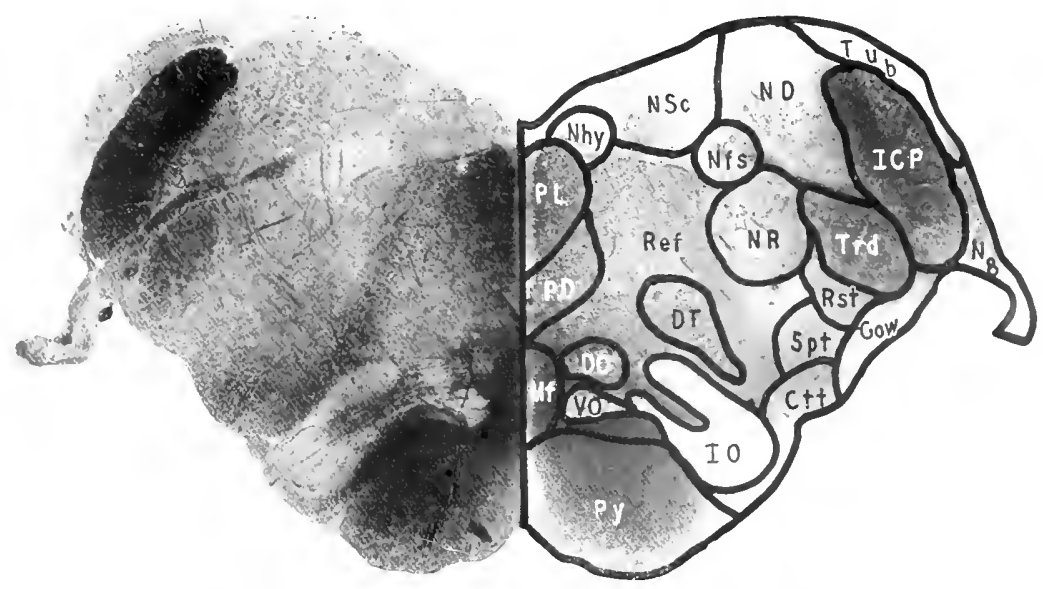

FIG. I22. MCETES SENICULUS. LEVEL OF THE VESTIBLLAR NLCLEI.

CTr, Central Tegmental Tract; DT, Deiterso-spinal Tract; do, Dersal Accessory Olive; gow, Ventral Spinocercbellar Tract; ICP, Inferior Cerebcllar Peduncle; IO, Inferior Olive; Mf, Me sial Fillet; , $D$, Deiters' Nucleus; Nfs, Facial Nucleus; Nsc, Nucleus of Schwalbe; $N 8$, Auditory Nerve; Nr, Nucleus of Rolando; NHY, Nucleus Hypoglossus; PD, Predorsal Bundle; PL, Posterior Longitudinal Fasciculus; Pr, Pyramid; Ref, Reticular Formation; RST, Rubrospinal Tract; SPT, Spinothalamic Tract; TKD. Descending Trigeminal Tract; TLB, Tuberculum Acusticum; vo, Ventral Accessory Olive. [Accession No. 148. Section 16j. Actual Size, $13 \times ; \mathrm{mm}$.]

tion arising from the fact that the animal depends more upon the hindlimbs in Iocomotion than do the lower forms. This requirement applies likewise to the partial attainment of the upright posture as well as the animal's tendency to sit upon its haunches and to balance itself in this position.

All of these factors demand a more extensive development of coordinative as well as equilibratory control, and this control in its more remote secondary effects has aided in the development of the hand. 
LEVEL OF THE EMERGENCE OF THE SINTH NERIE (FIG. I 23)

A remarkable feature at this level of the brain stem in mycetes is the appearance in its entire course of the emergent root of the abducens nerve.

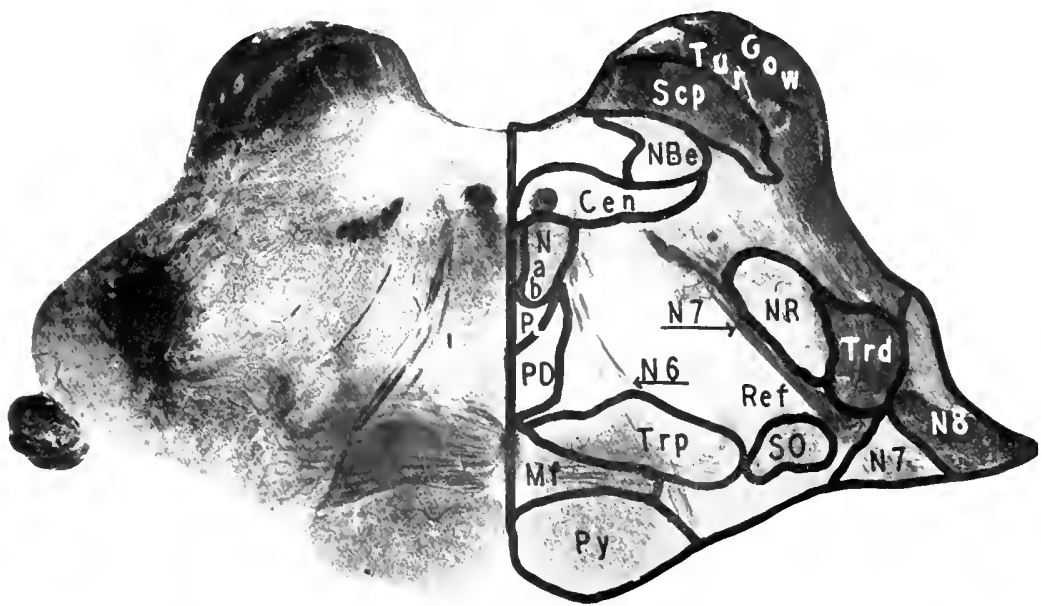

FIG. 123. MYCETES SENICULUS. LEVEL OF EMERGENCE OF SIXTH NERVE.

I LN, Central Gray Matter; gow, Ventral Spinucerebellar Trate; Wr, Nesial Fillet; Nab, Abducens Nucleus; NBE, Nucleus of Bechterew; NR, Nucleus of Roliandu; 6 , Abducens Nerve; N7, Facial Nerve; N8, Auditory Nerve; PD, Predorsal Bundle; PL, Posterior Longitudinal Fasciculus; Pr, Pyramid; REe, Reticular Formation; SrP. Superior Cerebellar Peduncle; so, Superior Olive; TRD, Descending Trigeminal Tract; TRP, Trapezoid Budy; tur, Tractus Uncinatus of Russel (Hook Bundle). [Accession No. 148. Section 230. Actual Size $18 \times 7 \mathrm{~mm}$.]

The origin of this nerve is seen in its nucleus ( $\mathrm{Nab}$ ), and its course dircetly ventrad through the trapezoid bock ( $\operatorname{Tr} \mathrm{p}$ ), the lateral portion of the mesial fillet ( $\mathrm{Mf}$ ), and its emergence Jateral to the pyramid ( Py), are exceptional in cross sections of the primate stem. No fibers of the pons are as yet apparent at this stage. The eentral gray matter ( Cen) is a narrow zone, which in its mesial angle contains the second portion of the facial nerve $\left(N_{7}\right)$. Its lateral angle is continuous with the nucleus of Bechterew ( $\mathrm{NBc}$ ). 
Situated above this latter nucleus are three important bundles of libers superimposed one above the other: the superior ecrebellar peduncte (Sep), the fasciculus uncinatus of Russel ( Tur), and the ventral spinocerebellar tract (Gow). The trapezoid body (Trp) and mesial lillet (Mf) lie dorsal to the pyramid ( Py ). At the lateral apex of the corpus trapezosideum is the superior olive ( $\mathrm{SO}$ ). The emerence from the axis of the seventh nerve in its relation to the fibers of the eighth nerve is elearly seen ( $N-$ and N8).

LEVEL THROLGH THE NHDDLE OF THE PONS VAROLII (FIG, 124)

At the level through the middle of the pons Varolii a clearer conception may be gained reararding the size and complexity of the pons. The stratum superficiale is a dense and relatively broad bundle of fibers making its way transversely into the middle cerebellar peduncle ( M c p). Dorsal to this is the stratum complexum containing the scattered bundles of the pyramidal system (Py), some transwerse fibers and the pontile nuclei (PN). In the most dorsal position is a fairly wide zone constituting the stratum profundum, the transverse pontile libers of which also enter the middle cerebellar peduncle.

Perhaps at no other level is it possible to obtain so comprehensive a view of the animal's motor capacity from structural indices. The size of the pens, inchuding its transverse fibers and nuclear masses, indicates a degree of cortical expansion in the cerebral hemisphere much above that attained by lemur or marmoset. It is significant of an animal capable of considerable coordinative control, one which has developed the lateral lobes of the cerebellum more than is to be observed in fower mammals. Because of this development it has acquired control over the upper extremity such as is commensurate only with animals possessing a more or less highly developed hand. Nor is all of the prominence attained by the pons Varolii directly ascribable to the increased demands in coordinative regulation of the upper extremity. These demands may be a primary incident or even an incentive to the 
increase in coordinative control of the body as a whole. Such additional control in coordination would arise from the profound readjustments occasioned by the assumption of the semi-ereet posture and partial biped locomotion

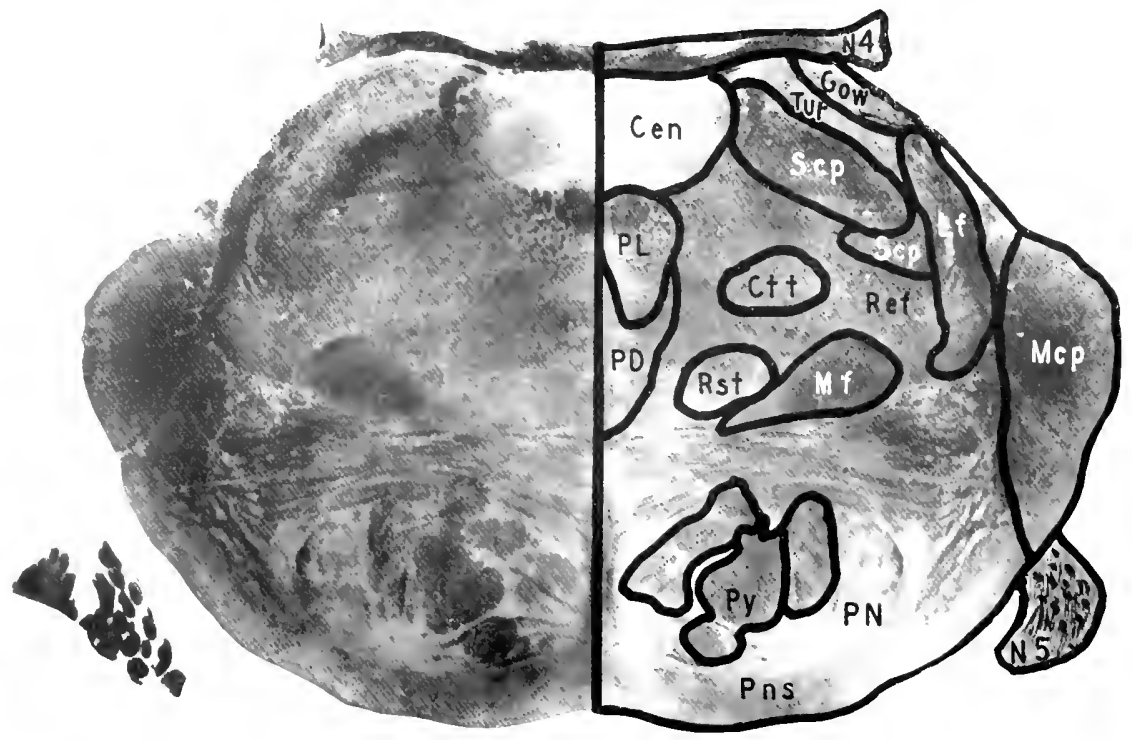

FIG. I 24. MCETES SENICULUS. LEVEL THROLGII MIDDLE OF PONS VAROLII. CEN, Central Gray Matter; ctT, Central Tegmental Tract; Gow. Ventral Spinocerebellar Tract; Lf, Lateral Fillet; MF, Nesial Fillet; MCP, Middle Cerebellar Peduncle; N.t. Trochlear Nerve; Ns, Trigeminal Nerve; IיD, Predorsal Bundle; PL, Posterior Longitudinal Faseiculus; PN, Pontile Nuclci; PNs, Pons; Py, Pyramid; Rif, Reticular Formation; RSt, Rubrospinal Tract; scP. Superior Cerebellar Peduncle; tur, Tractus Uneinatus of Russel (Ilock Bundie). [Aecession No. 148 . Section 305. Actual Size $1 ; \times 10 \mathrm{~mm}$.]

as well as from the fact that the animal is now able to sit upon its haunches and in this position use its hands for various new purposes. Similarly the seattered bundles of the pyramidal system, although disseminated amidst the stratum complexum, present a greater degree of prominence in mycetes than they do in Iemur or mamoset. They afford the basis for a structural 
index to contrast the probable difference in volit ional control inherent in these several species. That the quantitative diflerence favors myectes, there can be no doubt. Its behavioral reactions both in its learned and automatic movements are comsonant with this estimation.

On the beundary between the stratum profundum and the remainder of the brain stem is the mesial lillet (MI) whose size is considerably above that observed in lemur and mamoset. Here it is possible to form an idea of the relative volume of this ascending sensory pathway and so estimate the degree to which the animal has developed its discriminative sensibility. The increments to this aseending fasciculus of fibers appear to be due to atditional sensory contributions arising in the upper extremity and particularty in the hand.

In the tegmentum lateral to the mesial fillet is the lateral fillet (Lf), now approaching the inferior colliculus for another relay in the pathway of hearing. A dense bundle situated mesial to the lateral lillet constitutes the superior cerebellar peduncle $(\mathrm{Sc} p)$ which affords an opportunity of estimating to what extent the animal is equipped with a conduction system for coordinative control of the muscles. The superior cerebellar peduncte is larger than in lemur or marmoset, from which it may be inferred that mycetes is possessed of a more highly elaborated coordinating control.

The central gray matter $(\mathrm{Ce} n)$ surrounds the much reduced rentricular canal, the aqueduct of Sylvius. The roof of the aqueduct is formed by the medullary velum in which are the decussating fibers of the trochlear nerve $\left(\mathrm{N}_{+}\right)$on their way to the superior obligue muscle of the eveball. Ventral to these fibers is the ascending or mesenecphalic root of the fifth nerve.

\section{LETEL OF THE INFERIOR COLLICLLLS (FIG. 12j)}

At the level of the inferior colliculus several features of importance make their appearance. Among these is the tectal specialization of the inferior 


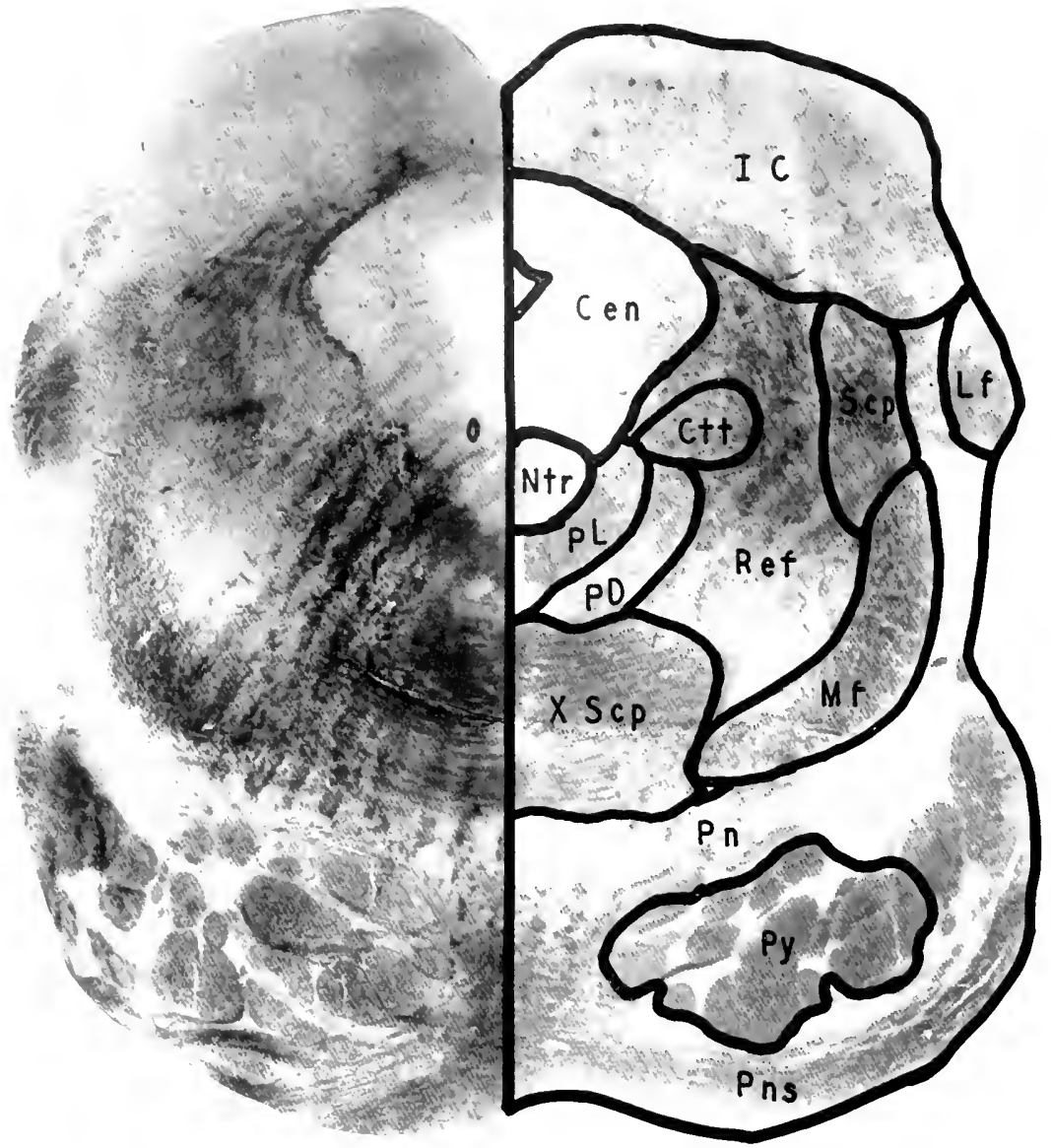

FIG. I2j. MICETES SENIClLLS. LEVEL OA THE INFERIOR COLLICULUS. IEN, Central Gray Natter; cir, Central Tegmental Tract; u, Juferior Colliculus: Lu, Lateral Fillet; MF, Thesial Fillet; NTr, Nucleus Trochlearis; PD, Predorsal Bundle; 1', Pesterior Longitudinal Fasciculus; pN, Pontile Nuclei; pNs, Pons; Pr, Pyramid; ReF, Retieular Formation; sop, Superior Cerobellar Peduncle; xsre, Crossing of the Superior Cercibellar Peduncle. [Accerion No. 4 \&. Section $3^{-0}$. Actual Size $13 \times 13 \mathrm{~mm}$.] 
colliculus (IC). The histological organization of the tectal region dischoses a stratification almost as complex as in lemur and marmoset and thus suggersts a functional capacity in the primitive correlating center of hearing of similar importance. The relation of such a correlating center to direct automatic acts of defense and oflense in response to auditory stimuli appears clear. The necessity for such a relation is as important in this arboreal animal as in those already considered.

A prominent feature at this level is the extensive substantia nigrat, an inclex suggesting the probable persistence of many highty complex automatic associated moxements. Ventral to the mesial fillet is the pons Varolii (Pns). It contains the pallio-ponto-cerebellar system of fibers as well as the fibers of the pyramidal system which latter, as in the oblongata, are not aggregated in a single bundle. From the size of these two fiber systems it is apparent to what extent the animal is endowed with volitional control from the cerebral cortex, as well as what concurrent cerebellar impulses must accompany the volitional stream which designs, initiates, directs and finally inhibits all voluntary movements.

LEVEL OF THE SLPERIOR COLLICULUS (FIG. I 26)

At this level, the superior collieulus (SC) serves as an important relay in the pathway of vision. Since there is still a considerable histological organization in this tectal region, it seems probable that the superior colliculus (SC) may retain some of its primitive visual function. That much of this function, however, has now been delegated to the occipital lobe is evident by the pronounced development in the calcarine or visual area of the cerebral cortex. The ventral portion of the central gray matter contains the nucleus oculomotorius (Noc) whose fibers pass forward and inward to the oculomotor sulcus from which they emerge to supply all of the extrinsic muscles of the eycball with the exception of the superior oblique and external 
rectus muscles. This nerve also supplies all of the intrinsic ocular muscles and the levator muscle of the upper evelid. It is especially signilicant that the commissural connections of the nucleus oculomotorius are much more prom-

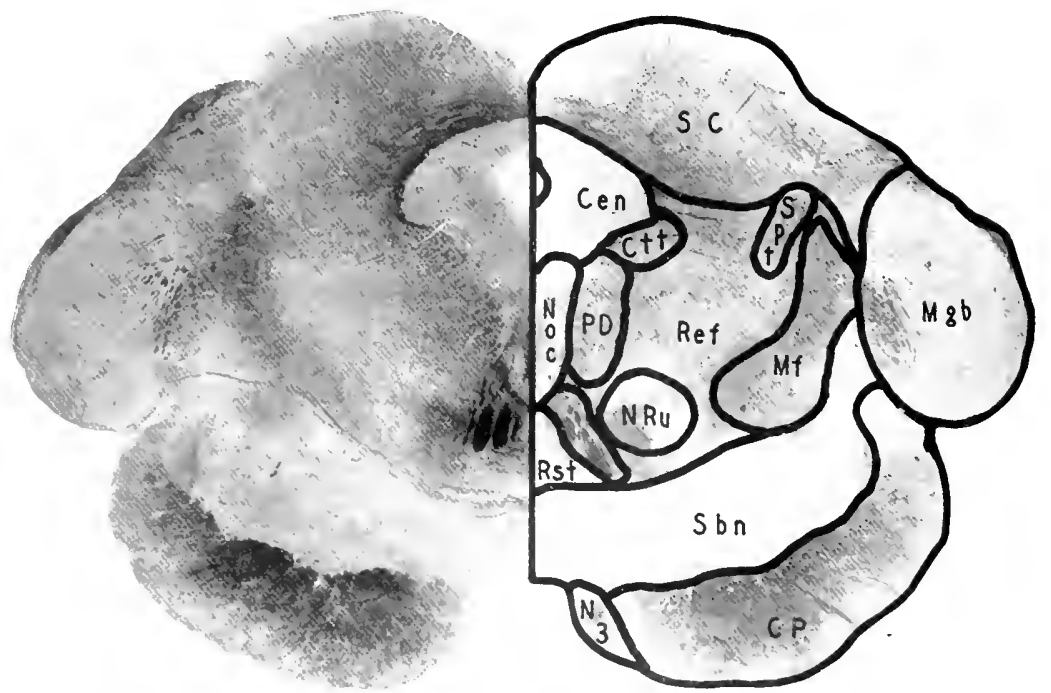

FIG. 126 . MCETES SENICLLLS. LEVEL OF THE SLPERIOR COLLICLLUS.

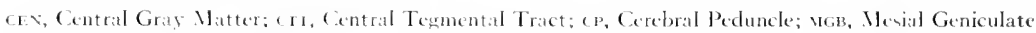
Body; Mr, Mesial Fillet; : We, Oculomotor Nucleus: NRe. Nucleus Ruber; v3, Oculomotor Nerve; PD,

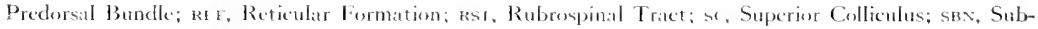
stantia Nigra; sir, Spinothatamic Tract. [Accession No. I 48 . Section for. Actual Size $18 \times 9 \mathrm{~mm}$.]

incent than in lemur or marmosct, thus implying a closer association in interocular movements of the eres and thereby securing a nearer approach to binocular vision and stereoseopic fusion.

Ventrolateral to the nucleus oculomotorius is the red nucleus (NRu) which is fairly wetl defmed. It constitutes a relay station in the course of the cerebello-spinal pathway. From it arise the fibers of the rubrospinal tract (Rst) over which pass impulses nccessary to muscular condination. In 
this sense the size of the nucleus ruber furnishes some clue of the corordinating capacity of the animal. Although more prominent than in marmoset or lemur, the nucleus ruber is not so latre as in some of the higher apes, which

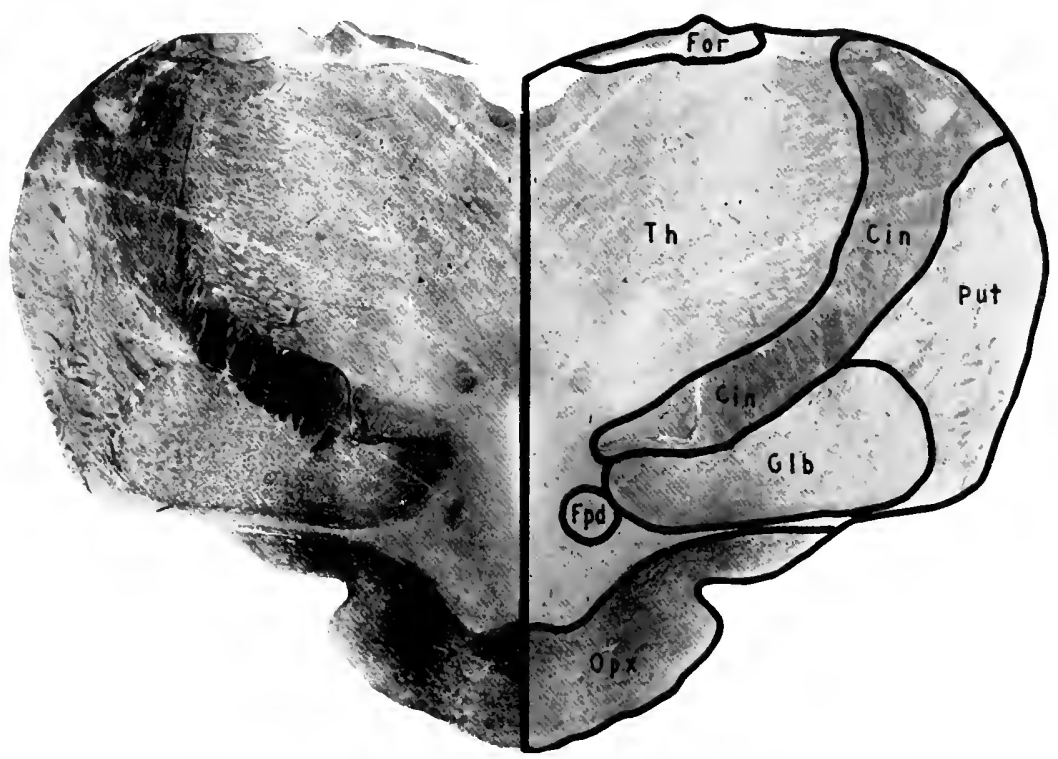

Fig. I $2^{-}$. MYCETES SENICULUS. LEVEL OF THE OPTIC CHIASi.

CrN, Internal Capsule; For, Fornix; f PD, Descending Pillar of Fornix; cle, Globus Pallidus; opx, Optic Chiasm; put, Putamen; ти, Thalamus. [Accession No. I 4 . Section 501 . Actual Size $28 \times 17$ mm.]

seems to justify the supposition that the animal's coordinative powers lie somewhere intermediate between the lowest and highest differentiation in the primate series.

LEVEL OF THE OPTIC CHIASM (FIG. I 27)

At this level the section shows the changes incident to the appearance of the optic thalamus ( $\mathrm{Th}$ ) and the optic decussation ( $\mathrm{Opx}$ ). The massive 
structure of the internal capsule $(\mathrm{Cin})$ is indicative, as are the cerebral peduncte and the pons Varolii, ol the high degree of neokinctic expansion exhibited by these monkeys. The behavional patterns have become ereatly

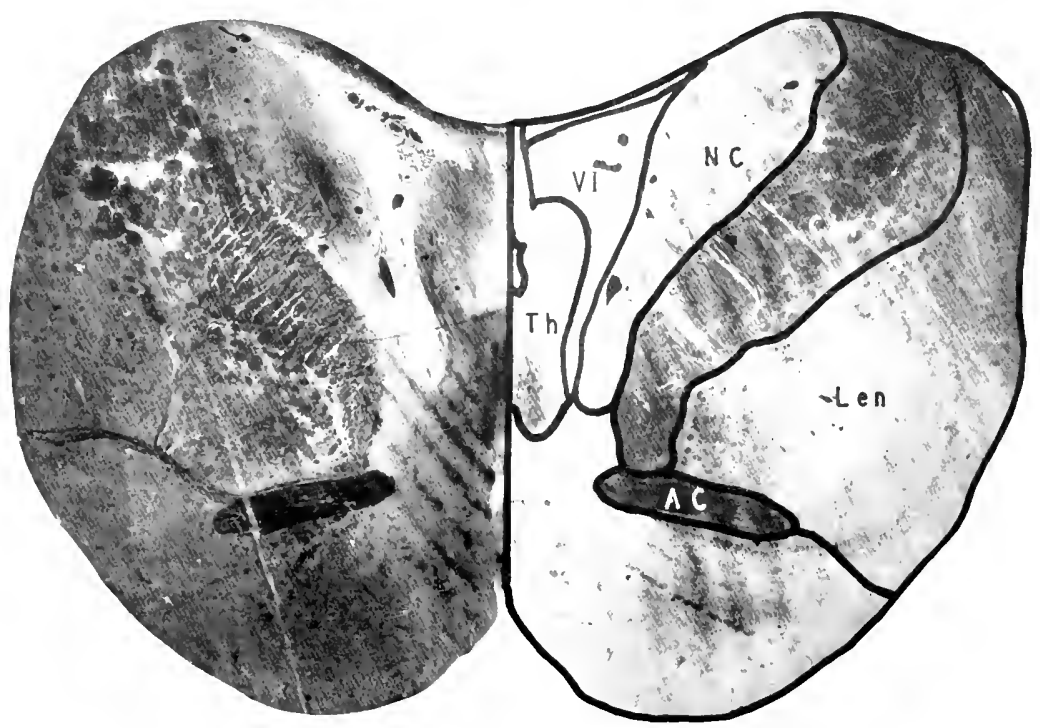

FIG. 128. MCETES SENICULlS. LEVEL OF THE ANTERIOR COMMISSURE. AC, Anterior Commissure; cri, Internal Capsule; LI. Lenticular Nucleus; NC, Candate Nucleus; th, Thalamus; 11, l ateral Ventricle. [Accession No. I 8 . Section 575. Actuat Size $28 \times 13 \mathrm{~mm}$.]

amplified in consequence of those new capacities made available by quadrumanous differentiation. To this new range of capacity should also be added those facilities of motion made possible through the prehensile tail, also spotien of as the lifth hand. Bordering on the outer surface of the internal capsule are the two major divisions of the lenticular nucless, namely, the grlobus pallidus (GIb) and the putamen (Put). 


\section{MCETES SENICULUS}

IEIEL OI TIL ANTERIOR COMMISSL RE IIC, I 28$)$

At the leved of the anterior commissure the brain stem hats terminated in its cephatic extremity. The upper limit of the sptic thalamus ( Th) is scen as it forms the anterior thalamic tuberele. The anterior commissure (AC) is approaching the midline from cither side, about to establish communication between the two halees of the axis. The other important struetures in this level are indicated by corresponding letters in the captions. 



\section{Cihapter VIII}

\section{RECONSTRUCTION OF THE GRAY MATTER IN THE BRAIN STEM OF MCETES SENICULUS}

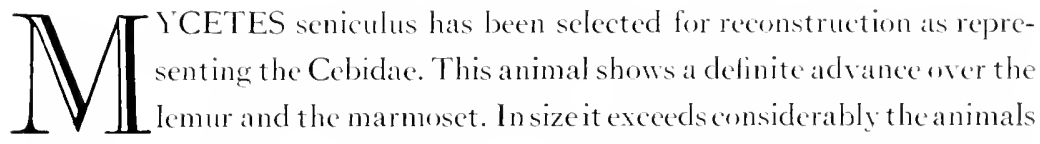
already mentioned and the brain reconstruction is correspondingly lareer than that found in either of the two preceding lorms.

\section{The Dorsal Sensori Neclei}

The nucleus of Goll first appears in the reconstruction as a dorsal extension of the central gray matter between the point of attachment of the dorsal gray column to the central gray column and the dorsal median septum. The nuclear mass is a narrow prolongation from the central gray column. It rapidly extends dorsally until it forms a core in the column of Goll. The nucleus is narrow, laterally compressed and presents a somewhat bulbous enlargement at its dorsal tip. At a somewhat higher level than the origin of the nucleus of Goll there appears on the dorsal margin of the central gray column a flat, sessile condensation in the central gray column which is the beginning of the nucleus of Burdach. At about the same level in the dorsal portion of the mass of white fibers forming the column of Burdach appear isolated masses of gray matter which coalesce and become attached to the dorsal extension of the central gray column to form the external nucleus of Burdach. The arboreal character of this nucleus, already mentioned in lemur, is further developect in mycetes.

The appearance of the nuclei of Goll and Burdach between the dorsomedian septum and the point of confluence of the dorsal gray column with the 
central grat column tends further to separate this latter structure from the midline. As the mass of the dorse-medullary nuclei reaches its maximum, the substantia relatinosi Rolandi which at this point is passing over into the substantial gelatinosa trigemini is shilted into its fixed lateral position. The heavy dorsal mass of the nueleus of Burdach overhangs laterally the substantia gelatinosa trigemini. The central gray matter at this point has merged to a considerable extent with the reticular formation. The transition between the substantia gelatinosa Rolandi and the substantia gelatinosa trigemini is essentially without a definite line of demareation. As the latter structure is traced upward, however, it constantly increases in size except for the constriction found at the midolivary level, termed the waist of the trigeminal nucleus.

\section{The Inferior Olitari Nucleus}

In the reconstruction, the inferior olivary nucleus shows a moderate advance over that found in the Lemur mongoz and the Callithrix jacehus. A slight indication of secondary plication now appears in the dorsal and rentral branches of the c-shaped nucleus. The ventral accessory olivary mucleus appears at about the point at which the dorsal sensory nuclei begin to assume proportions of any size. It first manifests itself as a round collection of gray material which llattens out obliquely from before backward and inward. At a somewhat higher level, isolated gray islands appear which coalesce and form a similar parallel flattened band, the dorsal accessory olivary nucleus. The chicf nuckeus appears between the lateral extremities of this accessory nucleus as a rounded mass which rapidly assumes the form of a Foop, the ventral branch of which fuses with the lateral extremity of the ventral accessory nuclens, while the dorsal branch is continued mesially parallel to the dorsal aceessory nucleus. The mesial extremities of the accessory nucke then fuse together. The aceessory nuclei attenuate and dis- 
appear leaving the loop of the chief nucleus to continue upward for a short distance, after which it also comes to an end. The focation of the inferior olivary nucleus eorresponds to that already described in lemur and marmoset.
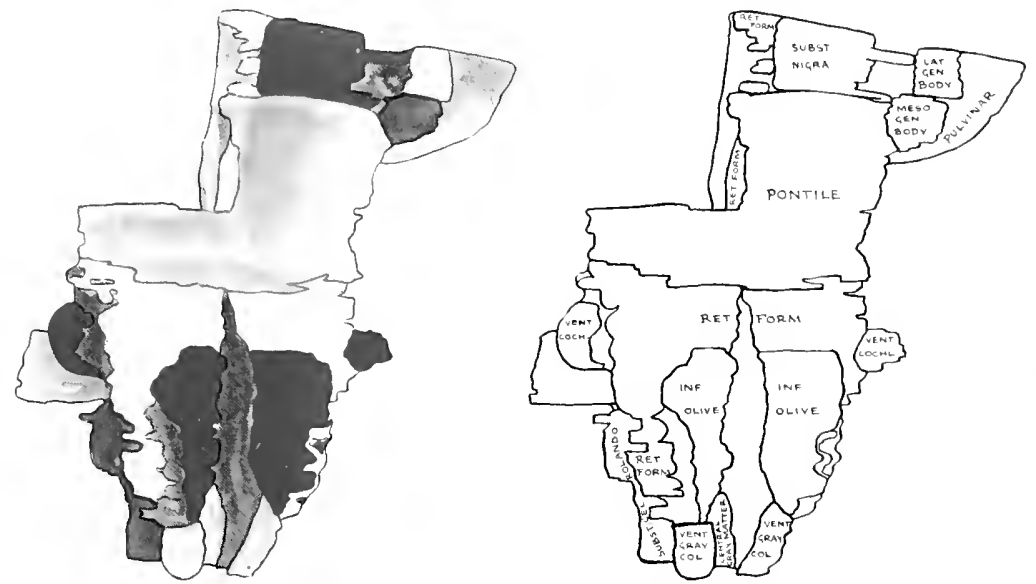

FIG. 129. VENTRAL SURFACE OF THE GRAY MATTER OF TIIE BRAIX STEM, MICETES SENICLLLS.

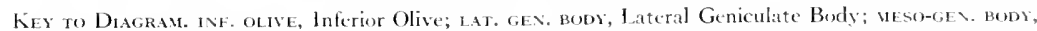

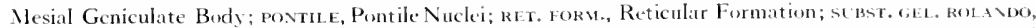

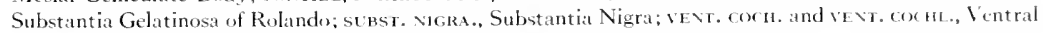
Cochlear Nucleus; ievt. GRas col., Ventral Gray Column.

The base of the nucleus approaches the ventrolateral angle of the brain stem, producing a slight elevation on the surface which corresponds to the olivary body found on the surface of the brain stem.

\section{The Reticular Formation}

The reconstruction of this mass of gray and white matter appears as a diserete body at about the middle of the pyramidal deeussation. It is separated from and lateral to the ventral gray column. It rapidly increases in size 
as the ventral uray columns diminish and finally the latter disappear by merging into the former at the level of the inferior olivary nucleus.

Thereticular formation furnishes the same matrix for the ascending and desecending fiber tracts found in the two preceding forms. It is surrounded on all sides, except the dorsal, by the aseending and descending fiber bundles of the stem. It is connected laterally with the mesial surface of the substantia gelatinosa triemini and clorsally with the bases of the nuclei of Goll and Burdach. Embedded in it rentromesially is the dorsal lamina of the inferior olivary nucleus together with the dorsal accessory olivary nucleus. As the reticular formation proceeds upward in the stem it gradually increases in size until it assumes considerable proportions. The nucleus lateralis of the reticular formation and the superior olive are developed to a somewhat greater extent than in lemur and marmoset. In the region of the midbrain the pronounced nuclear condensation of the reticular formation appears in the form of the nucleus ruber which is developed to a somewhat greater extent in this form than in either of the preceding types. In the dorsal aspect of the reticular formation are successively embedded the nuclei of the mesial somatic motor cell column, namely, the hypoglossus nucleus in the region of the medulla, the nucleus abducentis in the midpontile region, the nucleus trochlearis and the nucleus oculomotorius in the mesencephalic segment.

In the dorsolateral angle, between the subependymal gray matter and the cephalie extremity of the nucleus of Burdach, appears a condensation in the reticular formation which gires rise to the vestibular complex. The nucleus of Deiters separates the subependymal gray matter and the nucleus of Burdach, reaching its maximum diameter at a level somewhat above the midrentricular level of the stem. At this point the triangular nucleus of Schwalbe appears, and continues upward in its characteristic position. The nucleus of ron Bechterew lies lateral and dorsal to the rest of the vestibular complex in the lateral wall of the fourth rentricle. The reticular 


\section{RECONSTRUCTION OF MIYCETES SENICULUS}

formation seems to be continuous with the matrix of gray matter from which develop the zona incerta of the diencephaton and also that of the less differentiated hypencephalic gray matter.
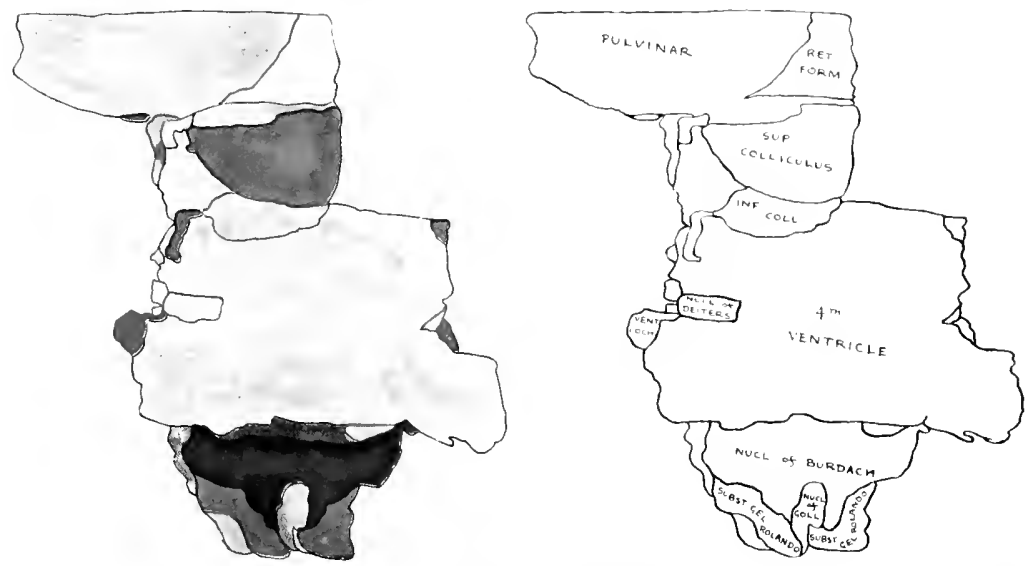

FIG. I 30. DORSAL SURFACE OF THE GRAY MATTER OF THE BRAIN STEM, MYCETES SENICULL'S.

Key to Diagram. inf. coll., Inferior Colliculus; Necl. of bu rdach, Nucleus of Burdach; Ner. of detters, Nucleus of Deiters; Nucl. of goll, Nucleus of Goll; RET. ForM., Reticular Formation; SébST. GLL. ROLANdo, Substantia Gelatinosa of Rolando; se p. Coldicelus, Superior Colliculus; VeNt roch, Ventral Cochlear Nucleus.

\section{The Postile Niclei}

In reconstruction the pontile nuclei appear rather abruptly at the level of the trapezoid body. The nucleus is considerably more massive than in the Lemur mongoz and the Callithrix jacchus, and is tunnelled on both sides by the descending pyramidal and pallio-pontile tracts. This again produces the typical arrangement of a lateral and mesial buttress, connected ventrally and dorsally by the superficial and the deep layer of the pontile mucleus. The simple arrangement of the nucleus as found in the Lemur mongoz and the marmoset now becomes somewhat more complicated with masses of nuclear 
material beginning to infiltrate into the bundles of the pramidal and the pallio-pontile system of fibers, producing a lacework of nerve cells and libers between the mesial aspeets of the two lateral and mesial buttresses. As is the case in the lemur and marmoset, the deep layer of the pontile nuclei, together with the dorsal portions of the lateral and mesial buttresses, becomes continuous with and serves, so to speak, as a support for the mesencephatic substantia nigra.

\section{The Vestibular Complex}

The reconstruction of this nucleus has been described as a condensation in the reticular formation arising at about the middle of the ventricular portion of the medulla oblongata. It appears first as a small, wedge-shaped mass of gray matter between the subependymal gray matter of the rentricular floor and the dorsal mass of the nucleus of Burdach. The nucleus of Deiters expands rapidly, becoming roughly triangukar in shape, with its base upon the subependymal gray matter, its lateral boundary facing toward the nucleus of Burdach, and its mesial boundary toward the subependymal ventricular gray matter and the reticular formation. The triangular nucleus of Schwalbe continues somewhat cephalad to the lateral ventricular recess and then merges with the reticular formation. The nucleus of von Bechterew is situated in the lateral wall of the fourth ventricte cephalad to the lateral recess. This last nucleus is so feebly developed as to be searcely demonstrable in the model.

\section{The Cochlear Complex}

As reconstructed, this nuclear collection conforms with the type found in the lemur and the marmoset. It represents a trough which covers the caudal, lateral and cephatic aspects of the entering cochlear nerve root. The 


\section{RECONSTRUCTION OF MCETES SENICULLS 230}

cochlear nerve, therefore, is nncovered by this nuclear material mesially where it comes inte contact with the brain stem. The nuclear material extends along the course of the nerve, interspersed between its libers. As
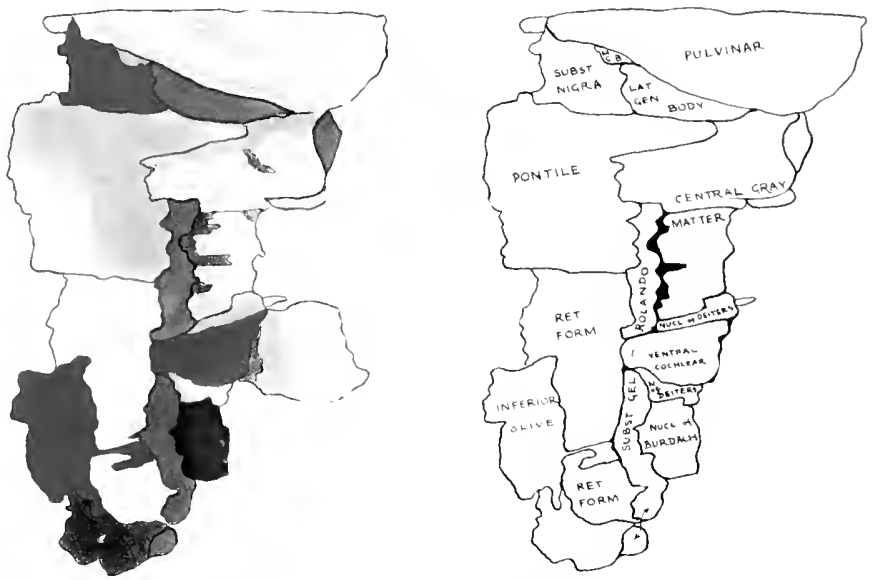

FIG. I3I. LATERAL SURFACE OF THE GRAY MATTER OF THE BRAIN STEM, MYCETES SENICULU'S.

Key to Dagram. Lat. Gev. Bobr, Lateral Geniculate Body; M.g.B., Mesial Geniculate Budy; Vec. OF burdach, Nucleus of Burdach; $\vee$ of deiters and vecz. of deiters, Nucleus of Deitets; pontile, Pontile Nuclei; ret. For.u., Reticular Formation; scbst. Gel. rolando, Substantia Gelatinosa of Rulando; stbst. Nigra, Substantia Nigta; ventral cochlear, Ventral Cochlear Nucleus.

the cochlear nerve is traced into the dorsolateral angle of the brain stem another nuclear complex comnected with the cochlear apparatus makes its appearance-the dorsal cochlear nucleus which lies in the lateral recess of the fourth ventricle, dorsal to the vestibular complex. This nucleus is triangular in shape, its base resting upon the subependymal gray matter, its lateral border directed toward the inferior and middle cerebellar peduncles and its mesial border lying against the vestibular complex. 


\section{Tie Stbstantia Nigra}

In the reconstruction, the substantia nigra appears in the reticular formation of the mesencephalon, apparently as a cephalie specialization in the deep Jarer of the pontile nucleus. Mesially it is eontinuous with the undifterentiated interpeduncular gray matter. Ventrally its surface is somewhat corrugated by the passage of the fibers of the pes pedunculi. Dorsally it is in contact with the reticular formation of the mesencephalon which is demarcated from it by the circumferential fiber bundles of this nuclear mass. Ventrolaterally in its upper portion it is hollowed out to a marked extent by a special nuclear aceumulation which takes place in this part of the substantia nigra. This nuclear mass presents a tangle of myelinated nerve fibers which seem to rise in the nucleus and pass into the reticular formation of the mesencephalon. Cephalically it is continuous with the subthalamic gray structures of the diencephaton and haterally it merges with the reticular formation in which are embedded the mesial geniculate bodies.

\section{The Colmiculi}

The reconstruction of the inferior colliculus appears as a rapidly increasing mass of gray matter supported laterally by the dorsal extension of the reticular formation. Dorsally it is continums with the dorsal grav matter of the tectum which separates it from its fellow of the opposite side and also provides a pathway for the inferior collicular commissure. At the midmesencephalie level the inferior colliculus diminishes in thickness and gradually disappears. In this region the dorsal extension of the tegmental reticular formation comes to the surface of the tectum of the midbrain. Immediately suceeding this, the superior colliculus appears, situated in an essentially similar position to that occupied by the inferior colliculi. Its dorsal and rentral extremities receive the same type of support as that of the 
inferior colliculus and it is connected across the midline with its fellow of the opposite side by the superior collieular commissure.

\section{The Niclel's Rlber}

In the reconstruction, the nucleus ruber in Mreetes seniculus appears as a fairly well-diflerentiated and encapsulated mass of uray matter in the mesial portion of the reticular formation. It receives at its caudal entremity the decussating fibers of the superior cerebellar peduncle. These fibers are enntinued about the nucleus, forming a capsule for it and many of them are continued upward bevond the nucleus ruber into the subthalamic region. The upper extremity of the nueleus ruber projects into the diencephalic reticular formation and the nucless in general seems to be located at a more cephalic level than is the case in the human brain stem.

\section{Tile Central Gray Matter}

The reconstruction of the central gray matter as first observed in the higher cervical level is somewhat cordiform in outline and is separated from the ventral gray column. To its dorselateral comers are attached the bases of the dorsal gray coltumms. As the ventricular level is approached a narrow prolongation of gray matter is seen to arise from its dorsal aspect and passing along the dorsal median septum it divides into two tongue-shaped processes which flare out on either side. This is the frrst indication of the opening of the fourth ventricle. The central gray matter passes outward and backward. gradually llattening into a narrow ribbon of gray matter lying under the ependyma of the fourth ventricle. There the narrow strip of gray matter is continued around the lateral boundaries of the ventricle, both in the inferior and superior medulary velum so that the entire ventricular cavity is surrounded by material derived from or continuous with the original central gray matter. The gray matter of the floor of the fourth ventricle is relatively 
smooth and presents little modelling of its surface in the lower half of the fourth ventricke. The walls are formed suceessively by the nuclej of Goll and Burdach and the nucleus of Deiters. In the upper hall of the ventricke the Hoor shows a single well-marked and rounded medial eminenee produced by the mass of gray matter forming the muckess abducentis, close to the midline and just above a line joining the two lateral recesses of the fourth ventricle. As the upper portions of the ventrick are approached the walls rapidly contract to form the narrow aqueduct of Sylvius which traverses the mesencephalon. The central gray matter of the mesencephalon is considerably thicker than that found in the lemur or the marmoset. It contains the dorsal extension of the trochlear and oculomotor nuclei which lie embedded in the dorsal region of the mesencephalic tegmentum. At the upper extremity of the mesencephalon the central gray matter is directly eontinuous with the subependymal gray matter of the third ventricle and the mesial thatamic nuclei. The most dorsal portion of the central gray matter in the mesencephaton is continuous with the epithalamic group of structures, while the most ventral portion is continuous with the hypencephalic structures. 


\section{Chapter IX}

\section{COMPARATIVE SUMIIARY OF STRUCTURES HAVING EVOLUTIONAL SIGNIFICANCE IN THE BRAIN STEMS OF TIHE LOWER PRINATES}

A Critical Comparison of the Pramidal Tract, Otiran Bodr, Dorsal Sensom Nuclei, Vestitular, Cerehellar and Pontile Nuclei, the Midhrain Colliculi and Oculomotor Decussation. Their Erolutional Significance in Relation to Bebation

Comparative Review of Strecteral and Bematioral Adaptations ERTAIN homologous constituents in the brain stem of the lemur,
tarsicr, marmoset and howling monkey manifest a measurable vari-
$\mathbb{d}$ ability in structural definition and relative size. Such variations seem to harmonize with equally wedl-ckefined modifications in the sensory and motor equipment utilized by these animals in their highly diflerentiated behavioral adjustments. That these variables should particularly involve the neokinetic elements of behavior might be presupposed from the fact that the progressive addition of new motor complexes pared the way to the highest crolutional development.

1. The Piramidal Tract in Relation to the Voluntary Control of the Extremities with Especial Reference to the Hand

Especially striking are the variations indicative of modification in volitional influence over the somatic muscles. The pramidal system has quite as much significance with regard to the degree of neokinetic activity as the cortex of the cerebral hemispheres. In direct proportion as the phyletic expansion of the neopallium has made possible new accessions of highly 
skilled perfomances, the pyramidal tract has progressively enlarged. Although this neopallial expansion adds new cortical fields for more extensive sensory correlation, its ultimate object is the behavioral expression made manifest in the total motor output from the cerebral cortex. The possibilities of increasing the richness of sensory associations within a single sphere of sensibility such, for example, as vision, are obviously dependent upon increase in its structural substratum. But when combinations of sensibility such as those within the realm of vision are incorporated in compound association of sight and hearing, taste and smell and all qualities of somatic sensibility, then even vaster possibilities for sensing the world are open to the animal. In its turn, this gradually advanemg conquest of the enviromment through arenues of the senses must find expression in new currents of behavior. It might be expected that the afferent convergenec of this sensory inthus would require a correspondingly expanded channel in the efferent pyramidal system. Indeed, it seems surprising that the pyramidal tract is no larger than it actually is. The pyramid, however, is a newcomer in the central axis. It is essentially a mammalian character in the brain, particularly implicated in the differentiation of the appendicular musculature. Its influence over the axial muscles, although potential, scldom reaches a high degree of specialization. The impulses which it conducts are preeminenty concerned in the execution of such skilled performances as belong to the group of complex learned reactions. Undoubtedly the most highy organized of these skilled acts are dependent upon the operation of the distal portions of the upper and lower extremities, namely, the feet and toes, the hands and fingers. It is in relation to the progressive adaptation apparent in the upper extremity that the pyramidal system is most intimately connected. Substantially little change occurs in the specialization of the lower extremity in the lower primates. The addition of the prehensile tail in certain of the South American monkeys undoubtedly requires an accession in volitional control 
of the caudal musculature. It is by no means so insistent in its demands as the rapidly differentiating structures of the upper extremity and particularly of the hand.

In lemur and tarsius, the py ramidal tract appears to be less prominent than in Mycetes seneculus. Such is the case also in marmoset. The hand of this animal has made a hesitating advance toward manual differentiation. and its pyramidal tract is hence less conspicuous than in the howling monkey.

\section{PLANIMETRIC COEFFICIENT}

These facts are clearly illustrated by certain coeflicients which show that the pyramidal area in proportion to the remainder of the cross section of the oblongata is greater in the howling monkey than in either marmoset, tarsius or lemur.

The numerical expression of this proportion may be temed a planimetric coefficient. It is obtained by means of projection drawings of the cross section in which the structure to be measured appears, the projection being produced at a fixed magnification. The area occupied by the structure under consideration is then determined by means of the planimeter, and in a similar manner the area of the hemisection in which the structure lies. The rat io of the structure whose coefficient is sought to the total hemisection of the axis is then computed and the figure taken to represent the planimctric coeffcient. The planimetric cocflicients of the pyramidal tract in lemur, tarsius, marmoset and mycetes are:

Planimetric Coefficients of Pyramidal Tract in Lower Primates

\begin{tabular}{|lcc|}
\hline & Species & Coeflicient \\
\hline Lemur & . ro \\
\hline Tarsier & .032 \\
\hline Marmoset & .064 \\
\hline Mycetes & $13^{-}$ \\
\hline
\end{tabular}


While these frgures may not in any sense be aceepted as definitive, they aflord a chose approximation to an actual estimate of the fact. From them it seems permissible to conclude that the increment in pramidal volume is proportional to that increasing demand lor control of motor performances made possible through the progressive develepment of the hand.

MORPHOLOGHCAL CONSHDERATHONS IN THE COMPARISON OF

LPPER EXTREMITIES IN MAN AND LOWER PRINATES

If the human upper extremity be accepted as the structural standard in the process of manual differentiation, ecrtain morphological conditions must be taken into account when comparing these parts of the human body with similar structures in the lower primates. Among these conditions are the proportimal length of the arm te the body, of the forearm to the arm, of the hand to the forearm, as well as the proportions of the metacarpals and phalanges, particularly the proportion of the metacarpal bones and phalanges of the thumb. There should likewise be incheded the degree of opposability of the thumb and the differentiation of the fingers, especially the finger nails and the cutaneous pads connected with the distal phalanges. Estimated in the light of such criteria, the upper extremity in lemur and tarsius falls considerably short of complete manual dilferentiation. In the case of mamoset, the proportions in the major segments in the limb are at variance with the accepted human standard. The diflerentiation of the fingers is particularly primitive. The thumb is short, the cutancous pads of the distal phalanges correspond more with the conditions presented by animak possessed of claws, and finally, the nails upon the fingers are much more claw-like than in any other form of primate.

In mycetes, however, the behavioral reactions made possible through differentiation of the hands place the animal much eloser to man than lemur, tarsier or marmoset. The performances of the howling monkey are 
much more humanoid than those of the still bower primates. Although it is distinctly subhuman in its manual achicrements, none the bess mycetes must be assigned a place well up in the class of detinite manual differentiation.

it. Tile Inferior Olimiry Nucleus in Relation to the Regulation of Molenents in the Eres, Head and Hands FUNCTION OF THE INIERIOR OLIYARY NUCLEUS

There is considerable cloubt concerning the function of the inferior olivary mucleus. Certain facts regarding it, however, are fairly obvious. The olive must be closely related in function to the cerebellum since its major connections are with that organ. The axons arising in the olivary substance pass as olivo-cerebellar fibers to the inferior cerebellar peduncle and thus reach the vermis and lateral cerebellar lobes. Whatever the precise function of this structure may be, its intimate association in the cerebellar reflex are implies an activity related to the coordinative control of somatic musculature. The inferior olive is interealated as a relay mucleus in some important pathway whose impulses are clestined to the cerebellum. It apparently serves to diffuse these impulses more extensively and thus bring into operation larger fields of cerebellar tissue in the interest of a high!y specialized coordinating activity.

Von Bechterew and other neurophysiologists are largely agreed that the inferior olive is functionally concerned with static coordination. Experiments upon $\operatorname{logs}$ in which the olive of one side has been injured cause a peculiar paralysis of the eye muscles with irregular nystagmic movements and simultaneous torsion of the body about its long axis. This torsion immediately follows the injury and attains its highest degree directly after the operation. In the course of time the torsion becomes less pronounced and the paralysis of the eye muscles together with the nystagmus diminishes. 
Recent experimental work upon cats (Pike), in which the inferior olive on one side was destroyed, produced ahmost identical results with those reported by Bechterew. The paralysis of the eye muscles, the nystagmus and the torsion of the body were all prominent symptoms as a result of eliscrete olivary lesions. The most striking feature of the disorder, however, was the torsion which took place in the trunk and neck. This torsion determined such a position of the body that the head and face of the animal together with its forelimbs were pointed one way, while the hind cxtremities pointed in the opposite direction. Repetitions of this experiment produced similar effects in all cases. These experiments were controlled in such a way as to exclude the results of injury to neighboring structures. The conclusion that the inferior olive is involved in the coordinative eontrol of the eye, neek and arm museulature seemed unavoidable.

Clinico-pathological observation sheds little light upon this problem. Cases in which lesions of the olive have been observed are usually masked by encrabehment of the pathological process upon some important afferent or efferent tracts in the oblongata. They have in no instance been discrete enough to permit of valid deductions regarding the function of this structure on the basis of pathological alteration in man.

\section{CONNECTIONS OF THE INFERIOR OLIVE}

These connections are of much significance in this question. The outstanding fibers related to the olivary body are those already mentioned as constituting the olivo-eerebellar pathway. These fibers undoubtedly establish the ultimate connection between the olive and various portions of the cerebellar cortex including both the vermis and the lateral Jobes. Another important connection is the central tegmental tract which lies along the ventrolateral aspeet of the olive and may be traced upward in the tegmentum of the pons into the midbrain in the region of the nucleus oculomotorius and 
mesencephatic nucleus of the trigeminal nerve. By some authorities this latter nucleus is aceredited with proprioceptive funcetions, receiving sensory stimuli from the eve muscles. Some libers of the central tegmental tract mas pass further ephalad in the direction of the basal ganglia of the endibrain and also into the posterior commissure. The main bulk of this bundle seems to terminate in the region of the nucleus oculomotorius. By means of it connection is established betreen the chief nuclei concerned in regulation of ocular movements and the inferior ulive. A small and poorly myelinized tract of fibers may be traced to the olive from origins in the cervical and upper thoracic segments of the spinal eord. This is the spino-olivary tract of Helweg.

In the absence of other alsecending or descending connections with this important nuclear structure it seems probable that the olivary nucleus is an intermediary station for impulses received from the muscles of the eye, neck, upper extremity and perhaps the upper portion of the trunk. It ultimately delivers these impulse's to the cerebeltum. Such connections might well serve the purposes of simultaneous coordination in the ocular, neck, arm and upper trunk muscles. The fact that experimental lesions of the inferior ofive disturb the coordination of the eye muscies and cause pathological torsion in the neck lends support to the theory that one of the functions of the olive, if not its chief function, is simultaneous coordination of eve, head and hand movements and also the performance of all highly skilled acts. This presumption is borne out by the progressive increase in the conspicuity of the olive while passing from the lowest of the primates to the highest members of this order.

\section{OLIVARY SLBDIYISIONS}

Morphologically several olivary subdivisions have been recognized. These include a portion which is old, often referred to as the paleo-olive, and 
a portion which is more recent, the nen-olive. Each of these subdivisions has been accredited with special connections in the cerebellum. This question, howerer, does not necessarily enneern the phyletic problem at present under consideration. Discrete differentiation of olivary segments and the siernificance of their connections are matters needing further investigation betore their real value as to the function of this nuclear structure is determined. Although there is underubted significance underlying the distinction between the phyletically old and new portions of the inferior olivary body, attention is here directed to the evolutional unfolding which has involved the structure as a whole rather than any changes affecting its individual parts.

EYE, IIEAD AND HAND MOVEMENTS, AND TIEIR CONTROL

As the hand gains in its eapacity to utilize motor patterns, the wider becomes its range of purposive reactions. The process of acquiring manual performances, as well as the actual execution of them once they have been acquired, neessitates certain directive inlluences. Vision especially becomes an important supplementary and even dominating factor. Without the aid of sight many complex movements of the hands could not be learned, and quite as certainly many acts would be deprived of their full effectiveness if the eyes did not supply the proper idea of distance and perspective.

Accepting the cooperation of vision as essential to the organization and performance of many highly skilled acts accuired by the animal, especially those resulting in the movements of the hands and fingers, it becomes clear that a che functional inter-relation between the movements of the eycball and of the hand must exist. It is necessary that the visual axes hold in focus the movements of the hand during the performance of acts which have been acquired with the supplementary cooperation of the visual function. In this sense the eye and the hand become essentially one organ, since the movements in the one must follow and hamonize with the movements 
in the other. The muscular structures produeing these mosements must therefore be integrated in a manner to produce this hamony of motor effect. Indeed, certain other eflectors are also implicated in this intricate activity which manifests itself in these simultaneous morements of ere and hand. To this group belong the muscles of the trunk which sustain the body in definite pesitions to support the movements of the head upon the neck. The muscles of the hindlimbs should atso be included in this catexory. The animal, especially in the ereet posture, requires the cooperation of the hindlimbs in support of the body thus to provide a stable basis for the eye and head movements which accompany the morements of the hand.

Syinergrc Units. One of the requisites for the precise control of such an extensive grouping of muscles in the body is the muscular coordination in each of the groups cooperating to produce the result. Such coordination is dependent upon the proper intermuscular relation of all the specialized uroups forming the agonist and antagonist muscles. Within each group there exists, under normal conditions, a definite relationship in regard to muscular tension. When one muscle, it may be a llexor, contracts to produce a flexor movement, its antagonistic extensor likewise contracts to such an extent as to impose a check or guiding effect upon the musele producing the morement. Each group of muscles because it acts in this manner to maintain this specialized intermuscular relation, has been called a stnergic unit. The entire body musculature is composed of synergic units which maintain this definite intermuscular relation when in action.

To secure such coordinate movement, one entire division of the central nervous system is set apart, namely, the cerebellum. Under the control of this organ the synergic units of the body are maintained in their proper relations to each other. By the same means proper intermuscular relation between the synergic units is established. The function which regulates coordinated action in the muscles of the body is known as stnergia. In the 
"peration of this function, the cerebellum must be in touch from instant to instant with the varying degrees of muscle tension existing in each muscle group of the body. Corebellopetal fibers furnish a physical means by which such eommunication is established. A continuous stream of afferent impulses is thus passing to the cerebellum during all phases of muscular activity. It is interesting in this connection to note that most of the afferent pathways to the corebellum from the musculature of the body pass upward in the spinocerebellar tracts whose destination is the vermis cerebelli. This portion of cerebellar organization is chiefly concerned with the axial and paraxial museulature, while the lateral lobes are much more engaged with the coordinative control of the appendieular muscles in the limbs. All of the aseending cerebellar fibers are believed to receive intermediate relay in precerebellar nuelei.

The column of Clark in the spinal cord is an example of such a precerebellar nucleus. It receives peripheral afferent fibers and in turn gives rise to fibers which constitute the dorsal spinocerebellar tract. A similar Iongitudinal nueleus, perhaps not so diseretely limited as the column of Clark, provides a relay for the fibers constituting the ventral spinocerebellar tract. Both of these precerebellar nuclei have the form of long cell columns extending through many segments of the spinal cord. In this respect they differ from the inferior olive which is also a conspicuous precerebellar nucleus. Th is nucleus is saceular in form and limited to the segments of the oblongata.

ETOLUTIONAL EXPANSION IN THE INFERIOR OLIVE

Such expansion as occurs in the spinal precerebellar nuclei must in the main be longitudinal. It is for this reason less conspicuous than the expansion in the inferior olive which is largely in the transverse diameters. The progressive enlargement of the inferior olivary nucleus in passing from the lowest of the primate order to man gives the impression of a much more striking evolutional process than is the case with other precerebellar nuclei. The olive is also more impressive from the fact that in its expansion there is 
a tendeney for it to become more definitely convoluted. This feature gares hand in hand with the progressive development of the lateral cerebellar lobes. Those forms having the laresest cerebellar hemispheres have also the most highly convohted inferior olivary nuckei.

The paralletism in clevelopment of olive and lateral lobes of the ecerebelhum depends upon the fact that the inferior olivary nucleus, in its capacity of a precerebellar relay station, sends its fibers not only to the vermis, but in very large measure to the lateral lobes as well. Such is not the case with the precerebellar nuclei situated in the spinal cord. Most of the libers arising in Clark's column, as well as those which give origin to the ventral spinoeerebellar tract, have their destination in the vermis of the cercbellum. The contrasts drawn by these morphological facts are not without evolutional significance. The spinocerebellar tracts represent a portion of the musculature with striking phyletic constancy, namely, the axial muscles of the body. The representation of these musckes when projected upon the cerebellar cortex requires for its elaboration the limited areas of the vermis only. This musculature is restricted to the trunk, the neck and such axial structures as those innervated by certain of the cranial nerves. No such functional limitation prescribes the representation of the inferior olivary body as a precerebellar nucleus. It expands as the cercbellar lobes expand, and having a widespread connection with them, exists in response to portions of the muscular system whose representation when projected upon the cerebellar cortex raches all areas both in the vermis and in the lateral cerebellar lobes.

Factors Underling Progressive Expansion of Inferior Olivary Nucleus. Apparently the same dynamic influences which have produced expansion in the cerebellar hemispheres are operative in the progressive expansion of the inferior olivary nucleus. Were it possible to seleet the one most compelling factor underlying such influence, it would doubtless be the progressive differentiation of the forelimb. This differentiation does not alone 
participate in the intimate specializations aceurring in the upper extremity. It involves those widespread adaptations comeurrent with and consequent upon the liberation of the forelimb from the responsibilities of locomotion. It conters into the complete assumption of upright posture, and modification of the lower extremities essential to this purpose, tonether with acquisitions of muscular condination incident both to bipedal locomotion and the perfection of manual dexterity.

Planimetric and Longitudinal. Coemficients of Olmary Bodr. Evidence in support of this view is found even in the fower primates where the comparison of lemur, tarsier, marmoset and mycetes reveals a progressive expansion in the inferior olive. The acempanying tabulation of the planimetric coeflicients of the nucleus indicates a volumetrie increment of roo per cent or more in the olive of myeetes as compared with the other three species.

Longitudinal coellieients of the olivary body, however, show even more extensive change. Together these two mensurations confirm the supposition that the inferior olive almost entirely cxpresses its expansion transversely within the limits of the oblongatal segments. It dillers from the spinal precerebellar nuclei whose expansion is thelly longitudinal. From a functional comparison of these four species it is clear that manual performances in mycetes are more complex and have a greater range of adaptability. As a structural indicator of this phyletic progress the inferior olive is of especial significance. It denotes the proficiency attained in the simultaneous movements of the eyes, head and hands.

Coefficients of the Inferior Oline in the Lower Primates

\begin{tabular}{|lccc|}
\hline & Species & Planimetric & Longitudinal \\
\hline Lemur & & .060 & .290 \\
\hline Tarsier & .042 & .180 \\
\hline Marmoset & .038 & .230 \\
\hline Mycetes & 120 & .260 \\
\hline
\end{tabular}


i1. Tile Dorsal Sensory Neclei in Their Relation to Discrininative Sexsibility in the Extremities

THE NECEEI OF GOLL, BLRDACH AND BLLNENAL

The nuclear structures in the dorsal columns, intercalated in the pathway of discriminate sensibility, assume importance in relation to motor performances which depend upon kinesthetic organization. The more perfectly an animal senses the morements and postures in the several parts of its bedy, the more completely is it able to adjust these parts to complex motor patterns. A low degree of kinesthetic organization is indicative of a limited rangeof reaction patterns. No specialized area of the nervous system affords a more illuminating index concerning the discriminative sensory influx than the dorsal sensory field. Experiments and clinical pathology havedemonstrated a diserete division in the oblongatal nuclei of these dorsal columns. Discriminative impulses from the muscles, tendons, joints and bones in the leng and tail find relay stations in their advance toward the cercbral cortex, in the nucleus of Goll. Similarly, impulses from the upper extremity are relayed in the nucleus of Burdach. The ancillary nucleus of Blumenau, known also as the lateral nucleus of Monakow, is connected with the nucleus cuncatus. It presents certain features in which it differs from the dorsal nuclei. Its staining reaction is more intense and its cells are somewhat larger. Various opinions have been held concerning its relay function, both for and against the belief that it is intermediary in advancing impulses from the upper extremity to the cerebellum. It seems clear, particularly in lenur and mycetes, that many fibers do make their way to the inferior cerebellar peduncle from this nucleus of Bhumenau. It is equally certain that the pathway itself gains in prominence with the inereasing degree of differentiation in the hand. While, therefore, no fmal opinion may be expressed with reference to the function of the nucleus of Blumenan, there is evidence to show that it serves as a relay for certain 
impulses which arise in the proprioceptive organs of the upper extremity and are destined for the cerebellum.

\section{THE NLCLELS OF ROLANDO}

The remaining nuclear structure in the dorsal sensory field, namely, the nucleus of Rolando (substantia gelatinosa trigemini) aceounts for the sensory innervation of the face and of the head rostral to the interparietal line. The exact course foltowed by the fibers conveying discriminative sensibility from the trunk, from the neck and from the back of the head is not so well understood as the tracts which comstitute the main conduction pathway from the extremities. It is prosible that many of the fibers from the trunk, back of the head and neck make their way to the oblongata after relay in the retieular formation. They may ineorporate themselves in the great sensory pathways of the dorsal columns to receive their relay in the nuclei of Goll, Burdach and Rolando. In any event, these axial fibers, representing the distribution of the dermatomes in the trunk, in the neek and in the back of the head, constitute more or less constant factors which in all probability vary but little from species to species. It is unlikely that any great variation, either in the capaeity of sensibility or in the demands for condnetion, arises in connection with the trunk. Such modifications as do oceur appear to be induced by eonspicuous variables such as the tail, the forelimb and the hindlimb. Thus it might be expected that in an animal possessed of a highly efficient prehensile tail, the muckeus of Goll would appear in larger dimensions than in an animal either possessed of no tail or having one of mueh more generalized functional significance. The chief nuclear expression connected with the development of the tail appears in the nucleus of Bisehoff. The development of the hand affects the column of Burdach which is much larger in anmals having a high degree of manual differentiation than in those manifesting but slight differentiation of this kind. 
In the case of the Rolandic mucleus, although the areat of innersation which it represents (the face and ventral portion of the head) is exquisitcly axial in its distribution, this sensory territory of the body manifests considerable functional variability aceording as the animal depends more or less upon the head and face for the direction of its lecomotion.

\section{A COIPARISOX OF TIIE NLCLEI OF GOLL AND OS BL RDACH IX TIIE IOWER PRIMATES}

A comparison of the nucleus of Goll in lemur, tarsier, marmoset and mycetes shows an actual increase in size in the howling nonkey, aceounted for largely by the presence of a well-defined nucleus of Bischoff. In lemur the planimetric coefficient of the nucleus gracilis $(\mathrm{Goll})$ is 4 . I per cent, in tarsius 2.6 per cent, in marmoset, 6.8 per eent, while in mycetes it reaches 13.1 per cent. All of these forms are essentially quadrumanal. Such incease as oceurs in the size of the nucleus of Goll in these species cannot be attributed to essential modifications in the hindimbs which, specialized as they are for arboreal Jife, become more or less standardized by this fact. They are subject to but little variation. The motive of this nuclear expansion must in consequence be somght elsewhere than in the specialization of the feet. The most obvious possibility to suggest itself is the specialization of the tail. In lemur, tarsier and marmoset the planimetric coefficient of the nucleus gracilis shows no striking differences. In these animals the tail serves as a balancing and steering organ. It has developed no prehensile qualities and thus has become but little specialized in its sensory eapacity. As might be presumed, such an organ would not exert much influence tending to effect expansion in the sensory receiving muclei.

In the case of myectes, however, the nucleus of Goll shows a marked expansion. Its coefficient cxeeeds that of marmoset by nearly - per cent and that of lemur by 9 per cent. Such a striking advance as this must have more 
than passing significance. The skillfull manner in which mycetes employs its tail supplies the reason for calling this orean a fifth hand, and hence the need of sensory specialization in this caudal appendage is evident. The tail at its tip is free of hair and presents upon its ventral surface parallel rugae not unlike the rugous markings upon the balls of the fingers and thumb. The animal utilizes its tail not merely for purposes of suspension during locomotion, but in many selective acts in which sensory discrimination is neeessary. A tail manifesting such a degree of deftness at once implies the acquisition of a Farge series of motor patterns. It must therefore be the case that the kinesthetic development in connection with the movements of the tail is largely expanded in mycetes as compared with lemur, tarsier and marmoset.

This expansion, howerer, is not confined to the nucleus of Goll. The planimetric coetlicients of the nucleus of Burdach show a similar increase in the size. In lemur this nucleus has a planimetric coeflicient of 4.9 per cent, in tarsius, of 2.9 per eent, in marmoset, of 4.3 per cent. In myeetes, the coeflicient is 11.3 per cent. Since the nucleus of Burdach, in the main, represents the diseriminative sensory influx from the upper extremity, the hand would prove a dynamic factor most likely to exert an influence favoring expansion. In lemur, manual specialization is not far advaneed. The thumb is short and lacks much of the opposability characteristic of the higher species. Both the forearm and arm are short and do not approximate the ideal proport ions of human conditions. In fact, the forclimb is still so largely implicated in locomotion that it possesses many characters inherent in a locomotor organ. Even more submanual is the forelimb in tarsier and marmoset. In both of these species, differentiation of the hand has made ineffectual attempts in the direction of human conditions. In the case of mycetes, however, the forelimb has advanced decisively toward ultimate manual differentiation. Its locomotor offices have been supplemented by the use of the prehensile tail which, permitting suspension of the body, affords opportunities for the freer use of the 
hand in acts of discrimination and selection. The planimetric eneflicient of the nucleus of Burdach in mreetes is slightly in excess of that of any of the other primates including the anthropoids and man. This observation will be more fully discussed in connection with humanoid and human manual differentiation. In general, it seems to indicate a strong adaptive influence operating in direct response to the specialization of the prehensile tail which hats largely freed the forelimbs from functions of locomotion. It has thus made them avaikble for more complex motor patterns utilized in exploring and further dominating the enviromment. The tabulation of exefficients follows:

Planinetric Coffficients of Dorsal Sfasory Niclei in Lower Primates

\begin{tabular}{|c|c|c|c|}
\hline & Species & Goll & Burdach \\
\hline Lemur & & .041 & .049 \\
\hline Tarsier & & .026 & 029 \\
\hline Marmoset & & 008 & 043 \\
\hline Mrcetes & & .131 & .113 \\
\hline
\end{tabular}

Longitudinal Coefficients of Dorsal Sengory Niclei in Lower Primates

\begin{tabular}{|c|c|c|c|}
\hline & Species & Goll & Burdach \\
\hline Lemur & & 2000 & 200 \\
\hline Tarsier & & Igo & 240 \\
\hline Marmoset & & .190 & 210 \\
\hline Mycetes & & 210 & 280 \\
\hline
\end{tabular}

Advances in the nucleus of Goll and more especially in the median nucleus of Bischoff are measurably demonstrable in mycetes as an apparent response to the adaptive modifications incident to the development of the prehensile tail. This species, compared with lemur, tarsier and marmoset, shows a similar advance in the nucleus of Burdach as a consequence of further manual clifferentiation. 


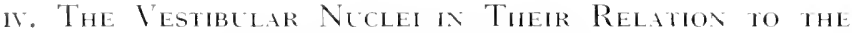 B.ALAXCING MECHANISM}

\section{EXTREME SENSITINENESS OF THE BALANCING MECHANISM}

This group of nuclei is fundamentally associated with the function of balaneing, that is, the maintaining of the bedy in the optimum phrsiological posture, or of righting the budy in the exent that it may for any reason be forced out of this posture. This posture itself, although subject to numerous modifications, presents a fairly well-generalized pattern in all vertebrates. In accordance with this pattern the anmal's best posture appears that in which the ventral surface of the body is nearest to the surface of the earth. This is true of fish, amphibia, reptiles and birds. From such a posture these animals may most readily initiate locomotion or remain in a resting phase preparatory to locomotion. This posture in mammals, with a lew notable exceptions, such as the sloth and the bat, is similar to that in the lower vertebrates. Any slight deflection in this posture tends to cause extensive disorganization in the anmal's behavior. Such disturbances may be artificially induced by pathological lesions affecting the nervous system, more particularly that part of the nervous system conneeted with the proprioceptive organization upon which balancing function depends. Thus the destruction of one semicircular canal will so thoroughly disorganize the animal's capacity for assuming and maintaining the optimum physiological posture as to make locomotion impossible. It also makes the animal incapable of maintaining itself in any position.

The mechanism upon which this important activity depends must needs be highly organized. This applies to its receptor organs as well as its central representation for receiving, converting and transmitting postural impulses to the musculature. Furthermore, this mechanism is extremely sensitive to many conditions of habitat and behavioral adjustments. Aquatic, aerial and 
arboreal adaptations create the most marked variations in this neural apparatus. The responsibility of the balancing mechantsm in animals whose life is spent largely in flight, soaring to erreat heights, or dropping swiftly from the air to alight upon the branches of trees is most exacting. It necessitates a mechanism capable of adjusting the body in postures most adrantageous for the use of wings. Adaptation to arboreal life imposes similar requirements upon the balancing apparatus. Such of the apes, for example, as are able to live almost exclusively in the trees and move from place to place by leaping, climbing and swinging, require a most delicately adjusted mechanism in the interest of equilibration.

\section{FLNCTION OF TIIE VESTIBLLAR NLCLEI}

The primary centers assoctated with balancing are the restibular nuclei. These nuclei serve as the chief receiving stations for the impulses flowing inward from the semicircular canals, the utricle and saccule. It is probable that even from the earliest stages of life these nuclear groups in the oblongata exert a pronounced influence upon the behavior of the young animal. With rare exceptions among the manmals, the power to assume and maintain the optimum physiological posture develops shortly after birth. The structural substratum for the early maturing of this function is found in the fact that the nerve fibers permitting communication between the proprioceptive organs have consummated their connections with the vestibular nuclei. These nuclei are in turn provided with efferent fibers necessary to the conduction of impulses destined to the somatic muscles. In this manner the reflex ares essential to maintain the physiological optimum posture are completed. The vestibular nuclei in the oblongata are, of themselves, sufficient to mediate the reflex impulses necessary to the proper balance of the body. On the other hand, there is evidence that many myclinized fibers, even at an early period of devclopment, pass to the region of the inferior colliculus. These axons 
have eomections with the lower portions of the neuraxis. They provide a series of relles ares which participate in the balancing function. That this function is primarily the concern of the lower scements of the brain below the diencephaton and endbrain seems clear on the basis of ontogenesis. It may be helel with a fair degree of ecrtainty that the rellex ares made possible through the restibular nuclei of the oblongata, perhaps supplemented by influenees from the midbrain, are sufficient for a considerable period of time in early life to carry on the reflex activities involved in the balancing reaction.

\section{CONNECTIONS OF THE VESTIBLLAR NLCLEI}

The several connections of the vestibular nuclei become of considerable importance in this relation. These nuclei, as already indicated, are primarily eonnected by aflerent libers with the proprioceptors of the internal car, including the saceule, the utricte and the semicireular canals. The nuclei have connection with the vermis of the cerebellum through the corpus juxtarestiforme, also with the midbrain, particularly the oculomestor nuelei.

\section{COMPARATINE DIMENSIONS OF DEITERS' AND SCHWALBE'S AREA IN THL LOWER PRINATES}

Conclusions based on comparative dimensions of Deiters' and Schwalbe's nuclei respectively indicate that the function of balaneing and maintaining the optimum physiological posture in all of the primates is essentially the same in effectiveness. Deiters' nucleus throughout the primate series manifests strikingly constant dimensions. It presents a maximum variation in its planimetrie coeflicients of less than 7 per cent, while its variation in its longitudinal coeflicients does not exceed + per cent. In the case of Schwalbe's nucleus apparently the same constancy obtains in so far as the planimetric coeflicient is concened, although in the comparative Longitudinal measurements of the nucleus a variational range of 6 per eent 
has been noted. The following tables grive the planimetric and longitudinal coefficients of Deiters' and Schwalbe's nuclei in lemur, tarsier, marmoset and mycetes:

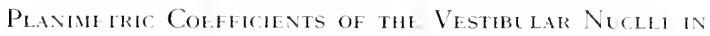

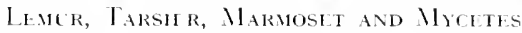

\begin{tabular}{|c|c|c|c|}
\hline & Species & Deiters' Nucleus & Schwallee's Nucleus \\
\hline Lemur & & $0 x_{2}$ & $.6+5$ \\
\hline Tarsier & & 180 & $.06,2$ \\
\hline Marmoset & & $0^{--}$ & 060 \\
\hline Mycetes & & IIt &.$(x)$ \\
\hline
\end{tabular}

Longtrodinal Coeffichents of rhe Vesteblak Nuclet in Limur, Tarsier, Marmoset and Mucetes

\begin{tabular}{|c|c|c|c|}
\hline & Species & Deiters' Nucleus & Schwalle's Nucleus \\
\hline Lemur & & 21 & .21 \\
\hline Tarsier & & 22 & $1^{-}$ \\
\hline Marmoset & & 21 & .20 \\
\hline Mycetes & & .18 & I \\
\hline
\end{tabular}

Such differences as do exist in the vestibular nuclei of these species appear to favor tarsius, a fact which denotes how much more this animal depends upon its balancing function than lemur, myectes or marmoset. This added funetional responsibility may be inherent in tarsius due to its locomotion. In myeetes the problem in balancing includes not only the ordinary locomotion of climbing, leaping and swinging by hands and feet, but also embraces the many postures of the body incident to suspension by means of the tail. Mycetes is capable of assuming positions in which the body is suspended while the hands and feet are freed for other activities than those of locomotion. In such positions as these the requirements of balance must be considerably greater than in other primates. The entire process of motor 
adjustment, operating upon a less stable base in mycetes calls into play the functional activity of additional balaneing reflexes. While the problems of balancing change from species to species aceording as the focomotor adaptation is made to arboreal, terrestrial or intermediate modes of life, the demands for cquilibration remain essentially the same throughout the primate order. This undoubtedly is due to the fact that although the equilibratory requirements of arboreal life may recede as the animal approaches neares to a strictly terestrial habit of living, these are replaced by new requisites for balancing induced by the gradual assumption of the erect posture, by bipedal and ultimate plantigrade locomotion.

That tarsius and mycetes should exceed other primates in the size of their vestibular areas is due to the fact that they have added to their balancing equipment certain ancillary mechanisms essential to peculiarities in their Incomotor specializations. Such specializations are conditioned by the prehensile tail or saltatory locomotion.

In their general erolutional signilicance, the restibular nuclei do not contribute so striking an example of progressive unfolding as is the case with many other structures. Nerertheless, their high specialization in mycetes is worthy of note. They reveal to what extent the development of a plasticcharacter like the prehensile tail may influence so fundamental a function as that regulating the equilibrium of the body. The absence of such a tail in lemur, tarsier and marmoset seems to make this differential element all the more significint in the evolutional sense.

\section{v. The Cerebellar Nuclei and tile Nucleus Ruber in Relation to Coordination}

Several relatively prominent cell groups are recognized and distinguished as cerebellar nuclei. They include the nucleus dentatus, nucleus emboliformis, nucleus globosus and nucleus fastigii. The globosal and fastigial nuclei belong 
to what may be called the medial cerebellar division. The nucleus dentatus and nucleus emboliformis, oceupyine a more lateral position, are regarded as constituents of the lateral cerebellar lobes. In the preceding descriptions attention has been dirceted particularly to the nueleus folobosus and the nucleus dentatus. Reconstructions of these structures have indicated how difficult it is to make intrinsic distinctions between the medial and the lateral nuclei. For this reason the dentate nucleus has been taken to include both the nucleus dentatus and the nucleus emboliformis, while the nucleus globosus incluckes the globosal and fastigial nuclei.

The division of these mucke into a medial and lateral group has much functional significance. The lateral group is in large measure representative of the appenclicular muscles of the body, that is, the upper and lower extremities. That this group represents the appendicular museles exclusively is not the case; but the main expansions in the mucleus dentatus occur in response to the progressive differentiation of motor capacity in the arms and legs.

THE DENTATE NLCLECS AND ITS CONCURRENT EXPANSION WITH THE CEREBELLUM AND CEREBRAL HEMISPHERES

Inasmuch as the dentate nucleus is the principal relay station for efferent impulses from the cerebellum, its significance in connection with this organ as a whole becomes correspondingly important. From the physiological point of view, it is fairly well established that conditions demanding greater coordinative control of the musculature have their structural response in definite expansions of the eerebellum. A comparison of different species of mammals discloses the fact that the central or vermal portions of the cerebelIum have participated less in such development than the lateral lobes. This is especially notable in the primates, in which the proportional size of the cerebellar hemispheres in relation to the vermis progressively increases in 
passing from the fowest apes to man. Concomitant with this increase of the lateral cerebellar lobes, there is an expansion in the dentate nucleus. The reason for this growth in the cerebetlar hemispheres and the corresponding development of the dentate nucleus is found in the connections of the comrdinating organ. The vermis of the cerebellum has a much more restrieted connection than the lateral Iobes. It is in communication by means of afferent spinecerebellar tracts with the spinal cord and by olivo-cerebellar fibers as well as restibulo-cerebellar fibers, with the oblongata. The lateral lobes, on the other hand, altheugh connected with the axial portions of the brain by olivo-cerebellar fibers, reecive their main tributaries from the pallio-pontocorebellar fibers. These axons connect the lateral hobes of the cerebellum with the hemispheres of the cerebrum. In other words, the vermis of the cerebellum responds to such inthux of impulses as may arise from cerebellar representation in the spinal cord and oblongata; whereas the cerebellar hemispheres are responsive to mure complex neural syntheses ereated within the cerebral cortex as well as in the oblongata. Impulses from these latter sources appear to reguire more expansive cerebellar receiving areas for their caboration than is afforded by the vermal cortex. It is apparent that the phyletic growth of the cerebral hemispheres has determined cerebellar expansion. In propertion as the cerebral cortex becomes more highly convoluted, the connections between the cerebral and cerebellar hemispheres enlarge and the lateral lobes of the eerebellum expand correspondingly.

The case of the vermis is different. Its connections are exchusively segmental, that is to say, with the definitely segmented portions of the central axis. The lateral cerebellar lobes, although possessing certain segmental connections, establish their preeminent communications by means of suprasegmental fibers. These latter fibers arise in portions of the central nervous system which have developed as superstruetures over and above the primordial segmented neuraxis. 
The dy namie significance of the suprasegmental divisions of the nervous system has already been mentioned in relation to the atual and potential expansions of the brain. Such expansions provide further eppertunity for increasing the range and number of neural syntheses in the progressive adaptations of animal behavior. To find the dentate nucless expanding concurrently with the lateral hemispheres of the cerebellum and the cerebral hemispheres reflects the tendency of this nucleus to participate in the progressive development of behavioral adaptation. For this reason, the nucleus may be aceepted as a reliable index of the condinative adaptability of the animal. Its size, propertions and definition may, to an extent at least, be taken to indicate the range and intricacy of behavioral adjustments of which an animal is capable.

Connectrons of the Dextate Niclecs. As the gateway of impulses passing out of the cerebellum, the nucleas dentatus has its major connection, by way of the superior cerebellar peduncle, with the red nucleus in the midbrain. This latter structure acts as an intermediate relay for the conduction of impulses through the axis to their various levels of distribution in the brain stem and spinal cord. The course of the fibers constituting the superior cerebellar peduncte need not be considered in detail further than to observe that by means of two major decussations, both of which oecur in the midbrain, the final connection between the dentate nueleus and the muscles is ipsilateral. In this way, the dentate nucleus on one side distributes the impulses from the cerebellum to the musculature of the corresponding side of the bodr. Acting thus in the capacity of the chief efferent distributing station in the cerebethm, the dentate nucleus is conneeted by means of cortico-dentate fibers with areas in the lateral lobes of the cerebellum as well as in the vermis. Syntheses of coordinating impulses arising in the cortex of the vermis and the lateral lobes thus make their way to the dentate nucleus and here find an outlet for their stabilizing influence over the muscles of the body. 


\section{THE NLCLELS GLOBOSLS}

The nucleus globosus chicfly represents the central or vermal portions of the cerebellum. Functionaly the rermis is more rigidly fixed and responds but little to the progressive expansions of behavior. It supplies coordinative control to the axial muscles which show considerably less adaptive variation than the appendicular muscles. These axial muscles determine primordial postural patterns of the body. From the phyletic standpoint their coordinative control is paleostatic. It has been present from the beginning of vertebrate organization when trunkal movements were the preeminent requisites of locomotion. The expansion of such trunkal movements, as behavior becomes progressively more complieated, is relatively small in comparison with that of limb morements. Hence the mucleus globosus shows no marked degree of development coneomitant with the ecrebellar lobes or the cerebral hemispheres. In this respect it diflers from the dentate nucleus.

\section{COMPARISON OF NUCLELS DENTATUS AND NUCLELS GLOBOSUS IN LOWER PRIMATES}

In general, the clentate nucleus appears most prominent in such animals as are possessed of the most highly clifferentiated forelimbs. These nuclear relations when applied to the lemur, tarsier, marmoset and myectes are made clear in the planimetric and Iongitudinal coefficients as shown in the tables:

Planimetric Coefficients of the Niclels Dentates and Nuclels Globosus in Lemir, Tarsier, Marmoset and Mrcetes

\begin{tabular}{|lccc|}
\hline & Species & Nucleus Dentatus & Nucleus Globosus \\
\hline Lemur & -.110 & .030 \\
\hline Tarsier & .050 & .037 \\
\hline Marmoset & .077 & .050 \\
\hline Mycetes & 130 & .032 \\
\hline
\end{tabular}


Longhtednal Cofffichents of the Nuglegs Dentates and Nechles Globoses iN Lemir, Tarsier, Marnosit and Mrohits

\begin{tabular}{|c|c|c|}
\hline Specie's & Nucleus Dentatus & Nucleus Globousus \\
\hline Lemur & 230 & I0 \\
\hline Tarsier & .180 & . I1 \\
\hline Marmoset & .150 & .10 \\
\hline Mycetes & .150 & . \\
\hline
\end{tabular}

Athough the differences in these species are not so striking as in the higher primates, they are sufficient to indieate that an evolutional process has impressed its influence upon the chief ecrebellar nuclei.

\section{THE NLCLELS RLBER}

The nucleas ruber of the midbrain, which is the principal relay station between the cerebellum and the spinal cord, is particularly sensitive to cerebellar expansion. It thus offers a reliable index of augmentation in coordinative control over the muscles. Since the red nucleus receives impulses directly from the nucleus dentatus, the increments in the former should be proportional to those in the latter. In other words, if there does occur an actual increase in the coordinative control arising from the cerebellum both the dentate and the red nuclei should show increments of expansion in their coefficients pari passu. That such is not the fact, either in the lower primates or in the primate series as a whoke, calls for explanation. In comparing the red nuclens in the lower primates, there is a progressive rise from the lemur to mycetes. This increase is so pronounced as to leave little question of a progressive expansion in this nuclear structure of the midbrain. The longitudinal coefficients likewise show a corresponding increment in the nucleus. 
These coefficients are shown in the acompanying table:

Coeffichents of the Red Nerlecs ix thf Lower Primates

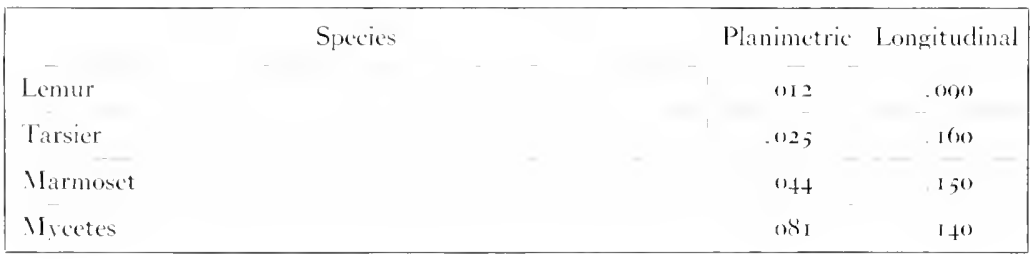

LACK OF STRICT FUNCTIONAL PARALLELISM BETWEEN

FIIE DENTATE NLCLELS AND THE NUCLECS RLBER

One fact, however. is not satisfactorily explained by these data; namely, that the inerement of the dentate nucleus in these species does not vary pari passu with the inerement of the red nucleus. This disparity probably indicates a lack of striet functional parallelism between the dentate nucleus on the one hand and the nucleus ruber on the other. Such disparity may be explained by eertain fibers arising in the red nueleus and passing forward through higher levels to the suprasegmental portions of the axis. There is also some evidence to indicate that certain descending fibers from the region of the corpus striatum connect the latter body to subadjacent aggregations of eray matter in the nucleus ruber. This nucleus maty, therefore, represent a composite relay station into which enter impulses not only from the cerebellum, but certain others from the corpus striatum as well. Thus, insofar as the functional significance of the red nucleus is concerned, variations in the increment of its expansion are perhaps less important as bearing upon the function of coordination than those of the dentate nucleus. It may be regarded, however, as collateral evidence in relation to this function, and is not without value in estimating the progressive changes gong forward in the carebellum. 
1. The Ponthe Viclei ix Their Relation ro the Regletion on Skilled Motemexis, Particllarly iN the Upper Extremt

THE PONS VAROLH AS AX INDEX OF INTELLIGENCI

A statement to the effeet that the pons Varolii may be held als an index of the intelligenee possessed by an animal has found considerable aceeptance. Allowing for a degree of exagereration inherent in all such asiomatic formulations, it may be safe to say that the pons Varolii does tor a large extent indjcate the proficiency attained in the power, range and complexity of skilled performances. A structure, therefore, providing direct indieations of such specializations would de fator represent the extent to which the intelligenee has been developed.

The size of the pons Varolii varies conspicuously in the different orders of mammals. Being primarily a mammalian structure, it has its lowest representation in those animals which have least developed the use of the fore or hind legs. Its highest development oceurs in those animals in which the forelimbs have become freed from the function of carrying the body, and are employed for purposes other than those of locomotion. Thus, while in monotremes and edentates the pons Varolii is small to the point of being almost negligible, in primates and most particularly in man, it reaches its greatest dimensions. The physiological substratum underlying this variation in size is defmite and significant. In the execution of any learned skilled performance, it has been shown that there is need for the concurrence of two simultaneous streams of innervation. In the first place, the design, pattern, extent and duration of the act must be devised and directed; its incentive must be constructed and its limitations prescribed. While the stream of nerve impulses constituting this synthesis is being built up and distributed to the effector structures, a second stream must run parallef with it in order to maintain the proper coordination of the muscles. That the incentive syn- 
thesis to any such skilled or learned performance has its origin in many areas of the cerebral eortex is the enencrally aceepted opinion of the present day. According to this view each specialized area of the neopallium mas, and probably does, participate in the formulation of this incentive synthesis. Kinesthetic sense, general body sense, vision, hearing, the sense of smell and eren of taste, together with certain higher discriminative faculties imparting the elements of judgment, all contribute to this composite body of impulses which finally combine to form an incentivesynthesis. The genesis of thesecond of the two concurrent streams is of equal importance. Each major functional region of the cerebral cortex-such, for example, as the frontal, the parietal, the temporal and the occipital lobe-gives rise to a group of fibers which, becoming collected, enter the corona radiata, thence pass through the internal capsule, into the cerebral peduncle, and ultimatcly end in the pons Varolii. These are known as the pallio-pontile fibers. Their several subdivisions are specifically indicated as the fronto-pontile, parieto-pontile, temporo-pontile and occipito-pontile contingents. Each contingent by means of synapses in a large nuclear mass of the pons Varohii, the pontile nuclei, gains ultimate connection with the lateral lobes of the cerebellum.

Those animals with small-sized lobes of cerebral cortex contribute correspondingly small contingents to this pallio-ponto-cerebellar system. In consequence, not only the number of fibers entering into the pons from this source, but the size of the pontile nucleus necessary to relay them therein, is correspondingly small. Henee, the animal equipped with a small cerebral cortex must of necessity have a small pons Varolii. From the functional standpoint, the smallness of the pons is indicative of an animal poorly equipped in the more complex varicties of skifled learned performances. For these reasons the size of the pontile nuclei may also be employed as a reliable index in estimating the degree of expansion in the cerebral cortex, and, from such estimation, in arriving at an opinion as to the degree to which that animal 
has developed its skilled performances. No more cogent indicator of these specialized functional capacities may be obtained in the brain stem. It is, perhaps, even safe to say that of all the structures in this part of the central nervous system, none is more reliable or important than these nuctei lodged in the pons Varolii.

COMPARISON OF PONTILE NLCLEI IN LOWER PRIMATES

In looking to this structure, therefore, for evidence of evolutional unfolding, a comparison of the lower primates gives the impression of a progressive development in this nuclear group of the pons. Such a structural expansion is also well borne out physiologically by the increment manifested by these animals in their acquired learned reactions, and more particularly those performances executed by means of the upper extremities.

A tabulation showing the planimetric coefficients of the pontile nuclei in lemur, tarsier, marmoset and mycetes is appended. From it, a progressive expansion is readily apparent, myeetes having nuclei nearly twice the size of lemur. There may be some question concerning the relatively high pontile differentiation manifested by the marmoset, an animal known to possess a manual differentiation quite inferior to that of lemur. In spite of this apparent diserepancy, there is a strong probability that the entire family of Hapalidae employ the upper extremities in a much more hand-like manner than is true of the lemurs. Hence, while structurally the hands in the marmo-

Coefficients of the Pontile Nuclei in the Lower Primiates

\begin{tabular}{|c|c|c|}
\hline Species & Planimetric & Longitudinal \\
\hline Lemur & .053 & .270 \\
\hline Tarsier & .057 & $.33^{\circ}$ \\
\hline Marmoset & $.09 j$ & .230 \\
\hline Mycetes & .103 & .350 \\
\hline
\end{tabular}


set have not attained the degree of specialization that characterizes lemur or myeetes, they still have derekped sufficient capacity for complex skilled performances to necessitate relatively extensive pontile nuelei.

\section{THE PALLIO-PONTO-CEREBELLAR SISTEM}

By means of the relay already referred to in the pons, the pallio-pontile srstem is continued into the cercbellum. This entire allection of fibers constitutes what is termed the pallio-ponte-cerebellar system. As these fibers take their origin in the cerebral cortex, they are spread out much in the manner of a fan, becoming convergent as they approach the internal capsule and cerebral peduncle. In their termination, also, they arain spread out in relation with the lateral lobes of the cerebellum. Thus, the pallio-pontocerebellar system has in relation with it two conspicuous fan-like radiations: one at its origin in the cerebral cortex, another in its termination in the lateral lobe of the cerebellum. This is a morphological fact of much significance, clearly indicating as it does the many regions of the cerebral cortex which are comnected with all areas of the lateral lobe of the cercbellum. Furthermore, as the cerebral hemisphere increases in size and prominenee during the comrse of evolutionary expansion, this pallio-ponto-cerebellar system likewise gains in volume. It contains a greater number of fibers in those animals possessed of large hemispheres with well-defined lobation than in those species in which lobation is more inconspicuous. It follows that in proportion as the number of fibers arising in the cerebral cortex is large, so also are the pontile nuclei.

Functional Significance of Pallio-ponto-cerebellar Fibers. Clinical and pathological conditions have not as yet yelded sat isfactory evidence concerning the functional significance of these pallio-ponto-cerebellar fibers. The reason for this deficiency is not far to seck. Lesions in the cerebral hemisphere near the surface of the cortex where these fibers take origin, in 
the corona radiata, or in the internal capsule where thes become converent toward the corebral peduncke, are not discrete enough to produce exclusive involvement of the pallio-pontile axons. Thus it is that no pure disturbance involving this system has yet been observed. Either the motor system or some part of the sensory system is simultaneously implicated by the lesion, and so adds elements which raise doubts as to the specific function of the pallio-ponto-cerebetlar fibers. Experimental lesions are complicated by similar diffeculties. Neither of these sources of information has, therefore, contributed as much as might be desired in revealing the functional activities of this system of axons. On the other hand, the increase of this system in animals capable of highty complex performances bespeaks a function which has a capacity for expansion directly preportional to the evolutional development of the cerebral hemispheres.

The origin of these fibers in the cerebral cortex, their relay in the pons Varolii, their termination in the lateral cerebellar lobes, declare them to be of utmost importance in some phase of neural activity whose mechanism ultimately depends upon the ecrebellum. This mechanism at the same time has as its essential coadjutor the controlling influence of the cerebral cortex. Whether it be finally decided that the functional capacity of the pallioponto-cerebellar system is primarily in the interest of coordination for the performanee of complex skilled acts, or whether it is shown that there exists some other reeiprocal relation between the cerebellum on the one hand and the cerebral cortex on the other, is a question for further investigation to decide. In either case the pontile nuclei serve as a relay for a great system of fibers arising in the neopallium. They show progressive expansion in proportion to the evolutional development of the endbrain. Such expansion goes hand in hand with the aequisition of more complex, more numerous, more varied voluntary performances, capable of producing a greater continuity in action. That motor activities characterized by such qualities as these are 
most commonly seen in those animals which have gained comparative freedom of the upper extremities from the offices of locomotion, is obviously true without further prool. As a corollary to the supposition that the pontile nuclei increase in proportion as the animal becomes more capable in its skilled performances, it is true that these nuclei also expand as greater manual differentiation is attaincel. It may therefore be held that the progressive increment in this important group of nuclei bears clelinite relation to the increasing capacities acquired as the forelimbs become more precisely capable of manual function.

vil. The Colliclli of the Midbrax in Their Relation to SigITT AND HEARING

TIIEIR PRIMORDIAL EMINENCE IN AUDITORY AND VISLAL FLNCTIONS

The history of the mesencephalon indicates that this portion of the brain has presided over many important functions during the development of the phylum. It quite as clearly clemonstrates the waning predominance of this part of the brain as evolution proceeded. Not the least important among the earlier functions of the midbrain are those connected with the special senses of sight and hearing. One portion of the midbrain has become so highty specialized for visual function that it has earned for itself in many of the lower forms of vertebrates the title of optic lobe. Thus in the fish, in the amphibia, in the reptifes and in the birds the optic lobe is one of the most conspicuous parts of the entire brain. Similarly, a more caudal portion of the roofplate of the midbrain became highly differentiated in comnection with the function of hearing. But one of the most striking marks of progress as the brain found opportunity to provide for more ample syntheses in the different sensory spheres is the manner in which the midbrain has lost its ancient prestige. Those extensive areas developed in relation to sight and hearing 
have gradually been deprised of their morphological prominence. In the primates they appear as inconspieusus dements covered by the groatly expanded endbrain.

In viewing the mesencephaton and its two sets of colliculi, the fact of their primordial eminence in auditory and visual functions must not be overtooked. Nor must it be comsidered a sudden departure from an old architectural design that these two areas of the brain have passed intorelat tive insignificanec. It was by the gradual delegation of visual and auditory functions to other regions that the midbrain became progressively redaced. Apparently the object of this delegation of former power to other areas was to enlist the activities of a more promising region. There was need of sullicient expansion to accommodate the rapidly growing clemand for more complex associations in the realms of sight and hearing. The portion of the nervous system which has shown the chief propensity in this direction is the telencephaton. It is the last of all the brain constituents to make its appearance in the process of individual as well as phyletic development. In the endbrain there are special regions known respectively as the auditory or temporal area and the visual or eceipital area, which have largely taken over the functions of hearing and of vision.

\section{COMPARISON OF THE INFERIOR COLLICULI OF LOWER PRIMATES}

Yet in spite of this assumption of functional activity on the part of the cerebral hemispheres, the midbrain has not altogether given over its original autonomy. A comparison of the lower primates, such as femur, with man clearly reveals this fact. Even a comparison of closely allied hower primates indicates that to some extent at laast the progressive delegation of function from the colliculi to the endbrain is in process. The inferior colliculus, connected with hearing, shows in its planimetric coefficients a definite dectine almost as striking in its longitudinal coeflicients. 
Cofficitnts of the Inferior Colliclli in thf Lower Prinates

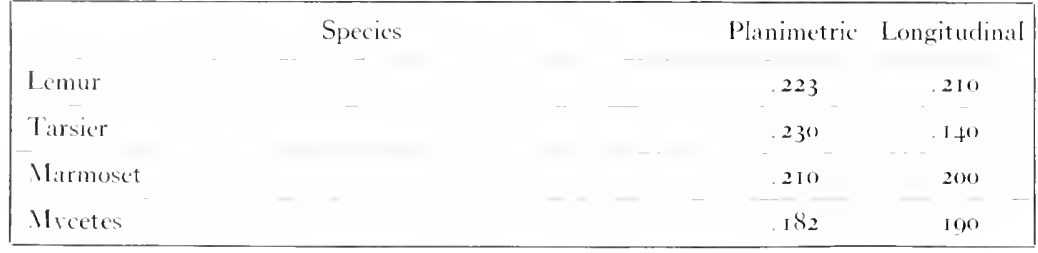

Coffficients of the Seperigr Colliclli in the Lower Primates

\begin{tabular}{|c|c|c|c|}
\hline & Species & Planimetric & Longitudinal \\
\hline Lemur & & $1+0$ & 2001 \\
\hline Tarsicr & & $.33^{-}$ & 200 \\
\hline Marmoset & & I 54 & 130 \\
\hline Mroctes & & .161 & 130 \\
\hline
\end{tabular}

This would seem to signify that the auditory function in passing from the lower to the upper end of the primate order has tended to lose much of its immediate reactive foree; in other words, auditory impulses transmitted to the central nerous system become proceressively more in need of the supervision by higher synthetizing areas. In these newer cortical areas they are more complexly associated, more extensively evaluated. Apparently the need of immediate retlex reactions in response to auditory stimulation is less important to the higher members of the primate gromp than to the lower species. Thus a sudden sound coming into the lemur's ficld of consciousness immediately provokes a motor response in the interest of defense or escape. The same somnd arising in the auditory sphere of man is first subjected to more extensive associational review before action is determined by it. The difference in behavior manifested by these two types of reaction indicates that a greater number of alternatives are possible to man than to such a low form of primate as the lemur. In the latter, the quick response to auditory stimuli would undoubtedly prove more to its advantage than a course of 
action in which the stimuli are furst submitted to a process of deliberation and selection.

The decline of the superior or visual colliculus is more conspicueus in the planimetric eofficients than that of the inferior colliculus; and furthermore the longitudinal coeflicients of the superior colliculus show al definite decrease in myectes if compared cither with the lemur or tarsius. The inference seems fair that the superior colliculus in tarsius is rested with more visual function than is the case with the other lower primates bere discussed. The decrease, therefore, in prominence of both the inferior and superion colliculus, altheugh it is not strikingly shown in the codlicients, must be aceepted as marking the inception of that gradual process whose linal consummation is secu in the conditions observed in man. These two midbrain structures, even within the circumscribed limits of the primate order, disclose a most illuminating reeord regarding the evolutional process which has taken place in the brain stem. Unlike other structures heretofore considered, their cridenee speaks in lavor of waning function, of a steady delegation of this function to other expanding portions of the brain. For those who may wish to realize more clearly how this part of the midbrain reveals the course of evolution, a review of the conditions in the mesencephalon of the lowe forms of vertebrates is especially recommended. Here may be seen the huge optic lobes of the fish, the bird or the reptile. Their size compared with the relatively insignificant colliculi of primates speaks strongly in favor of an evolutionary defloreseence which reaches its final stages in the human brain.

vili. The Oculomotor Decussation in Relation to Binocular Vision

Another notable feature in the mesencephalic portion of the brain stem is the internuclear connection between the two main cell groups in the oculomotor nucleus. This nucleus, involved as it is in the regulation of oculomotor 
movements, atfords the final common pathway for all ocular innervation with the exeeption of the superior oblique and the external rectus muscles. The important feature concerning the internuclear connection of this cell group arises from the fact that in the higher arades of the primate series, the nuclei of the two sides are most extensively connected by means of commisstral and decussating fibers. From the functional standpoint this interrelationship between the nuclei denotes an increasing capacity for condinating the nerve impulses arising in the two nuclear groups. Thus, the oculomotor nucleus which is provided with the least abundant intercommunication between the groups on the two sides would, in comparison with a similar nucleus having an extensive intereommunication, be capable of far less conjugate control of the museles moving the two eres.

\section{RELATION OF CLOSE INTERNLCLEAR CONNECTIONS TO BINOCULAR IISION}

The serial increase in this internuclear connection appears to be attended by an increasing degree of bincoular vision possessed by the animal. The establishment of such vision primarily requires that the visual axes of the two eyes shall be capable of maintaining the primary position of Listing, that is to say, in parallel. Also for the purposes of near vision with close focusing they should have the capacity of convergence to a certain degree at least. These two positions of the visual axes, in parallel and in envergence, depend upon the conperative action of the oculomotor muscles of the two eges. There must be a simultaneous adjustment in the contractural tension, not only in holding the gaze fixed upon distant and nearby objects, but in moving the eyes through horizontal as well as vertical ares.

The more closely, therefore, the oculomotor nuclei of the two sides are interrelated by means of connections between them, the more likely is such harmony of action to be obtained in the reulomotor movements. Conse- 
quently, the presence of a rich internuclear communication vouchastes the more accurate conjugation of the visual axes in the interest of bineculat vision.

Tile Neclees of Perian. The late Dr. John Hunter has demonstrated that a special medial group of cedls, the nucleus of Perlia, develops especially in the interest of ocular convergence. The nucleus is small or absent in animals possessing little or no attaimment of binocular stereoserpic vision. It is present in tarsius but in that species is much smaller than in the higher primates whose vision is effectively stereoscopic. The phy letic significance of this nucleus of Perlia corresponds closely with that of the interoculomotor decussation.

\section{EFFECT OF DEVELOPMENT OF STEREOSCOPIC VISION}

The development of stereoscopic vision has profound effects which far exced the limits of visual sensibility alonc. It actually produces al decisive influence upon the development of motion. It particularly affects those movements which depend for their execution upon the fine, minute and precise skilled acts employed in performances acquired and directed by vision. There are certain acts which may be accuired only if vision is capable of directing and furnishing the proper spatial relations for their guidance. Such a highly skilled performance as taking aim at a distant mark could be acquired and executed only with risual assistance. Acts in which a definite aim or direction is a prerequisite, although the distance from the eycs may be but slight, also require a similar degree of visual supervision.

COMPARISON OF THE VISUAL FUNCTION OF THE LOWER PRIMATES

A great number of skilled performances depend, therefore, upon the function of vision. They are often rendered impossible or defective if for any reason they are deprived of visual guidance. The largest number of these 
skilled acts pertain to those performances demanding the greatest manual dexterity, such, for example, as handwriting, carving, painting and the use of instruments, implements and tools. Many skilled performances of a much simpler natureare also dependent upon vision for their acquisition and retention. This fact may be discerned in the infant learning to grasp, hold and manipulate objects. It is, howerer, only as these manual activities become more complex, more exacting in their precision, that the full degree of visual regulation is demanded by them. The advantage of stereoseopic vision in producing perspective and proper distance relations then becomes indispensable. In other words, stereoseopic vision should be regarded as a fundamental contribution to the upbuilding of the most highly complex performances. Even in the fower primates this tendeney is elearly observed, as the coeflicients of the oculomotor decussation show. Thus, in the lemur, whose eres are widely separated and in which the need of extensive stereoscopic vision is not pronounced, the oculomotor decussation aecupies but 16 per cent of the entire oculomotor nucleus. Only a relatively small portion of this aggregation of cells is brought into close internuclear relation. This fact accords with the relatively limited degree of skilled performances of which these animals are capable. In tarsius it was impossible to estimate the extent of the decussation by mensuration. The animal possesses a certain degree of binocular vision which, however, is probably not stereosenpic.

Marmoset, on the other hand, shows a more extensive internuckear connection. Its longitudinal coefficient of the oculomotor decussation is 38 per cent, a fact which is quite in keeping with the closer relation of the eyes and a greater range of finer movements. It would seem, therefore, in this comparison, that binocular vision is more essential to the marmoset than to the lemur.

A still more striking difference is apparent in the mycetes, the oculomotor decussation of which occupies 69 per cent of the entire length of the 
aculomotor nucleus. This at once indicates a group of nuclei which have much cheser internuncial relation by means of the decussating and commissural fibers. Myectes exceeds lemur, tarsius and marmoset in its range of acepuired skilled movements. It has a much more hand-like disposition in the motor adaptations of its forclimbs. The tabulation of the lomgitudinal coefficients of the oculomotor decussation is:

Longht dinal Colfficients of Och lonotor Dercssanon in Lower Primatis

\begin{tabular}{|c|c|c|}
\hline & Species & Coefficient \\
\hline Lemur & & 100 \\
\hline Tarsier & & \\
\hline Marmoset & & 380 \\
\hline Mycetes & & $\log (x)$ \\
\hline
\end{tabular}

\section{The laportant Factor iN Progressive Developient}

\section{of Behayoral Activity}

If the progressive development in behavioral activity traced through these lower primates could be attributed to a single factor it might be ascribed to an increase in discriminative sensibility. The evidence of such an increase is apparent in comparing lemur, tarsius, marmoset and mycetes. The influx of new volumes of sensory stimuli from such an organ as the developing hand or incident to the progressive differentiation of the prehensile tail could not fail to introduce new powers for the direction of motion. It would inevitably expand kinesthetic memories and associations. By enriching the entire field of somesthetic sensation it supplies the basis for new motor activities. This expansion in discriminative sensibility is not limited to those impulses arising from the somesthetic receptors alone. Vision and hearing have likewise undergone a similar extension. The combinations and intercombinations among these several types of sensory perception thus 
provide dynamie material for a progressively widening sphere of behavioral performance.

The physiological substratum of such semsory augmentation may be seen in increments to the rolitional control of manual moxements. It is also witnessed in the expansion of coordinative regulation whese structural representation is seen in the elose interrelation between the cerebellum and the great ficlds of sensory pereeption in the cerebral cortex. It is apparent in the progressive development of coordination for simultaneous movements of head, ere and hand, structurally indicated by increase in the inferine olivary nucleus. The increment in the oculomotor decussation introduced for binosular and stereoseopic vision renders still more exact those skilled movements made possible through the influs of new sensory impressions. It leads directly to the uplouilding of more extensive kinesthet ic associations.

The dynamic ineentives determining all of this expansion may not yet be discerned with cleamess. If, however, some motive were presumed to direct the structural design of this presess, its goal might well be that instrument with which to dominate the enviromment most eflectively, such for example as the hand. 


\section{PART II \\ THE INTERMEDIATE PRIMATES}





\section{INTRODUCTION TO PART II}

$\mathbb{V}$

ALID objections may be urged against the establishment of such a group as the intermediate primates upon phylogenetie or paleontoIngrical grounds. But there are substantial reasons for this distinction because of cert ain likenesses in these brains. It should be understend, however, that such similarities as do exist in the encephalon of this intermediate group do not constitute an entirely satisfactory basis for the far-reaching generic associations which this grouping would secm to imply. They offer convenient criteria for distinguishing between these forms possessed of brains having relatively the most simple design, and these which have become more complex in their constitution.

The intermediate primates comprise all of the old-world monkeys with the exception of the three great man-like apes. According to this classification, the Hylobatidae or gibbons fall into the intermediate class. This group also comprises all of the members of the great family of Lasiopygidac, which includes the baboons, mandrils, the macaques and cynocephalous monkers, the mangabeys, guenons and langeurs. The most forcible objection which might be urged against the inclusion of the gibbons in this group is their many striking anthropoid characters. A survey of the central nervous system of these primates, however, would seem to justify the view that they are in many respeets more primitive than the man-like apes. In size of brain and in configuration of fissural pattern, the gibbons come much nearer to the lasiopygidal species than they do to the higher anthropoids.

The species of intermediate primates selected for description include Papio cynocephalus (Cynocephahus babuin), one of the large dog-headed baboons, Pithecus rhesus (Macacus rhesus), the common macaque of India, and Hylobates hoolock, the gibbon. 
Mang features in the behavior of the gibbon are noteworthy and raise the animal to a plane somewhat above that of the other intermediate primates. In hylebates the brachiating type of locomotion has replaced the pronengade specialization of lower primates. Swinging from the branches by the fong arms has obviously produced a greater erectness of the body in the gibbon than is true of any othere intermediate primates. The gibbon also is able to stand, walk and even run in the creet posture. This hybobate crectness therefore appears to be the first itep toward the manlike specializations of bipedal focomotion and bimanal differentiation. These facts warant the recosnition of the Proanthropoid Stage as reprenented by the ribbons. 


\section{Chapter X}

\section{PAPIO CINOCEPHALUS, TIEE COMIMON DOG-IEEDED BABOON, ITS BRAIN AND BEHAVIOR}

Its Position among the Primates; Measurements and Brain Indices; Surface Appearance of the Brain; Internal Structure of the Brain Stem in Cross Section

WE genus Papio comprises all of the eynocephalous or doy-headed
baboons. In general, these animals possess a massive body, and the
adult is remarkable for its great strength. As a group they are considered the lowest of the old-world or Catarrhine nonkeys. Because of the ir large size and great strength they are looked upon as dangerous animak particularly as they have ageressive, ugly natures.

\section{Appearance of the Baboon}

The face and head of the baboon are dog-like and elongated; the nostrils have a canine disposition. The tail is variable in length but never prehensile and sometimes only rudimentary. It is usually carried with a curve near the basal extremity arching away from the body, the remainder of the tail hanging straight downward. All species of papio possess callosities or fleshy pads about the buttocks which in some instances are of large size and Jrilliantly colored, the coloring being intensified especially in the females during the mating season. At such times these callosities in the females may increase in size so that they cover nearly the entire ghuteal region. Along the rostrum of eertain species there develop bony ridges elevated nearly to the lerel of the eyes. These ridges are most common in the males and the skin orer them is brightly colored. In the mandril the skin over the ridge is of a bluish color, while the skin on the bridge of the nose is red. This coloring adds considerably 
to the almost repulsive and unattractive countenance of the animal. The fore- and hindlimbs are of nearly equal length. The species run on their hands and feet with the eyes directed downward so that they are obliged to elevate

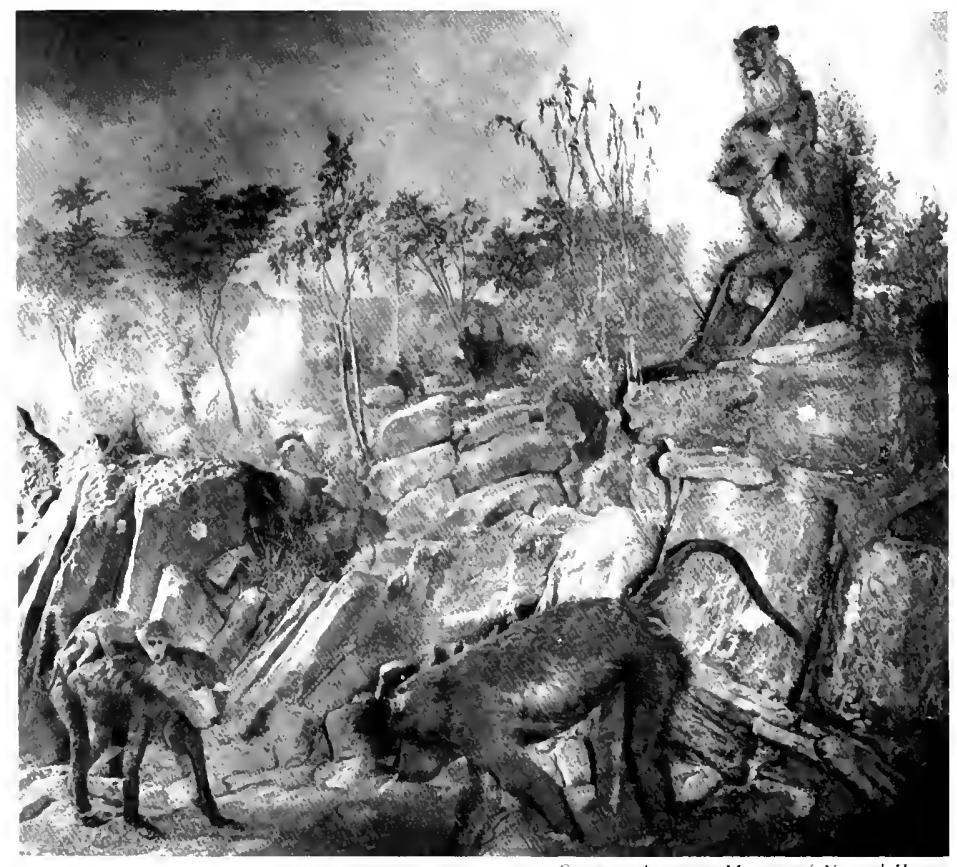

Constesy. American Mureum of Natural Haver

FIG. I 32. IIABITAT GROLP. BABOON AT THE WATER HOLE.

the large, overhanging eyebrows in the attempt to lexk upward and forward. The palms of the hands together with the soles of the feet are laid flat upon the ground in walking and rumning. The thumb is long and prominent, reaching to the middle of the first joint of the forefinger. The neck is also relatively loner, and check pouches are present. 
The Baboon's Habits in the Mild State ind M Captimy

These apes are gregarious and usually go in large herds. Often as many as a hundred individuals gather together in one herd. Because of their large

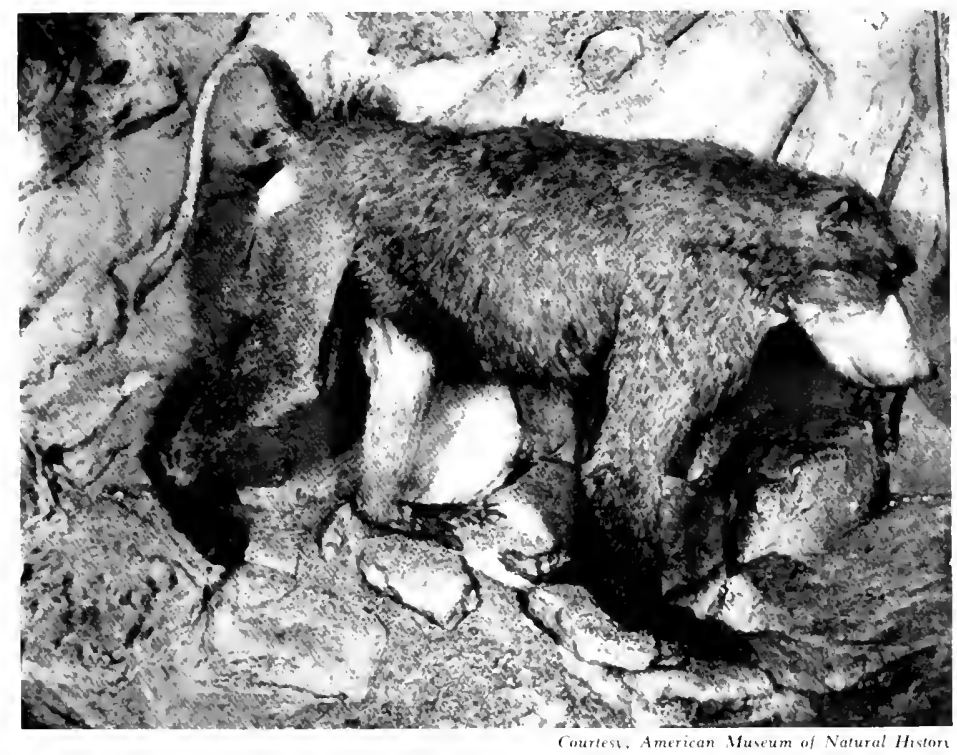

FIG. 133. PAPfO CYNOCEPHALUS (BABOON).

number and aggressive chispositions, they become formidable antagonists especially when irritated or disturbed. They hare canines which, being long and sharply pointed, are capable of inflicting dangerous and severe wounds. They appear to possess a series of articulate sounds, various in kind, resembling barks, grunts or even screams. Sometimes they make low and subdued murmurs, imparting to them various inflections which are comprehended at once by members of the herd. Often the slightest murmur of warning made by one member of the herd will determine a course of action on the part of all 
the rest. This is especially true in determining llight when the animals are engaged either in pillage or mischiel. Occupied in such operations as this, an outpost is usually set in some favorable point from which to give notice of the
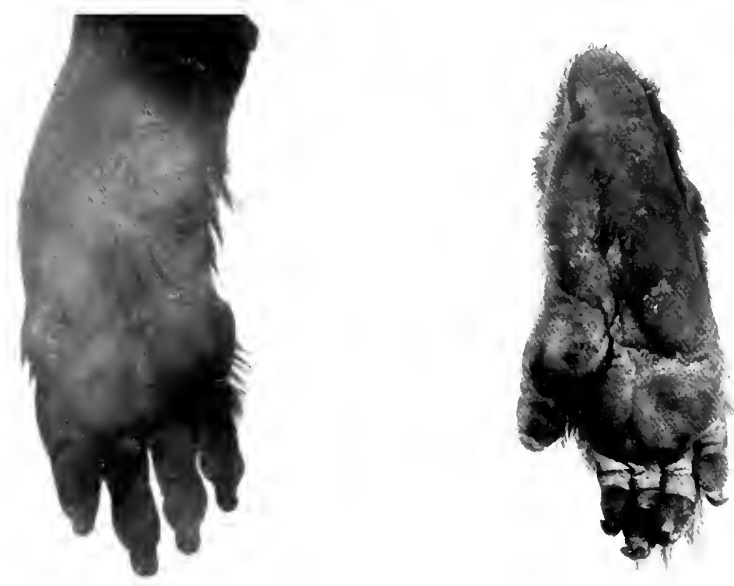

Courtest. American Museum af Natural Hevory

IIGS. 134 AND I3j. HAND AND FOOT OF PAPIO CYNOCEPHALUS.

LetT Palmar surface of the hand showing broadening of the palm with a hect-fike development in the hypothenar eminence, shortening of the digits including the thumb. These changes are in adaptation to terrestrial life.

Righr. Plantar surface of the foot showing shortening of the teres, bread batl of the fort and narrow hed, modifications for terrestrial lecomotion.

approach of a foe and thus enable the marauders to escape.

These baboons inhabit rocky places such as ravines, crags, or hilly promontories where grass and trees are scanty. Their favorite abodes are usually in such places as are surrounded by wide plains which enable them to lie in wait for an opportune moment to commit some pillaging excursion on a garden or field and at the same time to have all opportunity to escape on the approach of danger. They are much given to malicious mischief of this 
kind, for which reason they are both feared and despised by the inhabitants of the country which they infest. If attacked, they often turn upon their pursuers and in some instances inflict serious wounds upon their assailants.
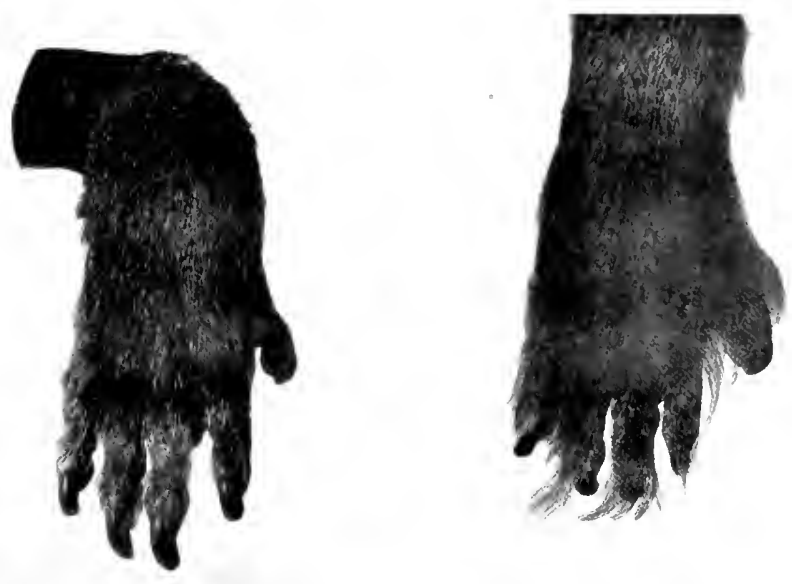

Courtest, American Mhenem of Netural Histort

FIGS. I 36 AND I 37 . HAND AND FOOT OF PAPIO CYNOCEPHALLS.

Left. Dorsum of hand showing slortening ofthe digits including the thumb, an evident adaptation tolocomotion upon the ground.

Rignt. Dorsum of foot, showing short toes, long toe nails, evidences of terrestrial adaptation.

Some species of papio, however, prefer to live in the dense forests and climb readily even in the loftiest trees. Those which live in the more open country show a marked agility in clambering among the rocks and gaining inacessible heights or positions with safety. The baboon is practically omnivorous although its chief food consists of roots, fruits, reptiles and insects. To procure these they are continually searching and turning over stones underneath which the desired objects of their quest may lic concealed.

In captivity the animals are both surly and unfriendly; even those born 
in captivity and reared thus are more diflicult to approach and much less teachable than most of the other apes. They are as vindictive, treacherous and unlikeable because of their disagreable dispositions as they are repellent to lowk at because of their more or less grotesque appearance. In teachability they show nome of that quick adjustment which is observed in most of the other monkeys. This fact, combined with their general tendeney toward savage reactions, has earned for them the reputation of being the lowest of the old-world monkers.

Their manual dexterity is limited to a marked degree, due probably to the fact that the forelimbs are used in locomotion more than in any other function. It is probable that their vision is less endowed with stereoscopie, binocular adjustments than is true of the apes who earry the body in such a manner that the head is for the most part in an upright position. The baboons seldom assume the ereet position even when supporting the body with the fordimbs upon some adjacent object. They do, however, sit upon their haunches in a somewhat erouched position but not nearly so freely as many of the other genera of Lasioprgidae.

\section{Geographical Distribition}

The genus Papio is eonlined almost exelusively to northem Africa and Arabia. The species investigated in this study is Papio eynocephalus, also spoken of as Cynocephalus babuin. The yellow baboon's habitat is Mechiterranean Africa, Nubia, central and castern Africa.

\section{Measurements and Indices of Papio Cynocephalus}

Individuals of this speeies vary consicterably in size and some of the older males are as large as members belonging to the dark-colored baboons. In general, the body length is about 1,500 or $1600 \mathrm{~mm}$. The tail is from 700 to) $730 \mathrm{~mm}$. Iong. 
Occipito-nasial lenerth of the stull

$1-3 \mathrm{~mm}$.

Interparietal width.

6. $2 \mathrm{~mm}$.

Width of the brain case.

$8-.3 \mathrm{~mm}$.

The dimensions of the brain including the cerebellum and brain stem are:

Longitudinal. ()) $\mathrm{mm}$.

Transverse (temporo-parietal or intertemporal). . $70 \mathrm{~mm}$.

Total weight of the brain. . . . . . . . . . . 127.-gm.

Total water displacement............... 125.o c.c.

Weight of the forebrain (including end-brain..... $109.0 \mathrm{gm}$.

and interbrain)

Weight of the midbrain........ . . . . 2.2 gm.

Wejght of the hindbrain.............

Upon the basis of these ligures, the following encephalic indices have been computed for the several divisions of the animal's brain:

Forebrain index..... ... ........ 83.0

Midbram index................. 3.0

Hindbrain index.................... 14.0

The forebrain index of 83 assigns the baboon to that class of animals possessed of a brain which indicates a fairly well-adranced manual development.

\section{Surface Appearance of the Brain in Papio Cynocephalls} LOBES AND FISSURES

The brain is definitely grencephalic in type. The lobation is distinct, the demarcation between the frontal and parietal lobes being clearly drawn by a prominent fissure of Rolando (Fig. I 38). This fissure leaves the superior longitudinal fissure almost at right angles, much in the manner of the 
cruciate fissure in lower mammals. It has a slight obliquity forward, however, approximating the general angulation of this fissure with the superior longrtudinal lissure as seen in the higher anthropoids and man. The frontal lobe
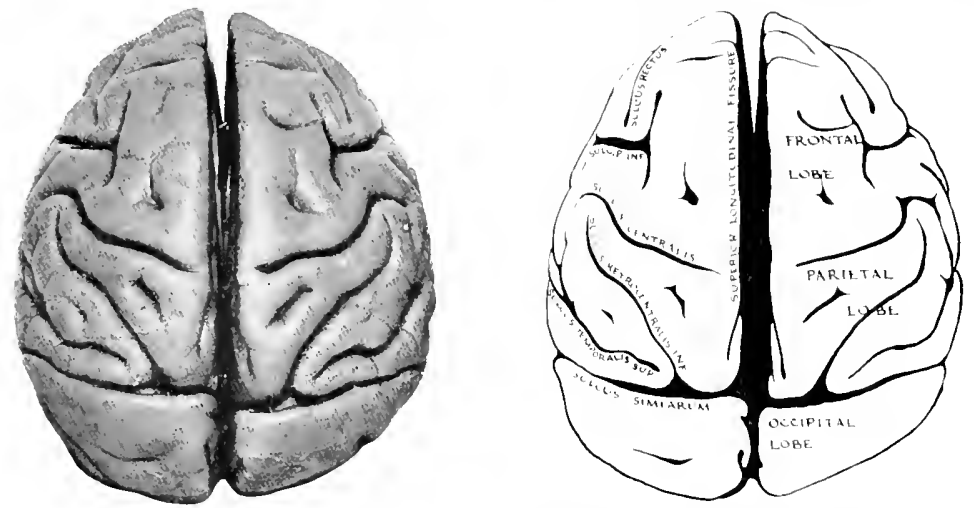

FIG. 138. DORSAL SLRFACE OF BRAI, PAPIO CYNOCEPHALES. [Actual Length $\rightarrow$ mm.]

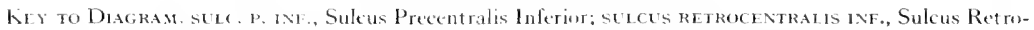
centralis Inferier; sulces tr moralis sup., Sulcus Temporalis Superior.

stands out sharply because of its marked orbital concavity into which the orbital plate of the frontal bone projects. A well-defined fissure of Sylvius extends backward and upward, more oblique in its general direction than that seen in the lower primates. It demarcates a well-defined temporal lobe the tip of which projects forward for a considerable distanee, giving it partieular prominenee in front of the horizontal limb of the fissure of Sylvius. A well-marked and long suleus simiarum separates the parjetal from the oecipital lobe, thus completing the topographical outline of the major hemispheral lobes on the convexity of the brain. The comvolutions and fissures are richest and most complex in the parictal and temporal lobes, and least pronouneed in the frontal lobe. The entire surface conliguration and the arrangement of the fissures produce the impression of a gyrencephalic pat- 
tern of moderate simplicity, in which, howerer, may Ix discenned atl the characters which later are more perfectly outlined in the higher anthropoid hemispheres.
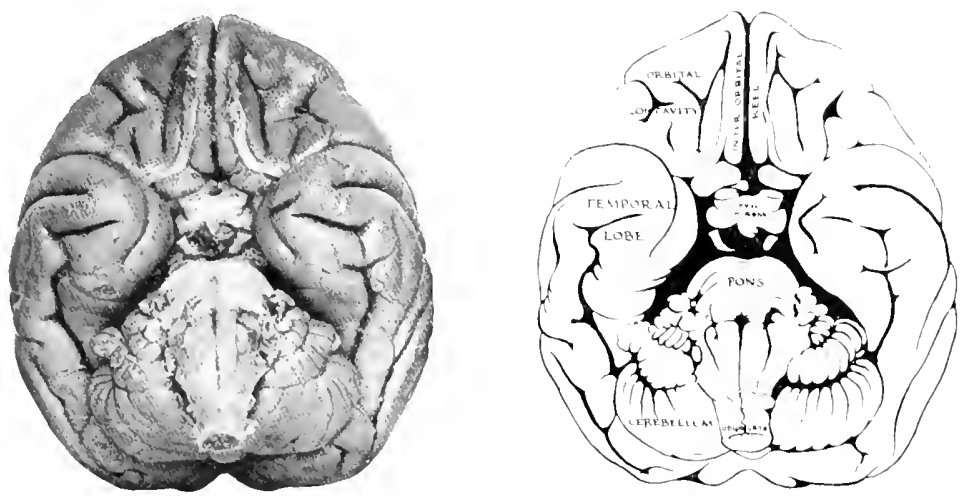

FIG. I 39. BASE OF BRAIN, PAPIO CYNOCEPHALLS. [Actual Length $\rightarrow 7 \mathrm{~mm}$.]

ORBITAL AND CEREBELLAR CONCAITTIES

As already indicated, the orbital concavity is a prominent feature, als is the case in all lower primates. Its inner margin is formed by a marked interorbital keel, along which the olfactors tract and bub extend, the tract being readily detachable up to the olfactory trigone. The incipience of a gurus rectus may be discerned in the beginning of an olfactory sulcus. The angulation of the chiasm with the tracts is typical of the primates. The cerebellar concavity is especially deep and most pronounced in the median line caudal to the splenium of the corpus callosum.

THE ENDBRAIN AND OTHER STRLCTLRES

The basal surface of the enclbrain, in its convolutional pattern, shows a distinct but somewhat feeble design typical of this region in the Anthro- 
poidea in general. The orbital surface of the frontal, the sphenoidal surface of the temporal and the oceipital surface of the occipital lobe all have indications of the typical fissures found in these regions. Sereral deep
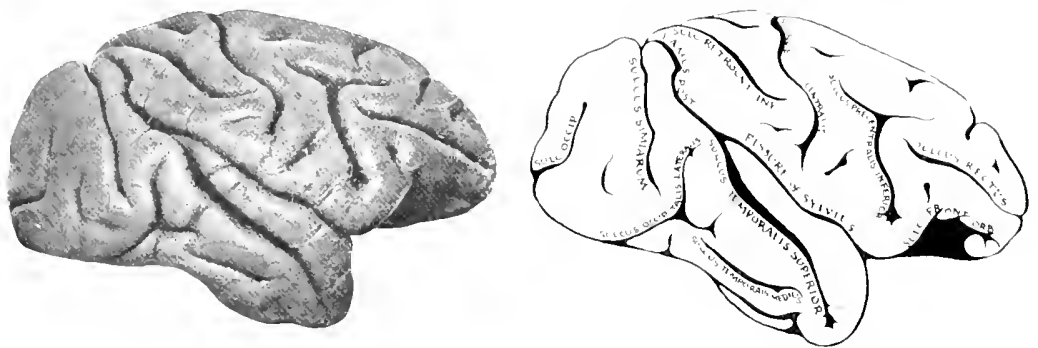

FIG. 1 fo. RIGHT LATERAL SURFACE OF BRAIN, PAPIO CINOCEPHALLS. [Actual I cingth $89 \mathrm{~mm}$.]

Key to Dagray. Rames post, Ramus Porterior of Sulci Temporali Superior; sule. Front. Orb, Sulcus Frontalis Orbitalts; sulc, actp., Sulcus Occipitalis (Inferiur); sulc. Retrocit. INF., Sulcus Retrocentralis Inferior.

annectent grres may be brought to light by the separation of the Sylvian fissure as well as the presence of a faintly outlined series of radiating gyres constituting the island of Reil. One deep annectent gyre is found midway between the two extremities of the sulcus semilunaris.

\section{THE CEREBELLUM}

The cercbellum in Papio is characterized by the relatively large size of the vermis which as ret manifests little tendency to hose its surface prominence. The tentorial surface is sharply gabled, the vermis rising as a marked median ridge-pole. The interfolial sulei are directly cont inuous without fissural interruption from vermis to lateral lobe. On the occipital surface two paramedian sulci separate the vermis from the lateral lobes, although the former have a marked prominence on this surface. The petroso-ventricular surface presents three elements: (I) a high elevated portion of the superior vermis, (2) the ventrieular portion, and (3) the petrosal area. 
THE BRAIN STEM

Numerous features upon the several surfaces of the brain stem in babom make this portion of the central nerrous system stand out in
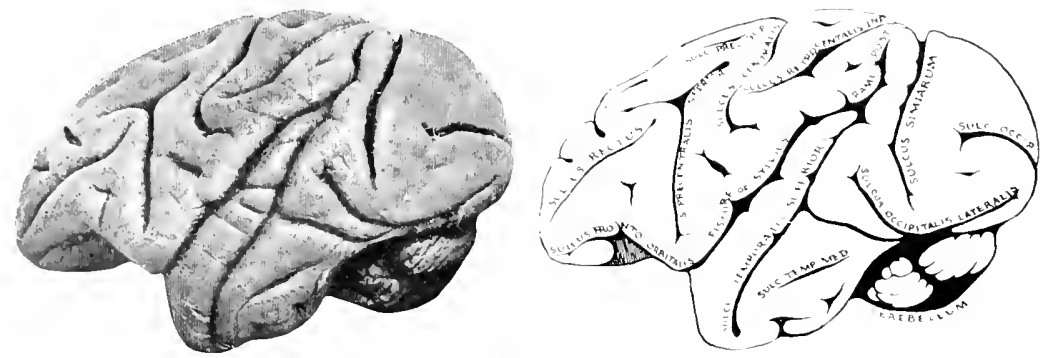

FIG. I 1 . LEFT LATER.AL SLRFACE OF BRAIN, PAPIO CYNOCEPHALIS. [Actual Length $89 \mathrm{~mm}$.

Key to Diagran. Ramus post., Ramus Posterior of Sulcus Temporalis Superior; sulc. occip., Sulcus

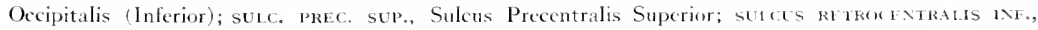
Sulcus Retrocentralis Inferior; sulc. TEmp. MED., Sulcus Temporalis Medius.

greater prominence than is the case with any of the lower primates.

The OBlongata. The oblongata presents a well-marked intermediate sulcus and two ventrolateral sulei upon its ventral surface. Two well-defined pyramidal elevations lie upon either side of the ventromedial suleus at its cephalie extremity; while the pyramids themselves are separated from two well-defined inferior olivary eminences by the ventrolateral sulei. The pyramids, as in other forms, taper caudally as they approach the lower extremity of their decussation, and in this area a faint indication of interlacing bundles interrupting the ventral sulcus may be seen, indicating the position of these crossing fibers. The relative prominence of the pyramidal elevations as well as the olivary eminences, as compared with the lower primates, signifies a progressive increase in the dimensions of these structures, and thus probably bespeaks some extension in the functions with which these two 
structures are concerned. In other words, the corticespinal comnection for the transmission of voluntary impulses shows expansion in the baboun as compared to the lower forms. The relative increase in the size of the
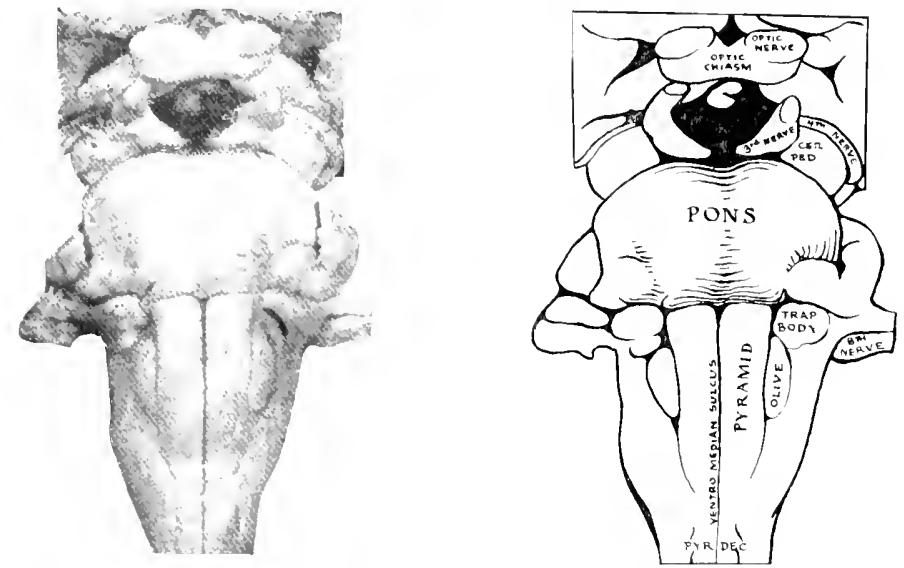

IIG. 142. VENTRAL SLRIACE OF BRAIN STEN, PAPIO CYNOCEPHALUS.

[Actual Length fo mm.]

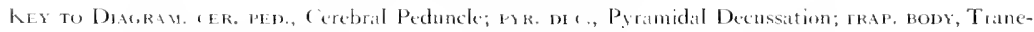
zoid Bods.

inferior olive points to an expansion in the reflex control of simultancous movements of eyes, head and hands as well as in all skilled, learned performances.

The Poxs Varolin. On the ventral surface of the oblengata, at its cephalic extremity, there appears the usual expansion of the neuraxis, the pons Varolii. A sharp line of cemarcation separates the oblongata from the pons, the bulbopontile sulcus. A small blind recess at the point where the ventromedian sulcus meets the bubopontile sulcus, forms the foramen caceum posticum. From the sulcus between the inferior olive and the pyramid, fibers of the twelfth nerve emerge from the oblongata. At the cephalic extremity of the pons is the optico-peduncular space bounded in front by 
the optic chiasm and optic tracts and caudally be the comverent hibers of the cerebral pedunctes. In this space is fodged the tuber cincreum, bearing the attachment of the infundibular statk and the mammillary bodies.
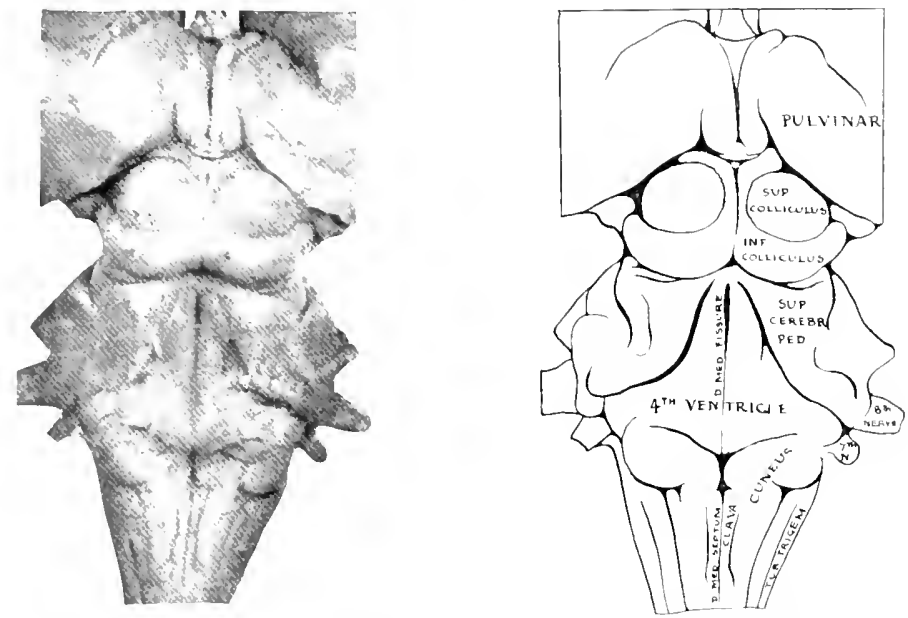

FIG. 1+3. DORSAL SLRFACE OI BRAIX STEM, PAPIO CYNOCEPHALLS. Actual l ength $4^{6} \mathrm{~mm}$.

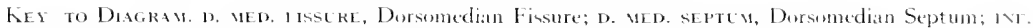

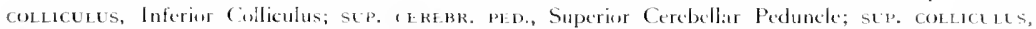

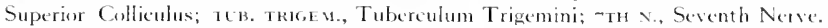

A well-defined median groove along the rentral surlace of the pons marts the position of the basilar artery. The pons itself has attained more prominenee in baboon than in the fower primates, and this may be taken as indicative of extensions in the pallio-pontile connection, in turn signifring an increase in the cerebral cortex. Since it is by means of the pons that ultimate connection between the cerebral hemisphere and the cerebellum is established, functionally, this connection as it is at present understond concerns itself with the coordination of the extremities. It is believed that 
the increased size of the pons thus indicates a greater capacity on the part of the animat to execute a wider range and a larger number of more highty shilled acts.

The Dorsal Aspect of the Brain Sten. Upon remoral of the cerebetlum, the dorsal aspect of the oblongata shows its two typical areas, the ventricular and the infraventricular regions, the ventricular area forming the inferior triangle of the fourth ventricle. In the infraventricular portion of the dorsal surface, the dorsomedian septum separates the two halves of the axis in the midline.

Upon either side of the dorsomedian septum, two eminences of considerable size appear. These eminences are the elava and the cuneus, which represent the projections caused by the presence of the dorsal sensory nuelei. Both of these eminences extend cephalad in the direction of the ventricular portion of the oblongata and gradually divaricate as the alar plates separate to expose the inferior angle of the floor of the fourth ventricle. This inferior angle of the ventricle is bounded by a fairly prominent clevation of the clava; while the cuneus is slightly more conspicuous. Both of these clevations decrease in prominence as they approach their cephatic extremities, and at the level of the lateral recess have disappeared as relief markings on the clorsal aspect of the medulla oblongata. The relative increase in development of the cuneus undoubtedly indicates accessions to sensory representation due to the further development of the forelimb and particularty the differentiation of the hand. The fact that the clava has not kept pace with the expansion of the cuneus bears out the lack of further sensory differentiation taking place in the caudal areas of the animal. Thus, although the hindlimb is highly specialized for purposes of locomotion and particularly of climbing either in trees or over rocky eminences, the failure to develop a prehensile tail and in fact, as in some species, to have no more than a mere caudal rudiment-reduces the inllux of nerve impulses arising in the hinder 
portions of the animal. This influx is certanly much inferior in volume to that of such forms as are persessed of definitcly prehensite tails, like myectes, spider monkers and wonlly monkeys. The tail in baboon, when developed to any extent, has its importance as a steering or balancing organ, a lunction much less exacting than that recuiring the discriminative elements of sensibility possessed by a prehensile organ.

Further cephalad, the dorsal surface of the axis presents the metencephaton and the exphalic continuation of the fouth ventricke, which is bounded upon either side by high elevations catused by the midde and superior cerebellar peduncles. In the floor of the fourth ventricle the markings are fairly conspicuous. The median suleus extends from the obex to the beginning of the iter and is well defined. It is crossed at about its middle by marked striae acusticae entering the floor of the ventricle at the level of the lateral recess. The inferior triangle of the fourth ventricte contains a depression upon either side of the median sulcus indicating the position of the nucleus hypoglossus, lateral to which the fovea vagi appears in plain outline. It is difficult to discern any specialization corresponding to the area postrema or the area plumiformis. In the cephalie triangle of the fourth ventricle the markings are less distinct, although immediately above the striae acusticae may be seen a slight elevation, the eminentia abducent is. There is no region in this portion of the ventricle which may be identified as the locus coeruleus. The elevations of the vestibular area are fairly well marked.

The midbrain along its dorsal aspect presents a characteristic quadrigeminal plate with the median sulcus intersected at right angles by the intercollicular sulcus. At the cephatic extremity of the median sulcus is the triangular depression, the fovea pinealis, in which is lodged the epiphysis. The quadrigeminal plates are well developed, the superior colliculi being 
larerer in all dianceres than the inferior collieuli, although both of these sets of elevations as compared with the fower primates are relatively less prominent.

The Ventral Slrace of the Midpraid. On the ventral surface of the midbrain are the two prominent bundles of libers which constitute the cerebral peduncles which appear in marked redief. This increase in prominence as compared with the lower primates is due to the fact that the eerebral cortex is more highly developed in the babern and supplies a greater number of fibers entering both the pyramidal and the pallio-ponto-cerebellar systems. This in itself has an important physiological bearing in that it signifies an increased wealth in skilled movements as well as an advanee in the coordination of the animal's morements.

The Lateral Aspect of the Braix Stem. The markings upon the lateral aspect of the brain stem are fairly pronounced. In the oblongata two prominent eminenees may be seen on the lateral surface, the tubereulum acusticum and the tuberculum trigeminum, the latter being in less conspicuous relief than the former. The tuberculum acustieum merges with the corpus restiforme without a sharp line of demareation. In the mesencephalon the mesial genieulate body forms a prominent clevation upon the lateral surface.

Interval Structure of the Brain Stem in Parlo Cinocephalls

Many features already described in the surface relief of the brain stem acquire even more significant proportions in eross section. These sections in the brain stem of the baboon furnish a survey of the internat structure at all of its most critical levels. In the discussions, the phrsiological significance of the several structures described will be considered briefly, since their general significance will be summarized at the conclusion of this part of the work. As in the case of the lower primates, it would be quite impossible to give in full detail all of the features contained in each one of the cross 
sections. It has been the purpose rather to select those structures which are more plastic in the evolutional sense and therefore show a greater range of morphological variability than the archaic, rigidly fixed portions of the brain stem. This makes necessary the omission of much description which might be desired by students requiring a general histological review of the various levels of the axis, and whike such omission is to be regretted, the inclusion of more histological detail would so encumber the text as to mate it needlessly burdensome.

LEVEL OF THE PYRAMIDAL DECLSSATION (FIG. $1+4$ )

At this bevel the most conspicunus features of the oblongata are the crossing fibers of the prramidal system (Pra) which have brought about the separation of the ventral gray column (Ven) from the central gray matter ( $\mathrm{C}(\mathrm{n})$ ). The width of the pyramidal fascicles forming the decussation is relatively broad, giving the impression of a pramidal tract with considerable capacity for voluntary control over the animal's musculature.

In the dorsal fields another feature of importance appears in the caudal extremity of the nucleus of Goll ( $N G)$. This mucleus lies immediatef lateral to the dorsomedian septum and is surrounded by a dense bundle of fibers constituting the column of Goll (CG). This extersive field of myclinized fibers arises from levels in the spinal cord particularly representing the dermatomes in the shin and the proprioceptors in the muscles, joints and bones of the lower extremities and tail. The column of Goll (CG) is separated from the next adjacent bundle of fibers, the column of Burdach (CB), by a fairly well-defined dorsal paramedian sulcus. The column of Goll is considerably less in its dimensions than the column of Burdach, warranting the inference that the influx of stimuli conducted by way of Burdach's fasciculus is of greater volume than that passing in by way of the 
fasciculus of Goll. The functional significance of this clisparity in the size of the two columns becomes apparent when the relation of Burdach's tract with the upper extremity, and especially its manual portion, is recalled.

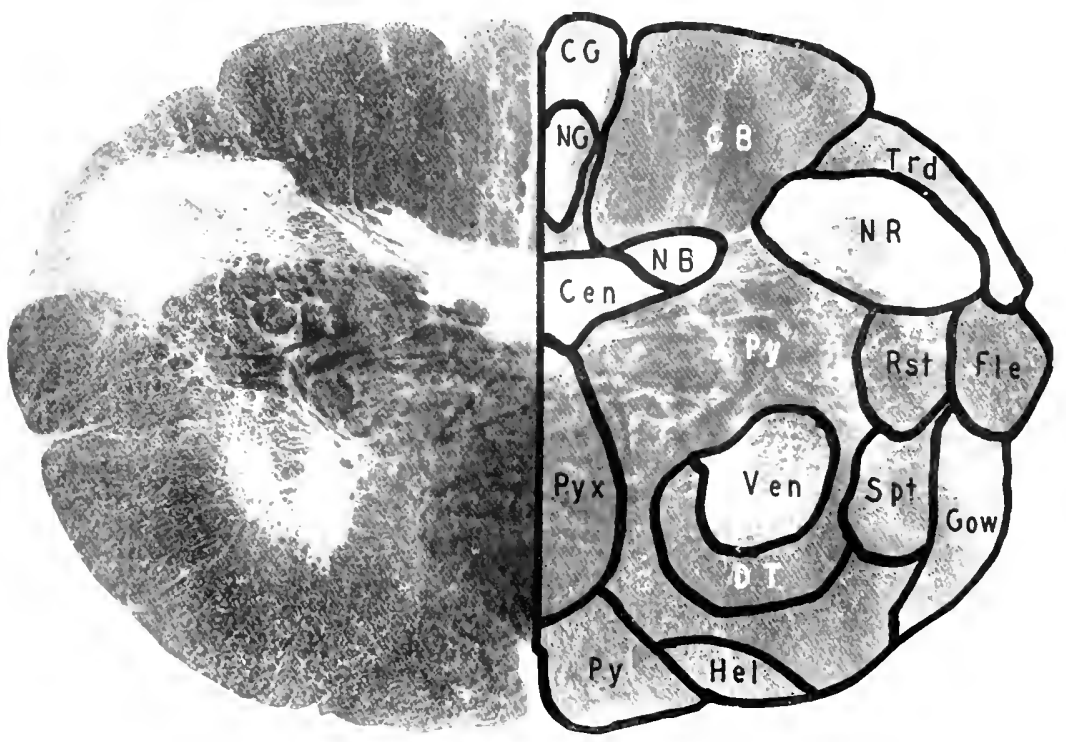

FIG. 1 t4. BABOON. LEVEL OF THE PYRAMIDAL DECLSSATION.

in, Column of Burdach; CFN, CentriI Gray Matter; CG, Column of Goll; DT, Deiterso-spinal Tract; FLE, Dursal Spinocerebellar Tract; cow. Ventral Spinocerebellar Tract: Hel, Spino-olivary Tract of Helweg: NB, Nucleus of Burdach; NG, Nucleus of Goll; NR, Nucleus of Rolando; Py, Pyramid; pyx, Pyramidal Decussation; RST, Rubrospinal Tract; SPT, Spinothalamic Tract; Trd, Descending Trigeminal Tract; IEN, Ventral Gray Column; xpr, Crossed Pyramidal Traet. [Accession No. 15o. Section 5. Actual Sizc (1) $\times 6 \mathrm{~mm}$.]

A collection of gray matter forming one of the most conspicuous clements in the dorsal fields at this level is the extensive substantia gelatinosa trigemini (NR) which acts as a relay station for all fibers bearing impressions from the trigeminal areas of the face and head. This area of innervation corresponds to the region anterior to the interparictal line. 
The intlux of sensory impressions from this region depends upon the dewree to which the head is used in directing the anmal's locomotion and as an instrument for exploration of its enviromment. As a rule, animals prosided with hair-covered lacial areas and hong vibrissae, such as the rodents and the cat family, are cquipped with a large receiving center for sensory stimuli arising in this region of the body. In anmals whose facial cutaneous areas are more or less completely denude of hair, in which also the hand and lingers have more or less taken the place of the face for the purposes of directing locomotion, there is a tendency for the substantia gelatinosa trigemini to decrease in size. The substantia gelatinesa in the baboon is somewhat less conspieums than it is in the several fower primates; and certainly much less prominent than in the carnivores or roclents. It is, however, more massive than in such forms as have come to depend almost exclusively upon the hand for the direction of their movements.

The entire dorsal field in this section, as in the case of the other species already considered, is significant as representing the complete discriminative sensory territory of the body. The portion of this field adjacent to the dorsomedian septum conveys impressions from the tail, lower extremity and lower portions of the trunk; the next succeding portion serves the upper trunk, arm and hand, while the most lateral portion represents the trigeminal areas of the face and head. It seems apparent in contrasting these three areas which serve as indices to the sensory influx from the main discriminative areas of the body, that the intermediate zone, or column of Burdach, is probably the largest of the three in baboon, thus strongly suggesting that the hand, forearm and arm have taken precedence from the standpoint of sensory importance over the other areas of the body.

Immediately lateral to the substantia gelatinosa, and lying upon the circumference of the axis, is a dense bundle of fibers representing the descend- 
ing tract of the fifth or trieminal nerve ( Trd). Other structures of intercst at this level should be noted; among them, the ventral gray column ( Ven ) cut off from its former attachment to the central gray matter (Cen) by the crossing fibers of the pyramidal system (Pyx).

Dorsal to the ventral sray column are the scattered bundles of the pyramidal tract (Py) as they are begimning to make their deseent from the oblongata into the spinal eord. Passing through these scattered pramidat bundles in a transverse direction are a few of the emergent fibers of the eleventh pair of cranial nerves, the spinal aceessory nerve. Along the margin of the section is a narrow band of medullary substance, constituting the circunferential zone. This consists of the major ascending spinocerebellar fibers ( Fle, Gow ). Lying internal to the circumferential zone, bordering upon the ventral gray column, is the intermediate zone containing in the central portion amome other tracts, the two deseending Deiterse-spinal tracts (DT) and in its more lateral portion, the spinothalamic and rubrospinal tracts $\left(S_{p} t, R s t\right)$.

LEYEL OF THE CALDAL EXTREMITY OF THE NLCLELS OF BLRDACH (FIG. $14 j$ )

At this level an illustration is introduced to show more clearly certain nuclear details in the dorsal sensory field. In this section, perhaps better than elsewhere, morphological specializations in the dorsal columms are evident. Thus in close relation to the corsomedian septum is the nuclear mass constituting the nucleus of Goll ( NG), lateral to which is the nucleus of Burdach (NB), and finally in the most lateral position, the substantia gelatinosa (NR). These three structures represent the relay stations for all the sensory afferent fibers coming from the head and neck, upper trunk and arm, lower trunk, leg and tail. Their preemption of the dorsal field gives the region its predominantly sensory character. On ejther side of 
the ventromedian suleus may be seen some of the crossing bundles of the pyramidal system and also some bundles prior to decussation (Py y). A large mass of gray matter adjacent to the ventral gray and apparcinty

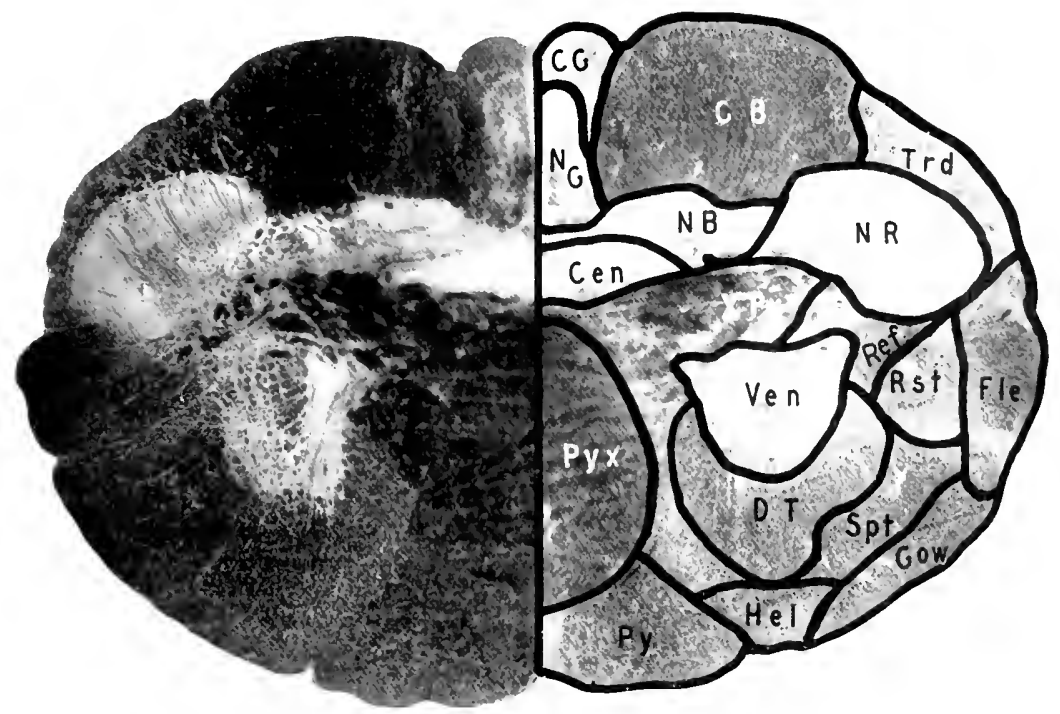

FIG, 145. BABOON. LEVEL OF CALDAL EXTREMITI OF NUCLEUS OF BURDACH. CB, Column of Burdach; CeN, Central Gray Natter; CG, Colunn of Goll; DT, Deiterso-spinal Tract; ILf, Dorsal Spinocerebellar Tract; cow, lentrat Spinocerebellar Tract; hec. Spino-olivary Tract of llelweg: NB, Nucleus of Burdach; NG, Nucleus of Goll; NR. Nueleus of Rolando; Pr. Pyramid; prx, Pyramidal Decussation; Ref, Reticular Formation; Rst. Rubrospinal Tract; SPT, Spinothalimic Tract; trd, Descending Trigeminal Tract; ves, Ventral Gray Column; xpr, Crossed Pyramidal Traet. |Accession No. 150. Section 25. Actual Size $12 \times 8 \mathrm{~mm}$.

contimuous with the substantia gelatinosa as well as the nucleus of Burdach, is the griscal portion of the reticular formation (Ref). Surrounding the reticular formation are the fibers constituting the intermediate medullary substance, and, upon the periphery of this area, the circumferential zone. 
LEIEL OF CALDAL EXIREMITY OF INFERIOR OLIVARY NICLELS (FIG. I 6 )

At this level the appearance of the cross section has undergone considerable change. The principal modification arises from the fact that a new mass of eray matter, hitherto not present, has made its appearance. This is the inferior olivary nucleus (IO) which lies dorsolateral to the fiber bundles comstituting the pramid (Py). Dorsal to the chicf olive is a smaller mass of eray matter, the dorsal acessory olive, while dorsal to the pyramid and ventromesial to the inferior olivary nucleus are some transverscly dispesed fibers extending mesially toward the raphe. These are libers of the mesial fillet (Mf) which have undergence decussation. The decussating fibers forming the mesial fillet constitute the internal arewate fibers, most of which take origin in the nucleus of Goll and form that portion of the fillet which here represents the lower extremity and tail. The prramid (Py) now has the appearance of a dense bundle oceupying the most ventromesial portion of the section. Its diameters, both transverse and antero-pesterior, arve it the proportion of about i to 8 of the entire section. This ratio funishes some idea as to the relative inpontance of the prramictal system in the regulation of motion, particularly if taken in reference to the corresponding system of fibers in the lemur where the proportion appeared to be about 1 to 10 . This increment in the pyramidal system signifies a functional inerease in the regulation of voluntary motion.

The dorsal muckei of Goll and Burdach ( NG, NB) are much increased in size as compared with the lower sections. The mucleus of Burdach (NB) appears to be comsiderably larger than the nucleus of Goll (NG), especially if estimated in connection with a number of scattered accessory nuclei surrounding it and usually known as the lateral nucleus of Blumenau. This increase in the nucleus of Burdach still further bears out the impres- 
sion that the volume of sensory impulses reaching the central nervous sistem from the upper extremity is larerer than that from cither the head and face or the lower extremity and tail. The substantia gelatinosa ( NR) is

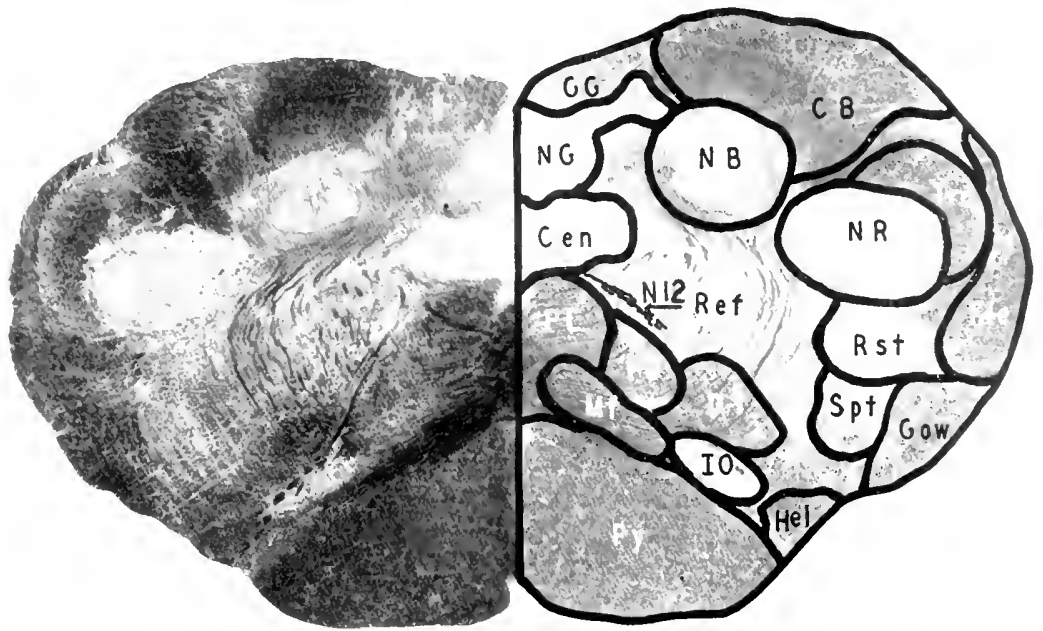

FIG. If6. BABOON. LEVEL OF THE CALDAL EXTREMIY OF TIE INFERIOR OLIYARY NUCLEUS.

CB, Column of Burdach: CEx, Central Gray Matter; CG. Column of Goll; dr, Deitersu-spinal Tract; FLe, Dorsal Spinocerebellar Tract; cow, Ventral Spinocerebellar Tract; Hes. Spino-olivary Tract of IJelweg; 10, Inferior Olive; wr, Mesial Fillet: NB, Nucleus of Burdach; NG, Nuclens of Goll; NR, Nucleus of Rulando;

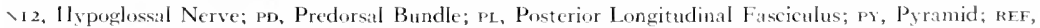
Reticular Formation; RST, Rubrospinal Tract; SPT, Spinothalamic Tract; TkD, Descending Trigeminal Tract. [Accession No. 150. Section 65. Actual Size $14 \times 8 \mathrm{~mm}$.]

surrounded by a large descending trigeminal tract (Trd). Dorsal to the decussating fibers of the mesial fillet (MI) and ventral to the central gray matter ( $\mathrm{Cen}$ ) is an important bundle of fibers, the posterior Iongitudinal fasciculus (PL).

Ventrolateral to the central gray matter may be seen a large collection of gray substance constituting the griseal portion of the reticular formation 
(Ref). This is penetrated by numerous internal areuate fibers extending in long sweeping curves from the region of the nucleus of Burdach, Corward, inward and backward, to enter the decussation of the mesial fillet. Passing diagonally through the reticular formation, and intersecting the arcuate libers, are axons of the twelfth nerve $\left(\mathrm{N}_{12}\right)$ as they are making their way from the hypoglossal nucleus at the ventrolateral border of the central sray matter.

LEYEL THROLGH THE MIIDDLE OF THE INFERIOR OLIVE (FIG. I 4, )

At this level the most conspicuous feature is the appearance of the somewhat irregular mass of gray matter lying in the ventral field of the section, but separated from the midline by the interposition of the pyramid $\left(P_{y}\right)$ and the mesial fillet (Mf). This mass of gray matter is the inferior olivary muchus (IO). It appears as a somewhat irregular, convoluted, saccular structure whose fundus is direeted toward the periphery and causes a slight clevation upon the surface already referred to as the olivary eminence of the oblongatal. Its hilus is directed dorsomesially: its cavity is filled with heavily myelinized axoms. Into it and through it pass arenate fibers, many of them in the direction of the restiform body on their way to the cerebellum. Ventromesial to the olive is a detached portion, the mesial aceesory olive ( VO), and dorsal to it a small detached portion, the dorsal accessory olive (DO). The significance of this latrge nuclear mass in the oblongata has already been discussed. Its probable relation to the function of controlling the simultaneous movements of head, eyes and hand and of facilitating the coordination of all skilled learned performances has been commented upon and the reasons for ascribing such regulation to it have previously been given (see page 2j3). Its increase in prominence, both as to size and configuration, when compared with the lower primates, speaks for an expansion in the function over which it presides. 
The central erat matter ( $\mathrm{Cen}$ ) is less extensive than it is in the preceding section. It now forms the floor of the widely opened fourth rentricle and contains in its ventromesial portion the nucleus hypongessi (Nhy).

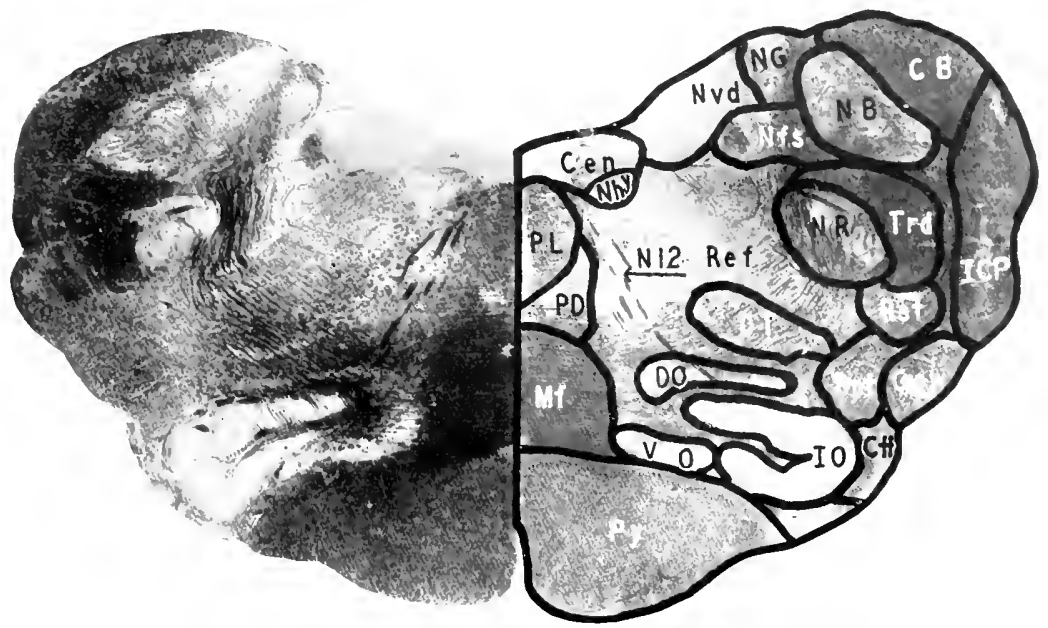

FIG. 147 . BABOON. LEVEL THROLGH THE MIDDLE OF TIE INFERIOR OLIVE. CB, Column of Burdach; CeN, Central Gray Matter; ( Olive; DT, Deiterso-spinal Tract; cow, Ventral Spinucerebellar Tract; icp, Inferior Cerebellar Peduncle; IO. Inferior Olive; MF, Nesial Fillet; $N B$, Nucleus of Burdach; NFs, Nucleus Solitarius; Nms, Hypoglossal Nucleus; NR, Nucleus of Rolando; vG, Nucleus of Goll; NwD, Dorsal Vagal Nucleus; NI 2, Ilypoglossal Nerve: PD, Predorsal Bundle; PL, Posterior Longitudinal Fasciculus; pr, Pyramid; Ref, Reticular Formation; RST, Rubrospinal Tract; sPt, Spinothalamic Tract; TRD, Descending Trigeminal Tract; vo, Ventral Accessory Olive. [Accession No. 150. Section 133. Actuil Size $1 ; \times 6 \mathrm{~mm}$.]

Emergent fibers of the twelfth nerve ( N 12 ) leave this nucleus from its mesial side passing ventrolaterally outward, many of them to penetrate the inferior olivary mucleus, funally emerging from the ventrolateral sulcus of the oblongata. In the central gray matter ( Cen) lateral to the nucleus hypoglossi is the extensive dorsal nucleus of the vagus or pneumogastric nerve into which a number of entering fibers make their way ( $\mathrm{Nvd}$ ). 
Lateral to the dorsal nucleus of the ponemogastric nerve is a compact oval bundle constituting the fasciculus solitarius ( $\mathrm{N} f \mathrm{~s}$ ). Some entering fibers of the pnemmogastric nerve are seen approaching the fascionlus solitarius. This mockeus belongs to the communis system. It convers descending fibers, ultimately entering into relation with the nucleus of the fascienlus solitarius which is eonnected with the sense of taste. It also receives libers from the glossopharyngeal nerve, supplying the tongue, and a large continenent from the pars intermedia of Wrisberg connected with the facial nerve. Ist phyletic constancy in the primates seems to argue that the sense of taste undergoes but little material alteration throughout this order of vertebrates.

Literal to the central gray matter, but separated by a narrow strand of libers, is the cephalic remmant of the nucleus of Goll (NG), which at this lerel is much attenuated. In a more lateral position is the mucleus of Burdach (NB). Ventral to the nucleus of Burdach is the substantia gelatinosa (NR) surrounded on its external surface by the dense bundle of the descending trigeminal tract (Trd). Oceupring a peripheral position in the dorsolateral aspect of the oblongata is a bundle of fibers which has been assembled from several sources and consists of axons, all of which are destined to enter the cerebellum. This structure is the restiform body or inferior cerebellar peduncle ( I C P). The griseal portion of the reticular formation (Ref) lies ventral to the central gray matter $(\mathrm{Con})$ and is penetrated by many arcuate fibess, most of which have their origin in the mucleus of Burdach (NB). These arcuate fibers pass forward and inward from the median line to decussate in the raphe and ascend as part of the mesial fillet (Mf). Some of these areuate fibers pass through the inferior olivary nucleus. Immediately adjacent to the median raphe and ventral to the central gray matter is the pusterior longitudinal fasciculus (PL) in front of which hies the collected mass of the ascending axons constituting the mesial fillet (Mf), while the dense bundles of axons comprising the pyramid ( Py) lie 
ventral to the fillet. Ventrolateral to the erriseal portion of the reticular formation is the intermediate medullary substance which entains the Deiterso-spinal tracts (DT) as well as the rubrospinal and spinothatamic tracts (Rst, Spt). On the periphery of this region is a narrom band of fibers, the circumferential zone, containing the ventral spinocerebellar tract (Gow). Immediately contiguous to the ventrolateral surface of the inferior olivary nucleus is the well-defined bundle of the central tegmental tract (Ctt) which connects this nuckear mass with structures in the midbrain.

\section{LEVEL OF THE VESTIBULAR NLCLEI (FIG. 1 48 )}

Here a prominent alteration takes place. This change involves the final disappearance of eertain sensory elements which at lower levels are predominant features in the oblongata, with the substitution therefore of certain sensory elements having a totally different function. The latter come to ecupy positions topographically identical with the sensory clements which they now replace. If the dorsal portion of the oblongata of the lower levels is notable for a single feature, it is the presence of the sensory rela! stations which take up and pass on those stimuli for discriminative sensibility arising in the tail, in the extremities, in the trunk and neck. Having fulfilled their mission by thus providing for the complete relay of these sensory impulses, the nuelei of Goll and Burdach disappear in order to make way for other sensory receiving stations which transmit impulses from propriosceptive receptors of a highly specialized variety. These latter receptors are lodged in the semicircular canals, in the utricle and saccule of the internal car. They are related to a function intimately concerned with the maintenance of body balance. Two large nuclei, collectively forming the vestibular arca of the oblongata, thus replace the nuelei of Goll and Burdach.

The second nuclear mass, by the addition of which this level becomes notable, is situated in a still more lateral position and receives fibers also from 
the intemal ear, but in this case, from the cochlear portion of it. It is intimately associated with the function of hearing. These collections of cells in the oblomerata form the cochlear nuclei, one of which appears as the

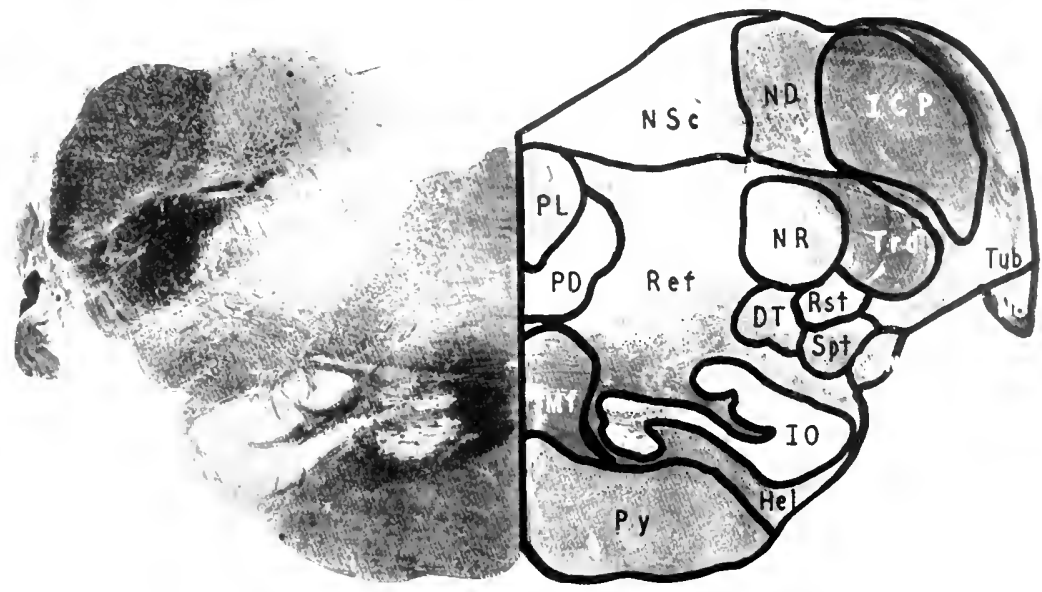

FIG. 148 . BABOON. LEVEL OF THE VESTIBLLAR NUCLEI.

D7, Deiterse-spinal Tract; gow, Ventral Spinexerebellar Tract; hel, Spino-olivary Tract of llelweg; ICP, Inferior Cerebellitr Peduncle; io, Inferior Olive; MF, Mesial Fillet; ND, Deiters' Nucleus; Nr, Nucleus of Rolando; xse, Nucleus of Schwalbe; N8. Auditory Nerve; PD, Predorsal Bundle; I'L, Posterior Longitudinal Fasciculus; «, Pyramid; Rer, Reticular Formation; Rst, Rubrospinal Tract; SPt, Spinothalimic Tract; TrD, Descending Trigeminal Tract; Teb, Tuberculum Acusticum. [Accession No. 150. Section Ir5. Actuat Size I6 $\times 7 \mathrm{~mm}$.

large protuberance on the dorsolateral aspect of the axis forming the tuberculum acusticum ( $\mathrm{T} u \mathrm{~b})$. The vestibular nucke comprise the triangular nuckeus of Schwalbe (NSc) which oceupies a position in the central gray matter in the dorsal field immediately below the floor of the fourth ventricle; and a mucleus consisting of large cells dispersed among which are many bundles of axons, Deiters' nucleus (ND). Both of these vestibular nuclei receive fibers from the vestibular portion of the ear, and although the exact function of each nucleus is not adequately understood, pathological 
lesions in and experimental disturbanees of the two nuclear structures produce definite disturbances in equilibration. These two nuelei, therefore, have becen aceepted as the principal relay stations for transmission of impulses necessary to the maintenance of the proper balanee of the budy. They thus become of primary importance in relation to the balaneing mechanism. Their size and general relations with reference to the rest of the section furnish some conception of the degree of balancing function necessary to the animal in order to maintain its equilibratory adjustments.

The dimensions of the vestibular mele in the baborm indicate that its balancing requirements have not inereased materially orer these of the lower primates; in fact, the numerical estimation of the area aceupied by these structures would show the restibular nuclei to be somewhat smaller than in any of the species already considered. This may be due to the fact that the baboon earries on its life for the most part upon the ground, and with the exception of a few species is not a tree-living animal. It has not acepuired the creet posture, and hene has placed no further obligations upon the balancing mechanism due to maintaining equilibrium on two fect.

In the extreme lateral region of the medulla oblongata is al portion of the enlargement forming the tuberculum acusticum ( Tub) into which enter fibers from the cochlear division of the cighth nerve. Immediatcly mesial to these fibers are some vestibular fibers which take origin in the proprioceptors of the vestibule of the intermal ear. These fibers pass inward and backward; some of them lateral to the deseending tract of the fifth nerve, some of them actually penetrating this bundle to reach the nucleus of Deiters (ND). Situated between the tuberculum acusticum (Tub) and Deiters' mucleus (ND) is the large oval bundle of densely compacted neurons comprising the restiform body (ICP). In this bundle are assembled the ascending fibers from the spinal cord and oblongata on their way to the cerebellum. The fibers arise from several different sources and 
consey to the cerebellum aflerent impulses necessary for the proper maintenance of cerebellar function. In this sense, the size of the restiform body (ICP) beeomes significant as an index to the degree of aflerent influx received by the cerebellum. The size of this structure in the babenon indicates an animal farly well equipped in coordinative control, although by no means as abundantly supplied in this respect as many of the higher apes.

Ventral to Deiters nucleus is a dense mass of deseending fibers, the descending trigeminal tract ( $\operatorname{Trd}$ ) and mesial to it, the substantia gelatinosit (NR). Ventral to the latter structure is a larece difluse mass of gray matter constituting the nucleus facialis for the innervation of the facial musculature. From this nucleus are seen streaming inward and backward a number of myclinated fibers in spray-like fashion toward the floor of the fourth ventricle. This is the first portion of the facial nerve.

The most rentral portion of the section is occupied by the compact bundles of the pyramidal tract ( $\mathrm{P}_{\mathrm{y}}$ ) immediately dorsal to which is a collection of crossing fibers constituting the secondary a vons of the auditory pathway.

\section{LEVEL OF THE CEREBELLAR NLCLEl (FIG. I $\left.f^{9}\right)$ )}

At the level of the cerebellar nuclei several structures which afford at basis for estimating the functional capacity of the cerebellum make their appearance. These are the cerebellar nuclei. A portion only of the cerebellum is shown in this section. The organ itself comsists of a central division, the vermis ( Ver), and two lateral lobes or hemispheres (Cbl). The mesial portion of the lateral lobes, the medullary vestibule, is shown. Situated in this vestibule is an irregular, diffuse collection of gray matter, the nucleus dentatus ( $\mathrm{Ndt}$ ). In this mucleus arise most of the fibers leaving the cerebellum, thus providing the major efferent path for cerebellar impulses concerned in cordinative control of the muscles. The size and 
configuration of the dentate nucleus are therefore of signifieance ats showing to what degree the cerebetlum contributes to the function of coordination. This muckes in Iower primates is a diffuse mass of cefls

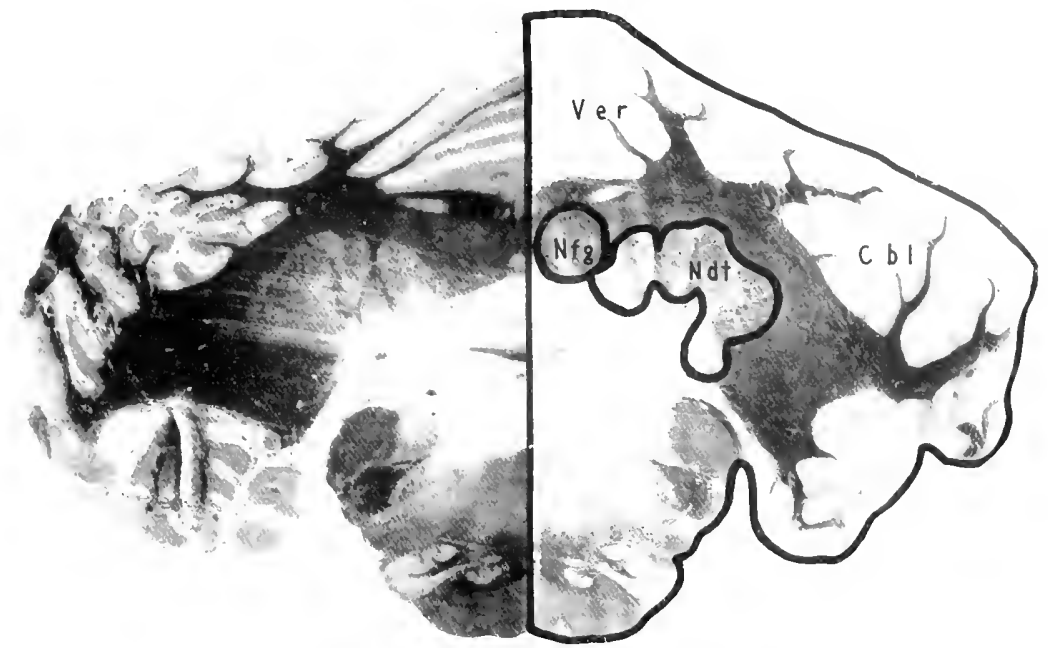

FIG. 1 49. BABOON. LEVEL OF THE CEREBELLAR NitClEI,

C81, Cerebellum; Not, Cerebellar Nuclei, Lateral Group; NFg, Cerebellar Nuclei, Me cial Group; vi r, Vermis Cerebelli. [Accession No. 150. Section 16 . Actual Size $37 \times 23 \mathrm{~mm}$.]

without convolutions, but in higher primates it is much convoluted and clearly circumscribed. The relatively small, irregular and non-convoluted nuclei of this group may be considered as primitive, since a comparative study of mammalia, or even of the primates, shows a distinct tendency for the dentate nucleus to become more indefmite in its outline and pattern, the lower the animal's position in the scale. Thus, a dentate nucleus with little or no convolution belongs to an animal whose cerebellar function is limited insofar as it does not regulate a complex series of highly skilled acts, but is organized for the more simple muscular reactions, such as seen in the 
quadruped type. The dentate nucleus of the baboon belomgs to this latter group. It is typical of an animal with strong quadrupedal tendencies and pessessed of novery wide range of highly shilled, learned motor performanees.

Mesial to the dentate nucleus is another collection of nerve edls. This is the nucleus fastigii. The fibers arising and terminating in this nucleus in the main make their way by the juxtarestiform body to connections with nuclei in the floor of the fourth ventricle, especially these which receive impulses from the semicircular canak, utricle and saccule. The nucleus fastigii is in this sense a structure most intimately concerned with the function of balaneing and may be regarded as one of the higher stations for ecuitibratory control. Its comparatively large size in baboun has a significance not unlike that of Deiters' nuckeus, indicating a considerable need on the part of the animal for a highly organized balaneing mechanism.

The vermis of the exebellum ( Ver) is primarily concerned with the coordinative comtrol of those muscles of the body which surround the axis and are immediately adjacent to it. This part of the cerebellum varies least phyletically, in this respect being quite unlike the lateral lobes which show in marked clegree a variability in size, in richness of foliation, in expansive tendence, all of which appear to bear a direct relation to the degree of functional capacity manifested by the upper and lower extremites.

\section{LEVEL OF THE ENERGENT FIBERS OF THE SIXTH NERVE AND \\ THE CALDAL FIBERS OF THE PONS VAROLII (FIG. J jo)}

At this level certain striking changes have accurred, more particularly those marked by the presence of many transversely disposed fibers erossing the ventral surface of the axis and forming the pons Varolii. Chief among these fibers, and the most rentral in position, are those forming the stratum superficiale pontis, dorsal to which are the scattered fasciculi of the prramidal system (Py). Dispersed among the bundles of the prramidal tract is the 
caudal extremity of the pontile nuclei (PN). Another feature of this level is the gradual diminution in size of the fouth ventricle now approaching its cephalic extremity and about to join the aqueduct of Sylvius. Its roof in

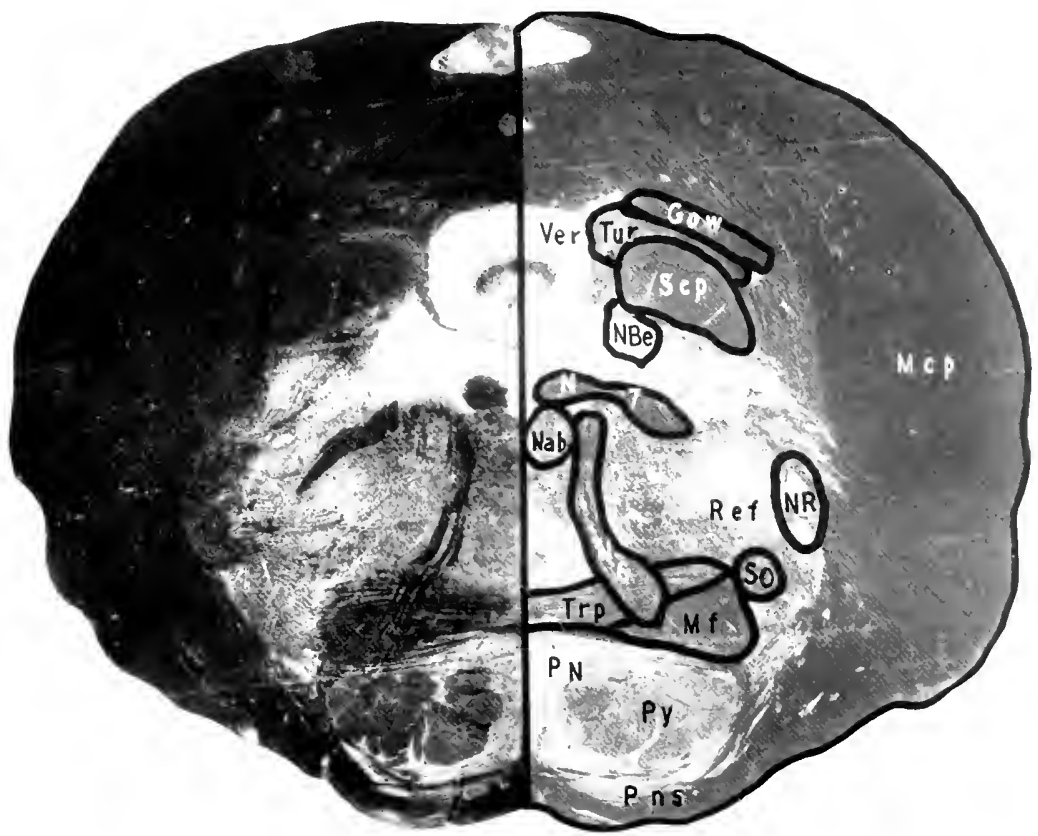

FIG. I jO. BABOON. LEVEL OF THE EMERGENT FIBERS OF THE SIXTH NERTE AND THE CALDAL FIBERS OF THE PONS VAROLII.

Gow, Ventral Spinocerebellar Tract; HCP, Middle Cerebellar Peduncle; MF, Mesial Fillet; NaB, Abducens Nucleus; NBE, Nucleus of Bechterew; , R, Nucleus of Rolindo; , 6 , Abducens Nerve; N-, Facial Nerve; P, Pontile Nuclei; pss, Pons Varolii; PY, Py ramid; ReF, Reticular Formation; scp. Superior Cerebellar Pedunele; so, Superior Olive; trp, Trapezoid Body; TLR, Tractus Uncinatus of Russel (Ilook Bundle); irR, lermic Cerebelli. [Accession No. 150 . Section 25-. Actual Size $22 \times 16 \mathrm{~mm}$.]

formed by a thin medullary layer, the superior medullary velum, resting upon which is the central portion of the vermis of the cerebellum (Ver). 
This section is motable also as showing the begimning of the middle cerebellar peduncle ( Nep) which consists of the collected axons arising from the pontile muelei to complete the comnection between the hemispheres of the cerebrum and the ceredxllum.

Two of the cranial nerves also appear in the section. One is the sisth cranial nerve (N6), whose nucleus abelucens ( Nab) lies immediately bencath the flewr of the ventriele in the central gras matter. A large number of myelinated fibers pass forward from the nucleus to emeres at the bulbepontile sulcus. The nervus facialis (seventh cranial nerve) ( N-), in its second pertion, appears as a circular bundle of fibers immediately bencath the Ilowe of the fourth ventricle and mesial to the mucleus abducentis. The fourth portion of this nere is seen extending obliquely forward and outward from the nueleus abelucentis, and rumning a course divergent with the emergent fibers of the abducens nerve. The seventh nerve supplies the muscles of lacial expression, while the sixth nerve innervates the external reetus muscle of the creball.

In the lateral angle of the ventricular space, and oceupying a position immediately lateral to the subependymal eray matter, is a collection of eells constituting one of the restibular nuclei, the nucleus of Bechterew (NBe). Dorsal to the nucleus of Bechterew, and forming the lateral beundary of the ventricular space, is a large oval mass of myelinated fibers, the superior cerebellar peduncle ( $S c p)$. This bundle represents the agragation of nerve fibers for impulses arising in the cerebellum and destined for the sereral lower levels of the neuraxis in the interest of coordinative control of the muscles. Along its dorsal aspect is a narrow bundle of decply myelinized fibers, the rentral spinocerebellar tract (Gow), which follows this circuitous course to enter the cerebellum.

In the central portion of the scetion are the crossing fibers constituting the upper portion of the trapezoid body (Trp) at whose lateral extremity is a nuclear collection, the superior olivary body ( $\mathrm{SO}$ ). In a position lateral 
to the emerging fibers forming the fousth portion of the serenth nerve is the substantiat acelatinosa ( VR), lateral to which is the now dense and compatet mass of the descending trigeminal tratet.

IEVEL AT THE MIDDLE OF THE PONS IAROLIISHOWING THE ENIERIVG FIBLRS OI IHE JIFTH OR IRIGEIINAL NERIE (I-IG, J jI)

At this level sereral noteworthy features make their appearanee. The most important of these is the broad band of entering libers of the fifth norve which make their way through the middle peduncle (Mcp), passing backward als a dense mass of myelinated fibers $\left(N_{j}\right)$, of which the more lateral portion constitutes the sensory root of the trigeminal nerve, and the more mesial, the motor rest. Sensory fibers are seen terminating in the cephalic portion of the substantia gelatinusa which here is somewhat convoluted in its appearance and is for this reason spoken of as the convolutiones quinti (NR). Nesial to this, and somewhat ventrally placed, are the more densely myelinized bundles of fibers taking origin in a nuclear mass, the nucleus masticatorius of the fifth nerve ( NM). Two of the ehief connecting links of the cerebellum appear at this level. The first is the middle cerebellar peduncle (Mcp) situated in the most xentral pesition of the section and sweeping outward and backward to cnter the cerebellum and distribute its fibers to the lateral lobes of that organ. It represents the connection of the cerebral cortex with the hemispheres of the cerebellum. The second great connecting link in the cerebellar system shown in this section is the superior cerebellar peduncle $\left(S_{c p}\right)$ situated in the lateral extremity of the fourth ventricle and representing fibers arising in the dentate nucleus, which form the great efferent pathway for impulses out of the cerebellum, destined for lower levels of the neuravis in the interest of courdinative control of the muscles. 
At the level of the middle of the pons Varolii (Pns) this structure attains its full dimensions and shows its three major lavers, the stratum superficiale, the stratum profundum and the stratum complexum. Seattered among these

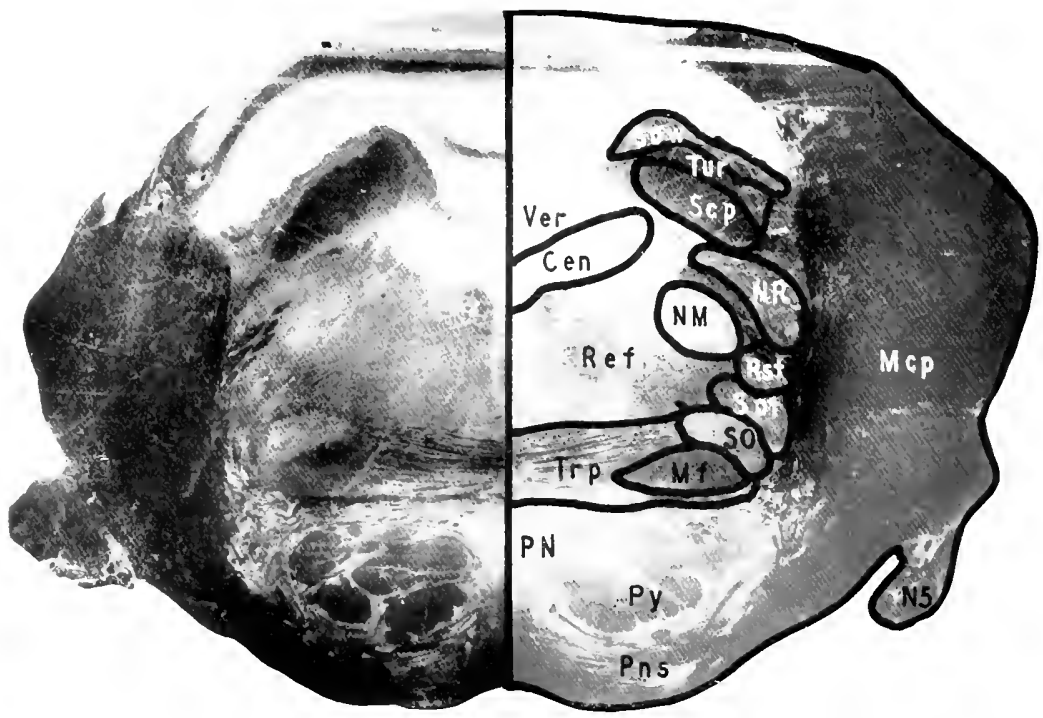

FIG. 1 i. BABOON. LEYEL AT THE MIDDLE OF THE PONS VAROLII, SHOWING THE ENTERING FIBERS OF THE TRIGEMINAL NERYE.

GEx, Central Gray Matter; Gow, Ventral Spinocerebellar Tract: McP, Middle Cercbellar Peduncle; Mf. Vesial Fillet: $\mathrm{V}_{3}$, Trigeminal Nerve; Nm, Nucleus Masticaturius Trigemini; NR, Nucleus of Rolando; PN, Pontile Nuclei; PNs, Pons Varolii; Pyramid; pro, REF, Reticular Formation; kst, Rubrospinal Tract; sce, Superior Cetcbellar Peduncle; so. Superior Olive; SPT, Spinothalamic Tract; tre, Trapezid Body; ter. Tractus Uncinatus of Russel (IJook Bundle); vek, Vermis. [Acession No. 150 . Section 282. Actual Size $22 \times 16 \mathrm{~mm}$.]

transverse fibers of the stratum complexum are groups of separated bundles of the pyramidal system ( Py ) and the large nuclear aggregationsof the pontile nuclei ( PN). All of the fibers emerging from the pons proceed laterally and, after relay in the pontile nucleus, assemble to form the middle cerebellar 
peduncle ( Ncp) which passes into the cercbellum to terminate in the lateral lobes of this organ. The three layers of the pons, including the pontile nuclei and the scattered bundles of the py ramidal system, const itute the hasis pomis. The dorsal boundary of the base of the pons is established by the transiersely disposed fasciculus forming the mesial fillet (Mf), dorsal to which is the tegmentum pontis. In the dorsal region of the section, immediatcly lateral to the much constricted fourth ventricle, is the superior cerebellar peduncte, and dorsal to this the uncinate tract of Russel ( $T u r$ ). A more heavily myelinized bundle lateral to this fasciculus is the ventral spinocerebellar tract on its way toward the rermis of the ecrebelhum (Gow). Some libers of the motor rout of the trigeminal nerve emerge from the nucleus masticatorius ( NN).

LEVEL OF THE INFERIOR COLLICULUS (FIGS. 1 ;2 AND $1 ; 3$ )

At this level certain features make their appearance which alter the external configuration of the brain stem. Nost prominent among these is the extreme narrowing of the ventricular cavity to form the beginning of the Sylvian aqueduct, while just above the roof of the aqueduet rise two clevations, one upon either side of a deep median sulcus. These structures constitute the inferior colliculi (IC), distinguishing characteristies of the quadrigeminal plate of the midbrain. Ventrally the convex contour of the section is undergoing some alteration due to the appearance of a deep median groove which tends to separate the two halves of the pons Varolii in the median line. This groove eventually becomes deeper in the next suceeding section to form a depression, the beginning of the interpeduncular space which separates one cerebral peduncle from the other. The separation is foreshadowed in this section on the ventral surface of the pons, where it is possible to discern the beginning of the right and left cerebral pecluncles. The stratum superficiale pontis and the stratum profundum pontis are well 
marked at this level, as is also the stratum complexum containing many transverse pontile fibers scattered among which are the bundles of the pyramidal system ( Py) and the large masses of the pontile nuclei (PN).

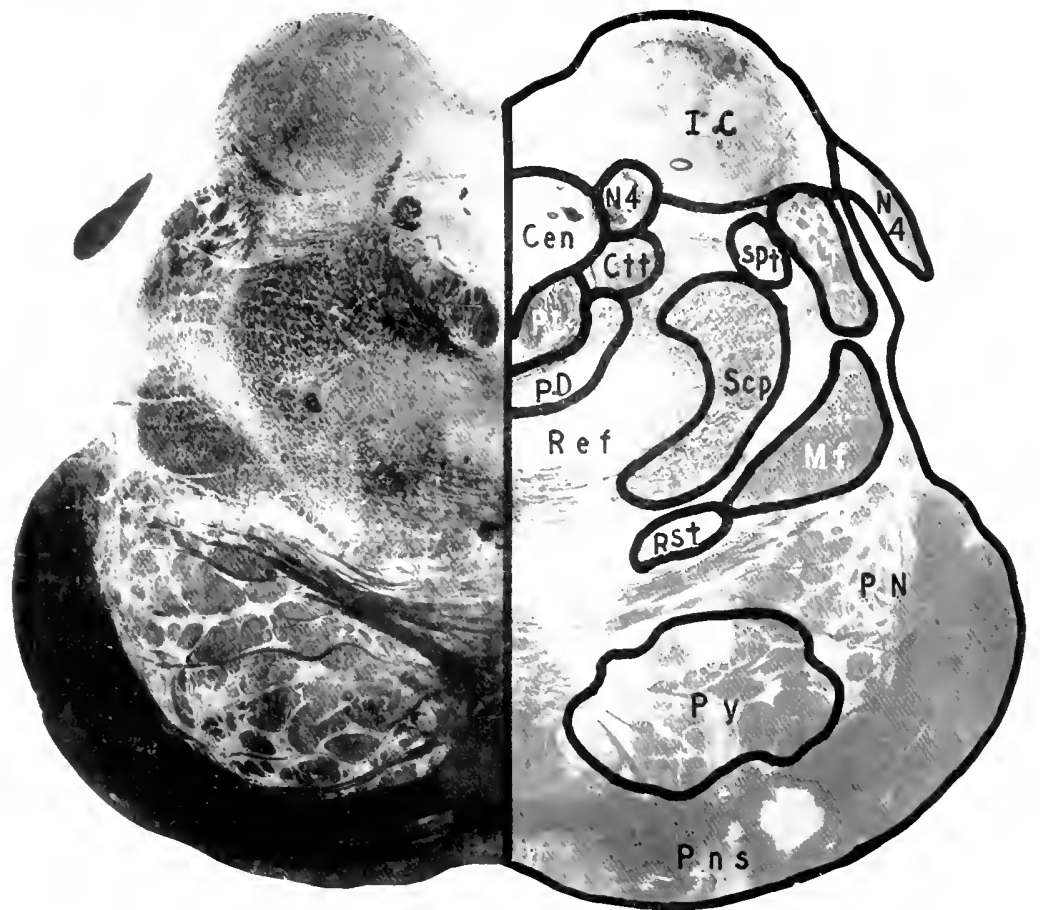

FIG. 152. BABOON. LEVEL OF THE INFERIOR COLLICULUS SHOWING ALSO THE ENERGENCE OF THE FOLRTH NERIE.

CEN, Central Gray Matter; cTT, Central Tegmental Tract; ic, Inferior Colliculus; LF, Lateral Fillet; MF, Mesial Fillet; N4, Trochlear Nerve; PD, Predorsal Bundle; PL, Posterior Longitudinal Fasciculus; PN, Pontile Nuclei; pys, Pons Varolii; pr, Pyramid; REF, Reticular Formation; RST, Rubrospinal Tract; sCP, Superior Cerebellar Peduncle; spr, Spinothalamic Tract. [Accession No. 150. Section 345. Actual Size $19 \times 15 \mathrm{~mm}$.]

The mesial fillet (MI) forms the boundary line between the basal and tegmental portions of the axis. 
The major changes appear in the tectat portions of this section as the inferior collieuli ( IC). These structures are significant because of the relation they bear to the sense of hearing. They are primitive receving

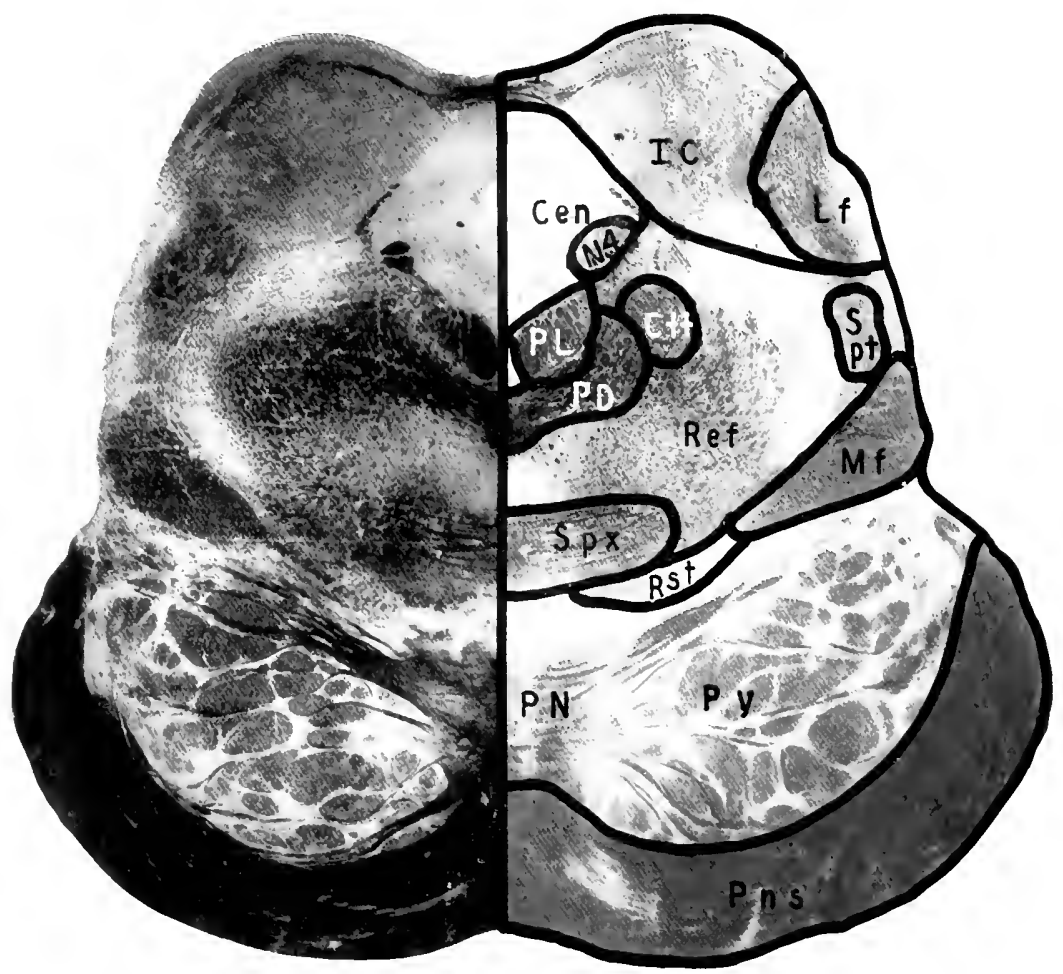

FIG. I j3. BABOON. LEIEL OF THE INFERIOR COLLICILIS.

CEn, Central Gray Matter; ctT, Central Tegmental Tract; IC, Inferior Colliculus; Lf, Lateral Fillet; MF, Mesial Fillet; N.. Trochlear Nerve; PD, Predorsal Bundle; PL, Posterior Longitudinal Fasciculus; PN, Pontile Nucleus: PNs, Pons Varolii; Py, Pyramid; REF, Reticular Formation; RST, Rubrospinal Tract; SPT, Spinothalamic Tract; spx, Crossing of Superio-Cerebellar Peduncle. [Accession No. 150. Section 351. Actual Size $19 \times 15 \mathrm{~mm}$. 
stations for this special sense. In the lower vertebrates they constitute the chicf central nervous mechanism for auditory impressions, and in them the main claboration of hearing is carried on. In most of the higher forms, particularly the mammals, these auditory colliculi have surrendered most of their original auditory function to cortical areas of the cerebral hemispheres. Their relatively large size in baboon is indicative of a retention of much of their primordial significance; while they are less conspicuous than in the lower primates, they are still larger than the corresponding structures in the large anthropoids and man. Undoubtedly they provide a rellex center for the immediate reflex translation of auditory stimuli inte motor responses active in escape or defense. These structures also show a certain degree of their original stratilication both in cells and fibers, being in this respect more conspicuous than in the higher anthropoids. From this it may be inferred that, while the auditory sense has been teleneephalized to a certain extent in the baboon, it has not underene an advanee to the cortex as marked as that in the primates at the upper extremity of the series.

Lateral and ventral to the inferior colliculus is the collected mass of fibers eonstituting the lateral fillet (Lf) bearing impulses over the secondary pathway of hearing to the primary recoiving station in the midbrain. A laree mass of transverse fibers, sweeping inward and forward toward the midline, eomprises the two major divisions of the superior cerebellar peduncle ( $S_{p x}$ ) now about to undergo its complete decussation preparatery to entering the red nucleus. The pyramidal tract (Py) together with the descending fibers of the pallio-ponto-cerebellar tract is situated along the ventral aspect of the axis. Dorsal to the pyramidal tract and stretching partially across the section at its lateral extremity is a mass of gray matter containing cells of several diflerent sizes, the dorsal extremity of the substantia nigra. The specific functions of this nuclear mass are not clearly understood; it is presumed to be essential 
to the regulation of certain automatic associated morements. The contrat gray matter ( Cen), considerably enlarged as compared with the lower levels, surrounds the caudal extremity of the Sylvian aqueduct. At its lateral extremity are several seattered bundles of nerve fibers, the mesenecphalic reot of the trigeminal nerve, while mesial to this rost alenge the ventral border of the central gray matter are two or more bundles of fibers, the elesecnding fasciculiof the trochlear nerve $\left(N_{f}\right)$. Upon its extreme ventral aspect the central gray matter is bounded by fibers forming the fasciculus longitudinalis posterior (PL) and the fasciculus predorsalis (PD).

\section{LEVEL OF THE SLPERIOR COLLICLLUS (FIG. I jt)}

At this level conspicums mesenephalic structures make their appearance. Chief among these are the much reduced remuants of the opt ic lobes of the lower vertebrates. These lobes, formerly serving as the end stations of visual sensibility, still retain a degree of stratification reminiscent of their condition in the lower forms. At least three distinct strata of alternating cells and fibers may be discerned microscopically. During the process in which the optic lobes have progressively delegated their visual function to the oceipital areas in the ecrebral cortex, a similar supersedence by the cerebral hemispheres has involved the sense of hearing as well as those modalities of general body sensibility essential to the production of the most nighly organized volitional movements. It is still evident even in the prinate order that a slow transference from the visual region of the midbrain to the higher visual eenters of the occipital tobe is in process.

Another element in this level is the oculonotor nucleus (Noc) which gives rise to the third cranial nerve whose fibers supply all but two of the muscles moving the eyeball. The fact that this oculomotor mucleus shows a relatively simple degree of development, particularly in its internuclear fibers, implies a relatively low degrec of oculomotororganizat ion. These 
conditions indicate that vision in the baboon is as yet only partially binocular and the convolutions in the occipital lobe bear out the presumption advanced on the strength of the interocular connections between the oculomotor

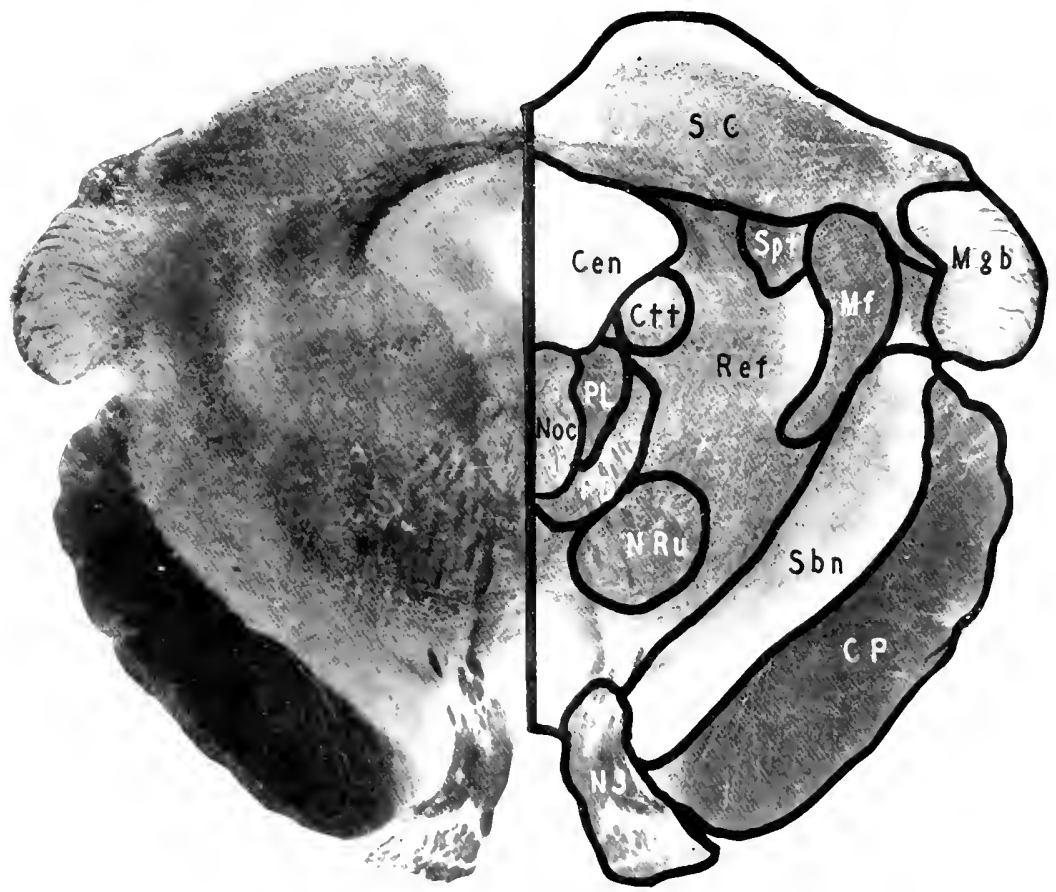

FIG. $1 j 4$. BABOON. LEVEL OF THE SLPERIOR COLliCUlus.

iev, Central Gray Matter; ctr, Central Tegmental Tract; CP. Cerebral Peduncle; MF, Nesial Fillet; vob, Mesial Geniculate Body; Noc. Oculomotor Nucleus; Nre, Nucleus Ruber; N3, Oculomotor Nerve; PD, Predorsal Bundle; Pr, Posterior Longitudinal Fasciculus; Ref, Reticular Formation; sbn, Substantia Nigral sr. Superiur Colliculus; Spt, Spinothalamic Tract. [Accession No. 150. Section 34r. Actual Size 19 X 12 mm.;

nuclei. The fibers of the oculomotor nerve ( $\mathrm{N}_{3}$ ) sweep forward and outward from the nucleus in their course to emerge from the brain stem in the sulcus oculomotorius. Ventrolateral to the central gray matter ( Cen) 
is the reticular formation ( $\mathrm{Re}$ ), to which attention is directed becaluse of its diffuse, indefinite character. In the ventromesial portion of the reticular formation, in the region through which the radiating fibers of the exculomotor nerve are passing, an ill-defined aggregation of gray matter represents the nucleus ruber ( N Ru). The indefinite character of this nucleus in baborm, as well as in the lower primates, is a fact of considerable significance. The nueleus merges with the adjacent reticular formation, producing the impression that it is but a part of this formation. To this point reference will be made subsequently in considering the retieular formation as a diffuse matrix in the tegmental portion of the stem out of which cortain discrete structures take their origin or seem to emerge by more exact delimitation of their boundaries. In this light, the reticular formation throughout the entire series of primates assumes a greater evohutional importanee than is usually attributed to it. This region of the brain stem is usually regarded as a terra incognita and henee passed over without especial comment because of its diffuse and nondescript character. To us it appears more as the territory on the outskirts of advaneing specialization, out of which, as the evolutional process goes forward, there develop more highly organized structures. It is not unlike a suburban area in the outlying regions of a community whose structural organization is progressively encroaching upon the as yet undeveloped fields. That so much of reticular formation still remains even in the highest primates might perhaps argue further potentialities of differentiation in this diffuse neural material. However this may be, emphasis is laid upon the gradual reession of a poorly differentiated portion of the axis, and its equally gradual replacement by more highly organized structures as the physical and physiological factors of evolution make their appearance in the progress of the primates.

Ventrolateral to the formatio reticularis is a large and broad field of gray matter containing cells of several sizes, the substantia nigra (Sbn), to 
which has been attributed the regulation, in part at least, of certain automatic associated movements. Immediately dorsal to the substantia nigra is the mesial fillet $(\mathrm{Mf})$. In a pesition in front of the oculomotor nucleus

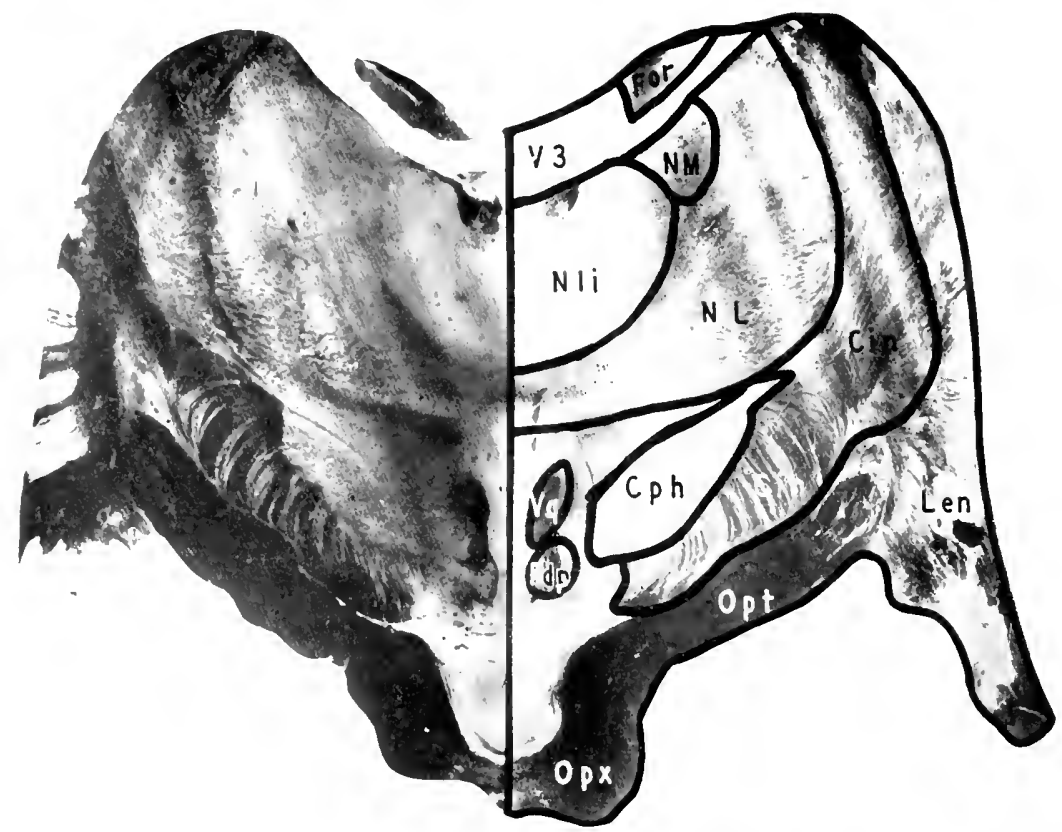

FIG. Ijj. BABOON, LEVEL OF THE OPTIC CIIASM.

a, Internal Capsule; cPH, Corpus Ilypothalamicum; IDP, Descending Pillar of Fornix; rok, Fornix; LeN, I enticular Nucleus; NL, Lateral Nucleus of the Thatamus; NLI. Nucleus Thatami Lateralis Internus; vM, Nucleus Medialis Thalami; opx, Optic Chiasm; opt, Optic Tract; 16, Fasciculus of Vicq D'Azyr; v3. Third Ventricle. [Accession No. 150. Section 525. Actual Size $33 \times 21 \mathrm{~mm}$.]

are two systems of decussating fibers, one, the dorsal decussation of Meynert through which the emergent fibers of the third nerve make their way toward the surface, and rentral to this is the ventral decussation of Forel. These decussations represent respectively the crossing fibers arising in the 


\section{PAPIO CINOCEPHALUS}

redicular formation of the midbrain to enter the predersal bundle on the one hand, and other decussatiner descending fibers arising in the red nucleus to form the rubrospinal tract.

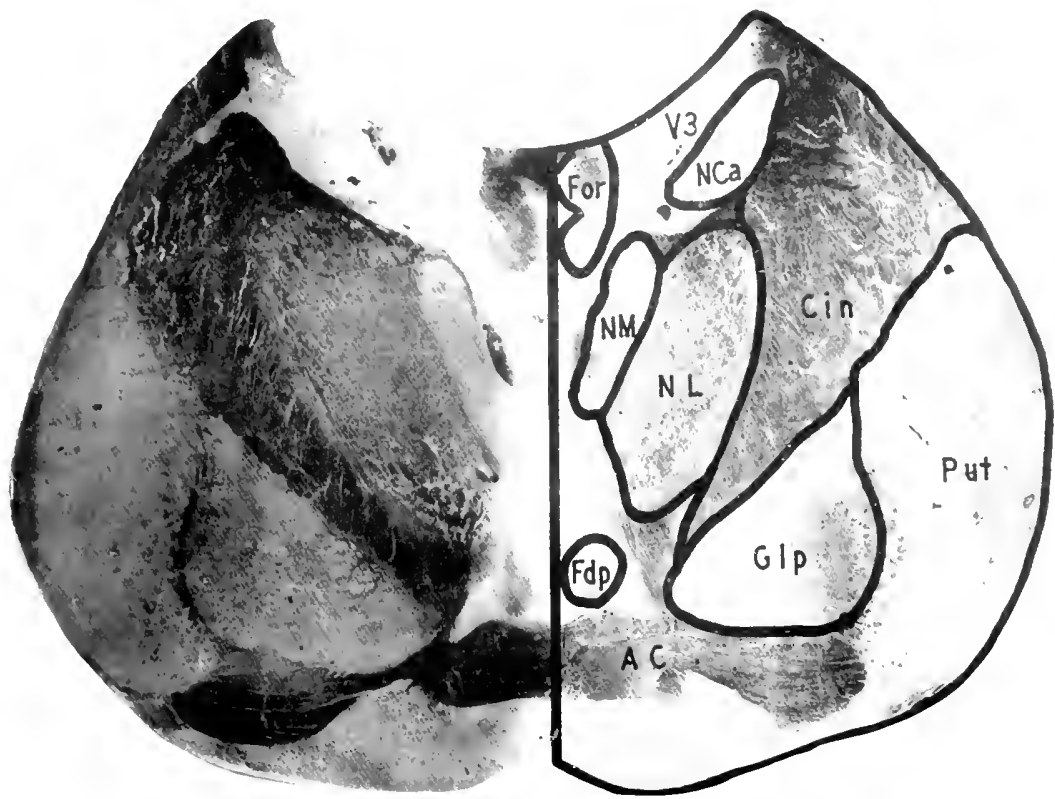

FIG. I $; 6$. BABOON. LEVEL OF THE ANTERIOR COMMISSLRE.

AC, Anterior Commissure; cov, Internal Capsule; 1-DP, Descending Pillat of the Fornix; 10 , Fornix; GlP, Globus Patlidus; Xca, Caudate Nucleus; NL, Lateral Nucleus of the Thatamus; Na, Nueleus Medialis Thalami; Pet, Putamen; v3, Third Ventricle. [Accession No. 150. Section 627. Actual Size $38 \times 21 \mathrm{~mm}$.]

A lateral projection in the cross section indicates the position of the mesial geniculate body ( $\mathrm{Igb}$ ), onc of the relay stations for the auditory pathway in its further course to the cortical region for hearing in the cercbral hemisphere. 
LEVEL OF TIE OPTIC CHIASM (FIG. I jj)

Here the crossing fibers of the optic pathway are the identifying feature $\left(\mathrm{O}_{\mathrm{px}}\right)$. The optic thalamus appears as another etement, which represents the last relay station for all the pathways of sensibility with the exception of the olfactory sense. In it ends the mesial fillet, and from it start those axons serving to eary the last relay of the somesthetic pathway from the thalamus to the parietal lobes of the cerebral cortex. Dorsal to the optic chiasm are crossing hibers which eonstitute the supraoptic commissure of Meynert. In a position dorsal to the optic tract (Opt) is a dense mass forming the internal capsule ( Cin). Bordering upon these fibers of the capsule is a collection of striated gray and white matter, the lenticular nucleus (Len ). This, being one of the most important portions of the endbrain, does not properly belong to the description of the brain stem. The remaining structures of interest in this section are indicated in the legend beneath the figure.

\section{LEVEL OF THE ANTERIOR COMMISSLRE (FIG. I ;6)}

At this level the section illustrates the eephatic limit of the brain stem, the last remaining structure of the anterior portion of the optic thalamus. The structures of topographical interest in this section are indicated by corresponding letters in the legend beneath the figure. 


\section{Chapier Xl}

\section{RECONSTRUCTION OF THE GRAY MATTER IN THE BRAIN STEN OF PAPIO CINOCEPHALUS}

7 PHE reconstruction of the brain stem of Papio cymocephahus begins in the lower medullary region. The higher levels of the spinal cord

L are not represented in the model.

In the fowest levels of the reeonstruction the contour of the central gray matter is already considerably flattened from before backward and drawn into an ahmost directy lateral position. The central gray matter gives rise at its dorsolateral extremities to the llattened cervix of the dorsal horn which expands at its termination into a more or less oval-shaped substantia gelatinosa trigemini. This structure has already assumed its lateral position which it maintains throughout the rest of its extent.

\section{The Dorsal Medullary Nuclei}

The nucleus of the cohmm of Goll eonsists of a narrow, laterally llattened ribbon of gray matter projecting dorsally from the body of the central gray matter. It is separated from its fellow of the opposite side by a thin investment of white matter. The nucleus entinues eephalad for some distanee without showing any material change until the caudal extremity of the inferior olivary nucleus is reached, when it rapidly expands, presenting a heavy mass of overhanging gray matter which is directed laterally under the influence of the opening of the fourth ventricle.

The nucleus of the eolumn of Burdach makes its first appearanec just below the level at which the nucleus of the column of Goll begins its rapid increase in size, as a thickened condensation in the dorsal surface of the central gray matter. This small mass of gray matter rapidly increases in size, expanding dorsally and laterally into a relatively rich arborescent 
mass which is constantly shifted faterad by the opening of the fourth ventricke until it overhangs, to a considerable extent, and almost obscures from view the substantia gelatimosa trigemini. The nuckess of the column of Goll reaches its maximum development at the level where the fourth ventricke opens and from that point it diminishes rather rapidly in size. It is gradually obscured from view by the floor of the fourth ventricle which approaches (losely to the dorsat mass of the nucleus of the column of Burdach, thus submerging the nucleus of the column of Goll.

The nuckess of the column of Burdach continues upward to a level considerably above the opening of the fourth rentricle, forming a part of the lateral boundary of the ventricle. As a result of its lateral displacement it orerhangs the substantia erelatinosa trigemini. It rather abruptly diminishes in size and disappears at about the mid-level of the inferior olivary nuelems.

The substantia gelatinosa trigemini extends upward in the lateral region of the neuraxis, increasing in all of its diameters to the inferior olivary level where it is covered over by the lateral overhanging extensions of the nucleus of the column of Burdach. It reappears embedded in the reticular matrix between the ventrolateral nuclei of the reticular formation and the nucleus of Deiters. At this level it undereses a reduction which has been comstantly found in this nuckeus and which may be termed the "waist of the trigeminal nucleus." From this point upward it increases in size until its maximum is reached as the caput of the nucleus in the mid-pontile level. It then suddenly undergoes reduction and clisappears in the upper pentile region where it presents on its mesial surface the rounded, obliquely directed masticatory motor nucleus of the trigeminal complex.

\section{The Inferior Olivaky Nuclecs}

In the reconstruction of the inferior olivary nucleus there is evident a considerable advance over that seen in the preeding forms. The ventral 
accessory olive makes its appearance at about the upper level of the pyramidal condensation as a llat band of gray matter disposed transversely with a slight inclination corsally at its mesial extremity. The mesial extrem-
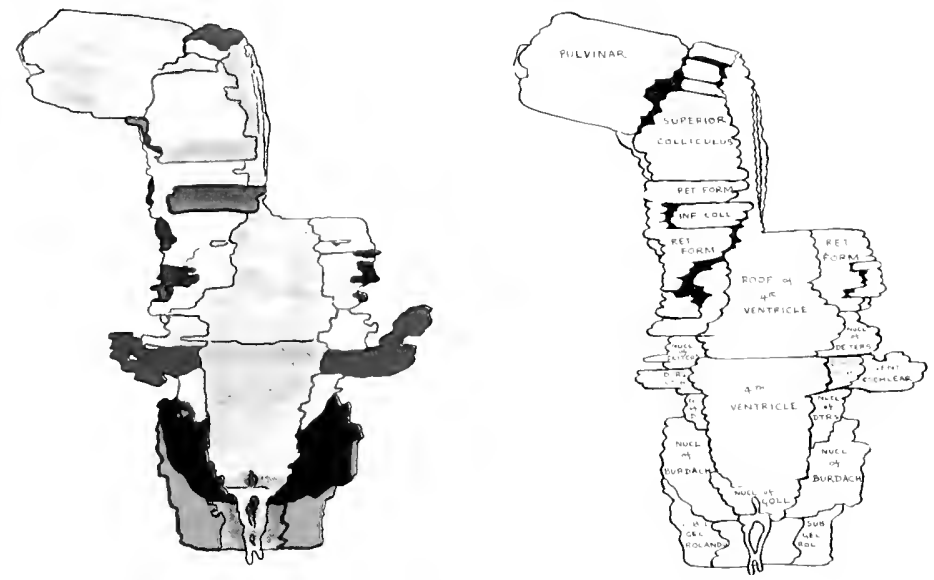

FIG. 1;7. DORSAL SURFACE OF THE GRAY MATTER OI THE BRAIN STEM, PAPIO CTNOCEPHALUS.

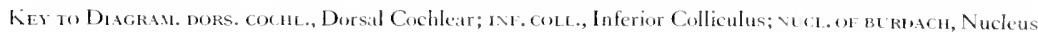

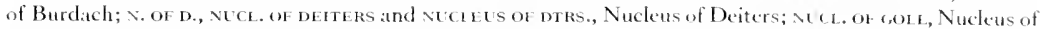
Goll; Ret. Forv., Reticular Formation; st B. GEL. Rol. and StbST. Gel. Rola Noo, Substantial Gelatinosa of Ruliando; veNt. coche, Ventral Cuchlear Nuchus.

ity of the nucleus turns backward upon itself, forming a hook-shaped mass of gray matter.

The dorsal accessory olive appears only slightly above the level of the appearance of the ventral aceessory nucleus as a small lamina of gray matter which continues upward as a rather narrow strand. At the level of appearance of the main mass of the inferior olivary nucleus it expands into a narrow flattened sheet which lies dorsal to the hilus of the inferior olivary nucleus. The main nucleus appears as the fourth rentricle begins to open in the form of a loop-shaped layer of gray matter, presenting a few simple reduplica- 
tions. These reduplieations appear mainly in the dorsal limb of the loop. The fundus is relatively thick and the ventral branch of the nucleus is somewhat curred, wh its concavity directed forward. The mesial extremity points almost directly toward its fellow of the opposite side. The dorsal branch of the loop is less extensive than the ventral branch, presenting the reduplications atrady mentioned. The hilus of the nuckeus is bridged over by the dorsal accessory ohivary nucleus. The whole olivary complex extends upward to a point just bedow the lateral recess of the fourth ventrick, where it rapidly reaches its termination.

The dorsal aceessory olivary nucleus and the dorsal branch of the inferior olivary mudeus throughout their entire extent lie in retatively elose contact with the ventral surface of the reticular formation, out of which they seem to differentiate.

\section{The Reticulak Formation}

As reconstructed, the reticular formation appears as a flattened lamina of gray matter applied to the lateral surface of the ventral gray columm. It extends dorsally and laterally to come into contact with the substantia gelatinosa trigemini. It increases rapidly in bulk, proportionally with the decrease in the ventral gray column which gradually becomes absorbed by the expanding reticular formation. In the midoblongatal region, the reticular formation forms a relatively massive structure, somewhat triangular in shape, its base being applied to the central gray matter mesiatly, and to the base of the nucleus of the column of Burdach laterally, while its apex extends between the inferior olivary complex and the substantia gelatinosa trigemini.

Continuing from this point upward, the reticular formation undergoes a considerable reduction, due chiefly to the increasing development of the inferior olivary nucleus, until the upper limit of this structure is 
reached, where it increases rapidly in size, thus becoming the main mass of the pontile tegmentum. It is irregular in its surface outline, being indented by the dorsal surface of the inferior olivary nucleus and the dorsal accessory
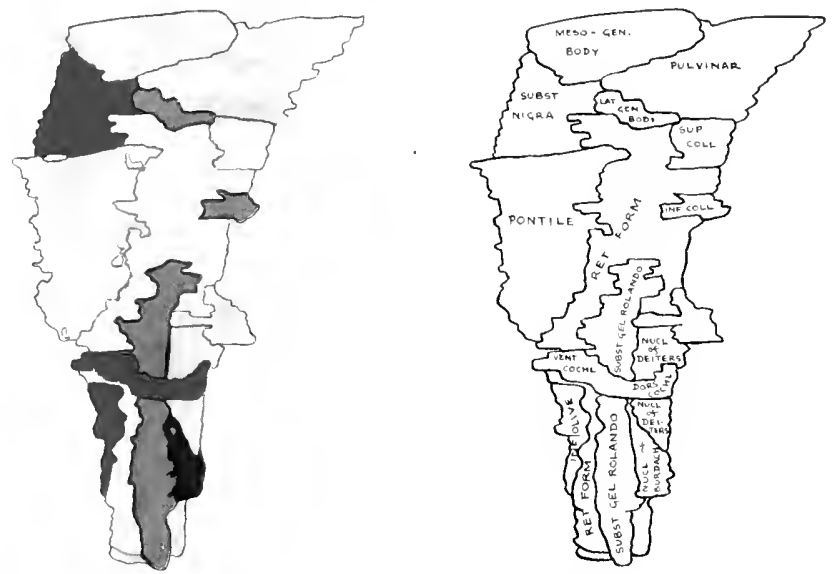

FIG. I ;8. LATERAL SURFACE OF THE GRAY MATTER OF THE BRAIN STEM, PAPIO CINOCEPHALUS.

Key to Diagram. doks, cochl., Dorsal Cochlear Nucleus; INF. coll., Inferior Colliculus; inf. olive, Inferior Olive; LAT. GEN. Bony, Lateral Geniculate Body: MESo-GEN. BODY, Nesial Geniculate Budy; NeCL. OF Burdach, Nucleus of Burdach; vect. ol deitirs, Nucleus of Deiters; Pontile, Pontile Nuclei; ret. Fora., Reticular Formation; subst. Gel. ROlavdo, Substantia Gelatinusa of Rolando; st bst. Nigra, Substantia Nigra; sup. coll., Superier Colliculus; vent, cochl., Ventral Cochlear Nucleas.

nucleus, laterally by the substantia gelatinosa trigemini and dorsolaterally by the base of the nucleus of Burdach and the beginning of the vestibular area.

Above the inferior olivary nucleus the reticular formation shows the effect of the developing trapezoid body by presenting a relatively decp excavation on its ventral surface close to the midline, in which the main mass of the trapezoid body lies.

Laterally the reticular formation is in contact with the substantia gelatinosa trigemini and above the level of this nuclear mass it presents a 
very irregular surface marked by the entrances and exits of the various fiber bundles connected with the colliculi and by the development of the lateral fillet from the trapezoid body. The course of this fiber tract can be definitely follewed along the lateral surface of the reticular formation.

Immediately prior to the formation of the lateral fillet the trapezoid body occupies a considerable cxeavation in the central portion of the ventral surface of the reticular formation. This bay is limited by mesial and lateral extensions of the reticular formation which pass ventrally to alford eontact with the dorsal layer of the mesial and lateral buttresses of the pontile nucleus.

Cephatad to the inferior colliculus the inferior brachium makes its appearance as the continuation of the acoust ic pathway and produces a groove on the surface of the mesenephalic reticular formation at which level this fiber bundle acts as the next relay to the mesial geniculate body. As the tract approaches this nuclear mass it again sinks into the reticular matrix and is corered wer by a lateral extension of the reticular formation.

Dorsally the reticular formation is in close contact with the body of the central gray matter, separated from it, however, by the circumferential condensation of fibers mainly represented by the posterior longitudimal fasciculus, the predorsal bundle and the mesial fillet. In the cephalic portion of the pontile termentum the reticular formation is disposed in a rather irregular fashion, presenting a lateral thin lamina overying the superior cercbellar peduncle as it enters the upper part of the tegmentum from the superior medullary velum.

As the pontile reticular formation is sueceeded by that of the mesencephalon the circumferential layer of the reticular formation becomes relatively thicker, whereas the central mass of the reticular formation diminishes in bulk due to the fact that the superior cerebellar peduncle is approaching the midline. 


\section{RECONSTRUCTION OF PAPIO CINOCEPHALUS $3+1$}

In the lower mesencephalic areas this process has continued so far that the central mass of the reticular formation gradually disappears and its mass assumes a much erreater expansion. In this recion of the mesencephaton the
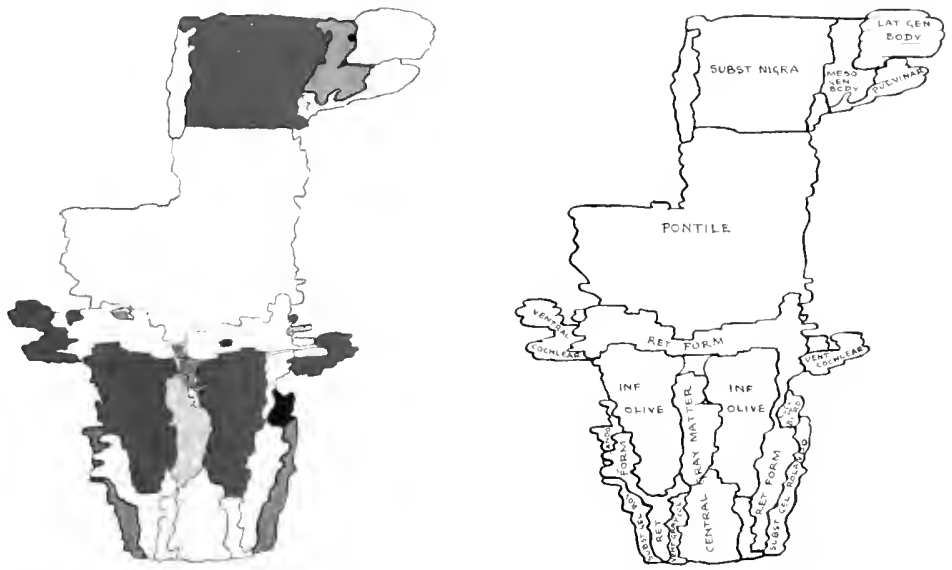

FIG. I ;O. IENTRAL SURFACE OF THE GRAY MATTER OF THE BRAIN STEM, PAPIO CYNOCEPHALES.

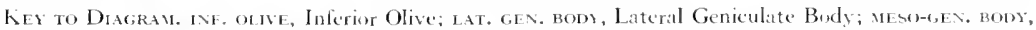
Mesial Genieulate Budy; >ece. OF Burd., Nucleus of Burdach; poNtne, Pontile Nuclei; Ret. Form., Reticular Formation; subst. Gel. ror. and sunst. gex. rol andoo, Substantia Gelatinosa of Rolandu; subst. Nigra, Substantia Nigra; vèt. cochlear, Ventral Cuchlear Nucleus; vivt. gras col., Ventral Gray Column.

reticular formation now gives place to a specialization forming the large nucleus ruber which is surrounded by a capsule derived from the superior cerebellar peduncle and descending striato-rubral fibers. The laterat mass of the reticular formation follow's closely the course of the superior cerebellar peduncle as this structure approaches the nucleus ruber. Above the level of the red nucleus the reticular formation again reaches the midline and its most central portion assumes its original position and importance. It is separated from the central gray matter by the longitudinally coursing median bundles 
of the posterior Iongitudinal fasciculus and the circumferential reticular fiber (c)llections.

\section{The Pontile Nicle}

In reconstruction, the pontile nuclei present an arrangement essentially similar to that found in the lower forms. The formation of a superficial and a deep layer connected at their mesial and lateral extremities by masses of gray matter which represent the lateral and mesial buttresses is present also in the baboon. The ventral and lateral surfaces of the pontile nuclei correspond accurately with the surface anatomy of the pons itsedf.

Mesially the mesial buttresses come into contact with one another at the median raphe. Caudally the pontile muclei arise in poorly develeped arciform nuclei which extend downward for a short distance upon the ventral surface of the collected pyramidal tract. At the median line the mesial buttresses are carried backward to come into contact with the ventromesial angle of the reticular formation. A similar arangement exists on the lateral aspect where the lateral buttresses extend backward to become continuous with the ventrolateral angle of the reticular formation. Between these two points of conlluence, mesial and lateral, the deep layer of the pontile nucleus is separated from the rentral surface of the reticular formation by the bay in which lies the trapezoid body.

The simple arrangement found in the lower forms is becoming more and more complex and the interior of the pontile nucleus is found to be traversed by numerous strands of nuclear material which pass from one side to the other, breaking up the pallio-spinal and pallio-pontile systems of fibers into smaller constituent masses.

As the stem is followed upward, the decp layer of the pontile nuclei is found to become directly continuous with the central portion of the substantia nigra, while the mesial and lateral portions of the substantia nigra rest upon the mesial and lateral buttresses of the pontile nuclei. 


\section{Tine Vestibllak Complex}

The vestibular complex appears on the surface of the reconstruction at about the mid-olivary level ol the brain stem. It is at lirst a small triangular mass of gray matter located between the lateral surface of the central gray matter and the cephalic extremity of the nucleus of Burdach. As it increases in extent and bulk it acts as a wedge separating the upper extremity of the nucleus of the column of Burdach from the central gray matter. It rapidly increases in its ventrodorsal extent until it becomes a prominent feature in the dorsolateral portion of the tegmentum. Its ventral eontinuation forms a rather sharp, wedge-shaped mass of gray matter which presentson its lateral surface a distinct concavity in which is lodged the inferior cerebellar peduncle. This portion of the complex is formed by the nucleus of Deiters which reaches its maximum extent at the midventricular level. From this point upward it rapidly diminishes in size, being replaced by the more dorsally situated nucleus of Schwalbe, the triangular nucleus of the vestibular complex. This structure lies dorsal and somewhat mesial to the nucleus of Deiters, mesial to the dorsal cochlear nueleus and crossed by the fibers of the striac acusticae. The triangular nueleus is continued upward for a short distance, gradually attenuating in size and merging with the indifferent reticular matrix of the lateral walls of the fourth ventricle above the level of the lateral ventricular recess. The third element in the vestibular nuelei, the nucleus of Bechterew, is found in the lateral wall of the ventrieular formation and is not represented in the reconstruction.

\section{The Cochlear Complex}

The coch lar eomplex seems to be definitely less developed than that in the three preceding forms. The nuclear masses are relatively small and poorly developed. The same arrangement is found to be present, that is, the almost complete investment of the entering nerve fibers. by the nuclear 
masses, the mesial surface only of the entering nerve remaining uncosered by nuclear material so that the trough arrangement of the nucleus about the entering nerve stem is maintaned. The dorsal cochlear nucleus, which is situated dorsal to the triangular nucleus of Schwalbe of the vestibular complex, is also relatively small and lies in contact with the lateral extremity of the central gray matter of the flowe of the fourth ventricle. The strands of gray matter connecting the rentral and the dorsal enchlear nuelei are also porily developed.

\section{The Colnocili}

The colliculi, which are situated in the tectum of the midbrain, appear relatively well developed in the baboon. The superien colliculus is elearly much more extensive than the inferior colliculus, the former being at least three times the vertical height of the latter. The inferior colliculus arises from the corsal extension of the reticular formation at the point of junction between the mesencephaton and the metencephaton. It is relatively inconspicuous and is separated from the larger superior colliculus by the intercollicular furrow, where the lateral extension of the reticular formation comes to the surface of the stem. At its lateral and upper extremities the inferior colliculus presents the begimning of the inferior brachium which passes from the inferior collieulus directly to the mesial geniculate besty. The inferior colliculus is continuous laterally with the reticular formation, while dorsally it is continuous with the inditlerent dorsal gray matter of the meseneephalom.

The superior colliculus arises, as does also the inferior, by a specialization in the tectum of the mesencephalon. It is in contact dersally with the indifferent dorsal gray matter lying in the median line. Laterally it is separated from the reticular formation by the dexelopment at this point of the superior brachium which serves to connect the superior colliculus with 


\section{RECONSTRUCTION OF PAPIO CYNOCEPIIALUS , $3+j$}

the lateral genienlate body. Mesially both of these nuctear structures are continued acess the midline by the respective superior and inferior collicular commissures.

\section{Tile Substantia Nigra}

In the recomstruction, the substantia nigra appears as a relatively massive melear coflection in the pes pedunculi of the mesencephalon. Situated ventral to it and leaving impressions upon its ventral surface are focated the pallio-spinal and pallio-pontile fiber systems. It is supported ventrally by the heary mesial and lateral buttresses of the pontile nuclei and throughout its transwerse extent by the deep laser of the pontile nueleus, from a specialization of which it secms to take origrin. It is in contact mesially with the indifferent interpeduneular gray matter and is piereed at this iunction by the emerging libers of the oculomotor nerve. Its dorsal surface is concave dorsally and is separated from the reticular formation of the mesencephalic tegmentum by the circumferential fiber accumulations which appear in this region, coursing longitudinally and transversely through the stem. At its lateral extremity it presents a melear condensation, from which fibers pass into the mesencephalic tegmentum. Laterally it sends a prolongation toward the mesial and lateral geniculate bodies. As the diencephalon is approached, the substantia nigra diminishes in size and seems to merge with the zona incerta of the diencephaton.

\section{The Nucleus Ruber}

The nucleus ruber appears in reconstruction in the more cephalic portion of the mesencephalie tegmentum and is encapsulated by the fibers received from the decussation of the superior eerebellar peduncle. It is fairly well developed and of moderate size. Its cephalic extremity approaches, if it does not fuse with, the reticular formation of the dieneephalon. 


\section{Tile Central Gray Matter}

The central gray matter in the baboom is first found as a transversely aranged mass of gray matter which laterally receives the base of the cervix of the dorsal horn. Dorsally the central gray matter presents the formation of the nucleus of the column of Goll which has already been cleseribed as narrow laminas of gray matter in the mesial dorsal white column, while the literal extension of the gray matter forms the dorsal horns. From the point of confluence of the dorsal horn with the central gray matter of the reticular formation, the uncleus of the column of Burdach arises. As the stem is followed upward, the lateral trend of these gray masses becomes evident, the substantia gelatinosa trigemini passing outwad into the lateral meridian of the cord, the nucleus of the column of Goll passing laterally and conforming to the epening of the lower extremity of the fourth ventriele, while between the nucleus of the column of Goll and the substantia gelatinosa trigemini appears the nucleus of the column of Burdach.

The body of the central gray matter rapidy flattens out into a narrow band of gray matter which forms the Iloor of the fourth ventricle. This floor is practically featureless, being, as in the other forms, almost smooth in the lower half of the ventricle. It gradually increases in its lateral extent until the level of the lateral recess is reached, from which point it then begins to contract.

The floor of the upper half of the fourth ventricle presents the medial elevation corresponding to the development of the nuclear mass forming the nucleus of the sixth cramial nerve, the mucleus abducentis. The walls of the upper half of the ventricle rapidly approach each other and at the junction of the metencephatom and the mesencephalon, the central gray matter again constitutes the relatively heavy wall surrounding the aqueduct of Sylvius. Ventrally this central gray matter is continued forward into a relatively long tongue of gray matter which passes forward in 
the midline of the mesencephalon. Laterally the central gray matter forms a heavy structure which gradually becomes more circularty arranged about the aqueduct of Sylvius. In the lower portion of the mesencephaken the nucleus trochlearis appears as a specialization in the ventral profongation of gray matter which we have found passing forward from the rentral aspect of the central gray matter. A similar arrangement is found also in the upper part of the mesencephaton where the nucleus ocukmotorius likewise develops in a ventral prolongation on either side of the midline. As the interbrain is approached the central gray matter elongates ventrally, forming the Jong, thin sheet of wray matter surrounding the aqueduct of Sylvius in its dorsal portion. This extension ventrally is produced by its approach toward its conlluence with the caudal portion of the third ventricle. Where the meseneephatom becomes continuous with the diencephalon the gray matter surrounding the aqueduct of Sylvius becomes continuous with the subependymal gray matter lining the third ventricte and the gray matter forming the mesial group of nuckei of the diencephaton. The central gray matter forming the roof of the Sylvian aquechuct becomes continuous with the structures in the reof of the dicnecphalon, while the floor of the aqueduct and the undiflerentiated medial interpeduncular wray matter merges with the hypencephatic recion. 



\section{Chapter XII \\ PITHECUS RHESUS, MACACUS RHESUS, ITS BRAIN AND BEHAVIOR}

Its Position among the Primates; Measurements and Brain Indices; Surface Appearance of the Brain; Internal Structure of the Brain Stem in Cross Section

7 PE genus Pithecus, which includes the macaques, is distributed throughout India, as far north as Cashmere and Tibet, extending L southward to the island of Ceylon and castward to the Bay of Bengal. These monkeys are also found in upper and lower Burma, Siam, Cochin China and the Malay Peninsula, as well as certain adjacent islands.

\section{Appearance and Behatiok of the Macaques}

In general, the macaques are much smaller in size than the baboons and for the most part are trec-living animals, inhabiting the jungle and forests usually on the borders of human habitation. In many species the face is free of hair, the ears prominent and protruding above the vertex of the skull. Some species are heavily bearded about the face and have a mane extending down the back of the head. The species here described, Macacus rhesus (Pithecus rhesus), is the common macaque of northern India which is held in great veneration by the Hindus, although not considered sacred by them. In certain of their temples large numbers of these macaques are kept and given the freedom of the building where they become bold and often troublesome.

The head of the macaque is much less dogr-shaped than that of the baboon. The eyes are closely set and the animal is prone to take a sitting posture on its haunches, holding the head upright so that the eyes are 
directed forward. Its attitude in sitting is distinctly humanoid, while its attention and gaze convey the impression of an attentive scrutiny of all that seems to hold its interest in its enviromment. Its nose is short with a fairly well-defined nasal bridge and nostrils directed downward characteristic of the Catarrhine type. The lips are thin and the upper one particulaty long, giving a tendeney toward a muzzle-shaped conliguration of the snout. The fore-and hindlimbs are of about equal length. The forclimbs areequipped with a well-clifferentiated hand, although the thumb is somewhat shorter than in the baboon. The toes, especially the great toc, have much more the arrangement of fingers, and the animal thus presents definite quadrumanal differentiation.

Its movements are quick and deft. It changes from one pusition to another with surprising swiftness and in an instant makes its way from the ground to some high altitude either in the trees or some other safe retreat. These monkeys are gregarious and tend to go together in herds, often of considerable size. If captured poung, the animal is easily trained and curickly learns many and often amusing tricks. It is full of mischief and curiosity. Macapues frequently become an actual nuisance in the neighborhood of towns where they may live in large numbers. When adult, they sometimes become quite ill-tempered, often savage, eren to the extent of attacking the inhabitants without much provocation. For the most part they live in cultivated tracts, alome the banks of streams, affecting rather than avoiding the habitations of man. These monkeys seem to have little fear of their human neighbors; indeed, they appear to enjoy the opportunity of molesting the inhabitants by many annoying pranks. Sometimes their attentions are vigorously resented and they are made the object of vindictive attacks. Their reaction on such occasions is most like that of tantalizing small boys who tatie an almost idiotic delight in the vain efforts of their pursucrs to overtake them, and continue their aggravating anties in order to prolong the 


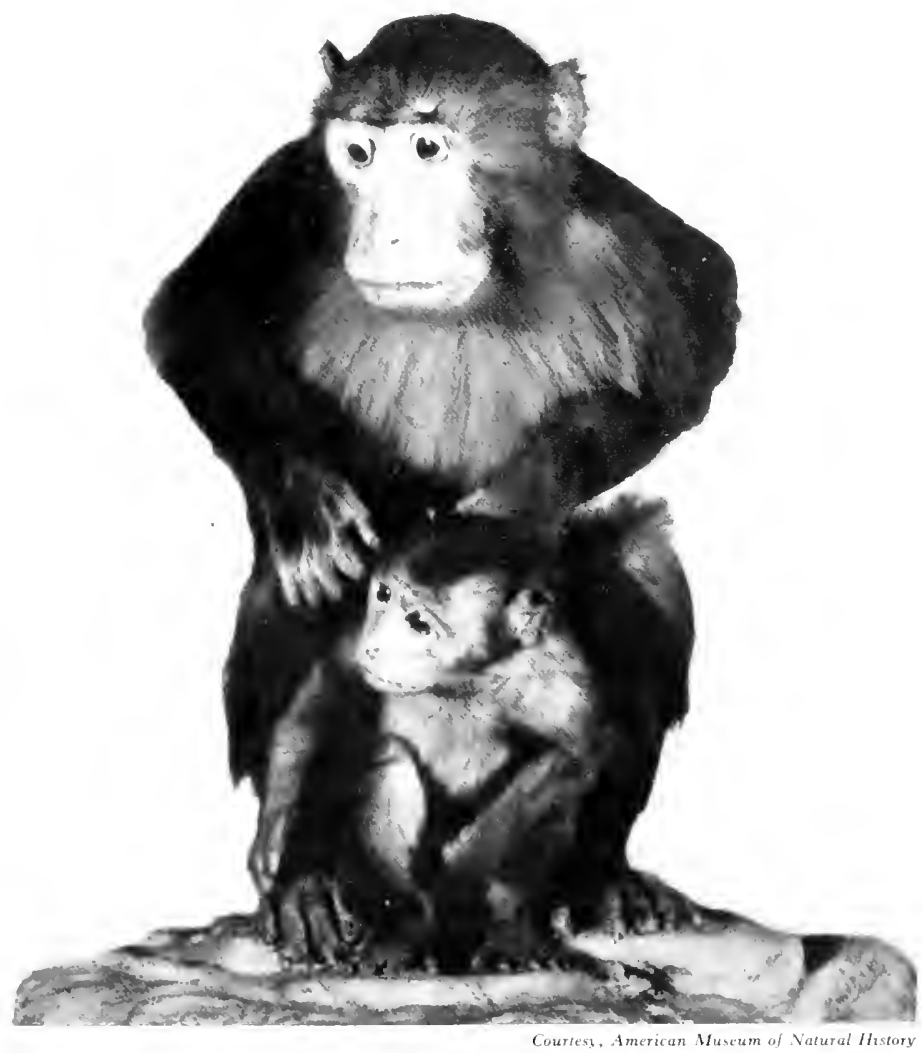

FIG. I60. MACACUS RHESLS. FLLL-GROWN MONKEY AND YOUNG. 
pleasures of the futile pursuit. If, perchance, threatened with capture, they often resort to concerted action in which a number of members of the group will take part in defending or rescuing one of the herd, which may be in difli-
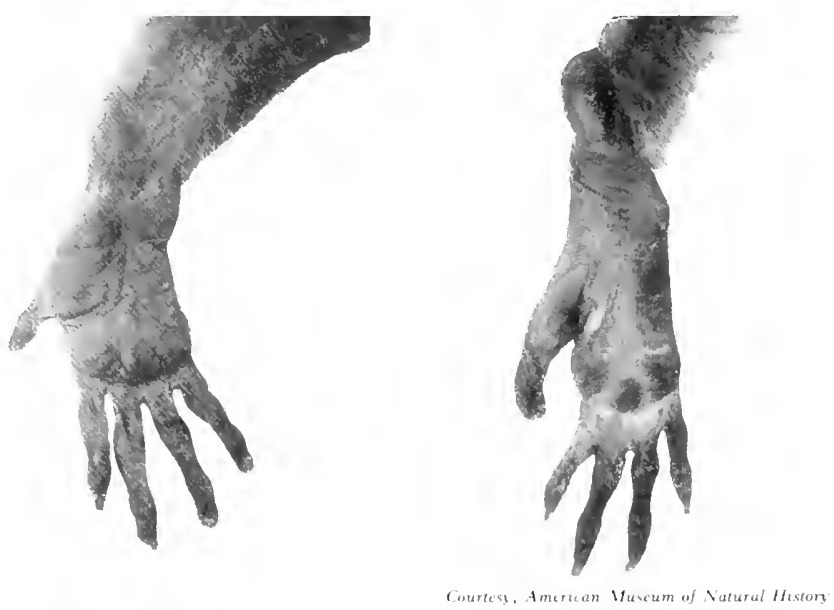

FlGS. I6I AND I62. HAND AND FOOT OF MACACLS RHESUS.

Lrit. Palmar surface of hand showing well-ceveloped manual eharacteristies, pronesenced digitation, short but oppesable thumb.

Ruint. Plantar surface of foxt showing well-developed heel, narrow sole. long, narrow toes, and long upposable hatlus.

culties. Among themselves they are constantly on the move. Repose seems totally Foreign to their behavioral program. Scampering, swinging, chattering, screaming, they go all day long among the trees, either without design in their actions, or changing some flecting purpose so frequently that their entire formula of behavior has the appearance of ceaseless, kaleidoscopic motion. They are very quarrelsome, constantly fighting or teasing cach other. And here, as in all of their activities, the object of their anger, the victim of their mirth is as quickly shifted as their lleeting attention. They feed upon spiders 
and many other kinds of insects, besides lruits and berries. Their motor mechanism not only adapts them to rapid moxements among the branchen of the trees, but enables them to travel with erreat speed over the surface of the
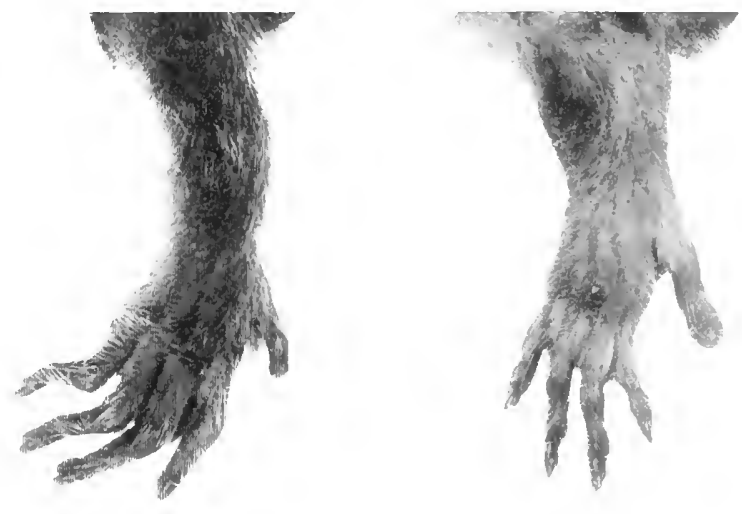

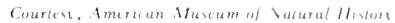

FIGS. 163 AND 164. HAND AND FOOT OF MACACLS RHESIS.

LLFr. Dorsum of hand shewing long stender fingers and well-develeped finger-nails.

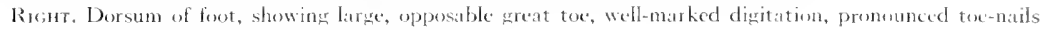
and general hand-like charaeters of the foot.

ground. Having no lear of the water, they are able to swim for long distances. As compared with the baboons, they show a greater mental alertness.

\section{Psichological Studies lpon the Pithecls Monkets}

Not a little exact psychological study has been devoted to the several species of pithecus monkeys, particularly concerning their ability to learn, their mentality and their capacity for derelopment of ideation. Kinnaman (1902), in his "Pithecus Rhesus," presents valuable data concerning the 
learning process, sensory discrimination, number reaction and tests of imitation. The results indicate a consickrably higher level of intelligence than that ascribed by Thorndyke to the new-world monkeys which he subjected to such tests. Kinnaman found evidence also of general ideas and reasoning, both of which, however, are of a low order. Hobhouse (101;) in a further contribution to our knowledge of the mental life of monkeys, in tests that were achirably adapted to gauge the ideational capacity of these subjects, ayrees in general with Kinnaman that the malacus monkey is possessed of definite jdeas.

In $1008 \mathrm{~J}$. B. Watson, testing the imitative ability of Macacus rhesus, found relatively little evidenee of other than extremely simple forms of icleation. On the other hand, Haggerty $($ anow), after much more extended investigation of sereral species of this family, obtained convincing evidenee of ideation and imitative behavior, and conchuded that these simian forms depended upon a certain deeree of ideational experience. Witmer (10) Io), in confirmation of Hagegerty's results, reports definitely imitative behavior in Pithecus irus; white the work of Shepherd (1910) agrees closely, so far as the evidence of ideation is concened, with Thorndyke. The species employed in his tests was Macacus rhesus; all of which, he believed, exhibited ideas of a low order or something closely corresponding to ideas. Franz (1907-1011), in conseguence of his study upon these monkeys, was able to throw no special light upon the problem of icleation, although his mode of approach took into account rather the function of various portions of the brain than the accurate description of various features of behavior. In 1011 , Hamilton, investigating both Macacus rhesus and Macacus irus, employed an ingenious quadruple choice method which showed that the two monkeys exhibited a fairly adequate type of ideational response.

Yerkes, in his extensive monograph, "The Mental Life of Monkeys and Apes" (1916), was able to disclose results which contrast rather sharply 
with those of previous observers. This no doubt was in consecpuence of more systematic, longer study, and experimental methods better suited to reveal the problem-solving ability on the part of the monkey. Yerkes interest centered on the question of the ability of the animal to farm the solution of relational problems of varying difliculties. On the basis of these observations, he constructed curves of learning. The Pithecus monkeys which he employed yielded evidence of ideation, and Verkes agrees with Thorndyke that free ideas are scanty in these animals; though ideas may derelop, they are rather concrete and definitely attached than free. He belieses that the general conclusions of previous experimental observers have done no real injustice to the ideational ability of monkeys. It is clear, however, that there are extreme differences in the mental development of different species of monkeys. The slow process of monkeys in the solution of their problems is quite surprising, however, but their suceess in such solutions is really less rapid than that of many of the Lower mammals, such for example as the pig.

\section{Measurements and Indices of Macacus Ruesus}

Total length of the animal.

Length of tail.

Total length of the skill

Occipito-nasal length...

Breadth.

Intertemporal width

Brain case.
$1260 \mathrm{~mm}$.

$33^{\circ} \mathrm{mm}$.

$1+j+\mathrm{mm}$.

$11 ;. ; \mathrm{mm}$.

()6. $3 \mathrm{mmm}$.

jo $\mathrm{mm}$.

$67.6 \mathrm{~mm}$.

The brain is distinctly gyrencephalic in type, with the fissure of Sylvius, the fissure of Rolando and the sulcus simiarum constituting the chicf fissural landmarks upon the convexity. As compared with baboon, the convolutions and fissures are about equal in prominence and size. 
The dimensions of the brain including the cerebellum and brain stem are:

Longritudinal.

Transverse or interparietal

Total weight of the brain

Weight of the forebrain

Neight of the midbrain

Weight of the hindbrain
$-8 \mathrm{~mm}$.

6- $\mathrm{mm}$.

$126 \mathrm{gms}$.

$10 \%$ grms.

2 gms.

$1 ;$ gims.

Total volume of the brain, determined by water displacement.

120 c.c.

Volume of the forebrain $101)$ c.e.

2 c.c.

is ce.c.

Upon the basis of these ligares, computed on the weight of the several portions of the brain, the following encephatic indiess were determined for the several divisions of the brain:

Forebrain index

St per cent

Midbrain inclex. . 2 per cent

llindbrain index $1+\operatorname{por}$ cent

Macacus rhesus, possessing as it does a fordorain index of $8+$ per cent, comes by this reason naturally into the group of those animals in which manual derelopment has progressed to a marked degree. This index places the animal distinetly higher than any of the lower primates.

Surface Appearance of the Brain in Macaces Rhesls LOBES AND FISSLRES

The convexity of the hemisphere shows much the same characteristic arangement as in baboon. The region of eortex comprised between the 
tissure of Rolando and the suleus simiarum, namely the parietal losbe, is much more richly convoluted than any other pertion of the surface of the macacus brain. The temporal lobe, which is a continuation of the parietal lobe ventrally, also has at marked clegree of fissural richness. The areat of cortex lying in front of the lissure of Rolando, namely the frontal lobe, is the least richly fissured and convoluted portion of the brain. The orbital surface presents a well-defined interorbital keel upon either side of which is a deep orbital indenture characteristic particularty of the simian brain. The fissures upon this surface correspond elosely to these observed in the baboon. The oceipital lebe, especially caudal to the suleus simiarum, shows less convolution even than the frontal area, but this lack of fissural pattern, so conspicuns on the lateral convexity of this region of the brain, is offset by the redative richness in fissures on the mesial and ventral surfaces of the occipital lobe. The ventral surface presents a deep cerebellar concavity. In general, it may be said that the eortex of the macacus brain corresponds closely to that of the baboon, its lobation being essentially the same and its fissures occupying similar pesitions. If there is any essential difference between these two types of cerebral hemisphere, it is to be found in the ereater richness in convolutional pattern of the macacus. The hemispheres of both of these species give a convincing representation of the simian type of brain, even in such minor detaits as the temporo-sphenoidal incisure and the ventral projection of the tip of the temporal hobe. In both instances, the occipital lobe overhangs and completely covers the tentorial surface of the cerebellum, a feature which is so typically primate that it may be regarded as a primarily identifying character of this order.

THE CEREBELLL M

The cerebellum presents a tentorial surface which, however, is more convex from side to side than is the case in the still higher primates. Its vermal 
ridge-pole also has a higher clevation. The foliation upon this surface is typical of all simians, i.e. continuous acress the midline orer the verm in in the lateral lobe without sulcal interruption. The oecipital surface presents at
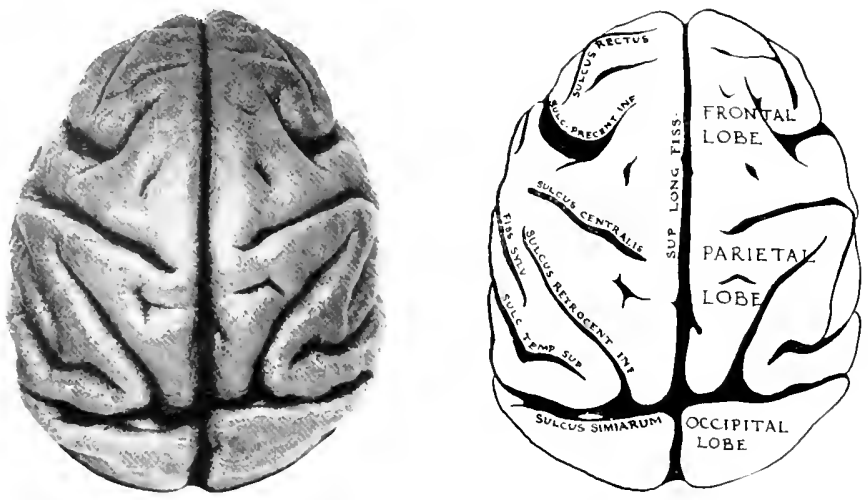

FIG. H6;. DORSAL SURFACE OF BRAIN OF MACACUS RHESLS.

[Actual Length $; 0$ mm.]

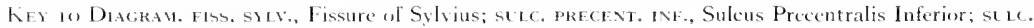
RETROCET. IVF., Suleus Retrecentralis Inferior; suze. Temis, scp., Sulcus Temporalis Superior; sur, LoNe. rass., Superior Longitudinal Fissure.

definite median clevation, the vermis, separated from the lateral lobes by the two paramedian sule; so that the vermal folia here are separated by definitely longitudinal sulci, white there is a deflection of the sulcal lines in the lateral lobes, downward and forward. The petroso-ventricular surface of the cerebellum presents its characteristic features. At its lateral extremity is the cerebello-pontile angle in which is contained a floceulus of moderate size. The remaining portion of this surface is in relation with the roof of the fourth ventrick, and thus, until the oblongata is removed by dissection, concealed from view. 
In general, the outhe of all of the structures appearing upon the surface of the brain stem in macateus has a clearness of definition which is not the case
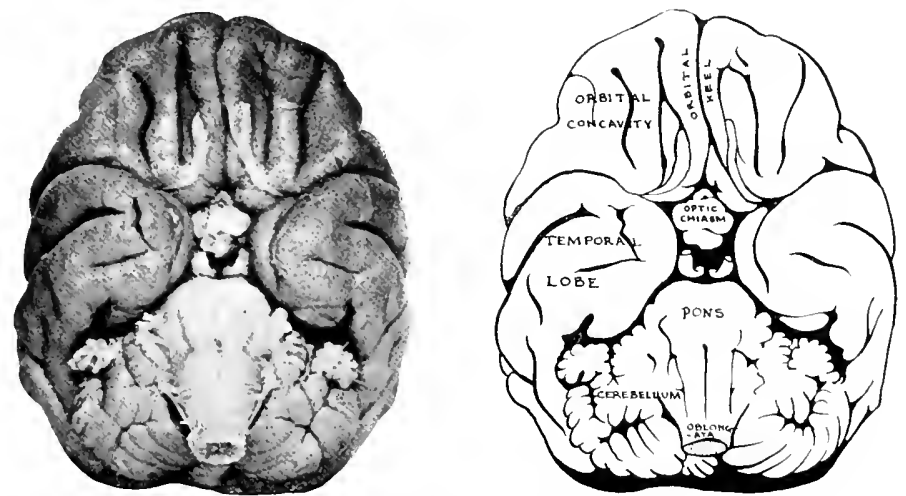

FIG. I66. BASE OF BRAIN OF MACACUS RIIESUS. [Actual length $56 \mathrm{~mm}$.]

in the lower primates, nor even in more closely allied species, such as Papio cynocephahus.

The Obloxgata. The oblongata, upon its ventral surface, presents a well-defined ventromedian sulcus, Hanked upon either side by two pronounced elevations, the pyramids. These pyramids extend from their bases which are situated above, in relation with the lower borcler of the pons Varolii, downward, and gradually attenuate to an apex, where many of the fibers pass inward and backward to form the pyramidal decussation. Lateral to the pyramid, and separated from it by a well-defined sulcus, is the eminence produced by the inferior olivary nueleus. The sulcus separating this structure from the pyramid is the preolivary sulcus. Dorsally the olivary eminence is bounded by the post-olivary sulcus separating it from a rather faintly outlined elevation on the lateral surface, 
which becomes more prominent as it extends toward the pons, the restiform body. In the eephalic region of this lateral area is another protuberance, the tuberculum acusticum.
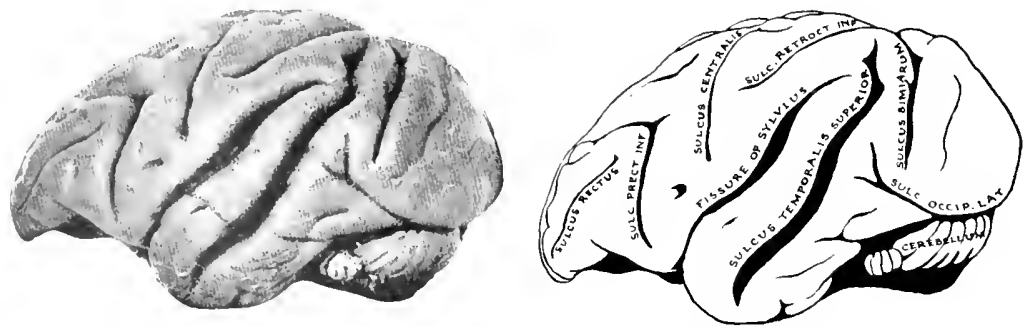

HIG. 16-. LEIT LATERAL SIRFACE OF BRAL, MACACLS RHESLS. [Actual Letngth $62 \mathrm{~mm}$. ]

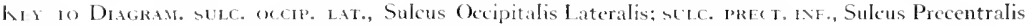
Interior: stie. Retroci. INF., Sulcus Retrocentralis.

The dorsal surface of the oblongata presents its two characteristic divisions, the ventricular and the infraventricular portions. The inlraventricular portion is directly eontinuous with the cervical portion of the spinal cord. As the inferior angle of the fourth ventricle is approached, two slight elevations appear on either side of the dorsal septum. The most mesial of these is the clava, an eminence produced by the presence in the dorsal liceld of the nucleus of Goll. At a shightly higher level, separated from the clava by the dorsal paramedian sulcus, a second elevation, the cuncus, makes its appearanee. Both of these elevations extend cephalad following the general divergence aceasioned by the opening of the ventricular space. Of these two clevations, which represent respectively the nucleus of Goll and the nucleus of Burdach, the latter is definitely larger than the former. The significance of this inequality arises from the fact that in macacus, the forelimb and hand, having gained predominance as sensory organs over 
the tail and lege, require more extensive relay stations for the conduction of scensory impulses to the brain.

The ventricular portion of the oblongata presents a characteristic
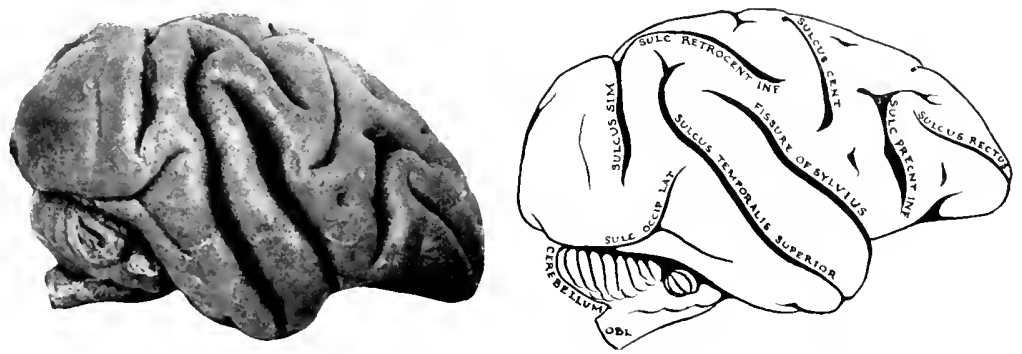

FIG. IG8. RIGHT LATERAL SLRFACE OF BRAIN, MACACLS RHESLS. [Actual Lecngth $62 \mathrm{~mm}$.]

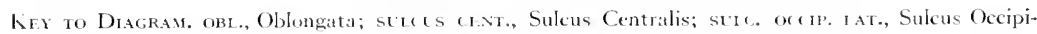

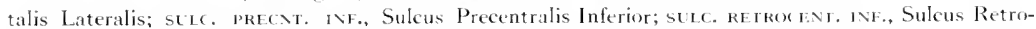
centralis Inferior; sclecs sm., Sulcus Simiarum.

arrangement, in the divarication of the alar plates and the opening of the ventricular space. The caudal angle is directed downward and covered for a short distance by a remmant of the central gray matter, the obex. The floor of the ventrick is bounded caudally by two high walls produced by the clevations of the cuncus and clava. These, however, gradually become reduced in height until they reach the level of the lateral recess, where they are on the same plane as the ventricular lloor. This floor is divided longitudinally by a deep median sulcus. Upon either side of this sulcus, in the Iower angle of the rentricle, is the trigonum hypoglossi in the position of the hypoglossal nucleus, and lateral to it, the sulcus limitans separating the trigonum hypoglossi from the fovea vagi, the fatter marking the position of the dorsal vagal nucleus. No area postrema or area plumiformis could be discerned in the spceimens cxamined. 
Cephalad to the eminenees of the cuncus and clava, apparently in direet continuty with them as they beeme attenuated and reach the level of the ventricular floor, is a marked elevation. This is the vestibular area
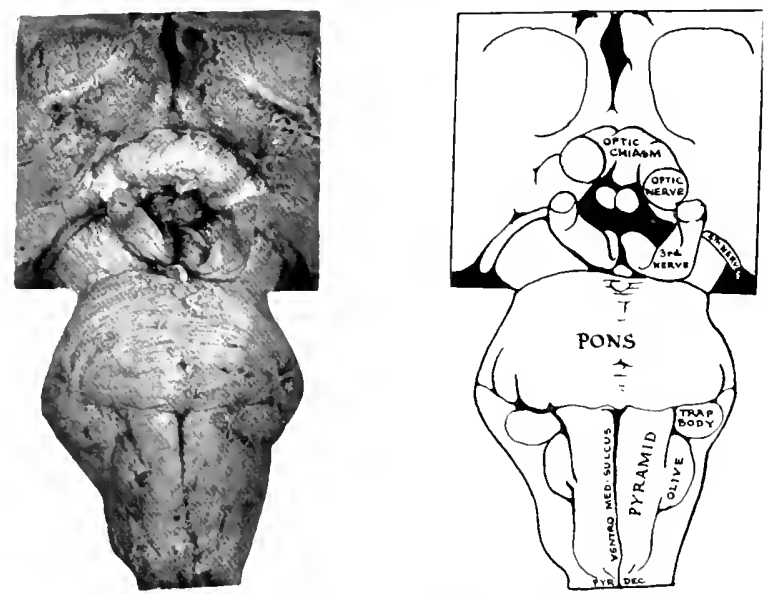

F1G. IOg. VENTRAL SLRFACE OF BRAIN STEM, MACACLS RHESLS. [Actual I ength, $+4 \mathrm{~mm}$.]

Key to Diagray. tray. Beds, Trapezoid Budy; pro. dec., Pyramidal Decussation; ventro med. selcus. Ventromedian Sulcus.

which contains the nuclear elements for the receipt of impulses from the internal ear and particularly related to the balancing mechanism. The marked prominence of this elevation in the relicf of the floor of the ventricle is indicative of the degree to which macacus depends upon its balancing function. A boundary between the eephalic and caudal triangles of the fourth ventricle is produced by the crossing striae acusticae, many of which pass obliquely downward, while a few ascend, passing over the outer surface of the vestibular eminenees. The apex of the eephalic angle of the ventricle marks the point of transition into the caudal orifice of the Sylvian aqueduct. 
Immediately above the acqueduct appears the cuadrigeminal plate of the midbrain, characteristically arranged in four symmetrical clevations, two of which are caudal in pesition, the inferior colliculi, while the two cephalic
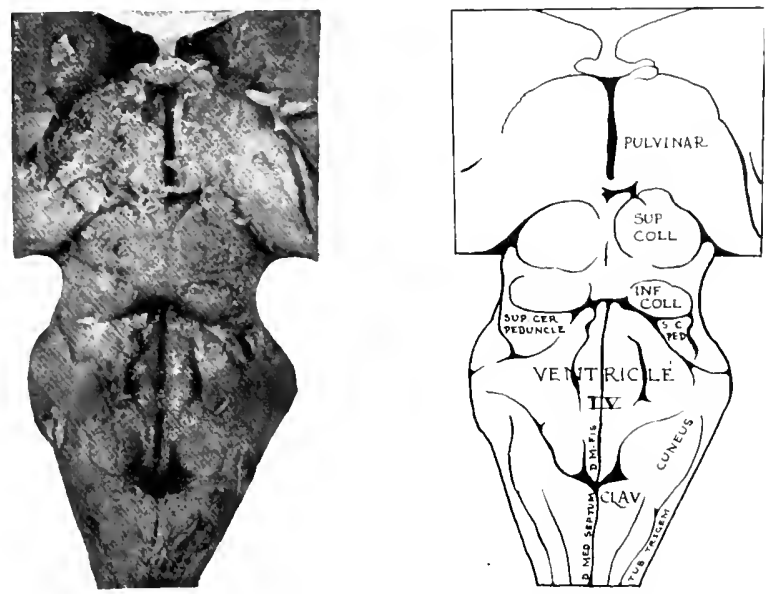

FIG. I7O. DORSAL SURFACE OF BRAIN STEM, MACACL'S RHESLS. [Actual Length, $4+\mathrm{mm}$.]

Key to Diagray. Clav., Clava; D. W. Fis., Dorsomedian Fissure: D. ved. Septer, Dorsomedian Septum; INF. Coll., Inferior Colliculus; StP. Clik. Pede vCle and S. C. PED., Superior Cerebellar Peduncle; si P. Coll., Superior Colliculus; tuB. trigen., Tuberculum Trigemini.

elevations form the superior colliculi. These latter are about twice the size of the inferior colliculi, and slightly more elevated as tectal structures. The four elevations are separated longitudinally by the median intercollicular sulcus, and transversely by the transverse intercollicular sulcus. On the lateral surface of the midbrain, extending from the inferior colliculus, is the brachium conjunctivum posticum which terminates in the mesial geniculate body. A similar brachium extends forward from the superior colliculus to terminate in the lateral geniculate body. 
Tie Poss Varolit. Upon the ventral surface of the brain stem the oblomgata is separated from a broad and llat band of transverse nerve fibers, the pons Varolii, by a well-dedined bulbopontile suleus, which latter marks the point of emerence from the brain stem of the sixth, seventh and eighth nerves. The prominence of the pons denotes the degree of development in the cerebral corter, especially the neopallium, both as to its general proportions as well as the richness of its convolutional and fissural patterns. Frem the functional standpoint such a pontile derelopment justilies the conchusion that macacus is an animal endowed with a rather extensive range of shilled performances; and lurthermore, capable of acquiring many learned reactions quite unknown in many of the lower primates. Indeed, such prominence in the pons bespeaks an animal capable of more complex behavior than its next lower congener, the baboon. This seems to be borne out by the reactions of these animals observed in captivity. The antagonism and stubbornness of the baboon in resisting attempts to teach it are in marked contrast to the rapid, almost uncanny acquisitiveness of the macacus tribes in learning new, if often most ageravating tricks.

The ventral surface of the pons presents a farly dece groove which contains the basilar artery. This surface terminates abruptly at its cephatic limit in the pontopeduncular sulcus where the cerebral peduncles begin. By their divergence, these peduncles create the interpeduncular space, which is limited above by the optic chiasm, and bounded laterally by the two cerebral peduncles and optic tracts. It contains the mammillary bodies, the region of attachment of the infundibular stalk and the tuber cinereum.

The Cerebral Peducles. The cerebral peduncles, as is the case of the pons Varolii, are more clearly defined than in the lower species, and this distinctness gives the impression of an animal possessed of more discretely organized behavioral reactions. This feature is of importance as it is one of the 
most considerable factors in weighing the evidence concerning the relation of the primates, one to another.

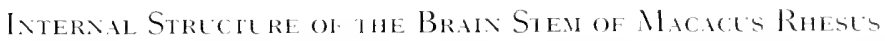

Although the levels at which the sections havebeen selected in the macacus brain do not exactly correspond with those of the baboon, they are so chosen as to cover all of the major features atready diseused in the brain stem of the other primates. The impression is gained at once that all of the chef nuclear structures stand out with a clearer definition than is the case in any of the previous specimens. This increasing clarity is a distinguishing feature in the higher primates and man.

LEVEL OF: THE PYRAMIDAL DECLSSATION (FIG. I-I)

At the ferel of the pyramidal decussation the outstanding feature is the crossing fibers of the pyramidal bundles and the influence which this decussation produces upon the arrangement of the gray matter. The crossing pyramidal fasciculi (Pyx) sweep backward and outward from their initial position on one side of the axis, across the midline to a lateral position on the opposite side, where they finally take up their descending course as the crossed pyramidal tract. In the process of crossing, these pyramidal fibers have followed such a course as to separate the ventral gray column (Ven) from the central gray matter (Cen). The distance between these two elements of the gray matter is considerably creater than in any of the other primates thus far considered, conveying the impression that the pyramidal system is itself more voluminous than in the Iower forms. This impression needs corroboration before it can be maintained that the pyramidal system in macacus is really more extensive and thus provides more ample conduction for voluntary control over the somatic musculature. The ventral gray matter ( $V$ ene occupies a position about midway 


\section{3,1,

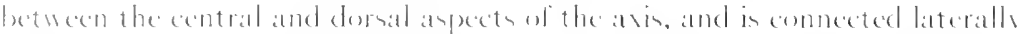

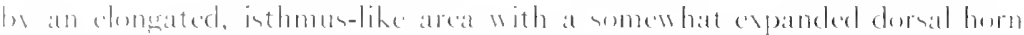

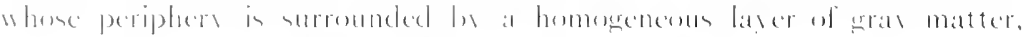

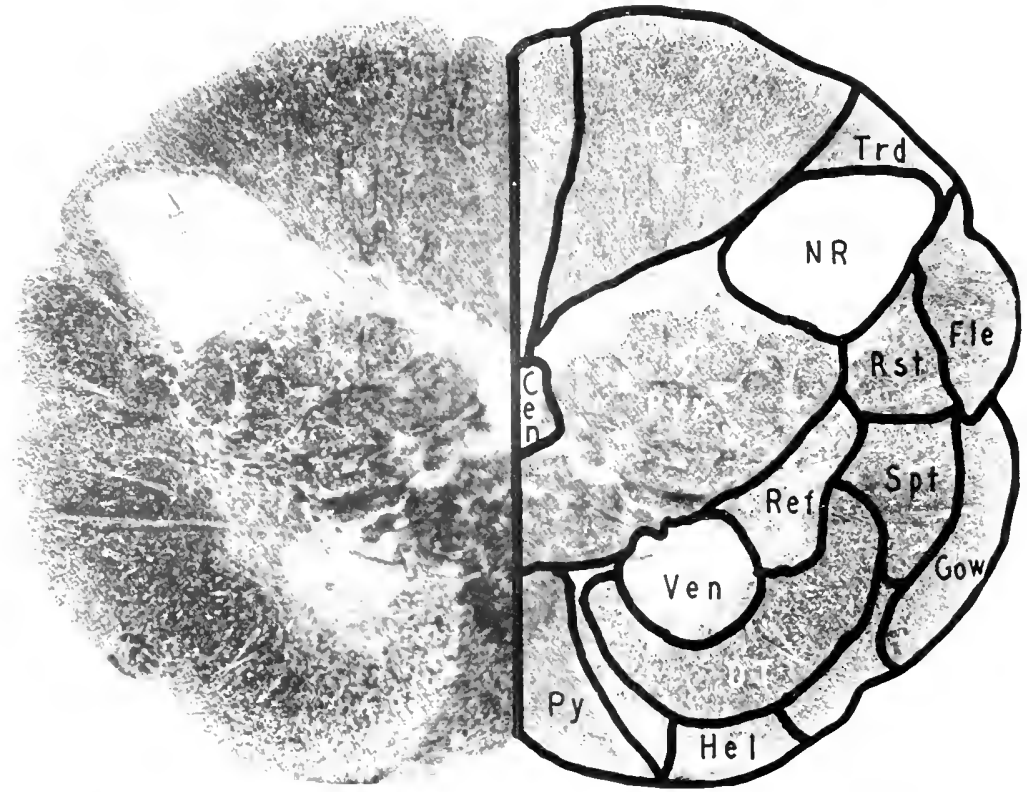

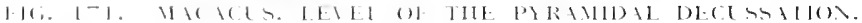

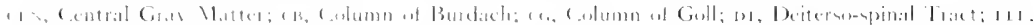

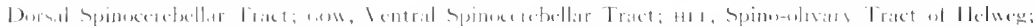

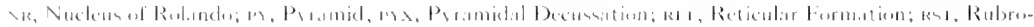

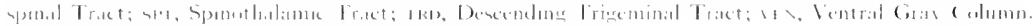

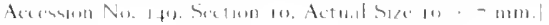

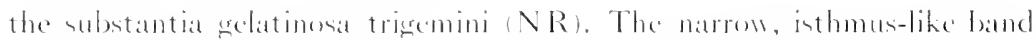
(1) Erall matter connecting this latter with the central grat matter forms the erevis of the dorsal horn. Dersal to the central grats matter (Cen), the cervis of the dersal hom and the subetantial gedatinosat trigemint is the 
expansive dorsal ficld in which, homever, there is ats yet no sign of those great sensory nuclei which serve as relays for the sensory pathways from the extremities. The broad expanse of this dorsal sensory lield indieates the

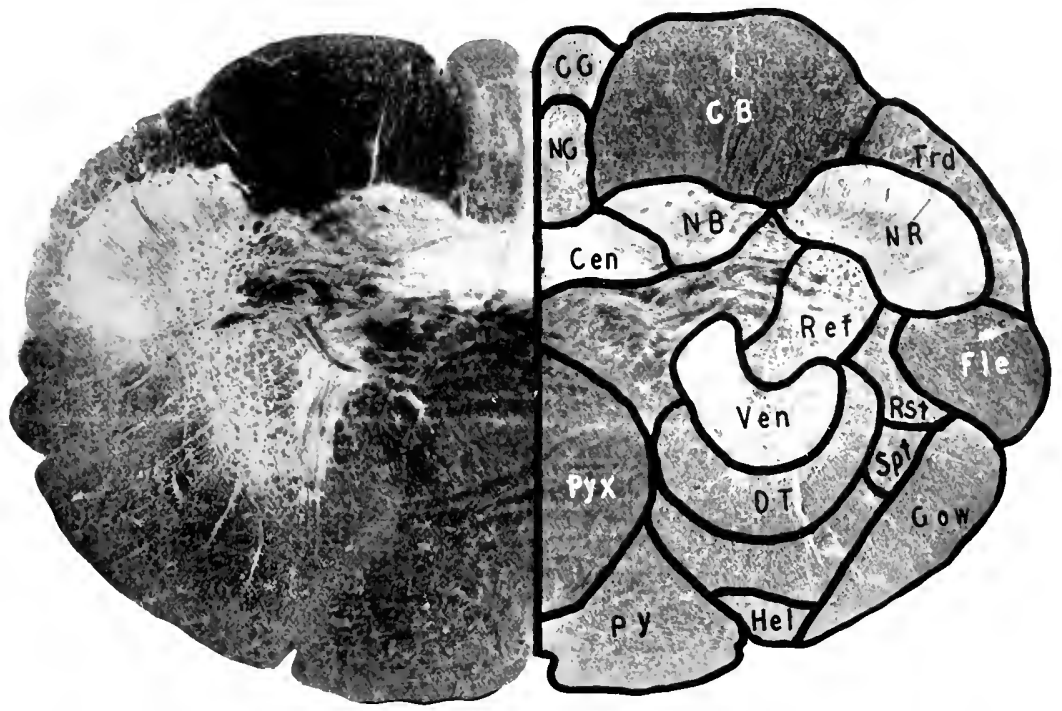

FIG. I-2. MACACLS. LEVEL OF CALDAL LIMIT OF DORSAL SENSORY NLCLEI. CeN, Central Gray Matter; CB, Column of Burdach; CG, Column of Gull; dr, Deiterso-spinal Tract: 1.1E, Dorsal Spinocerebellar Tract; sow, Ventral Spinocerebellar Tract; Hel, Spino-olivary Tract of llelweg: NB, Nucleus of Burdach; NG. Nucleus of Goll; NR, Nucleus of Rolando; Py, Pyramid; Pyx, Pyramidal Decussation; REF, Reticular Formation; RST, Rubrospinal Tract; SPT, Spinothalamic Trate; tRD, Descending Trigeminal Tract: vex, Ventral Gray Column. [Accession No. 1.9. Section 35. Actual Size $12 \times 8 \mathrm{~mm}$.]

capacity of the central axis for the conduction of sensory impulses concerned in discriminative sensibility. The faint indenture on the dorsal aspect of the section indicates the position of the dorsal paramedian sulcus which separates the column of Goll (CG) from the column of Burdach (C,B), thus furnishing some idea as to the relative dimensions of these two tracts. 
Judgment based upon this comparison would favor the pathway from the upper extremity as being more capacious for the purpese of sensory comduction. Should this impression be borne out by other facts, the inference that there has been an advance in the upper extremity, and especially the hand as a sensory organ, seems justified. This fact, taken in conjunction with the relatively small size of the substantia gelatinosa, as compared with the similar structure in other species, implies that the facial rexion of the amimal has lost some of its original importance as a sensory directing organ. In all probability much of this function has been delecrated to more capable sensory structures of the forelimb, particularly the hand.

Occupying the most ventral position in the cross section is the pyramidal system (Pyx), most of whose fibers are actively engaged in the process of decussation. On the ventrolateral aspeet of the section, lying external to the ventral gray matter, is the medullary substance constituting the circumferential zone, and mesial to this is the intermediate zone.

LEVEL OF THE CALDAL LIMT OF THE INFERLOR OLIVARY NLCLELS (FIG. IT3)

At this level certain striking changes have appeared. Most notable among these is a dense mass of gray matter situated in the ventral portion of the section, the caudal extremity of the inferior olivary mucleus (IO). In the dorsal sensory ficld there appear the huge masses of nuelear substance constituting respectively the nucleus of Goll (NG) and the nucleus of Burdach (NB). A feature of the inferior olivary nucleus is the sharper definition of its borders, giving it the appearance of a more discrete structure than in any of the lower species. This nucleus, as is the case with other structures, comveys the impression of an emergence from a more primitive indefiniteness. The central gray matter $(\mathrm{Cen})$ surounding the central canal oceupies a position somewhat more dorsal than in the previous level, indicating a general tendency of this pertion of the gray substance to move 
into the prosition ultimately occupied by the floor of the fourth ventricke. Dorsal to it, and adjacent to the dorsomedian septum, is a large nuclear mass surrounded by a small capsule of medullary substance, the nucleur

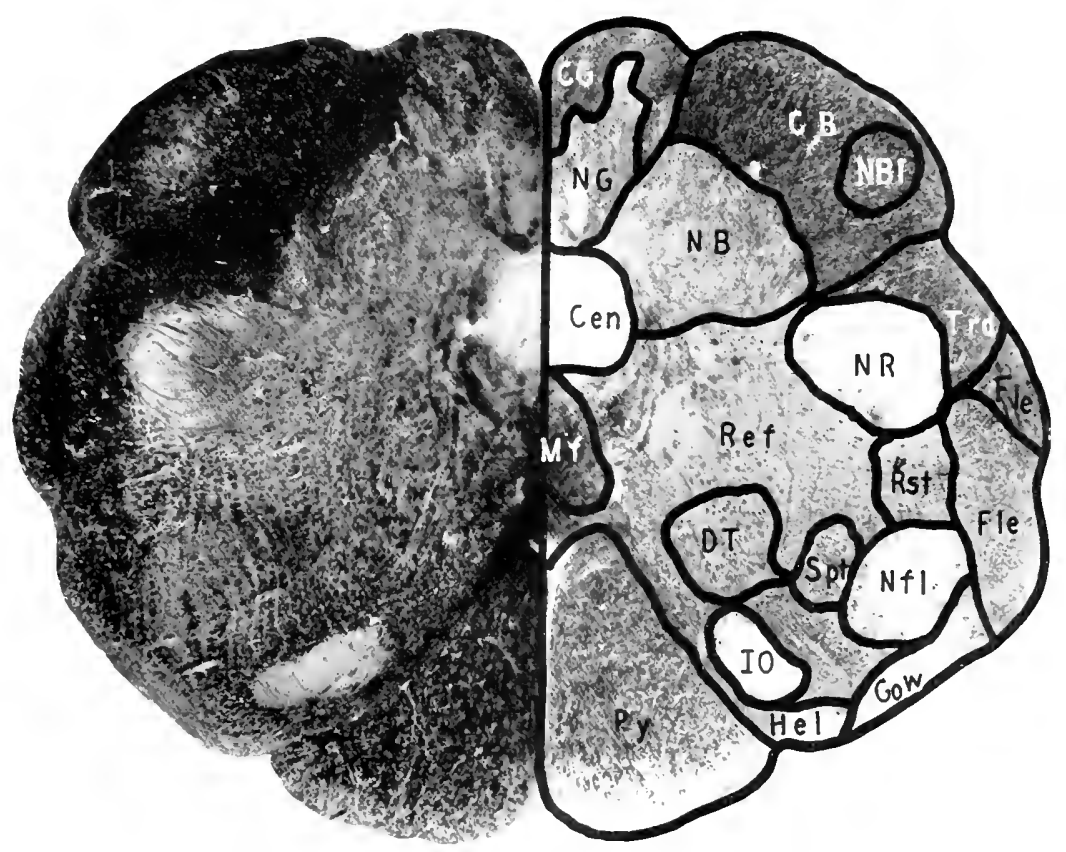

FIG, 173. MACACLS, LEVEL OF CALDAL LIMIT OF INFERIOR OLIARY NLCLELS. CEN, Central Gray Matter; CB, Column of Burdach; CG, Column of Goll; dr, Deiterso-spinal Tract; FLr, Dorsal Spinocerebellar Tract; gow, Ventral Spinocerebellar Tract; 11EL, Spino-olivary Tract of Helweg: 10 , Inferior Olive; MF, Mlesial Fillet; NB, Nucleus of Burdach; >BL, Nucleus of Blumenau; NG, Nucleus of Goll; Wrt, Facial Nucleus; Nr, Nucleus of Rolando; Py, Pyramid; REF, Reticular Formation; Rst, Rubrospinal Tract; SPT, Spinothalamic Tract; TRD, Descending Trigeminal Tract. [Accession No. 1 +9. Section go. Actuit] Size I I $\times 8 \mathrm{~mm}$.]

of Goll (NG), lateral to which, and separated from it by the dorsal paramedian sulcus, is the much larger nucleus of Burdach (NB). De- 
tached from this mocleus and lying near the periphery is an equally large sensory element, the nucteus of Blumenau (NBi). In a position ventral to the nucleus of Blumenau is the substantia gedatinesa trigemini (NR), in contact externally with the fibers of the descending trigeminal tract (T.d). It is now possible to compare with more eritical sense the relative dimensions of the three major elements entering into the dorsal sensory field, and representing the dermatomic areas of the bendy from the soles of the feet to the crown of the head. These elements serve all modalities of discriminative sensibility within the same limits. It is apparent that the column and nueleus of Burdach far exceed in size either of their neighboring structures, the nueleus of Goll (NG) situated mesial to them, or the substantia gelatinosa trigemini (NR) situated ventral to them. On the strength of this comparison, the conclusion seems tenable that the hand and upper extremity have gained much in prominenee as sensory organs over the head and face, which latter are only meagerly represented by the redatively small receiving station of the trigeminal nerve. Quite as much do the lower extremity and tail suffer by the comparison as sensory organs. In Macacus rhesus the tail is short and has developed none of that prehensile specialization which characterizes the new-wortd monkers.

Passing through the substantia gelatinosa trigemini (NR) are a few emergent fibers of the eleventh nerve, making their way toward the periphery of the axis. The fibers of the twelfth nerve are also seen taking origin in the ventral portion of the eentral gray matter ( Cen) and passing forward in the direction of the inferior olivary nucleus $(10)$. The reticular formation ( Ref) occupies a central position, and through it pass a number of intemal arcuate fibers from the nucleus of Burdach, while large masses of decussating fibers extend inward from erigins in the nucleus of Goll and pass mesially to enter the decussation of the mesial fillet (Mf). The collected bundle of the pyramid (Py) occupies its usual ventromesial position and affords a clear 
idea as to the relative size of the pramidal system in macacus. Lying upon the ventrolateral periphery is the circumferential zone, mesial to which is the intermediate zone. Some external arcuate fibers, apparently arising in the nucleus of Burdach, pass forward and inward to their decussation in the median raphe.

LEVEL THROLGH THE WIDDEE OF THE INFERIOR OLIYARY NCCLECS (HIG. $1^{-}$)

At this level, the addition to the inferior olive (1O) of the mesial and dorsal accessory olives (DO, VO) is clearly shown. This level, howerer, is more signifieant as again indieating the relative sizes of the three major nuclear relay stations for discriminative sensibility, oceupying the dorsal sensory field. Thus the nucleus of Goll ( NG) appears much smaller as compared with the nucleus of Burdach (NB), and the acessory nueleus of Blumenau ( NBl) (now showing some of its points of confluence with the more mesial cell mass of Burdach). It offers an almost convincing argument that the leg, foot and tail have been superseded in their sensery importanee by the development of the Corelimb and particularly the hand. The relative functional significance of the forelimb and hand, as represented by the nuclei of Burdach and Blumenau (NB, NBI), when compared with the sensory significance of the face and head, is clearly illustrated in the relatively small size of the substantia gelatinosa trigemini (NR).

The section also indicates the manner in which the internal arcuate fibers, arising in the nuckeus of Goll, sweep forward and inward as dense collected bundles, skirting the rentral gray matter, while those arcuate fibers arising from the nucleus of Burdach make their way by longer, nore graceful ares, in less dense compact bundles, penetrating in their passage the main mass of the reticular formation. Fibers of the twelfth nerve ( $\mathrm{N}_{12}$ ) (nervus hypoglossus) make their way from their nucleus (Nhy) in the ventral portion of the ecntral gray matter to the inferior olivary nucleus 
(IO). Dorsal to the pyramid (Py), and contaning at this level many of the compact bundles of decussating fibers, is the mesial fillet ( $\mathrm{If}$ ) as its fibers are beginning to turn cephatad after crossing the median raphe.

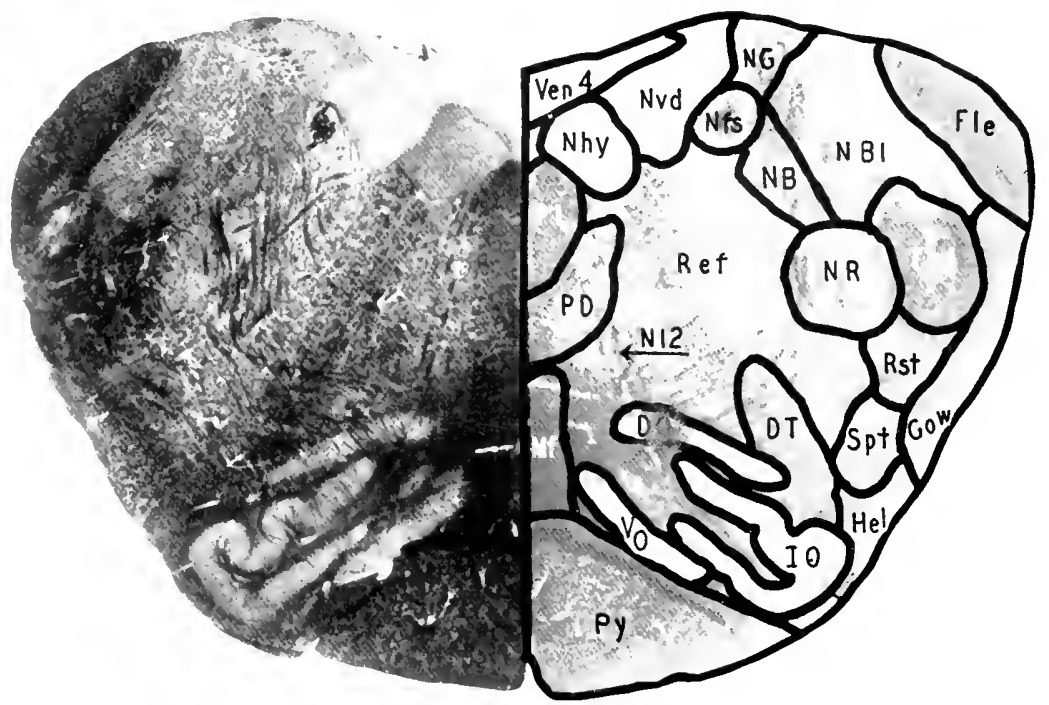

FIG. 174. MACACUS. LEIEL THROUGH MIDDLE OF INFERIOR OLIVARI NUCLELIS.

Do, Dursal Accessory Olive; DT, Deitersu-spmal Tract; fle, Dorsal Spinocerebellar Tract; gow, lentral Spinocerebellar Tract; MEL, Spine-olivary Tract of llelweg; 10 , Inferiur Olive; Mf, Mestal Fillet; NB, Nucleus of Burdach; NBe, Nucleus of Blumenau; NFs, Facial Nucleus; No. Nucleus of Gull; vis, 1 lypuglessil Nucleus; vid, Dorsal Vagal Nucleus; NR, Nucleus of Rolande; Nı2, Hypoglossal Nerve; PD, Predursal Bundle; PL, Pusterior Longitudinal Fasciculus; Pr, Pyramid; ReF, Reticular Formation; Rst, Rubrospinal Tract: SPT, Spinothalannic Tract; Tro, Descending Trigeminal Tract; Vev 4. Fourth Ventricle; vo, Ventral Accessory Olive. [Accessien No, 1+1). Section 1+1. Actual Size $13 \times 8 \mathrm{~mm}$.]

LEVEL OF THE VESTIBULAR NLCIEI (FIG, I ; j)

Here the cross section shows considerable alteration in its general configuration. Its diameters in the dorsal portion of the field are more extensive than in the lower sections. This is primarily due to the widening of the 
fourth ventricle and the appearance of the lateral recesses. Among the intrinsic modifications of the axis at this level is a group of nuclei connected with the internal car, scrving as relays for impulses concerned with the special

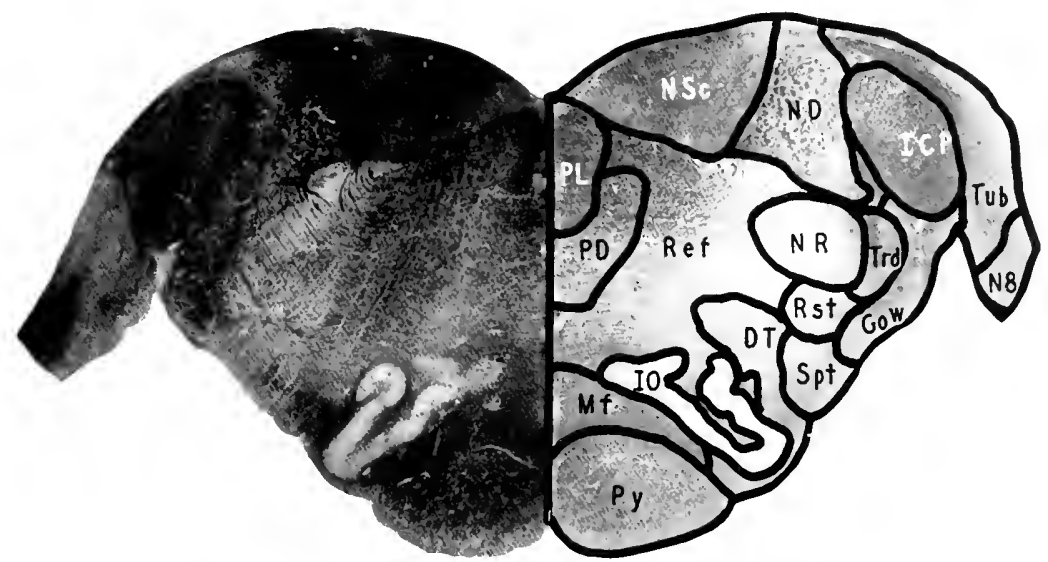

FIG. ITj. MACACUS. LEVEL OF THE VESTIBLlAR NUCLEI.

DT, Deiterso-spinal Tract; Gow, Ventral Spinocerebellar Tract; tcp, Inferior Cerebellar Peduncle; 1o, Inferiur Olive; MF, Mesial Fillet; ND, Deiters' Nucleus; NR, Nucleus of Rolando; Nsc, Nucleus of Schwalbe; N8, Auditory Nerve; PD, Predorsil Bundle; PL, Pusterior Longitudinal Fasciculus; Pr, Pyramid; REF, Reticular Formation; RST, Rubrospinal Tract; SP'T, Spinothalamic Tract; TRD, Descending Trigeminal Tract; тL B, Tuberculum Acusticum. [Accession No. 140. Section 185. Actual Size 1? $x-\mathrm{mm}$.]

sense of hearing as well as with the balancing mechanism. Situated immediately beneath the floor of the fourth ventriele, underlying the ependymal gray matter, is a large triangular nueleus of small cells, the nucleus of Schwalbe (NSc), and lateral to this a nucleus containing many Iarge cells, the nucleus magnocellularis of Deiters (ND). Dispersed among the cells of the latter nucleus are many small bundles of heavily myelinated axons. These two nuclei constitute the vestibular complex. They have assumed, in a general way, the positions oceupied in the Jower levels by the nuelei of Goll and Burdach. In the topographical relation of these 
muclear masses there is complete correspondence in all species thus far considered, from which it must be apparent that a definite principle of structural design regulates the manner in which this series of nuclei is lat dewn in the brain stem.

Beginning at the caudal extremity of the bblongata are the nuele for discriminative sensibility in the tail, ley and arm; immediately suceeding them in the next higher levels are the nuclear relay stations receiving impulses from the proprinceptors of the internal ear in the interest of the balancing function. Thus a superpesed series of nuclei in the dersal freld of the oblongata in the form of a long column makes provision for the primary way of all sensory impulses arising in the proprioceptors of the body. This is not merely of generie significance, for its long antecedent history in the vertebrates makes it a matter of phyletic moment.

Lateral to Deiters' nucleus, forming the extreme lateral structure of the cross section, is an elevation on the surface of the axis, the tuberculum acusticum ( $\mathrm{Tub}$ ), into which enter some of the fibers of the cochlear division of the cighth nerve (N8). This clevation forms a relay station in the pathway of hearing, so that in the tubereuhm acusticum and the two vestibuIar nuckei at this level, the chief receiving stations for the eighth nerve appear. Interposed between the tuberculum acusticum and Deiters nucleus is a dense oval bundle of fibers constituting the restiform body (ICP).

Mention should be made of the large size of the vestibular area, inasmuch as this element of the brain stem causes a promounced clevation in the floor of the fourth ventricle. Furthermore, the large dimensions of the vestibular complex in macacus indicate to what extent the balancing function is necessary in this animal.

Another feature at this level is the inferior olivary nucleus (1O) connected with which are the two aceessory olivary mucled. Attention is especially called to the clear-cut boundaries of the inferior olivary nucleus 


\section{PITIIECUS RIIESUS, MACACUS RHIESUS}

in macacus, tegether with the tendener toward befinite convolution of its structure, which appears in this species in such conspicuous development for the first time. This tendency to convolution is onc which will be seen to become more marked as the higher apes are approateded. It reachen its greatest degree of eomplexity in the brain stem ol man.

The pyramid ( Pr) oecupies its typical ventromesial position and altords an opportunity for estimating its size in relation to the rest of the cross sedetion. Dorsal to it are the bundles constituting the mesial fillet (.MI). Ventral to Deiters' nuckus, laintly outlined at this level, is the substantia gelatinosa trigemini (NR), upon the lateral border of which are the collected fibers of the descending trigeminal tract (Trd). The reticular formation (Red) is quite extensive and is penetrated by many areuate libers apparently arising in the mucleus of Deiters, to form the Deiterso-spinal tracts. If one feature may be signalized at this level, it is the great prominenee of the vestibular complex with the implication which it bears concerning the balancing function of the macacus.

\section{LEVEL OF TIE CEREBELLAR NLCLEI (FIG. I-6)}

At the level of the cerebellar auclei the organization of the cercebellar connection is indicated. The two groups of cerebellar muclei, namely, the mesial and the lateral groups, have all of that indefinite development which characterizes the lower primates. The lateral group ( $\mathrm{Ndt}$ ), whose largest constituent part is the nucleus dentatus, is a more or less dilfuse mass of nuclear substance surrounded by medullary tissue. It has none of the convoluted appearance or discrete outline prominent in the higher anthropoids. In this respect it allies itself closely with all the lower forms preriously described.

Situated in the rool of the fourth ventricle is the mesial muclear group $(\mathrm{Nfg})$, consisting of the nucleus fastigius and the nucleus globosus. Between 
the mesial and lateral groups of the cerebellar nuclei are the massive bundles of the juxtarestiform body. The roof of the fourth ventrick is formed by the nuclear substance of the cercbellar nuckei. Its floos still contains a large

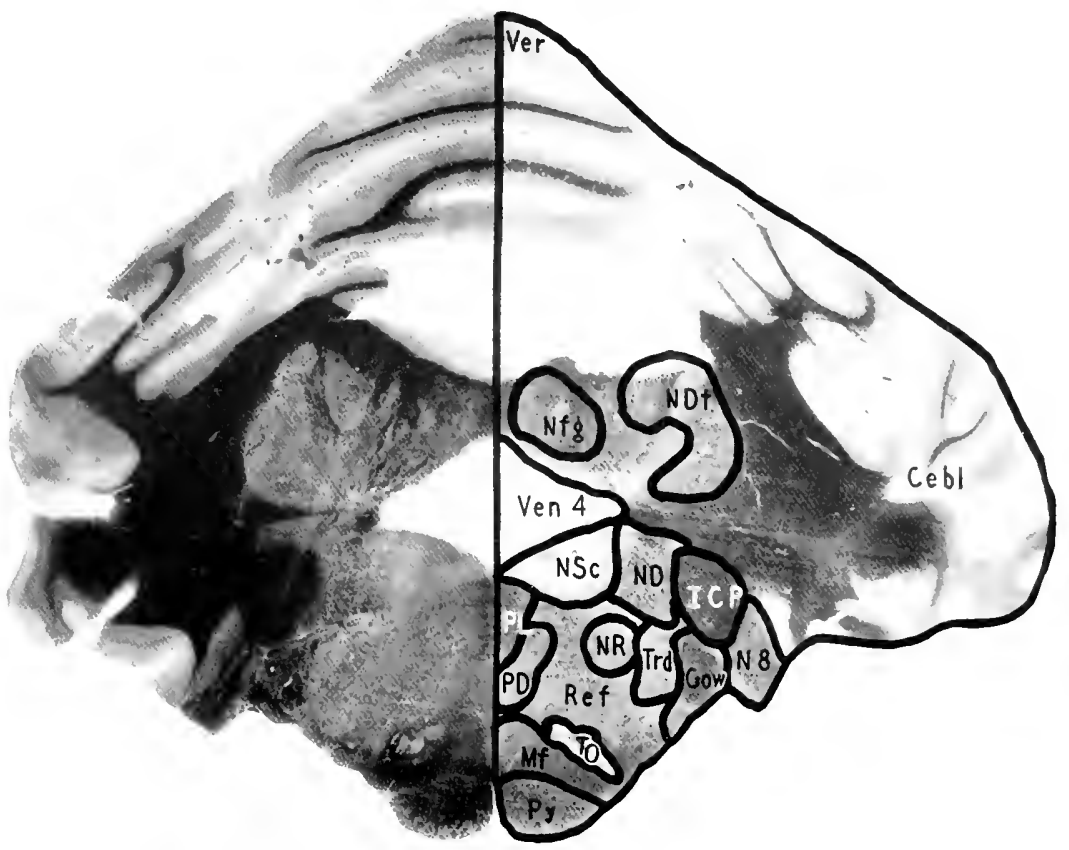

FIG. I 6 . MACACUS. LEVEL OF THE CEREBELLAR NLCLE1.

Cebs, Cercbellum; caw, Ventral Spinecerebellar Tract; ICP, Inferior Cerebellar Pedunde; Io, Inferior Olive: MF, Mesial Fillet; \D, Nucleus of Deiters; NDI, Cerebellar Nuclei, Lateral Group; NFG, Cerebellar Nuclei, Mesial Group; $\backslash R$, Nucleus ol Rolindo; Nse, Schwalbe's Nucleus; NS, Auditurs Nerve; pd, Predorsal Bundle; Pe, Posterier Longitudinal Fascicutus; PY, Pyramid; Rter, Reticular Formation; tro, Deseending

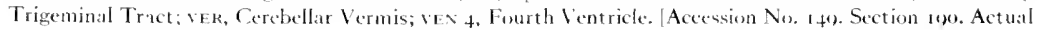
Size $18 \times 15 \mathrm{~mm}$.]

representation of Schwalbe's and Deiters' muclei (NSc, ND). The other clements at this kevel are indicated by letters in the caption. 
The principal feature illustrated by this recrom is the dilluse character of the cerebetlar nuclei. This condition at once indicates an animal porty provided with coordinative control over its skilled acts. This view of the behavior of macacus is further supported by the relatively small size of the lateral cerebellar lobes. The animal is noted, and even notorious, for its prankishness and its great agility as a climber. It is possible to teach these monkeys many amusing trieks, so that the conception of them as limited in their neokinctic performances perhaps does them injustice. On the other hand, the fact should not be overlooked that howerer much they may improve by training, these animals use their new acquisitions but little in the ordinary routine of their lives, and escaping from captivity, relapse to the simpler motor patterns essential to their primitive arboreal adaptations. It must, therefore, be accepted from such evidence as is elicited from the cerebellar nuclei and their connections, that the macacus species are, in fact, capable of a very limited range of skilled learned performances which they habitually employ in the pursuits of their daily lives.

LEVEL OF EIERGENCE OF SIXTH CRANIAL NERVE, NERIUS ABDLCENS (FIG. 1--)

At this level the section has undergone considerable change due to the appearance of the caudal portion of the pons Varolii (PN). This structure now adds a basal element to the neuraxis and makes distinguishable in it the basis and the tegmentum pontis. The pons here consists of but a few transverse fibers constituting the stratum superficiale pontis, and the eaudal extremity of the pontile nuclei contained within which latter are the somewhat seattered fibers of the pyramidal system ( Py ). The lateral continuation of the superficial stratum of the pons enters into and forms part of the massive middle cerebellar peduncle ( $\mathrm{Nep}$ ). The tegmentum at this level is separated from the basis by a number of transverse decussating fibers constituting the trapezoid body ( Trp) in whose lateral extremity is the 
superiorolivary body (SO). Lateral to this is a smalf portion of the nucleus facialis ( $\mathrm{Nf}$ ) which gives rise to the furst portion of the seventh nerve, al series of fine, myelinated fibers arranged more or less as a spray. It extends inward

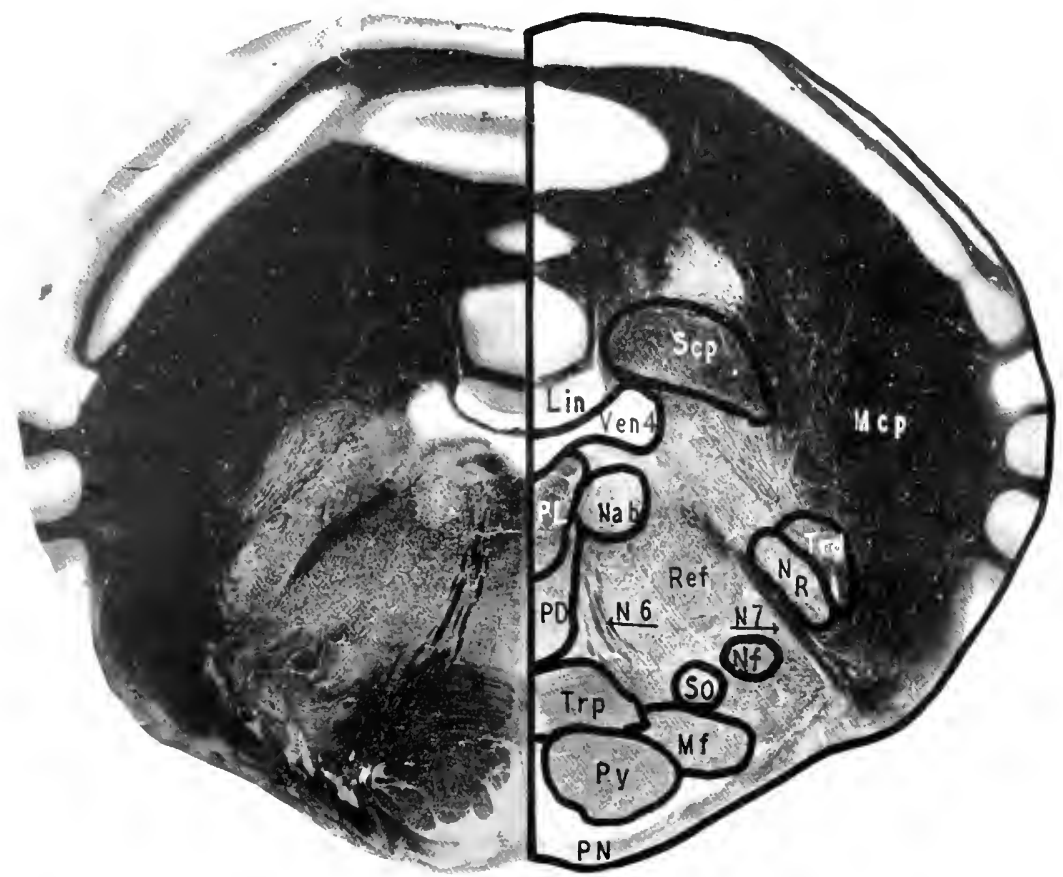

FIG. 17\%. MACACUS. LEVEL OF THE EMERGENCE OF THE SIXIH NERVE.

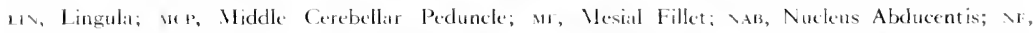
Facial Nucleus: NR, Nucleus of Relando: V6, Abducens Nerve: 1-7 Facial Nerve; pp, Predorsal Bundte: PL, Posterior Longitudinal Fasciculus; P., Pontile Nuclei; Py, Pyramid; REt, Reticular Formation: TRD. Descending Trigeminal Ttact; seP, Superior Cerebellatr Peduncle; so, Superior Olive; $\Gamma R D$, Descending Trigeminal Tract: Tk1, Trapezeid Budy; W. 4. Fesurth Ventricle. Accession No. 140. Section 230. Actual Size $20 \times 10 \mathrm{~mm}$.]

and backward toward the floor of the fourth rentricke. From the superior olivary nucleus a similar, but somewhat lareer spray of myelinized fibers 
extends backward and inward, apparently terminating in the large nuclear mass situated on the floor of the fourth ventricle. This latter is the nucleus abducentis ( $\mathrm{Nab}$ ) from which arise the fibers of the sisth nere to supply the external rectus musche of the eycball. They pass sucessively through the reticular formation ( Ref), the trapezoid body ( Trp) and the stratum superficiale pontis. The fiber connections between the superior olive and nucleus of the sixth nerve constitute the superior olivary peduncle. Axems from the superior olive to the sixth nerve nucleus serve the purpose of turning the eres reflexly toward the side from which the animal may hear a sudden or unexpected sound. The immediate deflection of the gaze toward the source of possible danger would thus be of service in the quick detection of an approaching enemy or other unfarorable factor.

Dorsomesial to the mucleus of the sisth nerve, lying between it and the subependymal gray matter on the floor of the ventricle, is a dense bundle of fibers constituting the second portion of the facial nerve $(\mathrm{N}-$ ) in its intramedullary course. The beginning of the third portion of this nerve, the genu facialis, lies immediately dorsal to the abducens nucleus, while the fourth division of the facial nerve forms a long bundie of heavily myclinized fibers extending obliquely forward and outward between the nuckeus of the seventh nerve and the substantia gefatinosa trigemini (NR).

Extending dorsolaterally from the substantia gelatimosa of Rolando is a radiating fasciculus which makes its way backward and in ward toward the angle of the fourth rentricle where it apparently terminates in a heavily myelinized bundle of fibers, the lasciculus mesencephalici trigemini. The fourth ventricke is much reduced preparatory to transition into the Sytrian aqueduct. Above it lies the superior medullary velum upon which rests the lingular lobule of the cerebellum ( $\mathrm{i}$ in). Dorsal to the mesenecphalie root of the fifth nerve is a dense bundle of libers constituting the superior cerebellar peduncle $\left(\mathrm{Sc}_{\mathrm{p}}\right)$. 


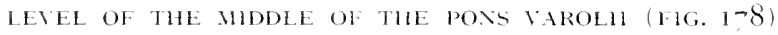

Here this structure attains its full dimensions. It presents the three characteristic pontile layers, the stratum superfeciale pontis, the stratum complexum pontis and the stratum profundum pontis. In the complex layer of the pons Varolii opportunity is alforded to estimate the size and extent of the pontike nuclei (PN) which appear to be considerably larger than in baboon. The pyramidal fibers ( Py) oceupy their usual position in the eenter of this layer, their bundles being much dispersed by the interposition of nuckar substance and many decussating fibers of this middle layer of the pons. The impression conveyed by the pons and its large nuclear mass is that it betomgs to an animal possessed of relatively high coordinative control in its skilled movements.

Situated between the basis and the tegmentum, as the boundary line between these two, is the mesial fillet (Mf); lateral to the mesial fillet is the lateral fillet (LI), in the dorsal extremity of which is the nucleus of the lateral fillet. A clense and large bundle of myelinized fibers in the extreme lateral position of the cross section is the middle cerebellar peduncle (Mcp), while situated in the dorsolateral angle of the section is a smaller dense bundle of fibers which represents the superior cerebellar peduncte $(\mathrm{Scp})$. On the periphery over this bundle of fibers is a thin band of myelinized axons, the ventral spinocerebellar tract $(G 0 w)$ on its way to the vermis of the ecrebellum. Interposed between this latter tract and the superior cerebellar peduncle is the tractus uneinatus of Russel ( T ur). Ventral to the dense fasciculus forming the middle peduncte, many fibers enter the axis. These axons are the corsal root fibers of the trigeminal nerve $(\mathrm{N}$;). Their course may be followed through the peduncle into the lateral aspect of the tegmentum where some of them end in relation with the cephalic extremity of the substantia gelatinosa trigemini (NR). 
The central gray matter (Cen) surrounds the much reduced ventricular space which is here approaching the caudal orifice of the Sytrian aqueduet. The major portion of the tegmentum is oecupied by the retieular

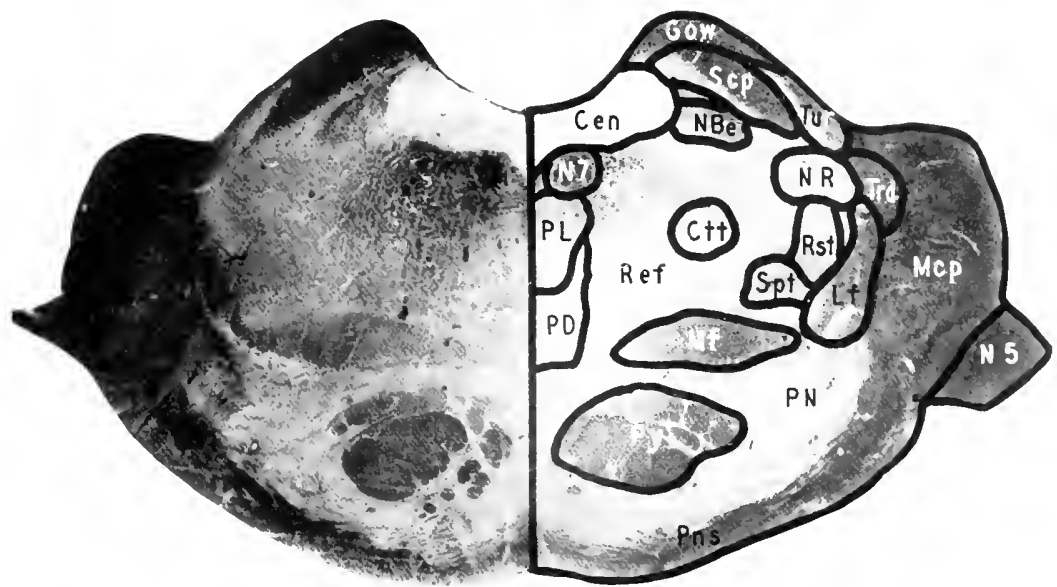

FIG. I -8. MACAClS. LEVEL THROLGH THE MIDDLE OF THE PONS MAROLII. CEN, Central Gray Matter; ctт, Central Tumental Trac1; gow, Ventral Spinocerebellar Trast: L., Lateral Fillet; MCP, Middle Cerebedlar Peduncle; 11, Mesial Fillet; \BE, Nucleus of Bechterew; \R, Nucleus of Rolando; `j, Trigeminal Nerve; N-, Facial Nerve; pro, Predorsal Bundle; pe, Pusterior longitudinal Fasciculus; pi, Pontile Nuclei; pas, Pons; py, Pyramid; Rer, Reticular Formation; Rst, Rubrospinal Tract; scr, Superior Cerebellar Peduncle; sPt, Spinecerebellar Tract; TRD, Descending Trigeminal Tract; Tur, Tractus Uncinatus of Russel (1took Bundle). [Accession Ni). 1 fo. Section 280 . Actual Size $21 \times 10 \mathrm{~mm}$.)

formation (Ref) in which are many transverse decussating fibers, some of which at least appear to take origin in the substantia gelatinosa trigemini ( NR), passing inward, it may be, as a seendary pathway for the conduction of impressions from the face and head. These fibers appear to decussate, as is the case of all sensory axons, in the median raphe.

LEVEL OF THE EMERGENCE OF THE FOURTH OR TROCHLEAR NERVE (FIG. ITO)

At this level, the neuraxis passes through its isthmial portion at or near the junction between the hindbrain and the midbrain. In its roofplate, which 
382

forms the superior medutlary velum above the beginning of the Sytrian aqueduct (IT), are the decussating fibers of the fourth or trochlear nerve $\left(N_{4}\right)$ as they emerge from the brain stem. This nerve supplies the

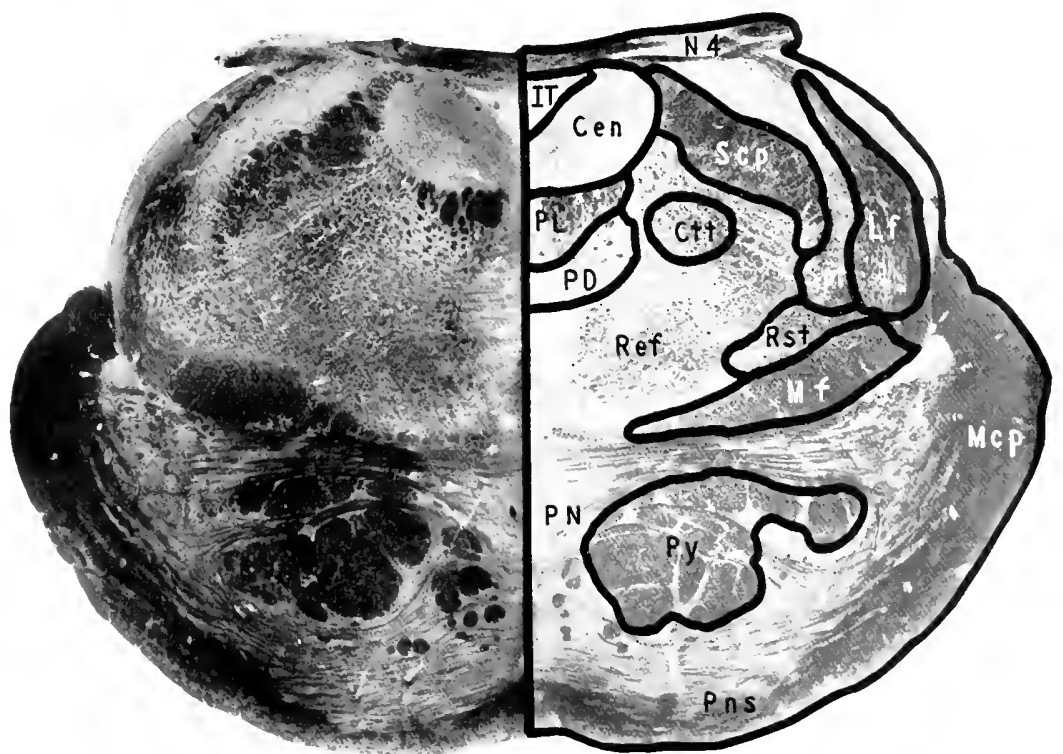

FIG. 1-O. MACACLS. LEIEL OF THE EMERGENCE OF THE TROCHLEAR NERIE.

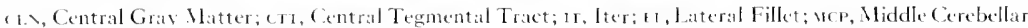
Peduncle; Mr, Mesial lïllet; \t. Truchlear Nerve; PD, Predorsil Bundle; PL. Pesterior Longitudinal Fascicu-

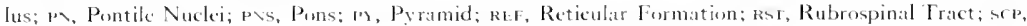
Superior Cercbellat Peduncle; sp. Spinothalamic Tratet. [Accession No. 1.4\%. Section 305. Actual Size $18 \times 12 \mathrm{~mm}$.

superior oblique muscle of the eycball and is the only one of the cranial nerve series which undergoes complete decussation before its emergence.

The three layers of the pons Varolii are still clearly defined and further opportunity is afforded to estimate the extensiveness of the pontile nuclei ( PN) whose bearing upon the derelopment of skilled movements has 
atready been discussed. The fibers constituting the pramidal system are still further separated by the interpesition of transwerse fibers and portions of the pontile nucker. The tegmentum is separated from the basis here by the mesial filtet (Mf) at whose lateral extremity, and extending dersally, is the lateral fillet (Lf). Mesial to the lateral fillet is a dense bundle, now somewhat scattered, the superior cerebetlat peduncle (Sep), about to make its characteristic swing forward and inward preparatory to decussattion in the midbrain. The reticular formation (Ref) occupies the major portion of the tegmentum. It contains at this level no specialized agergecrations of nuclear differentiation.

\section{LEYEL OF THE INFERIOR COLLICLLLS (FIG. 180)}

Here the contener of the axis is considerably altered by the appearance of two devations on its dorsal surface. These clevations, the inferior colliculi (IC), still show a marked degree of stratilication. Their prominence, together with this specialization, may be taken to indieate that some of the primitive function oser which they preside is still retained. Fibers of the lateral fillet (Lf) have atready entered inte the inferior colliculus; still others are approaching it. The prominence of these tectal structures, both in surface relief and histological differentiation, doubtless indicates that some portion, at least, of the function of hearing still has representation in these primordial centers of that special sense. It is noteworthy, howerer, that the coefficients of this structure, as compared with the Jower primates, show an actual decrease in size. This fact unquestionably implies that the telencephalizing process which is gradually transferring the major functional activities of the auditory sense to the temporal lobe of the cerebrat hemisphere, has made considerable advance in such animals as the macaque, as a consequence of which the tectum of the midbrain has lost much of its primitive auditory dominance. The central gray matter $(\mathrm{C} e n)$ surrounds the Syrian aque- 
duct. In its lateral portion are several dense bundles of myclinized axons representing the descending fibers of the trochlear nerve ( $\mathrm{N}_{f}$ ) as they pans dew mward to the level of their final decussation before emerenene from

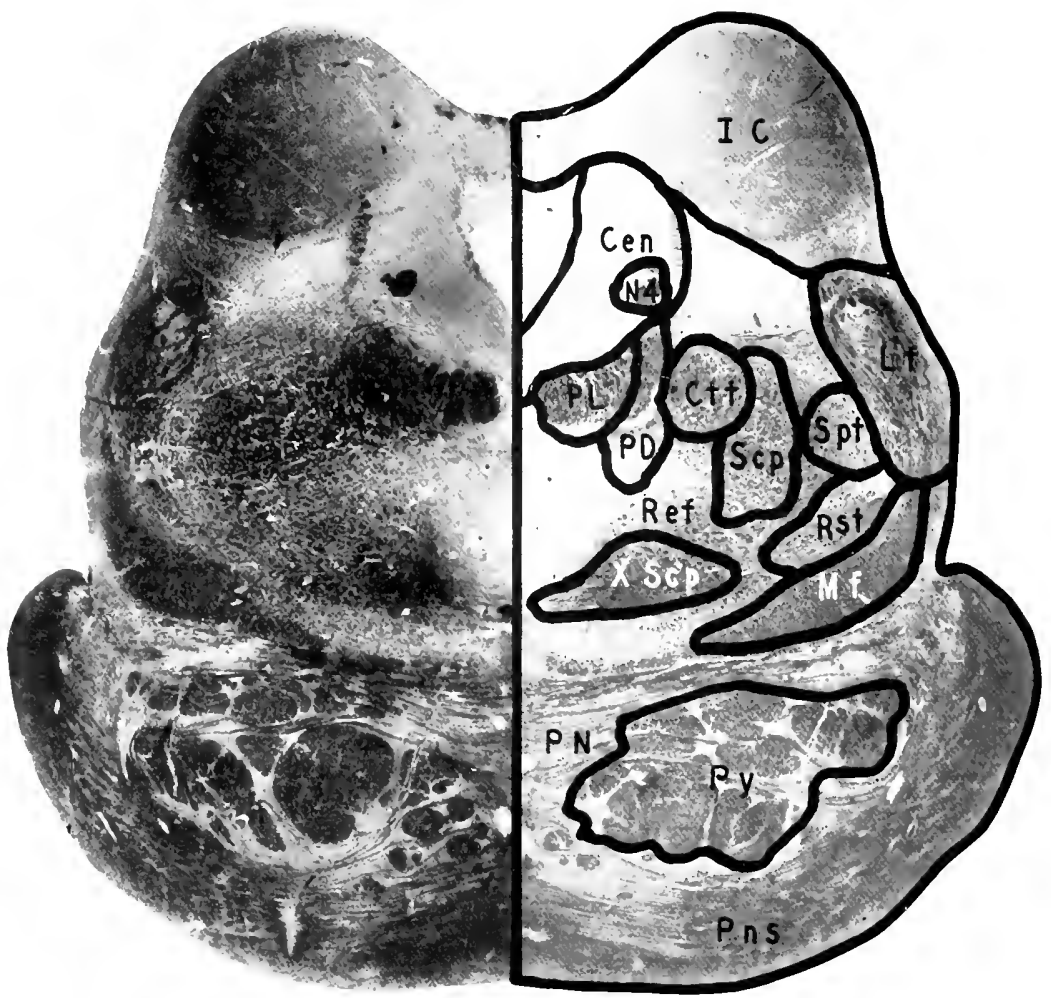

FIG. I80, IACACUS, LEVEL OF THE INFERIOR COLLICULUS,

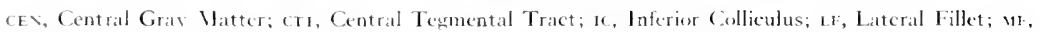
Vesial Fillet; , 4, Truchlear Nerve; PD. Predorsal Bundle: PL, Posterior Longitudinal Fasciculus; PN, Pontile Vuclei; PNS, Pons; Pr. Pyranid; kFF, Ruticular Formation; RST, Rubrospinal Tract; SCP, Superiur Cerebellar Peduncle; sp', Spinothalamic Tract; xore, Crossing of the Superior Cerclellar Peduncle, [Accession No. ito. Section 320 . Actual Size $16 \times 1+\mathrm{mm} .1$ 
the superior medullary vetum. Lateral to the fibers of the trochlear nerve, on the outer border of the central gray matter, are the scattered fibers from the tractus mesenecphalieus trigemini. The territory aceupied by the reticular formation (Ref) has at this level become somenhat obscured by the fibers of the superior cercbellar pectuncle ( Sep) which are sweeping inward and forward, about to undergo their decussation before coming into relation with the red nucleas. This decussation is shown as fully dereloped in the next section. The beundary between the basis and tegmentum, as at other levets, is indicated by the presence of the mesial fitlet $(\mathrm{Ml}$, from whose lateral angle extend dorsally many of the fibers of the lateral fillet ( $\mathrm{Lf}$ ), now making their way to the inferior colliculus.

The basis of the section still contains some of the typical characteristics of the pons Varolii in its three layers and also the disseminated condition of the pyramidal fibers ( $\left.P_{y}\right)$. There is, heswever, a tendency for the ventral groove of the pons to deepen and thus to foreshadow the beginning divergence of the basal portion of the axis, which ultimately oceurs in the cerebral pedunctes where an assemblage of the cortico-pontile fibers takes place and the pyramidal axons are reassembled into a single compact bundle.

LEVEL OF THE SUPERIOR COLLICULUS (FIG. I81)

Here the contour of the brain stem has again undergone modification due to the appearance of two fairty prominent elevations on its dorsal aspect and the development of a wide eleft in the middle portion of its base. These clevations are the superior colficuli (SC) which represent remnants of the optic lobes of the lower vertebrates. That they are reduced in size in all mammals, particularly the primates, is significant of the fact that the process of telencephalization of the visual function has been steadily progressing since the advent of mammalian forms. Visual function has for the most part been taken over by the occipital lobe in the cerebral hemisphere, a 
$3^{86}$

portion of the endbrain which in the primates has gained particular prominence. In all probability, little of the primordial responsibility for the function of rision is still rested in the superior colliculi. This portion of the brain,

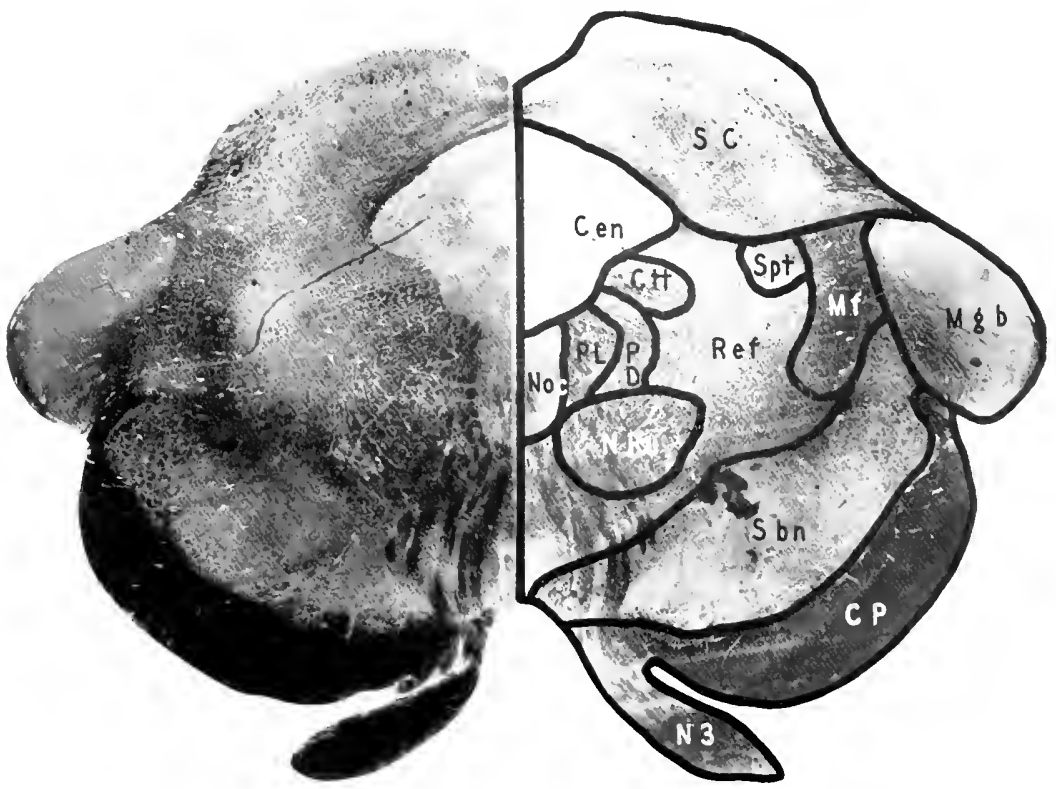

FIG. I8I. MACACUS. LEVEL OF THE SLPERIOR COILICLLUS.

ox, Central Gray Matter; CP, Cerebral Peduncle; CTT, Central Tegemental Tratet; Mr, Me sial Fillet;

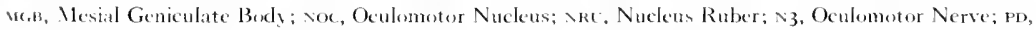
Predersal Bundle; PL, Posterior Longitudinal Fasciculus; RLs, Reticular Formation; sc, Superior Colliculus; SB〉, Substantia Nigra; spt, Spinothalamic Tract. [Accession No. 140. Section 388. Actual Size $19 \times 10 \mathrm{~mm}$.]

which for such a long period in vertebrate evolution held dominance in the animal's visual functions, has now become much reduced in this respect and appears as a relatively insignificant structural feature on the dorsal surface of the midbrain. As a matter of fact, the superior colliculus is somewhat larger than the inferior colliculus, and it still retains some degree of stratifica- 
tion reminiseent of its former high specialization when, as in the reptiles and birds, it presented fourteen distinct layers of alternating nerve cells and tibers.

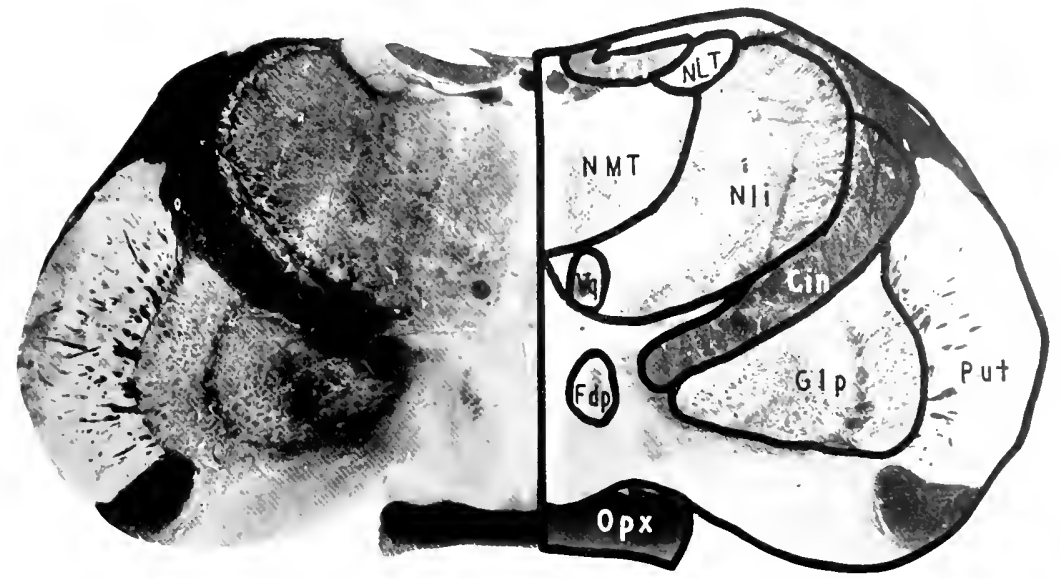

FIG. I82. MACACES. LEVEL OF THE OPTIC CHIASII.

(1) Internal Capsule; I De. Deseending Pillar of the Fornix; for, Fornis; c,Le, Globus Pallidus; \L, Nueleus Lateralis Internis Thalami; $\backslash L T$, Nucleus Lateralis Thalami; NuT, Nueleus Mesialis Thalami; opx, Optic Decussation: put, Putimen; we, Fasciculus of Vieg d'Azyr. [Accession No. 140. Section joj. Aetual Size $30 \times 16 \mathrm{~mm}$.]

The central gray matter $(\mathrm{Cen})$ surrounds the Sylvian aquecluct as it is approaching its eephalic orifiee to communicate with the third ventricle. Its ventral portion is much prolonged by the appearance in it of an extremely important nuclear body, the nucleus oculomotorious (Noc) of the third cranial nerve from which emerge fibers destined for the oculomotor groove. Here they kave the stem en route to supply all of the museles of the eyeball, both extrinsic and intrinsic, with the exception of the external rectus and the superior oblique. In the midline and connected with this nucleus are a number of fibers crossing from one side to the other. These are the commissural and decussating fibers associating the oculonotor nuclei. Their impor- 
388

tance has atready been mentioned in connection with the development of binocutar vision. Special reference is made to them in this place in order that there significance in the animal's behavior may be subsequently discussed.

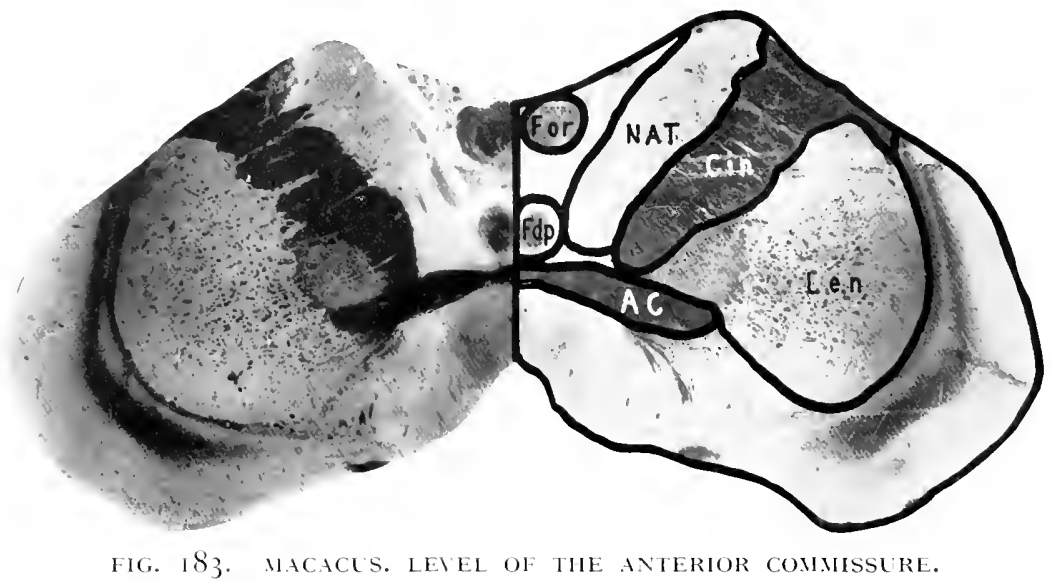

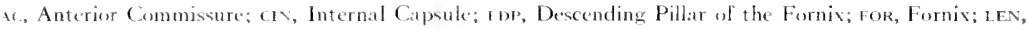
Lenticular Nucleus; it, Nucleus Anterior Thalami. Accession No. 1 40. Section 505 . Actual Size $30 \times 8 \mathrm{~mm}$.]

Ventral to the nucteus oculomotorius, although as yet poorly differentiated. is the nucleus ruber ( NRu) through which some of the emergent fibers of the oculomotor nerve pass. Lateral to this nucleus is the reticularformation (Ref), whose general appearance suggests the lack of highly specialized differentiation in this species. The lateral portion of this formation is in continuation with a small protuberance on the lateral surface of the midbrain, the mesial geniculate body ( $M \mathrm{~g} b$ ) which serves as onc of the relay stations in the secondary pathway of hearing.

The ventral aspect of the section shows a cleft in and about the midline. This is the beginning of the optico-peduncular space which separates the basis into the right and left cerebral peduncles (CP). These 


\section{PITHECUS RHESUS, MACACUS RHESUS}

peduncles now contain the compact bundles of the pallio-pont ilesystem which connect the cerebral cortex with the lateral lobes of the cerebellum and the compact bundles of the cortien-spinal tract for the transmission of volitional impulses to the somatic musculature. Immediately dorsal to the cerebral pechuncle is a large mass of eray matter, the substantia nigra (Sbn) whose relation to the eontrol of eertain automatic associated movements has been mentioned.

LEVEL OF THE OPTIC CHIASH (FIG, I82)

At this level, one of the most cephalie sections of the brain stem in this series is shown. A prominent feature is the optic thalamus which is separated by the internal capsule ( $\mathrm{Cin}$ ) from the lentieular nucleus, whose major portions are well illustrated, the globus pallichus (GIp) and the putamen ( $\left.\mathrm{P}_{1} \mathrm{t}\right)$. As this specialization in the diencephalie portion of the brainstem is highly complex and deserves separate treatment, the structures at this level are merely referred to as indicative of the marked changes in transition in the level at which the brain stem forms its final continuity with the endbrain. It is here that contact is ultimately established with those great expansions of the brain, the cerebral hemispheres. They, in later stages of evolution, have dominated all of the far-reaching modifications in behavior characteristic of mammals, reaching their constmmate expression in the achievements of man. 



\section{Chapter XIII}

\section{RECONSTRUCTION OF THE GRAY MATTER IN TIIE BRAIN STEN OF PITHECUS RHESUS}

HE reconstruction of this species follows the erencral lines already
laid down in the preceding reconstructions. It is particularly valu-
able as showing the structures in their interchation and continuity, and thus furnishes a more realistic idea of the actual disposition of the more important masses of gray matter in the brain stem. So far as possible, the descriptions have been made almost exchusively objective, reserving the space for comment on the significance of the structures for the chapters on summaries and conclusions.

\section{Tue High Cervical level of the Spinal Cord}

In the high cervical level of the spinal cord at which the reconstruction of the gray matter in macacus begins, the ventral gray column is already detached from the central gray eolumn by the decussating fibers of the pyramidal tract. In outline the ventral gray column is somewhat oval, directed ventrodorsally and laterally. It accupies the normal position of the ventral gray column in the spinal cord but is reduced in size. The central gray matter is somewhat cordiform in shape, presenting a ventral apex and a dorsal base from the lateral angles of which proceed the laterally compressed cervices of the dorsal gray column. The substantia gelatinosa trigemini is seated like a cap upon the dorsal extremity of the dorsal gray column and is already beginning to show the lateral swing occasioned by the appearance of the dorsal medullary nuclei and the opening of the fourth ventricle.

As the higher cervical segments pass into the lowermost levels of the wblongrata, the ventral gray column becomes increasingly interspersed with 
longitudinal fiber bundles and it gradually assumes the characteristic appearance of the reticular formation into which it merges.

\section{The Dorsal Sexsory Niclei}

The nuckeus of the column of Goll makes its first appearance in the reconstruction as a prolongation from the central gray column, in close proximity to the dorsal median septum. It rapidly assumes its maximum rentrodorsal extent and proceeds upward as a gradually thickening mass of gray matter maintaining its median position and separated from its fellow of the opposite side by only a narrow encapsulation of white matter.

Somewhat above the level of the appearance of the inferior olivary nucleus, there appear scattered masses of gray matter in the column of Goll, lateral to the main mass of the nucleus of the column of Goll. They establish connection with the stem of the nucleus, which becomes somewhat rounded in shape and then rapidly expands laterally. This expansion continues laterally until the dorsal extremity of the nucleus assumes a massive appearance, oceupying the major portion of the dorsal aspect of the oblongata. It is somewhat arboreseent in character, presenting masses of gray matter broken up and surrounded by penetrating, Iongitudinally coursing bundles of white fibers.

Cephalically, the nucleus of the column of Goll comes to rather an abrupt termination and its most cephalic portion mesially forms part of the caudolateral boundary of the fourth ventricle. Laterally it becomes submerged from view by the appearance in this region of the nucleus of Deiters.

The nucleus of the column of Burdach appears first as a rounded mass of nuclear material in the dorsal portion of the reticular formation. It is at this point encapsulated by fibers arising from the mucleus of Goll and, passing ventrally in an areade as the internal arcuate fibers, gives rise to the mesial fillet. Increasing in size and extending dorsally at about 
the mid-level of the nucleus of the column of Burdach, there appears a secondary portion of the nueleus situated laterally in the coflection of the aseending fibers of the column of Burdach, first as isolated groups of gray
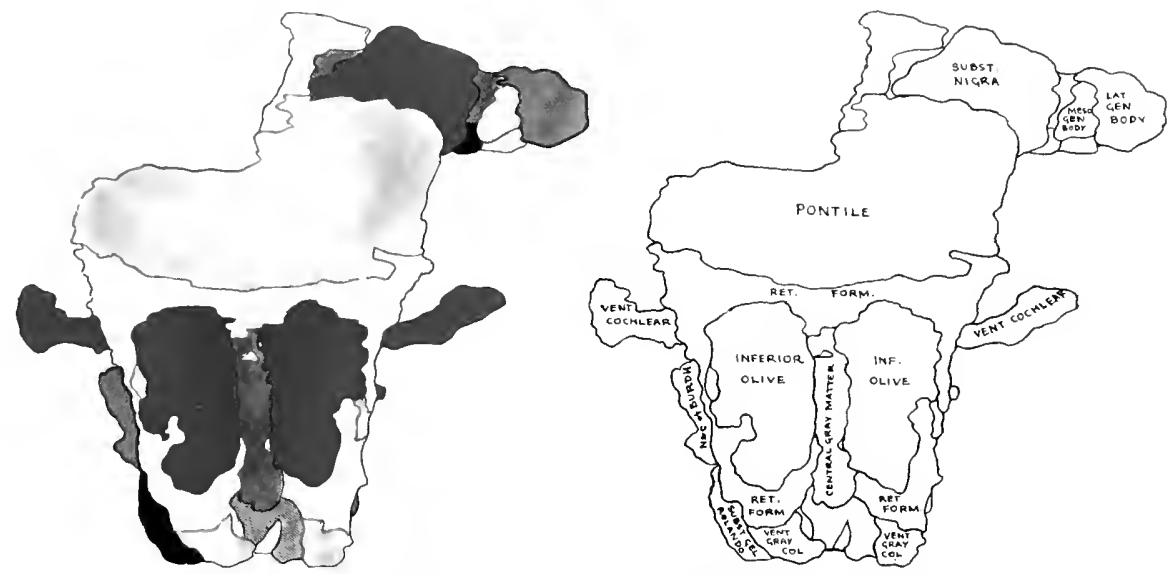

FIG. I84. VENTRAL SURFACE OF GRAY MATTER OF BRAIN STEM, PITHECUS RHESUS.

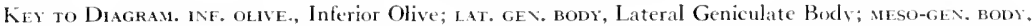
Mesial Genieulate Body; Nec. of Burdach, Nucleus of Burdach; pontrle, Pontile Nuclei; Ret. Forif., Reticular Formation; subst. get. rolavdo, Substantia Gelatinosa of Rolando; Subst. Nigra, Substantia Nigra; vent. Cochlear, Ventral Cochlear Nucleus; vent. grax Col., Ventral Gray Column.

matter which coalesce to form a large nuclear mass Iying lateral to the stem of the nucleus of the column of Burdach; this is the nucleus of Blumenau. It rapidly establishes connection with the mesial portion of the nucleus, its nuclear masses presenting the typical leafy arrangement characteristic of it. It extends laterally for a considerable distance and overhangs the prolongation of the substantia gelatinosa trigemini. Gradually encroached upon by the vestibular complex, it disappears from view, being entirely replaced by the vestibular nuclei. 
The substantia gelatinosa Rolandi has become relatively slender, and placed as a cap over the dorsal extremity of the dorsal gray column. As the highest cervical levels are approached, it is transformed, without any change whatserere in its morphological characteristies, into the substantia gelatinosa trigemini which thereafter serves as a reception nucleus for the descending fibers from the Gasserian ganglion. It passes gradually into the lateral position which is characteristic of this mass of gray matter in the primate brain, and at the level of the inferior olivary nucleus it assumes its permanent unchanging position. The nucleus continues upward, embedded more or less irregularly in the lateral surface of the reticular formation, appearing at times on the surface and at other times being submerged from view by the reticular formation. The usual eonstriction which has previously been noticed is present at about the middle of the inferior olivary nucleus. Here the substantia gelatinosa trigemini reaches its minimum diameters. From this point it continues gradually to increase in size until it reaches its maximum at about the mid-ventricular region of the stem, above which it continues and clevelops its expanded cephalic extremity called the caput. Just prior to its disappearanee it presents at its mesial and dorsal aspects the motor nucleus of the trigeminal nerve.

\section{The Inferior Olivary Nucleus}

The inferior olivary nueleus first appears in the reconstruction at the level of the exphatic extremity of the pyramidal decussation. Here it is a llattened lamina of gray matter directed mesially and slightly dorsally. This is the ventral aceessory olivary nucleus (paleo-olive). It extends mesially and somewhat clorsally forming a llat ribbon with its mesial extremity twisted so as to lie in a more direct ventrodorsal diameter of the stem. It ends cephatically by merging with the dorsal extremity of the dorsal lamina of the inferior olivary ancleus. The main mass of the inferior olivary 
nucleus appears somewhat above this level, dorsolateral to the ventral accessory olive where it is a plicated fold of gray matter, its fundus directed toward the ventmiateral angle of the brain stem. It presents a
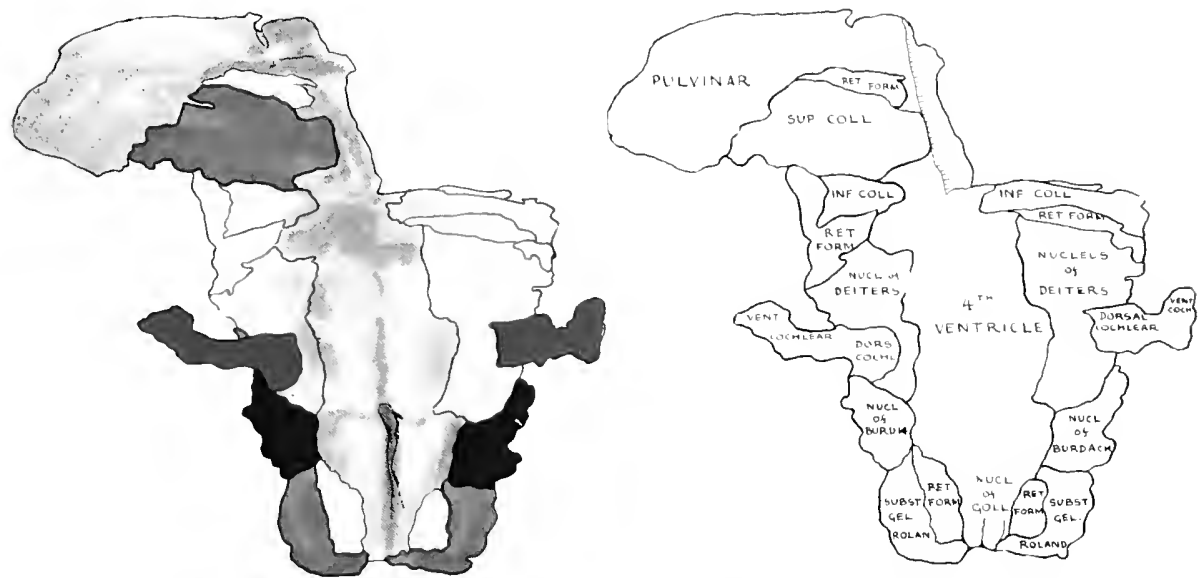

FIG. I 85. DORSAL SURFACE OF GRAY MATTER OF BRAIN STEM, PITHECUS RHESUS.

Key to Diagram. dors. Cocilz, Dorsal Cochlear Nucleus; inf. Coll., Inferior Colliculus; Necl. of Burd. and NUCl. OF BURDACH, Nueleus of Burdach; NuCl. OF DEtTERS, Nucleus of Deiters; NUCL. OF GOLL, Nucleus of Goll; RET. FORn., Reticular Formation; schst. Gel. Rolavdo, Substantia Gelatinosa of Rolando: sup. COLe., Superior Colliculus; vent. Cocir. and vevt. Cochlear, Ventral Cochlear Nucleus.

tendency toward plication, an undulating strand of gray matter showing a number of bends and folds. The ventral lamina is almost devoid of reduplications, whereas the dorsal lamina shows an increased irregularity produced by the appearance of numerous reduplications. At a Icvel somewhat above the appearance of the main mass of the inferior olivary nucleus, the dorsal accessory olivary nucleus appears as a flat, narrow strand of gray matter placed almost in the lateral meridian of the brain stem and overlying the hilus of the inferior olivary nucleus. It extends upward as a flat band in this 
same lecation and, gradually diminishing, it appears cephalically as a pluy in the hilus of the nucleus. Before it completely disappears it seems to fuse with the dorsal extremity of the inferior olivary nucleus. The entire inferior olivary complex extends upward to a level somewhat betow that of the middle of the ventricular cavity, where it ends rather abruptly, merging with the reticular formation in whose ventral surface it is cmbedded.

\section{Tile Reticllar Formation}

The reticular formation, as shown in the reconstruction, begins in the upper cervical levels by the appearance of isolated groups of nerve cells lying dispersed between the fibers of the lateral portion of the decussating pyramidal tract. It here receives the termination of the ventral gray column and then rapidly becomes the outstanding feature in the tegmentum of the rhombencephalon. It is quite irregular in outline and presents embedded in its substance and along its surfaces the various condensations of gray matter forming the nuclei of the brain stem and the collections of nerve fibers which form the ascending and descending tracts. At its ventrolateral angle it presents the constant condensations of nuclear material which form the lateral nucleus of the reticular formation and the superior olive, the two latter structures being somewhat more prominent and extensive than those lound in the preceding forms. On its ventral surface, extending from the cephalic limit of the pyramidal decussation to the mid-ventricular level of the stem, it forms a bed for the dorsal aecessory olivary nucleus of the olvary complex which at its beginning emerges from, and at its termination disappears in the matrix of the reticular formation.

Latcrally the retieular formation receives the substantia gelatinosa trigemini, while dorsomesially it affords attachment to the stem of the nucleus of the column of Goll and, somewhat more cephalically, to the base of the nucleus of the column of Burdach. It continues upward, 
increasing in size, into the tegmentum of the pons, where it is massive in form and supplies the main bulk of the gray matter of the metencephalic tegmentum.
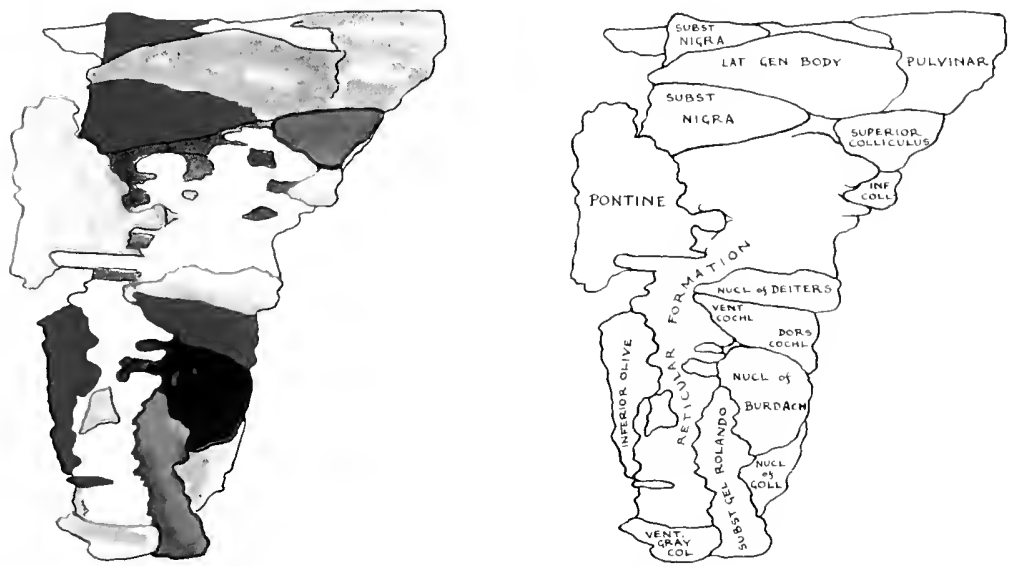

F1G. 186. LATERAL SURFACE OF GRAY NATTER OF BRAIN STEM, PITIIECUS RHESUS.

Key to Diagram. dors. Cocme., Dorsal Cochlear Nucleus; nff. Coll., Inferior Colliculus; inf. Olive, Inferior Olive; LAT. GEN. BODr, Lateral Geniculate Budy; NeC. OF BURDACH, Nucleus of Burdach; NuCl. OF deiters, Nucleus of Deiters; Necl. (of gole, Nucleus of Goll; pontine, Pontile Nucleus; sebst. gFe. rolaNdo, Substantia Gelatinosa of Rolando; subst. Nigra, Substantia Nigra; vent. Cocill., Ventral Cochlear Nucleus; vent. gray COL., Ventral Gray Column.

Above the level of the olivary complex the ventral surface of the reticular formation recedes rather rapidly from the surface, providing along its ventral surface a deeply excavated bay for the lodgment of the trapezoid body, formed by the secondary fibers from the cochlear system. Continuing upward in the metencephalon the retieular formation gradually diminishes in bulk, separated at first from the deep layer of the pontile nuelei by the trapezoid body. Above the level of the trapezoid body, the reticular formation comes into fairly close contact with the cleep layer of the pontile nuclei and presents 
in this region the bexinning mesencephalic appearance of the reticular formation with a large mesial mass and a lateral prolongation which turns outward and backward to eneircle the superior cerebellar peduncle as it enters into the mesencephalic tegmentum from the superior medullary velum. Befow the appearanee of the inferior eolliculi a prolongation of the reticular lormation passes around dorsally toward the midline.

Into the space between the superior collieulus and inferior collieulus a similar prolongation of the meseneephalie reticular formation passes laterally from the lateral portion of the retieular formation almost to the midline, thus separating the colliculi from each other. Similarly, above the superior colliculus a rather narrow extension from the most cephalic region of the reticular formation again comes to the surface close to the junction between the mesencephalon and the diencephaton. In the mesencephaton itself, the major portion of the mesial mass of the reticular formation gives place to that most characteristic nueleus of the mesencephalon, the nueleus ruber; while the lateral portion extends upward and outward and at the junction of the mesencephalon with the diencephalon it forms a bed for the mesial surface of the mesial geniculate body and then fuses ecphalieally with the indifferent reticular formation of the diencephaton. In the upper medullary levels of the brain stem the dorsal surface of the reticular formation is in fairly elose contact with the subependymal gray matter of the fourth ventricle and presents at its dorsolateral angle the specialization of the reticular formation, producing the vestibular eomplex.

\section{The Postile Nuclei}

In the pontile nuclei of Macacus rhesus is found for the first time an extension indicating the arciform nuclei which appear as a flattened layer of gray matter applied to the ventral surface of the prramid, conforming to its convex surface. This areiform nuelear formation is relatively poorly developed 
and almost immediately alter its first identification the typical alppearance of the pontile nuclei derelops. In its most caudal portions the pontile nucleus appears as an incomplete ring of nuclear material deficient on the lateral aspect and surrounding the relatively undivided prramidal traet fibers. As this structure is traced upward, the ring soon becomes complete, surrounding the pyramidal tract and the lowest fibers of the pallio-pont ile system of fibers and, at the same time, there are distinctly developed the two layers of the pontile nucleus (the superlicial and deep layers), which meet mesially and laterally the two buttresses of the pontile nuclei.

There is some indication of migration of masses of nuclear material in between the fibers of the two Iongitudinally coursing systems, producing a poorly developed, lace-like appearance. The pontile nuclei are materially heavier in formation and more extensive in distribution than in the preceding forms. As the mesencephalon is approached the mass of the pontile fibers gradually diminishes and the superficial layer contracts and extends further upward for only a short distance ventral to the developing cerebral peduncle. The deep layer becomes increasingly closer in proximity to the mesencephalic reticular formation and gradually is transformed into the substantia nigra.

\section{The Vestibllar Complex}

The vestibular complex makes its appearance first as a wedge-shaped mass of gray matter inserted between the subependy mal gray matter forming the floor of the fourth ventricle above the cephalic extremity of the nucleus of the column of Goll, and the mesial surface of the nucleus of the column of Burdach. Rapidly increasing in size, it replaces the nucleus of the column of Goll and displaces laterally the nucleus of the column of Burdach, thus bringing about through the agency of the opening of the fourth ventricle that lateral displacement which is characteristic of all of the dorsal medullary nuclei of the brain stem. 
The nucleus of Deiters' areal rapidly increases in size and maintains its position of contact with the subependy mal gray matter of the floor of the fourth ventricle. As the upper limit of the nueleus of the cohumn of Burdach is approached, the muclens of Deiters extends ventrally and laterally, assuming the position previously oceupied by the nucleus of the column of Burdach and presenting two prolongations - one mesial, clesely applied to the lateral surface of the reticular formation, the other lateral and in close proximity to the entering root of the cochlear nerve. In this recess formed by the mesial and lateral prolongations is lexated the ascending nuclear mass of the substantia grelatinosa trigemini (Rolando). Somewhat above the mid-rentricular level of the stem it rapidly diminishes in size and is superseded by the triangular nucleus, the nucleus of Sehwalbe, belonging to the vestibular complex which has tirst appeared just below the lateral recess of the fourth ventricke. The triangular nueleus rapidly becomes a comparatively bulky nucleus extending mesially to the base of the lateral wall of the ventricle, and laterally to the dorsolateral angle of the reticular formation. It extends upward almost to the upper himit of the metencephalon and then disappears gradually. The ascending nucleus of the restibular complex, the nucleus of Bechterew, is contained in the lateral wall of the fourth ventrick and is not of suffecient bulk to be represented satisfactorily in the reconstruction.

\section{The Cochlear Complex}

The cochlear complex of nuclei makes its appearance at the upper level of the inferior olivary nucleus as two masses of gray matter forming the ventral and dorsal cochlear nuclei. The large ventral eochlear nucleus is located at the extreme ventrolateral angle of the brain stem at the point of entrance of the cochlear nerve into the brain stem. It forms a fairly well-developed trough in which the cochlear nerve lies, covering this nerve on its cephatie, lateral and caudal surfaces. 
The dorsal cochlear nucleus, on the other hand, appears below the lateral recess of the fourth ventricle as a more or less triangular mass of gray matter in the extreme dorsolateral angle of the brain stem. At this point it is lecated dorsal to the nucleus. A certain amount of nuckear material lies interspersed between the fibers of the cochlear nerve extending between and connecting the dorsal and ventral cochlear nuclei. The dorsal and ventral cochlear nuelei appear below the level of the cochlear nerve and extend to a level higher than that of the nerve itself.

\section{Tile Substantia NigRa}

The substantia nigra appears in the reconstruction as a well developed and extensive mass of gray matter situated dorsal to the cerebral peduncle and supported by the deep layer of the pontile nucleus and the mesial and lateral buttresses. Between these two structures it rests upon the deep layer of the pontile nucleus from which it seems to develop. It extends upward throughout the extent of the mesencephalon, diverging laterally and somewhat dorsally to terminate in a rounded, blunt extremity which is separated from the mesial geniculate body by a relatively small intervening mass of the reticular formation and the fiber capsule of the mesial geniculate body itself. At the junction of the mesenecphalon and the diencephalon it comes to an end, separated from the corpus of Luys by a thin lamina of white matter.

\section{The Colliculi}

The inferior colliculus constitutes a poorly developed structure lying as a crescentic mass of gray matter in the tectum of the mesencephalon. It is supported laterally by the lateral extension of the mesencephalic reticular formation, while mesially it lies against the undifferentiated dorsal gray matter. It is separated from the superior colliculus by a deep narrow 
extension of the reticular formation which passes between it and the superior colliculus. The inferior colliculi are closely connected across the midline by the commissure of the inferior colliculi. The superior collicular elevation is much more massive than the inferior colliculus and is similarly situated, being separated from the central gray matter surrounding the aqueduct of Sylvius by a thin Lamina derived from the dorsal extension of the reticular formation. It is supported laterally by the same lateral extension of the meseneephatic reticular formation. Cephalically it is limited by a thin extension of the lateral mescneephalic reticular formation. Mesially it rests against the undifferentiated dorsal gray matter and is connected with its fellow of the opposite side by the enmmissure of the superior estliculus.

\section{The Red Nicleus}

The nucleus ruber is contained within the mesial mass of the mesencephalic reticular formation and receives at its caudal extremity the decussating superior cerebeflar peduncle which forms an encapsulating mantle of white fibers about it, thus definitely outlining it from the surrounding matrix of the reticular formation. Although it is the outstanding feature of the mesencephalon, it is relatively poorly developed in this form, extending upward eren beyond the junction of the mesencephalon and diencephalon into the substance of the latter division of the brain stem.

\section{The Central Grai Matter}

The central gray matter, as has been previously described, appears in the higher levels of the cervical cord as a roughty cordiform structure already separated from the ventral gray columns and providing a comnection with the laterally compressed dorsal horns. Continuing upward in this same position, it gives origin to the dorsal extensions which form the nucleus of the column of Goll, and at a somewhat higher level it presents the 
condensations situated more laterally than the preceding, which extension forms the nuclens of the column of Burdach. At the point where the mucleus of the column of Goll begins to increase in size, there appears a narrow, tongue-shaped prolongation of the central gray matter, which gradually approaches the dorsal surface and then, extending laterally, the entire mass of the central gray matter is drawn dorsally and laterally llattening out to form the 1 loor of the fourth ventricle. In its ventral surface lie embedded the dorsal nuclei of the ninth and tenth cranial nerves, and close to the midline appears the mucleus of the twelfth cranial nerve. Separating the gray matter of the ventricular floor and the reticular formation, lie the longitudinally coursing fiber bundles of the posterior fasciculus mesially, the fasciculus solitarius laterally, together with the peripheral condensation of fibers which circumferentially limits the reticular formation. In its lateral portion are embedded first the nucleus of the column of Goll, and then the nuclcus of the column of Burdach, which become separated from contact with the eentral gray matter by the appearance of the nucleus of Deiters.

In the cephalic portions of the myelencephalon and the metencephaton appear small masses of gray matter comnected with the ventral aspect of the central gray matter, extending along the tegmental raphe. These form a connected series of nuclei lying between the posterior longitudinal fasciculus, the predorsal bundle and the mesial fillet.

The central gray matter is in close contact with the vestibular and cochlear complexes throughout their extent in the metencephalon. At the upper limit of the triangular nucleus (Schwalbe) of the vestibular complex, the lateral walls of the ventricle begin to approach each other and as the upper extremity of the ventricle is reached, the floor, roof and lateral walls rapidly draw together and the aqueduct of Sylvius appears. The gray matter surrounding the aqueduct of Sylvius is relatively massive on all sides. Ventrally the central gray matter is continued forward as a long, tongue- 
shaped process which contains embededed within it the muclei of the fourth and therd cranial nerves. As the diencephalen is approached the ventrat extension of the central gray matter rapidly increases until the third rentricke appears where the central gray matter becomes continuous with the diencephalic subependymal gray matter and the mesial mass of the thatamic muctei.

The floor of the fourth ventricte shows practically no modeling in its fower half. Above the level of the lateral recess, howerer, there appear a retatively well-marked eminences on either sicle of the midline, separated from each other by a rather deep suleus, representing the undertying condensation of the gras matter to form the meleus of the sixth cranial nerve. 


\section{Chapter Xil}

\section{HILOBATES HOOLOCK, THE GIBBON, ITS BRAI AND BEHAVIOR}

Its Position among the Primates; The Proandbropoid Stape; Measurements and Brain Indices; Surface Aplearance of the Brain; Internal Structure of the Brain Stem in Cross Suction

P PHE gibbons are usually assigned to the group of the higher anthropoids, with the qualilication, however, that in this group ther are

I the most remote from man. In the ereneral appearance of their brain ther ally themselves much more closely with the intermediate primates. This, in combination with the fact that by their adaptive radiation they have become equipped preeminently if not exchsively as tree dwellers, seems to justify their inclusion with those intermediate forms already described. The designation of them as "Hylobates" is intended to indicate how exquisitely these "tree walkers" are specialized for arboreal habitat. Their lives are passed in the trees, through whose branches they move with a swiftness and case similar to those of a bird. When on terra firma they pass over its surface a little awkwardly, yet with mueh facility although compelled to balance themselves by holding their long arms over their heads and hastening their footsteps lest they lall. Once, however, their slender hands come in contact with the branches of a tree, a really marvelous change appears in their progression. Their uneertain gait is immediately replaced by a locomotion which has all the grace, the accuracy, the speed of a bird in llight.

\section{Appearance and Habits of the Gibbon}

The body and head of the gibbon are relatively small, little larger indeed, than some of the smaller macaques. The animal's legs are relatirely short and it has no tail. The characteristic feature of the gibbon is the 


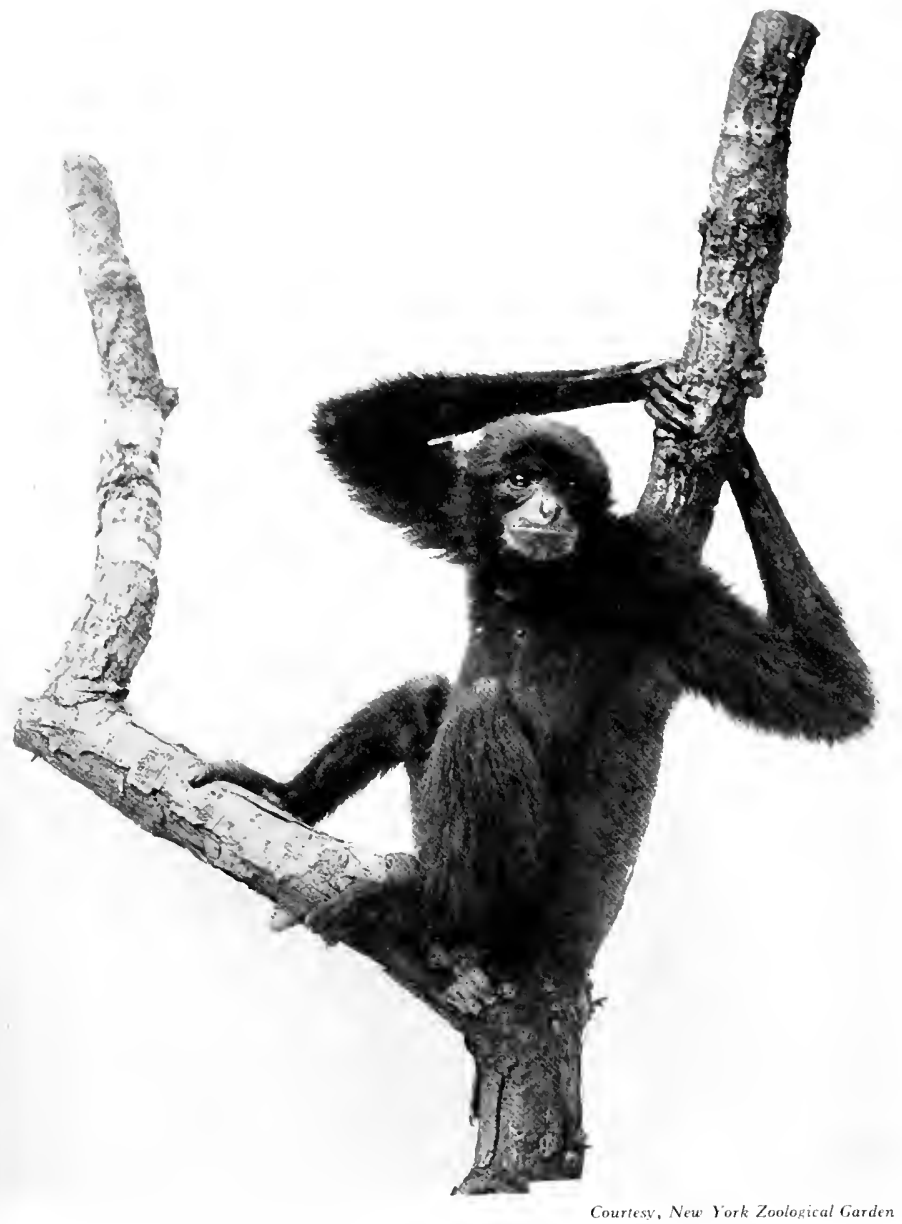

FIG. I 8-. HYLOBATES SYNDACTYLUS (GIBBON).

[406] 


\section{HYLOBATES HOOLOCK, THE GIBBON}

exceptional length of the forearm which so increases the entire length of the arm that the tips of the lingers touch the ground when the animal stands ereet. The slender hand is longer than the foot and the thumb is also long in

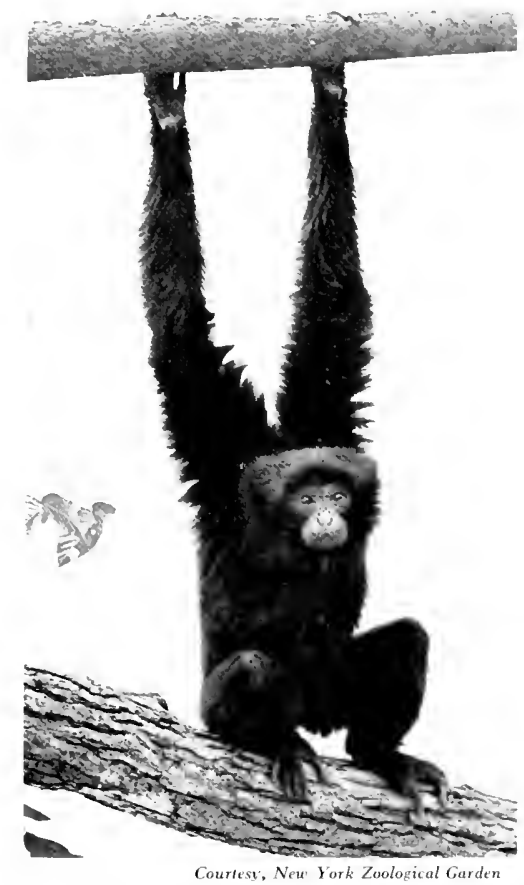

FIG. I 88. HYLOBATES SYNDACTYLUS (GIBBON).

Gibbon's brachiating tocomotion has favored erect posture and thus initiated the Proanthropoid Stage.

proportion. These animals are possessed of remarkable vocal power and can be heard for great distances. They go in troupes and usually early in the morning give voice to their peculiar chorus of calls which seems to cease, as if regulated by some prearranged schedule, in the early forenoon. 
One roung is produced at a time and the mother carries it under her body, the voung one clinging to her fur with hands and feet. This appendage to the mother cloes not seem in the slightest to embarrass her progress as she
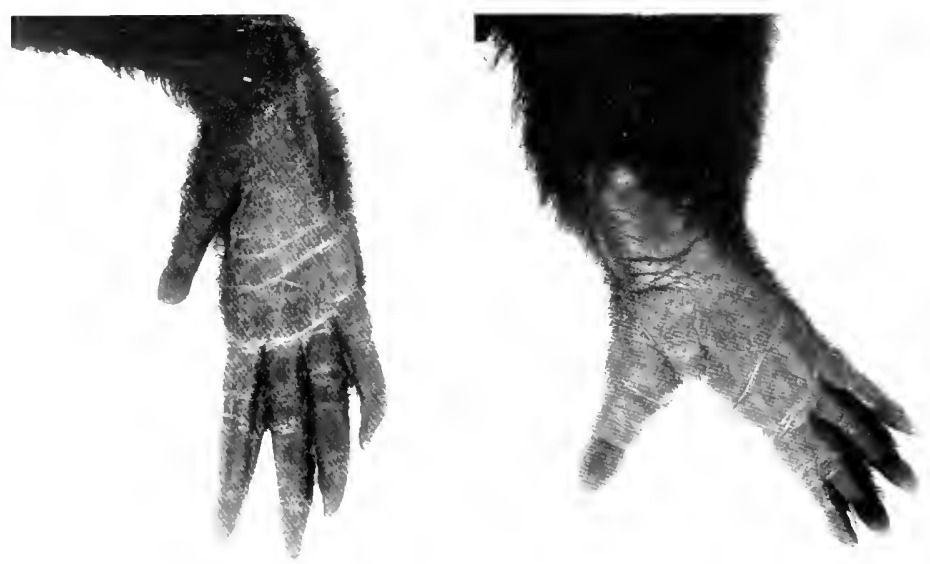

Courtesy, Americun Museum of Natural Histort

FIGS. ISO AND IQ). HAND AND FOOT OF HYLOBATES SYNDACTYLUS.

LEIT. Palmar surface of hand, showing the extremely long fingers developed in consequence of bratehiation.

The swinging type of lecomestion of the gibbon has produced this specialization in the hand. Fingers slaw some syondactylism.

Ricut. Plantar surface of the fout showing short heel, hong, powerful great toe, narked syndactylism of second and third toes. The fust is adapted to prehensile purposes involved in the brachiating locomotion.

makes her way through the forest, executing her great swings from tree to tree which are just as prodigious in their length as those made by the unencumbered male.

The gibbon is a delicate animal and rarely survives long in captivity. By disposition it is gentle, often affectionate. It is not averse to handling by strangers and will come close to the sides of its cage with arms extended through the bars so that its hands may be grasped and stroked. The gibbons 
never feave the forest and are distributed for the most part throughout southern Asia and the adjacent islands. A few species venture from the inland jungles to the vicinity of the coast.

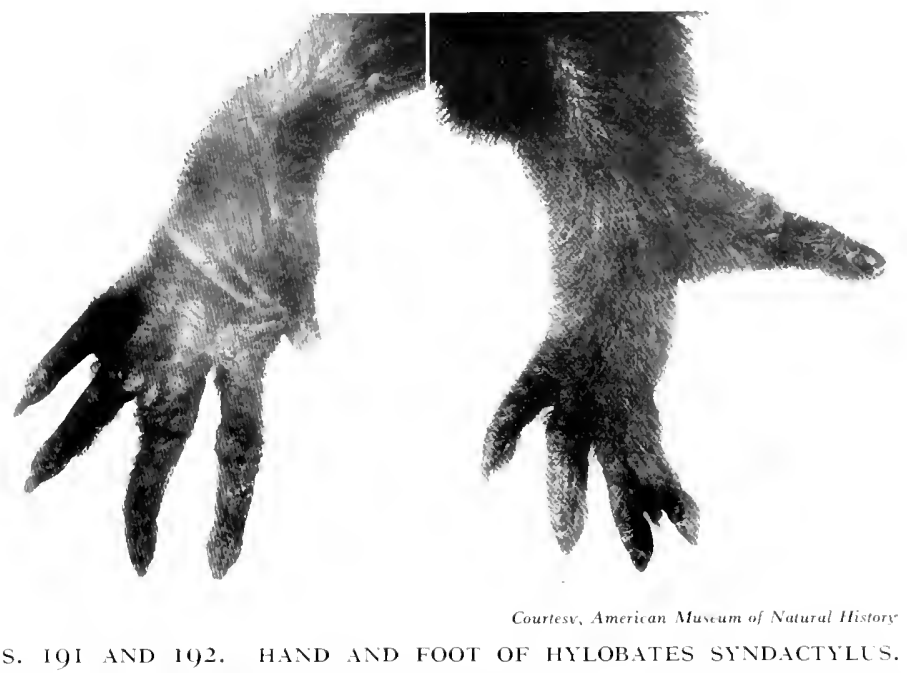

LEFT. Dorsum of hand showing long, slender fingers, well-developed finger-nails, a hand adapted to mrasping the branches in the gibbon's brathiating type of lecomotion.

Right. Dursum of foot showing marked hand-like characters in adaptation te brachiating lacomotion. The Iong. powerful, opposable greas toe is specialized for grasping purposes, comperating in this function especially with the svindactilic second and third teses.

THE HOOLOCK GIBBON

In general, the typical hue of the hookeck is black, although many varieties are found, as far as coloring is concerned. The hootocks, however, are most consistent in this regard. Such variations in color as do secur affect the female more than the male. The hootock gibbon is confined in its range to a limited district bounded by the Brahmaputra and Irawadi Rivers. It has a distinct aversion to water and cannot swim, a fact which 
probably cireumseribes its habitat to the region in which it is found. Like all members of this family, the hooleck is exquisitely arboreal. While it makes some successful efforts to progress over the surface of the ground, balancing its body in a rather awkward manner by holding its arms over its head, its life is passed essentially in the trees. The effects of brachiation are seen in the greater erectness of body which marks the beginning of the Proanthropoid Stage. Mr. Candler, who has studied the habits of this proanthropoid, gives such an interesting account of its actions, that it may be here quoted in part:

"He [Hoolock] swings along to the thinnest part of the bough or to the slender end of a bamboo until it bends to his weight, then with a swing and a sort of a kick-olf, he flies through the air seizing another bough and swinging along it with the unerring accuracy of a finished trapeze performer. I fancy he does very little walking in the wild state, for I have never seen a wild Hoolock on the ground. Moreover, they are only found in the dense jungle where the ground is everywhere covered with tangled vegetation. It is puzzling to me why these anthropoids, being so entirely arboreal in habit, should be lacking in such a useful appendage as the tail. The Hoolocks are extremely shy and it is most difficult to watch them as they are concealed by leaves high up on the tops of the bamboo clumps or forest trees. You may hear their cries all around as you ride quickly along the jungle track; but the moment you leave the path or look up at them there is a dead silence and searcely a leaf stirs until, tired of waiting, you move on again. The cry of the Hoolock is a characteristic sound in the Cachar jungle. It is a very pleasing note, rising and falling in intensity and reminding one somewhat in its rhythm of a pack of beagles giving tonguc on a scent, which is waxing and waning in strength as a larger or smaller number of the band join in the chorus. It is heard chiefly in the early morning, then all through the heat of the day there is silence but towards evening, as the sun sets, you may hear it again. 'Hoo'loo! Hoo'loo! Hoo'loo!' 
is supposed to describe the sound, but it is really quite indescribable in writing."

As in other species of apes, there is a special modification of the larynx which acts as a sort of resounding box and helps to make the sound carry, as it does, long distances. There is also a peculiar arrangement of the upper aperture of the larymx with its small and inadequate-lowking epiglott is, which resembles more the arrangement in birds than the leaf-like epiglottis in man. Mr. Candler believes that the hoolocks work their ground systematically in their search for food just as the planter plucks one section of his tea to-day and another seetion in a different part of the garden to-morrow. For he has found them filling the air with their cries along a particular stretch of jungle road one day, while the next day not one was to be heard; and then, perhaps a week later, they were back again in the same place as at first.

Living as they do in fairly Large communities, they are constantly on the move, and from what is known of their relatively good intelligence, it seems highty probable that their movements are guided by definite plans, and that they have some sort of governmental system. In Cachar, the tea planters often keep hoolocks for years at a time, permitting them to run about the compound quite frecly. Several such tame hoolocks were seen by Mr. Candler and were under his observation for several months at a time. They often would disappear and be away in the tree tops for days together, and at such times nothing tempts them to come down. But at length one of them seems to prefer to be sociable and he will then come and sit on the arm of a chair at breakfast, although he will never reach and snateh things off the table. His manners, in fact, are quite irreproachable, and he keeps himself remarkably elean. At sunset it is his custom to settle down to sleep, jammed tightly into the fork of a tree in a squatting position, usually with his arms over his head. In this semi-domesticated state, the hoolock seldom uses his voice, for he apparently finds mo necessity for chattering or calling to his 
fellows. A long list of fonds eaten by the houkek has been given by the numerous obervers. This includes fruits, leaves, roung shouts, spiders, insects, birds' exers and young birds. But much of this may be considered as conjecture, although there is and reason to bedieve that the diet is extremely varied. If captured voung, the hemlock is readily tamed. It is erentle, well disposed and enod tempered. It shows a marked intelligence, particularly in the acquisition of tricks and in adjusting itself to household regulation.

\section{Me islrements and Indices of Hylobates Hoolock}

The measurements of the heolock shom on the average:

\begin{tabular}{|c|c|}
\hline Body and head about & $m m$. \\
\hline Foot ... & $m m$. \\
\hline Stull & 114 \\
\hline Occipito-nasal Jength. & $90.0 \mathrm{~mm}$. \\
\hline Interparictal width. & 4) \\
\hline Breadth of brain case. & 61 \\
\hline
\end{tabular}

The dimensions of the brain including the cerebellum and brain stem are:

Longitudinal diameter. $6 ; ; \mathrm{mm}$.

Transicerse dianceter j) $\mathrm{mm}$.

The brain is distinctly gyrencephalic in type, presenting, as do the brains of all the other intermediate primates, a Sylvian, a Rolandic and a simian fissure, which distinctly set the boundaries of the frontal, parietal, temporal and occipital lobes upon the lateral convexity of the ecrebral hemisphere.

The weights of the several divisions of the brain are:

Forebrain

Midbrain

Ilindbrain

Total weight of brain jt gms.

2 gms.

$13 \mathrm{gms}$.

60) gms. 


\section{MYLOBATES HOOLOCK, THE GIBBON}

The water displacement of the brain is:

Forebrain

Midbrain

Hindbrain

Total displacement i3c.e.

$2 c e$

I1) C.e.

6 ) c.e.

The forebrain indices, computed on the basis of weight and volume, grive the gibbon a forebrain index of $8 \mathrm{I}$ per cent by weight and 82 per ecent by volume, thus placing it in the group characterized by manual diflerentiation, although it occupies a rather low position in this wroup.

Sirface Appearatce of the Brain in Hylobates Hoolock

From some of the more important superficial features on the external surface of the cerebral hemisphere, it is evident that the brain of the griblom in many respects is little more advaneed in its development than that of the baboon or macacus. The two great concavities on the basilar surface, i.e., the orbital concavity and the cerebellar concavity, are equally as promounced as in the other intermediate primates. This fact in itself calls attention to the degree of limitation imposed upon the frontal and occipital lobes in their expansion. For it is almost in direet proportion as these basal concavities become less pronounced, that the two important territories of the cortex, the frontal and the oceipital lobes, show progressive expansion. The olfactory bulb and tract are detachable as far back as the trigonum olfactorium. A rudimentary olfactory sulcus is present and a correspondingly rudimentary gyrus rectus. The interorbital keel is prominent. As in the case of the baboon and the macacus, the boundaries of the superior longitudinal fissure tend to diverge as they approach the oceipital pole. This divergence permits of a maked widening of the fissure which is in the interest of accommodating the superior rermis of the cerebellum whose appearance on the tentorial 
surface of this organ is shapply convex from side to side and thus forms a decisive ridge in the midline of the cerebellum. This ridge becomes progressively less distinct in the higher anthropesids and man. The divergence in
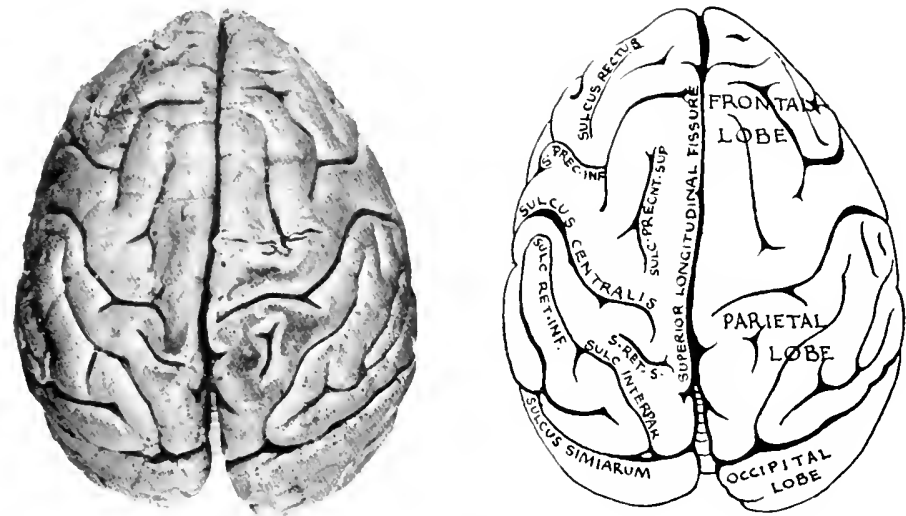

FIG. IO3 DORSAL SLRFACE OF BRAIN, HYLOBATES HOOLOCK.

[Actual Length, $70 \mathrm{~mm}$.]

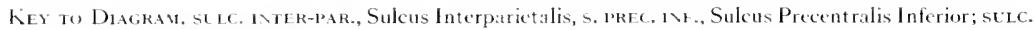
PRECNT. sup., Sulcus Precentralis Superior; SULC. RET. 1NF., Sulcus Retrucentralis Inferior; s. RI T. S., Sulcus Retrocentralis Superior.

the occipital portion of the superior longitudinal fissure of the higher forms gradually lessens, with the general effect that the oceipital region eventually conceals from view the entire tentorial surface of the cerebellum.

\section{FISSURES AND LOBES}

In its lissures and lobations, also, the cerebral hemisphere corresponds closely with the brain of the macaque and baboon. The fissure of Rolando separates the frontal and parietal lobes, the Sylvian fissure intervenes between the parietal and temporal lobes, the simian fissure separates the parietal and temporal lobes from the occipital lobe. The convolutional pattern in aII 
of these cortical areas is relatively simple. It is most complex in the parietal region and least conspicuous in the frontal lobes. In respect to lissural development, the gibbon shows less advance than either the baboon or macaleus.
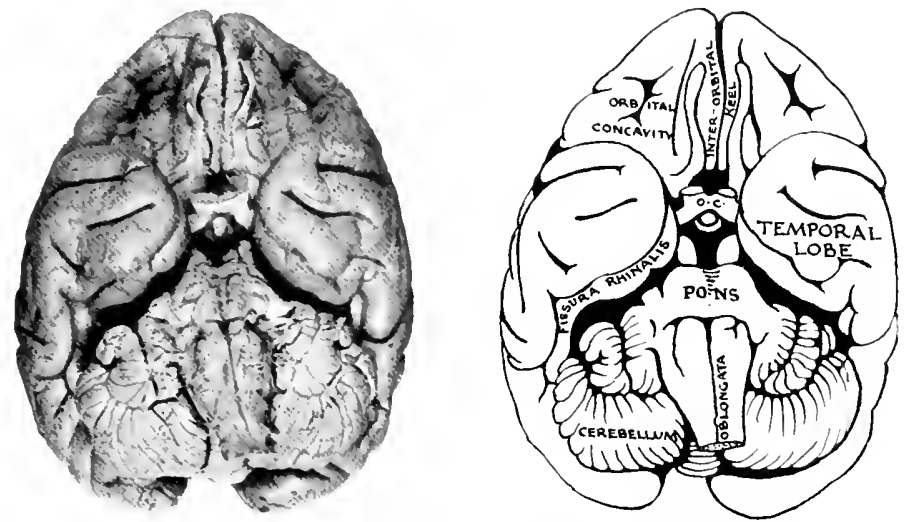

FIG. IG4. BASE OF BRAIN, HYLOBATES HOOLOCK.

[Actual Length, -o mm.]

Key to Diagrau. O.c., Optic Chíasm.

On the other hand, there is a richness of convolutional pattern in the occipital lobe, which does not exist in either of the other two forms. This fact, taken in conjunction with the much reduced appearance of the superior colliculus of the midbrain, indicates that in the gibbon most of the actual supervision of vision has been transferred to the occipital lobe. The fissures in the temporal Iobe, especially the superior temporal fissure, are well developed and this latter has connected with its extremity a well-defined angular gyrus.

The fissures of the basal surface of the frontal and temporal lobes give these regions an extremely simple appearance. In fact, the impression obtained from a survey of the cercbral hemispheres in gibbon allies this form much 
more closely with the group here identified as intermediate primates. Certatiniy, the superficial appearance of the eribbon's cerebral hemisphere places between it and the more highly complex endbrain of the great anthropoid
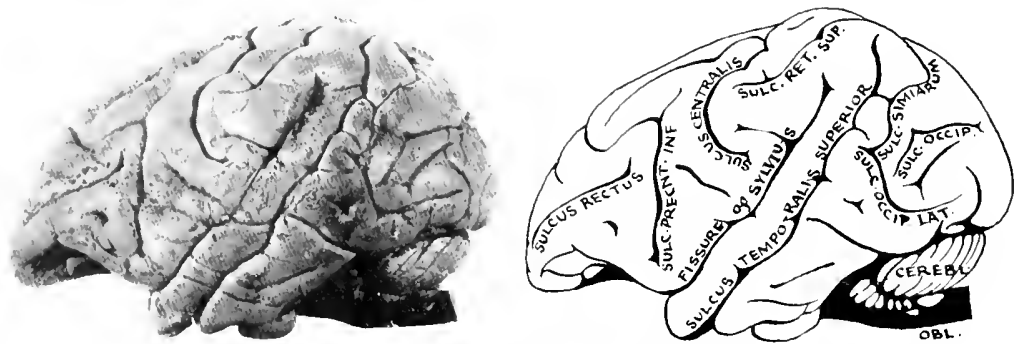

FIG. IG). LEFT LATERAL SLRFACE OF BRAIN, HYLOBATES HOOLOCK.

[Actuit leength,, $3 \mathrm{~mm}$.]

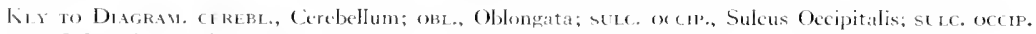
Lar., Sulcus Occipitalis Lateralis; suer. Prent. NF., Sulcus Precentrallis Inferier; sert. Re 1. sep., Sulcus Retrecentralis Superior; sete. Sintaken, Sulcus Simiartum.

apes a wide interval, so wide as to justify the opinion that in descent, the lineal relation between the gibbon and the anthropoid, however direct, must be quite remote.

\section{THE CEREBELLUM}

The cerebellum bears out this impression in conclusive manner. Its tentorial surface shows that marked convexity or gabling which culminates in a well-defined vermal ridge-pole. This feature is characteristic of intermediate and lower primates, hut gradually disappears in the higher anthropoids. On the tentorial surface of the cerebellum the interfolial fissures pass from the vermis to the lateral lobe without sulcal interruption, while on the occipital surface, a paramedian sulcus upon either side of the vermis interrupts the folial sulei in their passage from the median to the lateral expansions of 
the cercbellum. The petressi-ventricular surface of the cerebellum presents at bairly large fleceulus aceupsing the corebello-pentile angle. The mesial portion of this surface is in relation with the rosel of the fourth sentricle.
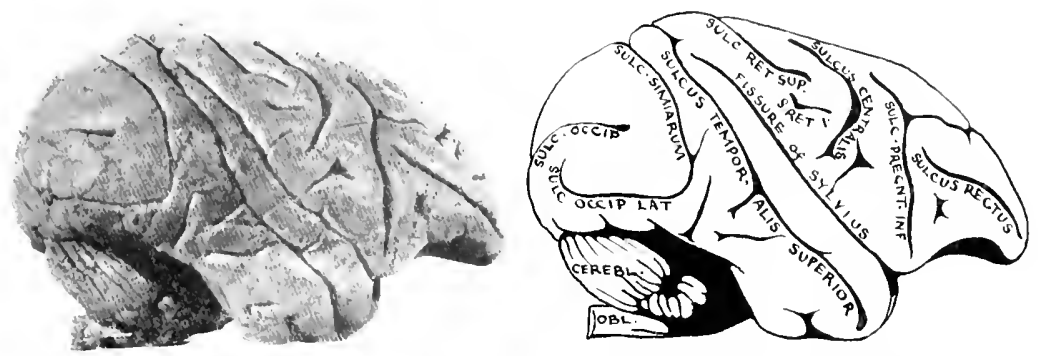

1IG. I06. RIGIIT LATERAL SLRFACE OI BRAIX, IILOBATES HOOLOCK. [Actual length $73 \mathrm{~mm}$.]

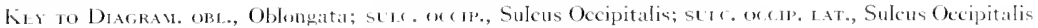

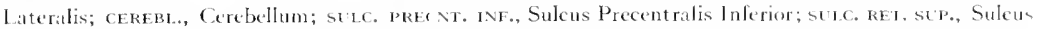
Retrocentralis Superior; stlc. smiakum, Sulcus Simiarum; S. RET. I., Suleus Retrocentralis Inferior.

\section{ITIE BRAIN STEM}

In the brain stem, the markings on the several surfaces in gribbon are more precise than in the lower primates, and about equally as distinct as they are in the baboun and macacus.

The Oblongata. The oblongata upon its ventral surlace presents a well-defined ventromedian suleus, which is flanked upon either side by two fairly prominent pramidal clevations. Lateral to the pyramid and separated from it by a pre-olivary suleus is a well-defined olivary eminence whose contour and proportions are somewhat more marked than in the other intermediate primates. The lateral surface shows the gradual gathering of the ascending spinocerebellar fibers until this collection forms the restiform body at the lower border of the pons Varolii. In the lower portion of the lateral surface there is a slight protuberance which marks the surface relief 
of the substantia gelatinosa trigemini. This trigeminal protuberance at the more cephalic levels of the oblongata is concealed from view by the superpesition of the fibers entering the restiform body. In the most cephalic
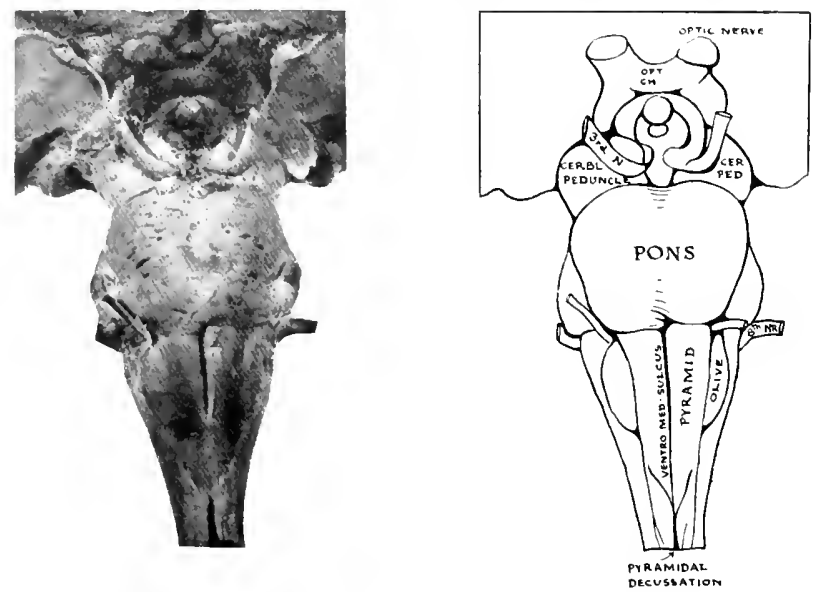

FIG. 197. VENTRAL SIRFACE OF BRAIN STEM, HYLOBATES HOOLOCK. [Actual Length $+5 \mathrm{~mm}$.]

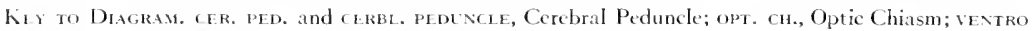
IIID. seleces, Ventromedian Sulcus; 3 RD x., Third Nerve; 8тн xr., Eighth Nerve.

portion of the lateral surface appears a well-defined protuberance, the tuberculum acusticum.

The dorsal surface of the oblongata presents its characteristic divisions, the ventricular and infraventricular portions. The infraventricular portion is characterized by the typical dorsomedian septum, upon either side of which appears a well-defined clava, separated by a dorsal paramedian sulcus from an equally well-defined cuneus. These elevations on the dorsal surface indicate respectively the presence of the nucleus of Goll and the nucleus of Burdach. 
In the ventricular portion of the dorsal surface appears the caudal angle of the fourth ventricke bounded laterally by the elevations of the clava and cuncus. At the angle of this ventricle is the trigonum hypoglossi which
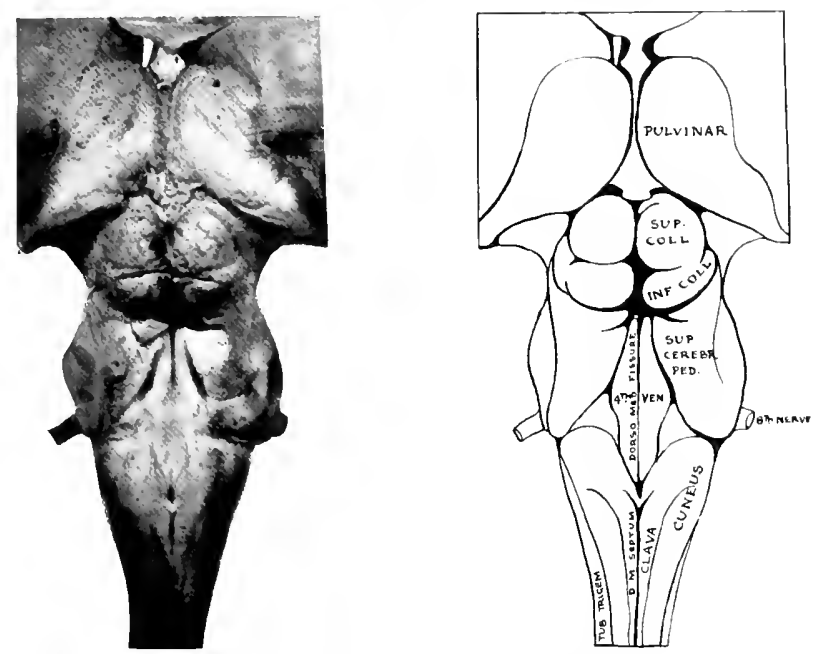

FIG. 198. DORSAL SLRFACE OF BRAIN STEM, MYLOBATES HOOLOCK.

[Actual Length $4 ; \mathrm{mm}$.]

Key to Diagran. D. M. Septum, Dorsomedian Septum; dorso. med. Fissl Re, Dorsomedian Fissure; 1 fF. COli.., Inferior Colliculus; sup. CEREBr. PED., Superior Cerebellar Peduncle; sce. Coll., Superior Colliculus;

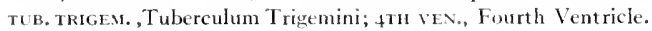

marks the position of the nucleus of the twelfth nerve; lateral to it, and separated from it by the sulcus limitans, is situated the fovea vagi above the dorsal nucleus of the pneumogastric nerve. The lateral walls constituted by the cuneus and clava become progressively reduced in altitude as they proceed cephalad, and finally at the level of the lateral recess have reached the plane of the ventricular floor. At this level, fibers of the eighth nerve make their entrance, as the striae acusticae; most of these fibers pass directly transversely inward to the dorsomedian sulcus. Below the level of the striae 
acenticale, a large devation appears in the Hoor marking the vestibular area. This fact aceords well with the exquisitely arboreal focomotion of the gibbon and revals one of the mest important regulating mochanisms which mates pessible its almost birclike passage through the forest. The median fissure becomes somewhat deeper as the caudal orifiee of the Sylvian aqueduct is approached, whike the superier cerebellar pedundes, forminger the lateral boundaries of the ventricke, converge toward the aqueduct. Immediatedy above this crilice of the acueduet the trochlear nerve emerges from the brain stem after decussation in the superior medultary velum. At this level appear the characteristic derelopments in the roof of the midbrain, the collicular eminences. Of these, as in other primates, the inferior colliculi are the smaller. Howerer, the disparity in size between these two sets of collieuli in gibbon is not so marked as in the macacus or baboon. This modification appears to foe due to the fact that the superior colliculus has test somewhat in prominenee as compared with the other two intermediate primates. The correctness of this observation gains support from the more complex development of the excipital lobe in eribbon when compared with the babonn or macacus, thus implying a still further delegation of visual function to the oceipital Jobe than in either of the other prinates mentioned.

The Poxs Varoliz. Upon the ventral surface of the axis the pous Varolii appears as a fairly prominent transwerse structure, separated from the oblongata by a well-defined bubopontile sulcus. It is also separated at its cephalic extremity from the cerebral peduncles by the pedunculo-pontile sulcus. The pons in the gibbon gives the impression of a greater degree of prominence than in either the baboon or macacus. The inference based upon the pentite appearance aceredits the gibbon with the possession of skilled morements more complex than either the baboron or the macacus.

The Ventral Surface of the Brain Sten. The brain stem upon its ventral surface terminates cephalically by the typical divergence of the two 
cerebral peduncles bounding the eptico-peduncular space. From this space emerese the two eculomotor nerres and in it are contained the mammillars bedies, the attadement of the infundibular stalk and the tuber cinereum.

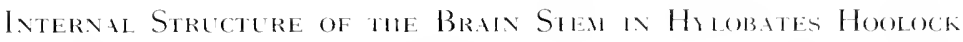

In some particulars the cross sections through the brain stem of gibbon show a slight advance, particularly in the definition of the structures when compared with the babenn and macacus. This applies more especially to the inferior olive and pontile nuclei. In other structural details the delinition in gibbon does not show any marked degree of progress wer the onther intermediate primates.

\section{LEIEL OF THE PIRAMIDAL DECLSSATION (FIG. I())}

Here the crossing fibers of the pyramid (Pyx) detemine a conspicuous rearangement in the axis. The effects of this decussation are seen in several notable features. In the lirst place, the usual separation of the ventrat gray column ( Ven) from the central gray matter $(C e n)$ is clearly shown.

This behavior on the part of the prramidal libers is of particular interest. It is primarily a mammalian characteristic. Furthermore, the pallio-spinat connection represented by the pyramid is peculiar to mammats. Decussation in conduction pathways of all varieties, whether intersegmental or projectional, is the almost invariable rule in the vertebrate neuravis. Whether, as Cajal believes, such crossing was determined by the universal decussation of the optic fibers throughout this phylum, or whether some other factors have been operative, the irresistible tendency for long fiber tracts to pass from one side of the brain to the other has exerted its intluence on the pramidal system. The nerve fibers in this system are alt neweomers among the conducting axons of the neuraxis. They were introduced by the mammats and represent the last accessional elements in the control of motor reactions. They are 
what may be called the modern acents of volitional behavior. According as their volume is large or small, they indicate the directing capacity of the cerebral cortex and as such transmit the orders of the supreme motor author-

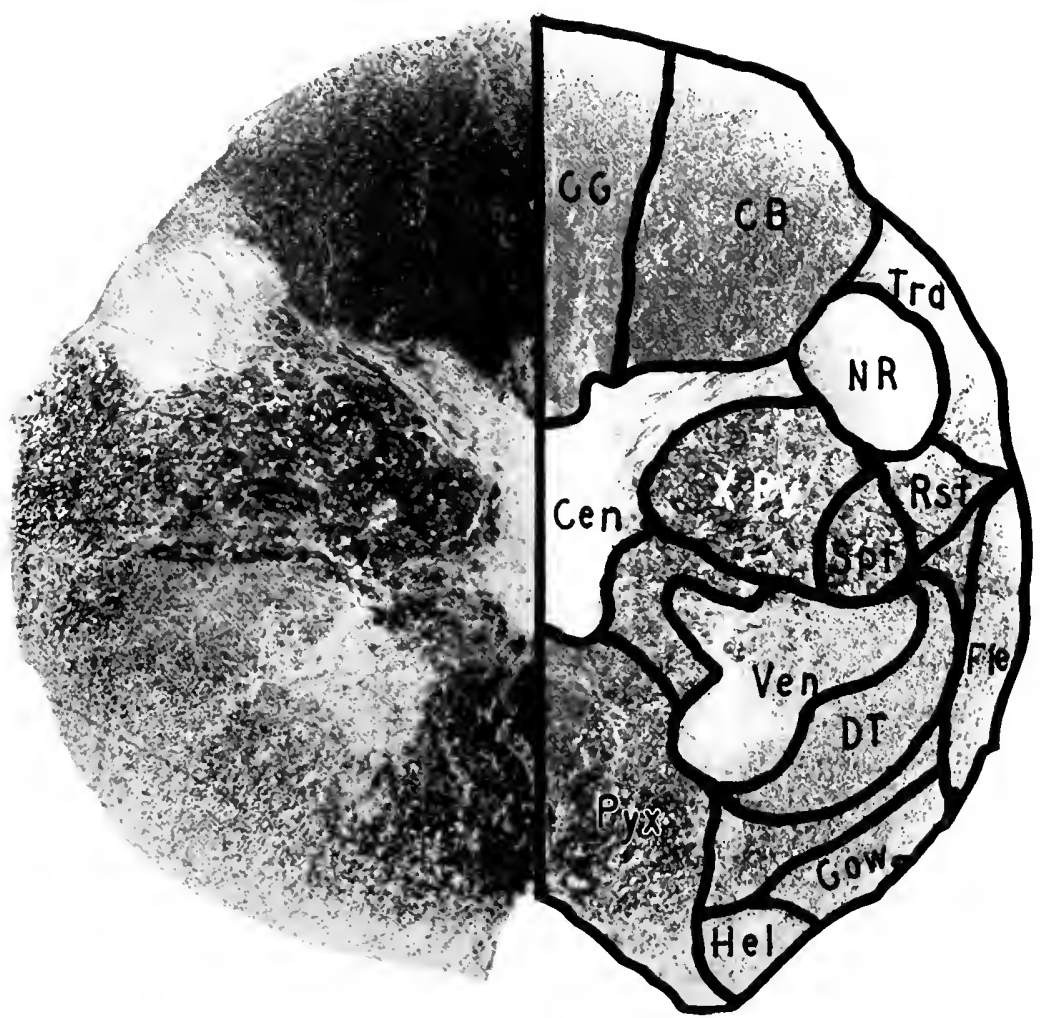

IIG. IG9. GIBBON. LEVEL OF THE PYRAMIDAL DECUSSATION.

CEN, Central Gray Matter; CB. Column of Burdach; CG, Column of Goll; ot, Deiterso-spinal Tract; FLE, Dorsal Spinocerebellar Tract; cow, Ventral Spinocerebellar Tract; Het. Spino-olivary Tract of Helweg; $\mathrm{NR}_{\mathrm{R}}$, Nucleus of Rulando; prx, Pyramidal Decussation; Rst, Rubrospinal Tratet: SpT, Spinothalamic Tract; TRD, Descending Trigeminal Traet; VeN, Ventral Gray Matter; XPs, Crossed Pyramidal Tract. [Accession No. If I. Section ;. Actual size $8 \times 7 \mathrm{~mm}$.] 
ity. Regardless of their number, these pyramidal fibers have submitted themselves to the influences which determine decussation. They do not follow exactly the same manner of erossing in all mammals, nor is their decussation equally decisive in all species. In some instances the pyramid is small and the crossing fibers produce relatively inconspicuous changes in the obtongata. Where, as in the primates, the decussation is large, it oceasions a most outspoken feature in cross section.

In certain mammals, the decussating fibers of the pyramid make their way almost furtively into the dorsal columns for their further descent into the spinal cord. In others, they cross with more conspicuity directly into the lateral columns. The primates, from one end of their order to the other, have established a fashion of pyramidal decussation which is distinctively their own.

With the possible exception of the transitional forms represented by lemur or of such anthropoid incipiency as is seen in the tarsiers, the pyramidal system of primates is larger than in all other mammals. The secondary effects of pyramidal decussation are witnessed in the wide detachment of the ventral gray column (Ven) from the ecntral gray matter (Cen) and also in the large field eventually occupied by the decussated fibers. This structural disposition and rearrangement is so decisive that any primate may be identified as such by the appearance of its pyramidal decussation.

Nere these facts of structural importance alone, they might carry but little weight in the presence of so many other satisfactory identifying characters. It is their dynamic significance, however, that gives them their true vahue. In this sense, they indicate the degree of neopallial development in the brain and the extensions in the cortical control of behavior. Through the gradual expansion of this mammalian contribution to the nervous system, the primate has progressively advanced to the highest stages of differentiation. 
The dorsal sensory field is represented by the columns of Goll and of Burdach ( $\mathrm{CG}, \mathrm{CB}$ ), together with the substantia getatinosa trigemini (NR) and its acompanying descending trigeminal tract (Trd). A comparison of these elements shows that the column of Burdach has increased in size relatively to the column of Goll. It is evident from this relation that the sensory territories of the upper extremity of gibben have gained in prominence. This advance is no doubt consequent upen the high degree of brachial and manual specialization essential to the animal's arboreal life. The comparatively small size of the mucleus of Rolando( NR) indicates that much of the tactile direction of locomotion must have been delegated to a more effective and highty specialized hand.

In the circumferential zone are the ascending fibers of the spinocerebellar tracts (FIe, Gow). The medullary area surrounding the ventral gray column contam the Deiterse-spinal tracts (DT), while in the intermediate zone are the rubrospinal and spinothatamic tracts ( Rst, Spt).

LEYEL OF TIIE CAL DAL EXTREMITY OF THE INFERIOR OLNE (FIG. 20O)

Here the transwerse diameters of the axis have increased considerably. This change especially affects the dersal sensory feeld, due to the appearance in it of the nuclei of Goll and Burdach ( NG, NB). Both nuclei are large but by actual measurement the nucleus of Burdach has a volume about twice that of Goll. The batter nueleus shows no median specialization characteristic of the nucleus of Bischoff. Since the gribbon does not develop a tail, the absence of this unpaired median nueleus might be expected. Connected with Burdach's nucleus there is a large isolated mass which constitutes the nucleus of Blumenau ( NBl). The substantia gelatinosa presents marked promincence and is in relation with a descending trigeminal tract (Trd) of considerable size. Estimated as a whole, the dorsal sensory field denotes the apportionment of the afferent influx. The territury of the upper extrem- 
its has oceasioned a notable increment in comscquence of the animal's high specialization for arboreal life. The ultimate formula of the elements in the dorsal field of the erreat apes and man is here more nearly approached

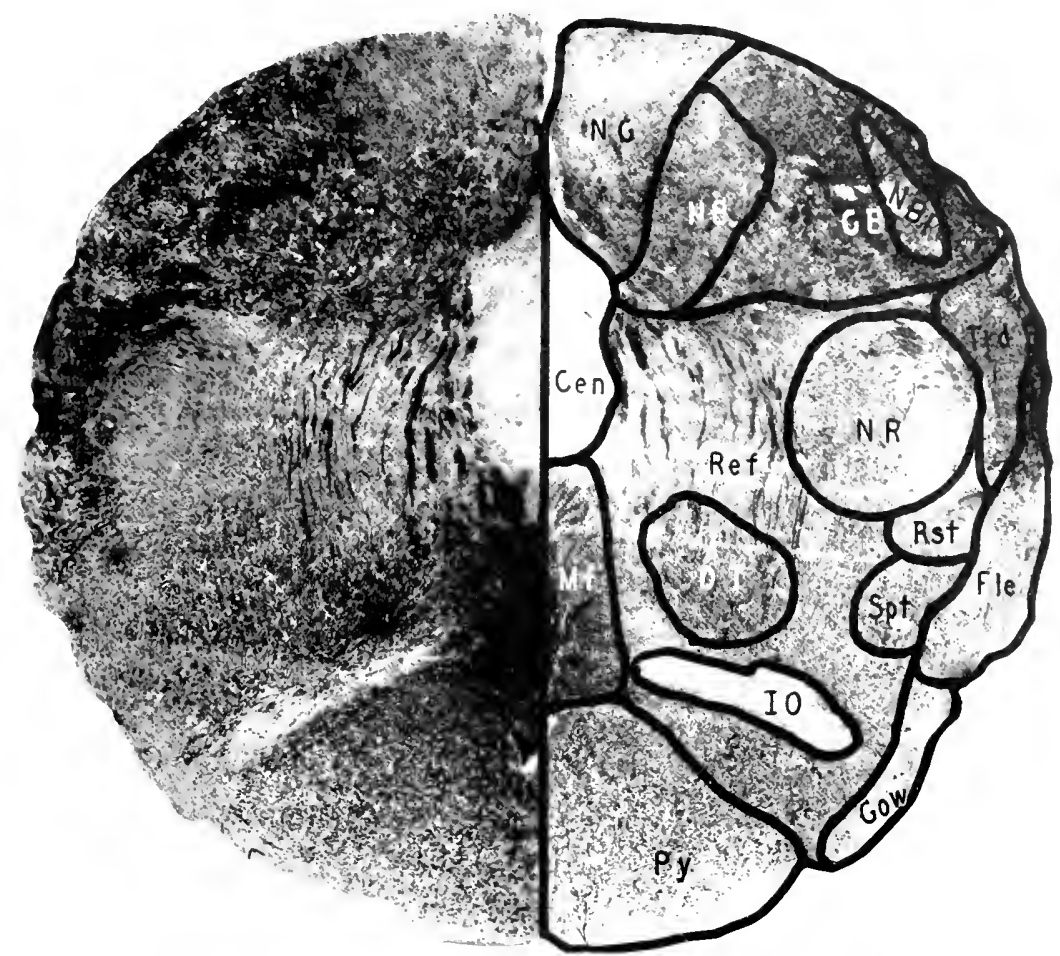

FIG. 200. GIBBON. LENEL OI THE CALDAL EXTREMITY OF THE IXIERIOR OLIVE. CB, Column of Burdach; CE\, Contral Gray Matter; or, Deiterar-spinal Tract; fri, Dorsal Spinocerebellar Tract; row, Ventral Spinocercbellar Tract: 10, Inferior Olive; uf, Mesial Fillet; vi, Nucleus of Burdich; $\backslash B L$, Nuckeus of Blumenau; NG, Nuckes of Goll; $\backslash R$, Nucleus of Rolinde; pr, Pvramid; RIF, Reticular Formation; Rst, Rubrospinal Tract; sPT, Spinothalamic Tract; TRD, Descending Trigeminil $\Gamma_{\text {rakt. }}$ [Accession N(1, 1+1. Section 16. Actual Size ") $\times 8 \mathrm{~mm}$.]

than in any of the primates betow this stage. Numerous coarse bundles of arcuate fibers arising in the meleus of Goll pass forward toward 
the median raphe. In their passage they almost completely separate the central gray matter (Cen) from connection with the substantia gelatinosa of Rolando (NR). The central gray matter has manifested decisive alteration. It is now almost quadrilateral in outline, with a narrow dorsal extension reaching backward into the dorsomedian septum. This tonguelike process indicates the preliminary rearangement incident to the opening of the fourth ventricle. In the lateral field the circumfercntial zone is characterized by the usual dorsal migration of the spinocerebetlar tracts. The dorsal spinocerebellar fasciculus (F) has changed its course to an oblique passage along the outer side of the descending trigeminal tract where its heavily myelinized fibers may be readily seen. The intermediate zone contains the rubrospinal (Rst), the spinothalamic $\left(S_{p} t\right)$ and the Deitersospinal (DT) tracts. The ventral field contains the fibers which constitute the pyramid ( Py), dorsal to which are the bundles of the posterior longitudinal and predorsal fasciculi. The internal areuate libers, as they eross the raphe to form the mesial fillet (Mf), somewhat obseure the outlines of the predorsal and posterior longitudinal bundles. Dorsolateral to the pyramid is a slender body of gray matter, the caudal extremity of the inferior olive (IO). An extensive, difluse reticular formation (Ref), lies between the olivary body and the nucleus of Rolando. It is traversed by numerous internal arcuate fibers and contains several indefinite nuclear aggregations, one constituting the lateral reticular nucleus and a second, the dorsal reticular nucleus.

A comparative survey of the six species of primates thus far considered must make impressive the striking similarities which characterize the corresponding cross sections of the brain stem. Level for level in hemuroid and anthropoid, the component structures are remarkably identical. So alike are they that the repeated descriptions of the several levels in the different species creates a degree of tedium felt by the reader no doubt as much as by 
the author. The repetition would be wholly objectionable and out of place were it not for one compelling argument which seems to make it justifiable. To recognize the morphological consistency, the unity of structural design, in the relation of so many intricate parts should sulfice to dispel all doubts concerning the chese generic asseciation of these animals. This unity is likewise convincing as to that influence which, working through the primate stock, has employed the same fundamental pattern to establish such conditions as result in progressively more efficient neural mechanisms and in better behavioral adjustments.

LEVEL THROLGH THE MIDDLE OF THE INFERIOR OLIVE (FIGS. 201, 202)

Here the most conspicuous feature is the appearance of the inferior divary nucleus ( IO). This structure here presents its full degree of development in the gibbon. Certain features of it are to be contrasted with the homologous structure in the lower primates. It has graned eonsiderably in its general dimensions, both transversely and longitudinally. But its real increase in prominence is due to its more convoluted configuration characteristic of the human and humanoid structure. In connection with it are its two accessory olives ( VO, DO). The central gray matter occupies a position immediately beneath the floor of the fourth ventricle. In its most mesial portion it contains the nucleus of the twelfth nerve ( $\mathrm{Nhy}$ ), whose emergent fibers ( $\mathrm{N}_{12}$ ) pass from the nucleus and make their way ventrolaterally toward the inferior olive. Lateral to the nucleus hypoglossus, and separated from it by the sulcus limitans in the central gray matter, is the dorsal nucleus of the pneumogastric nerve $(\mathrm{Nvd})$, some entering fibers of which may be discerned approaching this nuclear collection. Immediately adjacent and lateral to the dorsal nucleus of the tenth nerve is a dense collection of medullated fibers constituting the fasciculus solitarius surrounded by the nucleus of this fasciculus ( $\mathrm{Nfs}$ ). Ventral to the fasciculus solitarius is the 
substantia gelatinosa trigemini (NR), while lateral to it and contiguous with its external surface is the descending trigeminal tract ( Trd). Occupsing the most dorsal position in the lateral freld is the cephatic extremity of

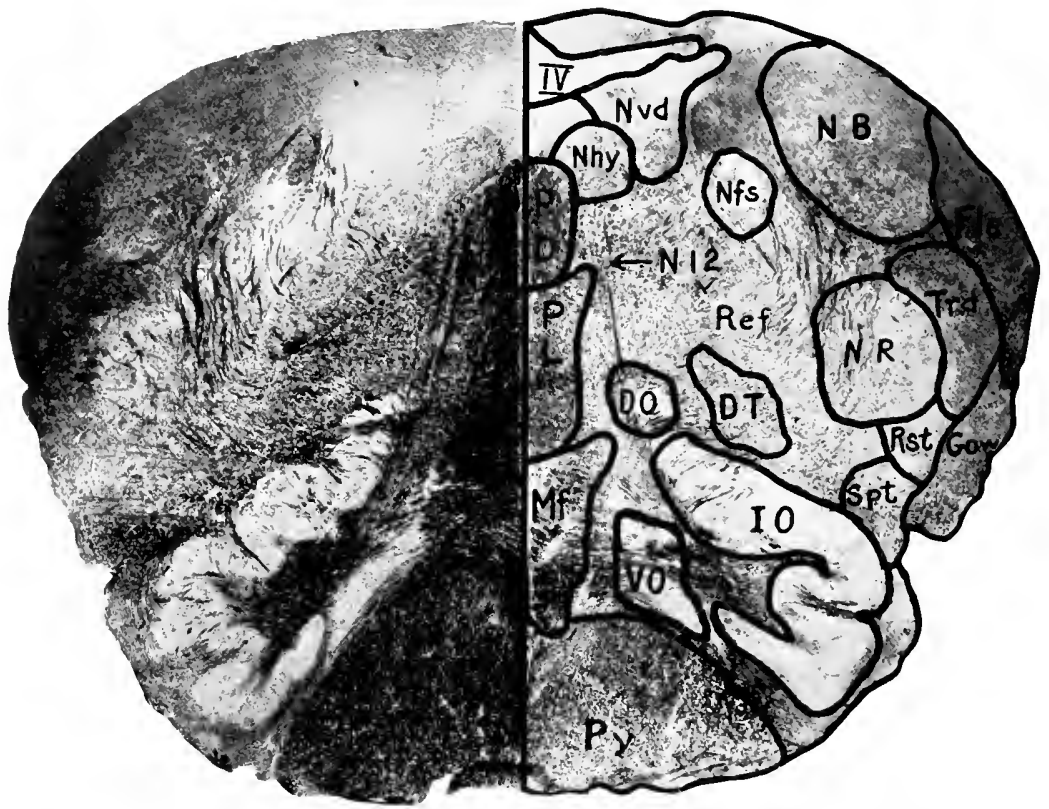

FIG. 201. GIBBON. LEVEL THROLGH THE MHDDLE OH THE INFERIOR OLITE. Do, Dorsal Accessory Olive; DT, Deiterso-spinal Tract; F. E, Dorsal Spinocercbellar Tract; couw, lentral Spinocercbellar Tract; 10 , Inferior Olive; $\mathrm{N}$, Fourth Ventricle; m, Mesial Fillet; VB, Nucleus uf Burdach; VFs, Nucleus Fascieulus Sulitarius; NHr, Jypoglossal Nucleus; \R, Nucleus of Rolandu; vid, Dorsal Vagal Nucleus; N12, Twelfth or Ilypeglossil Nerve; PD, Predorsal Bundle; p', Posterior longitudinal Fasciculus; P), Pyramid; ki F, Reticular Formation; Rst, Rubrospinal Tract; spt, Spinothalamic Tract; rkD, Descending

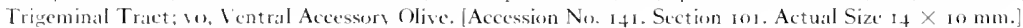

the nuckess of Blumenau (NBI), from which numerous internal areuate fibers make their way forward and inward through the reticular formation toward the median raphe, where they undergo decussation and enter the mesial fillet ( $\mathrm{MI}$ ) on their way to higher levels in the brain. 
The eneneral size of the nucleus of Blumenau (NBI) is suggestive, as in other levels, of the degree to which the foredimb and hand havedeveloped. Emphasis has been laid on the fact that the relatively poor development of

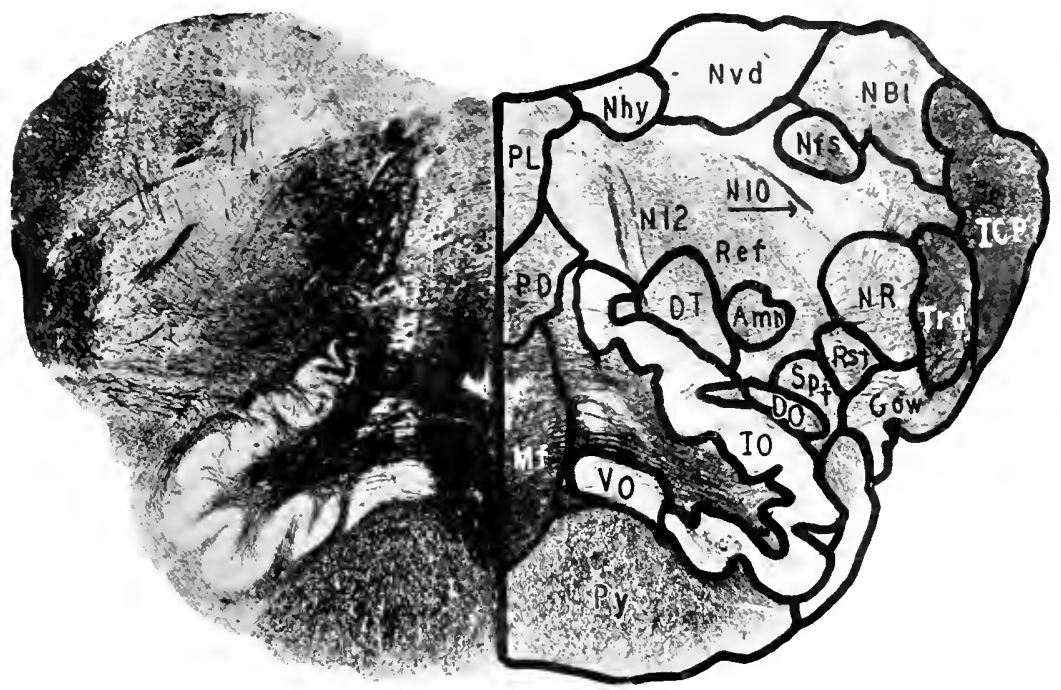

FIG. 202. GIBBON. LEVEL THROLGH THE MIDDLE OF TIIE IDFERIOR OLIVE. A1b, Nucleus Ambiguus; do, Dorsal Accessory Olive; dr, Deiterso-spinal Trict; cow, Lent ral Spinocerebellar Tract; ILP. Interior Cerebcllar Peduncle; Io, Inferior Olive; MF, Mesial Fillet; NB1, Nucleus of Blumenau;

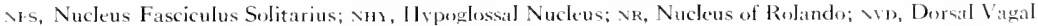
Nucleus; No, Tenth Cranial Nerve; \1 2, Twelfth or Itypogtossal Nerve; PD, Predorsal Bundle; Pe, Pusterior longitudinal Fasciculus; Py, Pyramid; ReF, Reticular Formation; Rst, Rubrospinal Tratet: spT, Spinothalatmic Tract; $T R D$, Descending Trigeminal Tract; 10, Ventral Aecessory Olive, [Accession No, 1 11. Section 131. At'tual Size $1+\times 8 \mathrm{~mm}$.

the hindlimb in gibbon and the high degree of proficiency attained by the uppere extremity and hand, especially for the purposes of its lleet locomotion, give marked structural prependerance to the nucleus of Blumenau. The prominence of the inferior olivary nucleus compared with the other forms may also be in direct relation with the flight-like locomotion of the animal 
which has been likened to the most skillful attainment of expert trapeze performers. The execution of such acts would require most active and precise visual supervision, both in the recognition of distance as well as in the selection of adequate supports to sustain the weight of the body as the animal makes its prodigious swinging flights through space from one limb to another. Inacuracy in visual judgnent and particularly in the simulaneous adjustment of head, eve and hand in the execution of such acts could not fail to be attended with catastrophe. Hence it is that the simultaneous movements of head, eve and hand become of greater importance to the gibbon than to the ground-living baboon or in the more conservative aerial feats of the macacus and allied monkeys.

The pyramid ( Py) oecupies its characteristic position in the ventral area of the cross section, but from its general dimensions, it appears to show no marked increase over this structure in the mataque and baboon. The cross section bears out the general impression convered by the appearance on the external surface of the oblongata. It seems probable that, despite the high development of the hand and especially of the forcarm in the adjustment to its arboreal locomotion, the gibbon has shown no great specialization in its skilled movements, generally speaking. The proficiency which the animal exhibits in the hindlimb would indicate less need for the volitional control in these parts of the body than that possessed by many of the other primates.

Dorsolateral to the olive is the reticular formation (Ref) through which pass many of the internal arcuate fibers. Its definition is less well marked than in the other intermediate primates. At the lateral extremity of the section is a bundle of fibers constituting the restiform body (ICP) which is carrying spinocerebellar and other ascending cerebellar fibers upward toward the cerebellum. 
IEVEL OF TIIE IESTIBULAR NUCLEI (IIG. 203)

At this level the configuration of the cross section is altered by the further marked enlargement of the fourth ventricke. Intricate changes depend

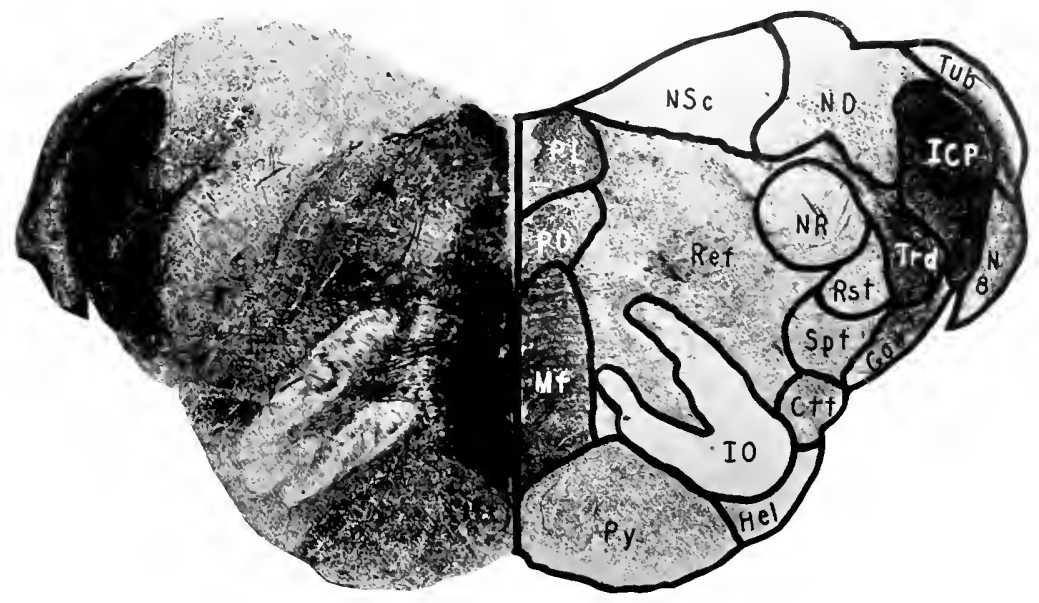

FIG. 203. GIBBON. LEVEL OF THE VESTIBUlar NUCLEI.

CrT, Central Tegmental Tract; gow, Ventral Spinocerebellar Tract; Hel, Spino-olivary Tract of Itelweg; ICP, Inferior Cerebellar Peduncle; IO. Inferior Olive; MF, Nesial Fillet; ND, Deiters' Nucleus; NR, Nucleus of Rolando; Nsc, Nucleus of Schwalbe; 8 , Auditory Nerve; PD, Predorsal Bundle; PL, Posterior Longitudinal Fasciculus; PY, Pyramid; REF, Reticular Formation; RST, Rubrospinal Tract; SPT, Spinothalamic Tract; TRD, Descending Trigeminal Tract; тUв, Tuberculum Acusticum. [Accession No, 141. Section 141. Actual Size $14 \times 7 \mathrm{~mm}$.]

upon the replacement of the dorsal columns of Goll and Burdach by the large elements of the vestibular area. The existence of a long proprioceptive column in the alar plate of the oblongata has already been noted. In its more caudal portion this column makes provision for the transmission of proprioceptive stimuli arising in the muscles and joints of the extremities and trunk. The cephalic division of this column serves in a similar capacity for the proprioceptors in the vestibular portion of the internal ear. This 
tristem is here represented by the nucleus triangularis of Sehwalbe (NSc) and the nucleus magnocellularis of Deiters (ND). Both of these nuclear -tructures are of relatively larger size than in mose other primates and indicate a balancing mechanism commensurate with the fecomotor specialization of the gibbon's arborcal life.

The fibers of the restibular division of the acoustic nerve penetrate the substantia srelatinosa triemini (NR) to enter Deiters' nucleus. Lateral to Deiters' nueleus is the corpus restiforme (ICP) superpesed upon which is the tuberculum acusticum ( $\left.T_{4}\right)$ ). The circumferential area is now cocupied laregely by the ventral spinocerebellar tract (Gow), mesial to which is the heary bundle of the descending trigeminal tract (Trd). The inferior olivary nucleus with its accessory bodies (IO) occupies its characteristic pesition and has its usual form. There is evident in it a slightly greater tendency toward convolution than observed in lower primates. Its definition is, however, somewhat more hazy than is true of higher members of this order. Dorsolateral to the olive is the central tegmental tract (Ctt), important because of its probable connections with the oculomotor nuclei and the meseneephalic root of the trigeminal nerve. This mesencephalic root, according to good authority, represents the proprioceptive conduction from the ere muscles. In this light the central tegmental tract may be regarded as the intersegmental link between the primary midbrain nuclei which receive afferent stimuli from ocular muscles, and the inferior olivary nucleus. Immediately dorsolateral to the olive and mesial to the central teomental tract is the spinothalamic tract $(S p t)$, while ventral to the substantia gelatinosa trigemini (NR) is the rubrospinal tract ( $R s t$ ). The reticular formation (Ref) is relatively larere. Ventromesial to the olive is the pramid ( Py) and dorsal to it in succession toward the flow of the ventricle are the mesial fillet (Nf), the predorsal fasciculus (PD) and the pesterior Iongitudinal fasciculus (PL). 


\section{HIOBATES HOOIOCK, THE CIBBON \\ LEVEL OI THE CEREBELL IR VICLE] (1 16. 204)}

At this level the cerebellum contains evidence of a decisive advance. This advance alfects the cerebellar nuckei and particularly the meleus den-

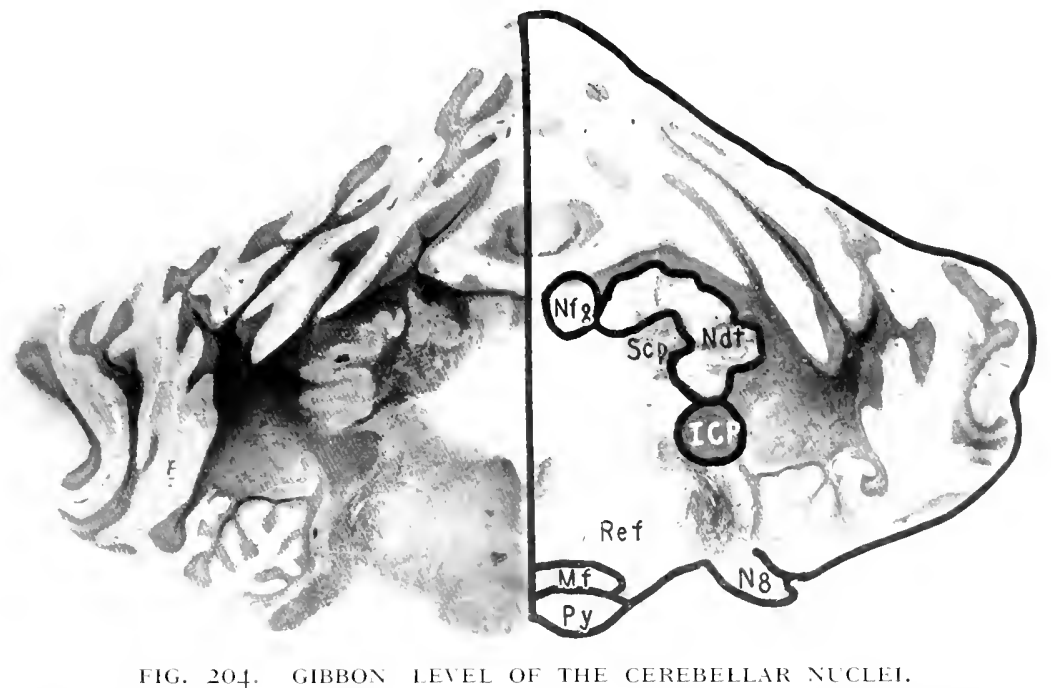

ICP, Inferior Cerebellar Peduncle; MF, Mecial Fillet; \DT, Cerebellar Nucled, Lateral Group; \ro, Cerebellat

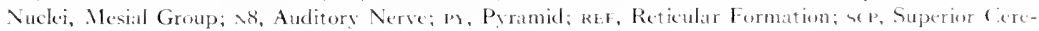
bellar Peduncte. Accession No $1+\mathrm{r}$. Section 1 i I. Actual Size $10<12 \mathrm{~mm}$.

tatus ( Ndt). For the first time this nucleus shows some of the tendencies in its development which foreshadow its ultimate configuration in the higher primates. In the species lower than gibbom, the dentate nucleus has had a more diffuse and somewhat amorphous appearance-amorphous at least in that it does not present any of those distinctive features which mark it in the great apes and man. A suspicion of the tendency to become convoluted may be detected in the baboon and macacus. In general, however, this tendency in both of the latter species is confmed to circumscribed and quite 
limited portions of the melear substance. The nucleus in the gibbon shows a number of well-defined plieations throughout its entire extent. Its hilus is dorsomesial in position and so disposed as to place its fundus in a ventromesial position. The general saccular arrangement of the nuclear substance is most pronounced along the fateral wall. Here also the folia or comrolutions are best defined. The mesial wall is much less developed in this respect. It gives the impression of a structure about to emerge from a difluse matrix, but as yet not possessed of the definition characteristic of ultimate development. In this sense the dentate nucleus in gribbon represents a transitional stage in which only a portion of it has attained its full evolutional differentiation. It affords an illustration of one of the most important movements in the process of unfolding which appears both in ontogenetic and phytogenetic derclopment. The gradual emergence of recognizable features out of a diffuse, more or less indefinite anlage is a rule in the genesis of all organs. The spinal cord, for example, in early fetal stages, shows but little differentiation of its principal histological features. In the early period of human development the dorsal and ventral gray columns are distinguishable but have many points of similarity. Only in infancy do these two eolumns of gray matter assume distinetive characters. During the first year of life it is often difficult to distinguish histologieally between the configuration of the several levels of the spinal eord, even when the comparison involves such widely removed portions as the cervical and sacral segments. Throughout adolescence and into adult life these differential features progressively assume their ultimate character. A similar proeess passing through gradient stages appears in the phytetic evolution of many structures in the nervous system. Such structures have their inception in a diffuse matrix and gradually acquire sharpness of definition together with speeifie characteristics. The dentate nucleus in gibbon, therefore, is of great interest morphologically if for no other reason than representing a deeisive stage of evolutional transition. I ts physiological signif- 
icance is equally important. It indicates the pronounced atecessions in coordinative control which this more advanced primate has acquired in response to its specialized arboreal locomotion. This detail of its neural oreanization approaches much nearer to the higher anthropoids than any of the intermediate primates.

Dorsomesial to the dentate nucleus is the nucleus fastigii ( $\mathrm{Nfg}$ ), while the inferior vermis projects into and fills most of the fourth ventricle.

\section{LEVEL OF THE EMERGENCE OF THE SISTH CRANIAL NERVE (FlG. 20j)}

At this level the most important features in the section are the abducens nucleus ( $\mathrm{Nab}$ ) situated in the floor of the fourth ventricle, the superior olive (SO) connected with the secondary cochlear pathway, and the appearance of the transverse fibers constituting the trapezoid body. The pyramid ( $\mathrm{Py}$ ) occupies its usual position in the ventromedian portion of the section, while dorsal to it, stretching across the section in a transverse manner, are many fibers connected with the secondary cochlear pathway of the trapezoid body. At the lateral extremity of this is a nuclear collection which forms the superior olive ( $\mathrm{SO}$ ), from which many fibers make their way to the nucleus abducentis. These latter constitute the peduncle of the superior olive, the fibers of which participate in reflex acts necessary to adjusting lateral gaze to the direetion from which sudden sounds may arise. The importance of such a direct reflex mechanism is apparent when the needs of instantaneous visual detection are considered in relation to acts of self-protection. Mesial to the nucleus abducentis ( $\mathrm{N}$ a b ) are the fibers which form the second part in the emergent course of the facial nerve. Other fibers constituting the fourth part of this nerve sweep forward and outward, mesial to the substantia gelatinosa ( NR). The central gray matter occupies the floor of the fourth ventricle whose roof is formed by the vermis of the cerebellum. 
LEVEL THROLGH THE MIDDLE OF THE PONS VAROLH (IIG. 206)

At this level all three layers of this structure may be discerned, namely, the stratum superficiale pontis, the stratum complexum pontis, containing

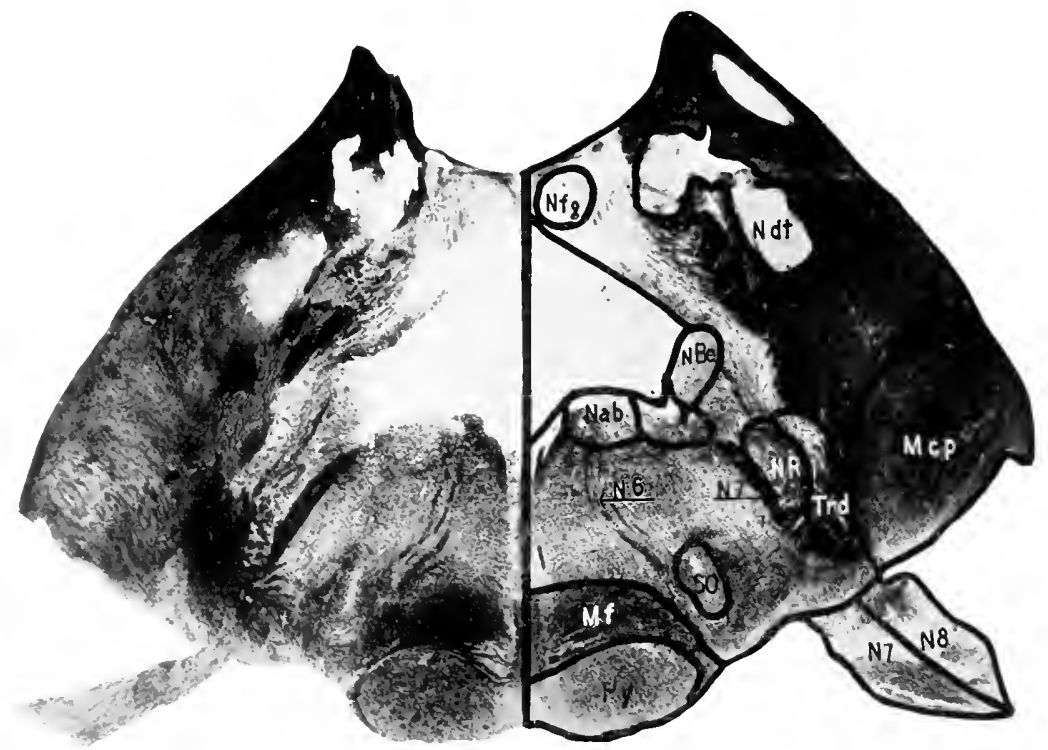

FIG. 20\%. GIBBON. LEIEL OF THE ENERGENCE OF THE SIXTH CRANIAL NERVE. MCP, Middle Cerebellar Peduncle; uf, Mesial Fillet; NAB, Abducens Nucleus; NBE. Nucleus of Bechterew;

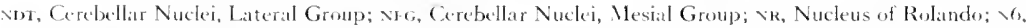
Abducens Verve; --, Facial Nerve; N8, Auditory Nerve; 1'Y, Py ramid; so, Superiur Olive; trd, Descendingr Trigeminal Tract. [Accession No. 1+1. Section 1-2. Actual Size $20 \times 16 \mathrm{~mm}$.]

some seattered fasciculi of the pyramid ( $P_{y}$ ), the pontile nuclear mass $(\mathrm{PN}$ ) and some decussating pontile fibers, and the stratum profundum pont is largely made up of transverse decussating fibers. At the lateral extremity of the section are the collected bundles constituting the middle cerebellar peduncle (Mep). Entering the brain stem at this level near the mesial surface are some dorsal root axons of the fifth nerve $\left(N_{j}\right)$ on their way to the 
substantia gelatinosa. From this nucleus many fibers pass ctorsally and mesially toward the angle of the fourth ventricle to form the tractus mesencephalicus trigemini.

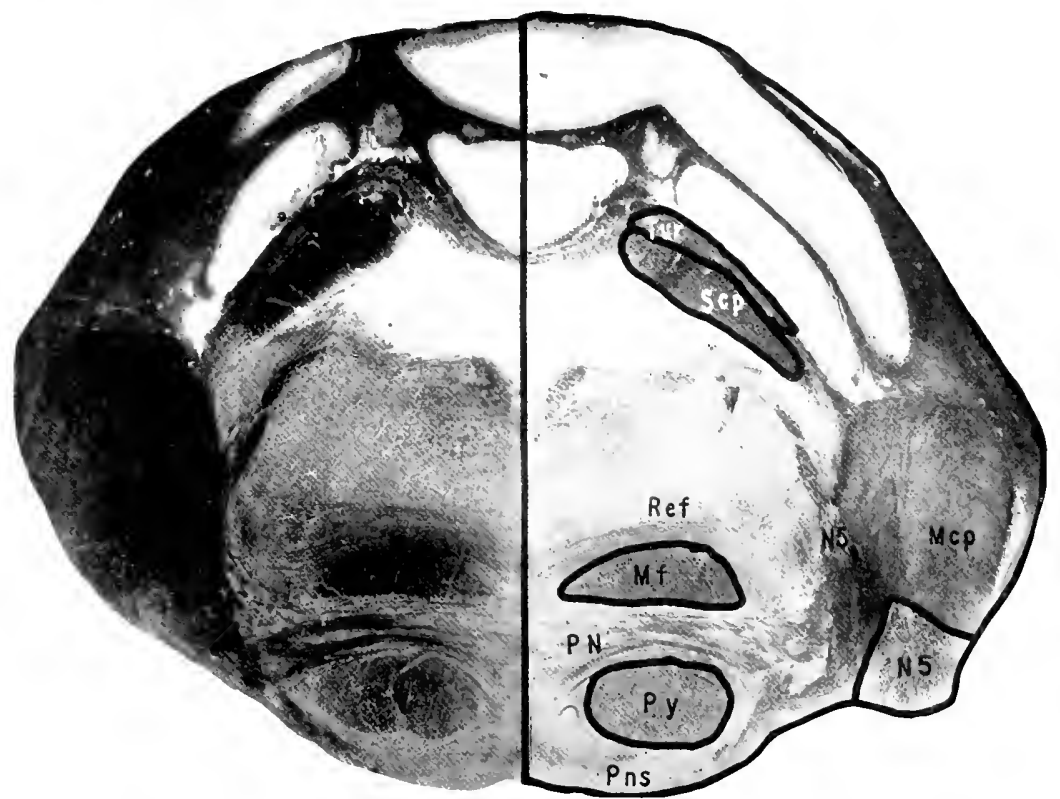

FIG. 206. GIBBON, LEVEL THROUGH THE MIDDLE OF THE PONS.

MCP, Middle Cerebellar Peduncle; MF, Mesial Fillet; N5. Trigeminal Nerve; PN, Pontile Nuclei; pis, Pons; Pr, Pyramid; Ref, Reticular Formation; scp. Superior Cerebellar Peduncle; Tur, Tractus Uncinatus of Russel (1look Bundle). [Accession No. 141. Section 186. Actual Size $21 \times 16 \mathrm{~mm}$.]

The central gray matter occupies a position immediately bencath the fleor of the fourth ventricle and serves to form the lateral ventricular boundary. At the lateral extremity of the section is a dense mass of fibers, the superior eerebellar peduncle (Sep), an index concerning the degree of coordinative control which the animal possesses. Compared with the other intermediate primates, the gibbon shows no marked increase in this par- 
ticular. The benndary between the tegmentum and basis pentis is provided by the mesial fillet (Mf), white the reticular formation (Ref) shows no speciatization of nuclear collections at this lavel.

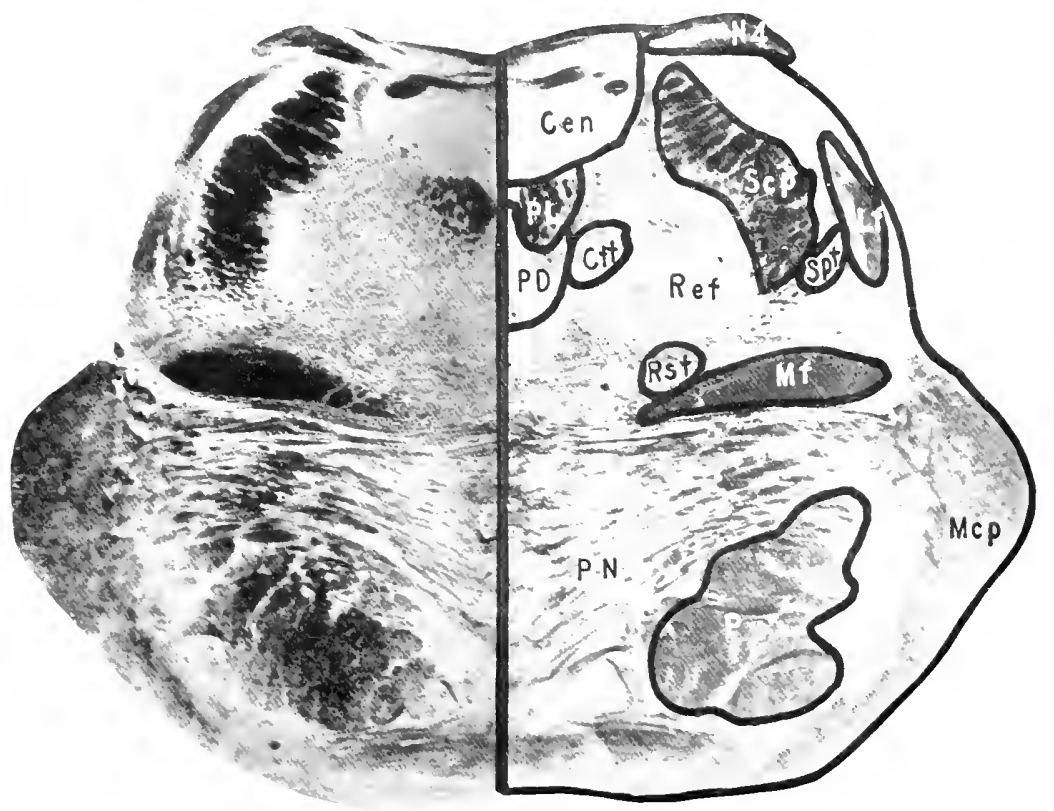

IIG. 20-. GIBBON. LEVEL OF THE EMERGENCE OF THE TROCIILEAR NERIE. AFv, Central Gray Matter; ctT, Central Tegmental Tract; LF, Lateral Fillet; M, Mesial Fillet; ace. Middle Cerebellar Peduncle; N4. Trochlear Nerve; pD. Predorsal Bundle; PL. Pusterior langitudinal Fasciculus; y, Pontile Nuclei; P, Pyramid; Rer, Reticular Formation; Rst, Rubrospinal Tract: sce. Superior Cerebellar Peduncle; spt, Spinothalamic Tract. [Accession No. 1+1. Sectiun 250. Actual Size 16 * $12 \mathrm{~mm}$.]

LEVEL OF THE EMERGENCE OF TIIE TROCHLEAR OR FOURTH CRANIAL NERIE (FIG. 20-)

Here the appearance of the section has undergone considerable modification che to the fact that the axis is approaching its mesencephalic portion 
where the larese space of the fourth ventricle is reduced ats it approaches the acpueduct of Sylvius. The central gray matter $(\mathrm{C} e \mathrm{n})$ surrounds the ventricle whose roof is formed by the superior medullary velum in which the libers of the trochlear nerve ( $N_{+}$) undereso complete decussation. These libers subsequently emerge in retation with the clorsal aspect of the isthmus. In the central portion of the central gray matter ( $\mathrm{Cen}$ ) are the dense bundles constituting the fasciculus longitudinalis posterior (PL) and the fasciculus predorsalis (PD). Lateral to the central gray matter are the fibers constituting the superior cercbellar peduncle $\left(S_{c p}\right)$ preparatory to their inward deflection toward their decussation in the midbrain. Ventral to these fibers on the circumference of the axis is a mass of medullated axoms forming the lateral filtet (Lf). At the boundary line between the tegmentum and basis are the transversely disposed bundles of the mesial fillet (Mf), while the general arrangement of the pons Varolii in its three characteristic layers appears ventral to this boundary. The pons here contains the stratum superficiale, the stratum complexum and the stratum profundum lying immediately ventral to the tegmental portion of the axis.

LEVEL OF THE INFERIOR COLLICULLS (F1G. 208)

Here the cross section shows further modification by the appearance of the two dorsal elevations constituting the primordial stations for the auditory pathway. These colliculi ( IC) form a prominent elevation in the quadrigeminal plate of the midbrain and show a degree of stratification which harks back to their highest specialization in the lower vertebrates. Entering into the inferior colliculus are the collected bundles of the lateral fillet ( Lf ) which serves to convey impulses from the lower relay stations in the pathway of hearing. The central gray matter ( Cen) completely surrounds the aqueduct of Sylvius. In its rentromesial portion is the caudal extremity of the 
nuckeus trochlearis ( $\mathrm{Ntr}$ ) from which the fourth eranial nervearises $(N+)$. In the lateral border of the central eray matter are the scattered bundles forming the tractus mesencephalicus trigemini (Tmt), while in at ventral

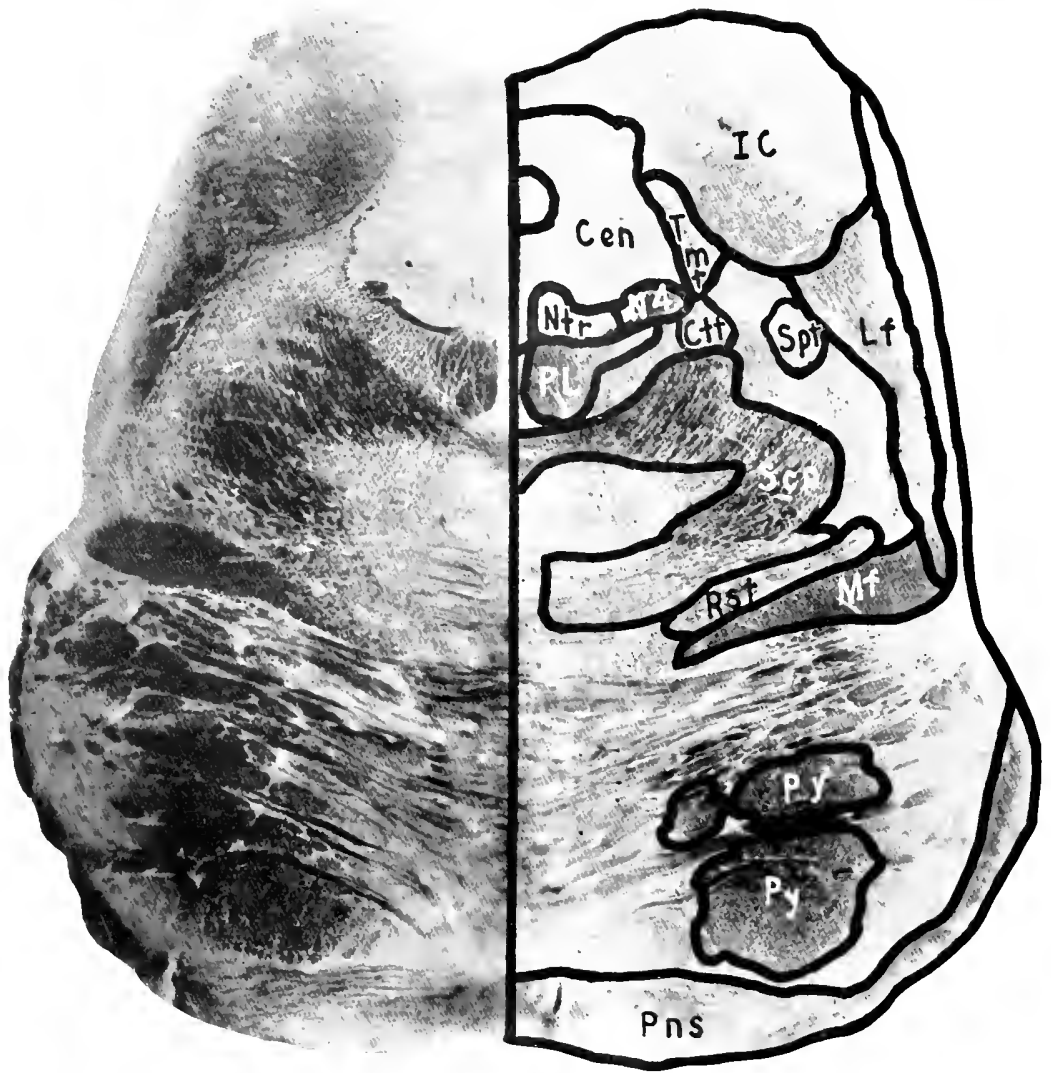

Fig. 208. GIBBON. LEVEL OF THE INFERIOR COLlicllus.

IEv, Central Gray Mlitter; ctT, Central Tegmental Tract; IC, Inferior Colliculus; Lf, Lateral Fillet; Mr. Mesial Fillet: NRr, Trapezoid Nuclens; N4, Trochlear Nerve; P', Punterior Longitudinal Fasciculus; PNs, Pons; py, Pyramid; RSr, Rubrospinal Tract; sCP, Superior Cerebellar Peduncle; spr. Spinothalamic Tract; пाт, Tractus Nesencephalici Trigemini. [Aceession No. I I. Section $2-8$. Actuat Size if $\times$ I $5 \mathrm{~mm}$.] 
position are fibers forming the posterior Iongitudinal fanciculum (PL) and the fasciculus predorsalis.

The tegmentum at this level is separated from the basis by the libers of the mesial fillet (Mf). The superior cerebellar pedunck $\left(S_{c} p\right)$ is about to make its decussation prior to entering the red nucleas.

LEVEI. OF THE SLPERIOR COLLICULLS (1IGS. 200, 2IO)

At this level the configuration of the brain stem again show's some conspicuous alteration. This is chicfly due to the appearance of the two elevations in the dorsal region of the midbrain which form the superior coll liculi (SC). In a ventral position appears a divergenee of the two cerebrapeduncles which forms the caudal boundary of the optico-peduncular space.

The superior colliculus in the gibbon, while somewhat less prominent than in the lower primates, even than in baboon or macacus, still retains a degree of its previous specialization. Traces of stratification may yet be detected in it. The central gray matter ( Cen) surrounds the small ventricular space of the aqueduct of Sylvius and contains the nuclear specialization forming the nucleus oculomotorius ( Noc). Near the median raphe many fibers from this nucleus cross to the opposite side, forming the oculomotor decussation. The nucleus ruber (N Ru), whose large size and clear definition are in contrast with all other forms heretofore discussed, occupies its characteristic position in the tegmentum. Because of its much greater definition and its more apparent emergence from the surrounding reticular formation, it seems to show some further advance in the development of that system which has control over the coordinative regulation of movement. On the other hand, the functional duality of this nucleus as a relay station should be borne in mind. It is possible that its increments, both in definition and in size, are due to augmentation from the striatal structures of the endbrain rather than to an increase of fibers arising in the cerebellum. In all probability, 
both factors have contributed some additional prominenee to the red nuckes in gibbon. That its striorubral portion has undergone expansion might be expected in an animal presenting such complex arboreal locomotion. That

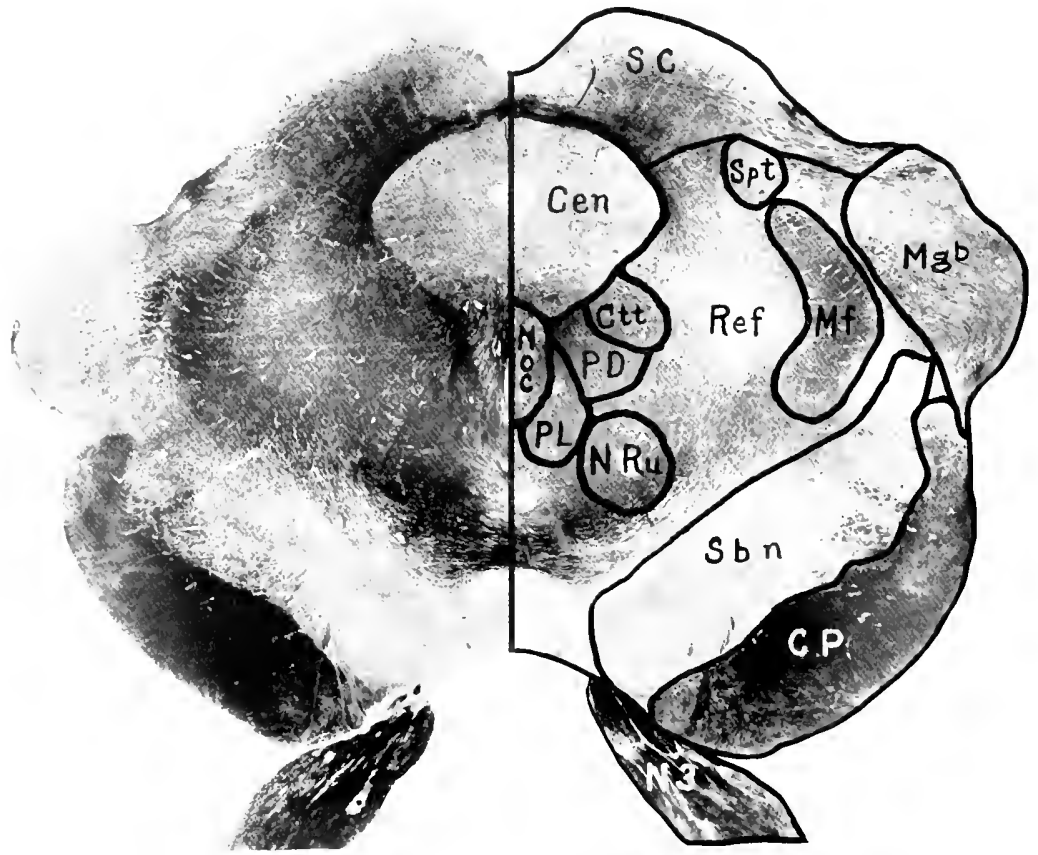

FIG. 200. GIBBON. LEVEL OF THE SLPERIOR COLLICULUS.

CEN, Central Gray Matter; cP, Cerebral Peduncle; ctT, Central Tegmental Tract; MF, Mesial Fillet; Mgb, Vesial Geniculate Body; Noc, Nucleus Oculomotorius; NRL, Nucleus Ruber; N3, Oculomotor Nerve; PD, Predorsal Bundle; PL, Posterior Longitudinal Fasciculus; ReF, Reticular Formation; sBN, Substantia Nigra; sc, Superior Colliculus; spr, Spinothalamic Tract. [Accession No. 141. Section 310 . Actual Size $30 \times 16 \mathrm{~mm}$.]

the cerebello-rubral portion of this nucleus has also undergone some expansion may be inferred from the increased size of the dentate nucleus. Surrounding the nucleus on all sides, and lying lateral to the central gray matter 
(Cen), is the reticular formation (Ref), in this species somemhat redued in size and prominence as compared with the lower forms. This reduction is duc largely to the comererence from it of the large red nuclear mass. In the

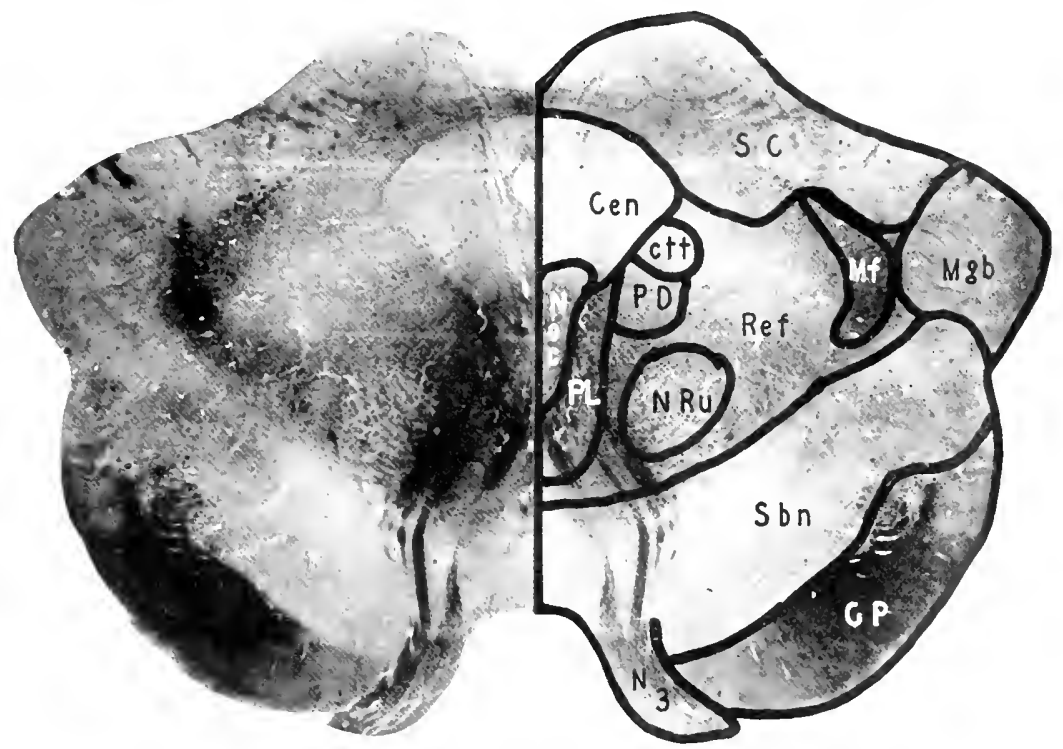

FIG. 210 . GIBBOX. LEVEL OI THE SUPERIOR COLLICLLL'S.

cex, Central Gray Natter; cP, Cerebral Peduncle; ctr, Central Tegmental Tract: Mf, Nesial Fillet: MgB, Mesial Geniculate Bodv; Noc, Nucleus Oculomotorius; ২kL, Nucleus Ruber; . v3, Oeulomotor Nerve; PD, Predorsal Bundle; PL, Posterior Longitudinal Fatsciculus; kr:F, Reticular Formation; sBv, Substantia Nigra; sc. Superior Colliculus. [Accession No. ${ }_{4} 1$. Section 350. Act ual Size $30 \times 16 \mathrm{~mm}$.]

lateral extremity of the section is seen a small protuberance, the mesial geniculate body $(\mathrm{Mgh})$. The gray matter of this nucleus secms to be confluent with another large nuclear aggregation situated ventromesial to it, the substantia nigra ( $\mathrm{Sbn}$ ). This mass of gray matter extends obliquely inward and forward from the region of the mesial genieulate body toward the optico-peduncular space and separates the basal portion of the mesen- 
cephalon from the tegnentum. The specific functions of the substantia nigra are vet surrounded by deubt, although many writers attribute to it some regulating controb of the automatic associated movements of the body.

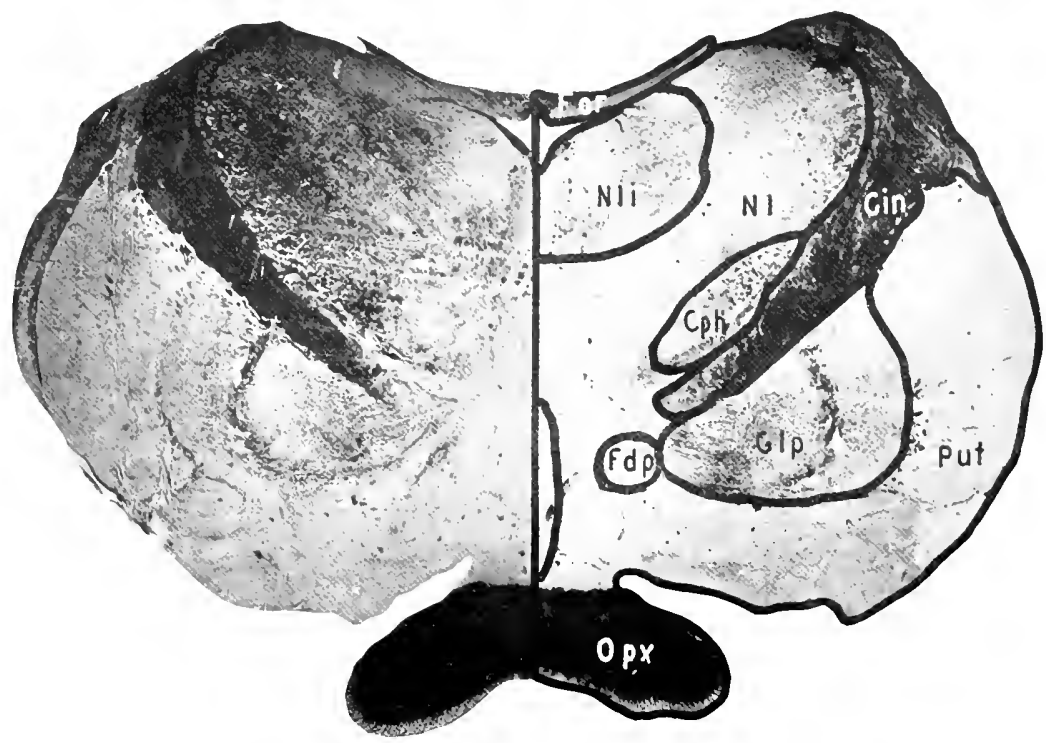

FIG. 211. GIBBON. LEVEL OF THE OPTIC CHIASM.

CrN, Internal Capsule; CPH, Corpus Ilypothalamicum; For, Descending Pillars of the Fornix; For, Fornix; Glp, Globus Pallidus; ve, Litteral Nucleus of the Thalamus; NLr, Internal Lateral Nucleus of the Thatamus; OpX, Optic Chiasm; pet, Putamen. [Accession No. 1+1. Section 4fu. Actual Size 3t $\times$ in mm.]

This opinion is in part conjectural, although the structure as a whole has the appearance of a very important element in the brain stem.

\section{LEVEL OF THE OPTIC CHIASM (FIG. 2 I I )}

At this level the configuration of the section again shows those marked alterations due to the fact that the brain stem is about to reach its cephalic termination. Some of the massive lateral additions of the endbrain are already 
apparent. The mest ventral structure in the cross section is the optic chiasm $\mathrm{O}_{\mathrm{px}}$ ) which takes the form observed in all primates, of a tatcral chongattion, together with the obtuse angulation in retation to the optic nerves and

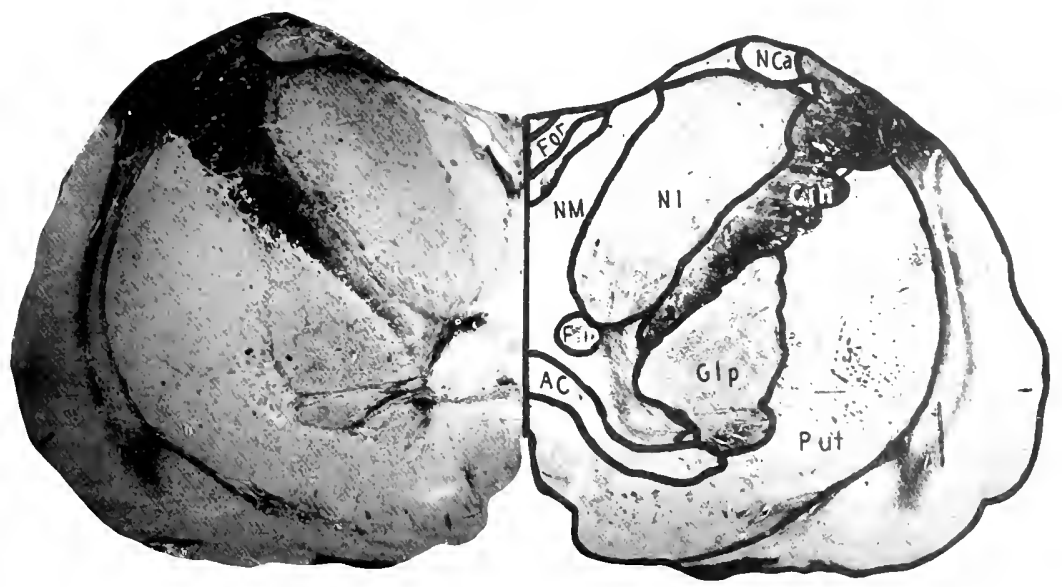

FIG. 2I 2. GIBBON. LEVEL OF THE ANTERIOR COMMISSURE.

AC, Anterior Commissure; CIN, Internal Capsule; FDP. Descending Pillits of the Fornis; 1 OR, Fornix; GLP, Globus Pallidus; NCa, Nucleus Caudatus; NL, Lateral Nucleus of the Thalamus; Ni, Nucleus Medialis Thalami; PtT, Putamen. [Accession No. 1.41. Section 486 . Actual Size $34 \times 10 \mathrm{~mm}$.]

optic tracts. The supra-optic portion of the third ventricle appears immediately dorsal to the optic chiasm. Flanking either side of the ventricle are the dense masses of the optic thalami, which in turn are separated by the internal capsule ( $\mathrm{Cin}$ ) from the lenticular portion of the stratum. This nucleus presents its two characteristic portions, the mesial and darker area constituting the globus pallidus $(G \mathrm{lp})$ and the outer and lighter portion, the putamen (Put). The evolutional significance of such complex elements as the thalamus and the lenticular nucleus could scarcely be approached within the limits of this work. 
Here the brain stem, as comedered in this work, commen to it cephatie termination. In the mid-rentral line is seen the narron cleft w the thisd

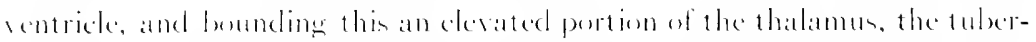
culum anticum, external to which is the cephalic portion of the lateral that-

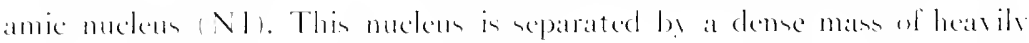
my dinized libers representing the anterior limb of the internal capsule (Cin) from an expandise nuckear pertion of the corpun strittum (Cilp. Put i. Passing ventrally inward twated the midline, threngh the portion al the corpun striatum, are the collected bundles forming the anterion commisure (AC). 


\section{CHAPTER XI}

\section{RECONSTRUCTION OF THE GRAY MATTER IN THE BRAIN STEMI OF HIYLOBATES IIOOLOCK}

IHE reconstruction of the gray matter of the brain stem in Ifylo-
bates hoolock begins at the caudal extremity of the inferion olivary
nucleus. The higher levels of the spinal eord are not represented in the model and the ventral gray columns have already mereed with the reticular formation.

\section{The Dorsal Medullari Niclet}

The nucleus of Goll, as first represented in the reconstruction, is already of considerable size. It is roughly quadrilateral in shape with a broad base which is confluent with the central gray matter. A large dorsal portion shows some tendency towards that lateral swing which characterizes these nuclei in the various brain stems already studied.

The nucleus of Burdach arises slightly more cephalad than the nucleus of Goll, in fact, at about the same level as that in which the inferior olivary nucleus appears. Its origin is represented by a thickening at the point of junction between the nucleus of Goll and the central gray matter. The nucleus rapidly increases in size, expanding laterally and, at its periphery, somewhat ventrally, thus showing the same tendency towards the lateral swing evidenced by all of these dorsal nuclear structures. It soon reaches its maximum size and contintes upward with little change. At the level of the lower third of the fourth ventricle it begins to diminish and rapidly comes to an end.

Directly ventral to the nucleus of Burdach is the substantia gelatinosa trigemini. This nucleus, as in other primates, has already reached a position widefy removed from the midline. It is oval in outline with its long axis 
directed somewhat obliquely from before backward and inward. It rests in a space hollowed out of the reticular formation which surrounds it upon its dorsal, rentral and mesial surfaces. Dorsomesiatly the substantia gelatinosa trigemini is in retation first with the mucleus of Goll and, more cephalically, with the nucleus of Burdach.

In the gibbon, the constriction in the substantia eclatinesa triecmini described in connection with the other primate brain stems is well defined, oceuring at about the level of the junetion of the upper and middle thirds of the inferior olivary nucleus. Above this point the substantia gelatinosa again enlares and passes upward in the lateral portion of the tegmentum to the upper metencephalic levels. At this point it expands to form its caput and is associated with the motor nucleus of the trigeminal nerve on its mesial aspect.

\section{Tile Inferior Olivari Nuclec's}

In Hylobates hoolock the inferior olivary mucleus has become a relatively massive and prominent structure. It presents a great number of secondary plications in its surface. The fundus of the inferior olive is deep and wide, with a number of sccondary loops. The accessory olivary nuclei are well developed. The ventral accessory nucleus begins below as a flat, elongated band applied to the inner half of the ventral branch of the main olivary mucleus. It extends upward in this position as a compressed lamina of gray matter lying between the inferior olivary nucleus and the pyramidal tract. As the ventral accessory nucleus is traced upward it gradually diminishes in size until it comes to an end apparently by fusing with the mesial extremity of the ventral branch of the principal nucleus.

The dorsal accessory olive begins at about the middle of the main olivary nucleus and appears as a narrow layer of gray matter applied to the inner portion of the dorsal branch of the olivary nucleus. It rapidly reaches its maximum transverse diameter and then, gradually diminishing, ends below 
the uppermost level of the main nucleus by fusing with the dorsal branch at its mesial extremity. The arrangement of the nucleus is similar to that found in other primates. Its deep surface lies embedded in the reticular for-
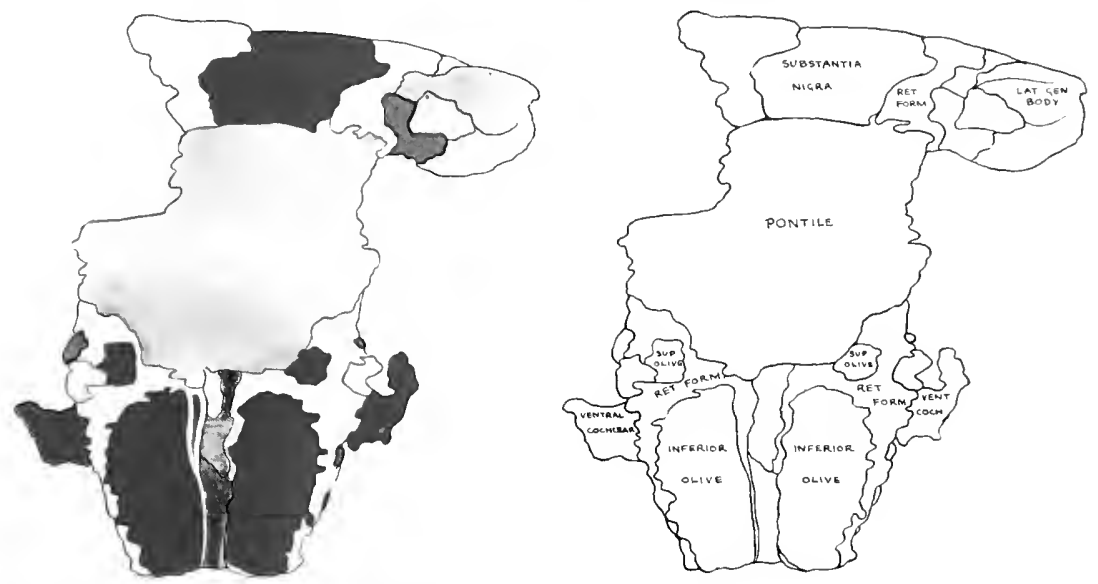

FIG. 213. VENTRAL SLRFACE OF GRAY MATTER OF BRAIX STEM, HYLOBATES HOOLOCK.

Key to Diagram. tat. gen. Boby, Lateral Geniculate Body; pontele, Pontil. Nuclei; ret. Fokm., Reticulat Formation; stp. olive, Supcrior Olive; vent, coch, and ventral comlear, Ventral Coxhlear Nucleus.

mation and the dorsal extremities of its two laminae are turned dorsally at their mesial extremities. The hilus opens toward the contralateral inferior cerebellar peduncle.

\section{The Reticular Formation}

The ventral surface of the reticular formation in its oblongatal and lower pontile portions is, to a grcat extent, in contact with the inferior olivary nucleus. Lateral to the fundus of the ofive the reticular formation approaches the surface of the stem and is uncovered except by peripheral fiber bundles. Dorsal to this uncovered area is the substantia gelatinosa 
trigemini which is situated in the dorsolateral angle of the reticular formation. Dorsal to the substantia gelatinosa this formation is covered by the fibers of the eolumns of Goll and Burdach and gives origin to the basal portions of the dersal sensery muclei. Mesially the reticular formation is continuous with the central gray matter. Its mesial surface is separated from its fellow of the opposite side by the longitudinal bundles situated adjacent to the raphe.

The pontile portion of the reticular formation on its ventral surface presents a deep excavation produced by the trapezoid body. Lateral to this excavation are located two nuclear masses of moderate size, forming the superior olive and the lateral reticular mucleus. As the superior cerebellar peduncle sinks decper into the reticular formation, a lateral reticular prolongation envelops the peduncular bundle over its Jateral surface.

In the mesencephalic portion of the neuraxis the reticular formation comes to the surface laterally, dorsal to the pontile nucleus and ventral to the colliculi. Somewhat ventral to the point at which the superior peduncle extends into the tegmentum is the pathway of the Jateral fillet.

The reticular formation, as it is followed further upward in the stem, becomes more disseminated by the superior eerebellar peduncle. It is funally separated into a mesial and a lateral portion by the appearance within it of the red nucleus. At the level of this nucleus and above this level the reticular formation becomes irregular and forms a matrix in which the mesial geniculate body derelops. In the diencephalon the reticular formation seems to meree with the zona incerta and other less werl-defined nuclear masses in the caudal portions of the diencephalon.

\section{The Pontile Nucle}

The pentile nuclei begin in the more cephalic Ievels of the medulla oblongata by the appearance of the arciform nuelei which partially surround the prramidal tract on its rentral, mesial and dorsal aspects. This arciform 
development becomes more extensive until it completely invests the pyramidal tract, thus forming the superficial and deep laters of the pontile nucleus. The superficial laver is convex in contour, corresponding to the
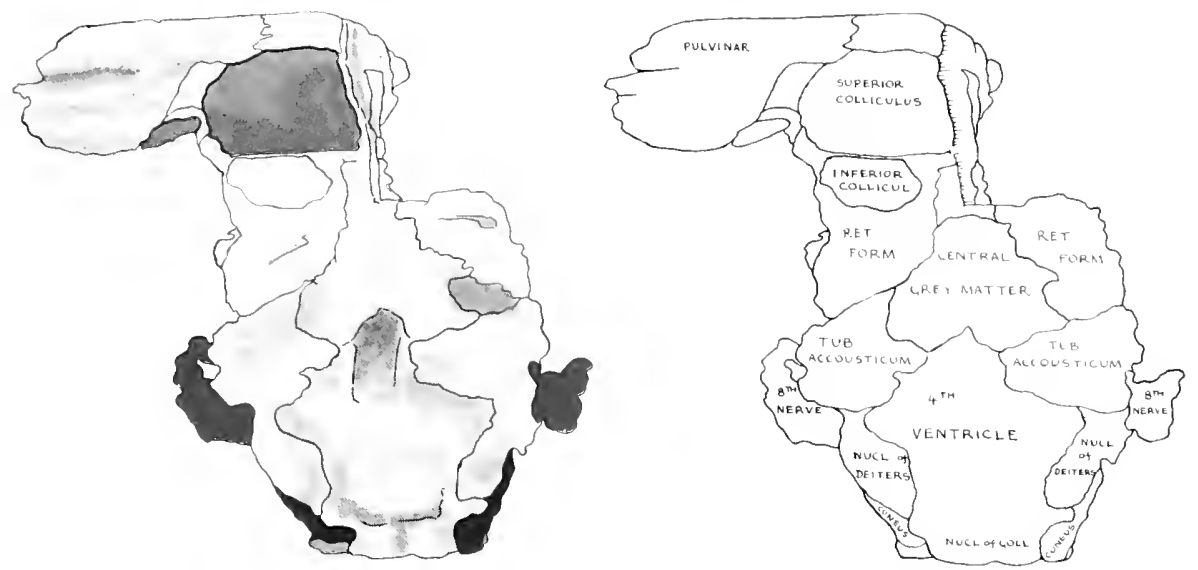

FIG. 2I 4. DORSAL SLIRACE OF GRAY MATTER OF BRAIN STEM, HYLOBATES HOOLOCK.

Key to Diagran. 1.NFerior collicul., Inferior Colliculus; Ne Cl. Of detters, Nucleus of Deiters; Necl. ot GOLL, Nucleus of Goll; Ret. Form., Reticular Formation; TL B. Accousticum, Tuberculum Acusticun.

surface configuration of the pons itself, whereas the deep layer is more or less straight or somewhat concave. Dorsally the mesial buttress comes into approximate contact with the rentral surface of the reticular formation. The same arrangement is found in the lateral buttress which, although irregular in outline, comes into intimate relation with the ventrolateral angle of the reticular formation. Between these two points of fusion, however, the ventral surface of the reticular formation and the deep layer of the pontile nuclei are hollowed out by the trapezoid body.

The scattered collections of gray matter which pass across the tumnel formed within the pontile nuclei are considerably increased. Continuing 
upward, the superficial baver of the pontile nucleus remains in contact laterally with the ventral surlace of the reticular formation of the meseneephalon. As the pontile nucleus approaches the isthmus mesencephali it rapidly decreases in size, leaving only the deep nuclear layer which continues upward to merge directly with the substantia nigra.

\section{The Vestibluth Complex}

The vestibular complex first comes to view on the surface of the reconstruction at the lower level of the fouth ventricle where it appears as a small, triangular, wedge-shaped mass, the nucleus of Deiters. It is intercalated between the lateral surface of the gray matter of the floor of the fourth ventricte and the eephatic portion of the nucleus of Burdach. The nucleus is continued forward, presenting a prolongation which overhangs the substantia gelatinosa trigemini. It reaches its maximum at about the midventrieular level. At this point its dorsal surface is covered by the beginning development of the triangular nucleus complex which gradually increases in size as the Deitersal nucleus diminishes. It passes upward in this position between the eray matter of the floor of the fouth ventricle and the retieular formation but diminishes in size as the upper pontile levels are approached. The nucleus of von Bechterew is continued from the upper portion of the triangular nucleus inte the lateral wall of the fourtl ventricle.

\section{The Cochlear Complex}

The cochlear complex is relatively large in contrast to that of Cynocephalus babuin, which is relatively small. The ventral nucleus of hylobates is well developed, having the same trough-like formation present in the other members of the primategroup. The roots of the nerves passing in to the nucleus are partially surrounded by the gray matter, leaving the mesial surface free. 
The dorsal cochlear nucleus is situated over the triangular nucleus of the restibular complex and is connected with the ventral cochlear nucleus by numerous strands of gray matter. The size of the cochlear nucleus is
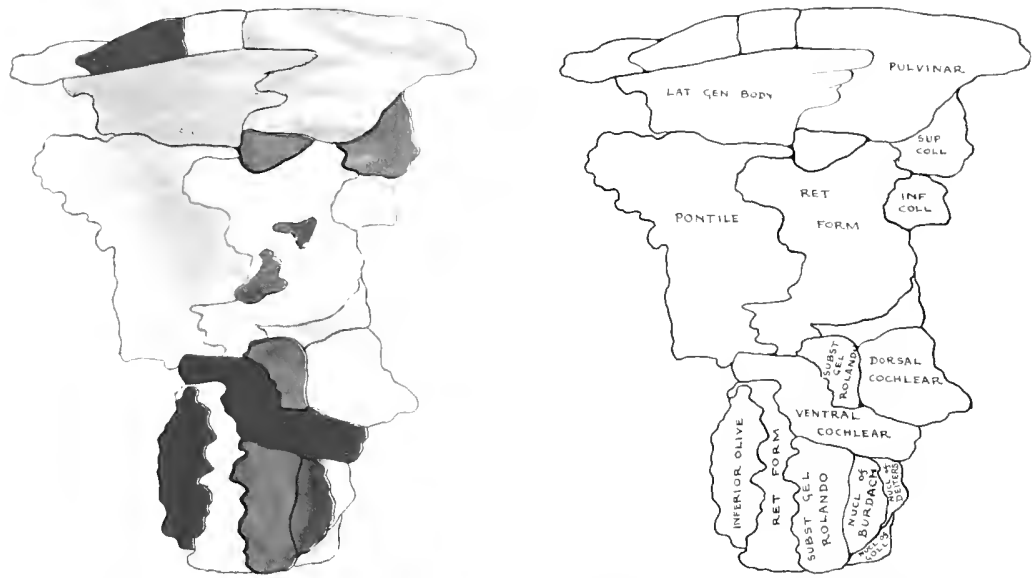

FIG. $2 \mathrm{I}$. LATERAL SURFACE OF GRAY MATTER OF BRAIX STEM, HYLOBATES HOOLOCK.

Key to Diagrau. dorsal cochlear, Dorsal Cochlear Nucleus; inf. coll., Inferior Collichlus; lat. Gen. Bodr, Lateral Geniculate Body; NuCl. OF Burdach, Nucleus of Burdach; Necl. OF Deiters, Nucleus of Deiters; Necl. of Goll, Nucleus of Goll; povtile, Pontile Nuclei; Ret. Foru., Ruticular Formation; SCBst. Gel. Rolavoo, Substantia Gelatinosa of Rolandr; sup. coll., Superior Colliculus; vevtral cochlear, Ventral Cochlear Nucleus.

commensurate with the relatively large size of the trapezoid body which produces a marked excavation in the ventral surface of the metencephalic reticular formation, separating this structure from the decp layer of the pontile nucleus.

\section{The Substantia Nigra}

The substantia nigra is developed as a massive nuclear coflection by a specialization from the deep layer of the pontile mucleus. This deep layer 


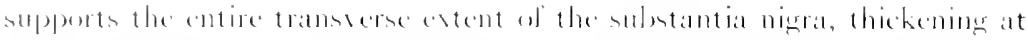

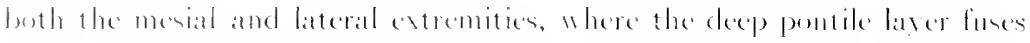
with the dorsal estremities al the mesial and lateral hottresses. It presents a

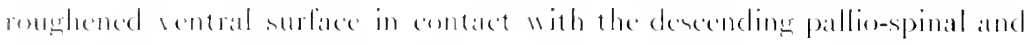

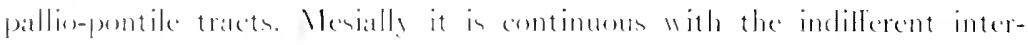

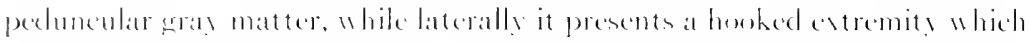

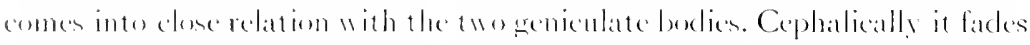

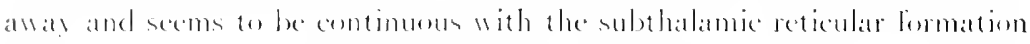
and the zoma incerta. The spectalization in its lateral portion, from which merve libers pass into the termentum, is well developed.

\section{Till Conteris}

These stractures appear at specializations in the dorsal extemsiom at

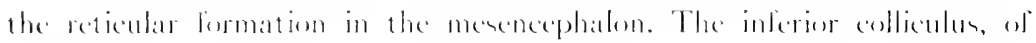
moderate size, reste upon the lateral cutemsion al the revicular formation

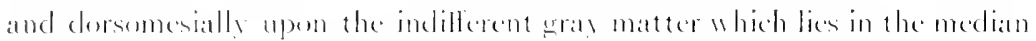
line. It is separated frem the superion colliculus bs the intereollienlitr sulems

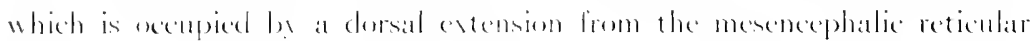

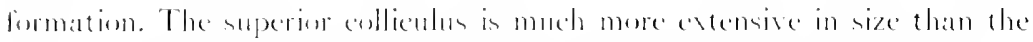
inferior colliculus and is similarls situated. Its lateral cotromity rests upon the lateral extensom of the mesenecphalic reticular formation, while its dorsal

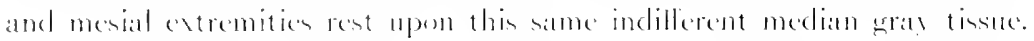

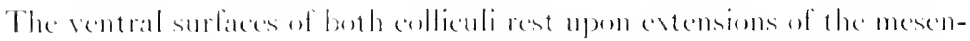
cephalice reticolas formation which prevents them from coming into actual contate with the central wail matter.

\section{THI: NicLels RIBER}

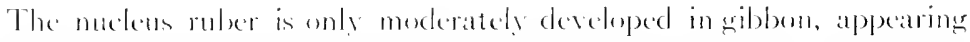
in the cephalic pretion of the mesenerphalon as a conclensation in the mesial 
part of the reticular formation. It is fairly well diflerentiated from the surrounding reticular matrix by the fiber capsule derived from the superior cercbellar pedunele. It is spherical in shape, its cephalic estremity estending up to, if not into, the diencephaton.

\section{The Central Gray Matter}

The central gray matter in gribbon in the lowest levels of the reconstruction appears as a more or less rectangular mass of gray matter receiving at its rentrolateral angles the reticular formation, dorsally the nucleus of Goll and at its dorsolateral angles, the substantia gedatinosa Rolandi. Passing upward the central gray matter presents a llat condensation which represents the beginning of the nucleus of Burdach.

As the central gray matter is followed upward in the stem it passes dorsad and at the same time expands laterally, until it is clisposed as a narrow, flat band lying upon the dorsal surface of the reticular formation.

The fourth ventricle presents very little modelling in any part. Above the mid-point there is the sugrestion of the nucleus abducentis, but this is not so well defined as it in some of the other forms.

As the gray matter is flattening out from side to side, a longr ventral prolongation stretches forward in the vicinity ol the raphe. This prolongation of the central gray matter extends almost to the base of the pyramid. Above, it passes into the reticular formation which gradually approaches its fellow of the opposite side. In the upper portion of the pontile regrion the Hoor of the fourth ventricle begins to narrow towards the aqueduct of Sylvius. The lateral walls contract and finally the cavity of the ventricle is reduced to the small dimensions of the iter. At the same time, the gray matter surrounding the aqueduct increases in thickness and gradually becomes changed in diameter. In the ventral prolongation of the mesencephalic central gray matter arise the condensations of nuclear material which grive rise to the 
fourth and third cranial neve nuclei. The griseal investment of the aqueduct of Sylvius is redatively heary. As the diencephalon is approached the ventrodorsal position of the central gray matter becomes more marked. Ventrally it is continuous with the indifferent interpeduncular graty matter which merges with that of the hypencephalic region. The hateral walls of the aqueduet of Sylvius are continuous with the subependymal gray matter lining the third ventricke. Dorsally the central gray matter luses with the habemular region. 
COMPARATIVE SUMNARI OF STRUCTURES HAVING EVOLUTIONAL SIGNIFICANCE IN THE BRAIN STEMS OF TIE INTERMEDIATE PRINATES

A Critical Comparison of the Prramidal Tract, the Olinary Nucleus, the Dorsal, Lestibular, Cerebellar and Pontile Nuclei, the Midhrain Colliculi and Oculomotor Decussation. Their Evolutional Significance in Relation to the Behavior of the Intermediate Primates. Comparison with Lower Primates

\footnotetext{
TN comparing the special structures of the brain stem selected because of their covolutional significance, the effort will first be made to contrast

L them as they appear in the three species of the intermediate primates; and then to note their eomparative relation to the members of the lower primate group.
}

1. Tile Prramidal Sistem in Its Relation to Volitional Control, Especially of the Extremities

The pyramidal system, one of the most reliable indices concerning the degree of volitional control possessed by the animal, has attained such promincnee that the motor cortex, and hence the motor capacity of these animals, may be assumed to represent a relatively high stage of development. Of these intermediate primates, the gibbon rather surprisingly reveals a planimetric coefficient considerably Iess than either the macacus or the baboon. This unexpected disclosure by means of measurement is partially suggested by easual inspection of the sections. It seems most likely that this disparity in pyramidal development arises from the faet that in gibbon, although most authorities place this animal in the group of the great anthropoids, the specialization of both fore- and hindlimbs is inferior to that of either macacus 
or baboon. As already noted, the hind leas are short and allord but imperfect means of focomotion upon the erround. Its fore extremities, on the other hand, are most highly specialized for arboreal locomotion, the forcarm being lomg. out of all proportion to the requirements essential for other skilled performances. The hand likewise has developed few of the more generalized capacities secon in other forms, but is particularly specialized as a swinging hook for reaching and grasping the branches as the animal makes its llight-like passage. In this light the behavioral development of gribbon acouds well with the relatively low planimetric coefficient of its pyramidal development.

Both the macacus and the baboon are about equal in the planimetric coeflicients of the pyramidal system, a fact which points to a behavioral development nearly on a par in these two species. Although macacus is essentially a tree-dwelling form, and the baboon mainly ground-living in habit, in both the development of hand and foot is essentially equal. Whatever slight advantage exists in the pyramidal eomparison of the baboon and macacus favors the latter, a relation which is in harmony with the behavioral differences in these two forms. The macacue is recognized to be more adaptable and is measurably more teachable than the baboon. The motor specialization of the former would thus be expected to be somewhat greater than that of the latter.

The planimetric coefficients of the pyramidal system of the intermediate primates are given in the appended tabulation:

Planmetric Coefficients of the Piramidal Sistent

\begin{tabular}{|l|c|c|}
\hline & Specics & Cocfficient \\
\hline Gibbon & Macacus & .38 \\
\hline Baboon & -146 \\
\hline
\end{tabular}


Compared group for group, the intermediate primates show at greater planimetrie coeflicient in the pyramidal system than the fower primates. In one instance alone does this lower eroup approach the intermediate one in this respect. Mrectes is about on a footing with giblon. In general, the intermediate primates show a striking advance in the organization of the pyamidial system, atthough this increase in pyramidal volume is not surprising when the behavioral expansions of the group are brought inte contrast with those of such forms as the femur the tarsius and the marmoset. The cleser approximation of mecetes to the figures of the intermediate species emphasizes again the high degree of specialization in these remarkable new-world monkeys. Because of their manual diflerentiation, as well as the functional capacity of their prehensile tails, they have developed a range of behavioral performances comparing favorably with their presumably more capable congeners of the old world.

1i. The Olivari Nucleus in Its Relation to the Regulation of Skilled Learned Performances

The olivary nucleus, by comparison among the intermediate primates, dearly indicates that the gibbon has gained preeminenee in this specialization of the brain. In definition of outline, in size, in degree of convolution, the olivary nucleus of the gibbon has every advantage over that structure in the macacus or baboon. From the functional standpoint, the conclusion may be drawn that in the simultaneous movements of the eve, head and hand, the gibbon has made a notable advance over its intermediate associates. This conclusion is in some respects diflicult to reconcile with the known facts of the animal's behavior. It does not accord with the conception that the forelimb, particularly the hand, of the gibbon is in many particulars inferior to that of the other intermediate primates deseribed. In no sense can it be said that the skilled manual performances of the gibbon are comparable with 
those of the macaleus or the baboun, either in complexity of organization or degree of dexterity. This marked specialization in the regulation of simultancous morements in eve, hand and head seems to be superlluous in so far as the gibben's behatrinal attainments are concened. There is that, however, in the skilled moter performanees of this animal which may call for such spontaneous coordination of oculo-cephato-graric movements ats the gibbon manifests. The prodigious swings which it makes from branch to branch in its flight-like locomotion demand, above everything else, the most accurate timing in the eordination between the eye and hand.

The planimetric coeflicients of macacus and baboon are practically equal; whatever little difference there may be favors the madeacus. The coeflicients of the inferion olivary nucleus in the intermediate primates are given in the appended table:

Coeficients of the Inferiok Olise in the Intermedite Prinhates

\begin{tabular}{|c|c|c|c|}
\hline & Species & Planimetric & Longitudinal \\
\hline Gibbon & & 155 & 240 \\
\hline Macacus & & .128 & 260 \\
\hline Baboon & & .125 & .220 \\
\hline
\end{tabular}

Contrasted with the lower primates the inferior olive shows a gain in prominenee in the intermediate forms. Myeetes, however, as might be expected, approaches fairly close to the intermediate primates in this regard. It is strikingly inferior to the gibbon whose high degree of olivary expansion furnishes an element upon the strength of which it may lay claim to some degree of lineal propinquity to the three great anthropoids.

iil. The Dorsal Nuclei in Their Relation to Discriminative Sensibility in the Extremities and Tail

The nucleus of Goll, representative of the discriminative sensory influx from the tail and lower limbs, furnishes convincing contrast in the inter- 
mediate primates. In the first place, the median unpatired nueleus of Bischolf has entirely disappeared and no strueture resembling this angeregation of eells in the dorsal column is found in any of the three species here compared. Inasmuch as this specialization of the dorsal sensory nucleus appears only in relation with those animals possessed of a prehensile tail or a tail used for propelling purposes, it has its importance in this fact. The nucleus of Goll, according to its measurements, is farener in both the baboon and macacus than it is in the gribbon. This disparity is considerable and striking, for the nucleus in gibbon is about half as large as in the other two forms. The importance of this incquality is notable because the gibbon belongs to those apes which possess no tails; hence all of the sensory specializat ion pertaining to that organ, in the capacity either of a prehensile, a steering or a balancing structure, has disappeared in the Hylobate species. The volume of aflerent impulses arising from the tail in the other monkeys has also decreased in the absence of prehensile function and by just so much the nucleus of Goll has become reduced in size. In addition, it mest be borne in mind that the fower extremities in the gibbon are poorly developed; that is to say, the legrs are not differentiated for focomotion on the ground. The main burden of focomotion lalls upon the upper extremities inasmuch as the animal's cxtreme development of brachiation is the one outstanding physical feature of its motor organization, from which fact the family has received the name of "treewalkers." But their walking is conducted by means of the arms and hands rather than the legs and feet. Thus the gibbon's inferiority in the development of the column of Goll may be attributed to the dual effect of absence of a tail and certain functional depreciations in the lower extremities. The baboon and macacus, on the other hand, have a fair representation of nuelear substance in the mucleus of Goll, indicative of hind extremities equipped with adecuate proprioceptive organs for the receipt of discriminative impulses. The afferent influx from the tail makes a not inconsiderable addition, 
although in neither of these species does the tail differentiate as a prehensile organ. In this light, the relative dimensions of the nucleus of Goll in the three intermediate primates is significant in two of them, macacus and baboon, because the inllux of discriminative impulses from the legs and tail is considerable. In the gribben, which possesses no tail, sensory stimuli are correspondingly redued. The coeflicients of the nucleus of Goll in macaeus, baboon and gibben are shown in the appended tabulation:

Coefficients of the Niclels of Goll in the Intermedite Primates

\begin{tabular}{|c|c|c|}
\hline Species & Planimetric & Longitudinal \\
\hline Gibbon & 034 & .150 \\
\hline Macacus & $0^{-6}$ & 210 \\
\hline Baboon & .086 & 210 \\
\hline
\end{tabular}

When the nucleus of Goll in the intermediate primates is compared with the eorresponding structure in the lower primates, equally striking contrasts become apparent. In mycetes, for example, this mucleus is the most conspicuous. The preeminence of the mucleus of Goll in the howling monkey is unquestionably related to the possession of a prehensile tail. Here again the specialization in structure brings about new spheres of activity in the realm of behavior. The nucleus of Goll in the gibbon has the smallest dimensions of all the primates thes far considered. Its size is even less than that of the lemur or marmoset. The specialization of the hindlimb, therefore, and the development of the tail, as these factors bear upon the influx of stimuli concerned in discriminative sensibility and thus become active in the organization of the animal's behavior, are clearly reflected in the primary receiving station for these impulses in the brain stem, the nucleus of Goll.

In the case of the nucleus of Burdach, however, the conditions are somewhat different. This nucleus in macacus is considerably larger than in either baboon or gibbon. In all probability the difference is to be attributed to the 
greater degree of differentiation in the upper extremity and hand. This interpretation gains in probability because in the babon the fore extremity particularly the hand, is influenced in its differentiation by adaptation to focomotion upon the ground, while in the gibben the hand and upperestremity are peculiarly adapted to arboreal locomotion. In macacus, however, there is some degree of freedom of the hand which approaches more nearly the humanoid standard of a forelimb. Not in size alone, but quite as much in the specialization of the aceessory nucleus of Bhumenau, the nucleus of Burdach shows a greater degree of differentiation in macacus than in gribbon or baboon. The planimetrie cocellicients of the nucleus of Burdach (including the aceessory nucleus of Blumenau) in baboon, macacus and gibbon are shown in the appended tabulations:

Coefficients of the Nuclees of Blrdach in the Intermediate Primates

\begin{tabular}{|c|c|c|}
\hline & Flanimetric & Longitudinal \\
\hline Gibbon & .068 & 150 \\
\hline Macacus & .086 & 200 \\
\hline Baboon & $.66_{j}$ & 200 \\
\hline
\end{tabular}

The longitudinal coefficients of the two dorsal groups of sensory nuclei are also given. From the latter tabulation, it is of interest to note the general consistency in length of both the nucleus of Goll and of Burdach. The only notable departure from this equality is the length of the nucleus of Goll in gibbon which is practically half that of the other forms. This fact accords with the observations already made on the basis of the planimetric coeflicients of this nucleus in gibbon.

As compared with the nucleus of Burdach in the lower primates, the planimetric figures show that in mycetes this nucleus is larger than in all other forms either of the lower or the intermediate groups. This predominance of myectes in both of its dorsal nuclear specializations must be 
considered as definitely influeneed by the possession of a prehensile tail. The substantiation of this view in regard to the nucleus of Goll presents far fewer difliculties than is the case with the nucleus of Burdach, yet the wider range of motor performance made possible by the prehensile tail may be urged as the basis of greater manual freedom and hence an increase in the volume of atlerent inthe from the uppere extremity.

\section{iv. The létibllar Necael and Their Relation to the Bulancing Mechanisi}

The functional capacity of the balancing mechanism in the intermediate primates, particularly as indieated by the mucleus of Deiters, appears most prominent in the gribbon. This oloservation is berne out by the facts recorded in connection with the surface markings of the oblongata in which the large protuberances on the floor of the fourth ventricle occasioned by the vestibular area were noted (p. +20). This preminence of the gibbon in the index of its balancing mechanism is undeubtedly due to the adjustments necessary in its arboreal hocomotion. The differences in these three species with reference to the triangular nucleus of Schwalbe are not great. It is probable that all three of these animals have nearly the same balancing problems to meet in their locomotion and station, which thus places their balancing mechanism about on a par. The coefficients of the vestibular areas in the macaeus, baboon and gribbon are griven in the appended tabulation:

Coefficients of Deiters' Area in the Intemiediate Prinates

\begin{tabular}{|c|c|c|}
\hline Species & Planimetric & Longitudinal \\
\hline Gibbon & .08 & .140 \\
\hline Macacus & $.0^{-5}$ & . IIO \\
\hline Baboon & .060 & IIO \\
\hline
\end{tabular}


Coefficients of the Extre Vestibular Area in the Intermediafe Primates

\begin{tabular}{|c|c|c|c|}
\hline & Species & Planimetric & Longitudinal \\
\hline Gilbon & & $1^{-\cdots}$ & $1+0$ \\
\hline Macacus & & 162 & 110 \\
\hline Babron & & . 133 & $1 \mathrm{I} 0$ \\
\hline
\end{tabular}

Even more interesting is the comparison of the internediate primates with those of the lower group. This contrast shows how nearly equal the balancing problems in all of these primates are. In this respect, however, myectes and tarsius exceed all of the other species. Here again, as in the case of the sensory nuclei of the dorsal column, it is undoubtedly the additional motor capacity and focomotor specialization that bring into play new raneses of motion connected with balaneing. These additions demand a mere effective mechanism for this function. But among the intermediate primates the gibbon, because of its peculiar arboreal focomotion, has a slightly more differentiated mechanism than its congeners in this group.

․ The Cerebellar Neclei in Their Relation to the Coordination of Movements, Especially the More Complex Movements of the Upper Extremities

Employing the dentate nucleus of the cerebellum as an important representative of coordinative function in the brain, it appears from a comparison of this structure in the intermediate primates that the baboom shows a somewhat greater specialization than either of the other forms. This comparison, which slightly favors the baboon, is somewhat perplexing at first glance. Taking into consideration the fact that this animal is specialized for rapid and almost perfect quadrupedal locomotion upon the ground, and at the same time has almost equal capacity for climbing in rocky places and even in the trees, it becomes evident that its musculature is in need of a high degree 
of coordinative control. Although it must be admitted that the manual diflerentiation in babom, while in some respects superior to that of gribbon, is in no way better than that of macacus, nevertheless, the chal responsibility foreed upon the forelimbs for leremotion upon the ground and in climbing entails a higher dexree of specialization of comdinative control than in either of the other two forms considered. Such an interpretation is none too strongly urged at this time. Other factors may be operative which as yet have not come to light. This explanation of the larger size of the dentate mucleus in the baboon than in the other intermediate primates, however, seems for the moment worthy of comsideration. The eneflicients of the dentate nucleus in the baborm, macaque and gibben are given in the appended tabulation:

Coefficients of the Dentate Nerlegs in the Intermediate Primates;

\begin{tabular}{|c|c|c|}
\hline Species & Planimetric & Longitudinal \\
\hline Gibbon & 134 & 210 \\
\hline Macacus & 155 & .180 \\
\hline Baboon & $10_{3}$ & 240 \\
\hline
\end{tabular}

It is perhaps of even greater significance that the nucleus dentatus in the intermediate primates is in all cases greater than the similar structure in the lower primates. This differenee would indicate a definite expansion in cercbellar function in passing from these lower to the higher forms. It points to a probable increment in the coordinative control of the musculature since these animals are becoming more highly specialized in their motor capacity, which gives them a wider range of behavioral adaptation.

The nuclear specialization in the midbrain which receives, as a relay station, the superior cerebellar peduncle, namely, the red nucleus, bears out the fact already observed in relation with the nucleus dentatus. The nucleus ruber is Iarger in the baboon than in either the gibbon or macacus, thus 
intimating that the relaying structure in the efferent pathway of impulses out of the cercbellum varies with the dentate nucleus from which these impulses arise. The planimetric coeflicients of the red nueleus are shown in the appended tabulations:

Planimetric Coefficients of the Red Nuclegs in the Intremedate Prinates

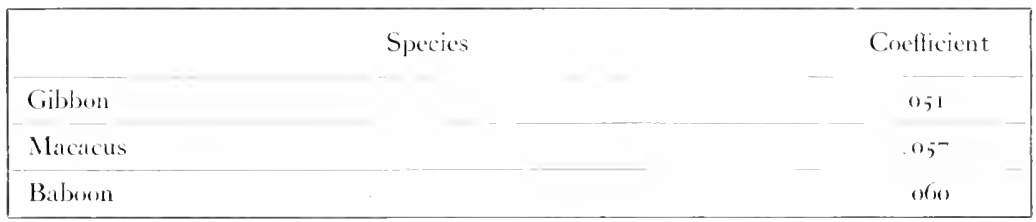

As compared with the similar strueture in the lower primates, the red nucleus is in general larger in the intermediate primates, with one exception, namely, Mycetes seniculus, which has a planimetrie eofficient greater than in all of the other forms thus far chescribed.

vi. Tile Pontile Nuclei and Their Relation to the Control of Skilled Movements, Espechally Complex Manual Performances

A comparison of the pontile nuclei, those structures of the brain to which such importance has been attached as indicative of the animal's capacity for acquiring skilled motor performances, shows that the gibbon is shightly more advanced in the line of this development. This fact does not accord with the observations with reference to the nucleus of Burdach which furnishes the basis for estimating the volume of discriminative influx from the upper extremity and hand. It will be recalled that in this review, the macaeus was aceredited with a higher degree of mamual differentiation than the other intermediate primates. On the other hand, the pontile nuclei seem to indicate that the gibbon is endowed with a high degree of specialization in its skilled movements, and is thus capable of a wider range of behavioral adaptation. It is difficult to reconcile this apparent discrepancy, since the macacus, by 
reason of the structural differentiation in its hand, its mode of life in the trees, its gencral reaction within its habitat seems to possess a wider range of motor diflerentiation. It may be that the gibbon is equally endowed in these respects. Being a more or lese redusive animal concernine whose beharior in the free state less is known than of the macacus, it impossible to say at present that its mamual performanees are actually inferior to those of the macalue. The figures do not indieate such a condition. Iet it is pensible that because of the rather low degree of differentiation in the lower limbs and feet, much more responsibility is imposed upon the fordimbs and hand. This, at least, would explain why the pontile nuclei are large in the gribbon. The division of labor between the hands and the feet in macacus and baboon is nearly equat; in the eribbon there is a marked inequality which gives the forclimb and the hand over-emphasis in their motor responsibility. The coeflicients of the pontile nuclei of the baboon, macaque and gibbon are griven in the appended tabulation. While the planimeteric dimensions in gibbon are somewhat larger than in the other species, the estimated mass of the muclei is nearly equal in them all.

Cuefficients of the Ponthe Niches in the Intermediate Primates

\begin{tabular}{|c|c|c|c|}
\hline & Species & Planimetric & Longitudinal \\
\hline Giblom & & 200 & 260 \\
\hline Macacus & & 150 & 340 \\
\hline Bitburn & & .164 & 310 \\
\hline
\end{tabular}

More significant, however, than the comparison between the several members of the intermediate primate group, is the fact that all of these three species show a definite superiority in their pontile nuclei orer the lower primates. This superiority is striking and decisive, leaving no doubt that in 
passing from the fower to the higher group there has been a definite increment in these nuclear structures. The gibbon, for example, as compared with the lemur, shows a pontile nuclear aggregation nearly four times as large. These nuclei in the gibbon are nearly twice as larese as they appear in either the mamoset or mrectes.

Whaterer difficulties, therefore, may seem to exist in estimating the relative importance of these nuclei so far as this is revealed by theirdimensions in the intermediate wroup, there can be no doubt of the expansion in the pontile nuclei in passing from the fower to the intermediate primates. This ma be accepted as indicative of a progressive functional increment in manual specialization.

\section{iii. The Midbrain Colliclia in Relation to the finctions of Sight AND HEARING}

The comparison of the inferior colliculi of the intermediate primates indicates a further decrease in functional prominence in these auditory relay centers. The inferior colliculus in gibbon is smaller and less well cleveloped than in either the macacus or the baberm. That some of the primordial auditory function is still rested in the inferior colliculus and acts in the interest of immectiate reflex adjustment to sudden noises or sounds is probably true. But the sense of hearing in gibbon appears to have undergone such amplification in its associational values that the auditury area of the cerebral cortex has taken supersedence over the more primitive midbrain region originally active in auditory function. Both the macacus and baboon seem to have retained more of the immediate reflex organization based upon the sense of hearing than is the case in gibbon; they seem to depend less than the gibbon upon the transmission of auclitory stimuli to the cerebral cortex before determining upon specific courses of action. This structure thus indicates the 
progressive adranee which has taken place in telencephalization, a process which is onc of the outstanding features in the evolution of the brain. Its consequences are seen in the advancement to the cerebral hemispheres of functions formerly vested in fower primordial pertions of the neuraxis. The coeflicients of the inferior colliculi are appended in the following tabulation:

Coeficients of the Inferior Colliclli in the Intermediate Prinates

\begin{tabular}{|c|c|c|c|}
\hline & Species & Planimetric & Longitudinal \\
\hline Gibbom & & 130 & 60 \\
\hline Nacacus & & $1^{-5}$ & 100 \\
\hline Balown & & 150 & .880 \\
\hline
\end{tabular}

A comparison of the inferior eolliculus of the intermediate group with that of the lower primates shows in even more striking manner the recession of this formerly prominent midbrain structure. It bears sut the idea of a progressive evolution in the sense of hearing. This is indicated by the steady advance which the nemal organization of this special sense has made in transferring its activities from a lower more limited area of the nervous system to a higher and more expansible territory.

The superior colliculus, somewhat less emphatically, gives similar evidence of gradual, progressive delegation of a highly specialized sensory function from lower to higher centers in the brain. The superior colliculus in the gibbon is smaller than either in macaeus or baboon. This lanet finds substantial confirmation in the external configuration of the occipital fobe where the fissural pattern in gibbon is richer and the convolutions more ample than in the other intermediate primates. The occipital area of the cerebral cortex in giblon thus appears to be more actively eneerned with the visual function than in macacus or babeon. The coeflicients of the superior colliculus of macacus, baboon and gibbon are appended in the following tabulation: 


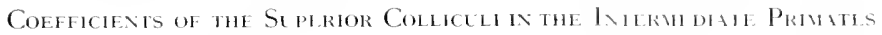

\begin{tabular}{|c|c|c|c|}
\hline & Species & Planimetric & Lomgitudinal \\
\hline Gibben & & 132 & $(x)$ \\
\hline Marcatcus & & $1 ; 8$ & 130 \\
\hline Biblom & & $1-3$ & 136 \\
\hline
\end{tabular}

The comparison of the Iower primates with those in the intenencliate group derelops a significant lact, namely, that the superior collicules in baberon is more prominent, by virtue of its larger size, than in any of the other species. Although not aiming to wer-estimate the value of a purely mensurational observation, it seems likely that the baboon, whose life is adapted to the open plains where danger may approach it from all directions and where the saleguarding by the visual as well as the auditory lookont becomes correspondingly important, requires a visul mechanism with greater possibilities for immediate rellex responses. In this way visual impressions from all sides may at once produee such protective attitudes and defense reactions as to guarantee the animal's safety in its more exposed habitat. In the comparison of the lower primates with the intermediate erroup, the planimetric estimations do not grive quite so convincing an account of telencephatization as is the case with the inferior colliculus; nevertheless, the evidenee of such a process may be elearty discerned. This portion of the midbrain is to be regarded as one of the important indices disclosing a definite line of evolutional modification.

\section{vil. The Oculonotor Decussation in Relation to Binocllar and STEREOSCOpic Vision}

This decussation between the oculomotor maclei on the two sides of the brain forms one of the significant criteria indicative of the progressive adaptation of skilled acts. The connection between these two nuclei becomes 
essential to adapt the oeular musctes to the needs of binocular vision. Among the intermediate primates, the interocular connection is considerably more extensive in baben than in macacus or gibben. The explanation of this preeminence in the baboon may be senght in the nature of its habitat and mode of life. Living as it dees in open places, its range of vision is consequently muth wider and it requires adjustment to varying distanees mueh more than is the case of the tree-dwelling animals whose visual ficlds are naturally circumscribed by the foliage among which they pass their lives. Thus in all probability, responding to the need for rapid adjustment of far and near vision, the baboon has developed a quality of visual perception which in certain respects surpasses that of the other intermediate primates. The Iongitudinal coefficients of the oculomotor decussation in baboon, macacus and gribbon are given in the appended tabulation:

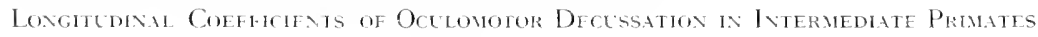

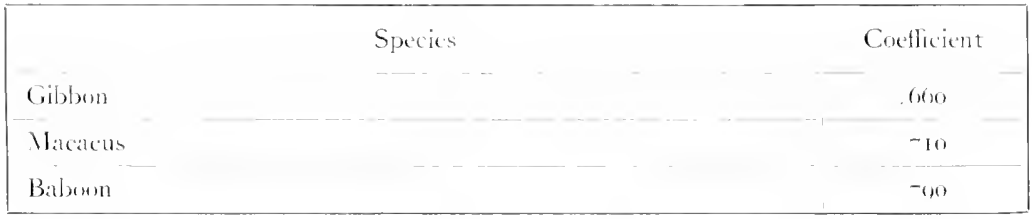

From these figures it is apparent that, when eontrasted with the lower primates, the degree of internuclear connection in the nuclei controlling the ere muscles of the intermediate group is much greater. This denotes a specialization in visual function in passing upward from the lower extremity of this order, in the interest of a higher type of ocular control. It especially introduces those clements of vision which grive more exact perception concerning distance, perspective and contour.

Were it possible to summarize all of the progressive specializations which have been noted, it might be said that whatever the variations and differences among the intermediate primates, these species as a gromp show definite, even decisive advances in all of the structural details regulating the 


\section{SL MIMARY OF STRLCTLRES}

fundamental behavioral reactions. These details indude the clements ensential to voluntary control of the extremities with especial referenee to the hand, the regulation of simultanerous movements of exes, head and hand, the increments of diseriminative sensibility dependent upom manual differentiation, the increase of condinative control of the musculature, the expansion of the range of skilled mesements, particularly manual performances, the teleneephalization in control of the functions of sight and hearing, and the progressive derelepment of binesular vision. 



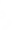





THE ASCENT OF PREHISTORIC MAN

MANS CULTURAL STAGES AND PHYSICAL DEVELOPMENT

TO THE END OF THE OLD STONE AGE

[DIAGONAL LINES INDICATE RACIAL, PERIODS.

DOT SHOWS CONJECTURED DATE OF EXTINCTION]

ICE AC.ES

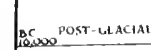

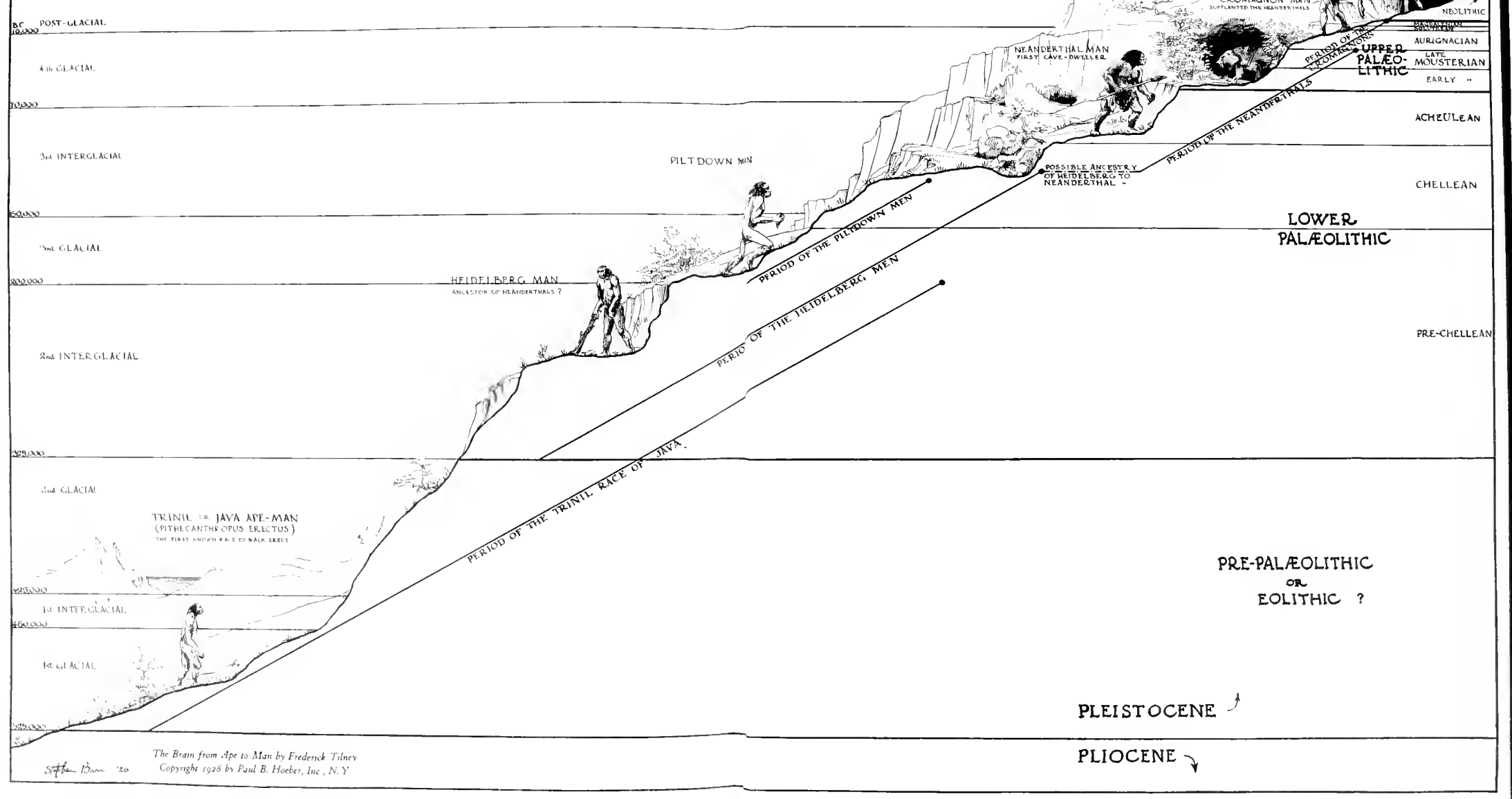


